WAYNE SANTOS DE ASSIS

SISTEMAS COMPUTACIONAIS DE APOIO À MONITORAÇÃO DE ESTRUTURAS DE ENGENHARIA CIVIL

Tese apresentada à Escola Politécnica da Universidade de São Paulo para obtenção do Título de Doutor em Engenharia. 
WAYNE SANTOS DE ASSIS

\section{SISTEMAS COMPUTACIONAIS DE APOIO À MONITORAÇÃO DE ESTRUTURAS DE ENGENHARIA CIVIL}

Tese apresentada à Escola Politécnica da Universidade de São Paulo para obtenção do Título de Doutor em Engenharia.

Área de Concentração:

Engenharia de Estruturas

Orientador:

Prof. Livre-Docente

Túlio Nogueira Bittencourt 
Este exemplar foi revisado e alterado em relação à versão original, sob responsabilidade única do autor e com a anuência de seu orientador.

São Paulo, 15 de junho de 2007.

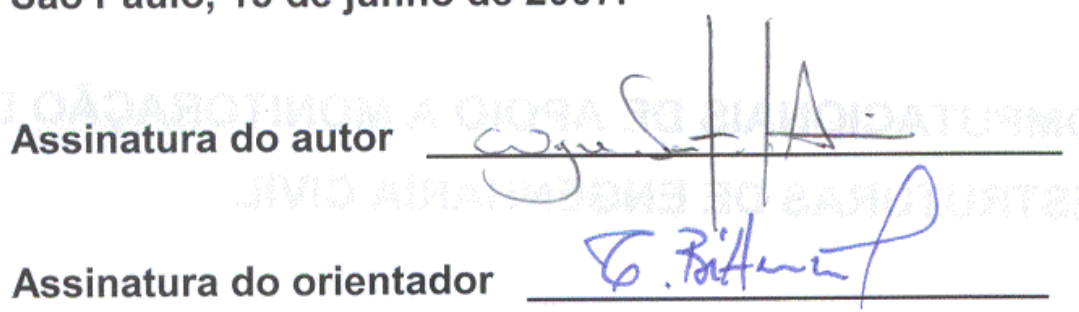

FICHA CATALOGRÁFICA

Assis, Wayne Santos de

Sistemas computacionais de apoio à monitoração de estruturas de engenharia civil / W.S. de Assis. -- ed.rev. -- São Paulo, 2007.

$265 \mathrm{p}$.

Tese (Doutorado) - Escola Politécnica da Universidade de São Paulo. Departamento de Engenharia de Estruturas e Fundações.

1.Tratamento e interpretação de dados 2.Monitoração de estruturas 3.Estruturas de concreto 4.Sensores elétricos 5.Sensores ópticos 6.LabVIEW I.Universidade de São Paulo. Escola Politécnica. Departamento de Engenharia de Estruturas e Fundações II. t. 
A Deus.

Aos meus pais e irmãos.

À minha noiva Angela. 
"Bem-aventurado o homem que acha sabedoria, e o homem que adquire conhecimento."

Provérbios 3:13 


\section{AGRADECIMENTOS}

A Deus, que me concede coragem para enfrentar todos os desafios apresentados pela vida, e força e ânimo nos momentos de fraqueza e desalento.

Aos queridos companheiros de vida: meus pais, João e Maria, que com muito amor, labor e sacrifícios proporcionaram as condições para o desenvolvimento da minha vida acadêmica, e aos meus irmãos, Wilton e Wellington. quatro anos.

À minha noiva Angela, pelo carinho, amor e paciência ao longo destes

Ao professor Túlio Nogueira Bittencourt, pela confiança depositada para o desenvolvimento deste trabalho e pela orientação, amizade e apoio.

Ao professor Joaquim de Azevedo Figueiras, da Faculdade de Engenharia da Universidade do Porto (FEUP), pela orientação, amizade, apoio e receptividade durante o período de desenvolvimento de atividades em Portugal.

Aos amigos do Laboratório de Estruturas e Materiais Estruturais (LEM) e do Laboratório de Mecânica Computacional (LMC), em especial ao Telmo Deifeld, Carla Costa e Leandro Trautwein, pela animadora e agradável presença de todos os dias.

Aos amigos do Laboratório da Tecnologia do Betão e do Comportamento Estrutural (LABEST) da FEUP, especialmente ao Helder Sousa, Américo Dimande, José António, Bruno Costa, Carlos Félix e José Sá, pela excelente acolhida, por todo o apoio no desenvolvimento dos trabalhos e pela disponibilidade para a troca de experiências acadêmicas e pessoais.

Aos engenheiros da Companhia do Metropolitano de São Paulo (Metrô) e da construtora Norberto Odebrecht, pelo suporte e informações necessários ao desenvolvimento dos trabalhos na estação metroviária Alto do Ipiranga.

A Marly e Janete, secretárias do Departamento de Engenharia de Estruturas e Geotécnica (PEF), e à Dona Vitória, secretária do Departamento de Engenharia Civil da FEUP, pela amizade e pela dedicação e auxílio nas questões relativas à burocracia acadêmica.

A Universidade de São Paulo (USP), pela oportunidade de amadurecimento pessoal e acadêmico, bem como pela vaga em um apartamento do seu condomínio residencial de 2002 a 2004.

À Coordenação de Aperfeiçoamento de Pessoal de Nível Superior (CAPES), pelo suporte financeiro proporcionado no Brasil e no exterior.

À FEUP, pela bolsa fornecida durante o período adicional de permanência em Portugal autorizado pela CAPES. 


\section{RESUMO}

Este trabalho apresenta o desenvolvimento de sistemas computacionais de apoio à aquisição, visualização e tratamento de dados provenientes de monitoração de estruturas de Engenharia Civil. Por meio dos sistemas construídos, torna-se possível adquirir, visualizar e filtrar informações com facilidade, ao mesmo tempo em que se permite avaliar a influência da temperatura, da retração e da fluência nos elementos estruturais monitorados. Buscando desenvolver as ferramentas computacionais em uma perspectiva alinhada com necessidades reais do setor, foram monitoradas duas pontes rodoviárias e uma estação metroviária, sendo utilizada instrumentação avançada baseada em sensores e equipamentos ópticos e elétricos, permitindo a medição de grandezas como deformação, temperatura, deslocamento e rotações. A experiência adquirida em campo encontra-se descrita, apresentando-se a estrutura e componentes dos modernos sistemas de monitoração e os principais resultados decorrentes da sua aplicação nas obras monitoradas. Nesse contexto, os sistemas computacionais construídos demonstraram ser úteis ferramentas, auxiliando nas diversas fases da monitoração estrutural, desde a aquisição até a interpretação dos resultados.

Palavras-chave: Tratamento e interpretação de dados, monitoração de estruturas, estruturas de concreto, sensores elétricos, sensores ópticos, LabVIEW. 


\begin{abstract}
This work presents the development of computational systems to support acquisition, visualization, and treatment of data from health monitoring systems of civil structures. With these systems, it is possible to acquire, to visualize, and to filter monitored data. It is also possible to evaluate the influence of temperature, shrinkage and creep in structural elements. The goal is the development of tools to fulfill real needs. For that, two bridges and a subway station were monitored using advanced instrumentation based on optical and electrical sensors. The acquired experience in field is described, presenting the structure and the various components of modern structural health monitoring systems, as well as the main results of application in the monitored structures. In that context, the built computational systems demonstrated to be very useful, aiding in the several phases of the structural monitoring from the acquisition to the interpretation of the results.
\end{abstract}

Keywords: Data processing and interpretation, structural health monitoring, concrete structures, electrical and optical sensors, LabVIEW. 


\section{LISTA DE FIGURAS}

\section{CAPÍTULO 1 - INTRODUÇÃO}

Figura 1.1 - Exemplos de pontes deficientes monitoradas: Horsetail Fall Bridge, em Oregon, EUA e Bolshoi Moskvoretskiy Bridge, em Moscou, Rússia. Fonte: SMARTEC (2007).

Figura 1.2 - Exemplos de obras monitoradas na Europa: barragem Luzzone (Bélgica) e ponte Colle d'Isarco (Itália). Fonte: INAUDI (2005).

Figura 1.3 - Tsing Ma Bridge, em Hong Kong, China: ponte pênsil permanentemente monitorada, com instrumentação realizada durante a construção. Fonte: CHAN et al. (2006).

Figura 1.4 - Ponte Ashidagawa (a), em Fukuyama, Japão, monitorada durante a construção (b, c). Fonte: SUMITRO e WANG (2005); DYNAMAG (2003).

Figura 1.5 - Cooper River Bridge, na Carolina do Sul, EUA: ponte estaiada monitorada durante a construção. Fonte: CTL GROUP (2006); STARMER (2006).

Figura 1.6 - Ponte dos Remédios durante intervenção. Fonte: COZZA (1997); TÉCHNE (1999).

Figura 1.7 - Ponte estaiada sobre o rio Pinheiros (a), Estação Santo Amaro do Metrô (b).

Figura 1.8 - Acelerômetros instalados em um estai (a) e medição de deslocamentos das aduelas (b).

Figura 1.9 - Ponte Bernardo Goldfarb.

Figura 1.10 - Ponte Construtor João Alves.

\section{CAPÍTULO 2 - SISTEMAS DE MONITORAÇÃO}

Figura 2.1 - Subsistemas de um sistema de monitoração.

Figura 2.2 - Microsensores MEMS (a, b) utilizados na construção de acelerômetros wireless. PCMAG (2007); NPL (2007). Fonte: LOUREIRO (2003).

Figura 2.3 - Estatísticas sobre alcance e frequência de observação de sensores sem fios em aplicações industriais. Alcance de comunicação (a) e intervalo entre observações (b).

Figura 2.4 - Exemplo ilustrativo da importância da definição de amostragens apropriadas. Simulação de sinais obtidos à taxa de uma amostra por segundo (a), uma amostra a cada cinco segundos (b), uma amostra a cada oito segundos (c) e uma amostra a cada dez segundos (d).

Figura 2.5 - Sistemas de aquisição para monitoração, com conversores A/D com resolução de 14 bits (a) e 24 bits (b). Fonte: NATIONAL INSTRUMENTS (2007). 
Figura 2.6 - Interface de programa para aquisição de dados desenvolvido pelo autor.

Figura 2.7 - Sistemas de aquisição para monitoração de estruturas: sistema de 26 aquisição com placa de aquisição USB (a), placa de aquisição PCl (b), data logger para sensores elétricos (c) e unidade de medição portátil para sensores ópticos (d).

Figura 2.8 - Tensômetro de Huggenberger. Fonte: HOFFMANN, 1989.

Figura $2.9 \quad$ - Estrutura de um extensômetro de resistência elétrica.

Figura 2.10 - Extensômetro de resistência elétrica, apresentando os elementos constituintes.

Figura 2.11 - Ilustração de EREs coláveis, modelo roseta tripla a $120^{\circ}$ e $135^{\circ}$ (a) e roseta tripla a $120^{\circ}$ pronto para uso (b). Fonte: OMEGA (2006).

Figura 2.12 - Ponte de Wheatstone, com extensômetro $\left(R_{2}\right)$ ligado em quarto de ponte.

Figura 2.13 - Extensômetro de corda vibrante para aplicações embutidas.

Figura 2.14 - Desmontagem de pilar provisório. Sensores de deslocamento foram utilizados para avaliação do progresso das atividades. Fonte: FONSECA (2003).

Figura 2.15 - Comparador elétrico de deslocamento.

Figura 2.16 - Funcionamento de transdutor capacitivo de deslocamento.

Figura 2.17 - Comparadores digitais de deslocamento (resolução de 0,01 mm e 0,0005 $\mathrm{mm}$, respectivamente). Fonte: STARRET (2006); MITUTOYO (2005).

Figura 2.18 - Elementos constituintes de um LVDT típico (adaptado de WIKIPEDIA, 2004).

Figura 2.19 - LVDT: tensão de saída em função da posição do núcleo.

Figura 2.20 - Utilização do sistema de nivelamento hidrostático. Elementos do circuito hidráulico: reservatório (a) e transdutor de pressão (b).

Figura 2.21 - Republic Plaza Building (a, b), edifício continuamente monitorado por GPS (c). Fonte: OGAJA (2001).

Figura 2.22 - Inclinômetro biaxial em obra monitorada (a) e características geométricas (b).

Figura 2.23 - Princípio de funcionamento de um termopar.

Figura 2.24 - Relação entre as resistências elétricas final e inicial e a temperatura para diferentes RTD's. Fonte: FERREIRA (2000).

Figura 2.25 - Sensor de temperatura PT100 conforme fornecido (a, b) e após encapsulamento (c).

Figura 2.26 - Sensor higrométrico capacitivo (a) e sua curva característica (b). Fonte: ROTRONIC (2001). 
Figura 2.27 - Composição de acelerômetros uniaxiais utilizando cubo de montagem (aresta de $24 \mathrm{~mm}$ ), chips de acelerômetros MEMS (b) e acelerômetro pronto para uso (maior dimensão: 28,3 mm). Fonte: RIEKER (2006); OMNI INSTRUMENTS (2007).

Figura 2.28 - Estrutura básica de uma fibra óptica.

Figura 2.29 - Guiamento da luz no interior do núcleo da fibra óptica.

Figura 2.30 - Esquema de funcionamento de uma rede de Bragg (adaptado de DUPONT, 2002).

Figura 2.31 - Interrogação de sensores de Bragg.

Figura 2.32 - Sistema de interrogação de redes de Bragg (a) e resultado típico (b).

Figura 2.33 - Equipamentos para trabalhos com fibras ópticas: clivador (a) e máquina de emenda por fusão (b).

Figura 2.34 - Ponte Versoix (a): instalação (b) e concretagem de sensores ópticos. Fonte: INAUDI et al. (1999); VURPILLOT et al. (1997).

Figura 2.35 - Ponte Jiangyin. Fonte: DORMAN LONG TECHNOLOGY (2007).

\section{CAPÍTULO 3 - SISTEMA DE VISUALIZAÇÃO E TRATAMENTO DE DADOS}

Figura 3.1 - Painel frontal (esquerda) e respectivo diagrama de blocos. Junto ao painel frontal estão as paletas de edição (esquerda) e controle, e acima do diagrama de blocos, a paleta de funções.

Figura 3.2 - Versão inicial do módulo para controle da aquisição de dados.

Figura 3.3 - Utilização do módulo de aquisição de dados.

Figura 3.4 - Módulo para controle da aquisição de dados (variação de uma grandeza no tempo).

Figura 3.5 - Módulo para controle da aquisição de dados (medição de duas grandezas físicas).

Figura 3.6 - Fases do ensaio: desempenho em serviço (a) e aplicação de carga até a ruptura (b).

Figura 3.7 - Utilização do módulo de aquisição durante ensaios dos modelos reduzidos.

Figura 3.8 - Sistema de visualização e tratamento de resultados.

Figura 3.9 - Ambiente para visualização seletiva de resultados.

Figura 3.10 - Ambiente para filtragem de resultados.

Figura 3.11 - Efeito da largura do intervalo usado no filtro de média móvel: sinal original (a), filtragem com $r=5$ (b), $r=20$ (c) e $r=40$ (d). 
Figura 3.12 - Efeito da largura do intervalo usado no filtro de Savitzky-Golay: sinal original (a), filtragem com $r=5$ (b), $r=20$ (c) e $r=40$ (d), utilizando um polinômio de $1^{\circ}$ grau.

Figura 3.13 - Ambiente para introdução de dados das seções de referência e de análise.

Figura 3.14 - Posicionamento dos sensores de temperatura na seção transversal de referência.

Figura 3.15 - Distribuição e componentes da temperatura em uma seção.

Figura 3.16 - Características geométricas modificadas.

Figura 3.17 - Relação entre a modificação da altura (a) e da largura (b) com a variação uniforme e com a variação do diferencial térmico.

Figura 3.18 - Relação entre a modificação do comprimento das consolas (a) e da 90 espessura das almas (b) com a variação uniforme e com a variação do diferencial térmico.

Figura 3.19 - Relação entre a modificação da espessura da laje superior(a) e inferior (b) com a variação uniforme e com a variação do diferencial térmico.

Figura 3.20 - Distribuição simplificada e componentes da temperatura em uma seção de referência.

Figura 3.21 - Etapas do método desenvolvido.

Figura 3.22 - Temperaturas medidas na seção $S_{r}$ e temperaturas estimadas para a seção $S_{i}$.

Figura 3.23 - Temperaturas medidas e temperaturas estimadas na seção $S_{i}$.

Figura 3.24 - Parte do código gráfico responsável pela estimativa de temperaturas.

Figura 3.25 - Ambiente para visualização e definição de temperaturas.

Figura 3.26 - Ambiente para seleção das temperaturas medidas e visualização das temperaturas estimadas.

Figura 3.27 - Ambiente para apresentação de deformações após compensação dos efeitos da temperatura.

Figura 3.28 - Ambiente para visualização das parcelas lineares da temperaturas analisadas.

Figura 3.29 - Ambiente para cálculo das deformações devidas à fluência.

Figura 3.30 - Ambiente para cálculo das deformações devidas à retração.

Figura 3.31 - Ambiente para apresentação dos resultados finais.. 
CAPÍTULO 4 - MONITORAÇÃO DO COMPORTAMENTO DA PONTE SOBRE O RIO SORRAIA

$\begin{array}{lll}\text { Figura } 4.1-\text { Vista da ponte sobre o rio Sorraia. } & 114\end{array}$

Figura 4.2 - Vista geral da obra durante a fase construtiva. 116

Figura 4.3 - Vista da ponte sobre o rio Sorraia durante construção. 116

Figura 4.4 - Tabuleiro da ponte, com indicação de elementos relevantes. 117

Figura 4.5 - Aplicação do método do avanços sucessivos na ponte sobre o rio Sorraia. 117

Figura 4.6 - Sensor de deformação comercial utilizado, próprio para ser embutido no 119 concreto.

Figura 4.7 - Cabeça sensora típica: características básicas (a) e aspecto final (b). 120

Figura 4.8 - Localização das seções instrumentadas da ponte sobre o rio Sorraia. $\quad 120$

Figura 4.9 - Identificação dos alinhamentos de referência. 121

Figura 4.10 - Estacas contempladas no plano de monitoração. 121

Figura 4.11 - Exemplos de sensores de temperatura (a) e umidade relativa (b) 122 existentes na ponte.

Figura 4.12 - Localização dos postos de observação do sistema de monitoração 123 permanente.

Figura 4.13 - Sistema de aquisição elétrico (a) e sistema de aquisição óptico (b). 124

Figura 4.14 - Arquitetura do subsistema de comunicação. 126

Figura 4.15 - Ambiente de configuração dos parâmetros da comunicação. 126

Figura 4.16 - Arquitetura do subsistema de processamento de dados. 127

$\begin{array}{lr}\text { Figura } 4.17 \text { - Arquitetura utilizador/servidor. } & 128\end{array}$

Figura 4.18 - Estrutura da base de dados. 131

Figura 4.19 - Página de entrada do site. 134

Figura 4.20 - Ambiente de consulta dos resultados a partir das seções instrumentadas (a), com sub-área para consulta por alinhamento, durante a prova de carga (b) e gráficos com resultados correspondentes às seleções realizadas (c).

Figura 4.21 - Ambiente de consulta dos resultados a partir dos alinhamentos (a), e curvas com resultados correspondentes às seleções realizadas (b).

Figura 4.22 - Ambiente de consulta dos resultados a partir de um sensor, na opção intervalo de tempo. 
Figura 4.23 - Ambiente para comunicação com os dataTaker DT500 instalados na obra.

Figura 4.24 - Seções instrumentadas da ponte.

Figura 4.25 - Seção S5.

Figura 4.26 - Janela de seleção de arquivo a ser lido.

Figura 4.27 - Visualização das deformações.

Figura 4.28 - Deformações selecionadas: ES5-2S.

Figura 4.29 - Visualização dos valores originais e filtrados.

Figura 4.30 - Utilização da janela auxiliar.

Figura 4.31 - Apresentação das temperaturas da seção.

Figura 4.32 - Seleção das temperaturas da seção, para análise.

Figura 4.33 - Compensação dos efeitos térmicos.

Figura 4.34 - Apresentação de histogramas da amostra original e dos valores compensados.

Figura 4.35 - Gráficos das parcelas térmicas computadas.

Figura 4.36 - Apresentação da estimativa das deformações devidas à fluência.

Figura 4.37 - Apresentação das temperaturas utilizadas na estimativa da deformação por fluência.

Figura 4.38 - Apresentação das deformações por fluência em um período selecionado.

Figura 4.39 - Apresentação da estimativa das deformações devidas à retração.

Figura 4.40 - Apresentação das deformações por retração em um período selecionado.

Figura 4.41 - Resultados do sensor ES5-2S antes (em vermelho) e depois das filtragens (em azul).

Figura 4.42 - Resultados do sensor ES5-2S antes (em vermelho) e depois das filtragens (em azul).

Figura 4.43 - Valores médios e desvios-padrão das deformações.

Figura 4.44 - Variação dos valores médios e dos desvios-padrão das deformações, em relação às deformações medidas.

\section{CAPÍTULO 5 - MONITORAÇÃO DO COMPORTAMENTO DA PONTE DO PINHÃO}

Figura 5.1 - Vista da ponte do Pinhão. 
Figura 5.2 - Ponte do Pinhão, com indicação dos tramos e pilares.

Figura 5.3 - Seções típicas: (a) longarina, (b) transversina e (c) contraventamento 160 inferior.

Figura 5.4 - Seção transversal de um dos tramos da ponte do Pinhão, passando a meio-vão.

Figura 5.5 - Vista inferior do primeiro tramo da Ponte do Pinhão, apresentando a designação para os elementos estruturais instrumentados.

Figura 5.6 - Vista do lado de montante do primeiro tramo da Ponte do Pinhão, apresentando a designação para os elementos estruturais instrumentados.

Figura 5.7 - Aspecto do extensômetro elétrico pronto para ser instalado.

Figura 5.8 - Ilustração de um extensómetro colado na superfície metálica.

Figura 5.9 - Extensômetros instalados nas seções S1, S2, S3, S4, S5 e S6.

Figura 5.10 - Extensômetros instalados nas secções S7, S8, S9, S10, S11 e S12.

Figura 5.11 - Plantas do primeiro tramo: (a) superior e (b) inferior.

Figura 5.12 - Extensômetros instalados nas seções S13 a S16.

Figura 5.13 - Extensômetros instalados na seção S17.

Figura 5.14 - Localização dos extensômetros instalados na seção S1

Figura 5.15 - Localização dos extensômetros ES1-2 (a) e ES1-1 (b), instalados na seção S1.

Figura 5.16 - Localização dos extensômetros instalados na seção S4.

Figura 5.17 - Ilustração dos extensômetros da seção S4.

Figura 5.18 - Sensores de deslocamento utilizados: sensor de pressão (modelo TS-01) e comparador elétrico.

Figura 5.19 - Localização dos sensores de deslocamento: Iongitudinalmente (a), sob a $3^{a}$ transversina (b) e esquema de ligação do sensor de pressão (c).

Figura 5.20 - Sensores de deslocamento após instalação: sensor de pressão DV3 (a) e comparador elétrico DV5.

Figura 5.21 - Localização dos transdutores de deslocamento para abertura de junta DJE1 e DJE2.

Figura 5.22 - Transdutores para medição de movimentos longitudinais DJE1 (a) e DJE2 (b).

Figura 5.23 - Ilustração dos inclinômetros biaxiais I1 (a) e I2 (b).

Figura 5.24 - Localização dos sensores T1, T2, T3 e T4: em corte (a) e em planta (b). 
Figura 5.25 - Sensor de temperatura T2.

Figura 5.26 - Localização do posto de observação PO1: vista lateral (a) e em planta (b).

Figura 5.27 - Posto de observação PO1.

Figura 5.28 - Localização do posto de observação PO2: vista lateral (a) e em planta (b).

Figura 5.29 - Posto de observação PO2.

Figura 5.30 - Características do veículo proposto para a prova de carga.

Figura 5.31 - Veículos durante o percurso A: posições 1 a 3 (a); disposição dos veículos (b);veículos na posição 3 (c) e na posição 4 (d).

Figura 5.32 - Veículos durante o percurso A: posições 4 a 6 (a), veículo A (b) e veículo $B$ (c) em marcha lenta.

Figura 5.33 - Posição dos veículos na seção transversal do tabuleiro: veículos A, B e C centrados na faixa de rodagem para os casos de carga 1a 6 (a), veículo $A$ em marcha lenta encostado na via mais a jusante (b), veículo B em marcha lenta encostado na via mais a montante (c) e veículo $\mathrm{C}$ em marcha lenta centrado na faixa de rodagem (d).

Figura 5.34 - Condução da prova de carga: Veículos durante o percurso A, na posição 3.

Figura 5.35 - Evolução da temperatura no decorrer do ensaio, medida pelos sensores T1, T2, T3 e T4.

Figura 5.36 - Deformações registradas na seção S2 ( $3^{a}$ diagonal a montante do lado do Pinhão).

Figura 5.37 - Deformações registradas na seção S3 ( $3^{\circ}$ montante a montante do lado do Pinhão).

Figura 5.38 - Deformações registradas na seção S5 (corda superior a meio-vão do $1^{\circ}$ tramo do lado de montante).

Figura 5.39 - Deformações registradas na seção S6 (corda inferior a meio-vão do $1^{\circ}$ tramo do lado de montante).

Figura 5.40 - Deformações registradas na seção S16 (meio-vão da 3ª longarina do lado do Pinhão).

Figura 5.41 - Deformações registradas na seção S15 (meio-vão da $3^{a}$ transversina do lado do Pinhão).

Figura 5.42 - Deslocamentos a meio-vão de cada tramo da ponte, medidos com os sensores de pressão DV1, DV2, DV3 e DV4.

Figura 5.43 - Deslocamentos verticais medidos na $3^{a}$ transversina do $1^{\circ}$ tramo, do lado do Pinhão, sendo utilizados os comparadores elétricos DV5, DV6 e DV7.

Figura 5.44 - Abertura da junta de dilatação localizada do lado do apoio móvel no $1^{\circ}$ tramo. 
Figura 5.45 - Rotações da seção do encontro E1, com Pinhão, do lado de Jusante, segundo a direção longitudinal.

Figura 5.46 - Modelo numérico para análise.

\section{CAPÍTULO 6 - MONITORAÇÃO DA LAJE DE FUNDO DA ESTAÇÃO METROVIÁRIA ALTO DO IPIRANGA}

Figura 6.1 - Construção da Estação Alto do Ipiranga, em São Paulo. Fotografias tiradas nos dias 25 de maio (a) e 22 de agosto de 2006 (b).

Figura 6.2 - Parede da estação. Camada de concreto projetado (a) e camada de concreto moldado (b). Fotografias de 12 de maio e 22 de agosto de 2006, respectivamente.

Figura 6.3 - Figura 6.3 - Execução da laje de fundo da estação. Preparação da superfície para lançamento do lastro de concreto magro (a) e posicionamento das armaduras negativas da laje (b). Fotografias de 12 de maio e 19 de maio de 2006, respectivamente.

Figura 6.4 - Planta da Estação Metroviária Alto do Ipiranga, na cota da laje de fundo. A região delimitada pela circunferência vermelha corresponde à área monitorada, sob o pilar P1.

Figura 6.5 - Unidades de medição para sensores ópticos utilizados na monitoração da estação: braggmeter de bancada (a) e braggmeter portátil (b).

Figura 6.6 - Sensor para medição de pressões sob a laje de fundo da estação (a) e detalhe da região sensível à variação da pressão, revestida por uma pedra porosa (b).

Figura 6.7 - Localização do sensor de poro-pressão, instalado sob o pilar P1, em planta (a) e em perfil (b).

Figura 6.8 - Sensor óptico para medição de deformações, com revestimento da região sensora e proteção metálica do cabo. Este tipo de sensor foi empregado na monitoração, e é adequado para ser embebido no concreto.

Figura 6.9 - Localização dos sensores de deformação nas armaduras (E2, E3, E4, EA, $E B, E C$ e ED) e dos sensores de deformação de embeber no concreto (C1, C2, C3 e C4). Sensores da região inferior (a) e superior (b) da laje de fundo.

Figura 6.10 - Sensor óptico para medição de temperaturas utilizado, com revestimento da região sensora e proteção metálica do cabo.

Figura 6.11 - Instalação do sensor de poro-pressão. Realização de abertura no lastro de concreto (a) para introdução do piezômetro (b, c).

Figura 6.12 - Testes para verificação do sinal fornecido pelo sensor de poro-pressão (a) e resultados obtidos (b), os quais confirmaram o adequado funcionamento do piezômetro.

Figura 6.13 - Preparação da superfície para colagem dos sensores de deformação nas armaduras $(a, b, c)$.

Figura 6.14 - Aspecto do sensor de deformação imediatamente após colagem na armadura. O dedo aponta para a região sensora da fibra. 
Figura 6.15 - Sensor de temperatura antes da instalação, com região sensora, fibra e conectores protegidos (a), e após a instalação.

Figura 6.16 - Arranjo da instalação no dia 15 de maio, antes da introdução da caixa de passagem (a) e aspecto final, com caixa de passagem para protegendo os conectores.das operações da concretagem (b).

Figura 6.17 - Apresentação esquemática dos sensores instalados na etapa 1.

Figura 6.18 - Condições da obra três dias antes do início das atividades da segunda etapa.

Figura 6.19 - Vista geral da obra no dia de início dos trabalhos da segunda etapa.

Figura 6.20 - Trabalho de regularização das armaduras (a), e aspecto final da região de aplicação do sensor, já regularizado e limpo (b).

Figura 6.21 - Aspecto dos sensores e da fibra óptica após a proteção (a) e trabalho de verificação dos sinais dos sensores instalados (b).

Figura 6.22 - Sensor para medição de deformações no concreto antes da instalação, com região sensora e fibra protegidos (a), e após a instalação (b), ao lado dosensor de deformaçãocolado na armadura.

Figura 6.23 - Sensor de temperatura após a instalação.

Figura 6.24 - Preparativos para o transporte dos conectores dos sensores instalados na etapa 1 para a novacaixa de passagem. $(a, b)$, que foi feito utilizando eletrodutos (c).

Figura 6.25 - Concretagem da segunda camada da laje de fundo da Estação Alto do Ipiranga (a) e caixa de passagem instalada no dia anterior.

Figura 6.26 - Representação esquemática dos sensores instalados na etapa 2.

Figura 6.27 - Opções de transporte do equipamento óptico de medição:guindaste $(a, b)$ ou escada da obra (c).

Figura 6.28 - Utilização da versão portátil da unidade óptica de medição.

Figura 6.29 - Etapa 3: coleta de resultados mediante transporte dos sinais da laje de fundo à superfície.

Figura 6.30 - Posicionamento do duto (a)e do cabo óptico (b).

Figura 6.31 - Emenda de fibras ópticas durante operações de introdução de conectores.

Figura 6.32 - Evolução da pressão na laje de fundo durante a monitoração.

Figura 6.33 - Evolução da deformação do concreto da laje de fundo.

Figura 6.34 - Excentricidade da força normal e provável distribuição simplificada das tensões no concreto, entre C2 e C1.

Figura 6.35 - Evolução das deformações das armaduras posicionadas na face superior da laje de fundo. 
Figura 6.36 - Evolução das deformações da armadura inferior da laje de fundo durante 240 a monitoração.

Figura 6.37 - Evolução da temperatura no concreto. 


\section{LISTA DE TABELAS}

\section{CAPÍTULO 2 - SISTEMAS DE MONITORAÇÃO \\ Tabela 2.1 - Principais características de alguns tipos de termopares (Fonte: STEPHENSON,1999).}

\section{CAPÍTULO 3 - SISTEMA DE VISUALIZAÇÃO E TRATAMENTO DE DADOS}

Tabela 3.1 - Características geométricas das seções estudadas. 97

Tabela 3.2 - Diferenças dimensionais e variações das parcelas térmicas. 97

$\begin{array}{lll}\text { Tabela } 3.3-\text { Valores de } k_{h} & 109\end{array}$

\section{CAPÍTULO 4 - MONITORAÇÃO DO COMPORTAMENTO DA PONTE SOBRE O RIO SORRAIA}

Tabela 4.1 - Cabeças sensoras instaladas no tabuleiro da ponte. 121

Tabela 4.2 - Características técnicas dos sensores de deformação instalados. 122

Tabela 4.3 - Distribuição dos sensores para medição de temperaturas e umidades 123 relativas.

\section{CAPÍTULO 5 - MONITORAÇÃO DO COMPORTAMENTO DA PONTE DO PINHÃO}

Tabela 5.1 - Principais características técnicas dos extensômetros elétricos utilizados. 165

Tabela 5.2 - Localização dos extensômetros instalados. 167

Tabela 5.3 - Descrição dos sensores de deslocamento instalados. 174

Tabela 5.4 - Especificações técnicas dos comparadores elétricos utilizados. 176

Tabela 5.5 - Especificações técnicas dos sensores de pressão. 176

Tabela 5.6 - Transdutores de deslocamentos para medição de aberturas de juntas. 177

Tabela 5.7 - Especificações técnicas dos LVDT's. 178

Tabela 5.8 - Inclinômetros instalados. 179

Tabela 5.9 - Características técnicas dos inclinômetros elétricos utilizados. 179

Tabela 5.10 - Sensores de temperatura instalados. 180 
Tabela 5.11 - Designação dos veículos.

Tabela 5.12 - Peso por eixo dos veículos utilizados na prova de carga.

Tabela 5.13 - Características geométricas e peso dos veículos utilizados na prova de carga.

Tabela 5.14 - Principais resultados pretendidos.

Tabela 5.15 - Sequência da prova de carga.

Tabela 5.16 - Deformações nas seções S13 e S16.

Tabela 5.17 - Deformações máximas obtidas na prova de carga.

Tabela 5.18 - Deformações máximas obtidas durante as passagens lentas.

Tabela 5.19 - Deslocamentos verticais máximos obtidos na prova de carga.

Tabela 5.20 - Deslocamentos verticais máximos obtidos durante as passagens lentas.

Tabela 5.21 - Abertura de junta e rotações máximas obtidas na prova de carga.

Tabela 5.22 - Deformações nos elementos estruturais: valores medidos e resultado numérico.

Tabela 5.23 - Flechas, abertura da junta e rotações da ponte do Pinhão: valores medidos e resultado numérico.

\section{CAPÍTULO 6 - MONITORAÇÃO DA LAJE DE FUNDO DA ESTAÇÃO METROVIÁRIA ALTO DO IPIRANGA}

Tabela 6.1 - Principais características técnicas do sensor de poro-pressão.

Tabela 6.2 - Principais características técnicas dos sensores ópticos de deformação para concreto.

Tabela 6.3 - Principais características técnicas dos sensores ópticos para medição de temperaturas utilizados.

Tabela 6.4 - Atividades de instrumentação.

Tabela 6.5 - Pressões na laje de fundo obtidas por meio da monitoração.

Tabela 6.6 - Deformações do concreto da laje de fundo.

Tabela 6.7 - Deformações das armaduras posicionadas na face superior da laje de

Tabela 6.8 - Deformações da armadura inferior da laje de fundo.

Tabela 6.9 - Temperatura do concreto da primeira camada da laje de fundo. 


\section{LISTA DE ABREVIATURAS E SIGLAS}

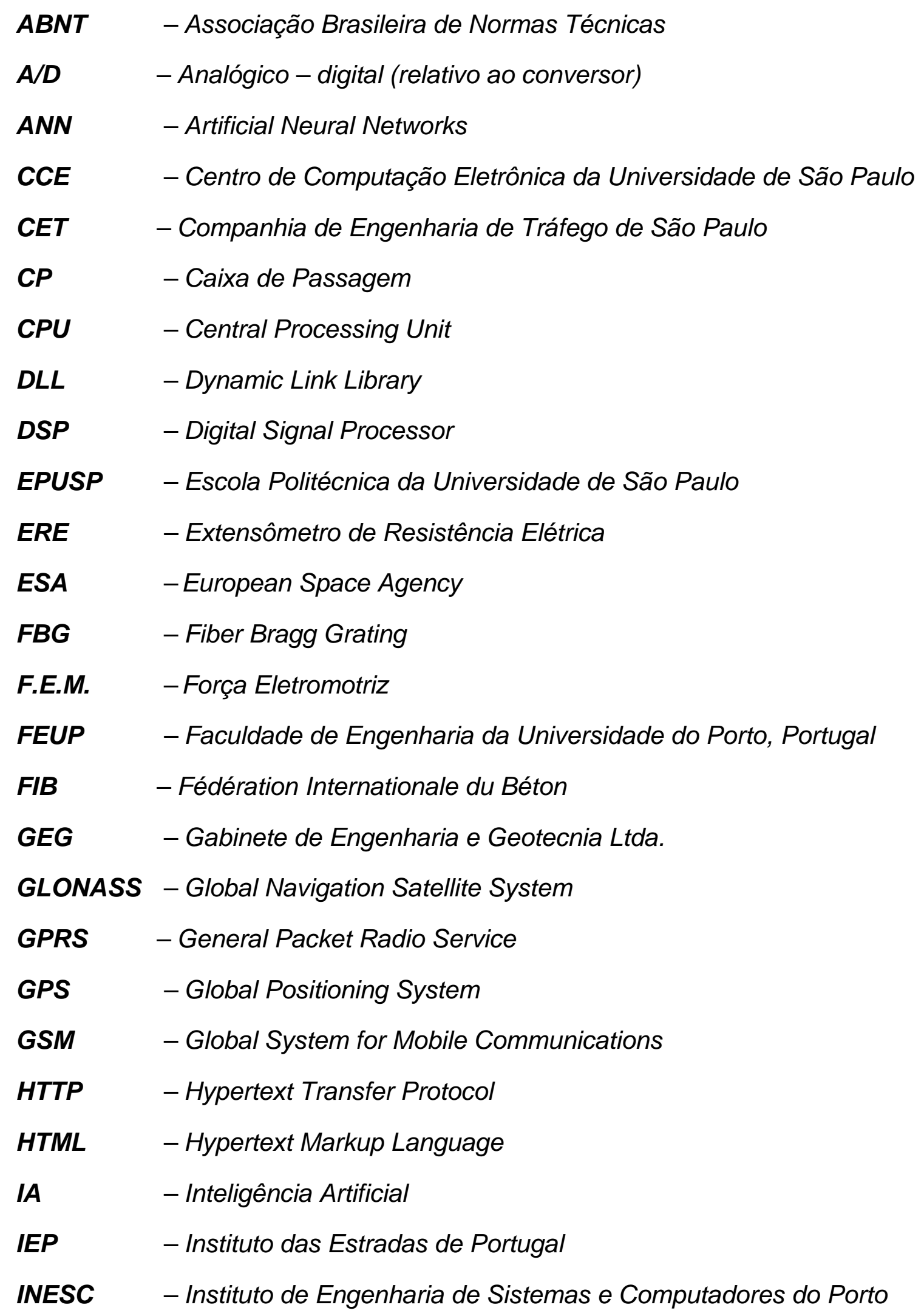


IPT - Instituto de Pesquisas Tecnológicas do Estado de São Paulo

LABEST - Laboratório da Tecnologia do Betão e do Comportamento Estrutural

LabVIEW - Laboratory Virtual Instrument Engineering Workbench

LVDT - Linear Variable Differential Transformer

MEMS - Micro Electro Mechanical Systems

Metrô - Companhia do Metropolitano de São Paulo

MIT - Massachussets Institute of Technology, EUA

NATM - New Austrian Tunneling Method

$\mathrm{PCl} \quad-$ Peripheral Component Interconnect

PCMCIA - Personal Computer Memory Card International Association

PHP - Hypertext Preprocessor

RNA - Redes Neurais Artificiais

RSSF $\quad-$ Rede de Sensores Sem Fio

RTD - Resistance Temperature Detector

SPRT - Standard Platinum Resistance Thermometers

SQL - Structured Query Language

TCP / IP - Transfer Control Protocol / Internet Protocol

UCC - Unidade Central de Controle

UNICAMP - Universidade Estadual de Campinas

UL _ - Unidade Local

UR $\quad$ - Unidade Remota

URL - Universal Resource Locator

USB - Universal Serial Bus

USD - United States Dollar (Dólar Americano)

VI $\quad-$ Virtual Instrument

WSN $\quad-$ Wireless Sensor Networks 


\section{LISTA DE SÍMBOLOS}

\section{Letras romanas maiúsculas}
A, $\mathbf{A}_{\mathbf{c}} \quad$ - Área da seção transversal
D - Diâmetro
$\mathbf{E}_{\mathrm{c}} \quad-$ Módulo de elasticidade do concreto
$\mathbf{E}_{\mathrm{cm}} \quad-$ Módulo de elasticidade do concreto aos 28 dias
Es $\quad-$ Módulo de elasticidade do aço
F $\quad-$ Força
GF - - Gage factor (fator de calibração)
I- - Momento de inércia
$\mathbf{K}_{\mathbf{v}} \quad-$ Constante inerente a sensores de corda vibrante
L $\quad-$ Comprimento
$\mathbf{L}_{c} \quad-$ Comprimento de referência
R $\quad$ - Resistência elétrica de um condutor
$\mathbf{R}_{\mathbf{T}} \quad-$ Resistência elétrica de um condutor à temperatura $\mathrm{T}$
T $\quad$ - Temperatura
$\mathbf{T}_{\mathbf{L}} \quad-$ Parcela linear da temperatura
$\mathbf{T}_{\mathrm{LS}}-\mathbf{T}_{\mathrm{LI}} \quad$ - Diferencial térmico linear
$\mathbf{T}_{\mathrm{NL}} \quad-$ Parcela não-linear da temperatura
Tu $\quad-$ Temperatura uniforme
TI - - Temperatura na fibra inferior
TS - - Temperatura na fibra superior
V - Diferença de potencial elétrico

Letras romanas minúsculas

a

- Aceleração 
$\mathbf{f}_{\mathrm{cm}}$

$f_{c k}$

$\mathbf{f}_{0}$

$\mathbf{f}_{\mathrm{f}}$

$\mathbf{f}_{u}$

$f_{y}$

h

h

k

k

I

m

n - Índice de refração

$\mathbf{n}_{\text {eff }} \quad-$ Índice de refração efetivo

$p_{e}-$ Coeficiente foto-elástico da rede de Bragg

r $\quad-$ janela de filtro

t - Instante no qual é realizada uma medição

x - Deslocamento

$\mathbf{x}_{0}-$ Valor de uma grandeza medida em vazio

y $\quad$ - Ordenada

yG _ Ordenada do centro de massa de uma seção

\section{Letras gregas maiúsculas}

$\Lambda \quad-$ Período espacial da modulação da rede de Bragg

\section{Letras gregas minúsculas}

$\alpha_{a} \quad-$ Ângulo limite 


$\begin{array}{ll}\alpha_{c} & - \text { Coeficiente de dilatação linear do concreto } \\ \alpha_{N} & - \text { Constante inerente a sensores de temperatura } \\ \varepsilon & - \text { Deformação específica } \\ \varepsilon_{0} & - \text { Deformação específica inicial } \\ \varepsilon_{c s} & - \text { Deformação de retração autógena } \\ \varepsilon_{c s} & - \text { Deformação total por retração } \\ \varepsilon_{c d} & - \text { Deformação de retração por secagem } \\ \varepsilon_{f} & - \text { Deformação específica final } \\ \zeta & - \text { Coeficiente termo-óptico da rede de Bragg } \\ \lambda_{B} & - \text { Comprimento de onda de Bragg } \\ \mu & - \text { Resistividade elétrica } \\ \rho & - \text { Coeficiente de Poisson } \\ \nu & \end{array}$




\section{SUMÁRIO}

RESUMO

I

ABSTRACT

II

LISTA DE FIGURAS

III

LISTA DE TABELAS

XIV

LISTA DE ABREVIATURAS E SIGLAS

XVI

LISTA DE SÍMBOLOS

XVIII

CAPÍTULO 1 - INTRODUÇÃO

1.1 - Considerações iniciais

1.2 - Objetivos e justificativa

1.3 - Organização da tese

CAPÍTULO 2 - SISTEMAS DE MONITORAÇÃO

2.1 - Introdução

2.2 - Componentes dos sistemas de monitoração

2.2.1 - Rede de sensores

2.2.1.1 - Rede de sensores sem fios

2.2.2 - Aquisição de dados

2.2.3 - Comunicação

2.2.4 - Tratamento de dados

2.2.5 - Avaliação e gestão dos resultados

2.3 - Métodos de medição das principais grandezas de interesse 29

2.3.1 - Deformações

2.3.1.1 - Sensores mecânicos

2.3.1.2 - Sensores elétricos

2.3.1.3 - Sensores de corda vibrante

2.3.2 - Deslocamentos 
2.3.4 - Temperatura e umidade $\quad 49$

2.3.5 - Acelerações 54

2.3.6 - Sensores a fibra óptica $\quad 56$

2.3.6.1 - Vantagens dos sensores a fibra óptica $\quad 62$

2.3.6.1.1 - Baixa atenuação 62

2.3.6.1.2 - Imunidade a interferência eletromagnética
e ruídos

2.3.6.1.3 - Isolamento elétrico 64

2.3.6.1.4 - Dimensões e peso reduzidos 64

2.3.6.1.5 - Segurança da informação e do sistema 65

2.3.6.2 - Desvantagens dos sensores a fibra óptica $\quad 65$

2.3.6.2.1 - Fragilidade 65

2.3.6.2.2 - Dificuldade de reparação em campo 66

2.3.6.2.3 - Competitividade econômica limitada a $\quad 67$

2.3.6.3 - Sensores convencionais x Sensores a fibra 68 óptica DE DADOS

3.3.1 - Metodologia para estimativa de temperaturas em uma seção

3.3.2 - Ambientes de visualização e filtragem de sinais de temperaturas

3.3.3 - Metodologia para compensação dos efeitos da temperatura nas deformações 
3.3.4 - Ambiente para estimativa da deformação por fluência 105

3.3.5 - Ambiente para estimativa da deformação por 108 retração

3.3.6 - Ambiente para apresentação dos resultados finais PONTE SOBRE O RIO SORRAIA

4.1 - Introdução

4.2 - Descrição da estrutura

4.3 - Descrição do sistema de monitoração

4.3.1 - Subsistema sensorial

4.3.1.1 - Medição de deformações

4.3.1.2 - Medição de temperatura e umidade relativa

4.3.1.3 - Sistema de aquisição de dados

4.3.2 - Subsistema de comunicação

4.3.2.1 - Arquitetura do subsistema de comunicação

4.3.3 - Subsistema de processamento de dados

4.3.3.1 - Arquitetura do subsistema de processamento de dados

4.3.3.2 - Descrição do funcionamento do sistema

4.3.3.3 - Sistema de consulta à base de dados (SCBD)

4.3.3.4 - Interface Web

4.3.4 - Avaliação do sistema de monitoração

4.4 - Aplicação do sistema de visualização e tratamento de dados

4.4.1 - Descrição do problema

4.4.2 - Aplicação à seção S5

4.4.3 - Análise dos resultados 
CAPÍTULO 5 - MONITORAÇÃO DO COMPORTAMENTO DA PONTE DO PINHÃO

5.1 - Introdução

5.2 - Descrição da estrutura 158

5.3 - Sistema de medição instalado 161

5.3.1 - Medição das deformações 163

5.3.2 - Medição de deslocamentos verticais 173

5.3.3 - Medição da abertura da junta de dilatação

5.3.4 - Medição de rotações

5.3.5 - Medição da temperatura 180

5.3.6 - Sistema de aquisição

5.4 - Condução da prova de carga

5.4.1 - Veículos utilizados 184

5.4.2 - Casos de carga 185

5.4.3 - Realização do ensaio

5.5 - Resultados da medição durante a prova de carga

5.5.1 - Temperatura ambiente 193

5.5.2 - Deformações 194

5.5.3 - Deslocamentos verticais 199

5.5.4 - Abertura da junta de dilatação e rotações

5.6 - Aferição e validação dos resultados da prova de carga

5.6.1 - Modelo de análise

5.6.2 - Interpretação dos resultados da análise numérica

CAPÍTULO 6 - MONITORAÇÃO DA LAJE DE FUNDO DA ESTAÇÃO METROVIÁRIA ALTO DO IPIRANGA

6.1 - Introdução

6.2 - Descrição da obra

6.3 - Sistema de medição instalado

6.3.1 - Medição das pressões

6.3.2 - Medição das deformações 
6.3.4 - Atividades de instalação 218

6.3.4.1 - Etapa 1

6.3.4.2 - Etapa 2

6.3.4.3 - Etapa $3 \quad 229$

6.4 - Apresentação dos resultados 233

6.4.1 - Pressão na cota inferior da laje de fundo 234

6.4.2 - Deformação do concreto 235

6.4.3 - Deformação das armaduras 238

6.4.4 - Temperatura do concreto 241

6.5 - Considerações finais 242

CAPÍTULO 7 - CONCLUSÕES E TRABALHOS FUTUROS 244

7.1 - Conclusões 244

7.2 - Propostas para trabalhos futuros 248

REFERÊNCIAS BIBLIOGRÁFICAS 250 


\section{CAPÍTULO 1}

\section{INTRODUÇÃO}

\subsection{Considerações iniciais}

Nos últimos quinze anos, a monitoração de estruturas de Engenharia Civil tem sido uma área de pesquisa bastante ativa ao redor do mundo, apresentando aplicações e resultados que têm demonstrado o potencial da monitoração como técnica para detectar e até mesmo prever falhas estruturais, com importantes reflexos na segurança e no aumento da vida útil das estruturas monitoradas (BASSEVILLE et al., 2004; GLISIC, INAUDI e VURPILLOT, 2002).

O atual estágio de desenvolvimento das técnicas e equipamentos para a monitoração de estruturas, que utilizam sistemas integrados com componentes de medição inteiramente automatizados, contrasta fortemente com os primeiros métodos de registro de medidas, os quais resumiam-se na observação do processo em andamento e leitura das medidas apresentadas pelos instrumentos de medição, com anotação dos valores em cadernetas. Essa metodologia exigia especial atenção do experimentador, sendo bastante cansativa (LEUCKERT, 2000). Com o advento dos computadores e posterior desenvolvimento de sistemas de aquisição, a atividade de registro de dados sofreu profundas modificações, tornando-se possível automatizar a aquisição e o armazenamento dos dados. Com a contínua disponibilização de recursos computacionais com capacidade de processamento cada vez maior, a Engenharia de Estruturas passou a ter à disposição recursos para a elaboração de modelos matemáticos sofisticados; e a partir dos avanços das pesquisas e desenvolvimentos em áreas como Eletrônica, Fotônica e Engenharia de Materiais, foram disponibilizados instrumentos para a realização de medições que pudessem aferir os resultados dos modelos e hipóteses de projeto, e igualmente 
capazes de fornecer os dados necessários à avaliação da segurança de estruturas em serviço e ao estudo do comportamento estrutural, permitindo conhecer a resposta da estrutura de forma contínua e viabilizando o aprimoramento de projetos futuros.

No cenário internacional, a importância da monitoração de estruturas no âmbito da Engenharia Civil é um fato consolidado. Em países como os EUA, Canadá, Inglaterra e Japão, dentre outros, o problema da degradação prematura de pontes rodoviárias vem sendo investigado com o auxílio de sistemas de monitoração (LAROCCA, 2004). Na figura 1.1 são apresentados dois casos de pontes cuja degradação e problemas de funcionamento motivaram a instalação de sistemas de monitoração.

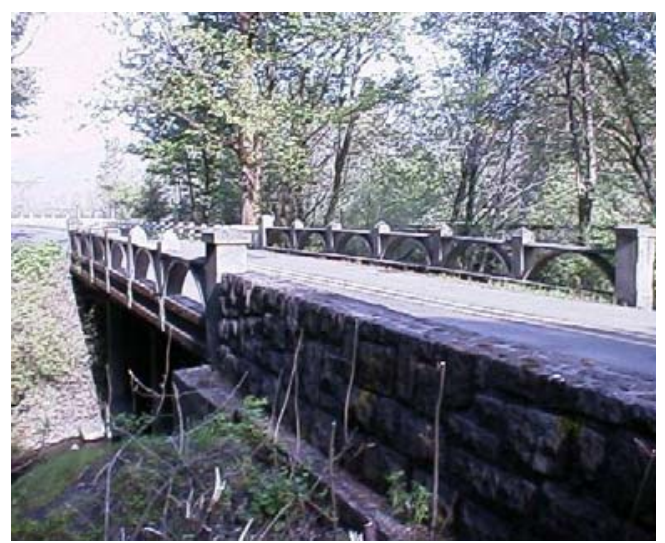

(a)

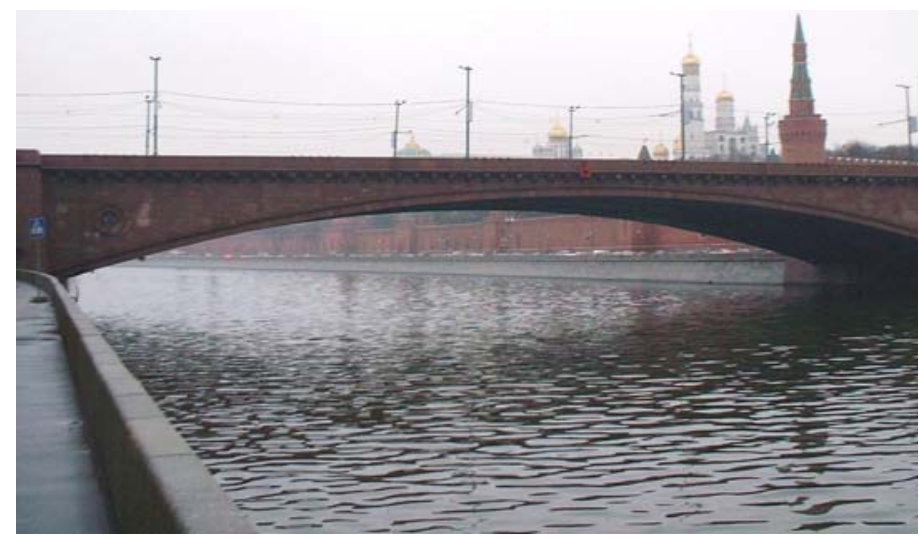

(b)

Figura 1.1 - Exemplos de pontes deficientes monitoradas: Horsetail Fall Bridge, em Oregon, EUA e Bolshoi Moskvoretskiy Bridge, em Moscou, Rússia. Fonte: SMARTEC (2007).

Nos EUA, há mais de seiscentas mil pontes rodoviárias (ALLEN, D. W., 2004), das quais cerca de $40 \%$ encontravam-se estruturalmente deficientes ou funcionalmente obsoletas (MERZBACHER, KERSEY e FRIEBELE, 1996), enquanto que no Japão uma significativa parte da infra-estrutura civil tem sofrido os efeitos da utilização intensiva e crescente ao longo de décadas, o que tem provocado um importante aumento dos gastos com manutenção. Estima-se que nesse país metade das pontes metálicas rodoviárias já excedeu a vida útil prevista, enquanto que cerca de oitocentas pontes em rodovias mantidas pelo governo japonês precisarão ser reconstruídas em um futuro próximo, exigindo investimentos de USD 5,2 bilhões. Esse valor corresponde a 2,6 vezes a quantia dispendida anualmente em manutenção e reabilitação, e a perspectiva de seu crescimento é motivo de 
preocupação para as autoridades governamentais e empresas responsáveis pela gestão de rodovias (MIZUNO, FUJINO e ABE, 2004).

$\mathrm{Na}$ Europa, o problema da deterioração da infra-estrutura civil decorre do fato que boa parte dela já está envelhecida ou envelhecendo, sendo reconhecido que sua reconstrução demandará custos muito superiores ao de um programa criterioso de manutenção das edificações. Este cenário implica na utilização da monitoração como agente capaz de fornecer o estado da estrutura observada com segurança, e seu uso já vem sendo feito em diversas obras em Portugal, Suíça, Itália, Áustria, Alemanha e Bélgica (GROSSO et al., 2001). Duas obras monitoradas na Europa, com instrumentações realizadas após a construção, são apresentadas na figura 1.2.

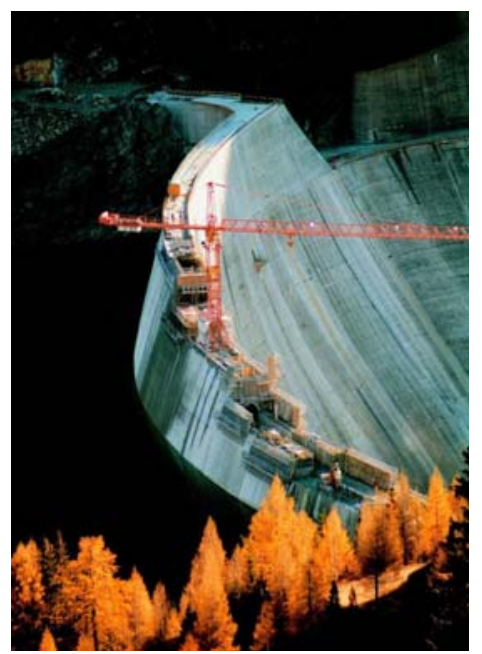

(a)

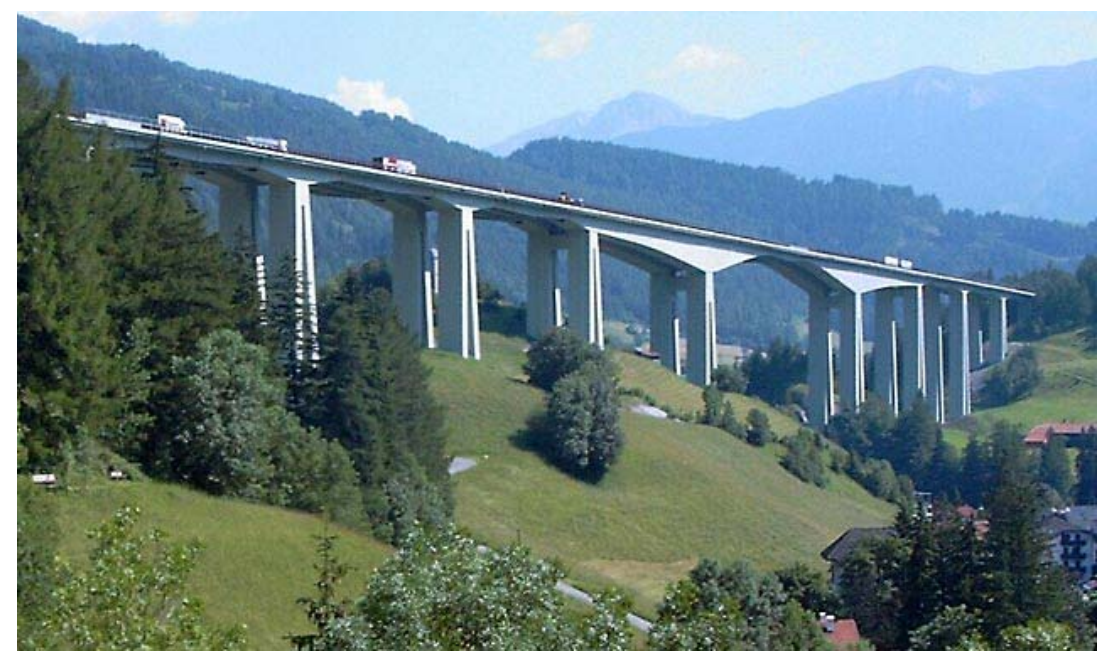

(b)

Figura 1.2 - Exemplos de obras monitoradas na Europa: barragem Luzzone (Bélgica) e ponte Colle d'Isarco (Itália). Fonte: INAUDI (2005).

Entretanto, a utilidade do emprego da monitoração não se restringe às edificações já afetadas pela ação do tempo ou do uso. Já é reconhecido que em estruturas novas, particularmente as que exigem elevados custos de construção, o uso da monitoração desde a fase construtiva é recomendável, pois possibilita identificar problemas ou danos estruturais nas suas etapas iniciais, permitindo a adoção oportuna das intervenções apropriadas. Programas de monitoração desta natureza, se corretamente implementados, podem estender a vida útil da estrutura consideravelmente, justificando economicamente o investimento no sistema de monitoração. Esta forma de pensar tem sido bastante praticada na Europa, nos EUA e na Ásia, principalmente na China, Cingapura, Coréia do Sul e Japão, onde muitos 
edifícios altos, grandes pontes e outras importantes obras possuem soluções de monitoração previstas desde a fase de projeto (KOH, KIM e CHOO, 2005; ZINGONI, 2005). Algumas obras instrumentadas e monitoradas desde a construção são ilustradas nas figuras 1.3, 1.4 e 1.5 .

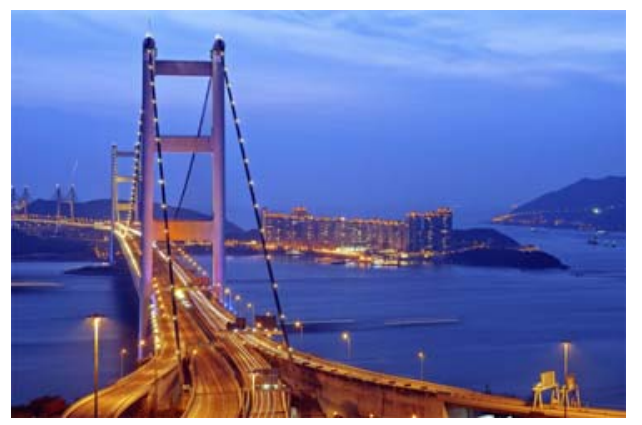

(a)

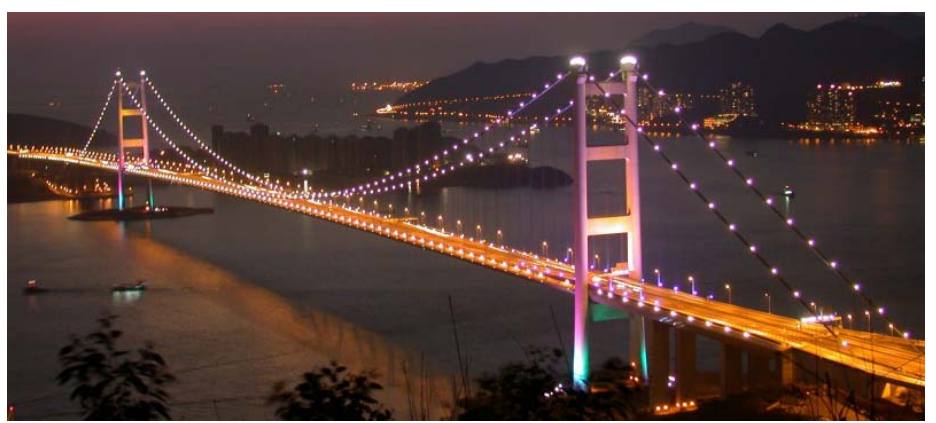

(b)

Figura 1.3 - Tsing Ma Bridge, em Hong Kong, China: ponte pênsil permanentemente monitorada, com instrumentação realizada durante a construção. Fonte: CHAN et al. (2006).

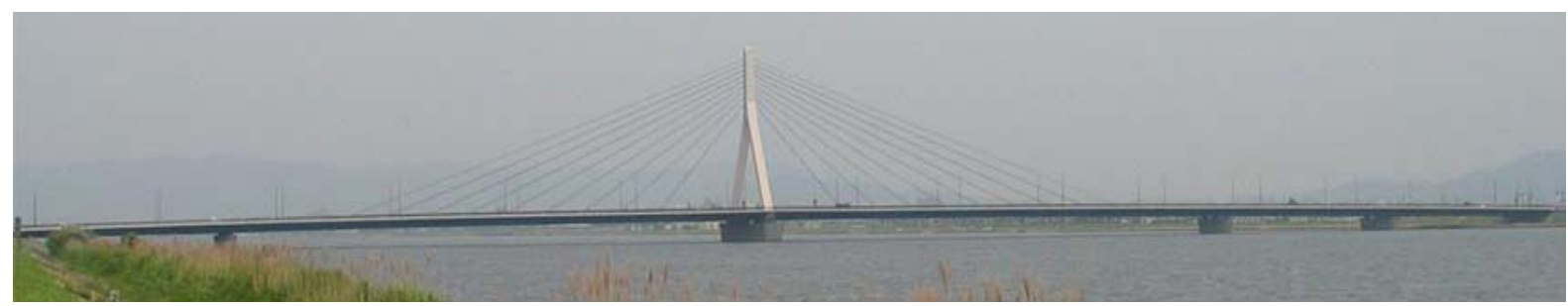

(a)

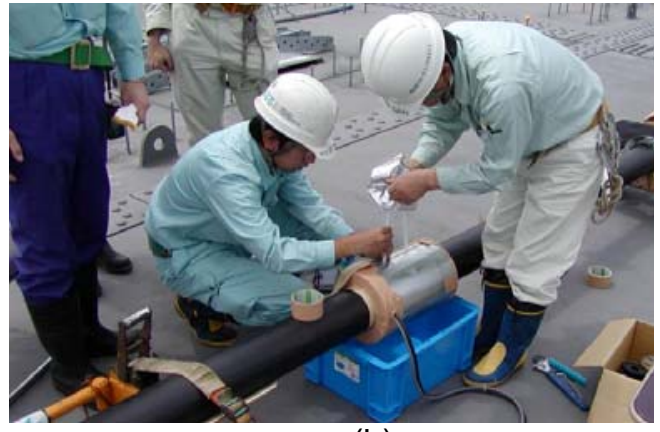

(b)

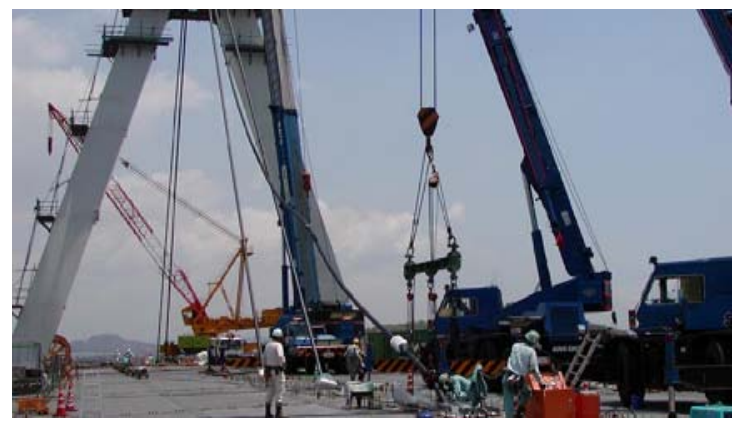

(c)

Figura 1.4 - Ponte Ashidagawa (a), em Fukuyama, Japão, monitorada durante a construção (b, c). Fonte: SUMITRO e WANG (2005); DYNAMAG (2003).

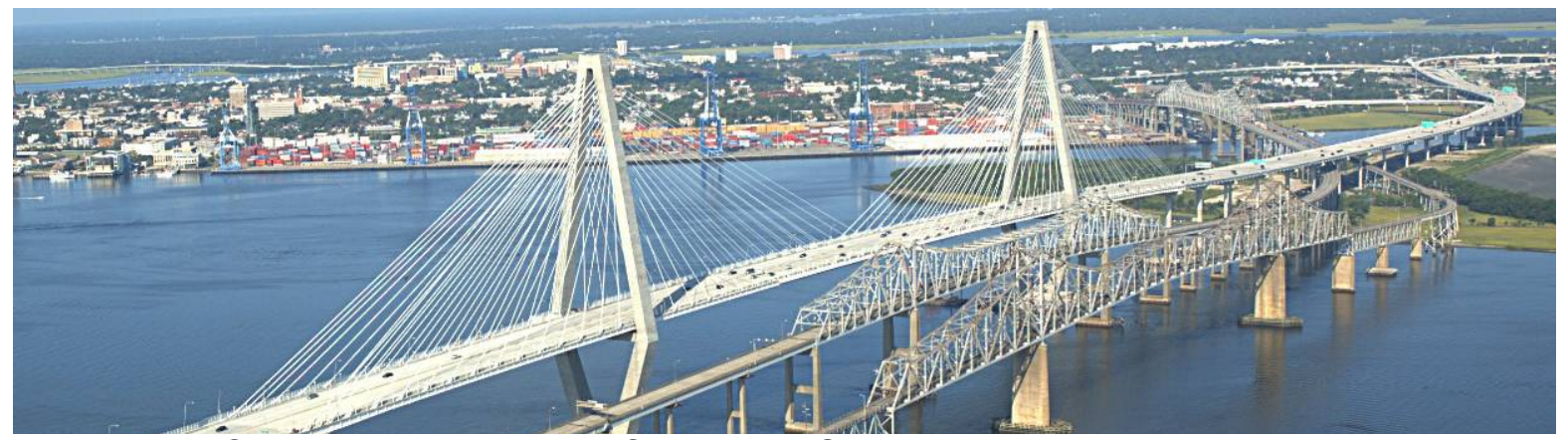

Figura 1.5 - Cooper River Bridge, na Carolina do Sul, EUA: ponte estaiada monitorada durante a construção. Fonte: CTL GROUP (2006); STARMER (2006). 
No Brasil, também podem ser encontrados vários exemplos de obras degradadas pela ação do tempo e da utilização, havendo nesse caso o problema da quase inexistência de políticas de manutenção periódica e preventiva de estruturas. Um caso típico da necessidade de acompanhamento periódico das condições de funcionamento de estruturas importantes e do potencial impacto decorrente da sua negligência ocorreu no dia 3 de junho de 1997. Naquele dia alguns funcionários da Companhia de Engenharia de Tráfego de São Paulo (CET) perceberam uma pronunciada abertura entre as juntas de dilatação em uma das pistas da Ponte dos Remédios, que liga os municípios de Osasco e São Paulo. Foi igualmente observado o repentino crecimento de uma fissura no tabuleiro, junto a um dos pilares, que chegou a atingir $15 \mathrm{~cm}$ de abertura (figura 1.6a). A partir do alerta emitido por esses funcionários, a ponte foi interditada às pressas, afetando todo sistema viário da região e demandando uma das maiores operações viárias da história da cidade, com prejuízos incalculáveis e aumento dos congestionamentos em dezenas de quilômetros por vários dias (KISS, 1999).

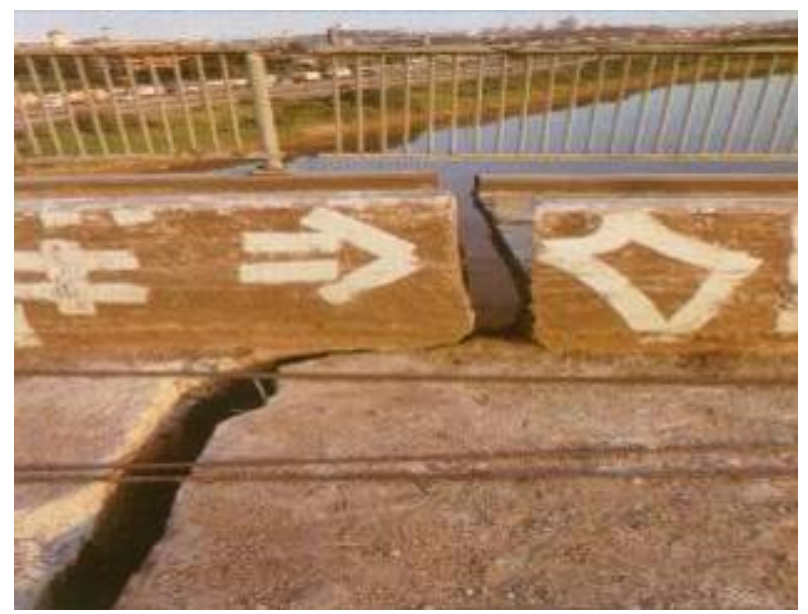

(a)

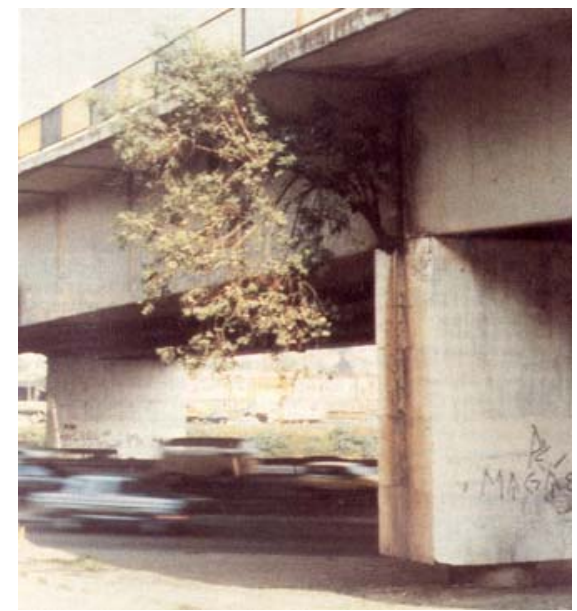

(b)

Figura 1.6 - Ponte dos Remédios durante intervenção. Fonte: COZZA (1997); TÉCHNE (1999).

$\mathrm{Na}$ época com trinta anos e sem manutenção até então (figura 1.6b), a Ponte dos Remédios se encontrava em péssimo estado de conservação, com cabos de protensão rompidos, diversas fissuras pronunciadas e falhas em juntas de dilatação, com séria possibilidade de colapso iminente. Após a conclusão das operações de recuperação estrutural a ponte foi liberada para utilização, mas desde então ela não recebeu qualquer tipo de manutenção, realidade compartilhada pela 
maior parte das pontes, viadutos, e outros importantes componentes da infraestrutura do país (SINAENCO, 2005).

No entanto, há exemplos positivos em relação à preocupação com a adequada condição de funcionamento de estruturas. Em São Paulo, algumas obras foram instrumentadas e monitoradas tendo em vista assegurar o atendimento das hipóteses de projeto ou o acompanhamento do processo construtivo. Uma dessas obras é a ponte estaiada sobre o rio Pinheiros, na qual funciona uma estação da linha 5 do sistema metroviário da cidade (figura 1.7). A ponte tem $220 \mathrm{~m}$ de comprimento, com vão principal de 122 metros. O tabuleiro de concreto protendido é sustentado por estais, ancorados em um pilar de $64 \mathrm{~m}$ de altura.

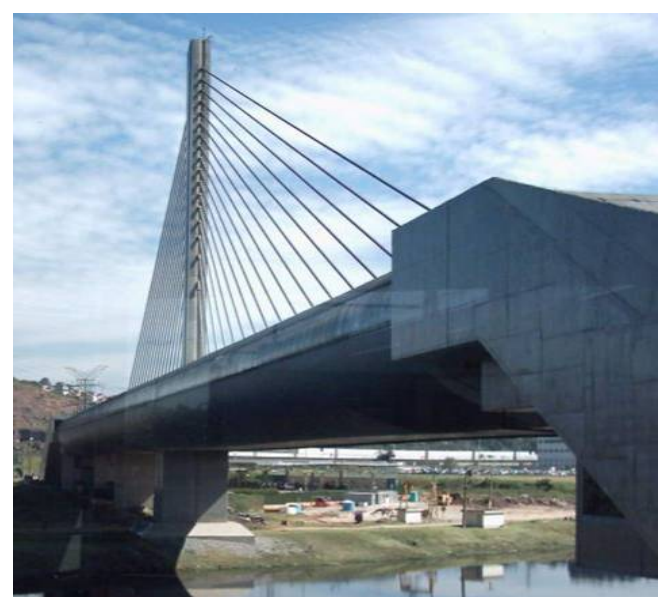

(a)

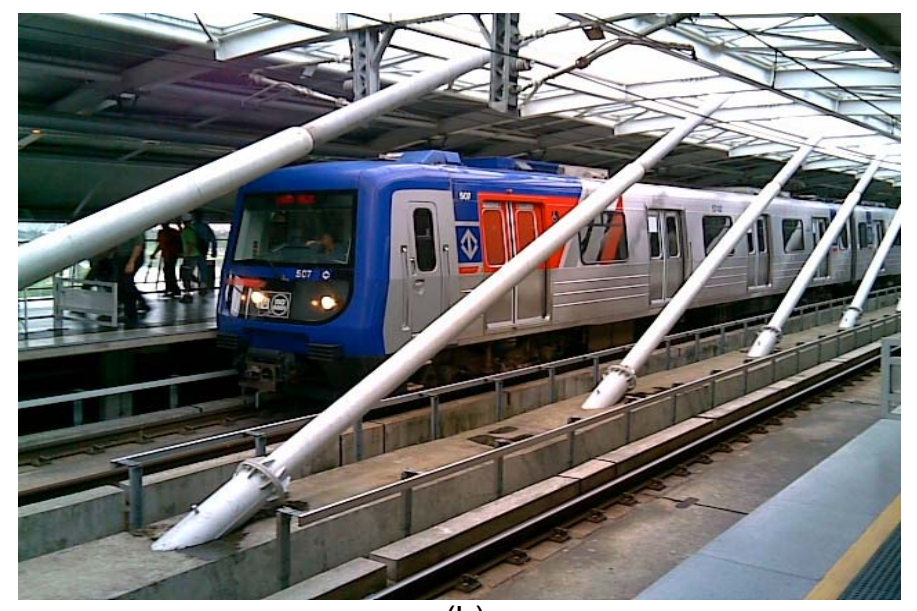

(b)

Figura 1.7 - Ponte estaiada sobre o rio Pinheiros (a), Estação Santo Amaro do Metrô (b).

A ponte foi monitorada da fase construtiva, em 2000, até o início da operação da estação, em 2002, com instrumentação realizada no interior da seção celular e em estais selecionados, sendo utilizados sensores para a medição de temperatura, deformações e acelerações, dentre outros dispositivos de medição (figura 1.8).

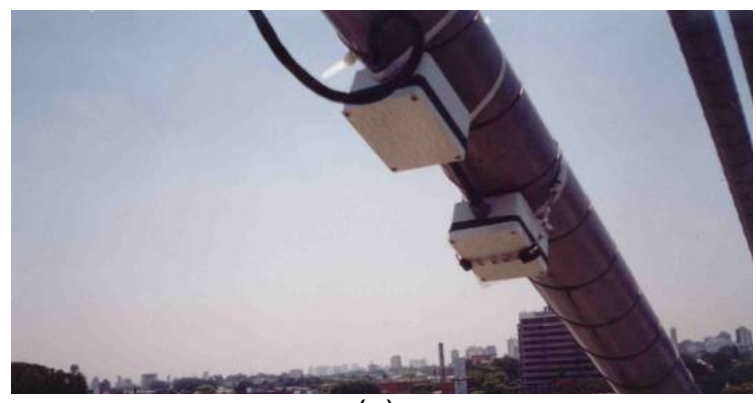

(a)

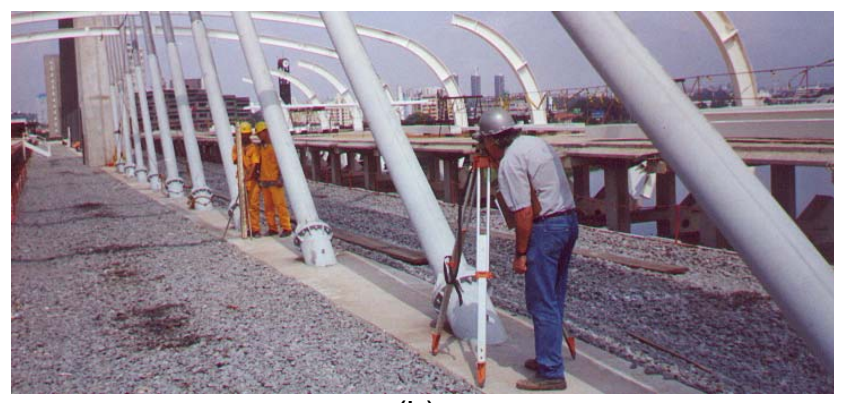

(b)

Figura 1.8 - Acelerômetros instalados em um estai (a) e medição de deslocamentos das aduelas (b). 
Outra importante obra-de-arte monitorada é a ponte Bernardo Goldfarb, localizada no bairro de Pinheiros, em São Paulo. A obra reúne uma complexa geometria dos vãos principais e das rampas de acesso, estruturas com eixos curvos em planta, variação de declividade transversal, largura variável das pistas nos tramos principais e tramos com diferentes comprimentos (figura 1.9).

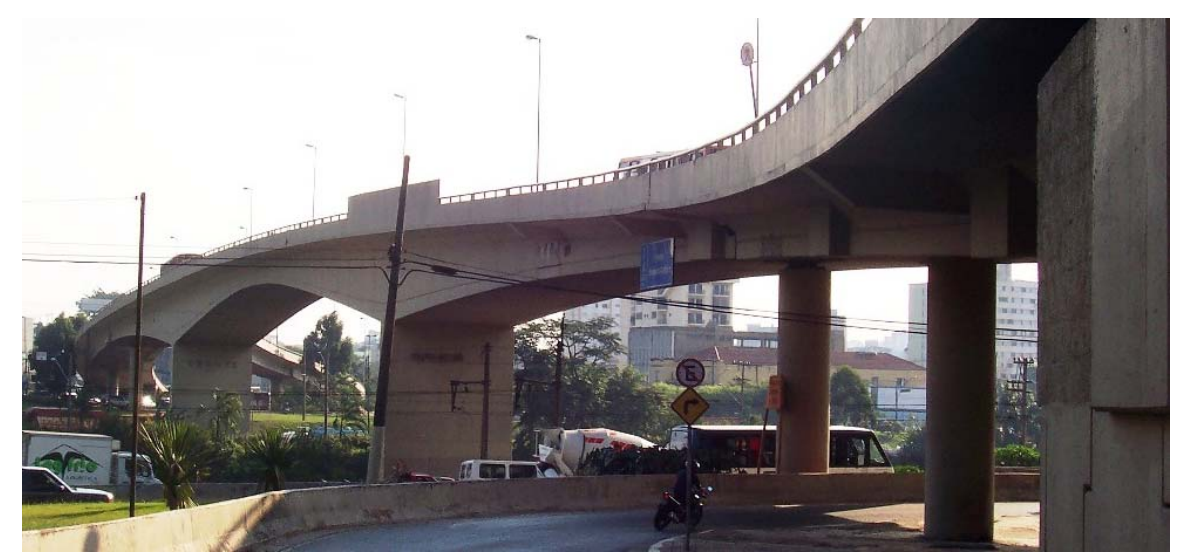

Figura 1.9 - Ponte Bernardo Goldfarb.

Os trabalhos de acompanhamento do comportamento da ponte foram realizados desde a construção, entre dezembro de 1992 e junho de 1994, e retomados posteriormente, entre março de 1996 e dezembro de 1997. A iniciativa de monitorar a ponte partiu da Empresa Municipal de Urbanização de São Paulo (EMURB), e decorreu da complexidade das soluções estruturais e método construtivo (avanços sucessivos) utilizados. O sistema de monitoração instalado contemplou a medição da deformação em dez seções, utilizando extensômetros elétricos, além de sensores elétricos de temperatura e de deslocamento. No final da obra, foi realizada uma prova de carga, na qual doze caminhões-betoneira carregados com brita foram utilizados, medindo-se deslocamentos, rotações e deformações. A repetição do ensaio no futuro permitirá a comparação dos resultados e avaliar o desempenho da estrutura, fornecendo informações capazes de apontar a eventual necessidade de intervenções (TÉCHNE, 1999).

Desde da interdição da Ponte dos Remédios, quando a Prefeitura de São Paulo percebeu a dimensão dos prejuízos e dos inconvenientes causados pela ausência de manutenção dos equipamentos públicos viários, foi iniciado um plano de inspeções visando identificar os problemas das principais pontes e viadutos da cidade, sendo investidos cerca de $\mathrm{R} \$ 90$ milhões na recuperação de nove obras-de- 
arte entre 2002 e 2004. Atualmente, o Instituto de Pesquisas Tecnológicas do Estado de São Paulo (IPT) desenvolve um trabalho de avaliação das condições estruturais de todas as pontes do Estado.

Além das obras apresentadas, diversas outras foram ou são continuamente monitoradas, como a ponte rodoferroviária sobre o rio Paraná, situada entre os Estados de São Paulo e Mato Grosso do Sul, uma das maiores obras da engenharia brasileira concluída nos últimos anos, constituída por um trecho de $2.600 \mathrm{~m}$ em estrutura metálica (26 tramos de $100 \mathrm{~m}$ ); a ponte Juscelino Kubitschek, sobre o lago Paranoá, em Brasília - DF, com tabuleiros estaiados em três arcos metálicos de 240 m de vão cada um, totalizando um comprimento de 720 m; ou a recém-construída ponte estaiada Construtor João Alves, em Aracaju - SE, com extensão total de 1850 m e vão central de 200 m (figura 1.10).

No plano acadêmico nacional, na área da monitoração estrutural merece destaque o trabalho desenvolvido por Elisabeth Penner, da EPUSP, no qual é realizada a avaliação do comportamento estrutural de pontes de concreto a partir de ensaios dinâmicos e modelos numéricos, obtendo-se resultados como as freqüências naturais de vibração, as deformadas modais e os fatores de amplificação dinâmica. Os ensaios foram realizados em rodovias brasileiras dos Estados de São Paulo e do Rio de Janeiro, no período de 1998 a 2000.

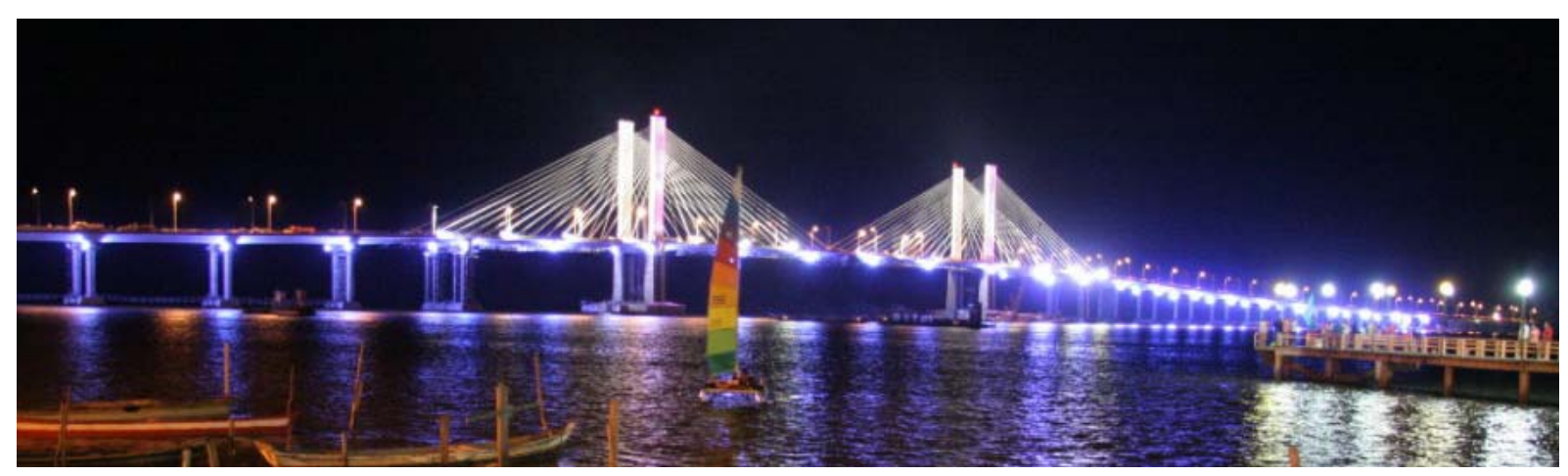

Figura 1.10 - Ponte Construtor João Alves.

A motivação para a realização desta tese é fundamentada na escassez e na necessidade de sistemas computacionais de apoio à atividade de monitoração de estruturas civis, quando do uso de recursos avançados, seja para a fase de aquisição e gestão da informação, seja para as etapas posteriores, contemplando a visualização, tratamento e interpretação dos dados. Busca-se também apresentar a 
estrutura típica dos sistemas de monitoração utilizados no exterior, visto que embora a Engenharia Civil nacional possua maturidade na utilização de técnicas de monitoração de estruturas, nem sempre a metodologia, equipamentos e tecnologia utilizados acompanham a atual tendência internacional.

\subsection{Objetivos e justificativa}

As atividades de pesquisa apresentadas nesta tese foram realizadas tendo em vista, primordialmente, o desenvolvimento de sistemas de apoio para a realização da aquisição, visualização e tratamento de dados, tendo em vista o fornecimento de suporte à tarefa de interpretação das informações provenientes de monitorações de estruturas civis.

Dentre as ferramentas de apoio a desenvolver, destaca-se um sistema de visualização e tratamento de dados para contribuir na solução de um problema atual, caracterizado pela dificuldade de visualizar e tratar, com eficiência e confiavelmente, em um sistema integrado, os dados provenientes de monitorações em estruturas de concreto armado e protendido utilizadas em Engenharia Civil. Na monitoração de estruturas, o tratamento dos dados obtidos constitui uma das atividades fundamentais, das quais depende qualitativamente o esforço envolvido na interpretação do comportamento estrutural e todo o investimento em equipamentos e na rede sensorial instalada. Justifica-se assim a materialização desta proposta de pesquisa, uma vez que as atividades nela previstas estão comprometidas com o interesse de aperfeiçoar e racionalizar o processo de tratamento e interpretação de resultados, visando oferecer um incremento de qualidade e segurança quando da monitoração estrutural em estruturas civis de concreto.

A principal contribuição desse sistema computacional, ao fornecer uma interface amigável na qual é possível visualizar e tratar resultados de forma seletiva ou correlacionada, e realizar filtragens facilmente, enquanto se avalia quantitativa e qualitativamente a influência da temperatura, da retração e da fluência nos elementos estruturais monitorados, reside em fornecer aos pesquisadores e profissionais envolvidos no processo de análise de resultados novas ferramentas 
computacionais, feitas sob medida para a visualização e apoio à interpretação de resultados de monitorações de estruturas de Engenharia Civil.

Outro objetivo da tese é a obtenção de experiência no campo da monitoração estrutural, envolvendo o planejamento, implantação e utilização de sistemas integrados de monitoração, utilizando algumas das mais recentes técnicas, sensores e equipamentos existentes. A capacitação obtida mediante as atividades de campo é importante, pois permite o desenvolvimento e a aplicação das ferramentas de apoio propostas no apropriado contexto, de acordo com as necessidades experimentadas. A experiência adquirida também deverá possibilitar a identificação dos principais problemas e dificuldades associados ao estabelecimento de sistemas de monitoração, e adicionalmente, viabilizará o compartilhamento do conhecimento adquirido, que no caso em questão, assume relevância em decorrência das atividades realizadas pelo grupo de pesquisa do qual o autor faz parte, como a monitoração de uma estrutura metroviária utilizando sensores ópticos.

\subsection{Organização da tese}

O texto da tese está dividido em sete capítulos, incluindo este capítulo introdutório.

No Capítulo 2 é salientada a importância da monitoração de estruturas civis na atualidade, apresentando-se o contexto de sua utilização e as perspectivas resultantes do seu emprego. O capítulo também traz uma revisão bibliográfica referente ao presente estágio de desenvolvimento dos sistemas de monitoração utilizados em obras civis, fornecendo uma perspectiva atualizada dos seus diversos componentes e potencialidades.

O Capítulo 3 aborda o sistema computacional de visualização e tratamento de dados e os módulos para controle do instrumento de aquisição de dados data logger dataTaker. Para a construção dos software foi utilizada a linguagem LabVIEW (Laboratory Virtual Instrument Engineering Workbench).

O Capítulo 4 apresenta as atividades de monitoração realizadas na ponte de concreto armado e protendido construída sobre o rio Sorraia, em Portugal, sendo 
apresentados o sistema de monitoração instalado (no qual foram utilizados sensores ópticos e convencionais) e o sistema computacional de apoio à monitoração desenvolvido e aplicado à obra. O capítulo também aborda uma aplicação do sistema de visualização e tratamento de dados, sendo consideradas as informações provenientes da monitoração da ponte.

O Capítulo 5 trata das atividades de instrumentação e observação do comportamento da ponte metálica do Pinhão durante a prova de carga. Neste capítulo, também são apresentados os resultados provenientes do uso do sistema computacional de visualização e tratamento de dados, além das principais conclusões das medições efetuadas durante a prova de carga.

O Capítulo 6 descreve as atividades envolvidas no planejamento, instrumentação e monitoração do comportamento da laje de fundo do poço da estação metroviária Alto do Ipiranga, edificação atualmente em construção que está localizada na Linha 2 - Verde, da rede de transportes metropolitanos da cidade de São Paulo. A construção da obra está sob responsabilidade da Construtora Norberto Odebrecht, por meio da sua subsidiária CBPO Engenharia Ltda. O capítulo traz os resultados, conclusões e experiências provenientes desta monitoração, na qual todos os sensores empregados utilizam a tecnologia de fibra óptica.

No Capítulo 7 são apresentadas as conclusões e contribuições deste trabalho, além de recomendações quanto ao desenvolvimento de futuras atividades, tendo em vista a continuidade da linha de pesquisa abordada. 


\section{CAPÍTULO 2} SISTEMAS DE MONITORAÇÃO

\subsection{Introdução}

Monitorar uma estrutura significa medir, avaliar e registrar sob forma gráfica, visual ou digital uma ou mais variáveis que descrevem o comportamento estrutural. O uso da monitoração tendo em vista o acompanhamento do comportamento estrutural (Structural Health Monitoring) é atualmente um campo emergente da Engenharia Civil, que por meio do emprego de sensores e equipamentos nãodestrutivos, aliados à análise das características do sistema estrutural observado, possibilita avaliar de forma periódica ou contínua a integridade e a segurança das estruturas monitoradas (SONDHI, 2006; THAKKAR, 2006).

Em virtude dos significativos avanços no campo de materiais e produtos voltados à construção civil, do aumento e inovações da industrialização dos processos construtivos e do aumento da esbeltez de elementos estruturais, têm sido verificadas respostas não previstas nas edifícações mais recentes, ocasionando, não raramente, patologias dos mais diversos tipos e graus, compromentendo proporcionalmente a segurança e o conforto dos usuários quando da sua utilização. Em estruturas civis mais antigas, tais como pontes, viadutos e estádios, verifica-se por vezes a necessidade de interdição, decorrente da associação de fatores como a ocorrência de carregamentos diferentes ou maiores que os previstos em projeto, degradação dos materiais constituintes dos elementos estruturais e aumento da agressividade ambiental. Esse cenário, somado às razões elencadas anteriormente, fez da monitoração um recurso cada vez mais reconhecido como essencial para a avaliação do comportamento das estruturas, ao permitir a medição frequente ou contínua das grandezas relacionadas com o comportamento estrutural, possibilitando um avanço progressivo dos conhecimentos numa perspectiva integrada de segurança, economia e funcionalidade da obra monitorada, 
contribuindo, inclusive, para o aperfeiçoamento dos critérios e técnicas a utilizar nas fases de projeto e construção.

O reconhecimento de que o nível de segurança de muitas estruturas em serviço é por vezes inadequado relativamente às exigências da regulamentação vigente, bem como a crescente conscientização dos efeitos econômicos e sociais determinados pelo envelhecimento das estruturas, deterioração e avarias, leva a uma necessidade do desenvolvimento de sistemas de manutenção para o aumento da vida útil ou definição de estratégias de reparação que é auxiliado através da monitoração. Nesse contexto, a monitoração e a observação são componentes importantes no controle da segurança da estrutura, que é constituído pelo conjunto de medidas a tomar com o fim de conhecer bem o estado atual da estrutura e detectar eventuais anomalias em tempo útil, possibilitando realizar intervenções e correções ou, pelo menos, evitar as mais graves consequências (BASTOS, 2004). Dentre os principais objetivos da monitoração de estruturas rassaltam-se os seguintes (FERNANDES e SANTOS,1992):

a) verificação das hipóteses que serviram de base à construção do modelo teórico considerado no projeto, no que tange tanto às teorias referentes ao comportamento estrutural quanto ao estudo e quantificação das ações;

b) controle da segurança estrutural, detectando, em tempo oportuno, eventuais deficiências de funcionamento;

c) obtenção de informações e experiência referentes à resposta estrutural decorrentes da utilização de novas técnicas de execução, do uso de novos materiais, da imposição de um acelerado ritmo de construção, da produção de obras mais otimizadas e da crescente agressividade do meio exterior.

Obtém-se assim clara percepção da relevância dos sistemas de monitoração de estruturas civis na atualidade, visto que podem, ao longo de todo o ciclo de vida das obras, auxiliar decisivamente na identificação de parâmetros relevantes acerca da resposta estrutural e da sua evolução, e proporcionar informações que, devidamente interpretadas, constituirão uma base sólida e 
oportuna quando da necessidade da adoção de medidas e tomadas de decisões importantes.

Essencialmente, um sistema de monitoração é constituído por uma rede de sensores integrada à estrutura, a qual é conectada a sistemas de aquisição, de armazenamento e processamento de informação, com ligação a uma central remota por meio de sistemas de comunicação, sendo que, atualmente, os equipamentos que compõem os sistemas de monitoração apresentam elevado grau de automação, versatilidade e flexibilidade (BERGMEISTER e SANTA, 2001). Nos sistemas de monitoração, o acompanhamento do comportamento das estruturas ao longo do tempo é realizado por meio da medição de grandezas como a deformação, o deslocamento linear ou angular, a temperatura, a umidade relativa e a força, entre outras. A partir da devida interpretação dessas informações, é possível determinar o estado da estrutura observada, e estudar, entre outros aspectos, o comportamento reológico e a durabilidade dos materiais constituintes, os efeitos estruturais decorrentes da adoção de um determinado processo construtivo e eventuais ocorrências relacionadas com a utilização indevida da obra (FÉLIX, 2005).

Baseando-se no conhecimento da condição da estrutura, podem ser adotadas as medidas mais apropriadas a fim de prolongar sua vida útil (GAO, 2005) e minimizar custos com manutenção (FENG et al., 2004). Neste contexto, a relevância da monitoração de estruturas fica patente diante do quadro constituído pelas mais de duzentas mil pontes deficientes só nos Estados Unidos, aliadas a mais trinta mil no Canadá, país onde entre cento e cinqüenta e duzentas pontes colapsam por ano, e a recuperação da infra-estrutura deteriorada exigirá investimentos de USD 49 bilhões (MUFTI, 2003). Nos EUA os gastos com a recuperação de pontes, considerando a usual técnica de avaliação das condições estruturais a partir de resultados de inspeções visuais e na resposta de modelos construídos utilizando o método dos elementos finitos, é de aproximadamente USD 10 bilhões por ano (CHASE, 2001). Essa quantia poderia ser expressivamente menor, uma vez que, ao contrário dos sistemas de monitoração, os métodos de inspeção visual não apresentam condições de fornecer aos modelos numéricos parâmetros suficientemente realistas associados ao comportamento e envelhecimento dos elementos estruturais observados, provocando muitas vezes a recomendação desnecessária pela recuperação ou substituição, além da possibilidade de não serem identificadas as estruturas que realmente necessitam de 
intervenção (CHANG, FLATAU e LIU, 2003). Em virtude do impacto econômico viabilizado pelas possibilidades da monitoração de estruturas de Engenharia Civil, tem sido despertado o interesse de diversos organismos internacionais ao redor do globo envolvidos com a gestão de pontes e vias de transporte (FERNANDO, 2003), os quais, em parceria com fontes de financiamento governamentais, têm participado ativamente no fomento à pesquisa nesse campo (LI, 2006; LIENHART e BRUNNER, 2003).

Principalmente a partir da década de 1990, o reconhecimento de que o nível de segurança de muitas estruturas em serviço é inadequado relativamente às exigências normativas, bem como a crescente conscientização dos efeitos econômicos e sociais decorrentes do envelhecimento, deterioração e avarias (BASTOS, 2004), levou ao desenvolvimento de sistemas de monitoração cada vez mais sofisticados, que permitem a detecção de problemas nas estruturas em estágios iniciais (CASAS, CRUZ e VILLALBA, 2006) e a obtenção das informações necessárias à implementação dos mais apropriados sistemas de manutenção para o aumento da vida útil ou à definição de estratégias de reparação. Assim, um sistema de monitoração ideal deve ser capaz de proporcionar continuamente informações sobre a ocorrência de qualquer alteração significativa na variável de interesse da estrutura monitorada. As informações sobre a condição de uma estrutura monitorada podem ser obtidas localmente, por meio da montagem de uma rede local, ou através do envio das mesmas para um local distante, podendo-se utilizar para tal, ferramentas computacionais apropriadas conectadas por um protocolo de comunicação conveniente ${ }^{1}$ (TCP/IP, por exemplo). Por conta da complexidade envolvida na construção de um sistema de monitoração, normalmente a equipe responsável pelo seu desenvolvimento é composta por peritos de várias áreas, tais como Engenharia de Estruturas, Engenharia Elétrica e Engenharia Eletrônica.

\footnotetext{
${ }^{1}$ Um protocolo de comunicação é um conjunto de regras e convenções necessárias para a comunicação entre computadores.
} 


\subsection{Componentes dos sistemas de monitoração}

Os sistemas de monitoração mais recentes são constituídos por componentes integrados que são responsáveis pelas etapas de medição, aquisição, comunicação, tratamento e avaliação dos resultados (MUFTI, 2001). Desta forma, um sistema de monitoração completo é formado pelos seguintes subsistemas:
a) rede de sensores;
b) aquisição de dados;
c) comunicação;
d) tratamento de dados;
e) avaliação e gestão dos resultados.

O esquema apresentado na figura 2.1 ilustra a relação entre os subsistemas supracitados, os quais serão abordados nos itens seguintes.

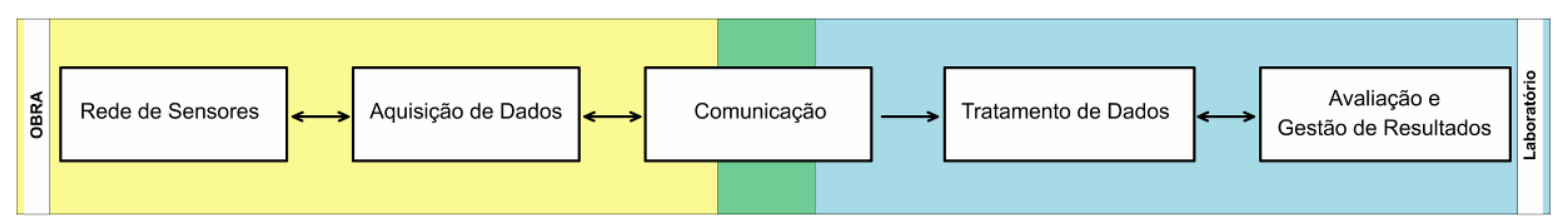

Figura 2.1 - Subsistemas de um sistema de monitoração.

\subsubsection{Rede de sensores}

Conforme apresentado na introdução deste capítulo, a medição constitui parte fundamental do processo de monitoração, e consiste no conjunto de operações que tem por objetivo determinar um valor de uma grandeza, sendo necessário para a sua realização o uso de instrumentos de medição apropriados ${ }^{2}$ (INMETRO, 1995). Na monitoração de estruturas, esses instrumentos são parte integrante da instrumentação utilizada.

${ }^{2}$ Instrumento de medição é o dispositivo utilizado para uma medição, sozinho ou em conjunto com dispositivos complementares (INMETRO, 1995). 
Entende-se como instrumentação todo o conjunto de dispositivos que interligam um processo a um processador, capaz de registrar as informações correspondentes às variáveis de interesse, com finalidade de monitoração ou controle. Mais especificamente, instrumentos de medição, circuitos condicionadores de sinais, conversores analógico-digitais (A/D) e digital-analógicos (D/A), multiplexadores e todos os dispositivos e procedimentos de tratamento da informação, constituem o que se designa como a instrumentação de um processo (NOLL, 2003).

Pelo fato de que a maior parte das grandezas é passível de uma conversão para uma grandeza elétrica (tensão ou corrente); o registro, a indicação visual e mesmo a digitalização dos sinais tornaram-se possíveis através da instrumentação eletro-eletrônica. A relativa facilidade de tratamento matemático dos sinais elétricos e a possibilidade de transporte da informação por meio de técnicas adequadas permite que se monitore praticamente todos os processos industriais, biológicos e físicos, incluindo-se também o comportamento de estruturas. No contexto dos sistemas de monitoração voltados a estruturas de Engenharia Civil, os instrumentos de medição comumente utilizados são os sensores e transdutores que constituem a rede sensora.

Sensores são dispositivos que sofrem mudança de comportamento ou das suas propriedades quando sujeitos a ação de uma grandeza física ou química, podendo fornecer direta ou indiretamente um sinal indicativo da grandeza. (REGAZZI, PEREIRA e SILVA, 2005). Os transdutores são dispositivos que convertem um estímulo (sinal de entrada) em uma resposta (sinal de saída) proporcional à transferência de energia, medição ou processamento da informação, sendo que em geral o sinal de saída é uma grandeza física de natureza diferente do sinal de entrada (NOLL, 2003; SEIPPEL,1983). Assim, todo transdutor contém um sensor, sendo o primeiro correspondente ao componente completo, com características geométricas, mecânicas e funcionais que possibilitam o seu uso para a realização de medições e ligação a equipamentos de aquisição de sinal.

Atualmente, para aplicações de monitoração em Engenharia Civil, encontram-se disponíveis sensores para medições de uma expressiva lista de grandezas, destacando-se os sensores para medição de deformações, temperaturas, deslocamentos, rotações, acelerações e umidade relativa, sendo que, 
para as medições destas grandezas, além dos convencionais sensores elétricos, já são bastante aplicados no exterior os sensores de fibra ópticas.

Os processos de fabricação de sensores têm experimentado várias modificações nos últimos 20 anos, com impactos diretos na qualidade, na confiabilidade e no preço dos novos produtos. Após os avanços tecnológicos na Eletrônica durante a década de 1980, que mediante o desenvolvimento dos circuitos integrados viabilizou com sucesso a integração de componentes para a construção de sensores, melhorando o desempenho e reduzindo os custos, a década de 1990 testemunhou o franco desenvolvimento das técnicas de fabricação de microestruturas. O atual estágio de maturidade do setor tem motivado a construção de sensores miniaturizados, muitas vezes fabricados sobre pastilhas de circuitos integrados, tornando possível a obtenção de microssistemas monolíticos, onde partes não-eletrônicas (sensores e atuadores), interface analógica (amplificadores) e processamento de sinais digitais são construídas no mesmo chip, originando um novo paradigma tecnológico, designado MEMS (Micro Electro Mechanical Systems Sistemas Micro-Eletromecânicos, ou Microssistemas Integrados).

Já podem ser encontrados no mercado alguns tipos de sensores baseados nesta recente tecnologia, com destaque para os acelerômetros MEMS, largamente empregados na indústria automobilística, aeronáutica e aeroespacial, mas também disponíveis para utilização na monitoração de estruturas de Engenharia Civil (SHINOZUKA et al., 2004; BERNSTEIN, 2003; LAL et al., 2002).

Esses novos sensores ampliam a apreciável variedade de sensores e transdutores disponíveis para a medição das grandezas monitoradas em estruturas civis, viabilizando novas soluções aos responsáveis pelo planejamento da monitoração, cujo êxito é em grande medida condicionado à seleção de sensores apropriados, capazes de proporcionar as informações requeridas com a qualidade exigida.

\subsubsection{Redes de sensores sem fios}

Recentemente, com o desenvolvimento de dispositivos integrados constituídos por sensores baseados na tecnologia MEMS, sistema de comunicação 
sem fio e tecnologia de circuitos digitais, surgiram os sensores wireless, ou sensores sem fios (figura 2.2). Estes sensores, que dispensam o uso de cabos e fios para o envio dos sinais previamente processados até a estação central, propiciaram a fundação de uma nova tecnologia na área de redes que tem sido chamada de WSN - Wireless Sensor Networks (ESTRIN et al., 1999) ou RSSF - Rede de Sensores Sem Fio (BARBOSA et al., 2005), e podem vir a constituir uma alternativa aos sensores convencionais, sobretudo em obras com várias seções instrumentadas e elevado número de sensores.

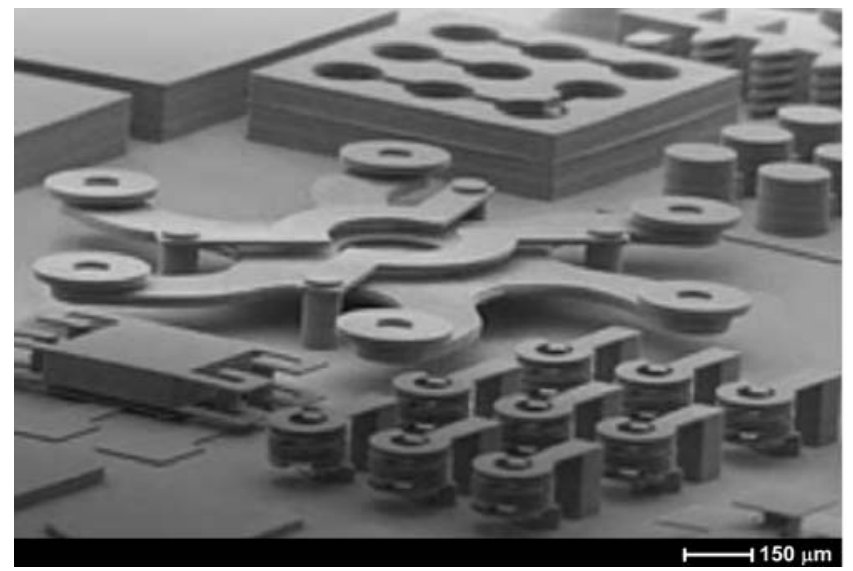

(a)

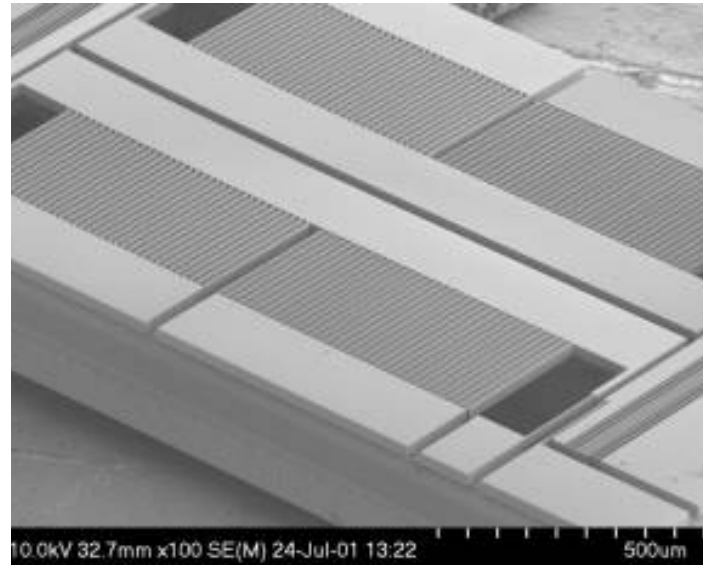

(b)

Figura 2.2 - Componentes MEMS ( $a, b)$ utilizados na construção de acelerômetros wireless. Fonte: PCMAG (2007); NPL (2007).

A tendência atual é que os sensores sem fios sejam prduzidos em larga escala, barateando o seu custo, ao mesmo tempo em que se prevê o aumento progressivo dos investimentos no desenvolvimento tecnológico desses dispositivos, levando a novas melhorias e capacidades, tais como o aperfeiçoamento dos protocolos de comunicação e redução do consumo de energia (LYNCH, 2004).

Em 2003, os sistemas baseados em sensores sem fio já permitiam a comunicação entre sensores (transmissores) e estações locais (receptores) separadas por distâncias superiores a $16 \mathrm{~km}$, viabilizando aquisições com frequências de até $1 \mathrm{~Hz}$ (figura 2.3) (LOUREIRO, 2003).

Comparando os sensores sem fio com os demais sensores, estes dispositivos apresentam como principais vantagens a eliminação da necessidade de cabos e fios, a facilidade de transporte, instalação, reparo ou manutenção. A principal desvantagem desses sensores refere-se à dificuldade de transmissão do 
sinal através de ambientes fechados com paredes maciças, ou à sua utilização de forma embutida.
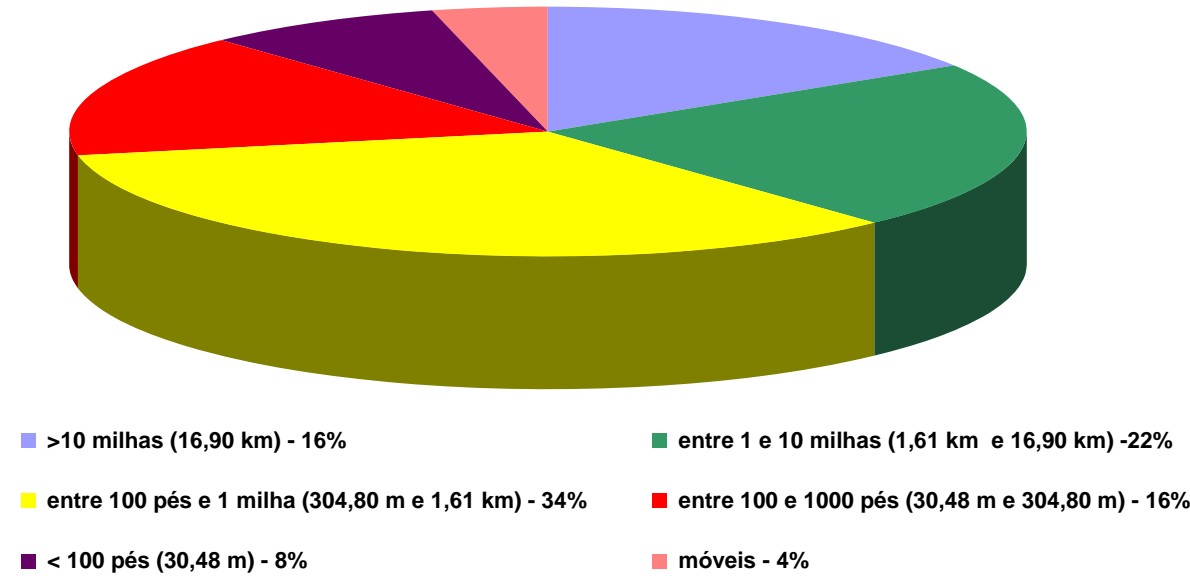

(a)

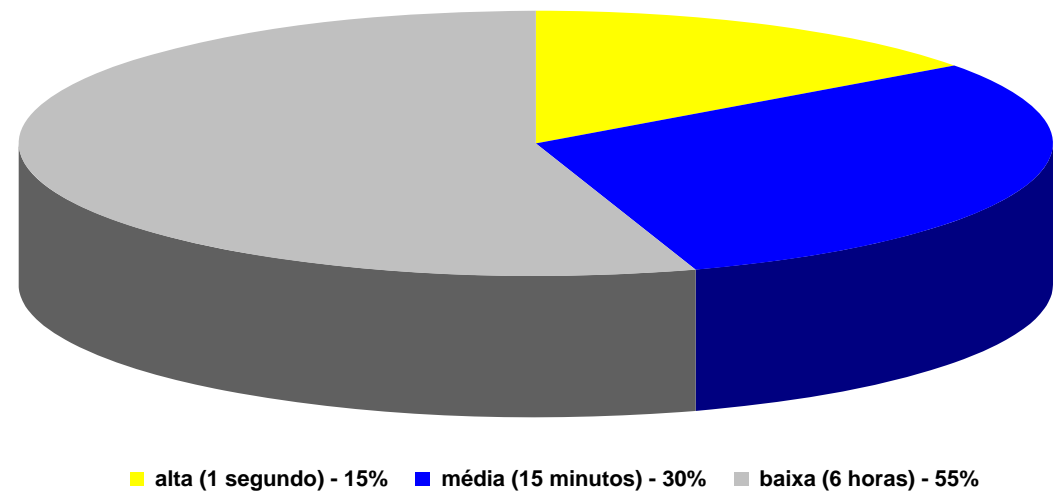

(b)

Figura 2.3 - Estatísticas sobre alcance e frequência de observação de sensores sem fios em aplicações industriais. Alcance de comunicação (a) e intervalo entre observações (b). Fonte: LOUREIRO (2003)

\subsubsection{Aquisição de dados}

A função básica de um sistema de aquisição de dados é capturar informações referentes às grandezas de interesse, provenientes do objeto de estudo, de modo a gerar dados confiáveis passíveis de manipulação posterior por meio de um computador. Na monitoração estrutural, os componentes dos sistemas de aquisição proporcionam o devido tratamento dos sinais elétricos provenientes da rede sensora instalada, os quais encontram-se associados aos valores absolutos ou variações das grandezas monitoradas. 
A partir da captura dos sinais provenientes dos sensores, o sistema de aquisição de dados atua convertendo apropriadamente os sinais elétricos (analógicos) em sinais digitais. Esses sinais digitais, posteriormente, poderão ser armazenados e analisados em um computador.

Um sistema de aquisição de dados básico é constituído por três componentes principais:

a) condicionador de sinais;

b) conversor analógico-digital (conversor A/D);

c) programa de aquisição de dados.

Os condicionadores de sinais são circuitos eletrônicos que adequam os sinais analógicos para a conversão digital. Os principais sub-componentes dos condicionadores são os amplificadores, filtros $\mathrm{e}$ isoladores. Por meio dos amplificadores, o sinal analógico é amplificado a fim de ajustar-se à faixa de entrada do conversor $A / D$. Os filtros são responsáveis pela redução dos ruídos do sinal analógico, diminuindo eventuais interferências oriundas de fontes diversas, que não estão associadas à grandeza medida. Os isoladores, quando presentes, têm a função de proteger os outros módulos do sistema contra eventuais sobrecargas de tensão e corrente, as quais têm o potencial de provocar danos irreversíveis aos circuitos eletrônicos digitais (LYNX, 2006).

Os conversores A/D desempenham a função de traduzir os sinais elétricos em uma representação numérica adequada ao tratamento digital do sinal aquisitado. Tendo em vista a tarefa crucial que esses componentes desempenham, deve-se tomar todos os cuidados necessários para que sejam fornecidas respostas de boa qualidade. Para tanto, é importante abordar as variáveis taxa de amostragem, resolução e faixa de entrada de conversores A/D.

Quando da entrada de um sinal analógico, o conversor A/D captura amostras deste sinal ao longo do tempo, e cada amostra é convertida em um número, dependendo do nível do sinal elétrico associado à amostra. Assim, denomina-se taxa de amostragem à frequência em que a amostragem de um conversor A/D é realizada. Quanto maior a taxa de amostragem, melhor será a qualidade do sinal de saída, mas em contrapartida, maior será o espaço em disco exigido para o armazenamento do sinal. Por outro lado, o uso de baixas taxas de 
amostragem, e em particular o emprego de taxas de amostragens menores que a frequência do sinal de entrada, pode produzir resultados sofríveis, com sinal de saída (que constitui a informação básica para as análises e tratamentos posteriores) pouco confiável ou mesmo sem correspondência com o fenômeno monitorado.

A taxa de amostragem mínima recomendável para a conversão analógicodigital de um sinal, conduzindo a uma boa relação entre a qualidade do sinal de saída e o espaço requerido para o seu armazenamento, é estabelecida pelo Teorema de Nyquist, também conhecido como Teorema da Amostragem, que define que a taxa de amostragem nas conversões analógico/digital deve ser pelo menos duas vezes o valor da freqüência máxima do sinal que se deseja capturar. Na prática, entretanto, a obtenção de excelentes reproduções do sinal de entrada pode exigir uma taxa de amostragem de cerca de dez vezes a frequência máxima do sinal aquisitado (CAMPILHO, 2000; OLSHAUSEN, 2000). Para exemplificar a aplicação deste teorema, se desejamos capturar um sinal com período de 15 segundos (frequência de $1 / 15 \mathrm{~Hz}$ ), a taxa de amostragem do conversor A/D para a conversão do sinal de entrada fornecido pelo transdutor deverá ser de pelo menos uma amostra a cada 7,5 segundos (frequência de $1 / 7,5 \mathrm{~Hz}$ ), conforme apresentado na figura 2.4 .

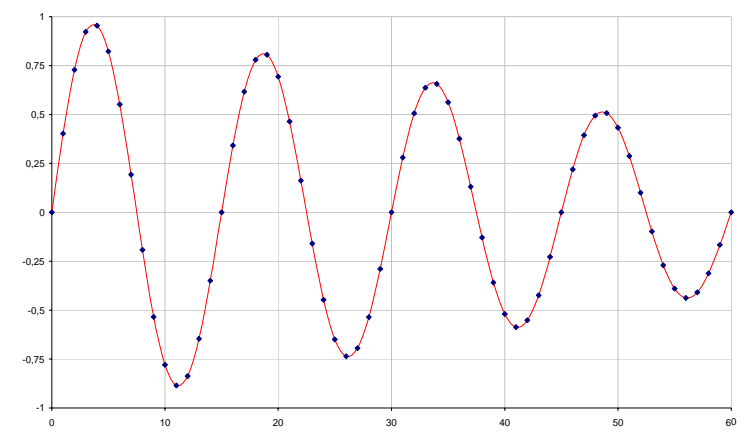

(a)

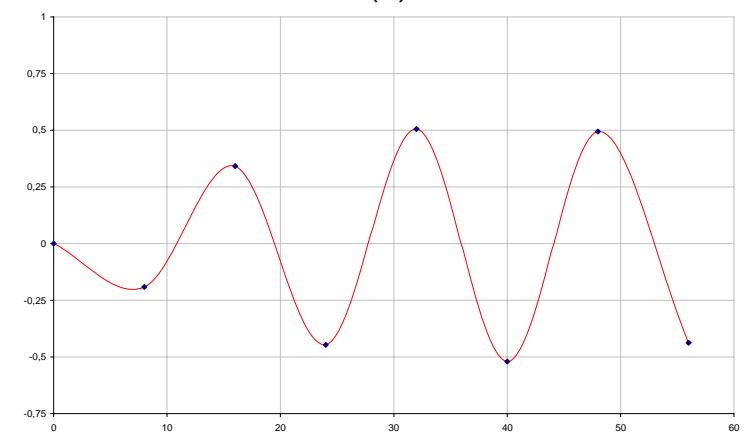

(c)

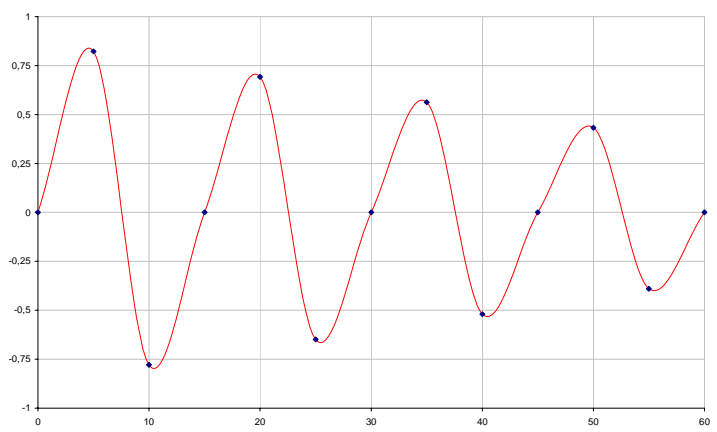

(b)

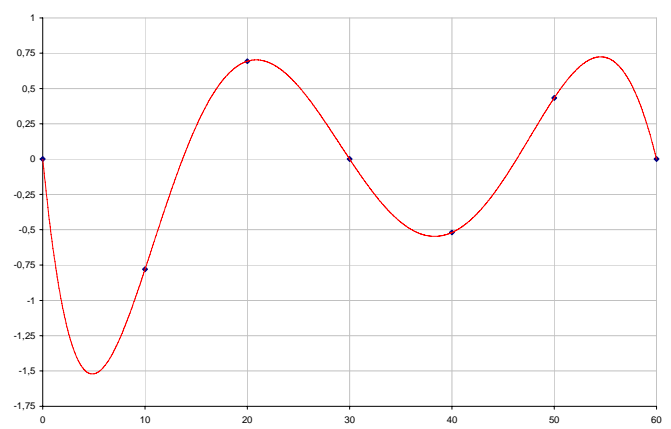

(d)

Figura 2.4 - Exemplo ilustrativo da importância da definição de amostragens apropriadas. Simulação de sinais obtidos à taxa de uma amostra por segundo (a), uma amostra a cada cinco 
segundos (b), uma amostra a cada oito segundos (c) e uma amostra a cada dez segundos (d).

A resolução de um conversor A/D associa-se ao número de divisões em que o sinal elétrico de entrada será particionado, e é medida em bits. Um conversor A/D de 8 bits proporciona a divisão de cada amostra do sinal de entrada em 256 partes $\left(256=2^{8}\right)$, fazendo corresponder ao sinal analógico um valor entre 0 e 255, enquanto um conversor de 16 bits divide a mesma amostra em 65.536 partes $\left(65.536=2^{16}\right)$, convertendo o sinal de entrada em um valor entre 0 e 65.535. Desta forma, quanto maior a resolução do conversor A/D utilizado, maior será a capacidade do sistema de aquisição de capturar as variações dos valores do sinal de entrada, resultando no fornecimento de sinal digital mais fiel ao sinal analógico e em resultados de melhor qualidade. Os sistemas de aquisição usualmente empregados para a monitoração de estruturas são equipados com conversores A/D de 16 bits, embora conversores A/D de 12, 14 e 24 bits também estejam disponíveis (figura 2.5).

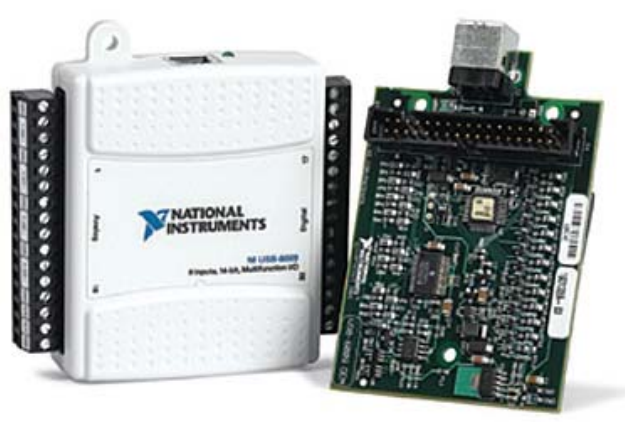

(a)

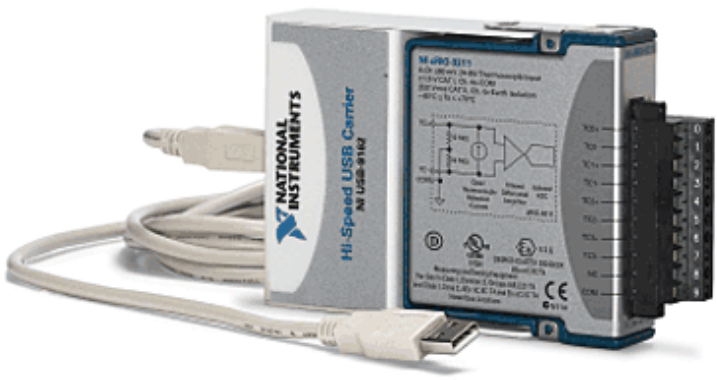

(b)

Figura 2.5 - Sistemas de aquisição para monitoração, com conversores A/D com resolução de 14 bits (a) e 24 bits (b). Fonte: NATIONAL INSTRUMENTS (2007).

A faixa de entrada de um conversor A/D corresponde ao intervalo de valores do sinal de entrada com o qual o conversor A/D trabalha, e é importante que os valores dos sinais analógicos, em tensão ou corrente, sejam compatíveis com a faixa de entrada do conversor A/D, de modo a evitar resultados com perdas qualitativas e quantitativas.

Os programas de aquisição de dados têm por finalidade controlar o sistema de aquisição, fornecendo uma interface por meio da qual o utilizador tenha total controle sobre o processo de aquisição. Adicionalmente, estes programas também viabilizam o armazenamento dos sinais aquisitados sob a forma de arquivos, para que posteriormente possam ser tratados e analisados. Os programas mais 
modernos fornecem também a visualização e pré-tratamento dos dados aquisitados, em tempo real (figura 2.6).

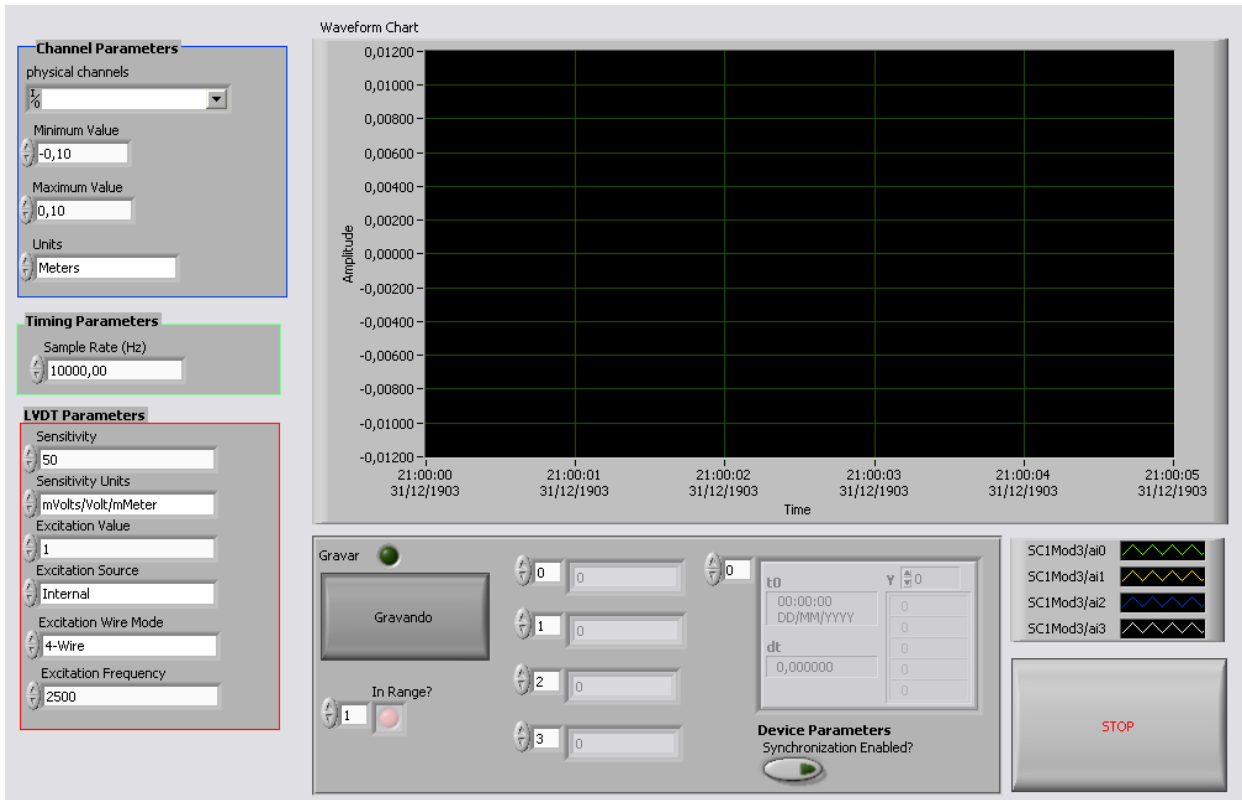

Figura 2.6 - Interface de programa para aquisição de dados desenvolvido pelo autor.

Verificou-se nos últimos anos um desenvolvimento significativo dos sistemas de aquisição de sinais, devido principalmente aos seguintes fatores (CRUZ, 2000):

a) os avanços das tecnologias microeletrônicas, que têm possibilitado o aumento das capacidades e velocidades dos processadores de sinais digitais (Digital Signal Processor - $D S P^{3}$ ), elementos centrais na realização do tratamento digital de sinal, responsáveis por conferir ao sistema de aquisição o nível de inteligência, autonomia e versatilidade exigido;

b) a crescente performance dos computadores pessoais, bem como a sua relação qualidade/preço e confiabilidade;

c) a existência de ferramentas de desenvolvimento de software de elevada qualidade, que permitem criar aplicações de alto nível com avançados interfaces gráficos, facilitando a comunicação do homem com a máquina;

\footnotetext{
${ }^{3}$ DSP's são microprocessadores especializados em processamento digital de sinal, sendo usados para processar sinais, seja em tempo real ou em off-line.
} 
d) o desenvolvimento de novas tecnologias de comunicação que permitem o controle remoto de instrumentos usando a internet como veículo de transmissão de dados.

Para fins de monitoração de estruturas de Engenharia Civil, os sistemas de aquisição geralmente são constituídos por placas de aquisição $\mathrm{PCl}$ (Peripheral Component Interconnect), PCMCIA (Personal Computer Memory Card International Association) ou USB (Universal Serial Bus) introduzidas no computador, ou por equipamentos que realizam as tarefas básicas de aquisição sem o auxílio de um computador (data loggers).

$\mathrm{Na}$ maioria das vezes, os sistemas baseados em placas de aquisição são mais econômicos e apresentam características como resolução e frequência de aquisição superiores aos dos data loggers, mas geralmente também conduzem a soluções centralizadas, levando ao uso de expressiva quantidade de cabos para a ligação aos sensores e à possível exposição do computador a um ambiente agressivo. Os equipamentos de operação autônoma, por só suportarem uma fração do número de sensores normalmente viabilizado pelas placas de aquisição anteriormente mencionadas, acabam apresentando um custo por sensor relativamente mais alto. No entanto, ao se considerar o fato que os equipamentos autônomos geralmente apresentam menor demanda energética, e permitem a adoção de soluções distribuídas e a proteção das unidades de aquisição (em armários, por exemplo), sempre que são atendidos os requisitos referentes ao número e tipos de sensores da rede e à freqüência de aquisição necessária, os data loggers constituem a melhor escolha para a monitoração de estruturas (figura 2.7). 


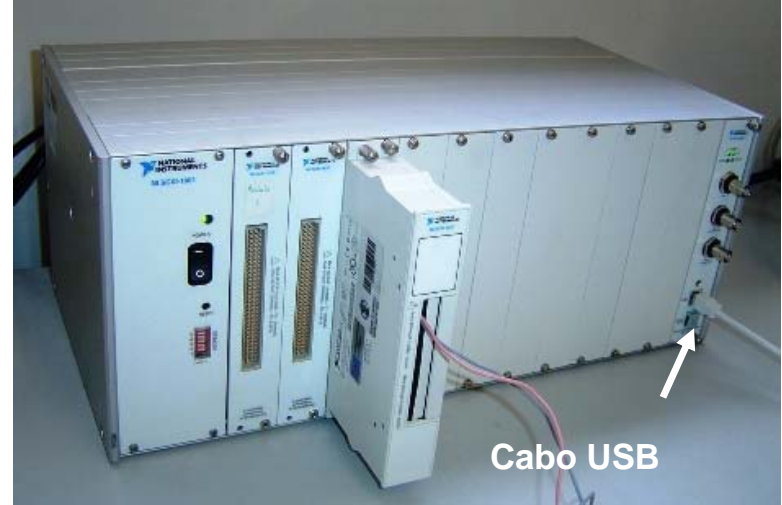

(a)

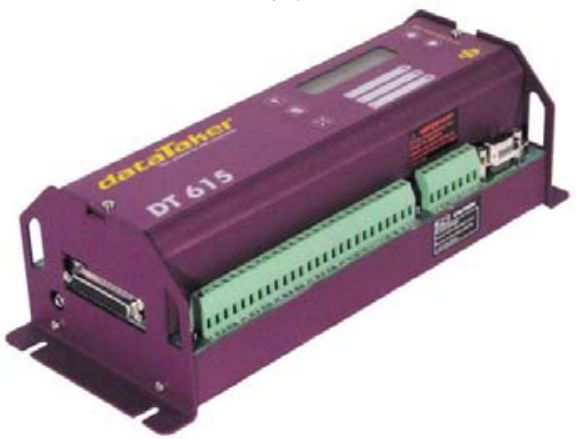

(c)

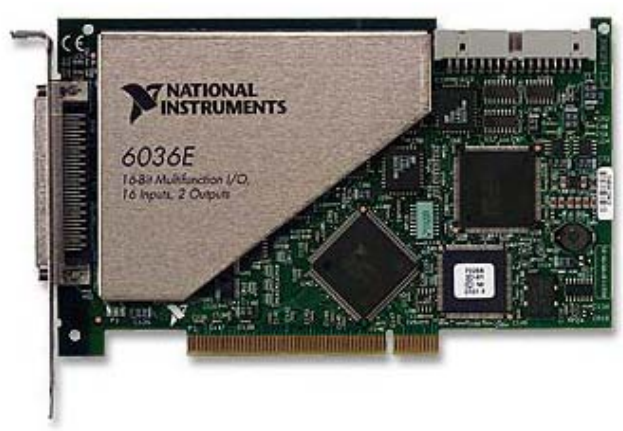

(b)

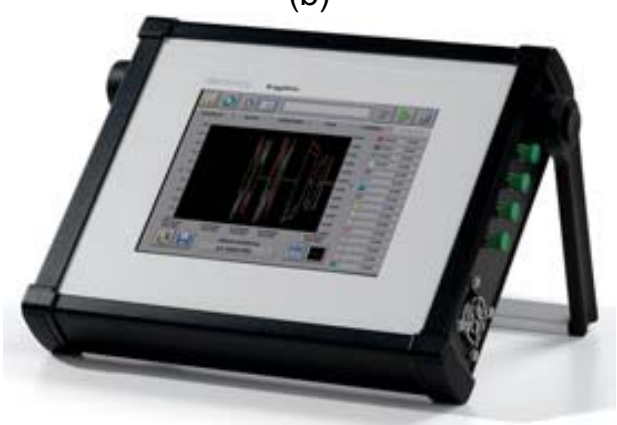

(d)

Figura 2.7 - Sistemas de aquisição para monitoração de estruturas: sistema de aquisição com placa de aquisição USB (a), placa de aquisição PCl (b), data logger para sensores elétricos (c) e unidade de medição portátil para sensores ópticos (d).

\subsubsection{Comunicação}

Após a aquisição de dados, é necessário que as informações digitalizadas sejam disponibilizadas ao utilizador de modo que estas possam ser convenientemente tratadas e analisadas em um computador. É nesse contexto que deve ser planejado o subsistema de comunicação, que será responsável pela transferência da informação do subsistema de aquisição de dados até o computador. Um bom sistema de comunicação deve viabilizar o transporte dos dados com integridade, de modo que estes cheguem ao destino sem perdas qualitativas ou quantitativas.

Quando da monitoração de estruturas, em geral, a informação é transferida ao computador por meio do uso de cabos, normalmente utilizando comunicação serial RS (RS-232, principalmente) ou comunicação USB. O inconveniente desta solução é a necessidade de deslocamento do responsável pela coleta dos dados até a obra, o que pode vir a ser oneroso e pouco prático, sobretudo quando a estrutura 
monitorada encontra-se a distâncias significativas do laboratório. Outra possibilidade, viabilizada pelos recentes desenvolvimentos do setor de telecomunicações, é o envio remoto da informação, sem utilização de cabos, utilizando o protocolo de comunicação Ethernet. A tecnologia envolvida nesse protocolo já está consolidada, e vem sendo empregada com sucesso na monitoração de estruturas no exterior.

\subsubsection{Tratamento de dados}

É sabido que o sucesso da implantação de um sistema de monitoração encontra-se diretamente relacionado não só à qualidade da instrumentação instalada, mas também à condução da interpretação dos resultados obtidos. Nesse contexto, o subsistema de tratamento dos dados da medição assume especial relevância, visto que os dados tratados constituem os elementos de suporte às atividades de interpretação, análise do comportamento da estrutura e tomadas de decisões.

Idealmente, a componente de tratamento de dados deve ser de fácil utilização, e possuir ferramentas de visualização e manipulação estatística de resultados que possibilitem realizar o tratamento da informação bruta procedente do sistema de aquisição de dados e disponibilizada pelo sistema de comunicação.

É esperado que os recursos disponíveis proporcionem ao utilizador uma visão preliminar, porém confiável, da resposta da estrutura monitorada, de modo a assegurar que a interpretação dos dados e a construção de modelos numéricos para fins de análises fundamentem-se em informações coerentes e adequadamente processadas.

\subsubsection{Avaliação e gestão dos resultados}

De posse dos resultados tratados, e após a condução da interpretação dos resultados e análises, é esperado que as informações obtidas permitam avaliar a 
condição da estrutura, e que as decisões cabíveis sejam tomadas com segurança. A prática internacional tem demonstrado que na maior parte das vezes, as avaliações relacionam-se com a verificação dos parâmetros e hipóteses adotados no projeto da obra e detecção de danos ou anomalias na estrutura, durante a construção, tendo em vista garantir a segurança da obra durante a fase de serviço. Em estruturas em recuperação ou em reconstrução, avalia-se sobretudo a eficiência das atividades de reparo, bem como as condições de segurança da estrutura que sofreu as intervenções (FARHEY, 2007; KO e NI, 2005; WONG e HUI, 2004).

Várias técnicas computacionais de suporte à análise das informações tratadas vêm sendo desenvolvidas ao longo dos últimos anos, destacando-se aquelas fundamentadas na Inteligência Artificial $\left(I A^{4}\right)$, tais como a Probabilidade Bayesiana (SOHN e LAW, 1999), a Lógica Fuzzy (TAHA e LUCERA, 2005) e as Redes Neurais Artificiais (RNA ou ANN - Artificial Neural Networks) (YUAN, WANG e PENG, 2005).

A Probabilidade Bayesiana é o método que possibilita representar numericamente o grau de certeza de um determinado evento ocorrer, diante de um cenário de incertezas (BRUYNINCKX, 2005). Uma aplicação cotidiana da Probabilidade Bayesiana é o filtro de Bayes, que permite classificar documentos por categorias e que é utilizado em servidores de e-mail para distinguir uma mensagem ilegítma, conhecida como spam, de um e-mail legítimo.

A Lógica Fuzzy tem como objetivo modelar o raciocínio humano de forma aproximada, tentando imitar a habilidade humana de tomar decisões racionais em um ambiente de incerteza e imprecisão. Esta técnica fornece um mecanismo para manipular informações imprecisas, permitindo inferir uma resposta aproximada para uma questão baseada em um conhecimento que é inexato, incompleto ou não totalmente confiável. O principal campo de aplicação tem sido em sistemas de controle e de suporte à decisão (FIGUEIREDO, VELASCO e PACHECO, 2005).

As RNA são sistemas inspirados nos neurônios biológicos e na estrutura de funcionamento do cérebro, com capacidade de adquirir, armazenar e utilizar conhecimento experimental (JORDAN e BISHOP, 1996). Visto que o cérebro humano é capaz de aprender e tomar decisões baseadas na aprendizagem, as RNA

\footnotetext{
${ }^{4}$ A Inteligência Artificial busca representar um comportamento inteligente utilizando modelos computacionais, nos quais tarefas intelectuais são sistematizadas e automatizadas (SILVA,2005; TIBIRIÇÁ, 2005).
} 
buscam fazer o mesmo, de modo que podem ser interpretadas como um esquema de processamento capaz de armazenar conhecimento baseado em aprendizagem, disponibilizando posteriormente este conhecimento para a aplicação de interesse.

A gestão dos dados oriundos da monitoração, tratamento e análise não deve ser encarada como tarefa de menor importância. Gerir os resultados é mais do que coletar e organizar a massa de informações disponibilizada. É preciso que a informação seja organizada de tal modo que esta possa ser transformada em conhecimento em tempo útil, e que esse conhecimento possa ser extraído de forma inteligente. Assim, a gestão dos dados assume especial relevância ao contribuir decisivamente para o ritmo do avanço do conhecimento do comportamento da estrutura monitorada. Ultimamente, em razão do substancial volume de dados produzido ao longo da monitoração, a gestão da informação tem requerido a produção de ferramentas específicas para armazenamento, organização e acesso à informação, sendo usual a utilização de tecnologia de banco de dados, com destaque para a Structured Query Language (SQL), ou Linguagem de Consulta Estruturada, que é uma linguagem padronizada para a definição e manipulação de bancos de dados relacionais ${ }^{5}$.

\subsection{Métodos de medição das principais grandezas de interesse}

Quando da monitoração de estruturas de Engenharia Civil, usualmente procura-se a resposta do sistema estrutural, que em geral pode ser encontrada a partir da análise conjunta das informações provenientes da associação de duas ou mais grandezas relevantes, dentre as quais destacam-se as deformações, deslocamentos, acelerações, temperatura, umidade e força, obtidas em elementos ou regiões de interesse que compõem o sistema investigado.

Naturalmente, a determinação das grandezas a serem monitoradas é dependente do tipo de problema existente (para o caso de monitoração de estruturas que já apresentam patologias) ou que se pretende evitar, bem como da profundidade da investigação realizada. A escolha das grandezas deve ser feita de

\footnotetext{
${ }^{5}$ Um banco de dados relacional é um conceito abstrato que define como armazenar, manipular e recuperar dados estruturados unicamente na forma de tabelas (CODD, 1970).
} 
forma cuidadosa e inteligente, para que posteriormente sejam definidos, qualitativa e quantitativamente, os sensores e os equipamentos auxiliares necessários (HARRIS e SABNIS, 1999).

A seguir, serão descritas as principais grandezas consideradas quando da obtenção de respostas e caracterização do estado de uma estrutura de Engenharia Civil, e como realizar a monitoração das mesmas.

\subsubsection{Deformações}

A medição das deformações, ou seja, das variações relativas de comprimento, numa dada direção, na superfície ou no interior de uma peça (ABCP, 1967; BASTOS, 2004; HETENYI, 1950), tem sido objeto de estudos desde o século XVII, sendo o ponto de partida os experimentos do cientista inglês Robert Hooke (1635-1703), que em 1678 verificou que os materiais ensaiados apresentavam deformações proporcionais às tensões que as produziam (HOOKE, 1678 apud HOFFMANN, 1989), fenômeno posteriormente formulado pela Lei de Hooke. Após Hooke, muitos pesquisadores realizaram estudos analíticos e experimentais, utilizando diversos materiais, tendo em vista a compreensão do comportamento dos sólidos e o estabelecimento de fórmulas e teorias associadas às observações.

Nas estruturas, as deformações decorrem da atuação de uma variedade de solicitações diretas ou indiretas. São exemplos de solicitações diretas as ações de valor conhecido, como as oriundas de carregamentos aplicados para fins de ensaios de carga, ou as ações de valor desconhecido, tais como as associadas aos carregamentos decorrentes do tráfego de veículos, vento ou sismos. Podem ser citados como agentes indiretos no desenvolvimento de deformações nas estruturas a variação da temperatura ambiente e as alterações nos materiais constituintes da estrutura, conforme se verifica em fenômenos reológicos como a fluência e a retração (FIB, 2003).

Existem diversos sensores, baseados em diferentes princípios físicos, através dos quais se podem medir deformações. Dentre os tipos de sensores de deformação mais conhecidos e utilizados, podem ser mencionados os indicados a seguir. 
a) sensores mecânicos;

b) sensores elétricos;

c) sensores de corda vibrante (acústicos).

Considerações sobre as principais características destes sensores serão feitas nos itens seguintes. Nos últimos anos, tipo de sensor de deformação que vem sendo cada vez mais utilizado é baseado na tecnologia de fibras ópticas.

\subsubsection{Sensores mecânicos}

Os sensores mecânicos para medição de deformações fazem parte de um segmento de instrumentos que estão entre os primeiros desenvolvidos para a monitoração de estruturas de Engenharia Civil. O tensômetro de Huggenberger é um destes sensores, sendo apresentado na figura 2.8. O princípio básico dos sensores mecânicos consiste na medição da variação de um comprimento de referência, medido na peça analisada, sendo obtida a deformação a partir da divisão da variação verificada pelo comprimento de referência. Embora apresentem excelente reprodutibilidade e utilização simplificada, estes sensores são muito pouco empregados atualmente, visto que só podem ser utilizados em experimentos estáticos, não oferecem condições para a determinação de deformações localizadas e principalmente por não serem compatíveis com os modernos sistemas de aquisição de dados.

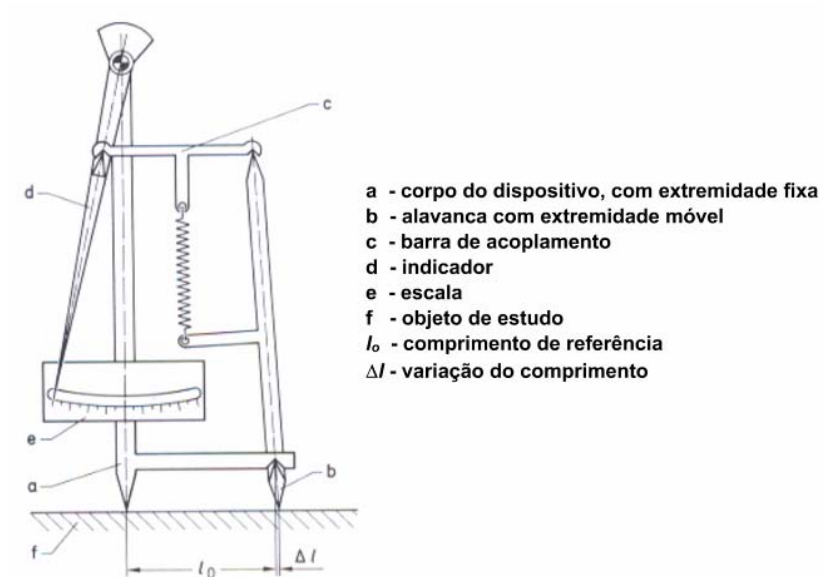

Figura 2.8 - Tensômetro de Huggenberger. Fonte: HOFFMANN (1989). 


\subsubsection{Sensores elétricos}

$\mathrm{Na}$ última metade da década de 1930, foi dada atenção a um efeito mencionado por Charles Wheatstone (1802-1875) em 1843, em sua primeira publicação sobre o circuito elétrico que receberia o seu nome. O efeito consistia na mudança da resistência elétrica em um condutor submetido a um esforço externo. Posteriormente, William Thompson (1824-1905, Lorde Kelvin após 1892) desenvolveu o trabalho iniciado por Wheatstone, conforme se verifica em uma de suas publicações de 1856 (THOMPSON, 1856; WHEATSTONE, 1843 apud HOFFMANN, 1989).

Havia uma explicação para que mais de oitenta anos decorressem até que fosse feita uma aplicação técnica do fenômeno observado por Wheatstone. Fundamentalmente, a razão estava nos baixos valores da variação da resistência elétrica de um fio, quando este é tracionado ou comprimido.

Em seus experimentos, Thompson utilizou galvanômetros ${ }^{6}$ de alta sensibilidade, que poderiam ser empregados para realizar medições de baixa frequência, mas suas características os tornavam inviáveis para utilização geral ou mesmo industrial.

Somente após o advento do amplificador eletrônico, inventado por Lee de Forest (1873-1961) em 1907, foi que as pesquisas tendo em vista a utilização prática dos experimentos e observações de Thompson avançaram de forma significativa.

Em 1938, nos Estados Unidos, o Prof. Arthur Claude Ruge, da Faculdade de Sismologia do Massachussets Institute of Technology (MIT), trabalhava na solução de um difícil problema de medição. Ruge investigava o comportamento de reservatórios elevados resistentes a sismos durante um terremoto, e para tal fim, construiu um modelo reduzido montado sobre uma plataforma vibratória. Na busca por um método que permitisse medir as pequenas deformações nas finas paredes do reservatório, ele constatou o fracasso de todos os sensores e técnicas para medição de deformações então disponíveis, e trabalhou no desenvolvimento de alternativas. Após numerosas tentativas frustradas, Ruge fixou finos fios metálicos em uma base de papel, adicionando terminais de conexão. No testes do protótipo,

\footnotetext{
${ }^{6}$ O galvanômetro é um instrumento utilizado para a medição de correntes elétricas de baixa intensidade (DOMINGUES, 2006).
} 
este foi colado em uma viga biapoiada, e os valores das medições efetuadas com o protótipo foram comparadas com os obtidos a partir dos dispositivos convencionais. Visto que foi encontrada uma relação linear entre as deformações dos sensores convencionais e os valores apresentados pelo protótipo, quando comprimido ou tracionado, e os resultados foram reprodutíveis, surgiu o extensômetro de resistência elétrica (ERE), ou strain gage. O invento de Ruge foi registrado no Comitê de Patentes do MIT em 1939, sendo patenteado no Registro de Patentes dos Estados Unidos em 1944, (KEIL, 1988; HOFFMANN, 1989; LEUCKERT,2000).

Devido ao aumento da praticidade e precisão nas mediçõs de deformações advindos do uso dos ERE's, sua utilização nos mais variados materiais (metais, polímeros, compósitos, madeira, concreto, etc.) e ramos da engenharia tem crescido desde a sua produção em escala industrial, vindo a tornar-se no mais comum dispositivo para medição de deformações em elementos estruturais, sendo também largamente utilizado na construção de transdutores para medição de outras grandezas.

Atualmente, o processo de fabricação dos ERE's mais comuns, denominados extensômetros de folha metálica (foil-gage), envolve a impressão da malha condutora por um processo de fotogravação em uma película metálica de reduzida espessura (de 3 a $6 \mu \mathrm{m}$ ), a qual é depositada sobre uma base de material plástico, resina de poliamida ou papel especialmente tratado, de espessura de 15 a $16 \mu \mathrm{m}$. Posteriormente, o lado impresso é revestido por um filme metálico, de modo que a espessura final do ERE pode alcançar até $25 \mu \mathrm{m}$ (figura 2.9).

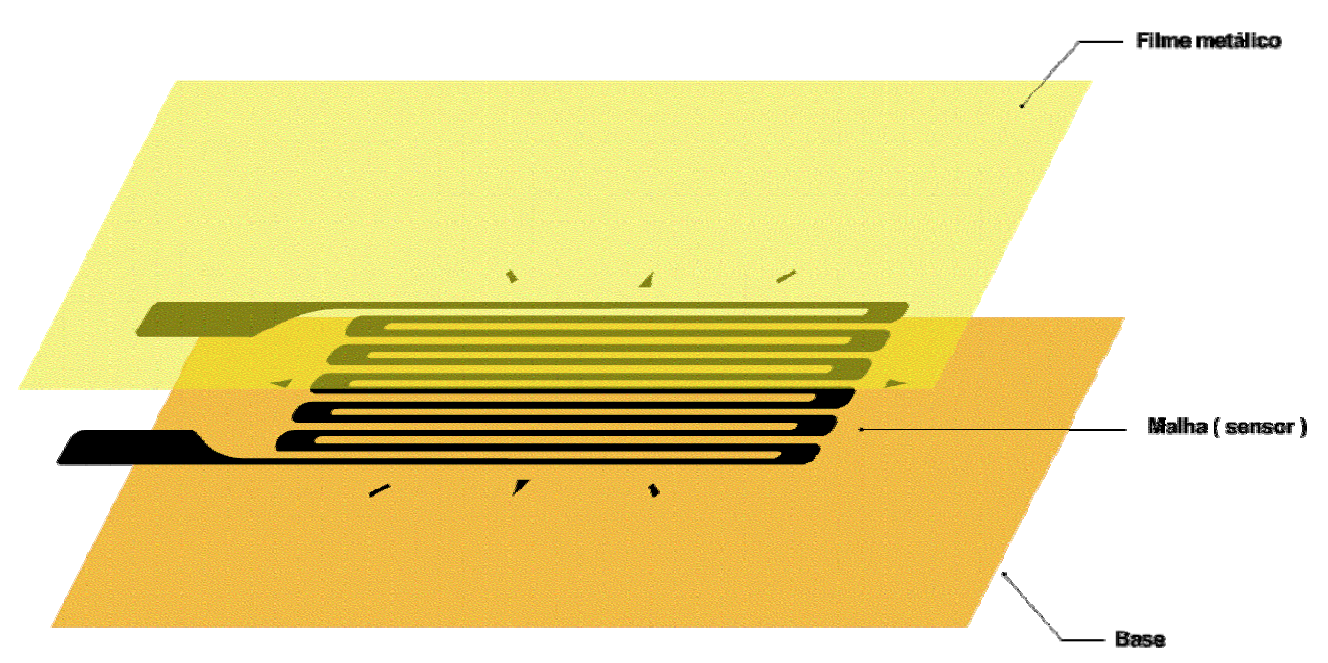

Figura 2.9 - Estrutura de um extensômetro de resistência elétrica. 
A malha geralmente é constituída por ligas de cobre-níquel, níquel-cromo ou ferro-cromo-alumínio, com geometria que visa a maximização da sua resistência elétrica e a minimização da influência das deformações na direção transversal à de medição nos resultados, que é obtida por meio da introdução de segmentos de maior área nas extremidades da malha (figura 2.10). Os ERE's podem ser construídos com geometrias diversificadas, viabilizando a medição de deformações em mais de uma direção, conforme apresentado na figura 2.11.

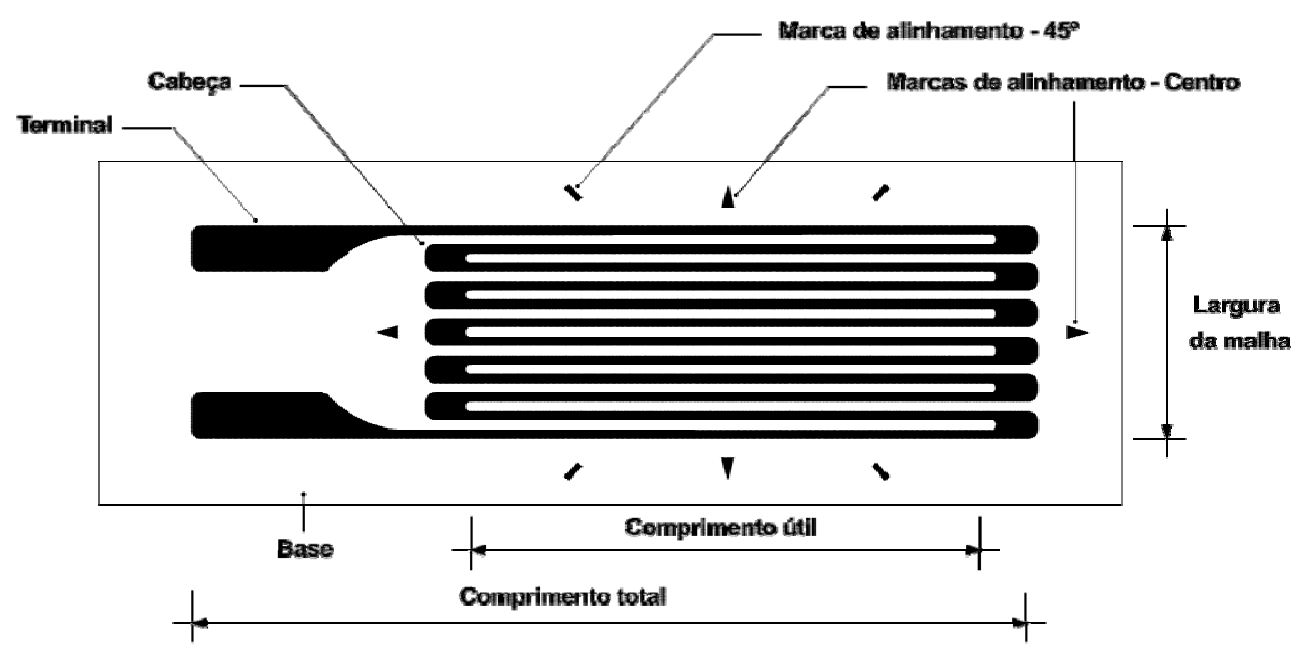

Figura 2.10 - Extensômetro de resistência elétrica, apresentando os elementos constituintes.

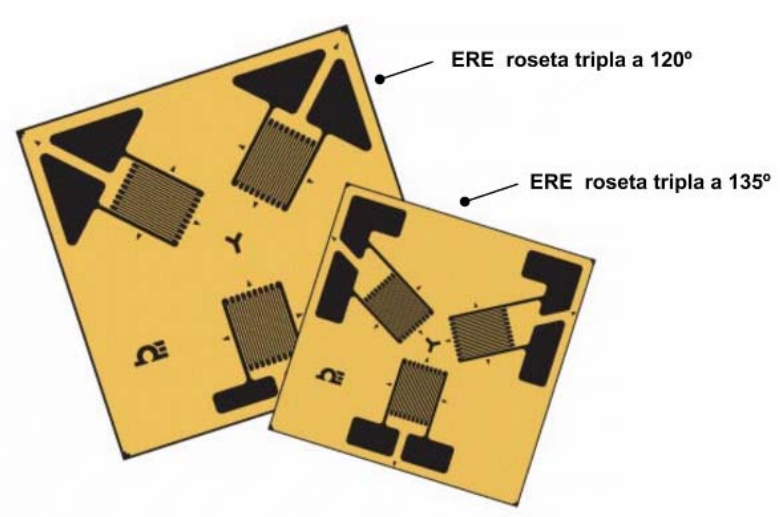

(a)

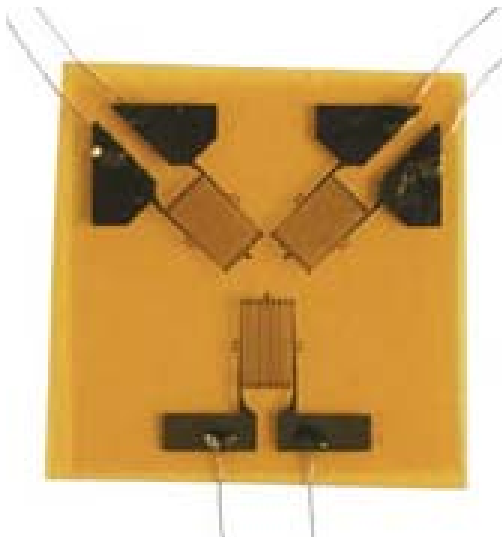

(b)

Figura 2.11 - llustração de ERE's coláveis, modelo roseta tripla a $120^{\circ}$ e $135^{\circ}$ (a) e roseta tripla a $120^{\circ}$ pronta para uso (b). Fonte: OMEGA (2006).

$\mathrm{Na}$ medição de deformações utilizando o ERE, assume-se que a deformação do objeto de estudo é transferida sem perdas para o extensômetro. Na maioria dos casos apenas a superfície do objeto pode ser monitorada, o que exigirá que haja boa aderência entre este e o sensor, que pode ser obtida por meio do tratamento superficial e emprego de adesivo adequado, o qual adicionalmente 
poderá funcionar como isolante elétrico (DOEBELIN, 1990). Na medição de deformações em regiões internas do objeto de interesse, como por exemplo, no interior de um elemento estrutural de concreto, é necessário que os ERE's sejam introduzidos durante o processo construtivo da peça, sendo necessária a devida proteção do extensômetro, que normalmente consegue-se mediante encapsulamento, geralmente utilizando-se materiais poliméricos.

Usualmente, os ERE's apresentam resistência elétrica de 120 ou $350 \Omega$, sendo que para utilizações especiais encontram-se disponíveis resistências de 500, 1000 e $5000 \Omega$. São alguns dos principais fabricantes de ERE's: BLH Electronics (EUA), HBM GmbH (Alemanha), Vishay Measurements Group (EUA) e Kyowa Electronic Instruments Co., Ltd. (Japão).

O princípio de funcionamento dos ERE's atuais continua sendo a relação existente entre a variação de resistência elétrica e a deformação experimentada pela malha condutora sujeita a um esforço externo. Considerando-se um condutor metálico homogêneo e isótropo constituído por um material com resistividade elétrica $\rho$, comprimento $L$ e seção transversal uniforme de área $A$, o valor da sua resistência elétrica $R$ é fornecido pela equação 2.1 :

$$
R=\frac{\rho . L}{A}
$$

Diferenciando a equação 2.1 , obtemos a equação 2.2 :

$$
d R=\frac{\rho}{A} d L-\frac{\rho \cdot L}{A^{2}} d A+\frac{L}{A} d \rho
$$

Considerando reduzidas variações da resistência elétrica, e dividindo os membros da equação 2.2 pela resistência elétrica "R", dada pela equação 2.1, teremos:

$$
\frac{\Delta R}{R}=\frac{\frac{\rho}{A} \Delta L}{\frac{\rho}{A} \cdot L}-\frac{\frac{\rho \cdot L}{A^{2}} \Delta A}{\frac{\rho . L}{A}}+\frac{\frac{L}{A} \Delta \rho}{\frac{L}{A} \cdot \rho}
$$

E, por fim:

$$
\frac{\Delta R}{R}=\frac{\Delta L}{L}-\frac{\Delta A}{A}+\frac{\Delta \rho}{\rho}
$$

É sabido que qualquer deformação da malha na direção ativa (alterando portanto o valor do comprimento do condutor) também estará associada a uma deformação que afetará a seção transversal do fio. Considerando-se que o fio 
utilizado na construção da malha apresente seção transversal circular, a área $A$ da seção será proporcional ao diâmetro, a relação entre os valores absolutos da deformação transversal e da deformação longitudinal será dada pela seguinte expressão:

$$
\frac{\Delta A}{A}=-2 . v \frac{\Delta L}{L}
$$

Onde $v$ é o coeficiente de Poisson, proposto pelo cientista francês Siméon Denis Poisson (1781-1840). Este coeficiente é definido pelo quociente, com o sinal trocado, do alongamento principal mínimo pelo alongamento principal máximo em um elemento sob estado simples de tensão, sendo fornecido, no caso em questão, pela equação 2.6 .

$$
v=-\frac{\left(\frac{\Delta D}{D}\right)}{\left(\frac{\Delta L}{L}\right)}
$$

Onde $D$ corresponde ao diâmetro do fio que constitui a malha do ERE.

Substituindo a equação 2.5 em 2.4, obteremos:

$$
\frac{\Delta R}{R}=\frac{\Delta L}{L}(1+2 v)+\frac{\Delta \rho}{\rho}
$$

Da equação 2.7, verifica-se que a mudança na resistência elétrica deve-se a fatores dimensionais, associados à variação do comprimento e da área do fio, e à variação da resistividade, resultante de distorções elásticas da rede cristalina do material do condutor (HOFFMANN, 1984).

Finalmente, a partir da equação 2.7, obtém-se as equações 2.8 e 2.9, apresentando-se nesta última o Gage Factor ou Fator de Calibração (GF, ou K), parâmetro a partir do qual, conhecida a variação de resistência a partir de um valor de referência, torna-se possível quantificar a deformação linear específica $\varepsilon$.

$$
\begin{gathered}
\frac{\left(\frac{\Delta R}{R}\right)}{\left(\frac{\Delta L}{L}\right)}=(1+2 v)+\frac{\left(\frac{\Delta \rho}{\rho}\right)}{\left(\frac{\Delta L}{L}\right)} \\
G F=\frac{\left(\frac{\Delta R}{R}\right)}{\left(\frac{\Delta L}{L}\right)}=\frac{\frac{\Delta R}{R}}{\varepsilon}
\end{gathered}
$$


O valor de GF é fornecido pelo fabricante do ERE, assumindo valores entre 1,85 e 2,15 .

Para o condicionamento de sinais provenientes de ERE's, usualmente emprega-se a ponte de Wheatstone, um circuito desenvolvido por Charles Wheatstone que permite a medição de impedâncias (resistências, capacitâncias e indutâncias) com grande sensibilidade.

Uma ponte de Wheatstone típica é apresentada na figura 2.12, e é composta por quatro resistências $R_{i}(\mathrm{i}=1,2,3$ e 4), sendo geralmente utilizadas para medir resistências de $1 \Omega$ a $1 \mathrm{M} \Omega$. A ponte é excitada nos terminais "A" e "D" por uma fonte de tensão, apresentando uma diferença de potencial $V$ entre estes terminais. Os terminais " $C$ " e "B" constituem a saída da ponte e a tensão $V_{o}$ entre eles é denominada tensão de saída. A ponte assim construída apresenta dois divisores de tensão independentes $(R 1+R 2$ e $R 3+R 4)$, denominados ramos da ponte. As resistências $R_{i}$, dispostas de forma simétrica, são denominadas braços da ponte.

O circuito pode ser montado com um ou mais extensômetros. O braço no qual se encontra instalado o ERE é denominado braço ativo da ponte, sendo possível utilizar um, dois ou quatro ERE's em um mesmo circuito. No primeiro caso, o circuito é denominado "ponte de um elemento ativo", dizendo-se que o extensômetro está ligado em quarto de ponte, admitindo-se que as outras três resistências não sofrem alteração do seu valor de referência, visto que não se encontram sujeitas a deformações (figura 2.12).

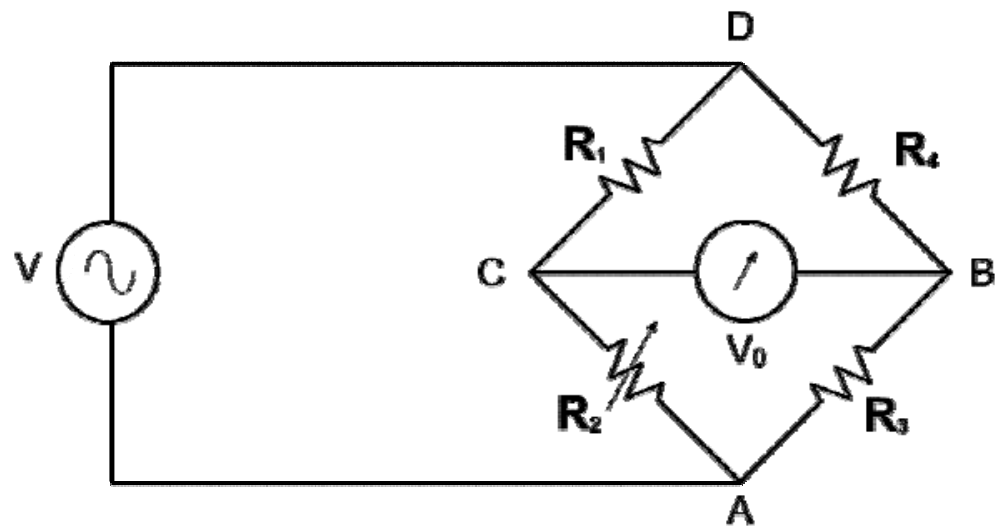

Figura 2.12 - Ponte de Wheatstone, com extensômetro $\left(R_{2}\right)$ ligado em quarto de ponte. 
No caso da existência de duas resistências variáveis, têm-se uma "ponte de dois elementos ativos" dizendo-se que os extensômetros estão ligados em meia ponte. Nesse caso, admite-se que os valores de referência das duas resistências restantes não sofrem modificações. Por fim, quando quatro extensômetros estão presentes em um mesmo circuito, tem-se a "ponte de quatro elementos ativos", com os extensômetros ligados em ponte completa (BORCHARDT, 1995).

Usualmente, a diferença de potencial $V$ utilizada é de poucos volts, de modo a não danificar os sensores envolvidos. $O$ baixo valor de $V$ implica em valores de $V_{0}$ da ordem de poucos milivolts para cada $1 \times 10^{-6} \mathrm{~m} / \mathrm{m}$ de deformação, tornando recomendável a amplificação do sinal de saída a fim de facilitar a sua medição (REGAZZI, 2005).

\subsubsection{Sensores de corda vibrante}

Outro tipo de sensor de deformação largamente utilizado em diversas aplicações, tais como em monitoração de barragens e pontes, ou como componente na construção de células de carga ou transdutores de deslocamentos, é o sensor de corda vibrante. O princípio de funcionamento dos sensores de corda vibrante é fundamentado na relação existente entre a frequência de vibração de uma corda tensionada, de frequência natural conhecida, e a tensão à qual essa corda está submetida.

A frequência natural $f$ é fornecida pela equação 2.10 , abaixo indicada:

$$
f=\frac{1}{2 L_{c}} \sqrt{\frac{F}{\mu}}
$$

Em que:

$L_{c}$ - é o comprimento de referência da corda;

$F$ - é a força aplicada na corda;

$\mu$-é a massa por unidade de comprimento. 
No interior de um sensor de corda vibrante típico, além de uma corda de aço, há uma bobina instalada próximo à corda, a qual gera um campo eletromagnético que é utilizado para iniciar a oscilação da corda, cuja frequência é determinada pela tensão a que se encontra sujeita. Logo em seguida, a frequência de vibração da corda é capturada, devendo ser posteriormente disponibilizada por um meio de sistema de aquisição de dados (SILVA et al., 2001).

Visto que a mudança na frequência de vibração depende da variação de um dos três parâmetros $\left(L_{c}, F\right.$ ou $\mu$ ), e que, no caso dos sensores de deformação, os parâmetros $L_{c}$ e $\mu$ são constantes, qualquer alteração da frequência de vibração estará correlacionada com uma modificação na força aplicada na corda, que por sua vez, implica em uma variação na deformação do sensor $(\Delta \varepsilon)$, a qual é dada pela equação 2.11 .

$$
\Delta \varepsilon=\varepsilon_{f}-\varepsilon_{0}=k_{v}\left(f_{f}^{2}-f_{0}^{2}\right)
$$

Onde:

$\varepsilon_{f}$ - é a deformação final;

$\varepsilon_{0}$ - é a deformação inicial;

$K_{v}$ - é um valor constante, que varia de acordo com as características mecânicas e geométricas da corda utilizada pelo sensor;

$f_{f}$ - é a frequência final;

$f_{o}$ - é a frequência inicial.

Os sensores de corda vibrante apresentam excelente resolução, da ordem de $1 \times 10^{-6} \mathrm{~m} / \mathrm{m}$, além de elevada durabilidade, ótima estabilidade, boa resistência à umidade e larga faixa de medição (até $3000 \times 10^{-6} \mathrm{~m} / \mathrm{m}$ ), constituindo-se na melhor solução para a monitoração de deformações no interior de elementos estruturais de concreto, principalmente para medições a longo prazo (SANTOS, 2002). Em relação à influência da variação da temperatura nas medições, gradientes de até $10^{\circ} \mathrm{C}$ interferem muito pouco nos resultados (FÉLIX, 2005), embora as versões mais modernas já disponham de um sensor de temperatura embutido, sendo também fornecido um gráfico para a realização compensações necessárias de forma adequada (figura 2.13). 


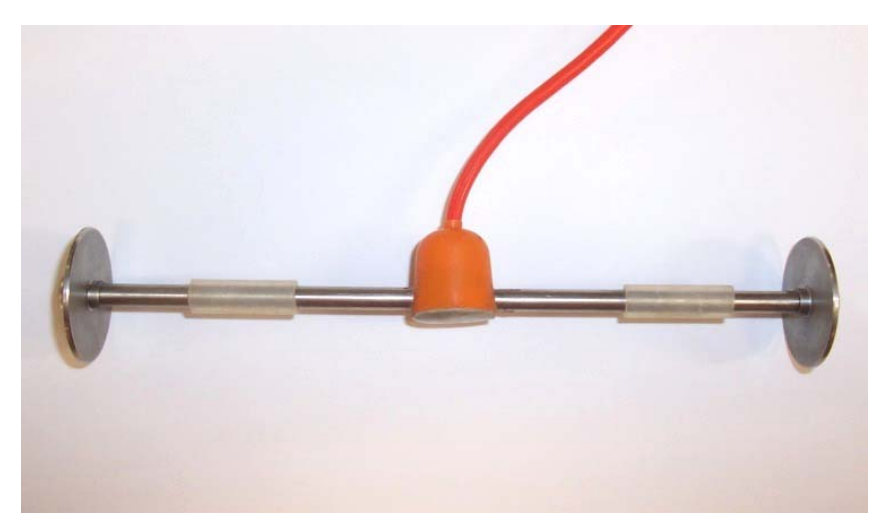

Figura 2.13 - Extensômetro de corda vibrante para aplicações embutidas.

\subsubsection{Deslocamentos}

O deslocamento de um ponto corresponde a uma transformação que se traduz pela mudança de sua posição, relativamente a um sistema de referência fixo (ABCP, 1967), e no âmbito da monitoração estrutural, sua medição em estruturas civis constitui tarefa da maior relevância quando da avaliação do progresso de processos construtivos sofisticados ou cuja evolução exija rigoroso acompanhamento, a fim de evitar problemas estruturais que ocasionem prejuízos à integridade e à futura vida útil da edificação. A medição de deslocamentos também é importante em edificações que apresentam respostas estruturais não previstas, bem como para avaliação do estado de segurança de estruturas.

Na figura 2.14 é apresentada a desmontagem de um dos pilares provisórios de 800 toneladas da ponte Infante Dom Henrique, localizada sobre o rio Douro, no Porto, em Portugal. O êxito do processo de desmontagem foi obtido por meio da utilização de um sistema de rotação e translação com controle e ajuste permanente da força introduzida pelos macacos hidráulicos, baseando-se o progresso das operações nas informações provenientes dos sensores de deslocamento instalados na ponte. 


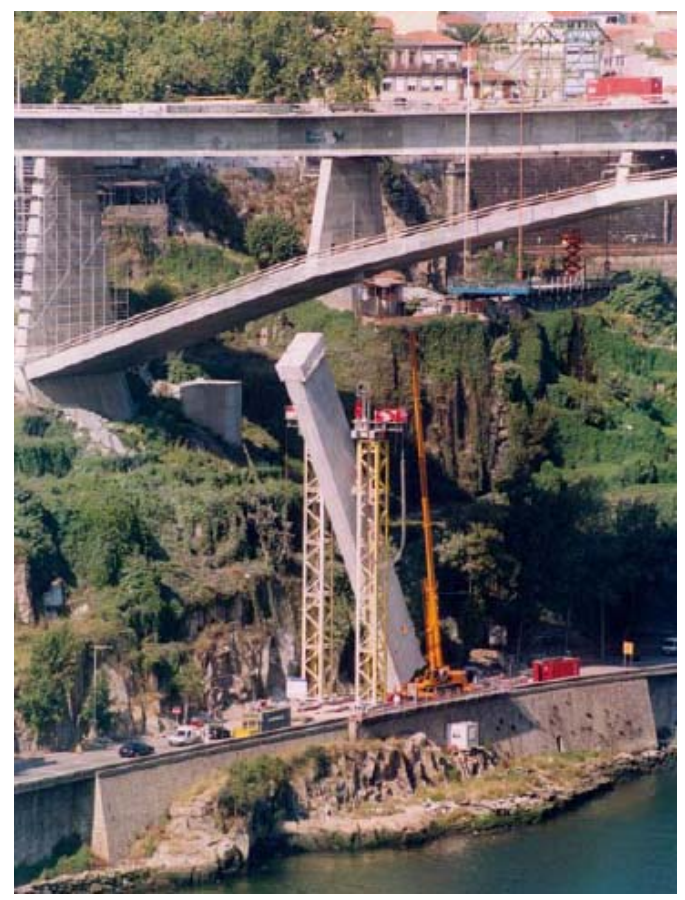

Figura 2.14 - Desmontagem de pilar provisório. Sensores de deslocamento foram utilizados para avaliação do progresso das atividades. Fonte: FONSECA (2003).

Atualmente há uma significativa variedade de dispositivos para a medição dos deslocamentos em estruturas de Engenharia Civil, encontrando-se entre os mais utilizados os comparadores elétricos, os transdutores capacitivos, os transdutores indutivos, os sistemas de nivelamento hidrostático e, mais recentemente, o sistema GPS (Global Positioning System).

\subsubsection{Comparadores elétricos}

Os comparadores elétricos (figura 2.15) são transdutores constituídos por um elemento elástico, geralmente construído em aço, cuja deformação por flexão, produzida pela ação que origina o deslocamento a ser medido, é captada por extensômetros de resistência elétrica montados internamente em posições adequadas. A deformação medida é convertida em deslocamento a partir da curva de calibração do dispositivo. Este princípio de funcionamento possibilita o armazenamento automático das medições. 


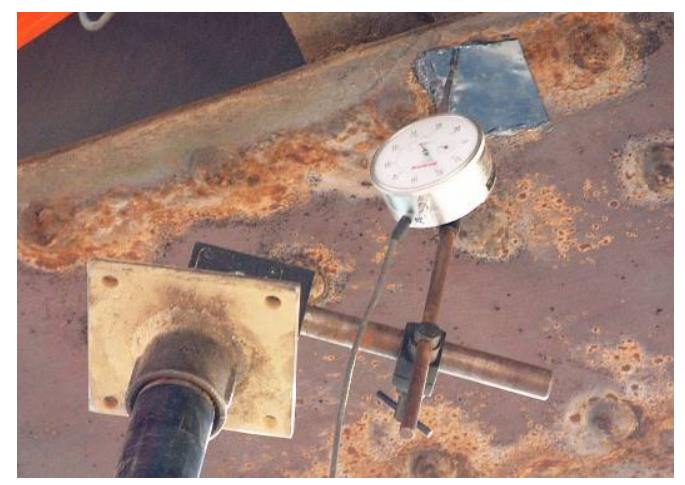

Figura 2.15 - Comparador elétrico de deslocamento.

\subsubsection{Transdutores capacitivos}

Nos transdutores de deslocamento capacitivos, o elemento sensor é constituído por um condensador, o qual apresenta uma variação do valor nominal da capacidade em função do deslocamento a ser mensurado. No esquema da figura 2.16 considera-se o caso de um transdutor capacitivo de deslocamento, no qual dois eletrodos são ligados às placas paralelas de um capacitor, as quais são separadas por uma película fina de um material dielétrico que pode movimentar-se em conjunto com a peça cujo deslocamento se pretende medir. O deslocamento da película implica em uma variação da capacidade do condensador, com a qual possui uma relação bem definida. Este princípio permite medir deslocamentos com elevada exatidão, estando disponíveis no mercado comparadores digitais capacitivos que permitem medir deslocamentos com resolução até 0,0005 mm (figura 2.17).

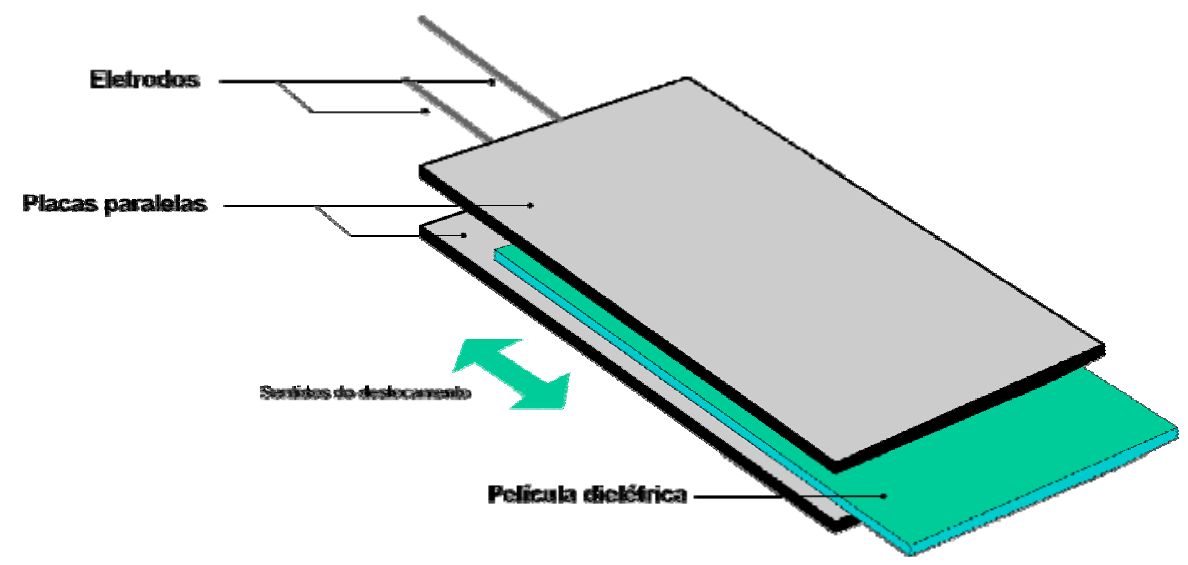

Figura 2.16 - Funcionamento de transdutor capacitivo de deslocamento. 


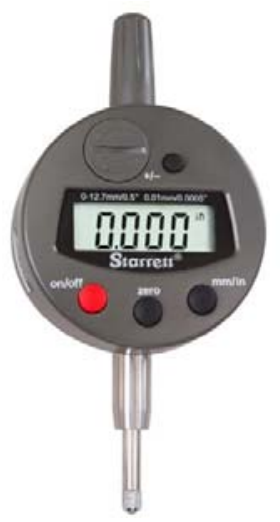

(a)

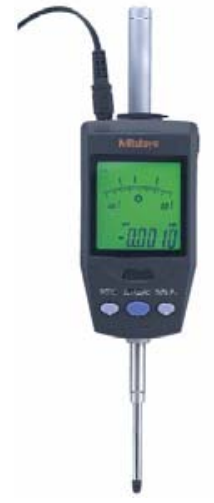

(b)

Figura 2.17 - Comparadores digitais de deslocamento (resolução de 0,01 mm e 0,0005 mm, respectivamente). Fonte: STARRET (2006); MITUTOYO (2005).

\subsubsection{Transdutores indutivos}

Dos transdutores indutivos de deslocamento, o mais utilizado quando da monitoração de estruturas civis certamente é o LVDT (linear variable differential transformer). Um LVDT típico é constituído por três bobinas, duas secundárias e uma primária, simetricamente espaçadas em torno de um tubo oco, no interior do qual há um núcleo deslocável constituído por material ferromagnético (figura 2.18). Quando o LVDT está em funcionamento, uma tensão alternada é aplicada à bobina primária, que se encontra posicionada entre as bobinas secundárias. Esta tensão na bobina primária induz uma tensão alternada às bobinas secundárias, que possuirá frequência igual à da tensão indutora, mas amplitude que dependerá da proximidade entre o núcleo magnético e cada bobina secundária. Quando o núcleo está centrado entre as duas bobinas secundárias, a tensão induzida nestas são iguais e de fase oposta, de maneira que a tensão de saída será nula (ALMEIDA, 2004; U. S. ARMY, 1987). Para medições de valores dentro do campo de deslocamentos do LVDT, que nos modelos mais comuns no mercado pode variar de $\pm 0.25 \mathrm{~mm}$ a $\pm 550 \mathrm{~mm}$, a relação entre o sinal de saída e o deslocamento associado é linear (figura 2.19). 


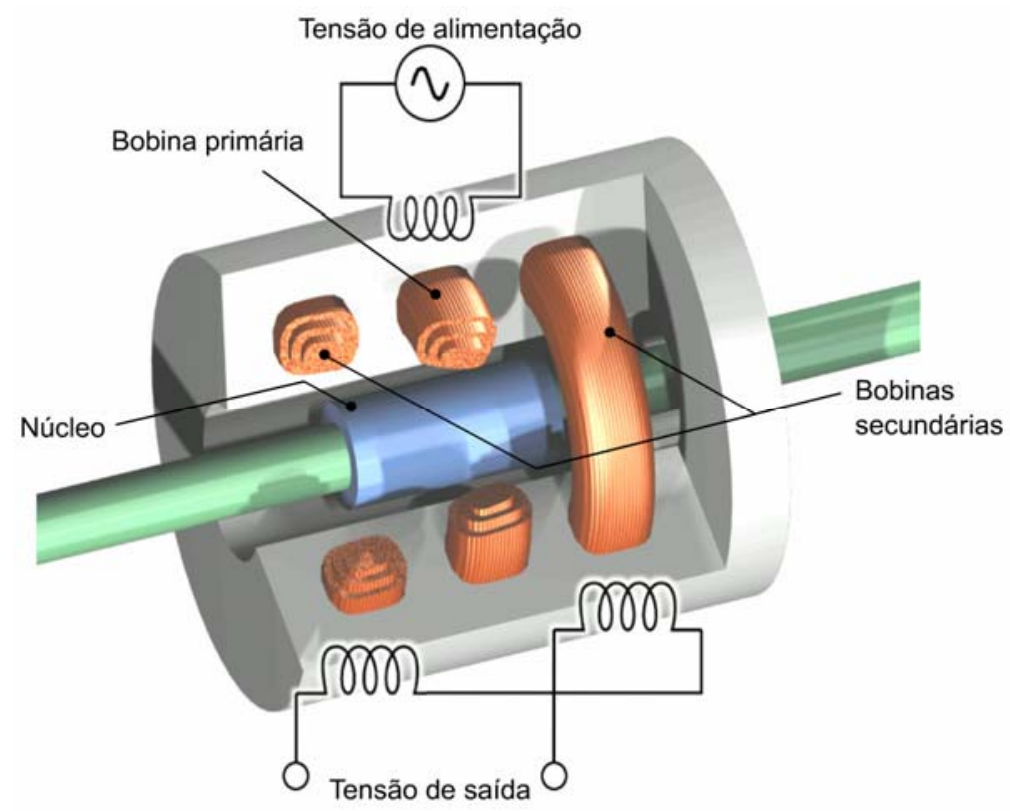

Figura 2.18 - Elementos constituintes de um LVDT típico (adaptado de WIKIPEDIA, 2004).

Muitos tipos de LVDT's apresentam excelente resistência à umidade e corrosão, além de excelente repetibilidade e boa estabilidade de longo prazo nas leituras. Entretanto, os LVDT's necessitam de aferição antes da montagem, e visto que não apresentam indicação direta do deslocamento, seu funcionamento exige recursos de amplificação eletrônica e conversão A/D (AFFONSO, 2004).
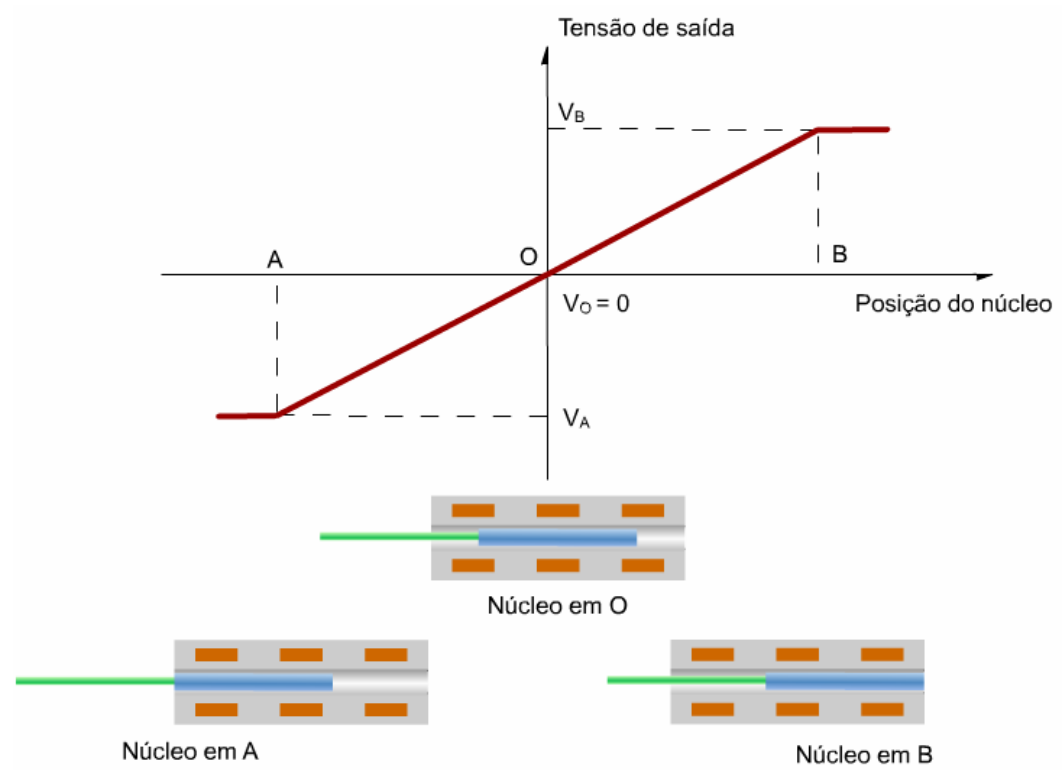

Figura 2.19 - LVDT: tensão de saída em função da posição do núcleo. 


\subsubsection{Sistema de nivelamento hidrostático}

O sistema de nivelamento hidrostático é baseado no princípio dos vasos comunicantes, possibilitando a medição de deslocamentos verticais a partir da diferença de nível entre a referência e ponto no qual o sensor está instalado. Esta diferença implica em uma variação da pressão hidrostática, que por sua vez guarda uma relação bem definida com o sinal de saída de transdutores de pressão, que contam com sensores piezoresistivos que têm por princípio de funcionamento a variação da resistência elétrica do elemento sensor com a variação da pressão mecânica experimentada. Estes transdutores apresentam auto-compensação às pressões atmosféricas e uma elevada exatidão nas medições, com resolução da ordem de $\pm 0.5 \mathrm{~mm}$.

Este sistema constitui uma excelente opção quando da medição de deslocamentos em tabuleiros de pontes, viabilizando a monitoração em ensaios estáticos quando não há a possibilidade do estabelecimento de referência em relação ao solo. A utilização mais comum deste método requer a instalação de um circuito hidráulico, que iniciando em um reservatório de água com um nível determinado e localizado em um ponto fixo, percorrerá os pontos de medição onde deverão ser instalados os transdutores de pressão, que serão responsáveis pela medição da pressão resultante da variação de cota dos respectivos pontos A principal desvantagem do uso deste sistema reside na eventual dificuldade de instalação do circuito, decorrente das condições de trabalho quando do emprego do processo (FÉLIX, 2005; FIB, 2003; SANTOS, 2002). A figura 2.20 ilustra a utilização desse sistema, efetuada durante a prova de carga da ponte sobre o rio Sorraia (cf. Capítulo 4), em Portugal. 


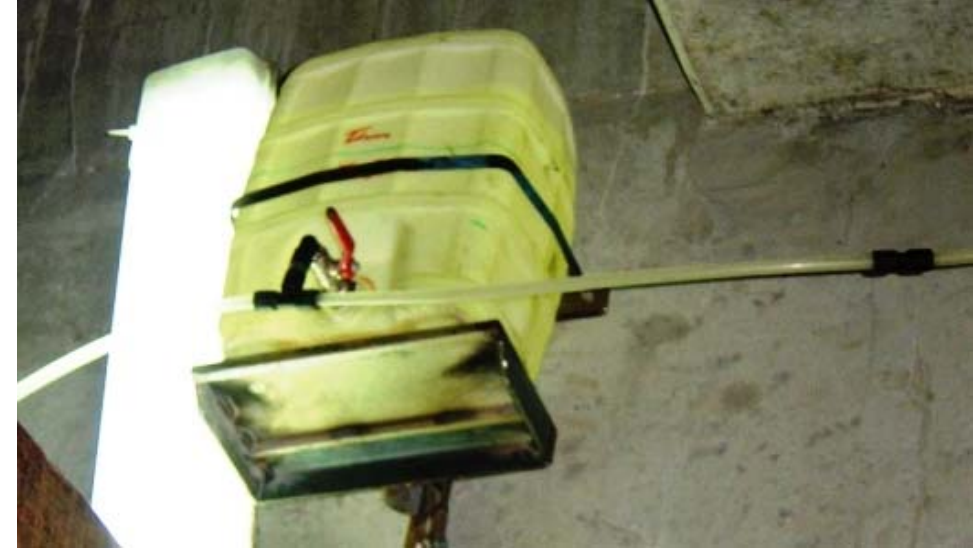

(a)

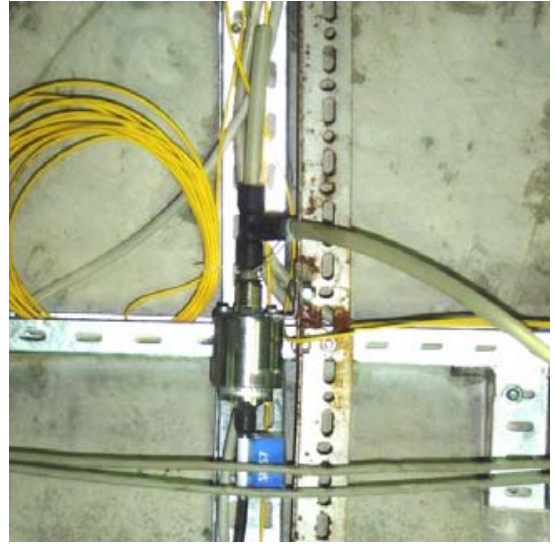

(b)

Figura 2.20 - Utilização do sistema de nivelamento hidrostático. Elementos do circuito hidráulico: reservatório (a) e transdutor de pressão (b).

\subsubsection{Sistema de posicionamento global}

O Sistema de Posicionamento Global, ou GPS (Global Positioning System), faz uso de uma sofisticada infraestrutura que conta com uma constelação de satélites e estações terrestres de controle tendo em vista o fornecimento de serviços de posicionamento global aos seus usuários (CHAVES, 2001). Esse sistema foi criado e é controlado pelo Departamento de Defesa dos Estados Unidos da América, podendo ser utilizado por qualquer pessoa, gratuitamente. Do ponto de vista do usuário, a utilização do GPS depende somente da aquisição de um receptor e da disponibilidade do sinal emitido por pelo menos quatro dos vinte e oito satélites do sistema. O receptor é responsável pela captura e descodificação dos sinais de rádio emitidos pelos satélites, realizando em seguida o cálculo da sua posição, em latitude, longitude e altitude, considerando a distância aos satélites e o instante da recepção dos sinais (MENZORI, 2005).

Atualmente, a faixa de amplitude de deslocamentos detectáveis com o GPS possibilita que o sistema seja utilizado para a medição de deslocamentos de estruturas de grande porte, tais como pontes, barragens,estádios e edifícios altos, em tempo real, de modo que o uso do sistema GPS na monitoração estrutural constitui o campo de estudos de vários grupos de pesquisa, sobretudo tendo em vista o aprimoramento do tratamento dos dados coletados, de modo a proporcionar 
medições com confiabilidade compatível com a apresentada pelos instrumentos convencionais (GHOSH et al., 2006; ROBERTS, MENG e DODSON, 2002).

Em monitorações de longo prazo, já é possível obter resolução de $5 \mathrm{~mm}$ a 10 mm na medição dos deslocamentos (JIANG, LU e GUO, 2002; SMARTEC, 2006), e em ensaios diâmicos, viabilizados pelas taxas de amostragem de até $20 \mathrm{~Hz}$ disponíveis (ÇELEBI, 2000; LI, 2006), com o apoio de filtros e técnicas apropriadas é praticável a obtenção de resolução de $0,5 \mathrm{~mm}$ para deslocamentos superiores a 2 $\mathrm{mm}$ (LAROCCA, 2004).

A figura 2.21 ilustra um caso de monitoração de deslocamentos utilizando o GPS. O edifício monitorado é o Republic Plaza Building, um dos mais altos de Cingapura, com $280 \mathrm{~m}$. Na intrumentação também foram utilizados acelerômetros e anemômetros, com o objetivo de determinar os carregamentos laterais provenientes do vento (OGAJA et al., 2001).

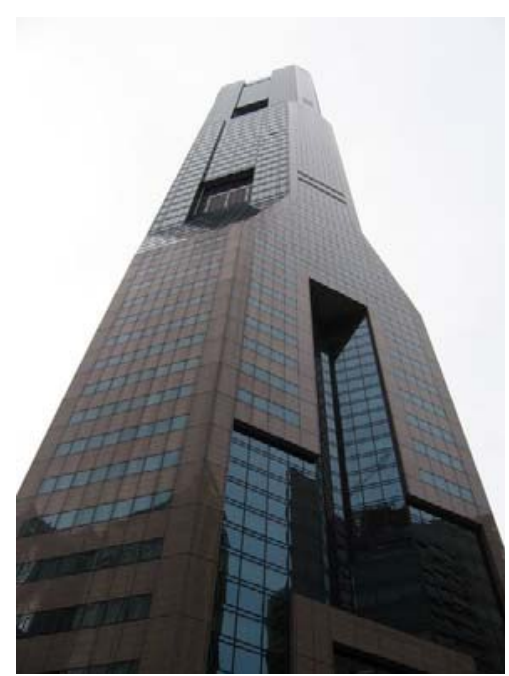

(a)

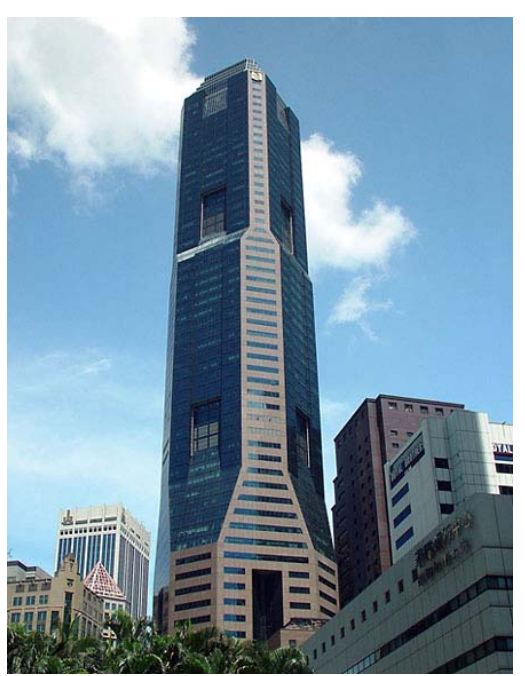

(b)

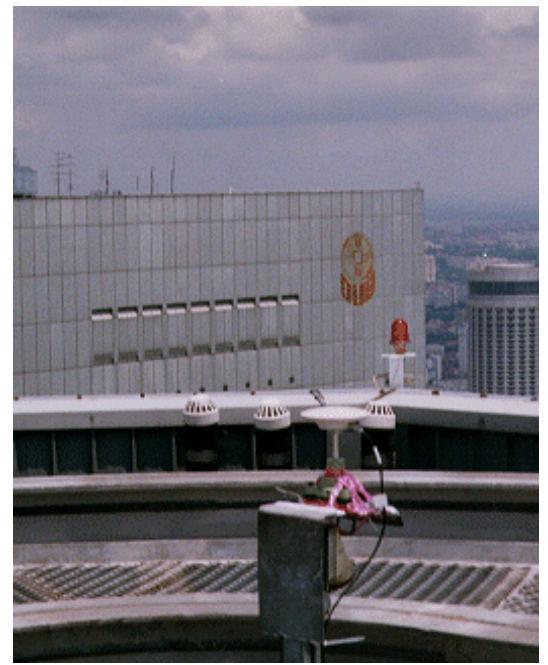

(c)

Figura 2.21 - Republic Plaza Building (a, b), edifício continuamente monitorado por GPS (c). Fonte: OGAJA (2001).

Quando da monitoração de estruturas, é desejável que o sistema de medição esteja disponível e forneça resultados confiáveis continuamente. Nesse contexto, uma das maiores desvantagens quando do uso do GPS reside no fato que a precisão, disponibilidade e integridade dos resultados é dependente do número e distribuição geométrica dos satélites disponíveis, podendo ser esperadas significativas variações dos resultados, em quantidade e qualidade, ao longo de um dia (BARNES et al., 2003). 
Considera-se que quando todos os satélites do projeto GALILEO ${ }^{7}$, entrarem em plena operação, este problema será solucionado (MENG, 2003).

\subsubsection{Rotações}

Quando da medição de deslocamentos angulares em estruturas de Engenharia Civil, busca-se geralmente a determinação de variações angulares em relação a um plano de referência, segundo uma direção ou em duas direções perpendiculares. Dentre os vários dispositivos disponíveis, destaca-se o inclinômetro elétrico, que possibilita realizar medições automatizadas de variações angulares em relação ao plano horizontal em até duas direções distintas, com resolução de até $0,001^{\circ}$ para uma faixa de medição de $\pm 10^{\circ}$.

Uma limitação da maioria dos inclinômetros reside na baixa taxa de amostragem disponível (entre 1 a 2 amostras por segundo), o que não torna o seu uso indicados em mediçõs dinâmicas. A figura 2.22 ilustra um inclinômetro biaxial fabricado pela Tokyo Sokki Kenkyujo Co. Ltd., modelo KB-1AC, instalado em uma obra monitorada pelo autor.

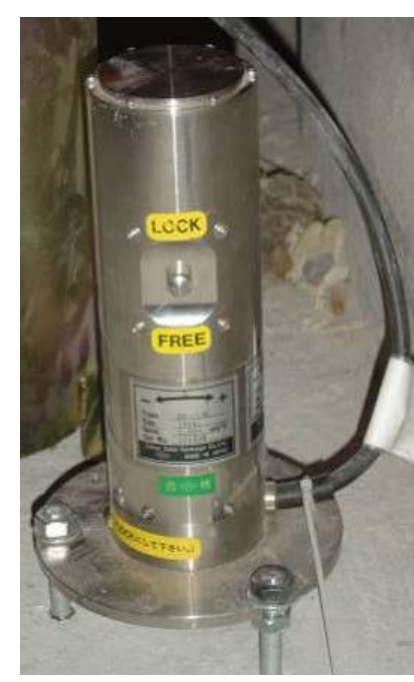

(a)

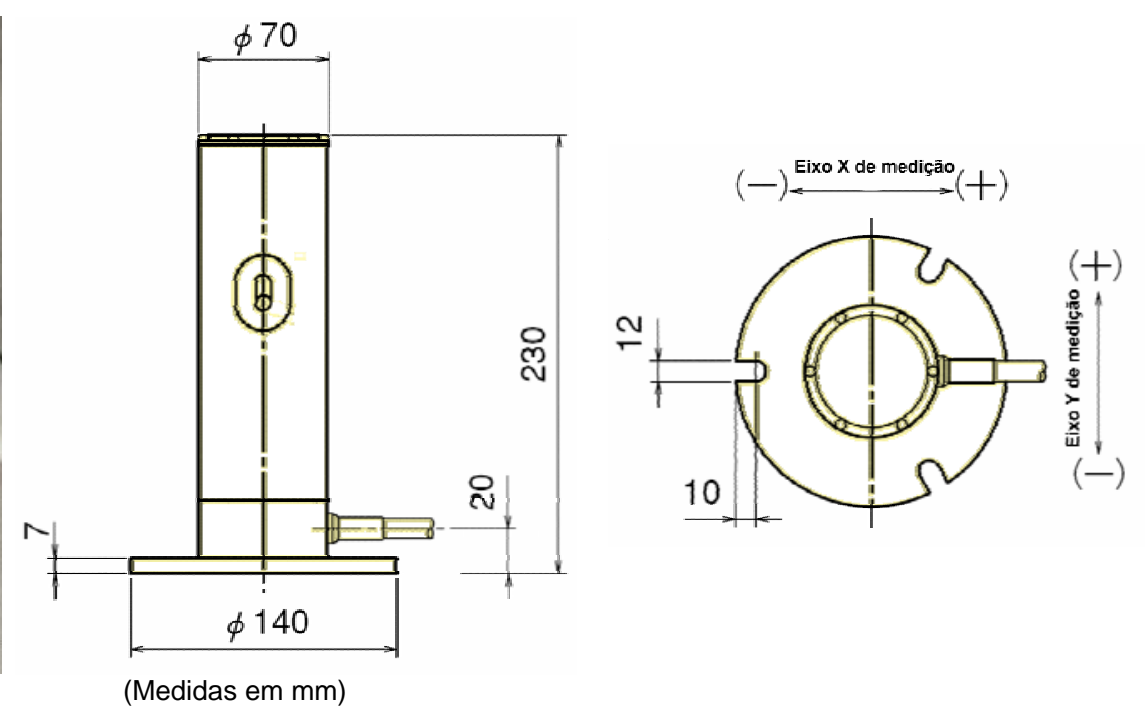

(b)

Figura 2.22 - Inclinômetro biaxial em obra monitorada (a) e características geométricas (b).

\footnotetext{
${ }^{7}$ O GALILEO é uma iniciativa de propósitos civis que visa disponibilizar serviços de radionavegação e posicionamento por satélites. O projeto é desenvolvido pela European Space Agency (ESA), prevendo-se que entre 2005 e 2008 sejam lançados 30 satélites em órbita terrestre com o objetivo de dotar a União Européia de tecnologia independente em relação ao GPS americano e ao GLONASS (Global Navigation Satellite System) russo (SIMON, 2005).
} 


\subsubsection{Temperatura e umidade}

As estruturas de engenharia, assim como todos os corpos da natureza, são constituídos por moléculas que se encontram em contínuo movimento. Quanto maior a agitação molecular, maior será a energia cinética média das moléculas do corpo em questão, a qual pode ser inferida a partir da sua temperatura, que fornece a medida do grau de agitação térmica molecular (CEFETES, 2006). A umidade relativa do ar é o índice mais conhecido para descrever o conteúdo de vapor d'água presente na atmosfera, e indica quão próximo o ar está da saturação. Já a umidade do concreto corresponde à relação entre a massa de água presente no concreto e a massa correspondente ao concreto seco.

É bem conhecido que durante a sua vida útil as estruturas encontram-se sujeitas a ações de origem ambiental, e no caso particular das estruturas de concreto, os efeitos da temperatura e da umidade do próprio concreto e do ambiente que as cercam são bastante relevantes em uma série de situações. Um exemplo típico é representado pela influência dessas grandezas em fenômenos como a retração e da fluência, que são responsáveis por perdas de protensão em pontes, viadutos e outras edificações de significativa importância. Adicionalmente, em obras nas quais há o desenvolvimento de elevadas tensões de origem térmica, é aconselhável a monitoração da temperatura durante a execução e utilização da estrutura.

Encontram-se comercialmente disponíveis diversos tipos de sensores para a monitoração da temperatura do ambiente e do concreto, sendo os mais utilizados os termopares (thermocouples) e os detectores de temperatura resistivos (RTD Resistance Temperature Detector).

Um termopar é formado pela junção de dois fios constituídos por condutores metálicos, de natureza distinta, na forma de metais puros ou de ligas homogêneas. Os fios são soldados em uma das extremidades, à qual se dá o nome de junta quente ou junta de medição, que deve ser posicionada no local cuja temperatura pretende se medir. A outra extremidade de cada um dos fios é levada ao instrumento de medição, originando a junta fria ou de referência e estabelecendo um circuito elétrico fechado. Em um circuito com tal configuração, enquanto houver uma diferença de temperatura entre as duas juntas, existirá uma força eletromotriz 
(f.e.m.) produzida pela difusão de elétrons através dos condutores do circuito, caracterizando o fenômeno conhecido como efeito Seeback (STEPHENSON, 1999) (figura 2.23).

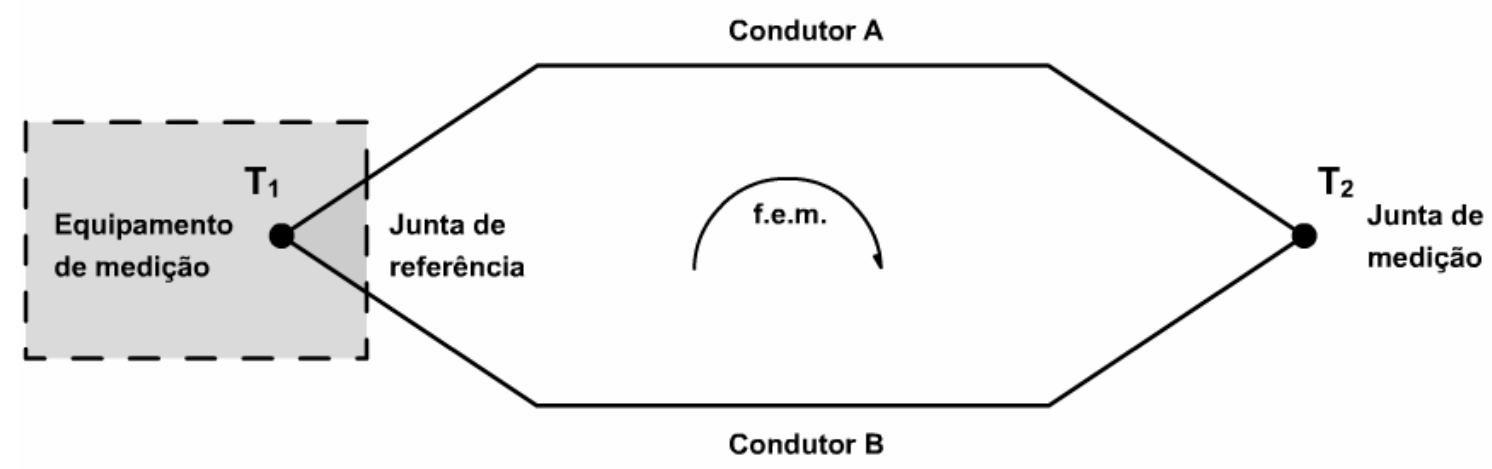

Figura 2.23 - Princípio de funcionamento de um termopar.

Se a temperatura da junta de referência é conhecida, a f.e.m. medida pelo sistema de aquisição permitirá conhecer a temperatura da junta de medição, pois a relação entre a f.e.m. e a temperatura é fornecida. Há diversos tipos de termopares disponíveis, definidos pelos metais utilizados na sua constituição, apresentando faixas de operação e resoluções variadas. Na tabela 2.1 é apresentada uma relação com os tipos de termopares mais comuns e suas principais características.

Tabela 2.1 - Principais características de alguns tipos de termopares (Fonte: STEPHENSON,1999).

\begin{tabular}{|c|c|c|c|c|}
\hline Tipo & $\begin{array}{l}\text { Materiais dos condutores } \\
\qquad(A-B)^{\star}\end{array}$ & $\begin{array}{c}\text { Faixa de } \\
\text { operação }\left({ }^{\circ} \mathrm{C}\right)\end{array}$ & $\begin{array}{c}\text { f.e.m a } \\
400^{\circ} \mathrm{C}(\mu \mathrm{V})\end{array}$ & $\begin{array}{l}\text { Incerteza da } \\
\text { medição }\end{array}$ \\
\hline$E$ & Cromel $^{\circledR}$ - Constantan & $-200 a+870$ & 28,946 & $\pm 1,0^{\circ} \mathrm{C}$ ou $\pm 0,40 \%$ \\
\hline $\mathrm{J}$ & Ferro - Constantan & $0 a+760$ & 21.848 & $\pm 1,1^{\circ} \mathrm{C}$ ou $\pm 0,40 \%$ \\
\hline $\mathrm{K}$ & Cromel $^{\circledR}-$ Alumel $^{\circledR}$ & $-200 a+1260$ & 16,397 & $\pm 1,1^{\circ} \mathrm{C}$ ou $\pm 0,40 \%$ \\
\hline $\mathrm{R}$ & $\begin{array}{c}\text { 87\% Platina }+13 \% \text { Ródio } \\
\text { 100\% Platina }\end{array}$ & $0 a+1480$ & 3,408 & $\pm 0,6^{\circ} \mathrm{C}$ ou $\pm 0,10 \%$ \\
\hline $\mathrm{T}$ & Cobre - Constantan & -200 a 370 & 20,810 & $\pm 0,5^{\circ} \mathrm{C}$ ou $\pm 0,40 \%$ \\
\hline
\end{tabular}

${ }^{*}$ Cromel $^{\circledR}$ e Alumel ${ }^{\circledR}$ são marcas registradas de ligas.

$\mathrm{Na}$ monitoração estrutural, os termopares são particularmente indicados para aplicações que envolvam a medição de elevadas temperaturas ou em condições que envolvam vibrações significativas e choques mecânicos (FIGUEIREDO, 2006), uma vez que o sensor apresenta excelente tempo de 
resposta, exigindo reduzido tempo para atingir o equilíbrio térmico com o ambiente no qual se encontra inserido.

Os detectores de temperatura resistivos são sensores que exploram a relação bem conhecida entre a mudança da resistência elétrica de certos metais, como a platina, níquel, cobre ou liga níquel-cobre, com a temperatura. Estes dispositivos são bastante estáveis e apresentam uma resposta à temperatura reprodutível por longo tempo com elevada exatidão, podendo fornecer resolução de $\pm 0,1{ }^{\circ} \mathrm{C}$ (RTD's simples, de uso industrial) a $\pm 0,0001{ }^{\circ} \mathrm{C}$ (caso dos SPRT's Standard Platinum Resistance Thermometers).

A dependência da resistência elétrica de um RTD típico com a temperatura é fornecida pela expressão 2.12, indicada a seguir:

$$
R_{T}=R_{0}\left(1+\alpha_{1} T+\alpha_{2} T^{2}+\alpha_{3} T^{3}+\ldots+\alpha_{N} T^{N}\right)
$$

onde:

$R_{T}$ - é a resistência do condutor do sensor na temperatura $T$;

$R_{0}$ - é a resistência do condutor do sensor na temperatura $T_{0}$

(normalmente, $\mathrm{T}_{0}=0^{\circ} \mathrm{C}$ );

$\alpha_{1}, \alpha_{2}, \ldots, \alpha_{N}-$ são constantes características do condutor do sensor.

O número de termos da equação 2.12 depende do condutor utilizado na construção do sensor, do intervalo de temperatura e da exatidão desejada. Na figura 2.24 é apresentada a dependência entre as resistências elétricas final e inicial e a temperatura para os principais tipos de RTD's, embora seja necessário ter em mente que, além da temperatura, a presença de impurezas ou deformações no sensor influenciam a variação da sua resistência elétrica com a temperatura. 


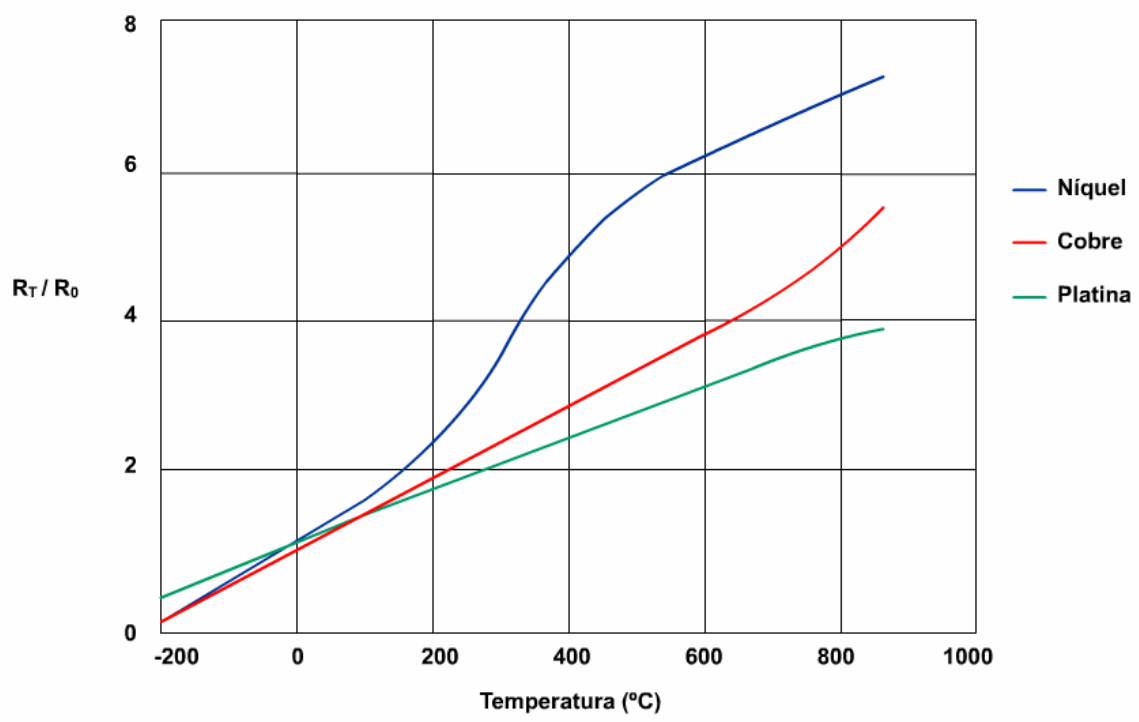

Figura 2.24 - Relação entre as resistências elétricas final e inicial e a temperatura para diferentes RTD's. Fonte: FERREIRA (2000).

$\mathrm{Na}$ monitoração de estruturas civis os RTD's são mais utilizados que os termopares, principalmente por fornecerem vantagens como mais exatidão na mesma faixa de medição e apresentarem maior estabilidade ao longo do tempo, apesar de normalmente serem mais caros. Enquanto um RTD de platina de uso geral custa entre USD 40,00 e 140,00, um termopar equivalente é encontrado no mercado por menos de USD 60,00. O RTD mais empregado na monitoração de estruturas é o PT100, sensor que possui esta denominação em razão de o material sensor ser constituído por platina, apresentando resistência a $0^{\circ} \mathrm{C}$ igual a $100 \Omega$. Em vista da fragilidade do sensor (figuras 2.25a e 2.25b), o seu uso normalmente é feito utilizando-se um encapsulamento apropriado, sendo utilizado para este fim segmentos de tubos de cobre ou aço inox de pequeno diâmetro (6 a $10 \mathrm{~mm}$ ) e comprimento variável (figura 2.25c). Na figura 2.25a, o fio de platina encontra-se protegido por uma superfície cerâmica, sobre a qual é aplicada uma proteção adicional (em azul), na interface entre a superfície e os terminais.

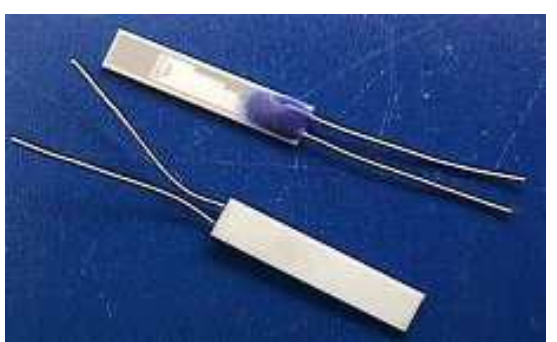

(a)

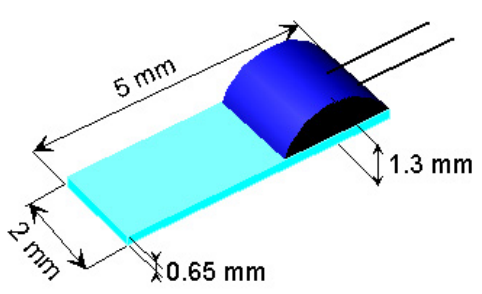

(b)

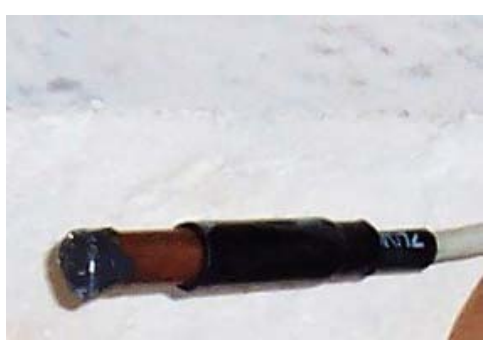

(c)

Figura 2.25 - Sensor de temperatura PT100 conforme fornecido (a, b) e após encapsulamento (c). 
Dentre os diversos sensores e princípios que proporcionam a monitoração contínua da umidade do concreto, merecem destaque os sensores higrométricos capacitivos. Estes sensores exploram a relação existente entre a constante dielétrica de filmes finos, compostos por polímeros higroscópicos, com o teor de água no ar ou no ambiente no qual estejam inseridos.

Nestes sensores, mediante pequenas variações da umidade do filme capacitivo são obtidas expressivas mudanças no valor da sua constante dielétrica, o que altera a capacitância do capacitor no qual está inserido, sendo fornecidas respostas com boa linearidade e estabilidade, embora com baixa frequência (de 0,1 a $0,01 \mathrm{~Hz}$ ). Esses sensores apresentam sinal de saída em corrente ou tensão, com resolução de cerca de $\pm 2 \%$ da faixa de medição de umidade relativa, normalmente cobrindo o intervalo de 0 a 1. A figura 2.26 ilustra um sensor capacitivo de umidade, juntamente com sua curva característica, relacionando a capacitância e a umidade relativa, a $23^{\circ} \mathrm{C}$.

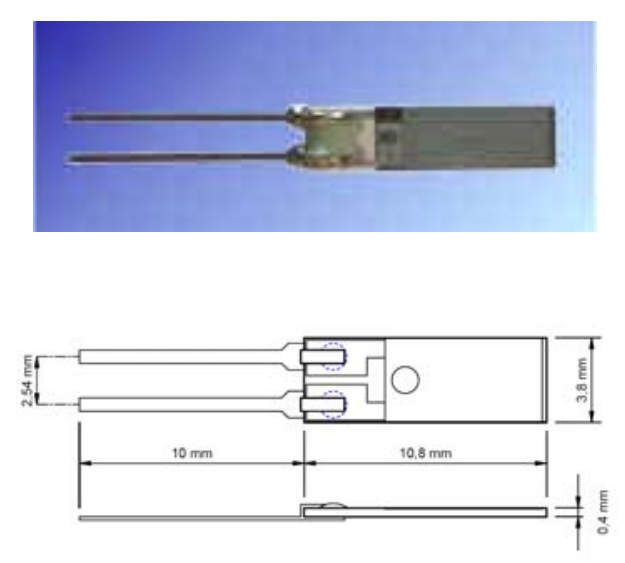

(a)

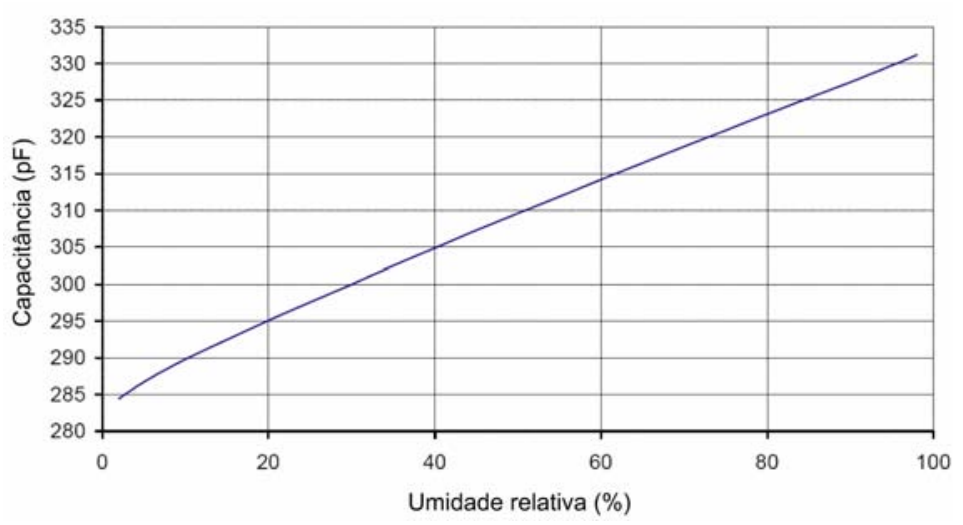

(b)

Figura 2.26 - Sensor higrométrico capacitivo (a) e sua curva característica (b). Fonte: ROTRONIC (2001).

Também há sensores que podem determinar simultaneamente a umidade e a temperatura do concreto, sendo construídos a partir da união de um sensor higrométrico com um sensor de temperatura (geralmente um RTD, modelo PT100). Adicionalmente, para a determinação da temperatura e da umidade relativa do arl pode ser utilizado o termohigrógrafo, um dispositivo que, além de medir, registra de forma gráfica e contínua as duas grandezas, embora apresente o inconveniente de não permitir a aquisição ou o armazenameno digital das informações. 


\subsubsection{Acelerações}

Os primeiros testes dinâmicos foram realizados pela indústria aeronáutica durante a Segunda Guerra Mundial, em uma tentativa de compreender o comportamento de elementos estruturais de aviões, principalmente aqueles sujeitos a carregamentos cíclicos e que repetidamente apresentavam falhas associadas a graves acidentes. Posteriormente, nas décadas de 1970 e 1980, investigações em busca das características dinâmicas de estruturas foram realizadas nos setores aeroespacial e petrolífero (CARDEN, 2004). O emprego de ensaios dinâmicos em estruturas de Engenharia Civil, principalmente em pontes, é bem mais recente, sendo frequentemente realizados quando são necessárias informações mais profundas associadas ao comportamento da estrutura (tendo por referência as premissas do projeto), quando se faz necessária a avaliação das condições de segurança ou integridade da estrutura, ou ainda em situações nas quais se pretende avaliar as condições de conforto que a estrutura oference aos seus usuários (CREMONA, 2004).

De modo geral, em um ensaio dinâmico a estrutura pode estar sujeita a vibrações ambientais, geralmente provocadas pela passagem de veículos de massa significativa ou pelo vento, ou pode ser submetida a uma excitação forçada, normalmente promovida por shakers hidráulicos ou eletromecânicos ligados à estrutura. Espera-se que os resultados obtidos possibilitem determinar as frequências naturais de vibração da estrutura e os seus modos de vibração, características que por estarem vinculadas às propriedades geométricas e mecânicas dos elementos estruturais, podem indicar com segurança a presença de danos a partir da variação dos seus valores (CHINTALAPUDI et al., 2006).

$\mathrm{Na}$ realização dos ensaios dinâmicos, são largamente utilizados os acelerômetros, que são sensores responsáveis pela conversão do movimento ou da sua variação em sinais elétricos. Encontram-se disponíveis no mercado acelerômetros baseados em diferentes principios de operação, com as mais variadas faixas de medição e resoluções, a preços bastante acessíveis, destacandose para monitoração de estruturas os acelerômetros piezoelétricos, piezoresistivos, capacitivos, e capacitivos MEMS (EREN, 1999). Alguns desses sensores, como os piezoelétricos e os capacitivos, exploram, com as devidas adaptações, o 
funcionamento de um sistema do tipo massa e mola (ESTEPA, 2006; EREN, 1999), sumariamente descrito a seguir.

Uma mola, enquanto na sua região de comportamento linear, é governada pela lei de Hooke, pela qual um deslocamento $x$ da mola, a partir de um referencial de posição, é proporcional à força $F$ aplicada, ou seja:

$$
F=k \cdot x
$$

Onde $k$ é a constante elástica inerente à mola.

Está igualmente envolvida no processo de medição a Segunda Lei de Newton, que relaciona a força aplicada a um corpo de massa $m$ e a aceleração $a$ produzida por meio da equação 2.14:

$$
F=m \cdot a
$$

Igualando as equações 2.13 e 2.14 , obtemos as equações 2.15 e 2.16 :

$$
\begin{aligned}
& m \cdot a=k \cdot x \\
& a=\frac{k \cdot x}{m}
\end{aligned}
$$

Da equação 2.6 é possível perceber que se a massa sofeu um deslocamento $x$, significa que a massa está sujeita à aceleracão dada pela equação 2.6, de forma que o problema de medir a aceleração se torna no problema de medição do deslocamento de uma massa. Assim, um acelerômetro que esteja baseado em um sistema de mola única só é capaz de medir a aceleração ao longo do eixo dessa mola, e denomina-se acelerômetro de eixo único, ou uniaxial. Para cada eixo ao longo do qual se deseja medir a aceleração é necessário um sistema como o descrito, podendo ser utilizada uma composição a partir de acelerômetros uniaxiais, empregando cubos de montagem, conforme indicado na figura 2.27a.

Na figura 2.27b, são apresentados alguns chips de acelerômetros MEMS, enquanto que a figura 2.27c ilustra um acelerômetro triaxial MEMS encapsulado e pronto para utilização. 


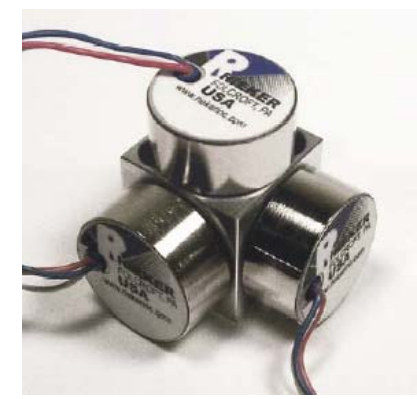

(a)

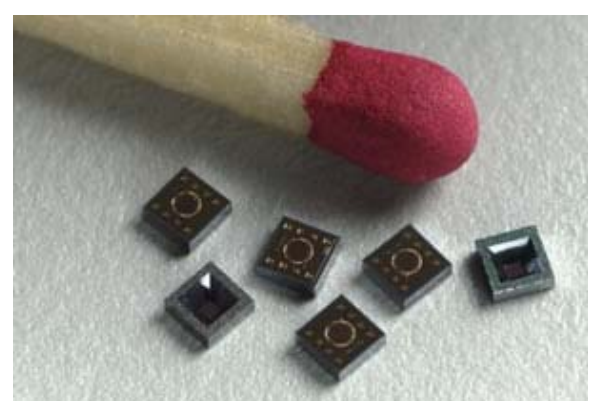

(b)

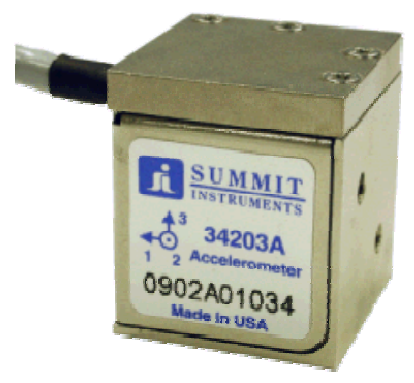

(c)

Figura 2.27 - Composição de acelerômetros uniaxiais utilizando cubo de montagem (aresta de 24 $\mathrm{mm}$ ), chips de acelerômetros MEMS (b) e acelerômetro pronto para uso (maior dimensão: $28,3 \mathrm{~mm}$ ). Fonte: RIEKER (2006); OMNI INSTRUMENTS (2007).

\subsubsection{Sensores a fibra óptica}

Os sensores a fibra óptica são dispositivos que permitem medir grandezas físicas ou químicas mediante uma alteração das propriedades da luz propagada na fibra óptica. Esse tipo de sensores é fruto dos grandes progressos tecnológicos na fotônica ${ }^{8}$, bem como do significativo crescimento da indústria do setor ao longo dos últimos trinta anos, que permitiu que componentes optoeletrônicos fossem ofertados a preços cada vez mais acessíveis, viabilizando o desenvolvimento de sistemas de monitoração baseados em fibras ópticas (VALENTE et al., 2002).

As fibras ópticas são guias de onda constituídos por materiais dielétricos de simetria cilíndrica que confinam radiação eletromagnética na região das frequências ópticas, ou seja, são estruturas não metálicas que possuem uma direção característica ao longo da qual uma onda óptica inserida se propaga com pequena perda (SANTOS, 2004). A estrutura básica de uma fibra óptica típica, feita de sílica, é constituída por três elementos: o núcleo, com diâmetro entre 5 e $50 \mu \mathrm{m}$; a casca, uma camada que envolve o núcleo, com espessura de 120 a $200 \mu \mathrm{m}$; e o revestimento primário, construído com material plástico ou silicone, que visa proteger as camadas anteriores contra choques mecânicos e excesso de curvatura. A figura 2.28 ilustra a estrutura acima descrita.

\footnotetext{
${ }^{8}$ A fotônica é a ciência cuja finalidade é o controle, manipulação, transferência e armazenamento de informações utilizando fótons. Os fótons são partículas fundamentais que se deslocam à velocidade da luz, com massa e carga elétrica nulas (QUIMBY, 2006).
} 


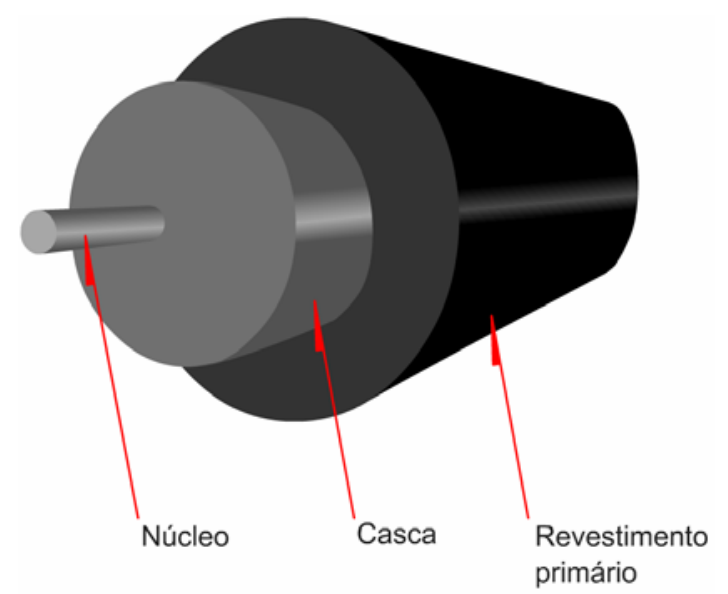

Figura 2.28 - Estrutura básica de uma fibra óptica.

Além dos componentes básicos, uma fibra óptica também pode receber revestimentos adicionais compostos por materiais plásticos, metálicos ou cerâmicos com o objetivo de proporcionar proteção mecânica superior e isolamento do sinal transportado.

O princípio fundamental que rege a propagação da luz em uma fibra óptica é o fenômeno físico denominado reflexão interna total. Para que este fenômeno ocorra, é necessário que o índice de refração do núcleo $\left(n_{1}\right)$ seja maior que o índice de refração da casca $\left(n_{2}\right)$ e que o ângulo de incidência da luz no núcleo seja menor ou igual do que o ângulo limite (também chamado ângulo de aceitação ou ângulo de Brewster), conforme ilustrado na figura 2.29 (REGAZZI, PEREIRA e SILVA, 2005; CASAS e CRUZ, 2003; LEIDERMAN,1998). O ângulo limite $\left(\alpha_{a}\right)$ está relacionado com os índices de refração $n_{1}$ e $n_{2}$ segundo a equação 2.17 (FOWLES, 1989).

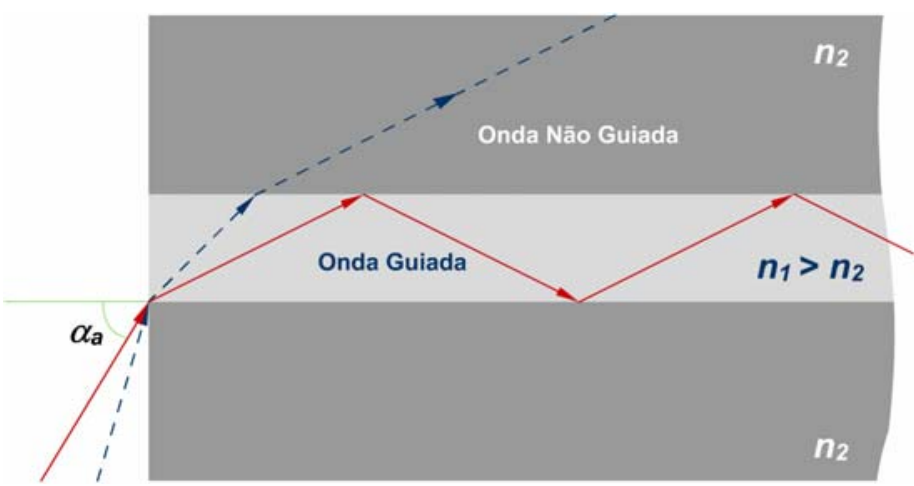

Figura 2.29 - Guiamento da luz no interior do núcleo da fibra óptica.

$$
\operatorname{sen}\left(\alpha_{a}\right)=\sqrt{\left(n_{1}^{2}-n_{2}{ }^{2}\right)}
$$


Desde as primeiras aplicações práticas das fibras ópticas, no início da década de 1950 (realizadas na área médica, na construção de equipamentos de endoscopia), ocorreram enormes avanços. Na época, uma das maiores dificuldades da aplicação dessa tecnologia fora dos domínios da medicina era a grande perda de potência luminosa (atenuação), principalmente devido à baixa qualidade das fontes luminosas e dos materiais utilizados na construção das fibras ópticas.

Com a invenção do laser em 1958, e percepção das suas potencialidades a partir de 1960, grandes esforços de pesquisa e desenvolvimento foram realizados tendo em vista o estabelecimento de um novo sistema de comunicações. O laser constituía uma fonte luminosa com potência e capacidade de transmissão enormes, viabilizando o desenvolvimento de sistemas de comunicações ópticas de longo alcance. A partir da segunda metade da década de 1960, os EUA, o Japão e a Europa investiram fortemente no domínio da técnica de construção de fibras ópticas com sílica de elevada pureza, e como resultado, surgiram as primeiras fibras com atenuações suficientemente baixas a ponto de possibilitar seu uso em sistemas de comunicação de longa distância. Desde então, como resultado dos contínuos e intensos investimentos no setor, uma série de outras aplicações para as fibras ópticas foram viabilizadas, e nos últimos vinte anos, a área de medições e instrumentação se encontra entre as que se expandem mais rapidamente (SAFAAIJAZI, 2003).

A partir de experimentos que demonstraram que uma única fibra óptica poderia ser usada como sensor, a variedade de grandezas medidas utilizando sensores ópticos cresceu rapidamente, assim como o número de sensores utilizados, e atualmente, centenas de estruturas de civis ao redor do mundo encontram-se monitoradas utilizando sensores a fibra óptica (DOORNINK, 2004).

$\mathrm{Na}$ monitoração estrutural, diversos tipos de sensores de fibra óptica têm sido utilizados, destacando-se os sensores de Fabry-Pérot, os interferômetros de luz-branca em fibra óptica, os sensores de Raman e Brillouin e as redes de Bragg em fibra óptica (fiber Bragg grating, ou FBG) (BONFIGLIOLI e PASCALE, 2003; ZHANG, BENMOKRANE e NICOLE, 2003; INAUDI et al., 2000; MEASURES, 2000; QUIRION e BALLIVY, 2000; TENNYSON et al., 2000; CHOQUET, LEROUX e JUNEAU, 1997; BELLEVILLE e DUPLAIN, 1993). Dentre esses, as redes de Bragg em fibra óptica, também conhecidas como sensores de Bragg, oferecem um conjunto de vantagens adicionais, tais como elevada estabilidade das respostas ao 
longo do tempo e reduzidas dimensões, que as tornam mais indicadas para aplicações de monitoração estrutural (ZHANG, ZHANG e BENNION, 2002; SLOWIK, SCHLATTNER e KLINK, 1998). Outras características essenciais que tornam os sensores de Bragg muito interessantes para as aplicações de Engenharia Civil são a capacidade de multiplexagem e a auto-referenciação. A multiplexagem permite que vários sensores possam ser integrados numa só fibra óptica, sendo interrogados utilizando-se um único equipamento. Já a auto-referenciação garante que as medições podem ser feitas tendo como referência a primeira medição (realizada por ocasião da fabricação do sensor, ou da instalação do mesmo).

Uma rede de Bragg é essencialmente uma microestrutura de dimensões reduzidas (geralmente menor que $1 \mathrm{~cm}$ ), que pode ser construída no núcleo de uma fibra óptica por métodos diversos utilizando radiação ultravioleta (MOSZKOWICZ, 2002). Essa microestrutura consiste em uma alteração periódica e localizada do índice de refração da fibra, que possibilita a reflexão seletiva de uma banda estreita de luz, centrada no comprimento de onda de Bragg da rede $\left(\lambda_{B}\right)$. Assim, a rede atua como um filtro, refletindo de forma eficiente o comprimento de onda que satisfaz a condição de Bragg, descrita pela equação 2.18:

$$
\lambda_{B}=2 n_{\text {eff }} \Lambda
$$

Onde:

$n_{\text {eff }}$ - é o índice de refração efetivo da fibra;

$\Lambda$ - é o período espacial da modulação da rede.

Quando a rede é submetida a ação de agentes externos que promovem a variação da grandeza monitorada, o comprimento de onda de Bragg ( $\left.\lambda_{B}\right)$ sofre uma mudança de valor, seja devido a alteração da periodicidade da rede $(\Lambda)$, seja pela modificação do índice de refração efetivo $\left(n_{\text {eff }}\right)$, resultando em um deslocamento espectral do comprimento de onda de Bragg $\left(\Delta \lambda_{B}\right)$ em relação ao comprimento de onda original. Dessa forma, conhecendo-se a relação existente entre a variação do comprimento de onda de Bragg e a variação da grandeza de interesse, torna-se possível utilizar a rede de Bragg como um sensor (DUPONT, 2002). A figura 2.30 ilustra esquematicamente o funcionamento de uma rede de Bragg. 
A existência de esforço mecânico longitudinal ou variação de temperatura sobre uma rede de Bragg provoca, devido aos efeitos foto-elástico e termo-óptico, uma relação entre a variação do comprimento de onda de Bragg e seu valor inicial que é descrita pela equacão 2.19 (SLOWIK, SCHLATTNER e KLINK, 1998):

$$
\frac{\Delta \lambda_{B}}{\lambda_{B}}=\left(1-p_{e}\right) \varepsilon+\zeta \Delta T
$$

Onde:

$p_{e}$ - é o coeficiente foto-elástico da rede de Bragg;

$\zeta$ - é o coeficiente termo-óptico da rede de Bragg.

Os coeficientes $p_{e}$ e $\zeta$ variam de acordo com os materiais que constituem a fibra óptica, e podem ser obtidos mediante calibração apropriada, embora uma boa aproximação da relação $\Delta \lambda_{B} / \lambda_{B}$ seja fornecida pela equação 2.20 (VALENTE et al., 2000; OTHONOS e KALLI, 1999).

$$
\frac{\Delta \lambda_{B}}{\lambda_{B}}=0,78 \varepsilon+9 \cdot 10^{-6} \Delta T
$$

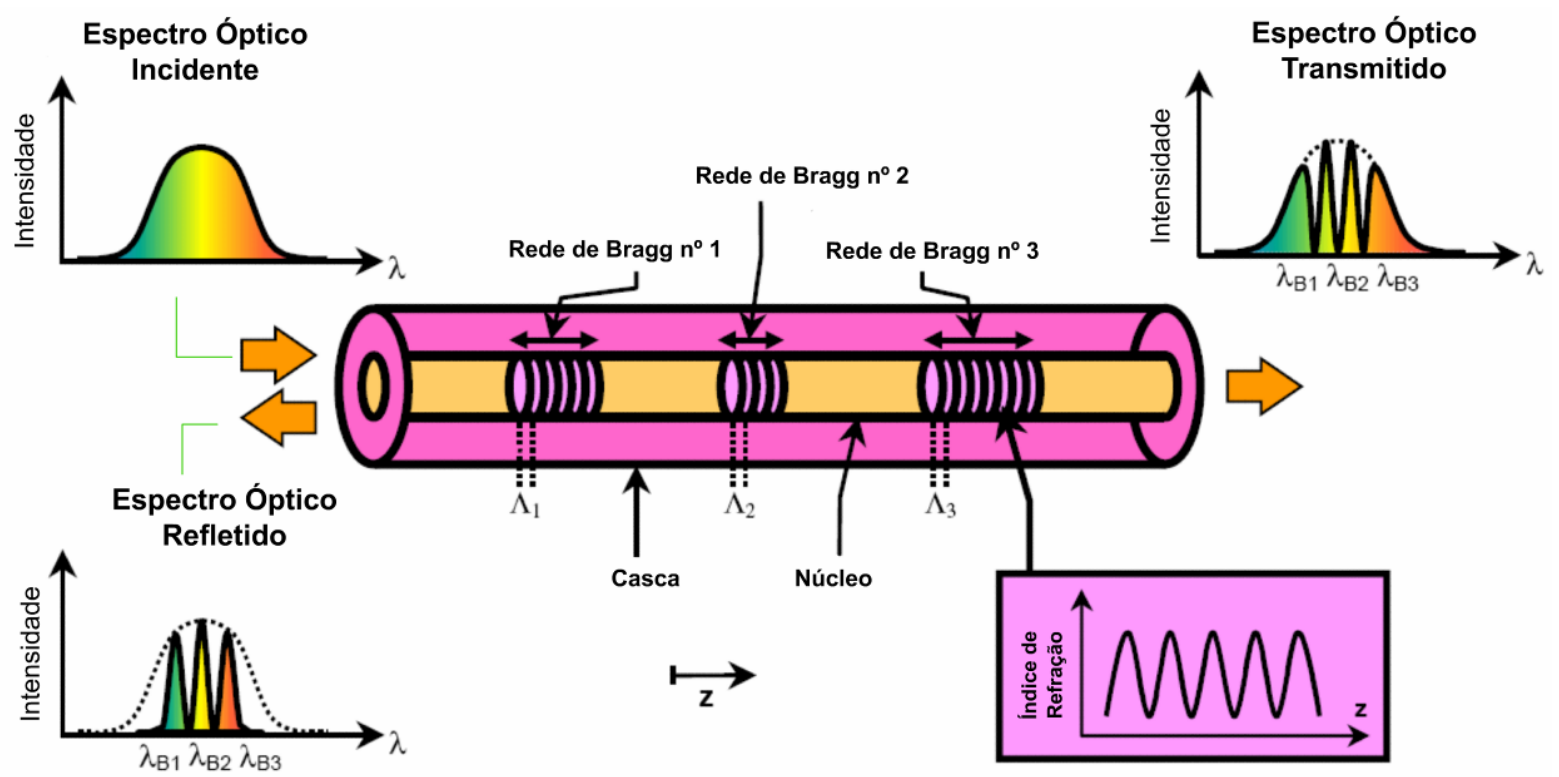

Figura 2.30 - Esquema de funcionamento de uma rede de Bragg (adaptado de DUPONT, 2002).

O sinal óptico de um sensor de Bragg é processado por um sistema de tratamento de sinal denominado interrogador, que pode empregar diferentes técnicas para medir o deslocamento do comprimento de onda decorrente das 
modificações induzidas na rede. A escolha do procedimento mais adequado depende principalmente das características das fibras e dos sensores, devendo-se considerar também o número de sensores interrogados, a extidão exigida, limitações de espaço, peso final do sistema de medição e o custo. Dentre as principais técnicas, destacam-se as baseadas em filtros de banda ajustável, em filtros fixos ou na multiplexação no tempo e no espectro, as quais têm sua relevância estabelecida sobretudo por apresentarem custos praticáveis.

Uma vez que em várias atividades de campo realizadas no escopo deste doutorado foram utilizados equipamentos de interrogação de sinal baseados em filtros de banda ajustável, será dada atenção ao princípio de funcionamento desta técnica.

A técnica fundamentada no uso de filtros de banda ajustável requer que cada sensor na fibra possua um comprimento de onda específico, obtendo-se como resposta vários sinais, em diferentes comprimentos de onda, correspondentes às reflexões de cada um dos sensores de Bragg presentes na fibra. Por meio da utilização de uma fonte de luz com largura de banda suficiente para cobrir todo o espectro contendo os comprimentos de onda dos sensores, a luz refletida por cada sensor pode ser separada pelo filtro ajustável, que é capaz de selecionar a luz refletida, deixando passar apenas uma banda estreita centrada no comprimento de onda da rede de Bragg analisada, que é lida por meio de um analisador de espectros ópticos (ou OSA - Optical Spectrum Analyzer) (ZIMMERMANN et al., 2006; OLIVIERI, 2004; VALENTE, 2000). A técnica é esquematizada na figura 2.31, sendo apresentado um sistema de interrogação e um resultado típico na figura 2.32.

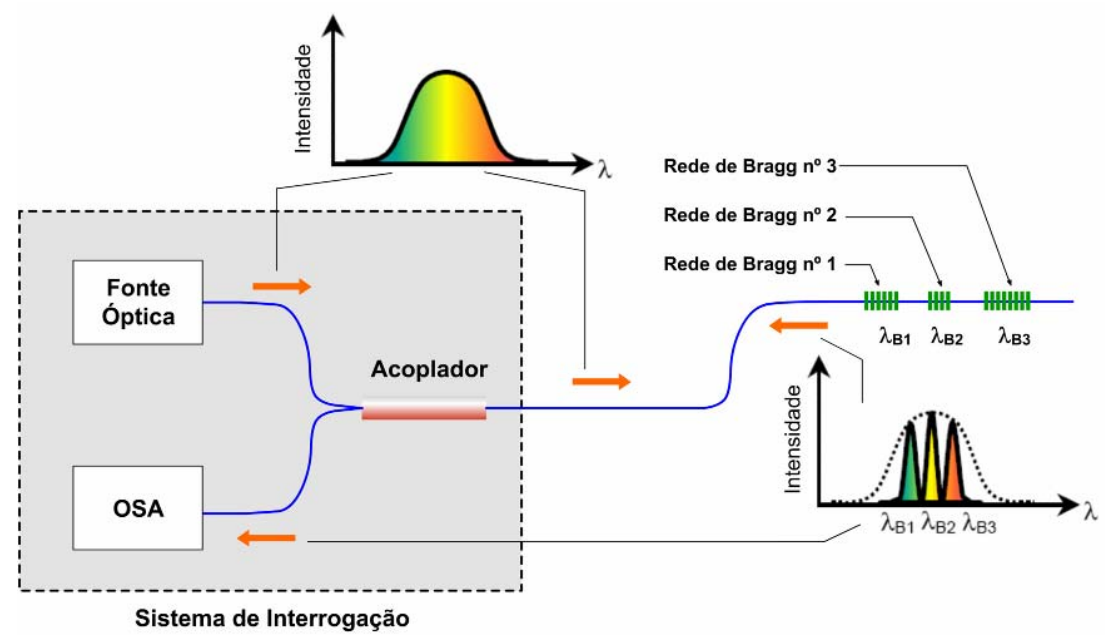

Figura 2.31 - Interrogação de sensores de Bragg. 


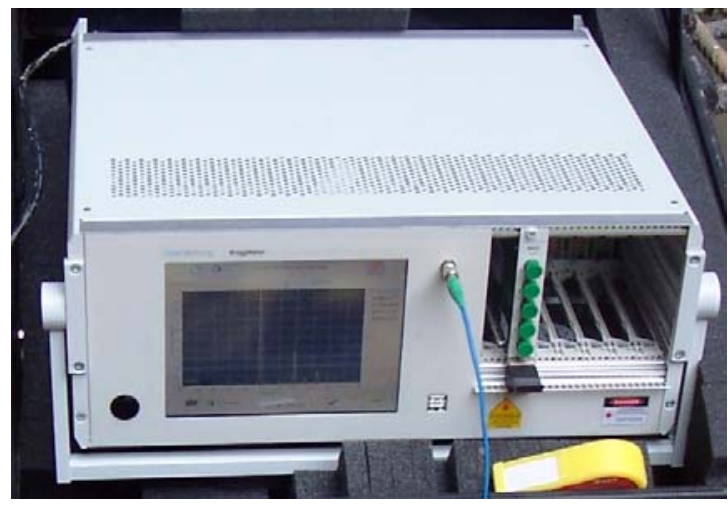

(a)

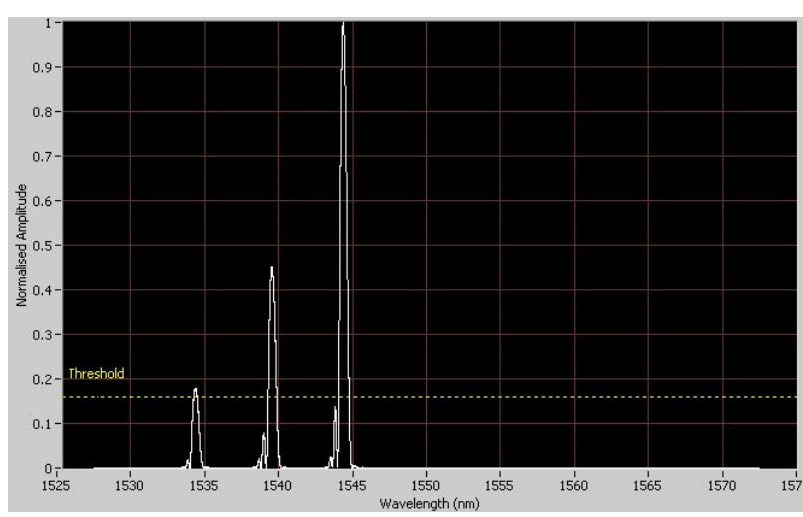

(b)

Figura 2.32 - Sistema de interrogação de redes de Bragg (a) e resultado típico (b).

A seguir, serão apresentadas as principais vantagens e desvantagens associadas aos sensores ópticos.

\subsubsection{Vantagens dos sensores a fibra óptica}

Em grande medida, os aspectos positivos associados aos sensores ópticos estão vinculados às características das fibras ópticas, que são componentes indissociáveis desse tipo de sensor. Dentre as diversas vantagens que lhes são inerentes, destacam-se (UDD, 2006):
a) baixa atenuação;
b) imunidade a interferência eletromagnética e ruídos;
c) isolamento elétrico;
d) dimensões e peso reduzidos;
e) segurança da informação e do sistema;

\subsection{Baixa atenuação}

A atenuação corresponde à perda de potência do sinal ao longo de sua propagação, e deve ser considerada quando do planejamento da implantação de um 
sistema de monitoração. As principais causas de atenuação em um sensor a fibra óptica são a absorção e espalhamento do sinal. A absorção corresponde à conversão da luz em calor, promovida por moléculas de $\mathrm{OH}^{+}$presentes na sílica e pelas moléculas dos dopantes utilizados para alterar o índice de refração do núcleo. $O$ espalhamento ocorre quando as interações entre a radiação eletromagnética transportada e os elétrons de átomos presentes no núcleo da fibra redirecionam a radiação em ângulos que impedem a sua propagação. A atenuação também pode ser provocada por fatores externos, como a existência de emendas nas fibras e conexões aos equipamentos (QUIRION e BALLIVY, 1998).

As fibras ópticas apresentam atualmente perdas de transmissão extremamente baixas, embora pesquisas com novos materiais prometam fibras ópticas com atenuação ainda menores. Desse modo, utilizando sensores a fibra óptica torna-se possível implantar com sucesso sistemas de monitoração que exijam grandes distâncias (até $100 \mathrm{~km}$ ) entre os elementos de uma rede sensora, ou entre a rede sensora e os sistemas de leitura, sem perdas apreciáveis dos sinais ópticos, assegurando a integridade da informação fornecida pelo sistema de monitoração (ZIMMERMANN et al., 2006).

\subsection{Imunidade a interferência eletromagnética e ruídos}

Um dos maiores problemas associados à transmissão de dados de qualquer tipo, seja elétrico ou óptico, é o ruído. O ruído do ambiente no qual o sinal é transmitido pode corromper o sinal, acarretando prejuízos que serão evidenciados durante o trabalho de análise e interpretação de resultados. Geralmente, os ruídos são decorrentes de radiação eletromagnética na vizinhança das cablagens, sendo as principais fontes os equipamentos elétricos pesados, as descargas elétricas atmosféricas e a ignição de motores.

Ao contrário dos cabos convencionais, nos quais a transmissão de sinal é realizada utilizando fios metálicos, as fibras ópticas não sofrem interferências eletromagnéticas, visto que são constituídas por materiais dielétricos. Adicionalmente, as fibras ópticas agrupadas em cabos ópticos não interferem 
opticamente umas nas outras, em função de o sinal propagado permanecer bem confinado a cada fibra (BORINSKI et al., 2001).

\subsection{Isolamento elétrico}

O material dielétrico que compõe a fibra óptica oferece excelente isolamento elétrico entre os sensores e os demais componentes do sistema de monitoração, e ao contrário dos sistemas que utilizam cabos metálicos, os sistemas baseados em sensores ópticos não necessitam de aterramentos. Além disso, quando um cabo de fibra óptica é danificado não ocorrem faíscas de curto-circuito. Esta característica é particularmente interessante na monitoração em áreas nas quais o risco de ocorrência de fogo ou explosão é considerável. A impossibilidade de choques elétricos quando do manuseio de cabos de fibras óptica permite que os mesmos possam ser reparados em campo, inclusive com os equipamentos de interrogação de sinal ligados e conectados (NASCIMENTO e DUARTE, 2002).

\subsection{Dimensões e peso reduzidos}

As fibras ópticas apresentam dimensões transversais comparáveis com as de um fio de cabelo humano. Mesmo considerando os encapsulamentos de proteção, o diâmetro e o peso dos cabos ópticos são bastante inferiores aos dos cabos metálicos utilizados para a mesma finalidade, em sensores convencionais. A expressiva redução das dimensões dos cabos, provida pelas fibras ópticas, permite aliviar o problema de espaço e de congestionamento em postos de observação. Consequentemente, os cabos ópticos oferecem vantagens quanto ao armazenamento, transporte, manuseio e instalação em relação aos cabos metálicos de resistência e durabilidade equivalentes. 
2.3.6.1.5 Segurança da informação e do sistema

As fibras ópticas não irradiam significativamente a luz propagada, implicando um alto grau de segurança para a informação transportada. Qualquer tentativa de captação de mensagens ao longo de uma fibra óptica é facilmente detectada, pois exige o desvio de uma porção considerável de potência luminosa transmitida.

\subsubsection{Desvantagens dos sensores a fibra óptica}

As principais desvantagens dos sensores ópticos estão associadas a algumas características das fibras ópticas e a aspectos negativos relacionados com o manuseio e reparo das fibras e custos ainda elevados dos sistemas de interrogação do sinais, ressaltando-se as indicadas a seguir:

a) fragilidade;

b) dificuldade de reparação em campo;

c) competitividade econômica limitada a monitoração em grande escala.

\subsection{Fragilidade}

O manuseio de um cabo óptico, seja durante a instalação dos sensores ou quando da realização de emendas, exige mais cuidados do que quando da utilização dos cabos dos sistemas de monitoração convencionais. As fibras ópticas, sobretudo quando não se encontram devidamente protegidas, podem quebrar com relativa facilidade, sendo necessário utilizar sensores com cabos apropriamente revestidos para o meio no qual a monitoração venha a ser realizada. 


\subsection{Dificuldade de reparação em campo}

Em razão das reduzidas dimensões envolvidas, a emenda ou substituição de fibras ópticas em campo exigem procedimentos e dispositivos de alta precisão, a fim de limitar as perdas de sinal. A junção ponto-a-ponto de dois ou mais segmentos de fibra óptica pode ser realizada de modo permanente através de emendas ou por meio de conectores mecânicos de alta precisão (TENNYSON, 2001).

Na figura 2.33 são apresentados dois equipamentos bastante utilizados para a emenda de fibras ópticas, em laboratório ou em campo: o clivador de precisão e a máquina de emenda por fusão. O clivador é dispositivo que proporciona o corte da fibra com alta precisão, de forma que a superfície resultante seja perfeitamente plana, buscando assim evitar perdas locais de sinal quando da emenda. A máquina de emenda é um aparelho capaz de unir duas fibras ópticas por meio da fusão das suas extremidades, com perdas mínimas ou nulas na região trabalhada. Esse equipamento possui um monitor que permite o acompanhamento de todo o processo de fusão, incluindo o alinhamento automático das fibras e informação da perda estimada decorrente da emenda. Para proteção da emenda, é possível utilizar um pequeno tubo de material plástico termocontrátil, que deve ser posicionado no local a ser protegido, sendo posteriormente fixado de modo permanente mediante aquecimento promovido pelo equipamento de emenda, que conta com um compartimento próprio para esta finalidade.
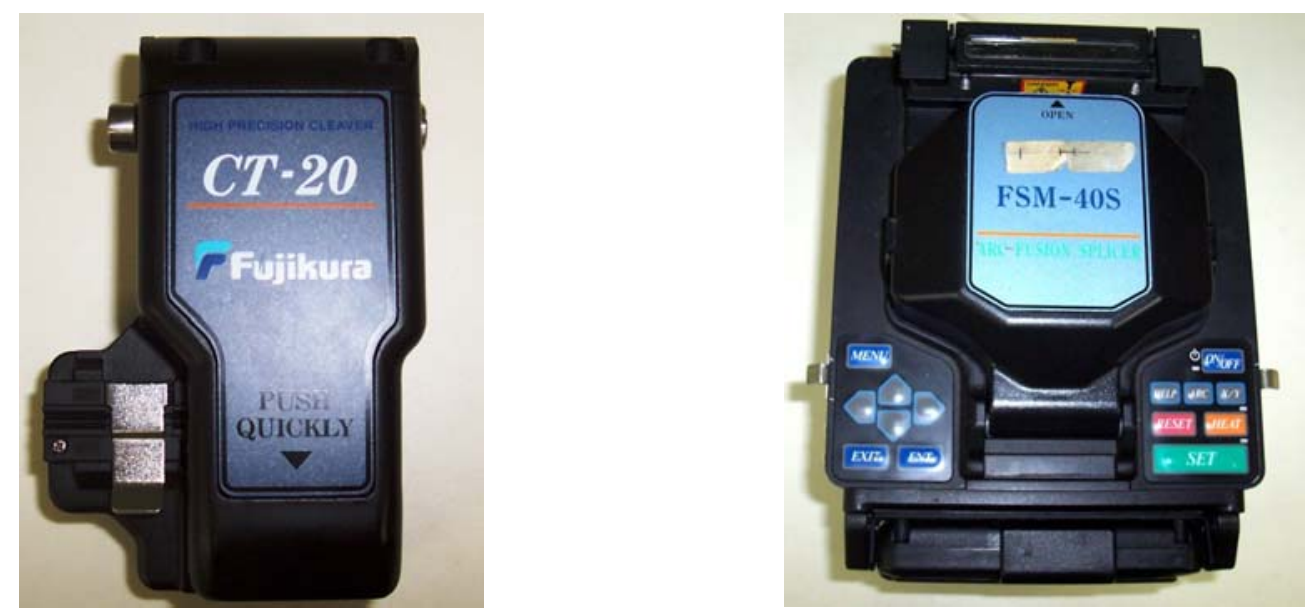

Figura 2.33 - Equipamentos para trabalhos com fibras ópticas: clivador (a) e máquina de emenda por fusão (b). 
2.3.6.2.3 Competitividade econômica limitada a monitoração em grande escala

Na monitoração de estruturas que envolvam poucos pontos de medição, o custo dos sensores e dos sistemas de interrogação de sinais ópticos impactam de forma decisiva e desfavorável no valor total de um sistema de monitoração, em relação aos sistemas convencionais. Entretanto, esta nova tecnologia já se mostra competitiva em monitorações envolvendo muitos sensores.

Enquanto o preço de mercado de ERE's próprios para embutir no concreto ronda os USD 15,00 por unidade, empregando equipamentos para aquisição e condicionamento de sinais que podem custar entre USD 300,00 e USD 2.000,00 por canal (dependendo do tipo de resposta e da qualidade exigida), um sensor óptico para a mesma finalidade pode custar entre USD 150,00 e USD 500,00, sendo necessários sistemas de interrogação que custam entre USD 15.000,00 e USD 30.000,00. Entretanto, como esses sistemas permitem realizar medições de até 100 ou 1400 sensores simultaneamente, resulta um custo de aquisição por sensor óptico entre USD 20,00 e USD 150,00, desde que a rede sensora seja suficientemente extensa.

$\mathrm{Na}$ figura 2.34 é apresentada a ponte Versoix, localizada em uma autoestrada em Geneva, na Suíça. Esta obra foi monitorada com 104 sensores ópticos, distribuídos em 12 seções, durante uma intervenção visando a sua ampliação, obtendo-se bons resultados (INAUDI et al., 1999; VURPILLOT et al., 1997).

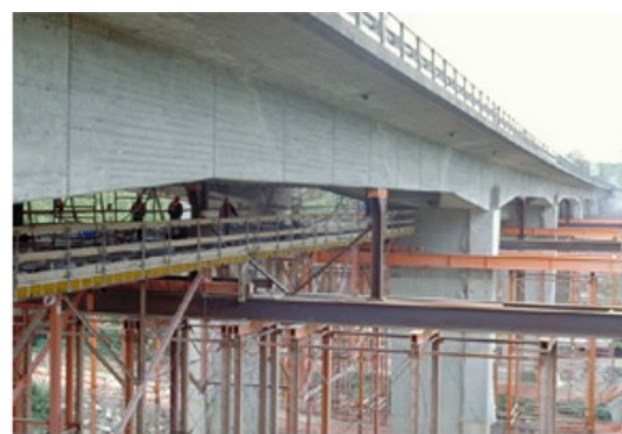

(a)

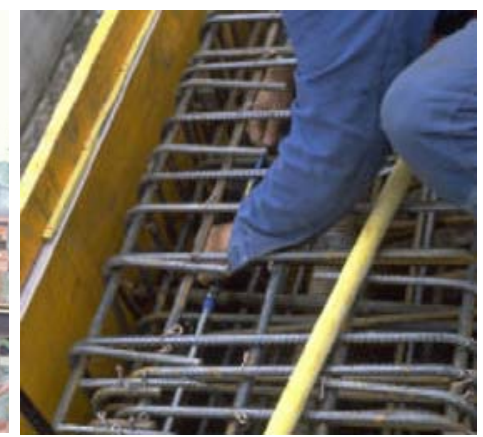

(b)

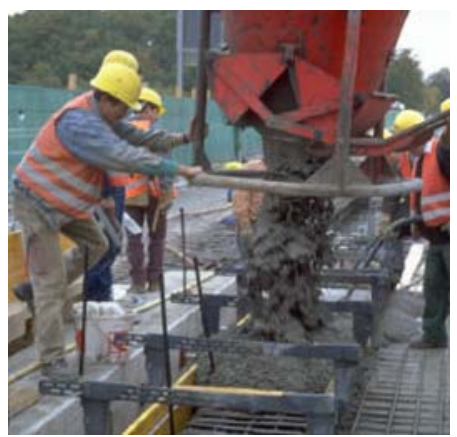

(c)

Figura 2.34 - Ponte Versoix (a): instalação (b) e concretagem de sensores ópticos. Fonte: INAUDI et al. (1999); VURPILLOT et al. (1997). 
Em razão do crescente investimento tecnológico que vem sendo feito e, principalmente, da proliferação das aplicações utilizando tecnologia óptica, a tendência é que haja a redução gradual dos custos dos sensores e equipamentos de medição, promovendo o aumento da competitividade desta nova solução de monitoração (SCHULZ, 1999).

\subsubsection{Sensores convencionais $x$ Sensores a fibra óptica}

O desenvolvimento e utilização dos sensores elétricos já remonta a cerca de sessenta anos, enquanto as pesquisas envolvendo sensores ópticos tiveram início há três décadas (RAO e HUANG, 2002). Este fato por si só confere aos sensores convencionais duas vantagens muito significativas sobre as novas tecnologias:

1) O ciclo de vida dos sensores, desde a fase de produção até os procedimentos de instalação e resposta em campo são bem conhecidos. Paralelamente, ao longo dos anos uma larga quantidade de tecnologia de suporte foi sendo desenvolvida, desde conectores e acessórios até sistemas de aquisição de sinais economicamente competitivos;

2) Em consequência do largo uso dos sensores convencionais em sistemas de monitoração, ocorreu a redução gradual do custo total da instrumentação desses sistemas. Trata-se assim de uma classe de sensores que já atingiu a sua maturidade, o que significa que é não é muito provável que, comercialmente, o seu preço possa ser reduzido de forma significativa.

Os sensores a fibra óptica, por outro lado, são provenientes de tecnologias relativamente recentes que estão atualmente sujeitas a muita investigação e desenvolvimento. $O$ principal fator que tem restringido o emprego dos sensores ópticos em monitorações correntes é o expressivo custo inerente aos equipamentos 
de suporte e aos sistemas de interogação de sinais, limitando a sua competitividade econômica às situações que exigem instrumentação em grande escala.

Entretanto, é preciso ter em conta que a tecnologia de fontes luminosas e detectores de luz, de onde provém os componentes que representam a maior parte dos custos dos sistemas de interrogação de sinais, está ainda sujeita a muitas evoluções. Espera-se que quando forem disponibilizados interrogadores de baixo custo, os sistemas de monitoração baseados em sensores ópticos virão a constituir excelentes soluções para monitorações correntes.

A figura 2.35 apresenta a Ponte Jiangyin, localizada na China, cujo vão central, com $1385 \mathrm{~m}$, é continuamente monitorado por meio de dezenas de sensores ópticos e convencionais distribuídos ao longo de nove seções (KO e NI, 2005). Esta obra é uma dentre dezenas de outras ao redor do mundo que utilizam sensores ópticos para o acompanhamento do comportamento estrutural.

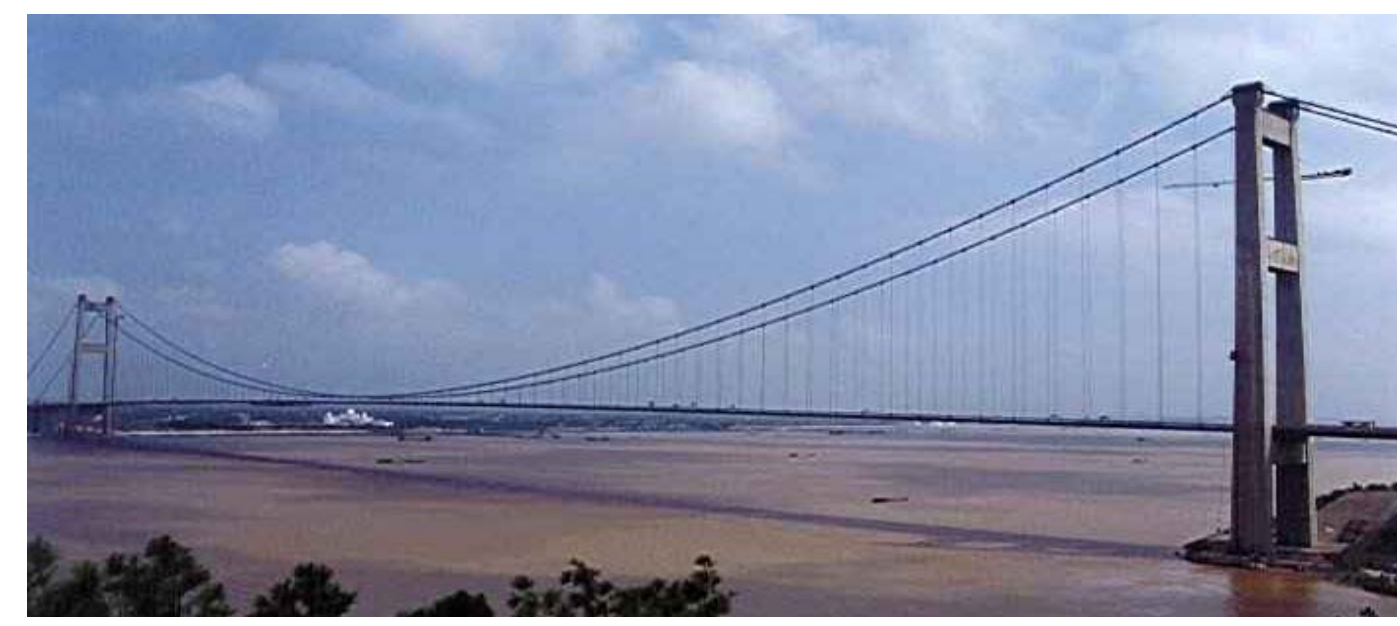

Figura 2.35 - Ponte Jiangyin. Fonte: DORMAN LONG TECHNOLOGY (2007).

\subsection{Considerações finais}

Neste capítulo foram apresentados os principais aspectos associados à importância, componentes e funcionamento dos atuais sistemas de monitoração aplicados à monitoração de estruturas civis, conferindo-se certo destaque à descrição dos principais métodos utilizados para o acompanhamento da variação das grandezas físicas que na maioria dos casos assumem maior relevância. 
A crescente atenção das autoridades públicas internacionais ao problema da contínua degradação das infra-estruturas civis e dos elevados custos envolvidos em operações de demolições, reconstruções ou reparos em condições emergenciais tem fomentado o reconhecimento da monitoração como método capaz de promover uma grande economia de recursos, visto que por meio da monitoração torna-se possível acompanhar o comportamento estrutural de forma permanente, viabilizando a identificação de problemas em tempo oportuno e conduzindo a um apropriado sistema de gestão das obras relevantes à sociedade.

Entretanto, para que um sistema de monitoração forneça resultados finais confiáveis ao longo da sua vida útil, é preciso que a equipe envolvida detenha o conhecimento requerido para a plena execução de todas as fases do processo, desde o planejamento da monitoração, passando pela seleção e instrumentação de sensores e equipamentos, até o tratamento e interpretação dos resultados, implicando na composição multidisciplinar do componentes do grupo.

Por fim, é importante considerar a recomendação de CHANG (2003), que nos adverte que apesar dos avanços tecnológicos terem permitido 0 desenvolvimento de sistemas integrados de monitoração de elevado nível de sofisticação, as inspeções visuais e a visita periódica de equipes de manutenção à obra não devem ser dispensadas, pois embora estas sejam limitadas em alcance e profundidade na determinação de problemas estruturais, podem fornecer informações complementares e identificar patologias ou anomalias de natureza distinta das detectáveis pelo sistema de monitoração instalado. 


\section{CAPÍTULO 3}

\section{SISTEMA DE VISUALIZAÇÃO E TRATAMENTO DE DADOS}

\subsection{Introdução}

$\mathrm{Na}$ monitoração de estruturas, a visualização e tratamento dos dados obtidos constituem atividades fundamentais, das quais depende qualitativamente 0 esforço envolvido na interpretação do comportamento estrutural. Ao redor do mundo, os sistemas desenvolvidos tendo em vista o tratamento, análise e interpretação de resultados têm em comum a apresentação de interface intuitiva e fácil utilização, disponibilizando ferramentas que fornecem ao usuário uma visão inicial do comportamento da estrutura monitorada, tendo por base as medições provenientes do sistema de monitoração. Usualmente, nos sistemas de tratamento de resultados são empregados modelos estatísticos para manipulação dos resultados, que consiste no uso de filtros para eliminação de ruídos e tratamento dos sinais oriundos dos sensores e algoritmos para correlação dos resultados e decomposição dos sinais em parcelas que podem facilitar a análise e a compreensão dos fenômenos envolvidos no comportamento estrutural. Adicionalmente, esses sistemas também podem fornecer um modelo de previsão do comportamento da estrutura, tendo por base os resultados já coletados e analisados (STRAUSS, 2004).

Ao longo deste capítulo, será apresentado o sistema de visualização e apoio à interpretação desenvolvido pelo autor, além do sistema para controle do instrumento de aquisição de dados data logger dataTaker, utilizando interface de comunicação serial (RS-232). Para a construção dos sistemas, foi ultilizada a linguagem de programação LabVIEW (Laboratory Virtual Instrument Engineering Workbench).

Desenvolvido pela National Instruments Corporation, e utilizado por pesquisadores e engenheiros de diversos países, o LabVIEW é uma linguagem de programação multiplataforma (podendo operar em sistemas operacionais como 
Microsoft Windows, Apple Macintosh e LINUX) que conta com conjuntos de objetos e funções disponibilizadas em extensas bibliotecas, os quais possibilitam criar eficientemente aplicativos para controle, aquisição e análise de dados. Os programas desenvolvidos nessa linguagem são denominados instrumentos virtuais, ou VIs (Virtual Instruments) (NATIONAL INSTRUMENTS, 2003). Tal denominação é dada em virtude de a aparência e as operações dos programas, de forma geral, simularem a de instrumentos reais (BISHOP, 2001).

$O$ fato de o LabVIEW proporcionar bibliotecas com ferramentas para ampla variedade de áreas (processamento de sinal, processamento de imagem, comunicações industriais, internet, acesso a bases de dados, etc.) fez com que ele progressivamente viesse a se constituir um poderoso ambiente de desenvolvimento de aplicações finais e de prototipagem rápida para uma significativa diversidade de profissionais (CARVALHO, 2001).

Ao contrário da maioria das linguagens de programação, que apresenta ambiente de desenvolvimento com código baseado em texto, o LabVIEW utiliza um ambiente de programação gráfico, no qual a atividade de programação é realizada em um ambiente denominado diagrama de blocos, que conta com uma paleta de funções que agrega várias bibliotecas numéricas e funcionais. Criado o diagrama de blocos, é feita a compilação para código de máquina. A interface é montada no ambiente designado por painel frontal, sendo que os itens que a constituem são disponibilizadas em uma paleta de ferramentas de controle, que contém dezenas de objetos que podem ser modificados com o auxílio de uma paleta de ferramentas de edição.

Um diagrama de blocos e seu respectivo painel frontal podem ser vistos no VI apresentado na figura 3.1, que permite realizar operações matemáticas básicas com sinais simulados, tendo sido construído pelo doutorando durante a fase de familiarização com a linguagem.

O código de um VI assemelha-se a um fluxograma, e graças ao sofisticado compilador gráfico da linguagem, o fluxo dos dados e operações podem ser monitorados, facilitando significativamente o processo de identificação e correção de erros. É possível também, por meio do uso de DLL (Dynamic Link Library), exportar e importar rotinas. 


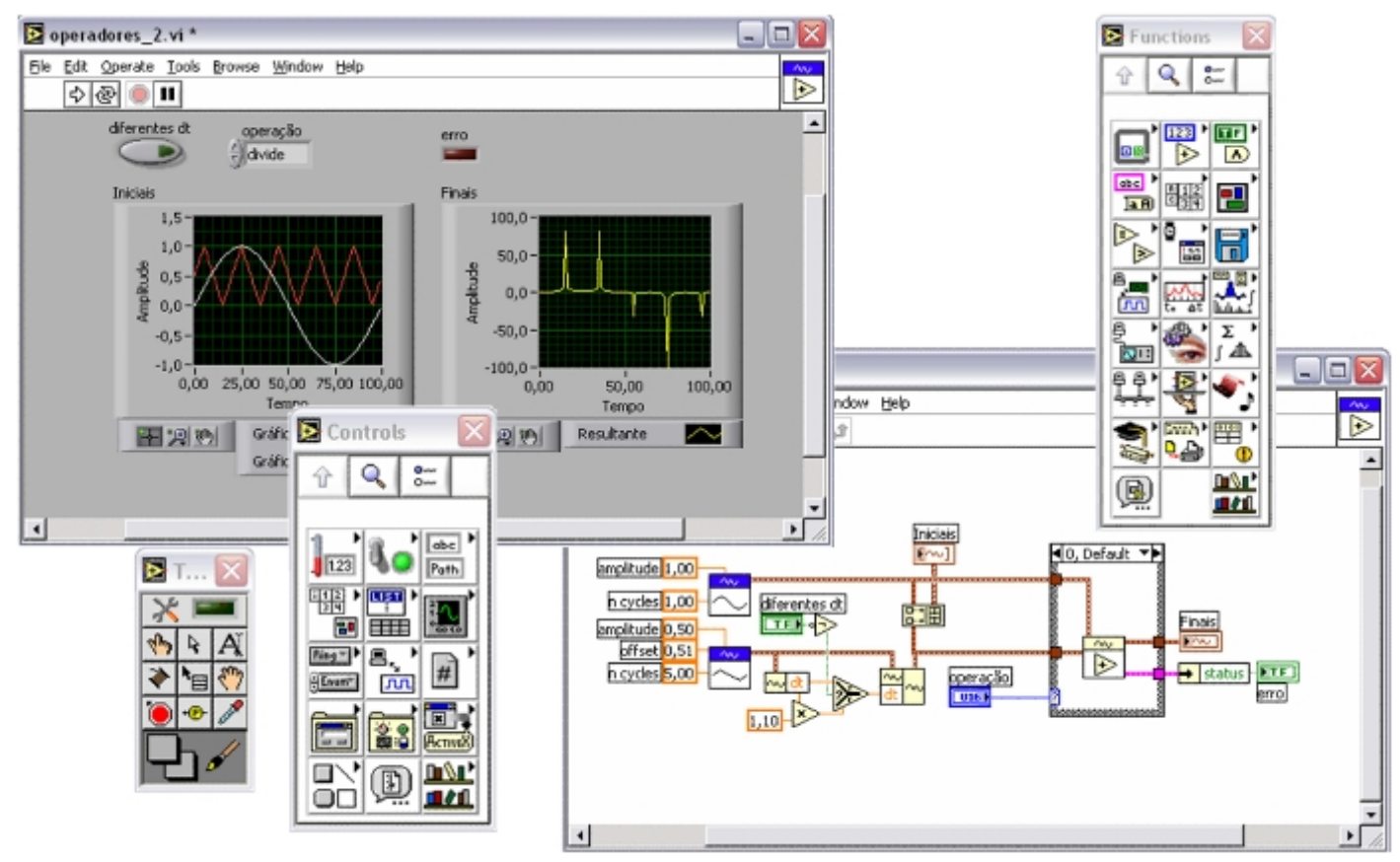

Figura 3.1 - Painel frontal (esquerda) e respectivo diagrama de blocos. Junto ao painel frontal estão as paletas de edição (esquerda) e controle, e acima do diagrama de blocos, a paleta de funções.

Assim, foi em virtude das características já apresentadas, associadas à possibilidade de desenvolver conteúdo voltado à visualização e tratamento de resultados com relativa facilidade, que a linguagem de programação LabVIEW foi escolhida para a construção do sistema tratado neste capítulo, sobressaindo-se, para este propósito, em relação a linguagens de programação como $\mathrm{C}++$ ou C\#.

\subsection{Módulo de aquisição de dados}

Para realizar o controle da aquisição por meio dos data loggers fabricados pela dataTaker, o autor desenvolveu um módulo computacional a partir do driver dataTaker para o LabVIEW. O módulo construído permite, para aquisições com data loggers das séries DT500 ou DT800, utilizando a interface de comunicação RS-232 (serial), controlar parâmetros como taxa de amostragem, armazenamento dos dados na memória interna do data logger ou no disco rígido do computador e configurar alarmes. Controles para a configuração da comunicação serial também estão disponíveis, bem como o tipo de protocolo a ser utilizado quando da aquisição. Há indicadores que permitem saber quando existe a comunicação de forma apropriada 
e também quando se está processando e armazenando os dados. A aquisição pode ser acompanhada em tempo real, conforme apresentado nas figuras 3.2 e 3.3, que ilustram a aplicação da primeira versão do módulo, utilizado para a realização de testes de funcionamento de sensores e equipamentos de postos de observação. $O$ gráfico da figura 3.2 corresponde às deformações provenientes de um ERE colado a uma barra de alumínio, sendo que o ERE estava conectado ao posto de observação apresentado no canto superior direito.

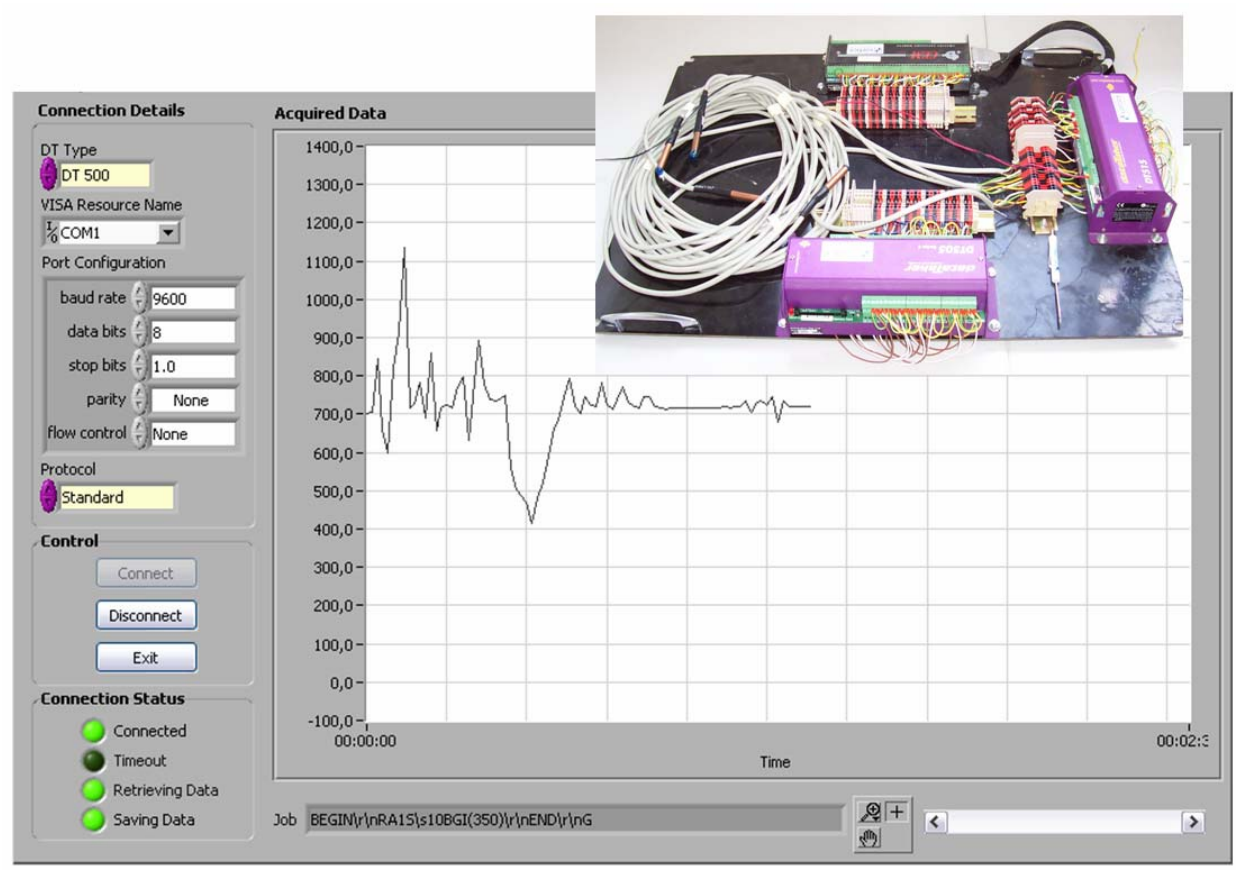

Figura 3.2 - Versão inicial do módulo para controle da aquisição de dados.

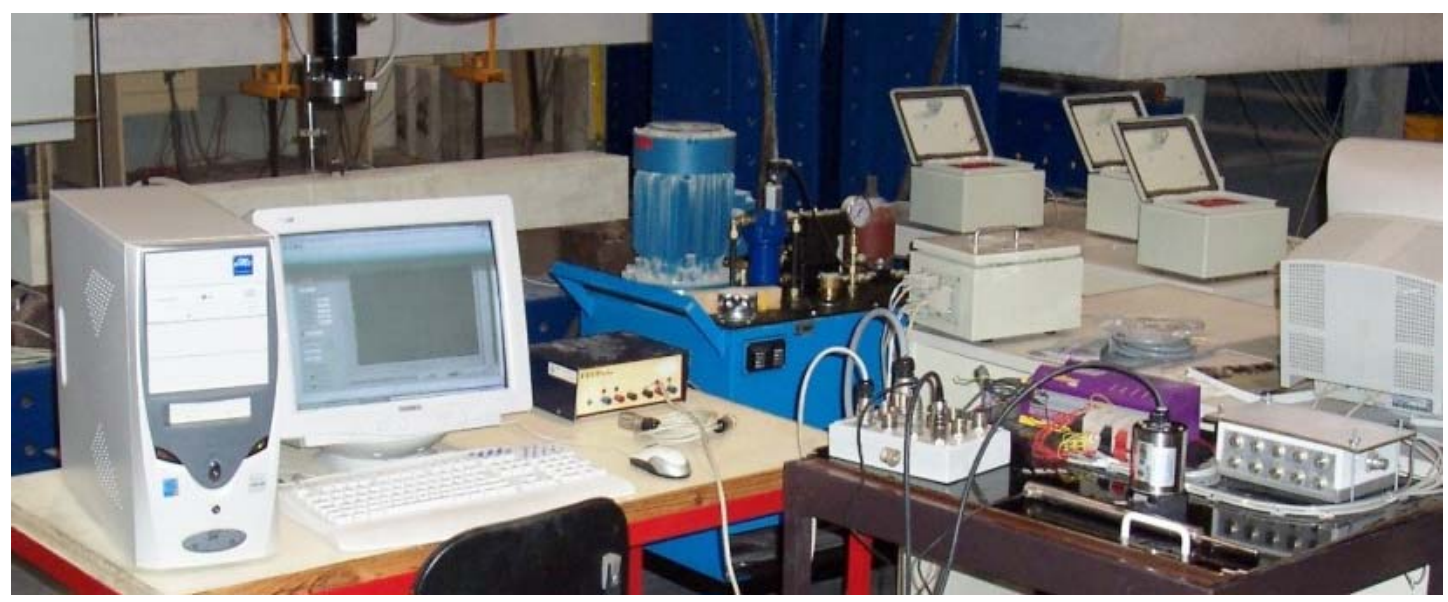

Figura 3.3 - Utilização do módulo de aquisição de dados.

As versões mais aperfeiçoadas do módulo de aquisição, apresentadas nas figuras 3.4 e 3.5, foram utilizadas como ferramentas de apoio à avaliação no 
Concurso DARTE, realizado no Porto, Portugal, no escopo das atividades do evento Betão Estrutural 2004. O concurso buscava estimular os alunos a aplicar conhecimentos adquiridos ao longo do curso de Engenharia Civil, mediante o dimensionamento e construção de um modelo reduzido de uma ponte de concreto estrutural, para ser ensaiada sob cargas verticais aplicadas ao longo do tabuleiro, premiando os autores dos melhores trabalhos.

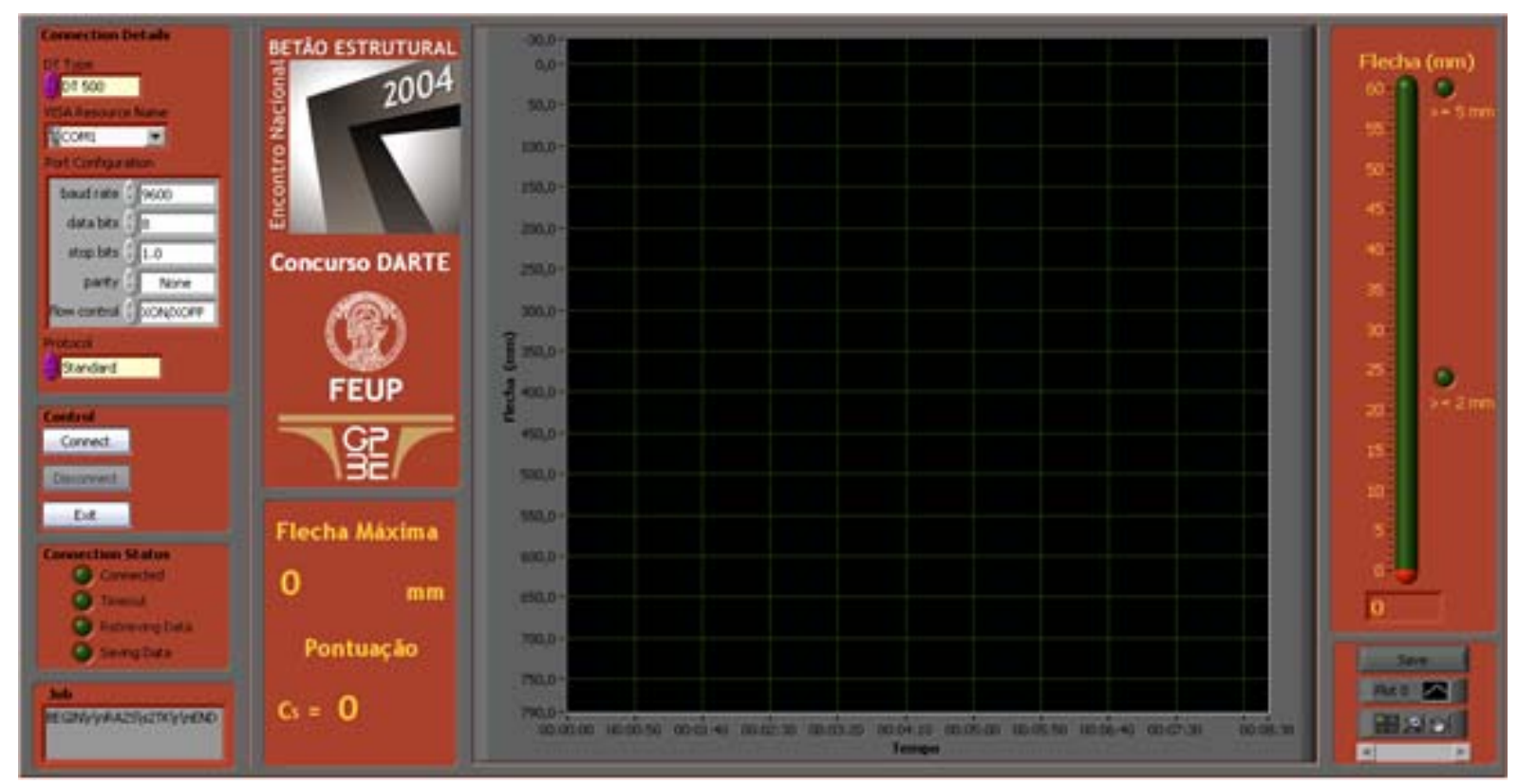

Figura 3.4 - Módulo para controle da aquisição de dados (variação de uma grandeza no tempo).

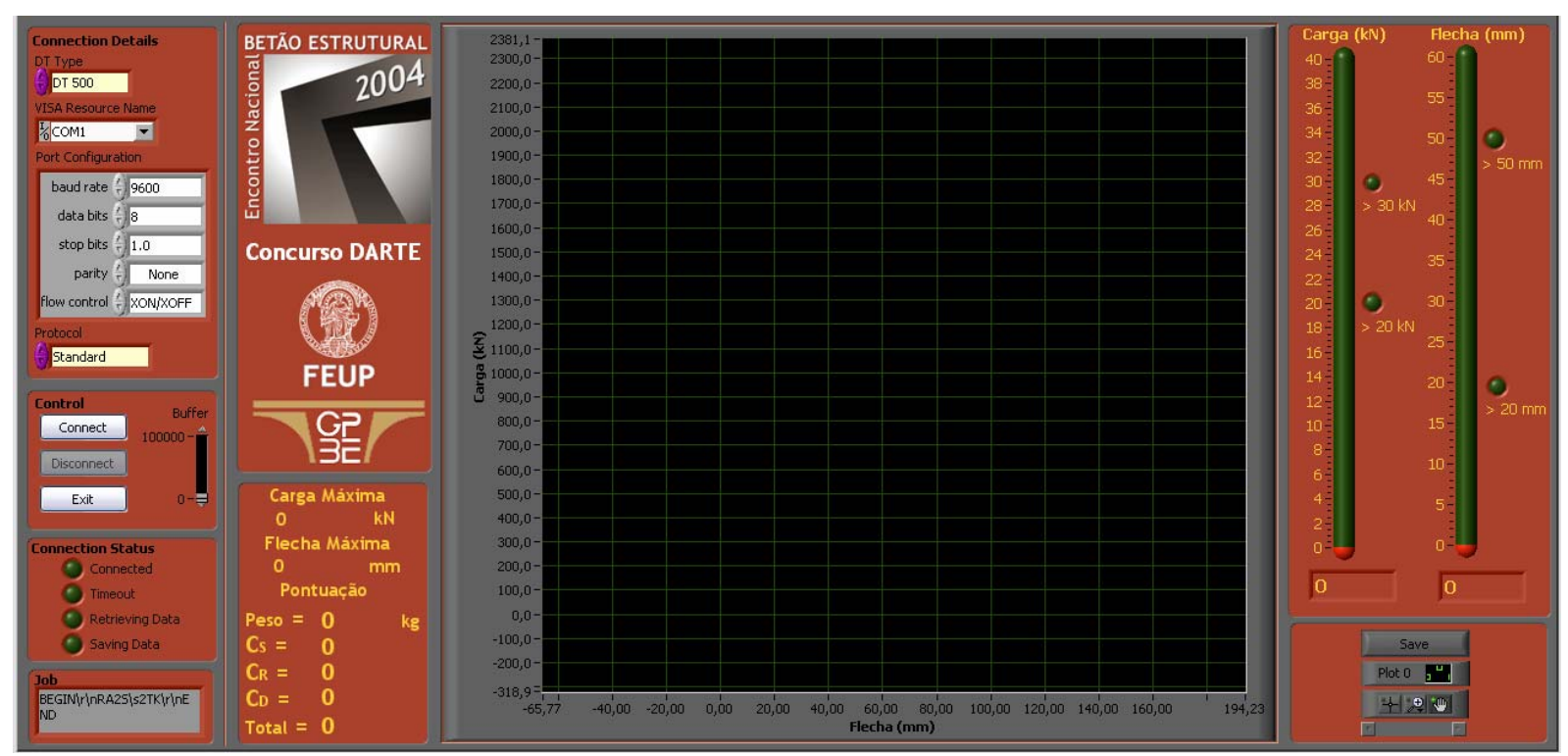

Figura 3.5 - Módulo para controle da aquisição de dados (medição de duas grandezas físicas).

A avaliação de cada um dos modelos envolvia 0 atendimento às especificações de geometria, materiais e cura do concreto definidas pelo concurso, 
dependendo também do desempenho do modelo quando submetido a duas fases de carregamento. Na primeira fase do ensaio, era aplicada em cada modelo uma carga de $5 \mathrm{kN}$, que percorria o tabuleiro. O deslocamento máximo do meio-vão, medido por meio do uso de um LVDT, com sinais aquisitados por um DT500, deveria ser inferior a $2 \mathrm{~mm}$. Todas as flechas superiores a $2 \mathrm{~mm}$ sofreram uma penalização em termos de classificação final, e a partir dos valores superiores ao máximo exigido, medidos em décimos de milímetro $(a)$, era calculado o coeficiente de serviço $\left(C_{s}\right)$ segundo a formulação indicada na equação 3.1 .

$$
C_{s}=\left\{\begin{array}{lc}
30, & \text { se } a \leq 2 \\
30\left[1-\left(\frac{a-2}{3}\right)^{2}\right] & \text { se } 2<a \leq 5 \\
0, & \text { se } a>5
\end{array}\right.
$$

Na segunda fase, era avaliado o comportamento do modelo até à ruína, mediante a aplicação de uma carga vertical crescente no meio do vão central até a ruptura da seção. A ruptura considerava-se atingida quando, após atingida a carga máxima $\left(P_{u}\right)$, a carga atuante no modelo fosse inferior a $90 \%$ desta. Complementarmente, considerava-se atingida a ruptura se o deslocamento medido sob o ponto de aplicação da carga $\left(d_{u}\right)$ atingisse os $100 \mathrm{~mm}$ ou quando fosse atingida uma carga de $50 \mathrm{kN}$, calculando-se os coeficientes de ruptura $\left(C_{r}\right)$ e deslocamento $\left(C_{d}\right)$ conforme indicado nas equações 3.2 e 3.3. A pontuação total de cada participante era fornecida pela equação 3.4 :

$$
\begin{gathered}
C_{r}= \begin{cases}50, & \text { se } P_{u}>30 \\
50\left[2\left(\frac{P_{u}-20}{10}\right)-\left(\frac{P_{u}-20}{10}\right)^{2}\right], & \text { se } 20<P_{u} \leq 30 \\
0, & \text { se } P_{u} \leq 20\end{cases} \\
C_{d}= \begin{cases}20, & \text { se } d_{u}>50 \\
20\left[2\left(\frac{d_{u}-20}{30}\right)-\left(\frac{d_{u}-20}{30}\right)^{2}\right], & \text { se } 20<d_{u} \leq 50 \\
0, & \text { se } d_{u} \leq 20\end{cases} \\
C_{f}=C_{s}+C_{r}+C_{d}
\end{gathered}
$$


O módulo de aquisição desenvolvido realizava a aquisição dos dados e as operações indicadas nas equações 3.1 a 3.3 em tempo real, à medida em que o ensaio era conduzido, fornecendo a pontuação total de cada participante imediatamente após a conclusão do experimento. Na figuras 3.6a e 3.6b são apresentados alguns dos experimentos realizados, enquanto a figura 3.7 ilustra a utilização do sistema em uma das sessões públicas do concurso, durante a avaliação de um dos modelos.

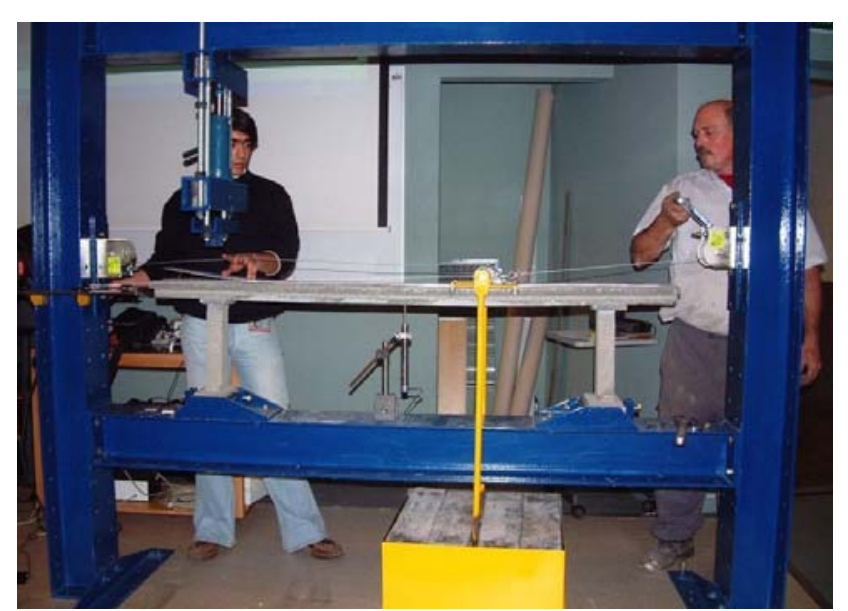

(a)

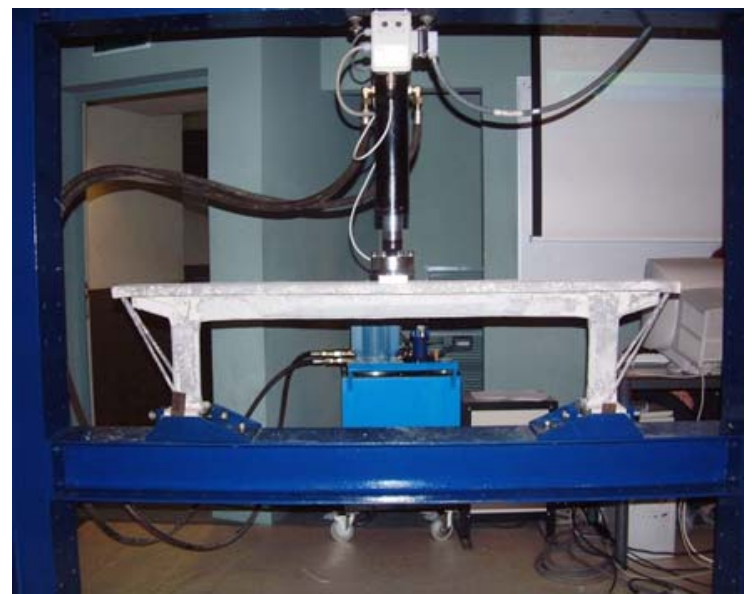

(b)

Figura 3.6 - Fases do ensaio: desempenho em serviço (a) e aplicação de carga até a ruptura (b).

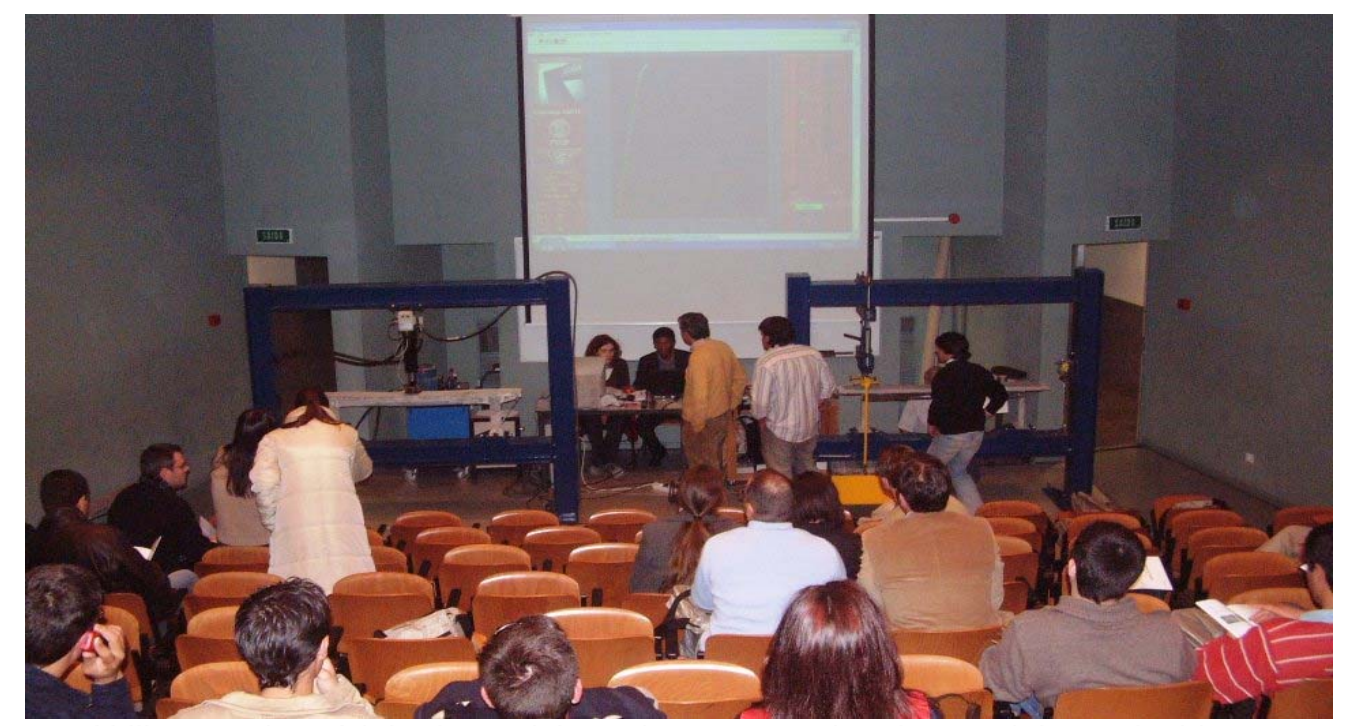

Figura 3.7 - Utilização do módulo de aquisição durante ensaios dos modelos reduzidos.

As atividades realizadas utilizando o módulo de aquisição, seja durante a fase de testes de sensores e equipamentos, seja em campo, têm atestado a sua robustez, validando-o como uma ferramenta útil para o apoio às atividades de monitoração. 


\subsection{Sistema de visualização e tratamento de dados}

O sistema integralmente desenvolvido pelo autor com a finalidade de possibilitar a visualização e o tratamento dos resultados obtidos a partir da aquisição de dados é apresentado na figura 3.8. Ele é composto por doze ambientes, sendo:

a) dois para a visualização dos dados originais (abas Deformações-Abrir e Temperaturas-Abrir);

b) dois para a apresentação de gráficos especificados (abas DefSelecionar e Temp-Selecionar);

c) dois para a filtragem dos dados referentes a um gráfico selecionado (abas Def-Filtrar e Temp-Filtrar);

d) um relacionado com a estimativa de temperaturas em pontos selecionados de uma seção, a partir das temperaturas conhecidas em uma seção com geometria similar (aba Seção);

e) um para a determinação da componente da deformação devida à variação de temperatura (aba Def-Efeito da Temp);

f) um para a apresentação das temperaturas uniformes, das parcelas lineares da temperatura atuantes na seção analisada e dos diferenciais térmicos (aba Componentes Temp);

g) um para a estimativa da deformação devida à fluência na seção em análise, podendo ser utilizados os registros das medições de temperatura do período (aba Fluência);

h) um para a estimativa da deformação devida à retração na seção em análise, permitindo a utilização das temperaturas medidas no intervalo de interesse (aba Retração);

i) um para a subtração das parcelas de deformação devidas à temperatura, fluência e retração da deformação inicialmente lida, fornecendo uma estimativa do valor da deformação sem os efeitos térmicos e diferidos (aba Deformação - Final). 


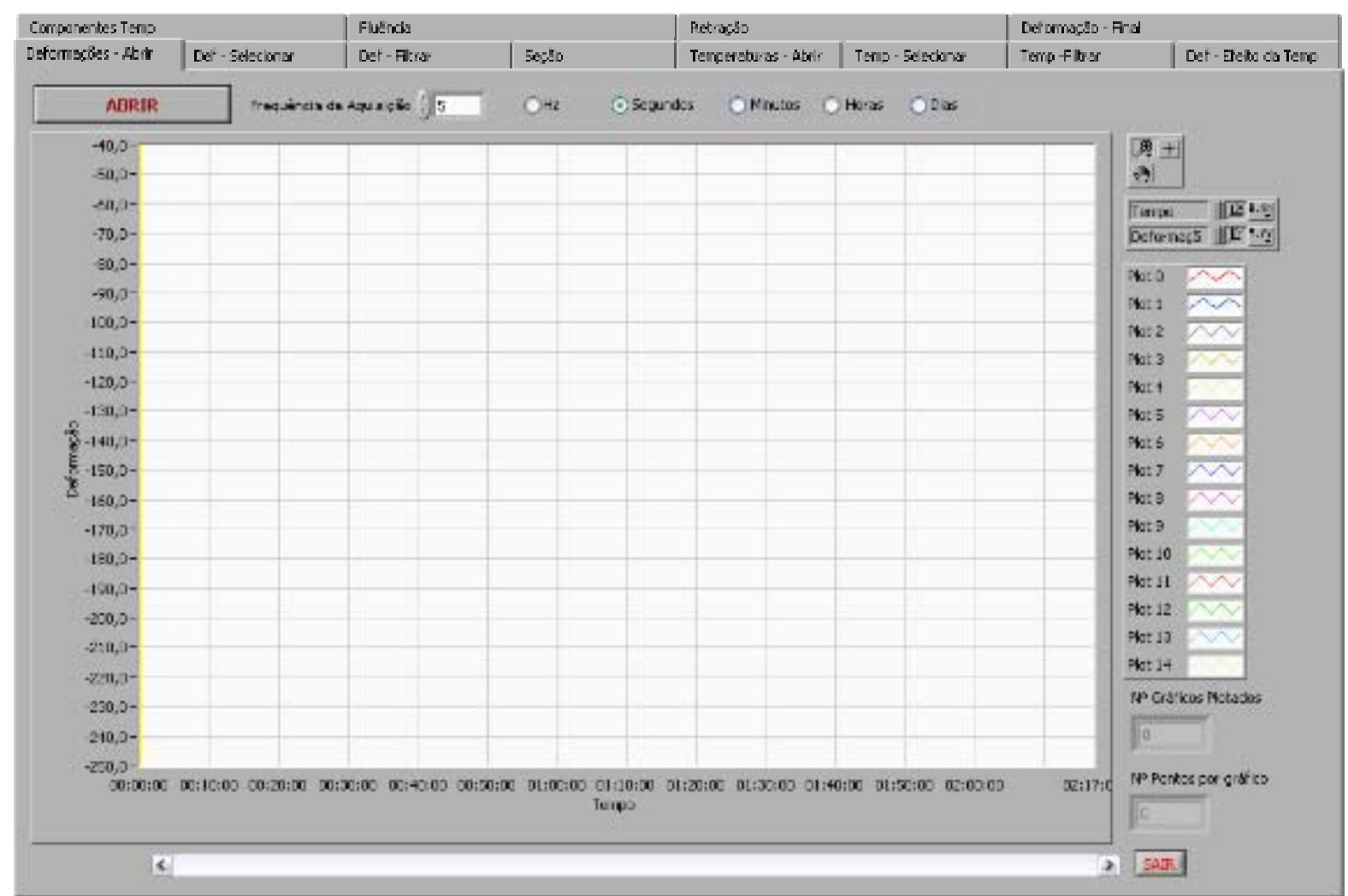

Figura 3.8 - Sistema de visualização e tratamento de resultados.

Nos ambientes de visualização de dados (abas Deformações-Abrir e Temperaturas-Abrir) é possível, por meio do botão abrir, selecionar um arquivo de dados com extensão .txt (texto), .xls (excel) ou .Ivm (LabVIEW measurement) e ver todos os gráficos associados à aquisição realizada, sendo indicado também o total de gráficos presentes no arquivo lido e o número de amostras por gráfico (canto inferior direito da figura 3.8).

Pode-se também utilizar ferramentas como zoom, deslocamento da área visível e modificar, para cada gráfico, a cor, espessura e tipo de linha (contínua, tracejada, traço ponto ou traço dois pontos), escolher entre apresentar ou não apresentar os pontos que constituem o gráfico, modificar o tipo de ponto e exibir ou não exibir uma linha unindo os valores medidos, sendo possível também unir os pontos da medição mediante segmentos interpolados ou por segmentos do tipo degrau. Para facilitar a identificação, é inicialmente associada uma cor e um número a cada gráfico, sendo possível também atribuir a escala de modo auto-ajustável para cada um dos eixos, a fim de permitir o melhor enquadramento dos gráficos apresentados. Essas características de visualização foram estendidas aos demais ambientes do sistema. 
Para a definição do eixo temporal utilizando tempos relativos, é possível definir a frequência de aquisição utilizada, sendo que tal procedimento é válido para os casos em que o intervalo entre duas medições consecutivas é o mesmo ao longo do período a ser analisado. O seletor de frequência de aquisição pode ser visto na região superior da figura 3.8, abaixo das abas.

De modo a permitir que gráficos de maior interesse para um determinado estudo fossem selecionados e apresentados, foram criados dois ambientes para plotagens selecionadas. Neles, é possível definir os gráficos que serão apresentados a partir de um seletor, no qual o usuário informa a identificação do gráfico inicial e quantos gráficos a partir deste (inclusive) se deseja visualizar. 0 ambiente conta com um cursor móvel (linha vertical amarela, na figura 3.9) por meio do qual é possível conhecer, para um instante qualquer, o valor da deformação correspondente.

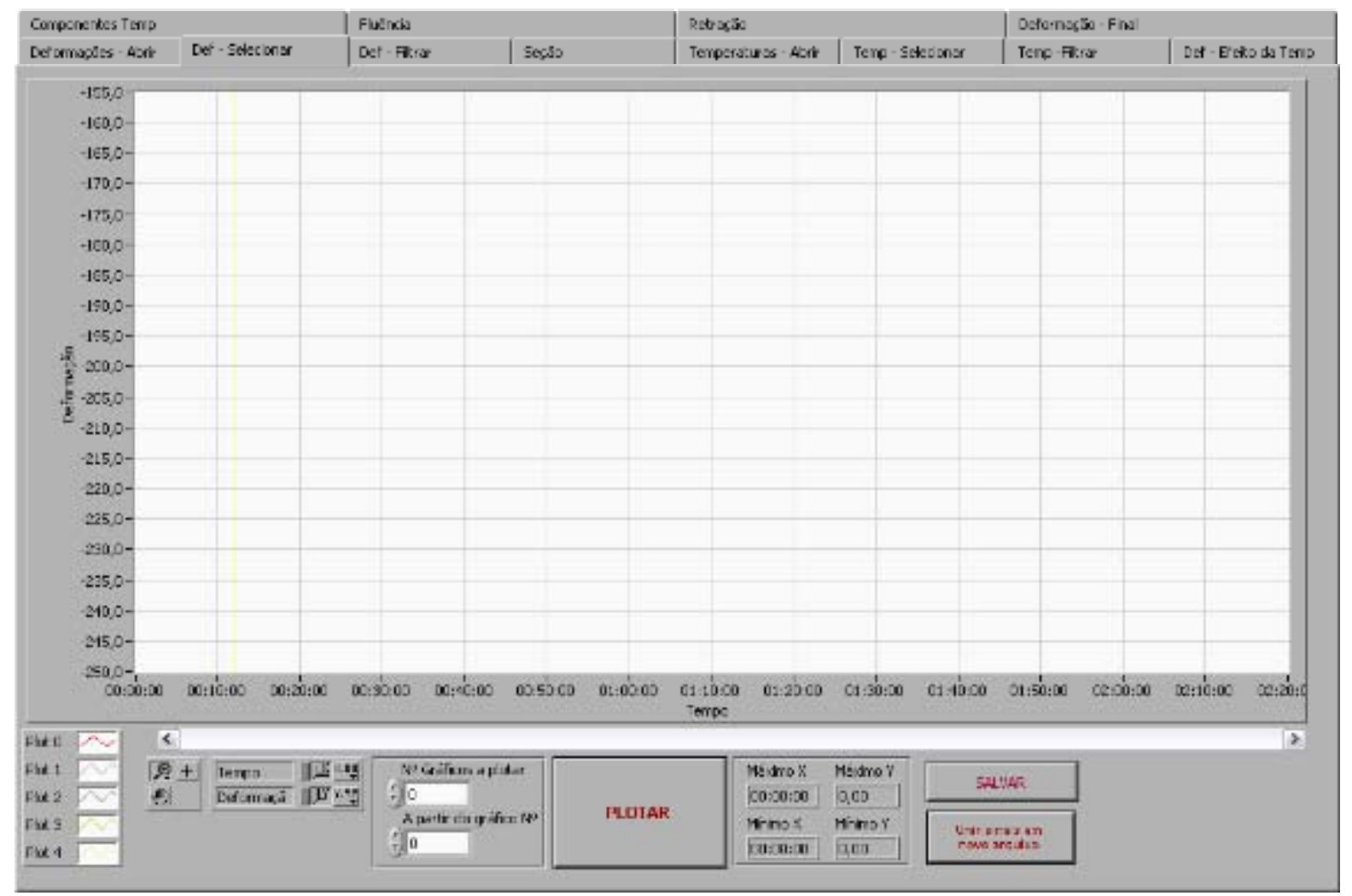

Figura 3.9 - Ambiente para visualização seletiva de resultados.

O ambiente informa os valores máximos e mínimos das leituras selecionadas, em termos de tempo e deformação, possibilitando também salvar os gráficos selecionados (seja a figura ou os dados). Também foi desenvolvida uma 
função para unir dados de dois arquivos distintos em um só, o que viabiliza o estudo com resultados cujos gráficos não sejam consecutivos.

Para possibilitar, em um gráfico selecionado, a realização de suavização de ruídos na medição, foi construído o ambiente presente na aba Def-Filtrar. Nele, são disponibilizados dois tipos de filtros de sinais, além de uma janela auxiliar para visualização de regiões selecionadas do gráfico estudado, antes ou depois da aplicação do filtro selecionado, sem que seja necessário modificar qualquer propriedade de visualização do gráfico principal. À esquerda do botão plotar, na região inferior direita da figura 3.10, podem ser vistos os controles da dimensão da janela auxiliar, apresentada no canto superior direito. A janela auxiliar e os controles de edição da aba Def-Filtrar são automaticamente abertos quando selecionado o componente checkbox Editar.

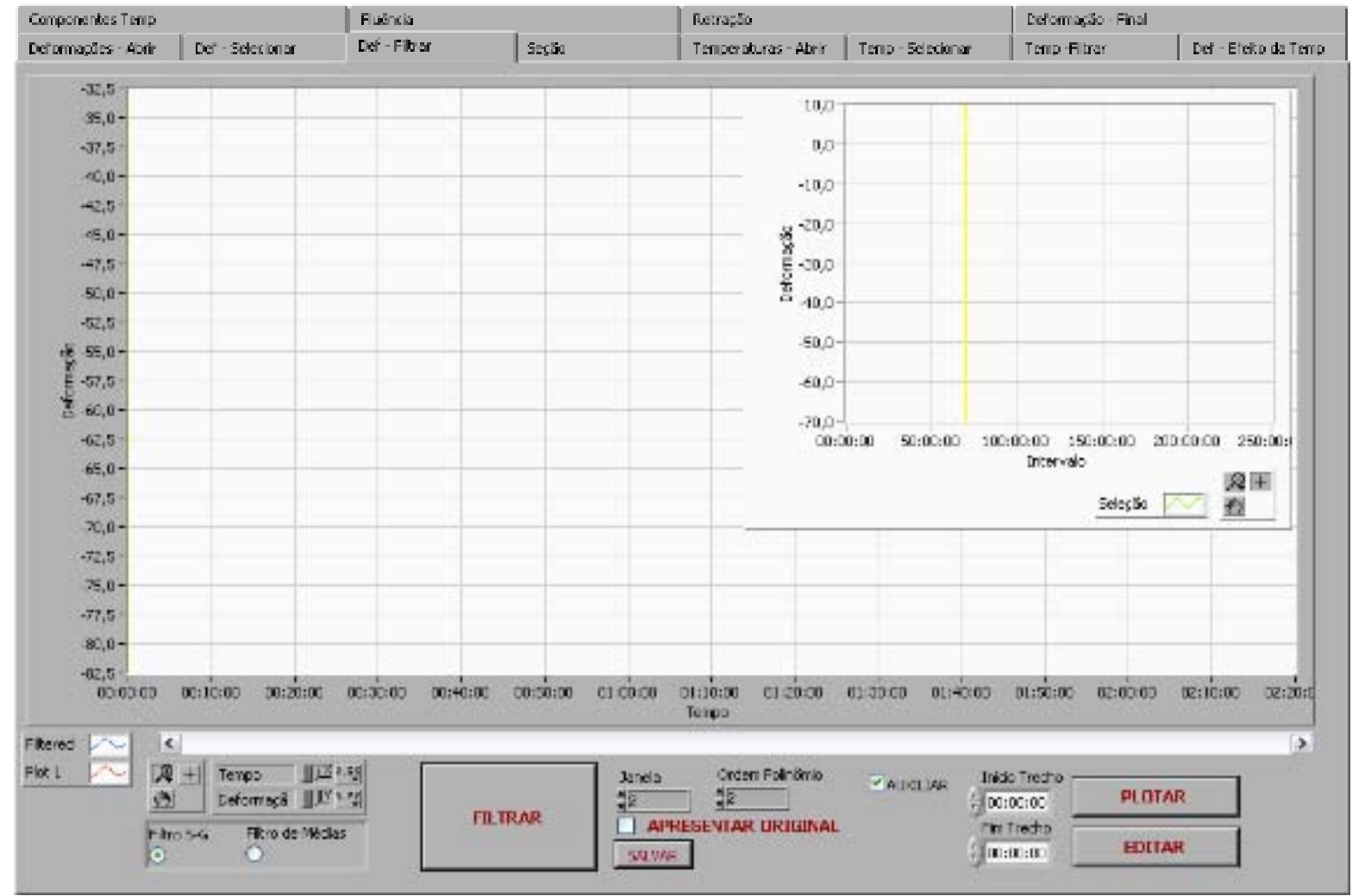

Figura 3.10 - Ambiente para filtragem de resultados.

A necessidade da implementação de filtros se verifica por várias razões. Um dos principais motivos decorre da interação das ondas eletromagnéticas (ondas de rádio, campos magnéticos, etc.) existentes no ambiente onde é realizada a medição, podendo ocorrer sobreposição e modulação dos sinais obtidos. Um exemplo prático desse tipo de interferência é a presença de picos com amplitude relativamente 
constante e freqüência de $60 \mathrm{~Hz}$ adicionados ao sinal, sendo que tal interferência é comum e provém da rede elétrica. A fim de minimizar os ruídos dos sinais aquisitados, foram implementados dois tipos de filtros digitais no ambiente def-filtrar, os quais se encontram entre os mais utilizados para o tratamento de sinais: o filtro de média móvel e o filtro de Savitzky-Golay.

O filtro de média móvel tornou-se, nos últimos anos, uma ferramenta de uso comum para a suavização de ruído em sinais, sobretudo devido à sua simplicidade teórica (MELLO, 1998). A idéia básica do método é dividir o sinal analítico em uma série de intervalos com a mesma largura, seqüencialmente e ponto a ponto, e substituir o valor do ponto central do intervalo pelo valor médio do intervalo, conforme indicado na equação 3.5 :

$$
\begin{gathered}
y_{i}=\text { Média }\left(\mathrm{J}_{\mathrm{i}}\right) ; \text { para } i=0,1,2, \ldots, n-1, \\
J_{i}=\left\{x_{i-r}, x_{i-r+1} \ldots, x_{i-1}, x_{i}, x_{i+1} \ldots, x_{i+r-1}, x_{i+r}\right\}
\end{gathered}
$$

$\mathrm{Na}$ equação 3.5, $n$ corresponde ao número de pontos que constituem o gráfico original, de modo que o gráfico de saída apresenta número de pontos igual ao do gráfico de entrada, $y_{i}$ representa o valor de cada uma das novas ordenadas, proveniente da média aritmética dos valores que pertencem a $J_{i}$. $O$ número de elementos de $J_{i}$ depende do valor atribuído a $r$, a janela do filtro, de modo que em $J_{i}$ sempre haverá $(2 r+1)$ elementos. Cada um dos constituintes de $J_{i}$ corresponde ao valor de uma ordenada, de maneira que $x_{i}$ representa a ordenada original do i-ésimo ponto do gráfico.

O filtro de média móvel é de rápida execução e funcionamento relativamente simples, entretanto, os resultados que este tipo de filtro produz para sinais com picos estreitos é pobre. Verifica-se também alguma distorção do sinal tratado, sendo esta distorção diretamente proporcional à janela utilizada, conforme ilustrado na figura 3.11 .

Os gráficos da figura 3.11b, 3.11c e 3.11d correspondem à aplicação do filtro de média móvel utilizando janelas de 5, 20 e 40 valores, respectivamente, às deformações provenientes da monitoração da ponte do Pinhão (cf. Capítulo 5), em uma das seções instrumentadas (figura 3.11a). Os resultados selecionados compreendem a leitura de 3270 valores, com frequência de aquisição igual a $1 \mathrm{~Hz}$. 


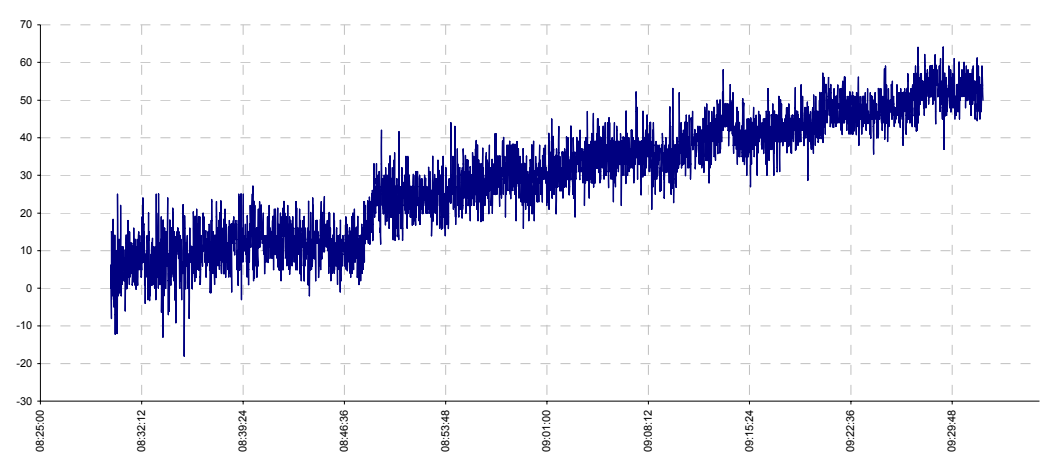

(a)

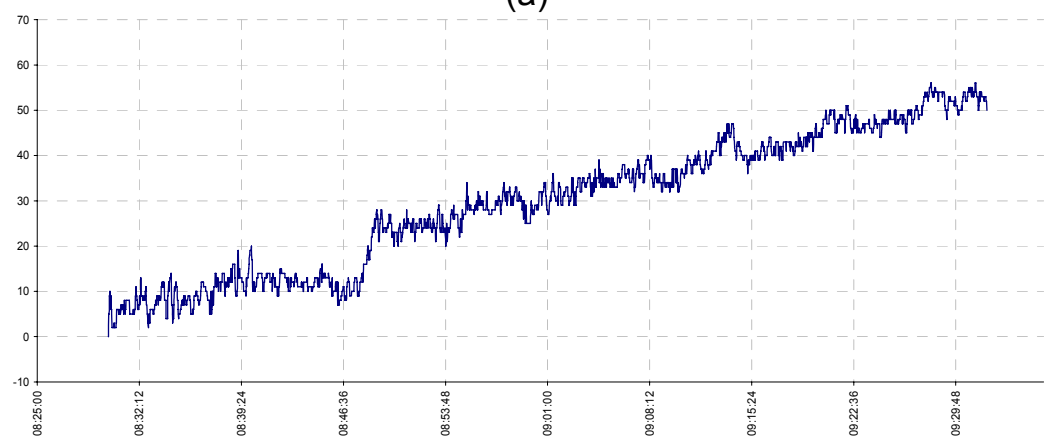

(b)

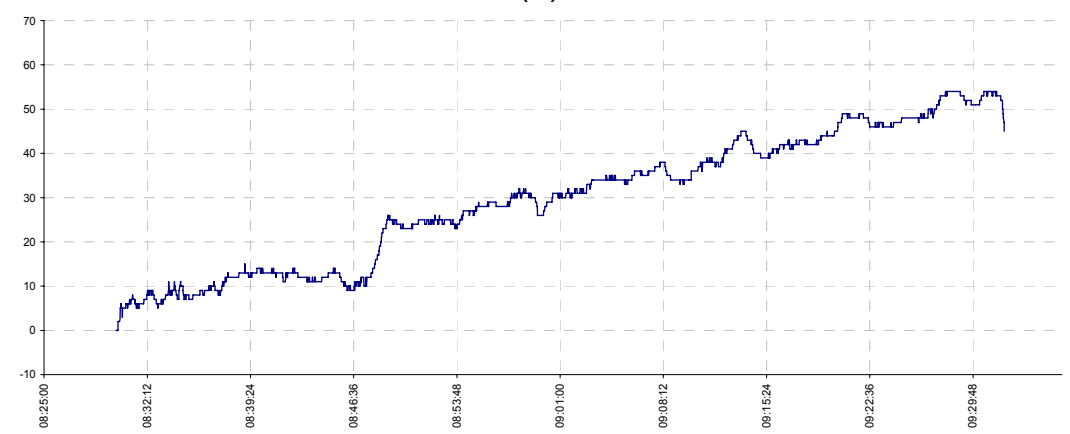

(c)

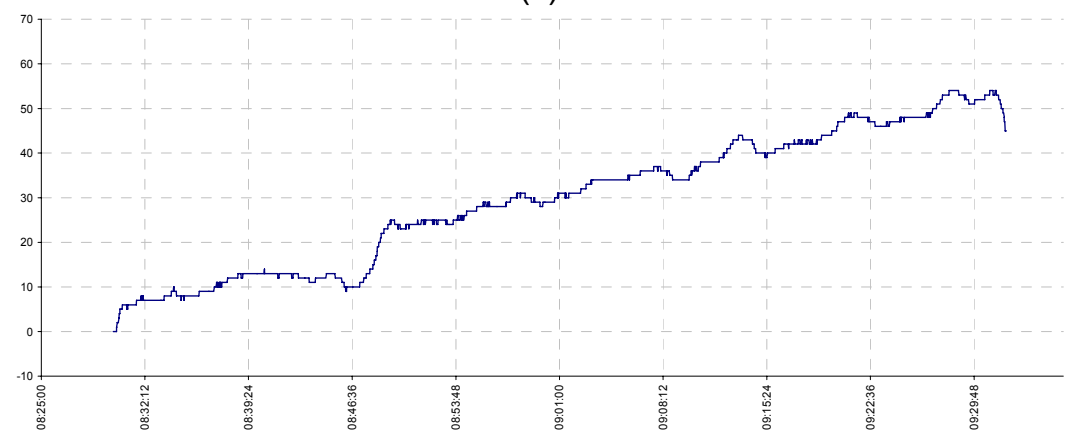

(d)

Figura 3.11 - Efeito da largura do intervalo usado no filtro de média móvel: sinal original (a), filtragem com $r=5(b), r=20$ (c) e $r=40$ (d).

O Filtro de Savitzky-Golay é também bastante utilizado para o tratamento de dados, sendo porém menos sensível à largura do intervalo pois o novo ponto, isto é, o ponto do sinal já suavizado, é obtido por meio do ajuste dos pontos do intervalo utilizando-se um polinômio e não pela simples média dos pontos vizinhos, como ocorre com o filtro de média móvel (SAVITZKY e GOLAY, 1964). Esta característica 
permite que o filtro de Savitzky-Golay seja aplicado a sinais com picos estreitos, apresentando resultados superiores aos obtidos com o filtro de média móvel. A sequência de etapas utilizada para a filtragem é apresentada a seguir (CERQUEIRA et al., 2000):

a) Define-se a origem do sinal;

b) Define-se a largura do intervalo;

c) Define-se o ponto central do intervalo;

d) Remove-se o ponto central do conjunto de pontos do intervalo;

e) Ajusta-se, por meio do método de mínimos quadrados, um polinômio de grau variável aos pontos restantes;

f) Utiliza-se o polinômio para estimar o valor do ponto removido;

g) Desloca-se o intervalo para o ponto seguinte ao sinal original, repetindo-se as etapas anteriores.

A fim de que seja possível comparar a qualidade das respostas fornecidas, na figura 3.12 são apresentados os resultados provenientes do tratamento dos mesmos sinais da figura 3.11a, utilizando o filtro de Savitzky-Golay com intervalos idênticos aos empregados na filtragem com o filtro de média móvel, ajustando-se os pontos por meio de um polinômio de $1^{\circ} \mathrm{grau}$.

Neste exemplo, percebe-se claramente a superioridade da qualidade das respostas obtidas mediante o uso do filtro de Savitzky-Golay, entretanto é preciso salientar que quando do emprego de qualquer filtro é importante estar atento às respostas obtidas, comparativamente ao sinal original, a fim de que não haja perdas excessivas de informação útil, implicando em prejuízo para a confiabilidade dos resultados e da análise posterior.

Em relação à estrutura de programação requerida para realizar as filtragens, foi necessário que após a abertura do arquivo as coordenadas dos pontos fossem associadas a vetores. Desta forma, a partir das funções de manipulação de vetores disponíveis no LabVIEW tornou-se possível separar grupos de vetores, permitindo a visualização de gráficos de maior interesse e, após ser feita uma duplicação interna de um vetor associado a um gráfico selecionado para filtragem e edição, realizar as operações de interesse nessa cópia. 
85

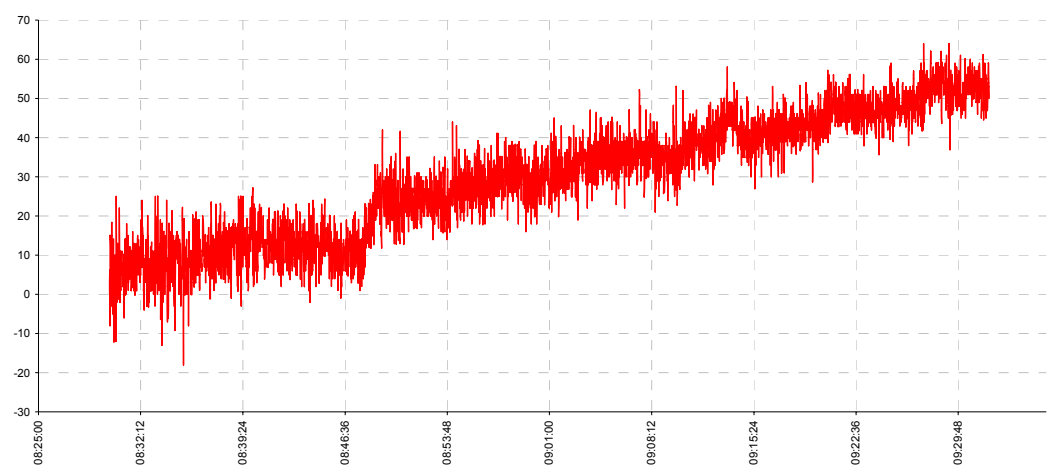

(a)

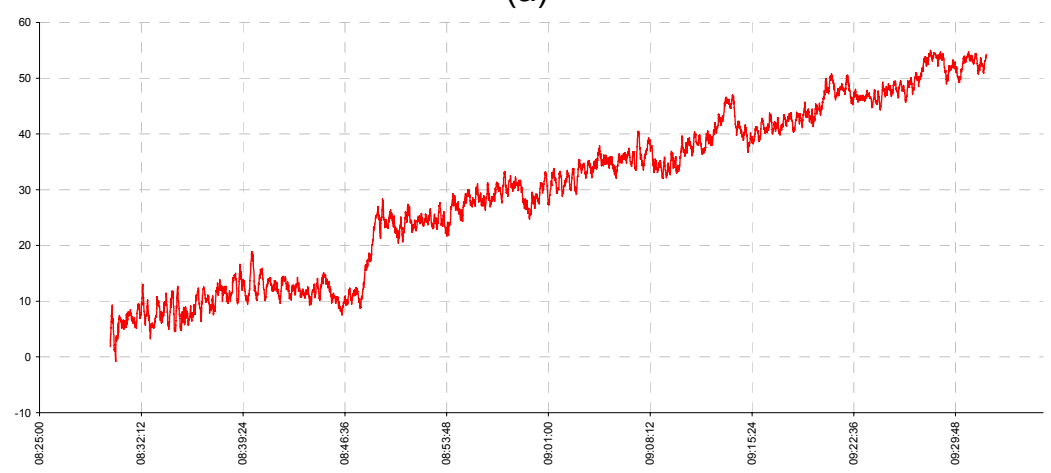

(b)

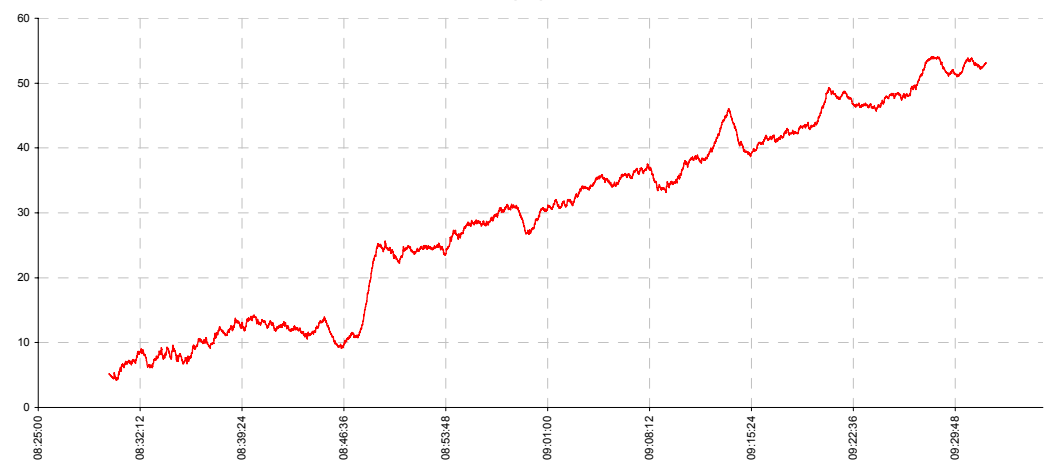

(c)

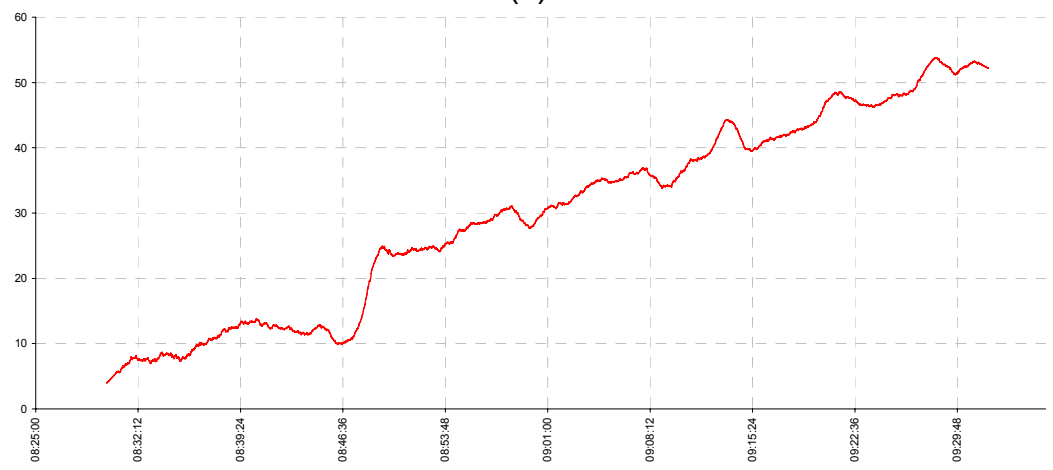

(d)

Figura 3.12 - Efeito da largura do intervalo usado no filtro de Savitzky-Golay: sinal original (a), filtragem com $r=5$ (b), $r=20$ (c) e $r=40$ (d), utilizando um polinômio de $1^{\circ}$ grau. 
O ambiente da aba Seção, apresentado na figura 3.13, fornece os elementos iniciais que viabilizam a obtenção de uma estimativa das temperaturas em uma determinada seção, a partir das temperaturas conhecidas em uma outra seção. O método utilizado na construção da estimativa foi desenvolvido pelo autor, constituindo-se em uma contribuição no campo da monitoração de estruturas. Conforme será apresentado a seguir, a aplicação da metodologia fornece resultados estimados aceitáveis, bastante próximos aos valores experimentais.

A relevância da possibilidade de estimar temperaturas é importante, uma vez que não é rara a inexistência de sensores de temperatura em locais onde posteriormente os mesmos se mostram necessários, bem como por vezes os sensores podem sofrer avarias, e caso não haja redundância, corre-se o risco de se perder pontos de medições.

A seguir, será apresentada a metodologia desenvolvida.

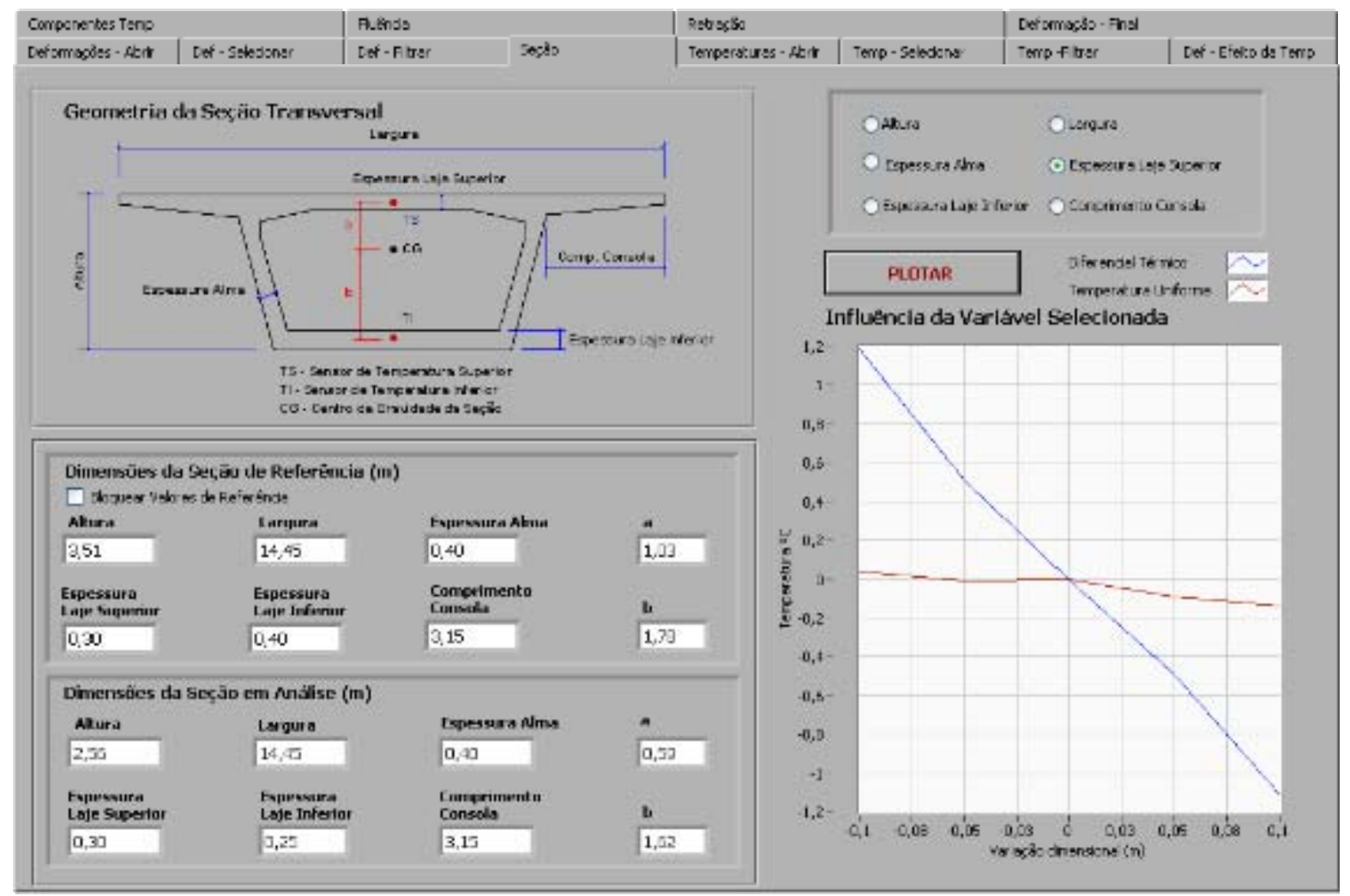

Figura 3.13 - Ambiente para introdução de dados das seções de referência e de análise. 


\subsubsection{Metodologia para estimativa de temperaturas em uma seção}

Para a obtenção das temperaturas estimadas, considera-se que a estrutura em análise possui seção transversal celular, e que na seção de referência, onde as temperaturas são conhecidas, encontram-se disponíveis os registros da medição de pelo menos dois sensores de temperatura, um dos quais posicionado na laje superior (TS) e o outro na laje inferior $(T I)$, conforme ilustrado na figura 3.14.

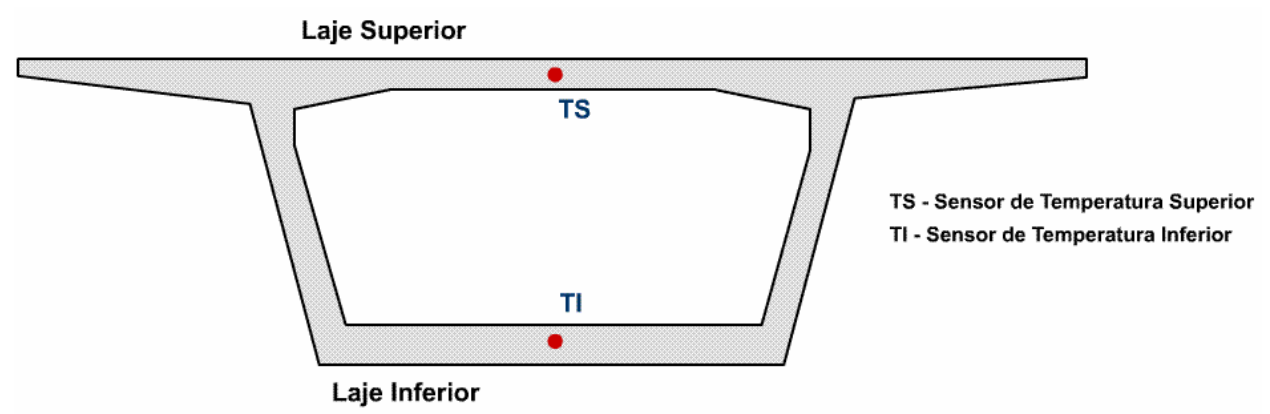

Figura 3.14 - Posicionamento dos sensores de temperatura na seção transversal de referência.

Geralmente, a distribuição das temperaturas ao longo da seção transversal de uma estrutura de concreto não é linear, podendo ser dividida, conforme esquematizado na figura 3.15 , nas parcelas uniforme $\left(T_{U}\right)$, linear $\left(T_{L}\right)$ e não-linear $\left(T_{N L}\right.$ ) (SOUKHOV, 2000; ROBERTS-WOLLMAN, BREEN e CARWRSE, 2002).
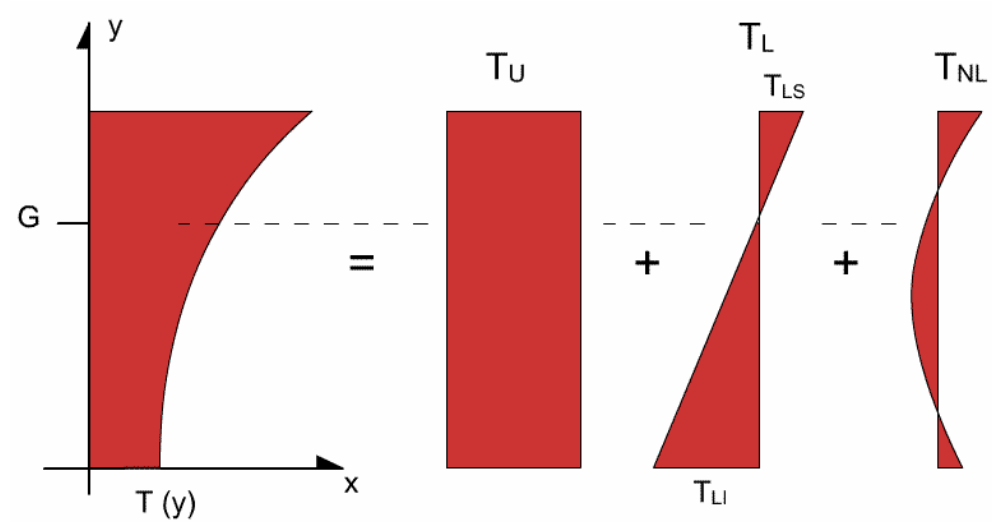

Figura 3.15 - Distribuição e componentes da temperatura em uma seção.

Segundo BRANCO e MENDES (1993), em relação aos efeitos decorrentes da ação dessas componentes térmicas, a variação da parcela uniforme se encontra associada exclusivamente às alterações do comprimento do eixo dos elementos estruturais, enquanto à variação da parcela linear corresponderão as alterações de 
curvatura. Quanto à variação da parcela não-linear, esta é responsável pela origem de tensões auto-equilibradas, sem que sejam verificadas deformações. Considerando a distribuição não-linear das temperaturas, as parcelas $T_{U}$ e $T_{L}$ são fornecidas pelas equações 3.6 e 3.7, enquanto a tensão não-linear vinculada a $T_{N L}$ é calculada pela equação 3.8. A configuração resultante é compatível com a manutenção do estado plano de uma seção, após esta sofrer uma variação de temperatura $\Delta \mathrm{T}$.

$$
\begin{gathered}
T_{U}=\frac{1}{A} \int_{A} T d A \\
T_{L}=\frac{h}{I} \int_{A} T\left(y-y_{G}\right) d A \\
\sigma_{N L}=-E \alpha_{c}\left(T-T_{u}-T_{L} \frac{y}{h}\right)
\end{gathered}
$$

Onde:

$A$ - é a área da seção transversal;

$T$ - é a temperatura na ordenada y;

$h$ - é a altura da seção;

I - é o momento de inércia da seção;

$y_{G}$ - é a ordenada do centro de massa da seção;

$E$ - é o módulo de elasticidade do concreto;

$\alpha_{c}-$ é o coeficiente de dilatação linear do concreto.

De fato, em uma estrutura livre de restrições em relação às variações dimensionais de origem térmica, à variação de temperatura $\Delta T$ em uma fibra qualquer de uma seção, corresponderá uma alteração do comprimento $\Delta \mathrm{L}$ igual ao produto do seu comprimento inicial $L$ pelo coeficiente de dilatação linear do concreto $\alpha_{c}$, conforme a equação 3.9 .

$$
\Delta L=L \alpha_{c} \Delta T=L \Delta \varepsilon
$$

Onde $\Delta \varepsilon$ é a variação da deformação linear específica da fibra. 
Uma vez que quase sempre a parcela $T_{N L}$ só é relevante nas primeiras idades do concreto (FALKNER e ZICHNER, 1985), e durante a fase de serviço usualmente possui valores reduzidos, podendo até mesmo ser desconsiderada (THURSTON, PRIESTLEY e COOKE, 1984), as investigações envolvendo a resposta de estruturas de concreto aos gradientes térmicos conferem especial relevo às parcelas $T_{U}$ e $T_{L}$. Um exemplo típico, e relevante como elemento de suporte à metodologia proposta, é fornecido pelos estudos realizados por SILVEIRA (1996), que avaliou a influência da alteração da geometria de uma seção transversal nos valores das variações uniformes $\left(\Delta T_{U}\right)$ e das variações dos diferenciais térmicos $\left(\Delta\left(T_{L S^{-}} T_{L I}\right)\right)$.

A partir de uma seção celular de referência, foram modificadas, uma a uma, características geométricas como a altura, largura, comprimento das consolas, espessura da laje superior, espessura da laje inferior e espessura da alma (figura 3.16), sendo observadas as modificações dos parâmetros térmicos de interesse.

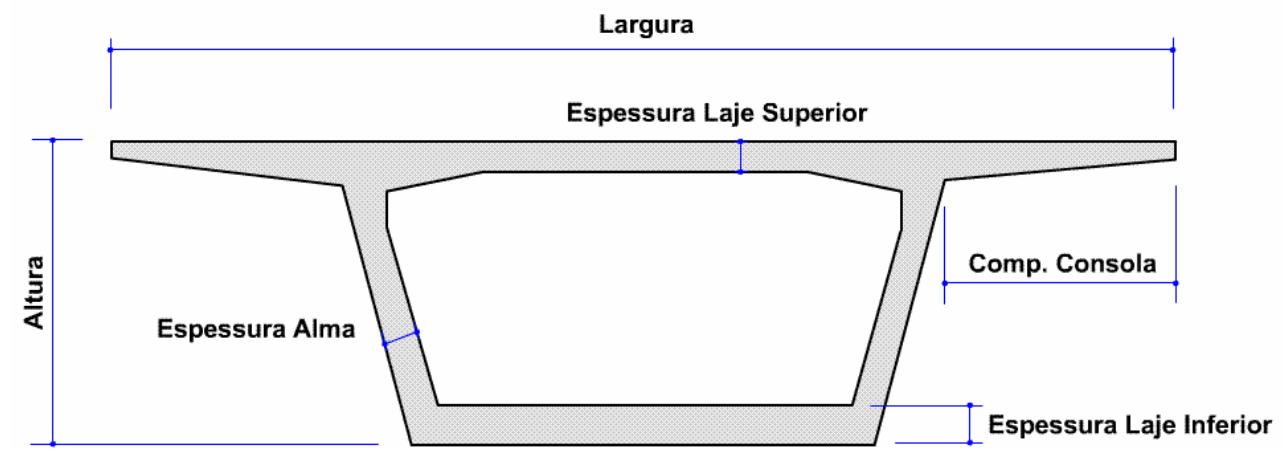

Figura 3.16 - Características geométricas modificadas.

Nas figuras 3.17, 3.18 e 3.19 são apresentados gráficos construídos pelo autor, nos quais a variação das características geométricas da seção transversal é relacionada com as variações uniformes e com os diferenciais de temperatura, sintetizando os resultados obtidos no estudo supracitado. Nos gráficos, o eixo horizontal corresponde à variação da característica geométrica, em metros $(\mathrm{m})$, enquanto o eixo vertical está associado à variação térmica em graus centígrados $\left({ }^{\circ} \mathrm{C}\right)$. 
Influência da Variação da Altura

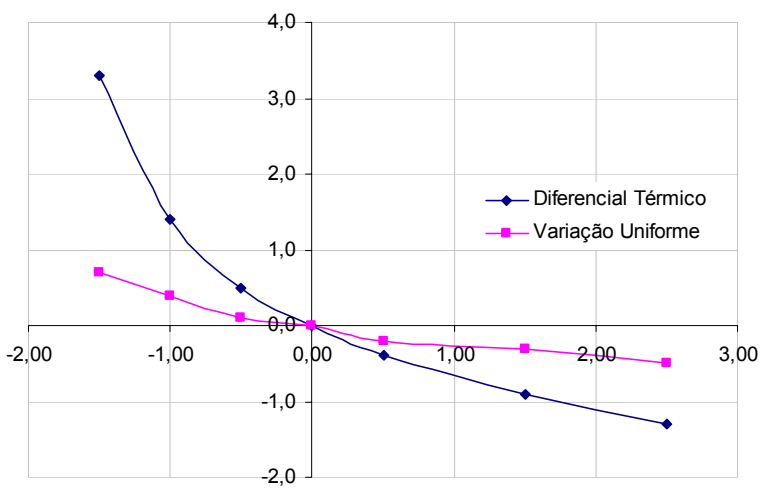

(a)
Influência da Variação da Largura

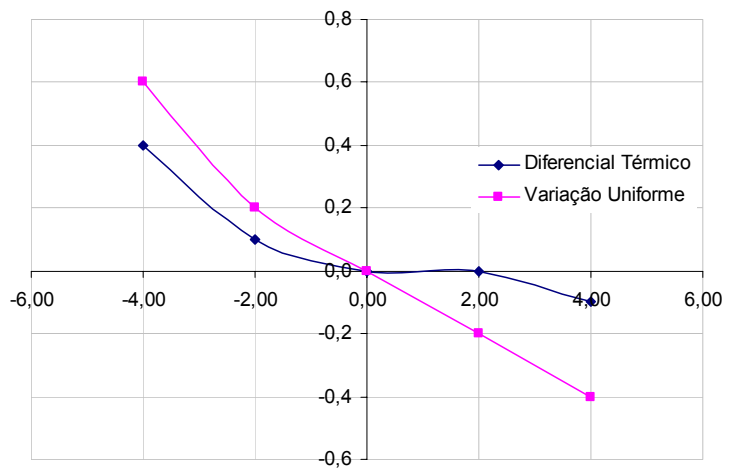

(b)

Figura 3.17 - Relação entre a modificação da altura (a) e da largura (b) com a variação uniforme e com a variação do diferencial térmico.

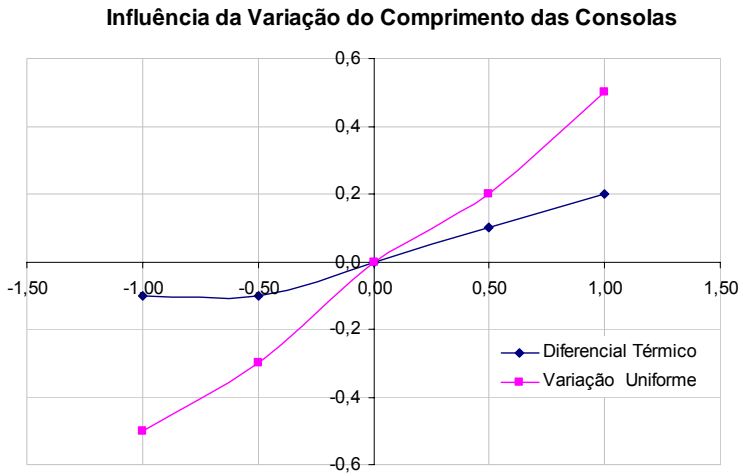

(a)

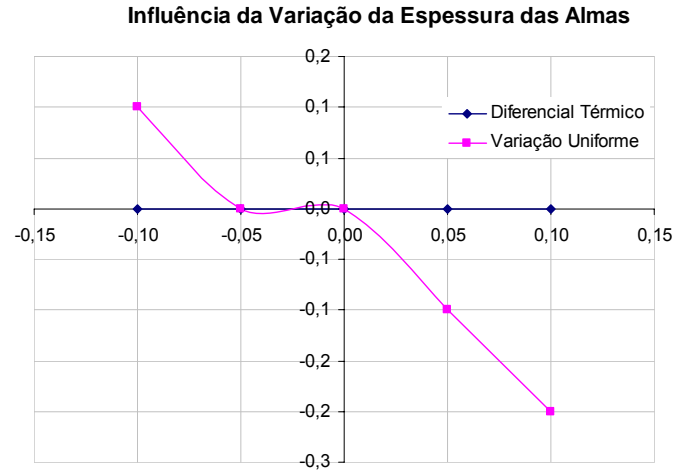

(b)

Figura 3.18 - Relação entre a modificação do comprimento das consolas (a) e da espessura das almas (b) com a variação uniforme e com a variação do diferencial térmico.

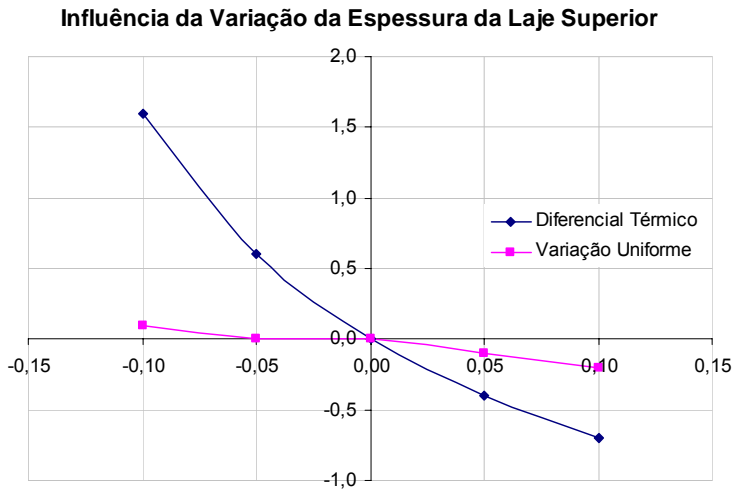

(a)

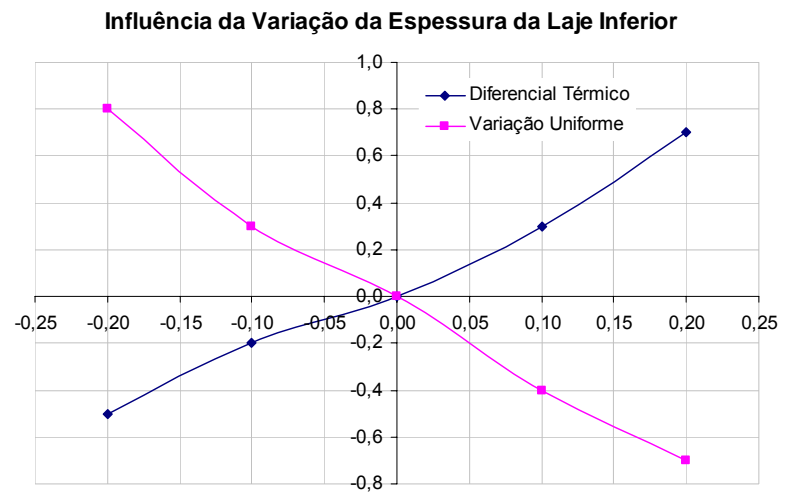

(b)

Figura 3.19 - Relação entre a modificação da espessura da laje superior(a) e inferior (b) com a variação uniforme e com a variação do diferencial térmico.

A partir das informações fornecidas pelos gráficos acima, percebe-se que é possível obter a variação uniforme e o diferencial térmico em uma seção celular qualquer, desde que se conheça a temperatura uniforme e as temperaturas lineares 
superior e inferior em uma seção celular de referência, e que a diferença entre as características geométricas das duas seções esteja inserida na faixa estudada.

Para a determinação da temperatura uniforme e do diferencial térmico na seção de referência, em um dado alinhamento, basta que seja conhecida a temperatura em dois pontos, sendo um na laje superior $\left(T S_{r}\right)$ e o outro na laje inferior $\left(T I_{r}\right)$ (cf. figura 3.14), conforme será apresentado a seguir.

Tal afirmação é válida porque quase sempre a distribuição das temperaturas ao longo da seção pode prescindir da parcela não-linear, de modo que a distribuição das temperaturas assume uma forma mais simplificada, ilustrada na figura 3.20 .

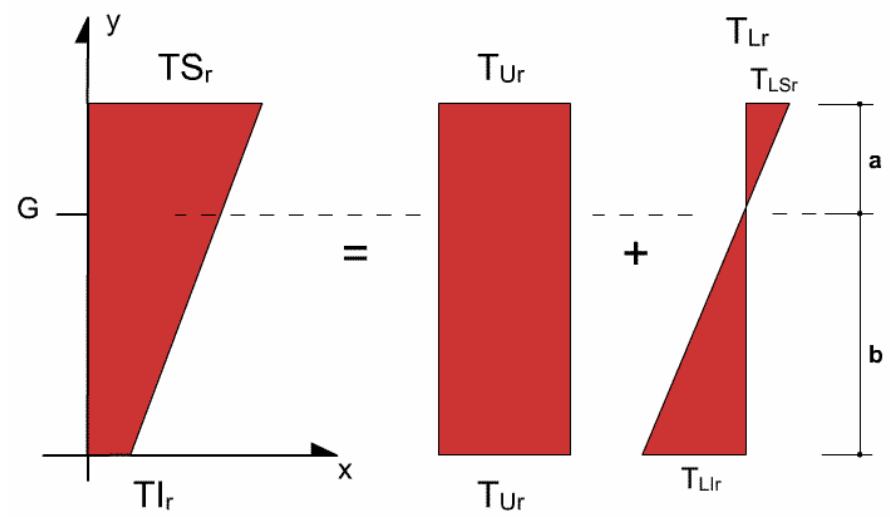

Figura 3.20 - Distribuição simplificada e componentes da temperatura em uma seção de referência.

Da figura 3.20, é possivel observar que a compatibilidade entre o valor de $T S_{r}$ com os valores de $T_{U r}$ e $T_{L S r}$, bem como o valor de $T I_{r}$ com os valores de $T_{u r}$ e $T_{\text {LIr }}$ implica em:

$$
\begin{gathered}
T S_{r}=T_{U r}+T_{L S r} \\
T I_{r}=T_{U r}-T_{L I r}
\end{gathered}
$$

Denominando a distância entre o ponto de leitura de $T S_{r}$ até $G$ de a, e a distância entre $G$ e o ponto de leitura de $T I_{r}$ de $b$ (cf. figura 3.20), teremos:

$$
\begin{gathered}
T_{L S r}=\frac{T S_{r}-T I_{r}}{\left(1+\frac{b}{a}\right)} \\
T_{L l r}=\frac{b}{a} T_{L S r}
\end{gathered}
$$


Das equações 3.10 e 3.12 decorre que:

$$
T_{U r}=T S_{r}-\left[\frac{T S_{r}-T I_{r}}{\left(1+\frac{b}{a}\right)}\right]
$$

Ficando demonstrado como obter as temperaturas uniforme e lineares superior e inferior em uma seção, a partir dos valores de $T S_{r}$ e $T I_{r}$.

Entretanto, uma vez que a temperatura uniforme $\left(T_{U r}\right)$ e o diferencial térmico ( $\left.T_{L S r} T_{L I r}\right)$ da seção de referência são conhecidos, é possível calcular, na seção cujas temperaturas são desconhecidas, a temperatura uniforme $\left(T_{U i}\right)$ e o diferencial térmico $\left(T_{L S T} T_{L l i}\right)$, pois o valor de cada uma das duas grandezas desconhecidas corresponderá, respectivamente, ao valor da grandeza conhecida na seção de referência adicionada a uma variação, obtida em função das diferenças geométricas entre as duas seções.

As relações entre as diferenças de geometria e a variação uniforme $\left(\Delta T_{U}\right)$ associadas aos gráficos das figuras 3.17 a 3.19 são apresentadas nas equações 3.15 a 3.20 .

$$
\begin{gathered}
\Delta T_{U}=-0,0258 \Delta h^{3}+0,1054 \Delta h^{2}-0,2843 \Delta h-0,0411 \\
\Delta T_{U}==0,0005 \Delta l^{4}-0,0021 \Delta l^{3}-0,0021 \Delta l^{2}-0,0917 \Delta l \\
\\
\Delta T_{U}=0,2667 \Delta l_{c}{ }^{4}-0,2667 \Delta l_{c}{ }^{2}+0,5 \Delta l_{c} \\
\Delta T_{U}==2000 \Delta e_{a}{ }^{4}-66,667 \Delta e_{a}^{3}-25 \Delta e_{a}{ }^{2}-0,8333 \Delta e_{a} \\
\Delta T_{U}=2000 \Delta e_{s}{ }^{4}-66,667 \Delta e_{s}{ }^{3}-25 \Delta e_{s}{ }^{2}-0,8333 \Delta e_{s} \\
\Delta T_{U}=208,33 \Delta e_{i}^{4}-8,3333 \Delta e_{i}^{3}-7,0833 \Delta e_{i}^{2}-3,4167 \Delta e_{i}
\end{gathered}
$$

Com:

$$
\begin{aligned}
\Delta h & =h_{i}-h_{r} \\
\Delta l & =I_{i}-I_{r} \\
\Delta l_{c} & =I_{c i}-I_{c r} \\
\Delta e_{a} & =e_{a i}-e_{a r} \\
\Delta e_{s} & =e_{s i}-e_{s r} \\
\Delta e_{i} & =e_{i i}-e_{i r}
\end{aligned}
$$


Onde:

$\Delta h$ - é a variação da altura $h$;

$\Delta l$ - é a variação da largura l;

$\Delta l_{c}$ - é variação do comprimento da consola $I_{c}$;

$\Delta e_{a}$ - é a variação da espessura da alma $e_{a} ;$

$\Delta e_{s}$ - é a variação da espessura da laje superior $e_{s} ;$

$\Delta e_{i}-$ é a variação da espessura da laje inferior $e_{i}$.

O índice $i$ no segundo membro das equações 3.21 a 3.26 representa a medida da característica geométrica na seção $i$, onde se pretende estimar as temperaturas, enquanto o índice $r$ representa a medida da característica geométrica na seção de referência $r$, onde as temperaturas são conhecidas.

As relações entre as diferenças de geometria e a variação do diferencial térmico $\left(\Delta\left(T_{L S}-T_{L I}\right)\right)$, associadas aos gráficos das figuras 3.17 a 3.19 , são apresentadas nas equações 3.27 a 3.32 .

$$
\begin{gathered}
\Delta\left(T_{L S^{-}} T_{L I}\right)=-0,0095 \Delta h^{6}-0,0229 \Delta h^{5}+0,1905 \Delta h^{4}-0,1929 \Delta h^{3}+0,153 \Delta h^{2}-0,8504 \Delta h \\
\Delta\left(T_{L S}-T_{L I}\right)=-0,0003 \Delta l^{4}-0,0031 \Delta l^{3}+0,0135 \Delta l^{2}-0,0125 \Delta l \\
\Delta\left(T_{L S}-T_{L I}\right)=0,0667 \Delta l_{c}^{4}-0,0667 \Delta l_{c}^{3}-0,0167 \Delta l_{c}^{2}+0,2167 \Delta l_{c} \\
\Delta\left(T_{L S}-T_{L I}\right)=0 \Delta e_{a} \\
\Delta\left(T_{L S}-T_{L I}\right)=666,67 \Delta e_{s}{ }^{4}-200 \Delta e_{s}{ }^{3}+38,333 \Delta e_{s}{ }^{2}-9,5 \Delta e_{s} \\
\Delta\left(T_{L S}-T_{L I}\right)=-83,333 \Delta e_{i}^{4}+16,667 \Delta e_{i}^{3}+5,8333 \Delta e_{i}{ }^{2}+2,3333 \Delta e_{i}
\end{gathered}
$$

Uma vez calculadas as variações necessárias, obtêm-se:

$$
\begin{gathered}
T_{U i}=T_{U r}+\Delta T_{U} \\
\left(T_{L S i} T_{L l i}\right)=\left(T_{L S r} T_{L I r}\right)+\Delta\left(T_{L S}-T_{L I}\right)
\end{gathered}
$$

Admitindo-se que:

$$
\begin{aligned}
T_{L S i} & =T_{L S r}+m \\
T_{L I i} & =T_{L I r}+n
\end{aligned}
$$

E denominando a distância entre o ponto de estimativa de $T S_{i}$ até $G$ de $a_{1}$, e a distância entre $G$ e o ponto de estimativa de $T l_{i}$ de $b_{1}$, teremos:

$$
T_{L S i}-T_{L l i}=\left(T_{L S r}+m\right)-\left(T_{L l r}+n\right)
$$




$$
\begin{gathered}
a_{1}\left(T_{L I r}+n\right)=b_{1}\left(T_{L S r}+m\right) \\
T_{L S i}-T_{L l i}=\left(T_{L S r}+m\right)-\frac{b_{1}}{a_{1}}\left(T_{L S r}+m\right) \\
T_{L S i}-T_{L l i}=\left(T_{L S r}+m\right)\left(1-\frac{b_{1}}{a_{1}}\right) \\
\frac{T_{L S i}-T_{L l i}}{\left(1-\frac{b_{1}}{a_{1}}\right)}-T_{L S r}=m
\end{gathered}
$$

E assim, das equações 3.34 , 3.35 e 3.41 :

$$
T_{L S i}=\frac{\left(T_{L S r}-T_{L I r}\right)+\Delta\left(T_{L S}-T_{L I}\right)}{\left(1-\frac{b_{1}}{a_{1}}\right)}
$$

Resultando que:

$$
T_{L l i}=\frac{b_{1}}{a_{1}} T_{L S i}
$$

Consequentemente:

$$
\begin{gathered}
T S_{i}=T_{U i}+T_{L S i}=\left(T_{U r}+\Delta T_{U}\right)+\frac{\left(T_{L S r}-T_{L l r}\right)+\Delta\left(T_{L S}-T_{L I}\right)}{\left(1-\frac{b_{1}}{a_{1}}\right)} \\
T I_{i}=T_{U i}-T_{L l i}=\left(T_{U r}+\Delta T_{U}\right)-\left(\frac{b_{1}}{a_{1}}\right)\left[\frac{\left(T_{L S r}-T_{L l r}\right)+\Delta\left(T_{L S}-T_{L I}\right)}{\left(1-\frac{b_{1}}{a_{1}}\right)}\right]
\end{gathered}
$$

Ficando demonstrada a possibilidade de obtenção das temperaturas da seção $i$ a partir das temperaturas da seção $r$, considerando no cômputo a influência das diferenças geométricas entre as seções. Um esquema com as etapas do método discutido é apresentado na figura 3.21. 
A partir das seções $S_{r}$ e $S_{i}$

Etapa 1

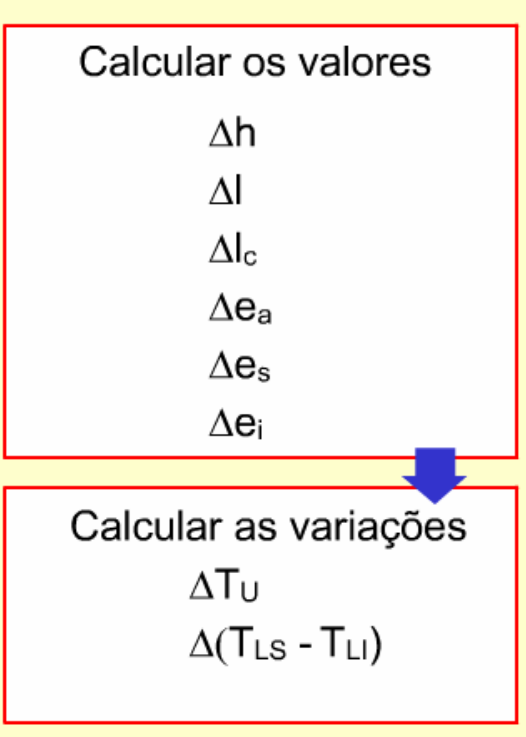

A partir das temperaturas $\mathrm{TS}_{\mathrm{r}}$ e $\mathrm{TI}_{\mathrm{r}}$

Etapa 2

Selecionar um par de temperaturas $\mathrm{TS}_{\mathrm{r}}$ e $\mathrm{TI}_{\mathrm{r}}$

Calcular as parcelas térmicas

Tur

TLSr

TLIr

\section{Utilizando $\mathbf{a}_{1}, \mathbf{b}_{1}$ e os cálculos} das etapas anteriores

Etapa 3

Calcular as parcelas térmicas

TUi

$\mathrm{T}_{\mathrm{LSi}}$

TLIr

\section{Obtenção das temperaturas $\mathrm{TS}_{\mathrm{i}} \mathrm{e} \mathrm{Tl}_{\mathrm{i}}$}

Figura 3.21 - Etapas do método desenvolvido. 
Para validação do método proposto foi realizado um experimento em uma estrutura real, a ponte sobre o rio Sorraia, localizada em Portugal (cf. Capítulo 4). A ponte é constituída por aduelas que apresentam seção transversal celular, como ilustrada na figura 3.14, sendo adequada à aplicação do método.

Na seção transversal de referência $S_{r}$ utilizada $^{9}$, as temperaturas no interior do concreto são monitoradas continuamente por meio de dois sensores PT100, um dos quais instalado na laje superior e o outro na laje inferior.

A seção transversal $S_{i}{ }^{10}$ na qual se desejava estimar as temperaturas $T S_{i} \mathrm{e}$ $T I_{i}$ se encontrava a uma distância de $30 \mathrm{~m}$ da seção $S_{r}$, e a medição de temperaturas em seu interior não foi prevista no plano de monitoração.

Para que fosse possível avaliar apropriadamente as temperaturas estimadas da seção $S_{i}$ a partir dos dados da seção $S_{r}$, foram instalados quatro sensores PT100, sendo:

1) um na face interior da laje superior da seção $S_{r}\left(T S_{r}\right)$;

2) um na face interior da laje inferior da seção $S_{r}\left(T I_{r}\right)$;

3) um na face interior da laje superior da seção $S_{i}\left(T S_{i}\right)$;

4) um na face interior da laje superior da seção $S_{i}\left(T l_{i}\right)$.

A tabela 3.1 apresenta os principais dados geométricos das seções $S_{r}$ e $S_{i}$, enquanto na tabela 3.2 podem ser consultados os valores das diferenças dimensionais. Essas diferenças, assim como os demais cálculos envolvidos neste estudo, foram realizados pelo sistema computacional desenvolvido, que na aba seção (figura 3.13) dispõe de campos para a introdução das características geométricas das seções $S_{r}$ e $S_{i}$.

Uma vez que as diferenças geométricas encontram-se inseridas nos respectivos intervalos dos gráficos 3.17 a 3.19 , podem ser calculados os valores $\Delta T_{U}$ e $\Delta\left(T_{L S}-T_{L I}\right)$, conforme indicado nas equações 3.15 a 3.20 e 3.27 a 3.32 .

9 Corresponde à seção S5 da ponte apresentada no capítulo seguinte. 
Tabela 3.1 - Características geométricas das seções estudadas.

\begin{tabular}{l|c|c}
\hline $\begin{array}{c}\text { Característica geométrica } \\
\text { da seção transversal }\end{array}$ & $\boldsymbol{S}_{\boldsymbol{r}}(\mathbf{m})$ & $\boldsymbol{S}_{\boldsymbol{i}}(\mathbf{m})$ \\
\hline Altura $(h)$ & 3,51 & 2,56 \\
\hline Largura $(l)$ & 14,45 & 14,45 \\
\hline Comprimento da consola $\left(I_{c}\right)$ & 3,15 & 3,15 \\
\hline Espessura da alma $\left(e_{a}\right)$ & 0,40 & 0,40 \\
\hline Espessura da laje superior $\left(e_{s}\right)$ & 0,30 & 0,30 \\
\hline Espessura da laje inferior $\left(e_{i}\right)$ & 0,40 & 0,25 \\
\hline $\mathrm{a}$ & 1,03 & 0,59 \\
\hline $\mathrm{b}$ & 1,78 & 1,62 \\
\hline
\end{tabular}

Tabela 3.2 - Diferenças dimensionais e variações das parcelas térmicas.

\begin{tabular}{c|c|c|c|}
\hline $\begin{array}{c}\text { Diferenças } \\
\text { dimensionais }\end{array}$ & $S_{i}-S_{r}(\mathbf{m})$ & $\Delta T_{U}$ & $\Delta\left(T_{L S}-T_{L I}\right)$ \\
\hline$\Delta h$ & $-0,95$ & 0,35 & 1,28 \\
\hline$\Delta l$ & 0,00 & 0,00 & 0,00 \\
\hline$\Delta l_{c}$ & 0,00 & 0,00 & 0,00 \\
\hline$\Delta e_{a}$ & 0,00 & 0,00 & 0,00 \\
\hline$\Delta e_{s}$ & 0,00 & 0,00 & 0,00 \\
\hline$\Delta e_{i}$ & $-0,15$ & 0,49 & $-0,32$ \\
\hline
\end{tabular}

Da análise de resultados obtidos a partir de outros experimentos realizados pelo autor, percebeu-se que a melhor combinação de $\Delta T_{U}$ e $\Delta\left(T_{L S}-T_{L I}\right)$ é obtida quando são utilizados os menores valores não-nulos de cada variável, de modo que neste caso: $\Delta T_{U}=0,35$ e $\Delta\left(T_{L S}-T_{L I}\right)=-0,32$.

Calculando-se os valores das parcelas térmicas $T_{U r}, T_{L S r}$ e $T_{L I r}$ para cada par de temperaturas $T S_{r}$ e $T I_{r}$, obtêm-se em seguida os valores de $T_{U i}, T_{L S i}$ e $T_{L l i}$ e as temperaturas $T S_{i}$ e $T I_{i}$. Na figura 3.22 são apresentadas as temperaturas $T S_{r}$ e $T I_{r}$ da seção de referência, juntamente com as temperaturas $T S_{i}$ e $T I_{i}$, que foram calculadas utilizando o sistema computacional desenvolvido. Foram realizadas 242 leituras, com intervalo de 5 minutos entre cada uma delas. 


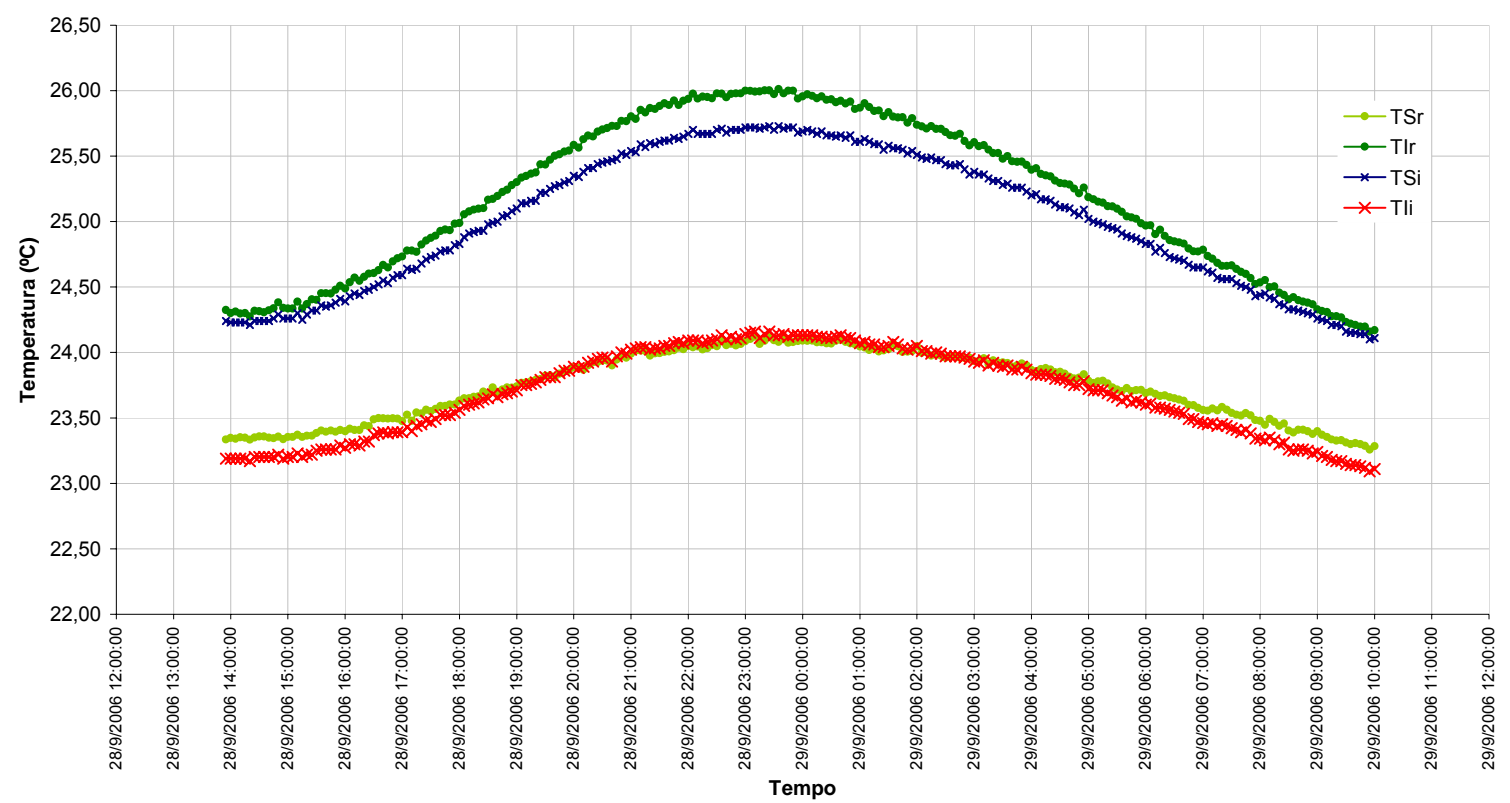

Figura 3.22 - Temperaturas medidas na seção $S_{r}$ e temperaturas estimadas para a seção $S_{i}$.

$\mathrm{Na}$ figura 3.23 são apresentadas as temperaturas estimadas e as temperaturas medidas na seção $S_{i}$, permitindo comparar as respostas obtidas pela metodologia proposta com valores de campo. A média da diferença entre os resultados estimados e os medidos é de $-0,019^{\circ} \mathrm{C}$ para $\mathrm{TS}_{\mathrm{i}}$ e $-0,079{ }^{\circ} \mathrm{C}$ para $\mathrm{Tl}_{\mathrm{i}}$.

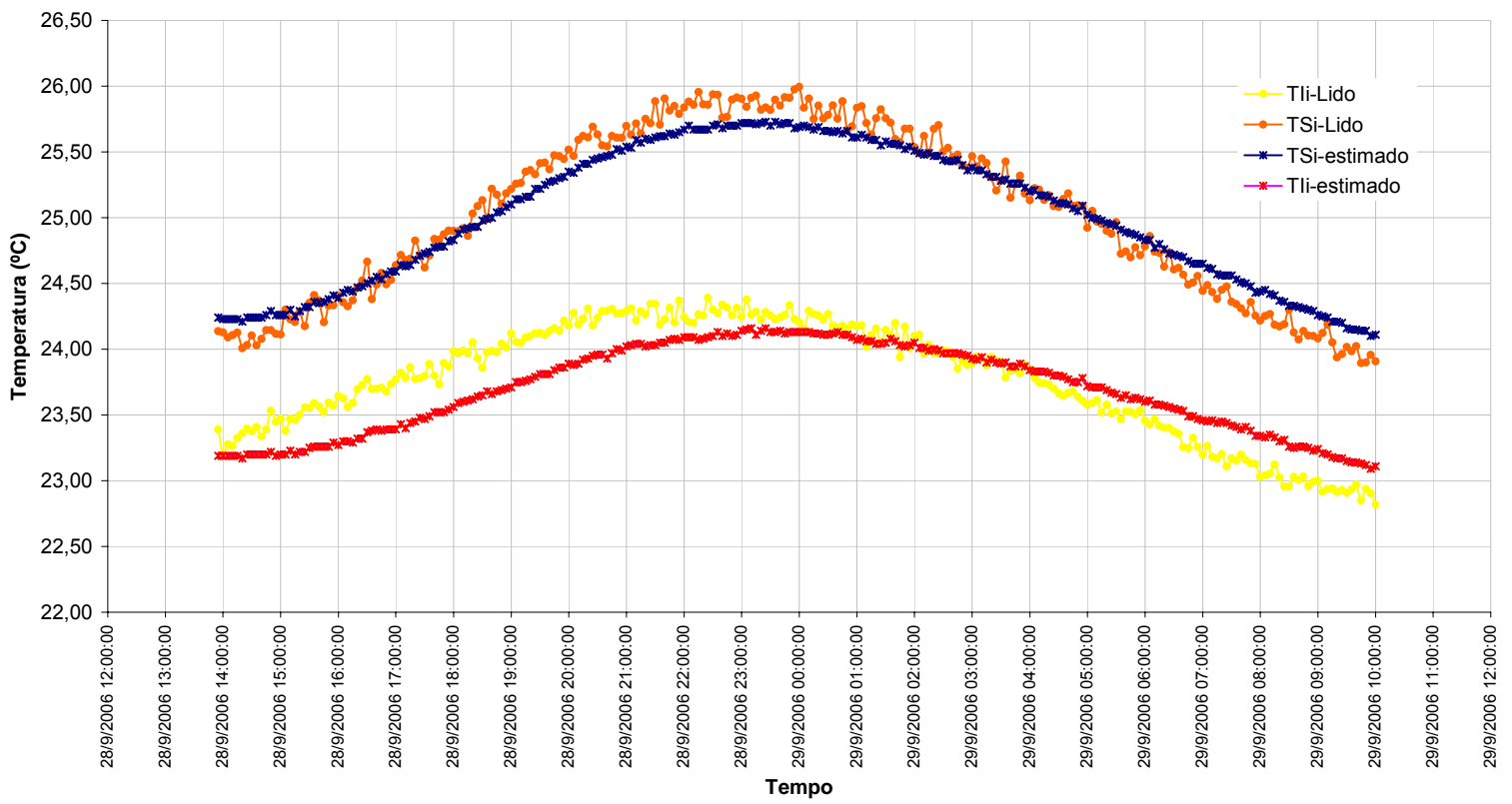

Figura 3.23 - Temperaturas medidas e temperaturas estimadas na seção $S_{i}$. 


\subsubsection{Ambientes de visualização e filtragem de sinais de temperaturas}

Nos ambientes das abas Temperaturas-Abrir e Temp-Selecionar estão presentes as mesmas funcionalidades vistas nas correspondentes abas de deformações, e promovem a visualização de gráficos associados à monitoração de temperaturas, ao passo que em Temp-Filtrar se encontram as funções e interface idênticas às apresentadas em Def-Filtrar.

Uma diferença significativa entre as abas Temperaturas-Abrir e Deformações-Abrir está no componente checkbox Temperaturas TS e TI da seção desconhecidas, que quando selecionado, informa ao sistema que as temperaturas que serão lidas referem-se às temperaturas $T S_{r}$ e $T I_{r}$, fornecendo na aba Temp Selecionar um ambiente para visualização das temperaturas estimadas $T S_{i}$ e $T I_{i}$, que são calculadas utilizando os dados introduzidos nas duas abas anteriores, empregando a metodologia descrita no item 3.3.1. Para fins ilustrativos, uma parte do código envolvido nesta tarefa é apresentado na figura 3.24.

Quando o sistema calcula $T S_{i}$ e $T I_{i}$ ele adota essas informações para a realização das demais análises que envolvam o fornecimento de temperaturas. A figura 3.25 ilustra o ambiente Temperaturas-Abrir com os dados $T S_{r}$ e $T I_{r}$ apresentados na figura 3.22, enquanto a figura 3.26 apresenta os gráficos de $T S_{i}$ e $T I_{i}$ calculados para a seção $S_{i}$ cujos dados encontram-se disponíveis na figura 3.13 e na tabela 3.1.

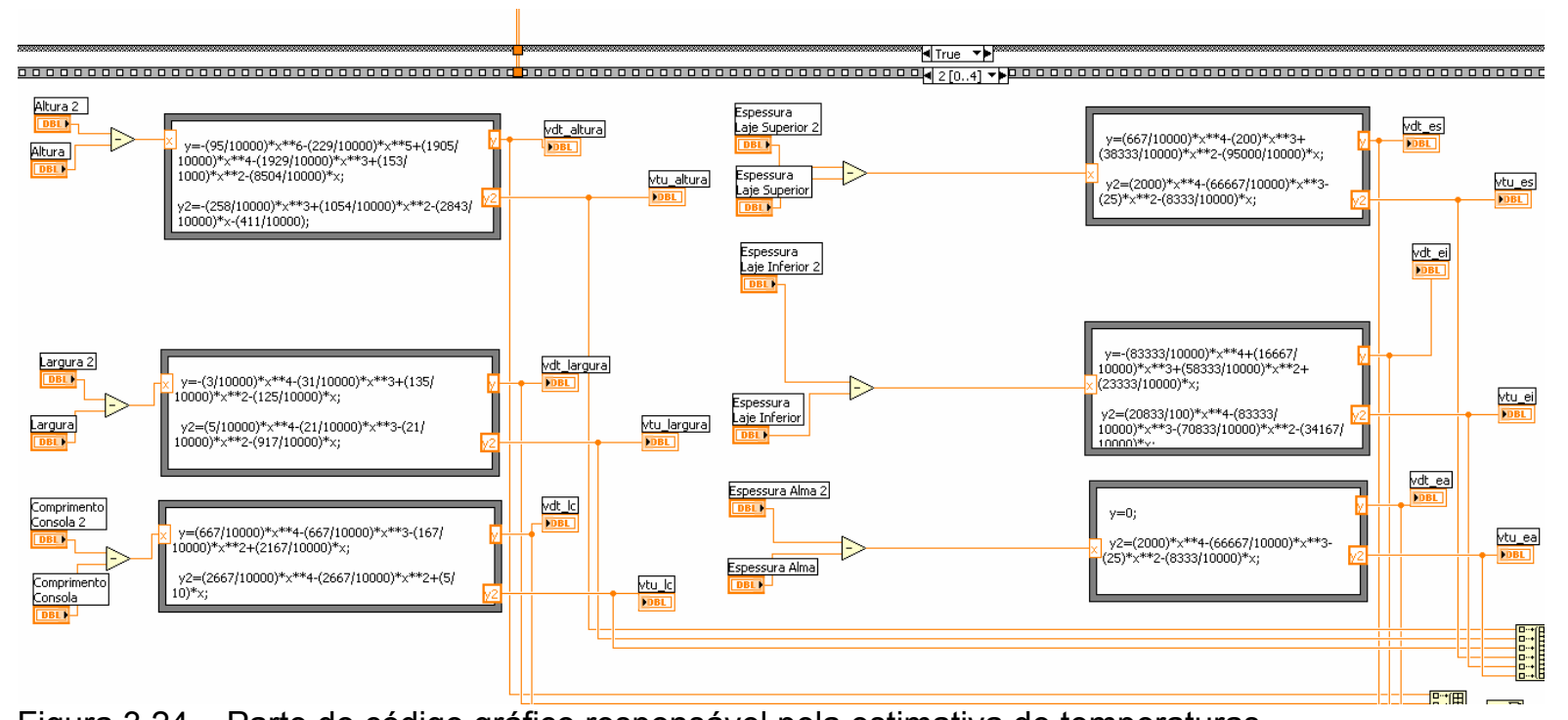

Figura 3.24 - Parte do código gráfico responsável pela estimativa de temperaturas. 


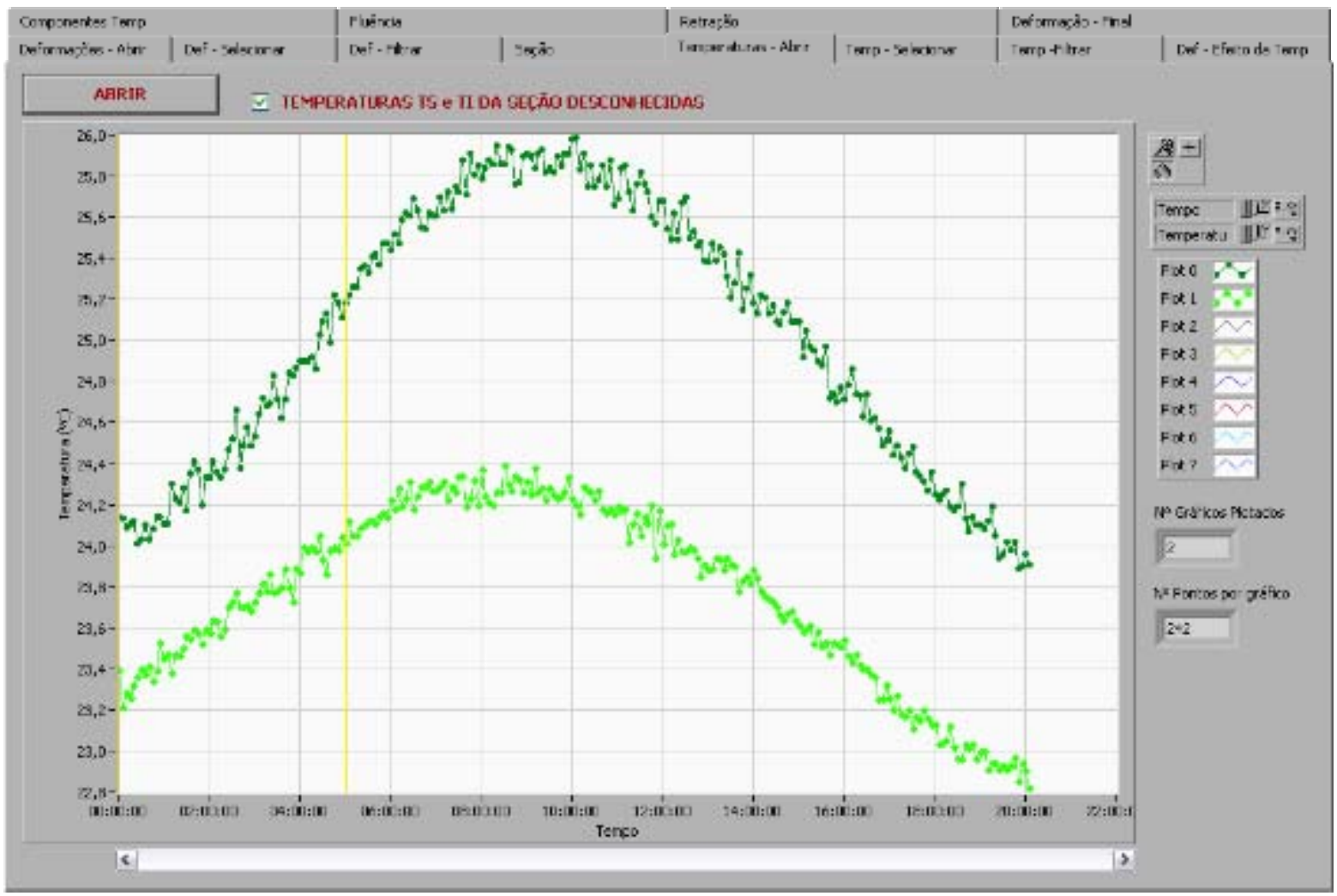

Figura 3.25 - Ambiente para visualização e definição de temperaturas.

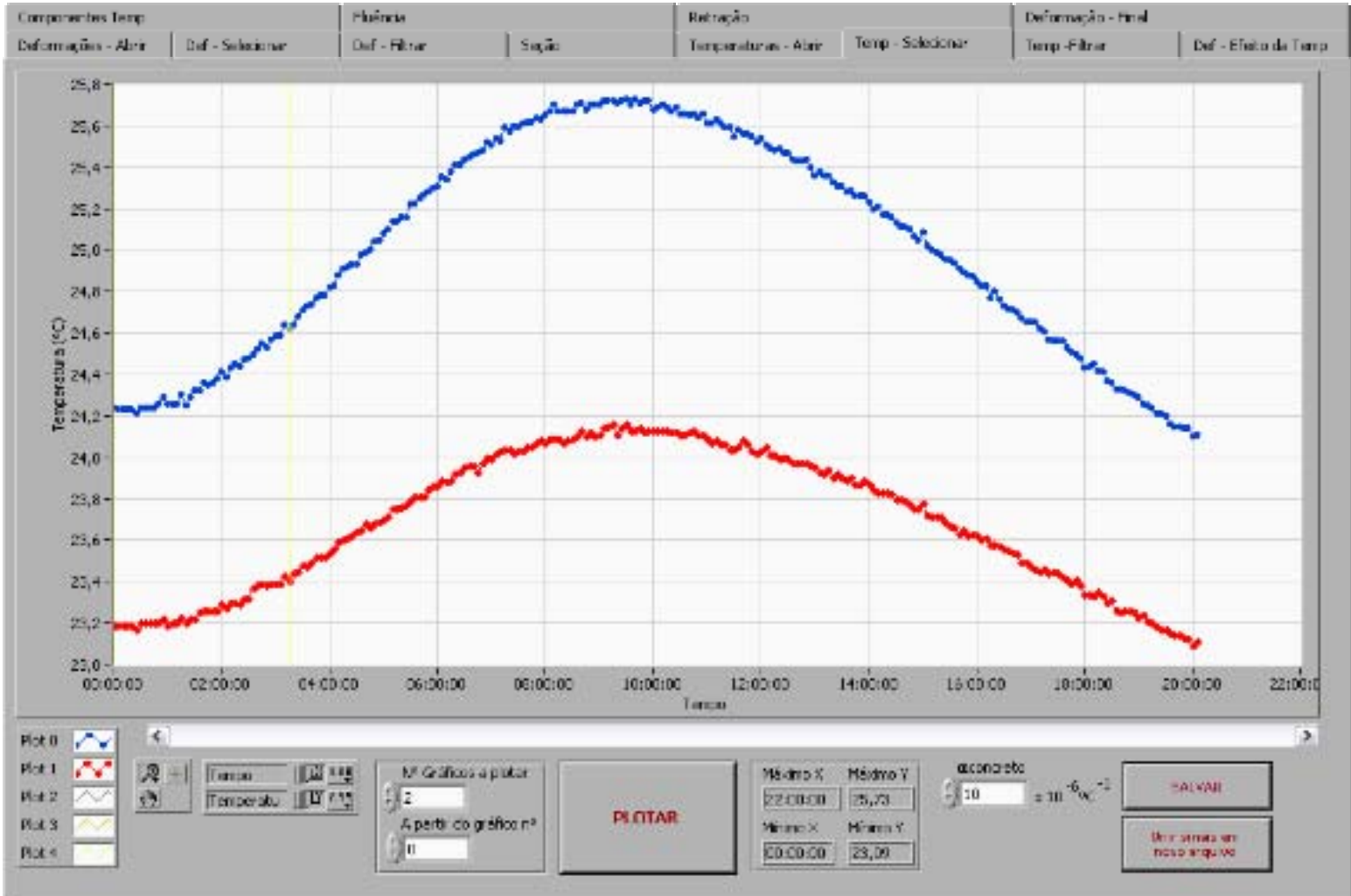

Figura 3.26 - Ambiente para seleção das temperaturas medidas e visualização das temperaturas estimadas. 
Para a apresentação da estimativa das deformações na estrutura provocadas pelas variações de temperatura, bem como para exibir as deformações resultantes após a compensação dos efeitos térmicos lineares, foi construída uma aba designada Def-Efeito da Temp, ilustrada na figura 3.27. Neste ambiente estão disponíveis funcionalidades como a geração de histogramas dos resultados e apresentação das deformações antes e depois da compensação térmica, cuja metodologia é descrita no próximo item.

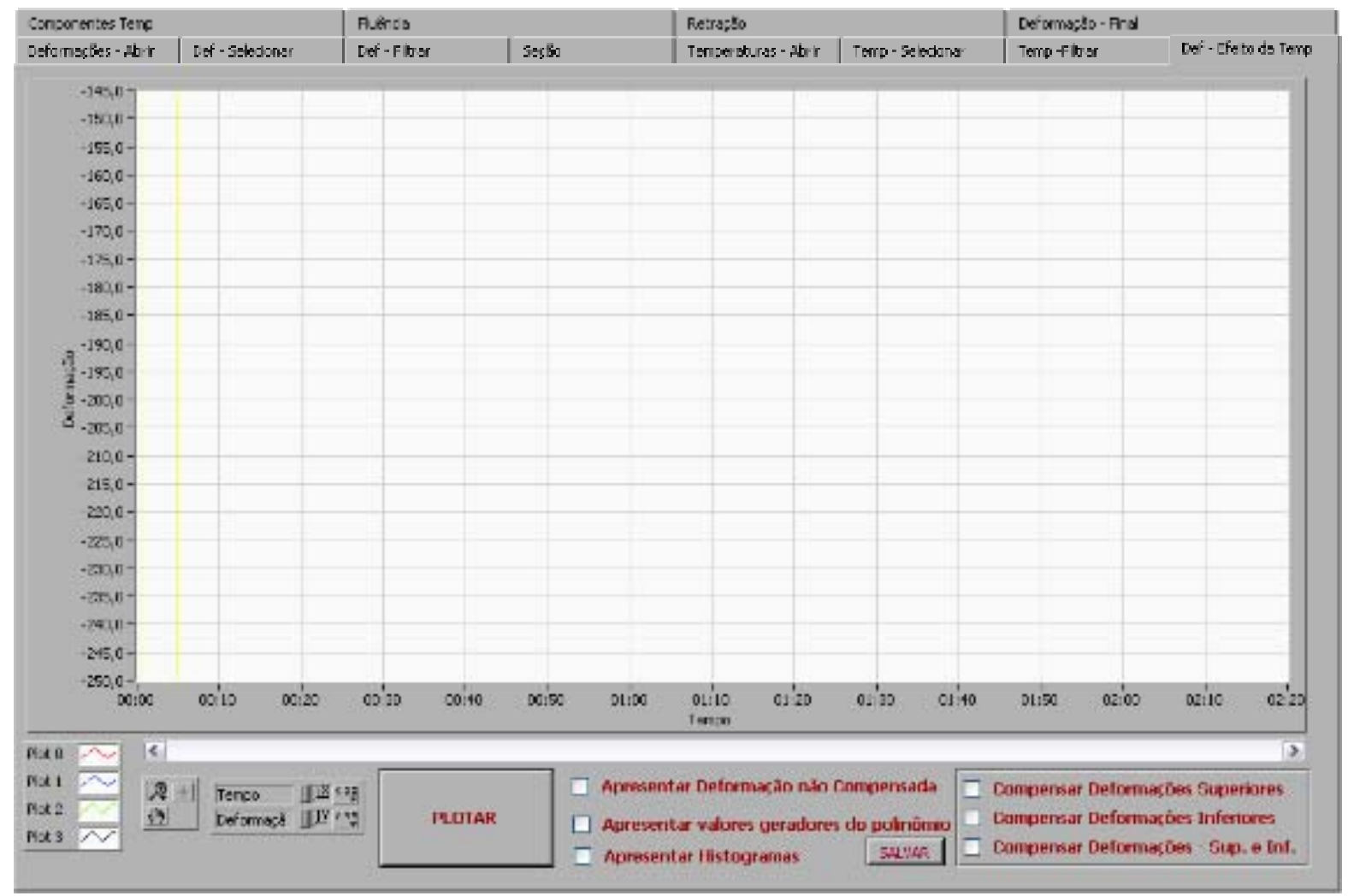

Figura 3.27 - Ambiente para apresentação de deformações após compensação dos efeitos da temperatura.

\subsubsection{Metodologia para compensação dos efeitos da temperatura nas deformações}

É sabido que quando da monitoração de estruturas, sobretudo nas que se desenvolvem ao longo de extensos períodos de tempo, há uma clara influência das temperaturas experimentadas pelos elementos estruturais nas medições realizadas. Segundo SILVEIRA (1996), as variações térmicas ambientais diárias provocam o 
aparecimento de tensões internas auto-equilibradas e estão também associadas a variações dos esforços hiperestáticos, de modo que os efeitos dessas ações, juntamente com as deformações de fluência e retração, devem ser devidamente considerados na fase de projeto, a fim de que sejam evitados problemas como a fissuração generalizada, podendo levar até mesmo à interrupção da utilização da obra.

A literatura técnica destaca duas formas distintas de estudar as ações térmicas, de modo a considerar apropriadamente os seus efeitos nas estruturas de concreto. Uma das abordagens é fundamentada no tratamento estatístico das variáveis térmicas mais importantes, tais como a radiação solar, a temperatura do ar e a velocidade do vento, utilizando-se modelos numéricos na busca dos valores característicos das variações térmicas, os quais consideram diversos casos de combinações de atuação simultânea das grandezas estudadas.

A segunda forma consiste na determinação, analítica ou experimental, da temperatura em uma ou várias seções, levando em consideração as condições reais da estrutura estudada, determinando-se as variações uniformes e os diferenciais térmicos, sendo os seus efeitos calculados posteriormente. Essa é metodologia empregada neste trabalho, mediante as etapas descritas a seguir:

\subsubsection{Etapas do método}

No sistema desenvolvido, o método para quantificação e remoção da parcela de deformação devida às temperaturas está estruturado em 2 etapas.

A primeira etapa tem como objetivo determinar a variação da deformação na fibra superior, corrigida em relação à presença de efeitos térmicos lineares $\left(\Delta \varepsilon_{C S}\right)$. O primeiro passo consiste em quantificar a variação de deformação nas fibras superiores devido à temperatura $\left(\Delta \varepsilon_{T S}\right)$, a qual pode ser calculada após o cômputo da variação das temperaturas ( $\triangle T S)$ nessas fibras. Visto que:

$$
T S=T_{U}+T_{L S}
$$

Teremos:

$$
\Delta T S=\Delta T_{U}+\Delta T_{L S}
$$


O passo seguinte consiste em calcular a deformação na fibra superior $\left(\varepsilon_{\mathrm{TS}}\right)$, sendo que esta é dada por:

$$
\varepsilon_{T S}=\alpha_{c} \Delta T S
$$

Subtraindo-se o valor de $\varepsilon_{\text {TS }}$ obtido a partir de uma leitura qualquer do valor calculado a partir da primeira medição, teremos a variação $\Delta \varepsilon_{\mathrm{TS}}$, conforme a equação 3.49 .

$$
\Delta \varepsilon_{T S}=\varepsilon_{T S}-\varepsilon_{T S, 0}
$$

Em seguida, é feita a remoção da parcela $\Delta \varepsilon_{\mathrm{TS}}$ dos valores lidos, calculando a variação da deformação nas fibras superiores $\left(\Delta \varepsilon_{s}\right)$ e subtraindo desta quantidade o valor de $\Delta \varepsilon_{\mathrm{TS}}$. $O$ valor obtido corresponde à variação da deformação na fibra superior, livre dos efeitos térmicos removidos (equação 3.51).

$$
\begin{gathered}
\Delta \varepsilon_{S}=\varepsilon_{S}-\varepsilon_{S, 0} \\
\Delta \varepsilon_{C S}=\Delta \varepsilon_{S}-\Delta \varepsilon_{T S}
\end{gathered}
$$

$\mathrm{Na}$ segunda etapa, busca-se a variação da deformação na fibra inferior, corrigida em relação à presença de efeitos térmicos lineares $\left(\Delta \varepsilon_{C I}\right)$.

O primeiro procedimento neste caso será calcular a variação das temperaturas $(\Delta T I)$ nessas fibras. Visto que:

$$
T I=T_{U}-T_{L I}
$$

Teremos:

$$
\Delta T I=\Delta T_{U}-\Delta T_{L I}
$$

No passo seguinte, é calculada a deformação na fibra inferior $\left(\varepsilon_{T_{1}}\right)$, sendo seu valor dado por:

$$
\varepsilon_{T l}=\alpha_{c} \Delta T I
$$

Semelhantemente ao que foi feito na primeira etapa, obtemos a variação $\Delta \varepsilon_{T S}$ subtraindo o valor de $\varepsilon_{T l}$ do valor calculado a partir da primeira medição, conforme a equação 3.49 .

$$
\Delta \varepsilon_{T l}=\varepsilon_{T l}-\varepsilon_{T l, 0}
$$

Em seguida, remove-se dos valores lidos a parcela $\Delta \varepsilon_{\mathrm{Tl}}$, calculando a variação da deformação nas fibras inferiores $\left(\Delta \varepsilon_{1}\right)$ e subtraindo desta quantidade o valor de $\Delta \varepsilon_{\mathrm{TI}}$. $\mathrm{O}$ valor obtido conforme a equação 3.57 corresponde à variação da deformação na fibra inferior, livre dos efeitos térmicos lineares. 


$$
\begin{gathered}
\Delta \varepsilon_{l}=\varepsilon_{l}-\varepsilon_{l, 0} \\
\Delta \varepsilon_{C l}=\Delta \varepsilon_{l}-\Delta \varepsilon_{T l}
\end{gathered}
$$

Na terceira etapa, são calculados os valores das deformações superiores e inferiores, a menos dos efeitos térmicos filtrados nas etapas anteriores, utilizando-se as equações 3.58 e 3.59 , respectivamente.

$$
\begin{gathered}
\varepsilon_{C S}=\left(\varepsilon_{S, 0}-\varepsilon_{T S, 0}\right)+\Delta \varepsilon_{C S} \\
\varepsilon_{C l}=\left(\varepsilon_{l, 0}-\varepsilon_{T l, 0}\right)+\Delta \varepsilon_{C l}
\end{gathered}
$$

Em relação ao procedimento de remoção dos efeitos da temperatura, o sistema construído conta com um ambiente projetado para a visualização das parcelas $T_{U}, T_{L S}, T_{L I}$ e $\left(T_{L S}-T_{L I}\right)$, relativas às temperaturas analisadas, sejam reais ou estimadas. O ambiente está localizado na aba Componentes Temp, ilustrada na figura 3.28 .

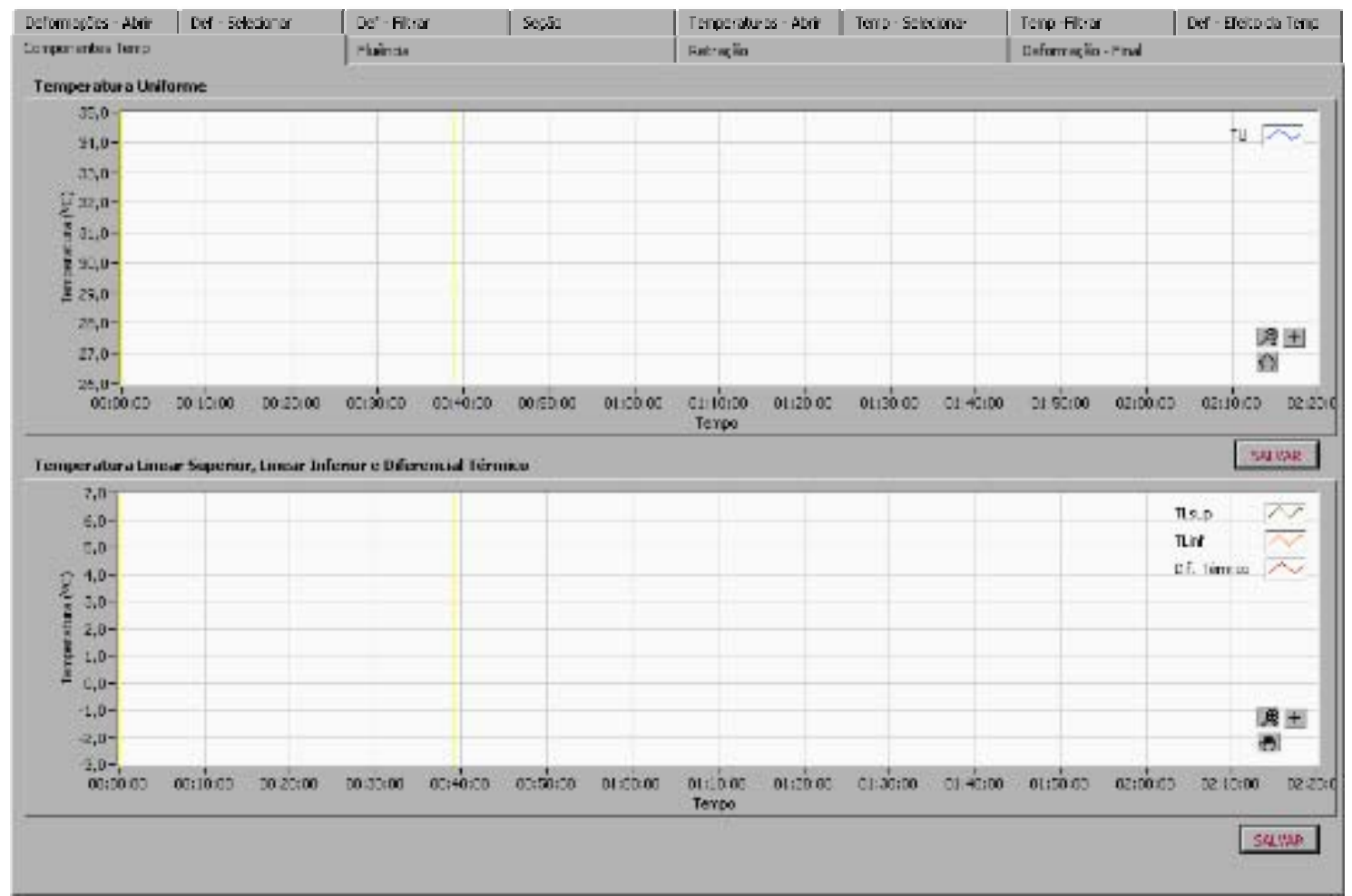

Figura 3.28 - Ambiente para visualização das parcelas lineares das temperaturas analisadas. 


\subsubsection{Ambiente para estimativa da deformação por fluência}

O comportamento do concreto é caracterizado por uma complexa relação entre tensão, deformação e tempo. Na aplicação de um carregamento em uma estrutura de concreto, ocorre em primeiro instante, uma deformação instantânea, a qual é seguida de um acréscimo de deformação ao longo do tempo. Esse fenômeno é denominado fluência. Quando da utilização do concreto como material estrutural, a compreensão dos efeitos da fluência e sua quantificação em peças e situações relevantes são indispensáveis.

A partir de inúmeros estudos já realizados (NEVILLE, 1997; MEHTA e MONTEIRO,1994), verificou-se que a evolução da fluência depende de diversos fatores, tais como: teor de umidade do concreto, umidade ambiente, dimensões do elemento estrutural, composição do concreto, temperatura ambiente, tipo de cimento utilizado, tempo de aplicação da carga e idade do concreto no instante do carregamento.

A fim de prover um ambiente para estimar a fluência em estruturas de concreto, foi construída a aba Fluência. Nela, os principais fatores relacionados à quantificação da fluência foram considerados, sendo utilizado o modelo de previsão de fluência do Eurocode 2 (EC2, 2003). A seguir, é apresentada a formulação do modelo, sendo indicadas as equações e procedimentos utilizados para a obtenção do coeficiente de fluência $\varphi\left(t, t_{0}\right)$, a partir do qual pode ser estimada a fluência em uma seção de um elemento de concreto.

O coeficiente de fluência é dado por:

$$
\varphi\left(t, t_{0}\right)=\varphi_{0} \beta_{c}\left(t, t_{0}\right)
$$

Onde:

$t$ - é a idade do concreto em dias no momento considerado;

$t_{0}$ - é a idade do concreto expresso em dias a partir da data da aplicação da carga.

$\varphi_{0}$ é o coeficiente nominal de fluência, valendo:

$$
\varphi_{0}=\varphi_{R H} \beta\left(f_{c m}\right) \beta\left(t_{0}\right)
$$


$\varphi_{R H}$ é o fator que considera o efeito da umidade relativa $R H(\mathrm{em} \%)$, definido por:

$$
\begin{gathered}
\varphi_{R H}=1+\frac{1-R H / 100}{0,1 \sqrt[3]{h_{0}}} \text { para } \mathrm{f}_{\mathrm{cm}} \leq 35 \mathrm{MPa} \\
\varphi_{R H}=\left[1+\frac{1-R H / 100}{0,1 \sqrt[3]{h_{0}}} \alpha_{1}\right] \alpha_{2} \text { para } \mathrm{f}_{\mathrm{cm}}>35 \mathrm{MPa}
\end{gathered}
$$

Onde $f_{c m}$ é a resistência média à compressão do concreto, aos 28 dias (em $\mathrm{MPa})$.

$\beta\left(f_{c m}\right)$ é o fator que considera a resistência característica do concreto, calculado por:

$$
\beta\left(f_{c m}\right)=\frac{16,8}{\sqrt{f_{c m}}}
$$

$\beta\left(t_{0}\right)$ é o fator que considera o efeito da idade do concreto quando da aplicação do carregamento, calculado por:

$$
\beta\left(t_{0}\right)=\frac{1}{\left(0,1+t_{0}^{0,20}\right)}
$$

$h_{0}$ é a espessura equivalente do elemento de concreto, sendo calculado por:

$$
h_{0}=\frac{2 A_{c}}{u}
$$

Em que:

$A_{c}$ - é a área da seção transversal $\left(\mathrm{em} \mathrm{mm}^{2}\right)$;

$u$ - é o perímetro do elemento em contato com a atmosfera (em $\mathrm{mm}$ ).

$\beta_{c}\left(t, t_{0}\right)$ é o coeficiente que define o desenvolvimento da fluência no tempo, fornecido por:

$$
\beta_{c}\left(t, t_{0}\right)=\left(\frac{t-t_{0}}{\beta_{h}+t-t_{0}}\right)^{0,3}
$$

Onde $\beta_{\mathrm{H}}$ é um coeficiente que depende da umidade relativa $(\mathrm{RH}$ em \%) e da espessura equivalente do elemento $\left(h_{0}\right.$, em $\left.\mathrm{mm}\right)$, calculado pelas equações $3.68 \mathrm{e}$ 3.69 .

$$
\beta_{H}=1,5\left(1+(0,012 R H)^{18}\right) h_{0}+250 \leq 1500 \text { para } \mathrm{f}_{\mathrm{cm}} \leq 35 \mathrm{MPa}
$$




$$
\beta_{H}=1,5\left(1+(0,012 R H)^{18}\right) h_{0}+250 \alpha_{3} \leq 1500 \text { para } \mathrm{f}_{\mathrm{cm}} \geq 35 \mathrm{MPa}
$$

$\alpha_{1 / 2 / 3}$ são coeficientes que permitem considerar a influência da resistência do concreto, definidos por:

$$
\begin{aligned}
& \alpha_{1}=\left[\frac{34}{f_{c m}}\right]^{0,7} \\
& \alpha_{2}=\left[\frac{34}{f_{c m}}\right]^{0,2} \\
& \alpha_{3}=\left[\frac{34}{f_{c m}}\right]^{0,5}
\end{aligned}
$$

$\mathrm{O}$ efeito da temperatura dentro da faixa de 0 a $80^{\circ} \mathrm{C}$ na maturidade do concreto é levada em conta a partir da equação 3.73 .

$$
t_{T}=\sum_{i=1}^{n} e^{-\left(4000 /\left\{\left[273+T\left(\Delta t_{i}\right)\right]-13,65\right\}\right.} \Delta t_{i}
$$

Sendo:

$t_{T}$ - a idade do concreto ajustada com a temperatura, substituindo $t$ nas equações correspondentes;

$T\left(\Delta t_{i}\right)$ - a temperatura em ${ }^{\circ} \mathrm{C}$ durante o período de tempo $\Delta \mathrm{t}_{\mathrm{i}}$;

$\Delta t_{i}$ - o número de dias onde a temperatura prevalece constante.

Para a execução das operações da equação 3.73 , o ambiente conta com um sistema de leitura de arquivos que permite ao utilizador selecionar temperaturas oriundas de monitoração. Além da execução do cálculos com as variáveis apresentadas, calculando o coeficiente de fluência e as deformações por fluência, o ambiente permite também que a partir das deformações calculadas, um período específico seja escolhido, sendo utilizadas as deformações selecionadas para a compensação da parcela de deformação devida à fluência. O intervalo de interesse tem o seu comprimento automaticamente ajustado ao intervalo temporal das deformações a compensar, com manutenção dos valores extremos da deformação por fluência do período, sendo interpolados os valores intermediários. O ambiente é apresentado na figura 3.29 . 


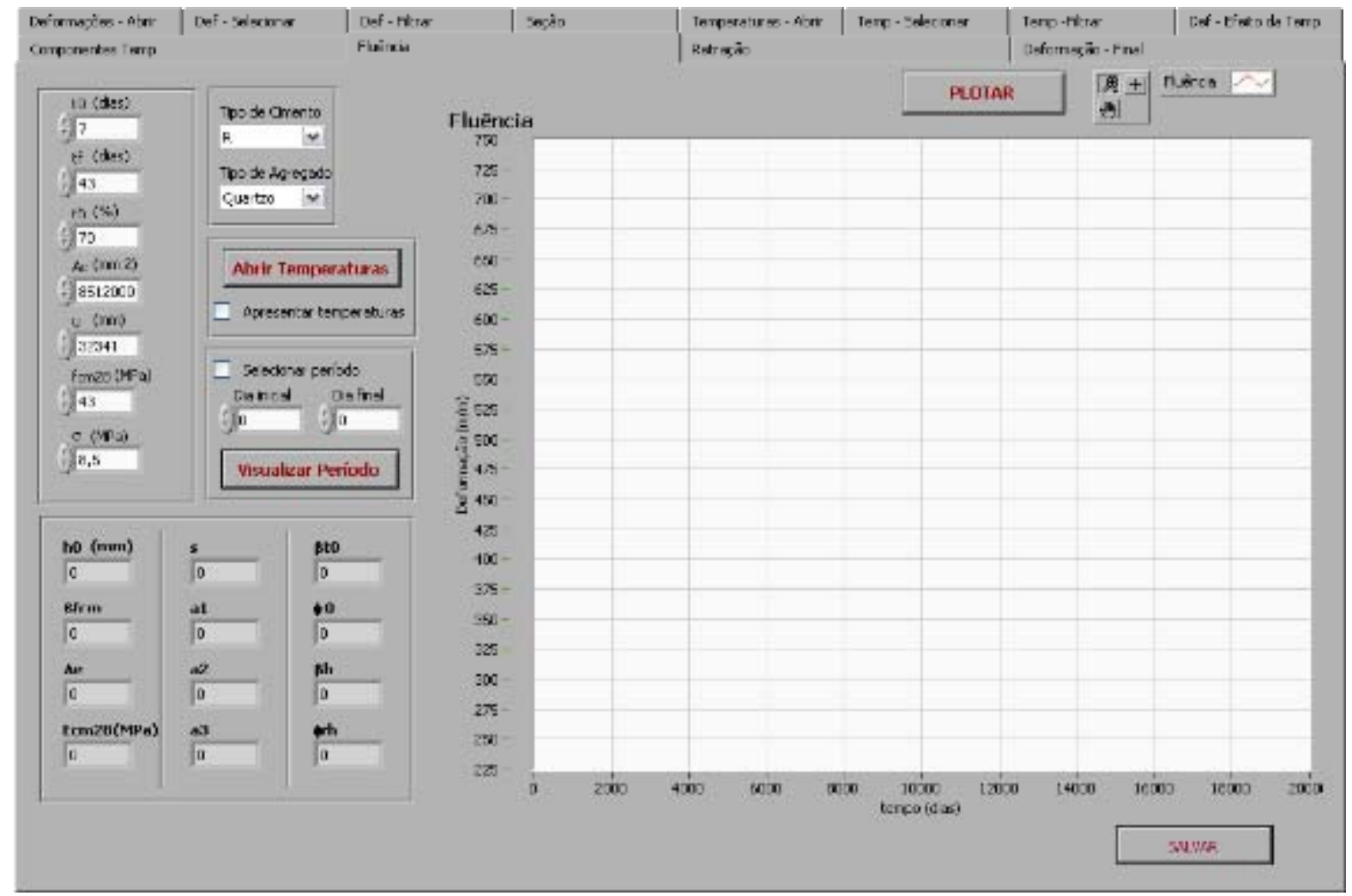

Figura 3.29 - Ambiente para cálculo das deformações devidas à fluência.

\subsubsection{Ambiente para estimativa da deformação por retração}

Buscando proporcionar um ambiente para estimar a deformação por retração em estruturas de concreto, foi construída a aba Retração. Nesse ambiente, os principais fatores relacionados à quantificação da retração foram considerados, sendo utilizado o modelo de previsão de retração do Eurocode 2 (EC2, 2003). A formulação do modelo é apresentada a seguir, indicando-se as equações e procedimentos envolvidos na estimativa.

A deformação total por retração $\left(\varepsilon_{c s}\right)$ é composta por duas parcelas, a deformação de retração por secagem $\left(\varepsilon_{c d}\right)$ e a deformação de retração autógena $\left(\varepsilon_{\mathrm{ca}}\right)$, sendo válida a equação 3.74 .

$$
\varepsilon_{c s}=\varepsilon_{c d}+\varepsilon_{c a}
$$

A deformação de retração por secagem básica $\varepsilon_{c d, 0}$ é calculada por:

$$
\varepsilon_{c d}(t)=\beta_{d s}\left(t, t_{s}\right) k_{h} \varepsilon_{c d, 0}
$$


Com:

$$
\begin{gathered}
\beta_{d s}\left(t, t_{s}\right)=\frac{\left(t-t_{s}\right)}{\left(t-t_{s}\right)+0,04 \sqrt{h_{0}^{3}}} \\
\varepsilon_{c d, 0}=0,85\left[\left(220+110 \alpha_{d s 1}\right) \exp \left(-\alpha_{d s 1} \frac{f_{c m}}{f_{c m 0}}\right)\right] 10^{-6} \beta_{R H} \\
\beta_{R H}=-1,55\left[1-\left(\frac{R H}{R H_{0}}\right)^{3}\right]
\end{gathered}
$$

Sendo:

$f_{c m}$ - a resistência média à compressão do concreto, aos 28 dias (em MPa);

$f_{\text {cmo }}-10 \mathrm{MPa}$;

$t$ - a idade do concreto em dias;

$t_{s}$ - a idade do concreto no início da secagem em dias;

$\alpha_{d s 1}-$ coeficiente que depende do tipo de cimento, igual a:

3 - para cimento classe S (cimento de endurecimento lento);

4 - para cimento classe $\mathrm{N}$ (cimento de endurecimento normal);

6 - para cimento classe $\mathrm{R}$ (cimento de endurecimento rápido).

$\alpha_{d s 2}-$ coeficiente que depende do tipo de cimento, igual a:

0,13 - para cimento classe $S$;

0,12 - para cimento classe $\mathrm{N}$;

0,11 - para cimento classe $R$.

$\mathrm{RH}$ - a umidade relativa do ambiente (em \%);

$R H_{0}-100 \%$;

$k_{h}$ - é um coeficiente dependente de $h_{0}$, de acordo com a tabela 3.3.

Tabela 3.3 - Valores de $k_{h}$.

\begin{tabular}{c|c}
\hline $\boldsymbol{h}_{\boldsymbol{0}}$ & $\boldsymbol{k}_{\boldsymbol{h}}$ \\
\hline 100 & 1,0 \\
\hline 200 & 0,85 \\
\hline 300 & 0,75 \\
\hline$\geq 500$ & 0,70 \\
\hline
\end{tabular}


$h_{0}$ - é a espessura equivalente do elemento de concreto, dado por:

$$
h_{0}=\frac{2 A_{c}}{u}
$$

Em que:

$A_{c}$ - é a área da seção transversal $\left(\mathrm{em} \mathrm{mm}^{2}\right)$;

$u$ - é o perímetro do elemento em contato com a atmosfera (em $\mathrm{mm}$ );

A deformação por retração autógena é dada por:

$$
\varepsilon_{c a}(t)=\beta_{a s} \varepsilon_{c a}(\infty)
$$

Com:

$$
\begin{aligned}
& \varepsilon_{c a}(\infty)=2,5\left(f_{c k}-10\right) 10^{-6} \\
& \beta_{a s}(t)=1-\exp \left(-0,2 t^{0,5}\right)
\end{aligned}
$$

A resistência característica do concreto é dada por:

$$
f_{c k}=f_{c m}-8
$$

A resistência à compressão média do concreto no tempo $t$ à temperatura média de $20^{\circ} \mathrm{C}$ é dada por:

$$
\begin{gathered}
f_{c m}(t)=\beta_{c c(t)} f_{c m} \\
\beta_{c c(t)}=\exp \left(s\left[1-\left(\frac{28}{t}\right)^{1 / 2}\right]\right)
\end{gathered}
$$

Sendo:

$f_{c m}(t)$ - a resistência média do concreto em $t$ dias;

$f_{c m}$ - a resistência média à compressão do concreto, aos 28 dias;

$\beta_{c c}(t)$ - um coeficiente que depende da idade $t$ do concreto;

$t$ - a idade do concreto (em dias);

$s$ - é um coeficiente que depende do tipo de cimento, igual a:

0,20 - para cimento classe R;

0,35 - para cimento classe $\mathrm{N}$;

0,38 - para cimento classe $S$. 
O módulo de elasticidade médio aos 28 dias para concretos com agregados de quartzo é dada por:

$$
E_{c m}=22\left[\frac{f_{c m}}{10}\right]^{0,3}
$$

A variação do módulo de elasticidade com o tempo é dada por:

$$
E_{c m}(t)=\left(\frac{f_{c m}(t)}{f_{c m}}\right)^{0,3} E_{c m}
$$

Onde:

$E_{c m}(t)$ - é o módulo de elasticidade do concreto no tempo $t$;

$\mathrm{E}_{\mathrm{cm}}$ - é o módulo de elasticidade do concreto aos 28dias.

De modo similar ao que está disponível na aba Fluência, o ambiente da aba Retração também dispõe da funcionalidade de escolha das deformações de um período de tempo específico, utilizando as deformações selecionadas para a compensação da parcela de deformação devida à retração. O intervalo selecionado tem o seu comprimento automaticamente ajustado ao intervalo temporal das deformações a compensar, com manutenção dos valores extremos da deformação por retração do período, sendo interpolados os valores intermediários. O ambiente é apresentado na figura 3.30 .

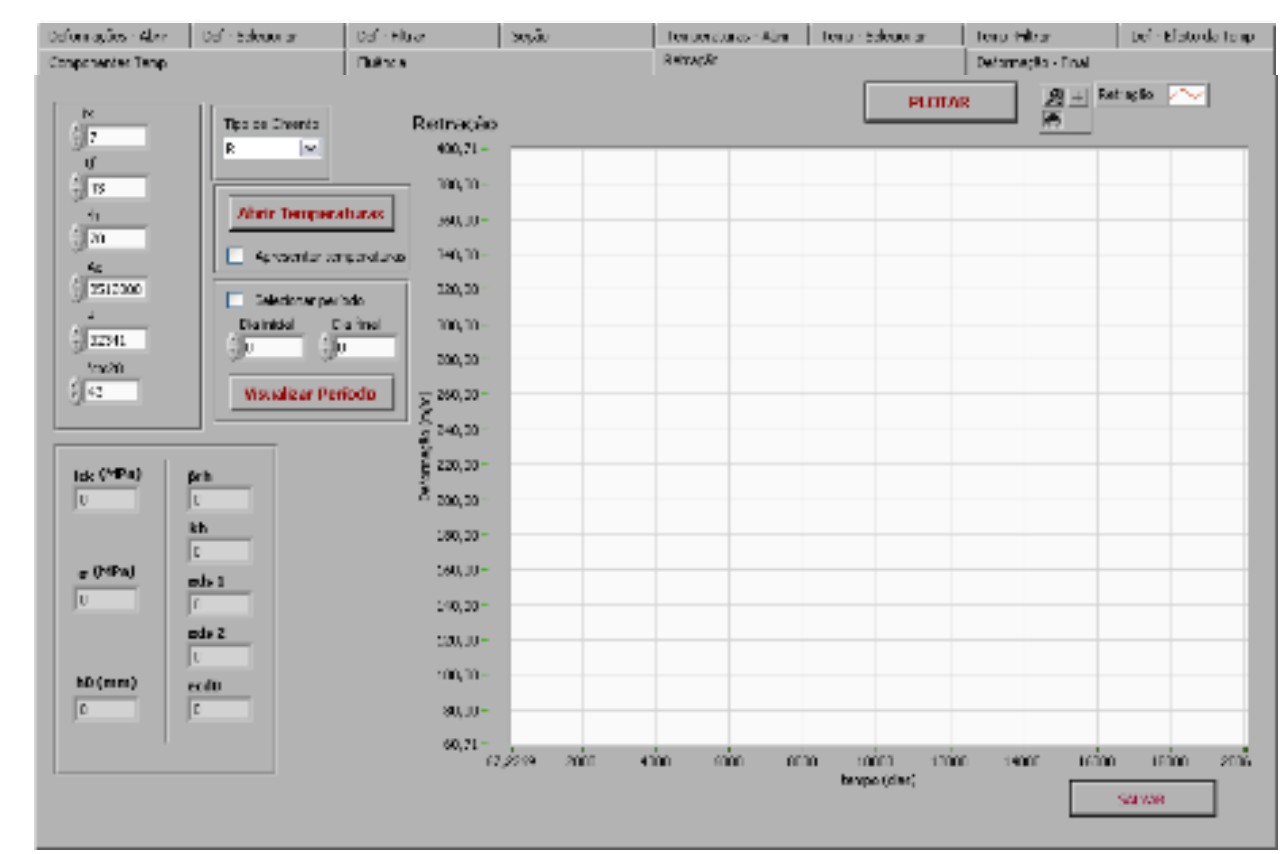

Figura 3.30 - Ambiente para cálculo das deformações devidas à retração. 


\subsubsection{Ambiente para apresentação dos resultados finais}

Para apresentação dos resultados das deformações compensadas em relação aos efeitos térmicos, à fluência e à retração, foi construído o ambiente da aba Deformação-Final, ilustrado na figura 3.31. Nesse ambiente também é possível apresentar as parcelas que foram deduzidas da deformação original, encerrando as funcionalidades do sistema de visualização e tratamento de dados desenvolvido.

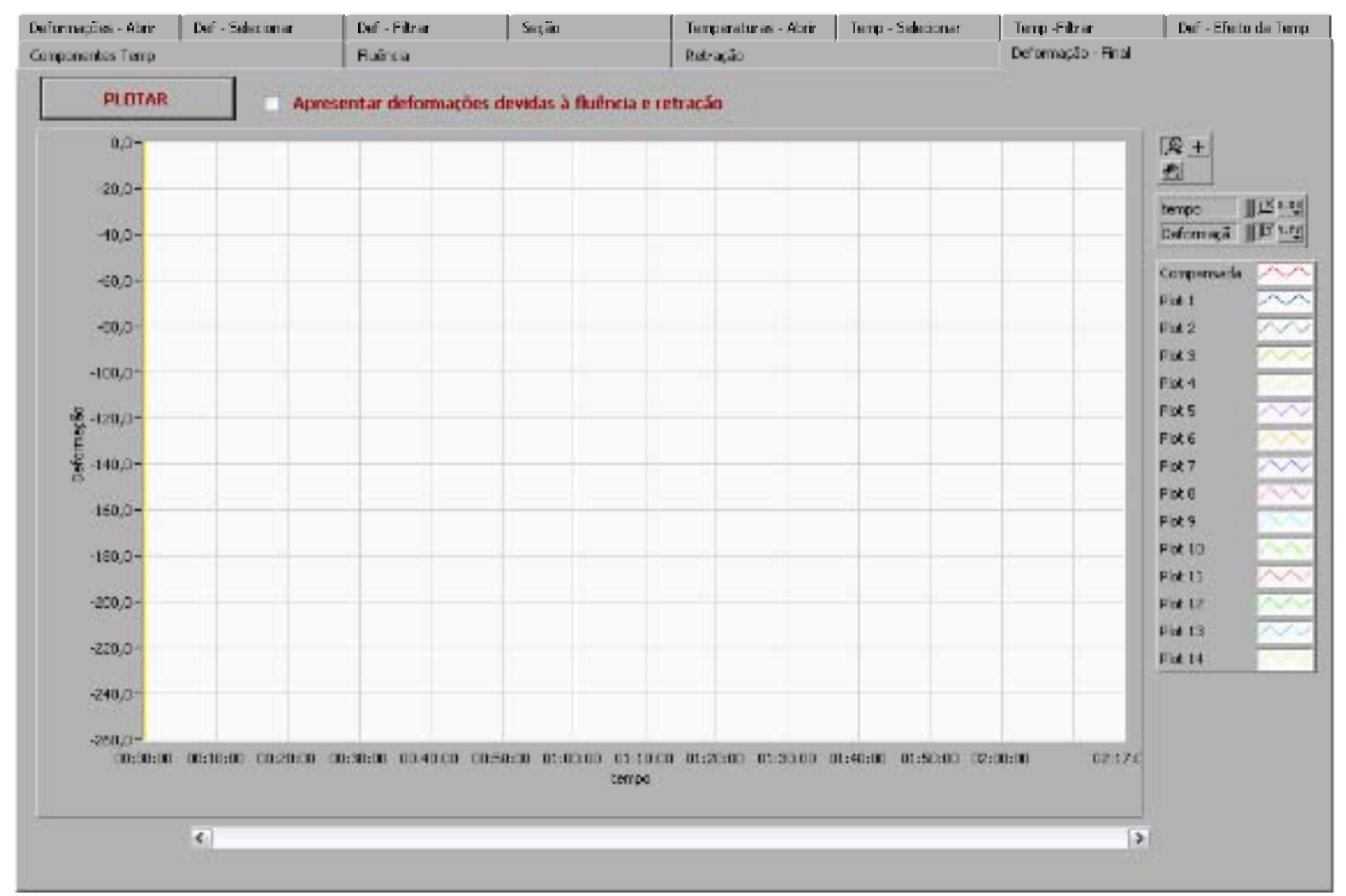

Figura 3.31 - Ambiente para apresentação dos resultados finais.

Uma exemplo de aplicação do sistema é apresentado no próximo capítulo, na qual as funções puderam ser exploradas em plenitude. No Capítulo 5, a utilização do sistema ficou restrita à filtragem de ruído dos resultados, embora tal contribuição tenha sido relevante, visto que proporcionou à equipe de análise de resultados (da qual o autor fez parte) significativo ganho de tempo que pôde ser dedicado às tarefas de interpretação de resultados. 


\subsection{Considerações finais}

Neste capítulo, foram apresentados três módulos desenvolvidos para a aquisição de dados utilizando data loggers dataTaker, quando da utilização da interface de comunicação RS-232, além do sistema para a visualização e tratamento das informações provenientes da monitoração estrutural. As características e funcionalidades das ferramentas desenvolvidas foram abordadas, considerando-se que atendem aos respectivos objetivos propostos: colaborar para o incremento da qualidade e do controle na aquisição dos dados e contribuir no processo de interpretação adequada das medições efetuadas utilizando modernos sistemas de monitoração.

Em relação ao sistema de visualização e tratamento de dados, conferiu-se destaque às funções de filtragem, à metodologia desenvolvida para a estimativa de temperaturas em seções, a partir das temperaturas conhecidas em uma seção, à metodologia desenvolvida para a compensação dos efeitos térmicos nas deformações medidas e aos métodos empregados para o cômputo e compensação das deformações devidas à retração e à fluência. Além desses tópicos, foram cobertos os aspectos relacionados às funções gráficas disponíveis e à introdução de dados e operação do sistema.

No experimento realizado para validar a metodologia proposta para a estimativa de temperaturas em seções, a reduzida diferença entre os valores de temperatura obtidos pelo método e as temperaturas medidas por sensores de temperatura insatalados na seção $S_{i}$ evidenciam que 0 método fornece satisfatoriamente os resultados dele esperados. Apresenta-se no próximo capítulo uma aplicação dos métodos para compensação dos efeitos térmicos e diferidos, sendo utilizados os resultados oriundos da monitoração de uma ponte rodoviária. 
CAPÍTULO 4

MONITORAÇÃO DO COMPORTAMENTO

DA PONTE SOBRE O RIO SORRAIA

\subsection{Introdução}

O presente capítulo refere-se às atividades de instrumentação e observação do comportamento da ponte de concreto armado e protendido construída sobre o rio Sorraia (figura 4.1), em Portugal, e à aplicação dos sistemas de apoio desenvolvidos durante a monitoração da obra. Objeto de estudo de um projeto de pesquisa Português, esta ponte foi instrumentada de forma a viabilizar a monitoração da sua condição estrutural ao longo de todo o seu ciclo de vida, desde a construção. Este projeto foi financiado pela Agência de Inovação, S.A. (Adi) e liderado pela Brisa Auto-estradas de Portugal, em parceria com a Faculdade de Engenharia da Universidade do Porto (FEUP) e com o Instituto de Engenharia de Sistemas e Computadores do Porto (INESC).

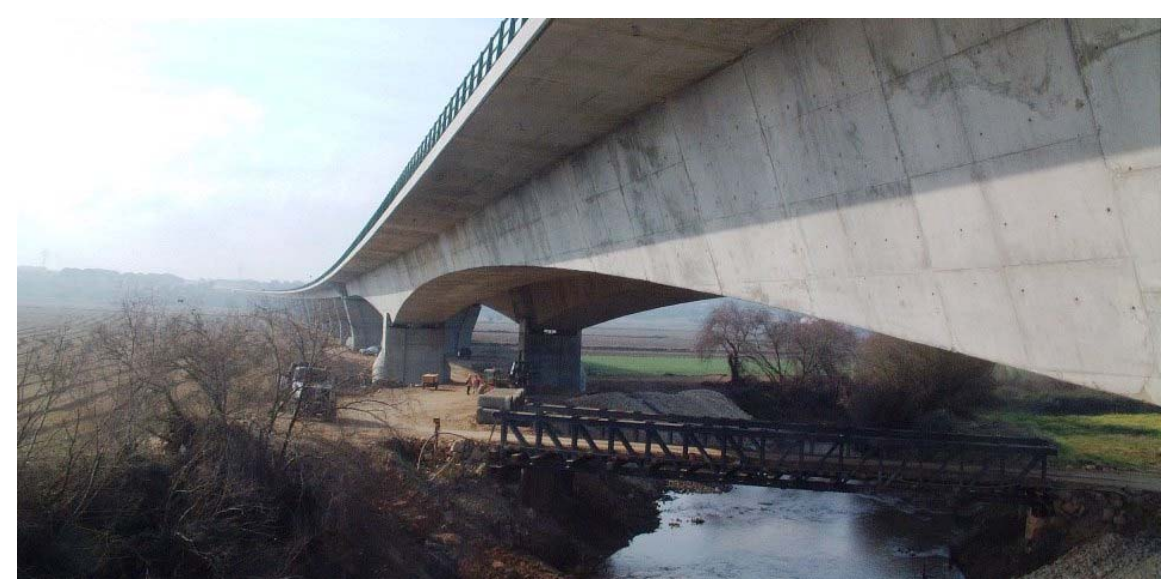

Figura 4.1 - Vista da ponte sobre o rio Sorraia.

Os trabalhos apresentados a seguir foram relizados durante a permanência do autor em Portugal, entre os meses de Maio de 2004 e Julho de 2005, mediante a 
concessão de uma bolsa de doze meses no âmbito do Programa de Doutorado com Estágio no Exterior (PDEE - CAPES) e uma bolsa de investigação interna da FEUP, durante três meses. Posteriormente, uma segunda bolsa de investigação da FEUP permitiu o regresso do autor a Portugal para o desenvolvimento de atividades de pesquisa por dois meses, de Agosto a Outubro de 2006. Nesse período foram feitos os experimentos e parte do código do sistema de visualização apresentados no capítulo anterior.

A próxima seção traz uma sumária descrição da estrutra da ponte, enquanto na seção 4.3 é apresentado o sistema de monitoração desenvolvido pela para o acompanhamento do comportamento estrutural, fruto do trabalho da equipe constituída pelo LABEST - FEUP e INESC, com ativa participação do doutorando em todas as fases. A seção 4.4 apresenta uma aplicação do sistema computacional apresentado no Capítulo 3, tendo como objeto de estudo uma das seções monitoradas da ponte.

\subsection{Descrição da estrutura}

Localizada no concelho de Santarém, em Salvaterra de Magos, na AutoEstrada A13, a ponte sobre o rio Sorraia é parte de uma obra de arte com um comprimento total de $1666 \mathrm{~m}$, constituída por três partes independentes, a saber:

a) viaduto de acesso Norte;

b) ponte;

c) viaduto de acesso Sul.

Na figura 4.2 é apresentada uma vista geral da ponte durante a fase construtiva, em julho de 2004, juntamente com os viadutos de acesso.

A ponte sobre o rio Sorraia é constituída por uma estrutura com dois tabuleiros paralelos de três tramos cada, com $270 \mathrm{~m}$ de comprimento, tendo $120 \mathrm{mo}$ vão central e 75 m os vãos laterais. Cada tabuleiro apoia-se em dois pilares centrais (P1 e P2) e em dois pilares de transição (PT-N e PT-S), que efetuam a ligação entre 
a ponte e os viadutos de acesso Norte e Sul, respectivamente com $487 \mathrm{~m}$ e $909 \mathrm{~m}$ de comprimento (SOUSA et al., 2005). A figura 4.3 traz uma fotografia aérea da ponte, obtida durante a fase construtiva, na qual as atividades de instrumentação com sensores de imersão no concreto foi realizada.

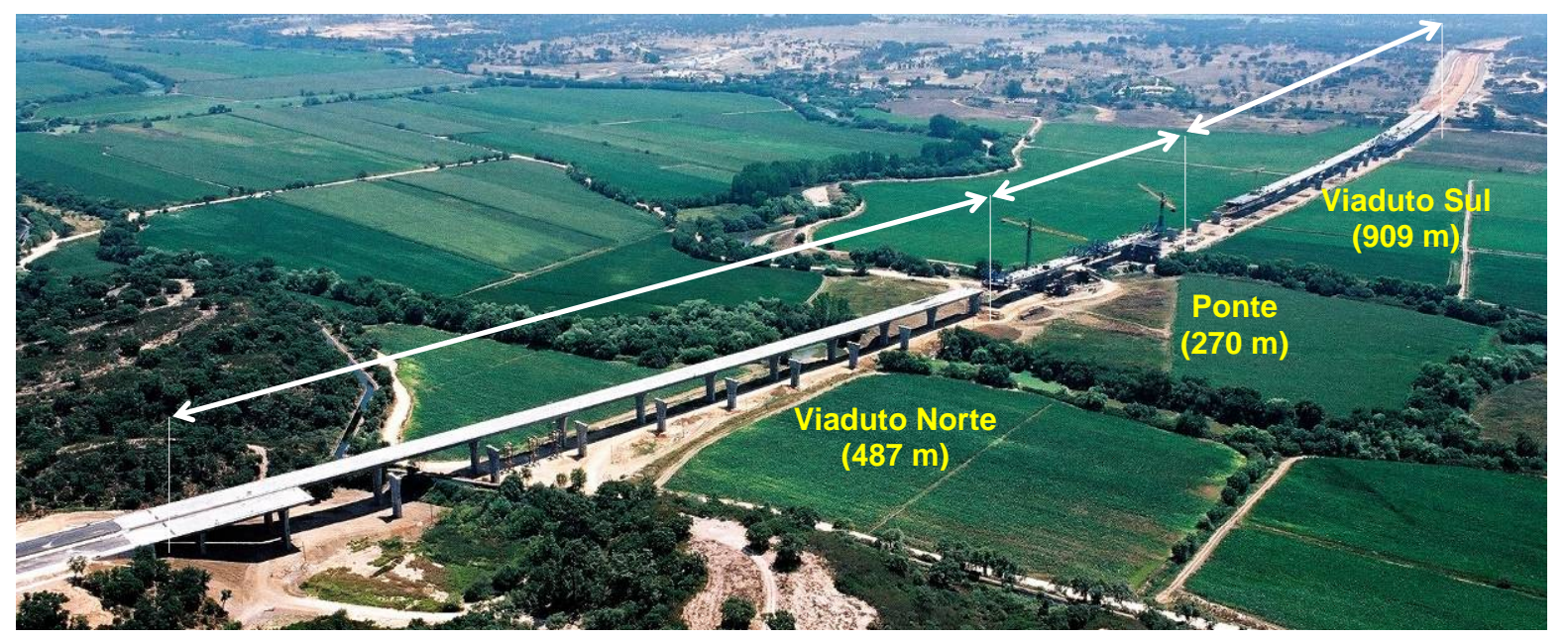

Figura 4.2 - Vista geral da obra durante a fase construtiva.

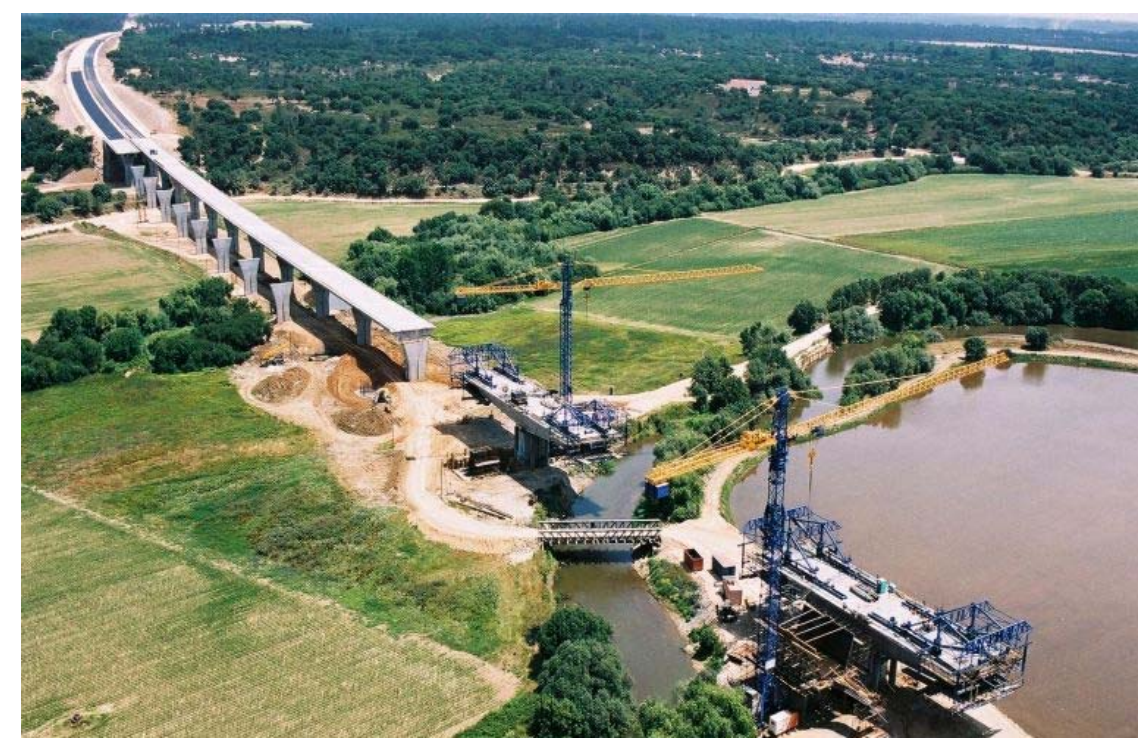

Figura 4.3 - Vista da ponte sobre o rio Sorraia durante construção.

Cada tabuleiro, protendido longitudinal e transversalmente, consiste num caixão monocelular com 14,45 m de largura e altura variável entre os 6,00 m sobre os pilares e os 2,55 m a meio do vão central e nas extremidades dos tramos laterais, conforme indicado na figura 4.4 . 
Os pilares centrais são retangulares, com $6 \times 3,5 \mathrm{~m}$ de seção, paredes de 0,60m de espessura e entre 7,00 e $8,00 \mathrm{~m}$ de altura. A fundação destes pilares é indireta, constituída por 5 estacas com 2,0 m de diâmetro e 35,0 m de comprimento.

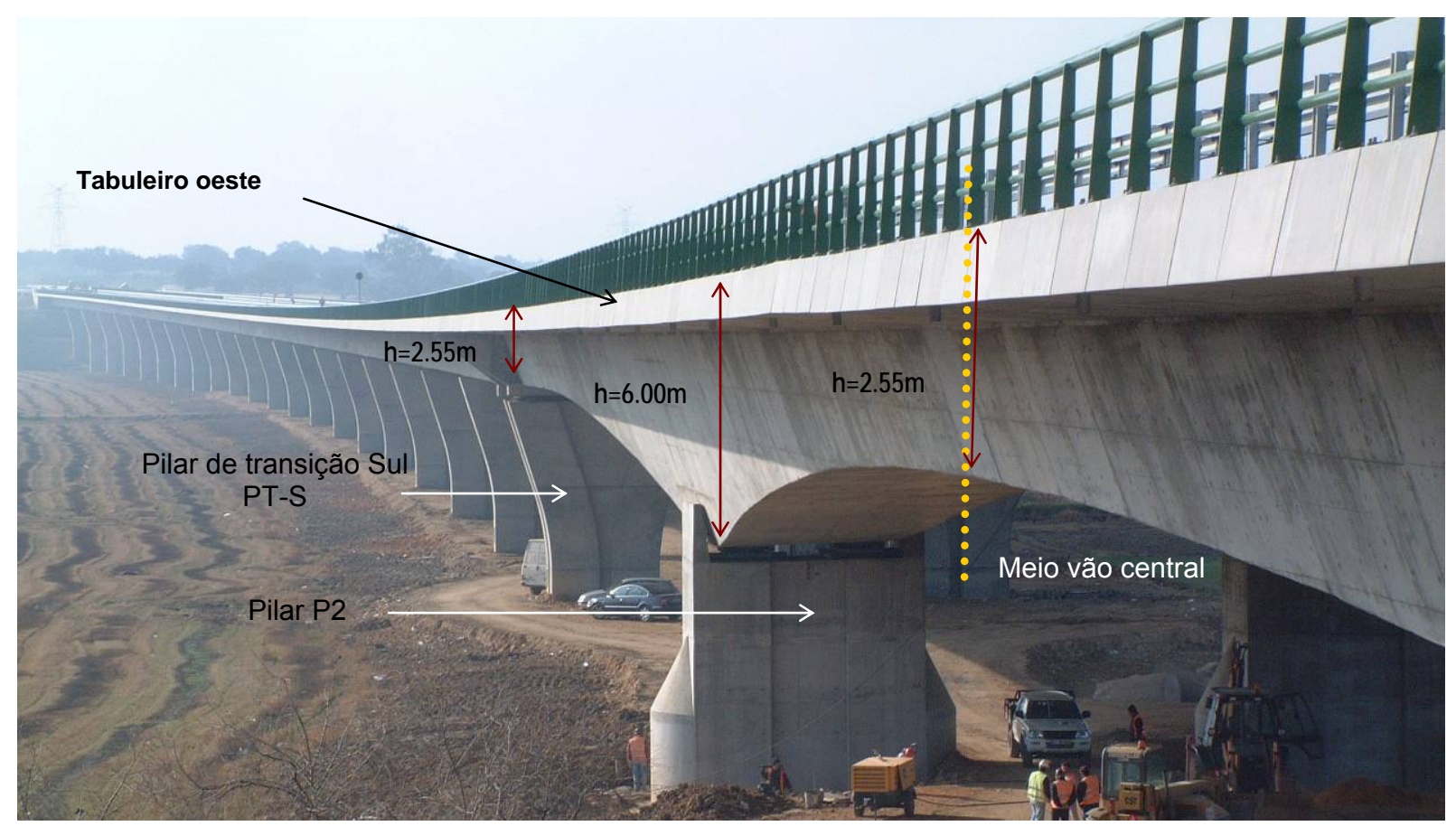

Figura 4.4 - Tabuleiro da ponte, com indicação de elementos relevantes.

A necessidade de atravessar o rio Sorraia obliquamente e a impossibilidade de executar apoios intermediários determinaram a execução do tabuleiro pelo método dos avanços sucessivos, com concretagem in situ de aduelas com comprimento máximo de $5,0 \mathrm{~m}$ e peso até $1500 \mathrm{kN}$. A figura 4.5 ilustra o método dos avanços sucessivos sendo aplicado na obra.

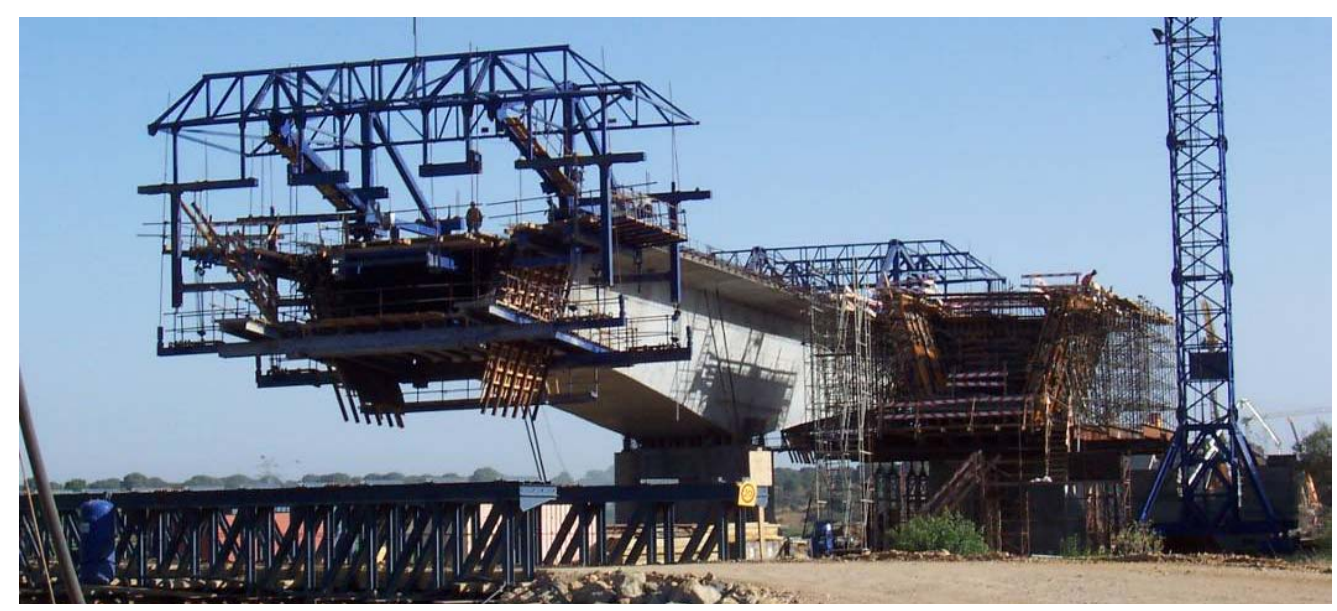

Figura 4.5 - Aplicação do método do avanços sucessivos na ponte sobre o rio Sorraia. 
Na seção seguinte, será apresentado o sistema de monitoração instalado, sendo fornecida também a avaliação dos componentes envolvidos e sua contribuição ao sistema.

\subsection{Descrição do sistema de monitoração}

O sistema de monitoração encontra-se estruturado de forma que as tarefas associadas ao seu funcionamento estão distribuídas em três subsistemas:

a) subsistema sensorial;

b) subsistema de comunicação;

c) subsistema de processamento de dados.

As principais características e funcionalidades de cada um desses subsistemas, e a avaliação do desempenho e contribuição efetiva de cada um dos três componentes ao sistema de monitoração constituirão objetos de apreciação dos itens seguintes.

\subsubsection{Subsistema sensorial}

O subsistema sensorial é constituído pelos sensores elétricos e ópticos instalados, pelo sistema de aquisição de dados e pela infra-estrutura montada para a comunicação física entre os sensores e o sistema de aquisição. A finalidade deste subsistema é proporcionar as informações referentes à variação das grandezas monitoradas de modo a permitir o acompanhamento e a avaliação do comportamento estrutural da obra.

O tabuleiro da ponte foi contemplado com a instalação de um sistema de monitoração remoto que conta com sensores de resistência elétrica e sensores de fibra óptica. Os sensores instalados realizam a medição de deformação do concreto, 
além da monitoração de temperatura e umidade relativa. Existem no interior do tabuleiro dois postos de observação com equipamento de aquisição de sinais, bem como um sistema de comunicação que permite a transmissão remota de informação. A seguir, será feita a descrição dos sensores e equipamentos que constituem este subsistema.

\subsubsection{Medição de deformações}

Neste sistema de monitoração a medição da deformação do concreto é feita através de sensores convencionais de resistência elétrica comerciais, próprios para embutir no concreto (figura 4.6), e por uma classe de sensores desenvolvidos especialmente para a monitoração desta obra. Estes sensores especiais, denominados cabeças sensoras, foram confeccionados nos laboratórios da Universidade do Porto (UP), buscando-se obter, por meio das dimensões e materiais empregados, boas respostas em termos de deformação da estrutura mesmo após a fissuração do concreto (nas regiões de interesse) e elevada durabilidade. Uma cabeça sensora típica é constituída por três sensores: um sensor óptico e um extensômetro elétrico (para a medição de deformações) e um sensor óptico para medição de temperaturas. Desta forma, cada cabeça sensora fornece dois registros de deformação do concreto, sendo um proveniente do sensor de fibra óptica e outro proveniente do sensor de resistência elétrica. Os três sensores são encapsulados por meio de uma resina, sendo as extremidades constituídas por fibras de carbono adensadas. A figura 4.7 apresenta uma dessas cabeças sensoras, utilizada para monitoração da seção S2.

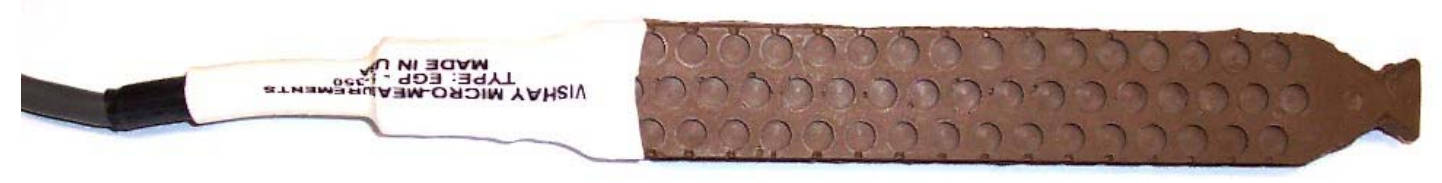

Figura 4.6 - Sensor de deformação comercial utilizado, próprio para ser embutido no concreto. 
A distribuição dos sensores na ponte sobre o rio Sorraia foi feita a partir da análise de esforços da estrutura para as cargas permanentes, estabelecendo-se sete seções transversais ( 1 1 a S7) para instrumentação permanente, sendo a seção S1 mais a norte e a S7 mais a sul, conforme ilustrado na figura 4.8.

Para o arranjo dos sensores por seção, foram estabelecidos 3 alinhamentos verticais (alinhamento 1 à esquerda, do lado oeste, alinhamento 2, central, e alinhamento 3 à direita, do lado leste) e 3 alinhamentos horizontais (alinhamento inferior - I, alma - A e alinhamento superior - S). A figura 4.9 ilustra os alinhamentos referidos. Em relação à monitoração das fundações, foram instrumentadas quatro estacas, destacadas na figura 4.10.

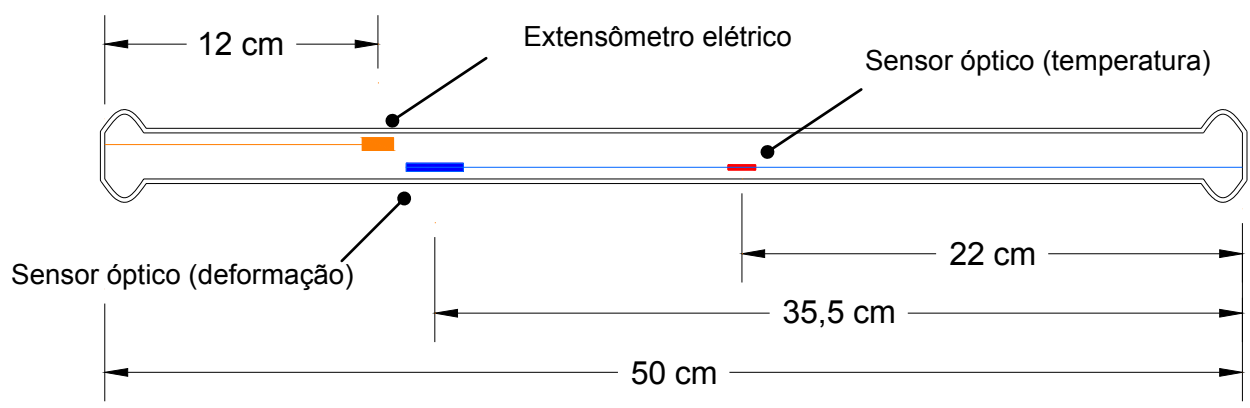

(a)

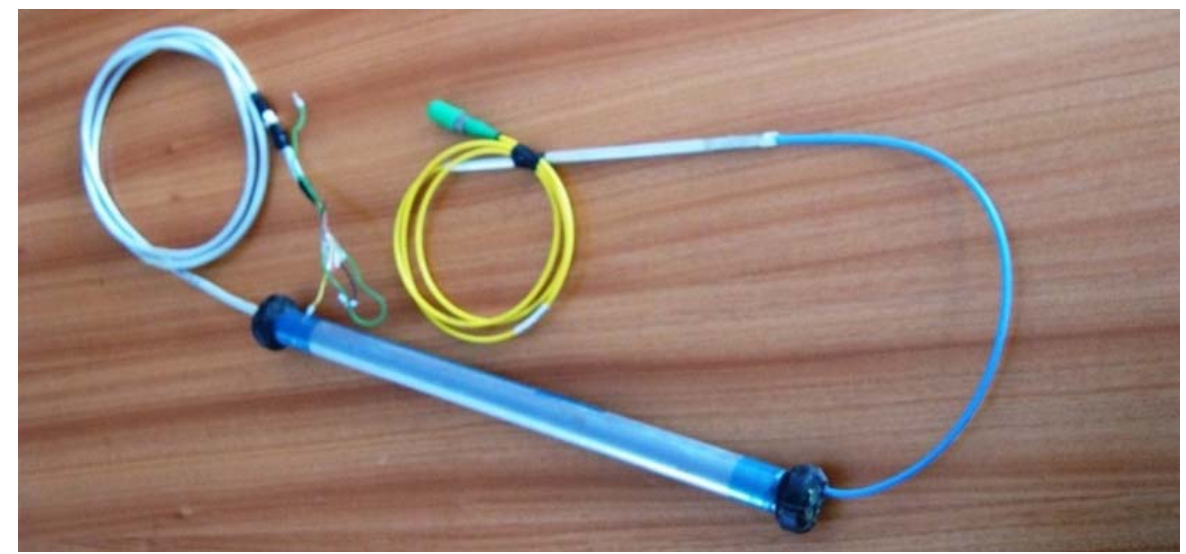

(b)

Figura 4.7 - Cabeça sensora típica: características básicas (a) e aspecto final (b).

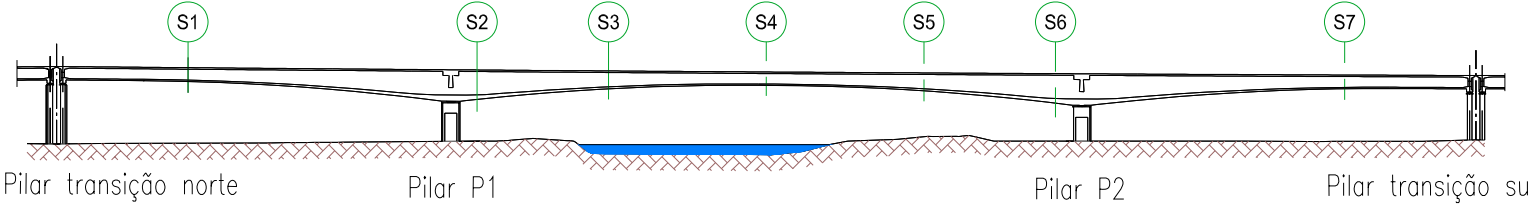

Figura 4.8 - Localização das seções instrumentadas da ponte sobre o rio Sorraia. 
Figura 4.9 - Identificação dos alinhamentos de referência.
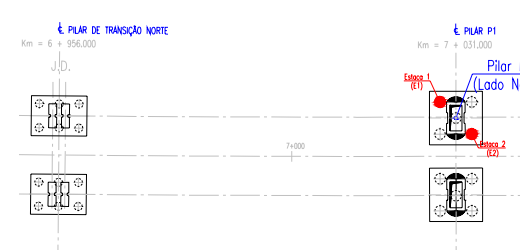

Figura 4.10 - Estacas contempladas no plano de monitoração.

Para exemplificar a designação dos elementos sensores, uma cabeça sensora $(\underline{\mathrm{C}})$ localizada na Seção $\underline{5}$ no alinhamento $\underline{2}$ e no banzo $\underline{\text { Superior tem a }}$ designação CS5-2S (deformação em S5 na interseção do alinhamento vertical 2 com o alinhamento horizontal S). Na tabela 4.1 estão resumidas as nomenclaturas utilizadas para designar as cabeças sensoras instaladas no tabuleiro da ponte. As principais características técnicas dos sensores de deformação instalados são indicadas na tabela 4.2 .

Tabela 4.1 - Cabeças sensoras instaladas no tabuleiro da ponte.

\begin{tabular}{c|c|c|c|c|c|c|c}
\cline { 2 - 8 } & \multicolumn{7}{c}{ Seção } \\
\hline Alinhamento & S1 & S2 & S3 & S4 & S5 & S6 & S7 \\
\hline $1-I$ & CS1-1I & CS2-1I & - & CS4-1I & - & CS6-1I & CS7-1I \\
\hline $1-A$ & - & CS2-1A & - & - & - & CS6-1A & - \\
\hline $1-S$ & CS1-1S & CS2-1S & - & CS4-1S & - & CS6-1S & CS7-1S \\
\hline $2-I$ & - & - & CS3-2I & CS4-2I & CS5-2I & - & - \\
\hline $2-S$ & - & - & CS3-2S & CS4-2S & CS5-2S & - & - \\
\hline $3-I$ & CS1-3I & CS2-3I & - & CS4-3I & - & CS6-3I & CS7-3I \\
\hline $3-A$ & - & CS2-3A & - & - & - & CS6-3A & - \\
\hline $3-S$ & CS1-3S & CS2-3S & - & CS4-3S & - & CS6-3S & CS7-3S \\
\hline
\end{tabular}


Tabela 4.2 - Características técnicas dos sensores de deformação instalados.

\begin{tabular}{c|c|c}
\hline \multirow{2}{*}{ Característica } & \multicolumn{2}{|c}{ Especificação } \\
\cline { 2 - 3 } & Resistência elétrica & Fibra óptica \\
\hline Faixa de temperatura de funcionamento & $-45^{\circ} \mathrm{C} \mathrm{a}+55^{\circ} \mathrm{C}$ & $-10^{\circ} \mathrm{C} \mathrm{a}+70^{\circ} \mathrm{C}$ \\
\hline Resistência elétrica $\left(a 4^{\circ} \mathrm{C}\right)$ & $350.0 \pm 0.8 \% \Omega$ & - \\
\hline Comprimento de onda $(\mathrm{nm})$ & - & $\begin{array}{l}1520-1570 \text { (definido pelo } \\
\text { equipamento de aquisição) }\end{array}$ \\
\hline
\end{tabular}

\subsubsection{Medição de temperatura e umidade relativa}

Visando conhecer as condições ambientais que envolvem a ponte ao longo do tempo, o sistema de monitoração contempla a medição das temperaturas do ambiente e do concreto, bem como a umidade relativa ambiental. Encontram-se instalados sensores de temperatura $(T)$ resistivos do tipo PT100, os quais foram produzidos pelo LABEST a partir do uso de componentes dísponiveis no mercado, e sensores resistivos para medição de umidade relativa (HR) com o intuito de caracterizar o ambiente externo e o interior do caixão.

$\mathrm{Na}$ figura 4.11 são apresentados exemplares dos sensores existentes na ponte sobre o rio Sorraia para medição da temperatura e umidade relativa. A tabela 4.3 informa a distribuição e nomenclatura dos sensores para medição da temperatura e umidade relativa.

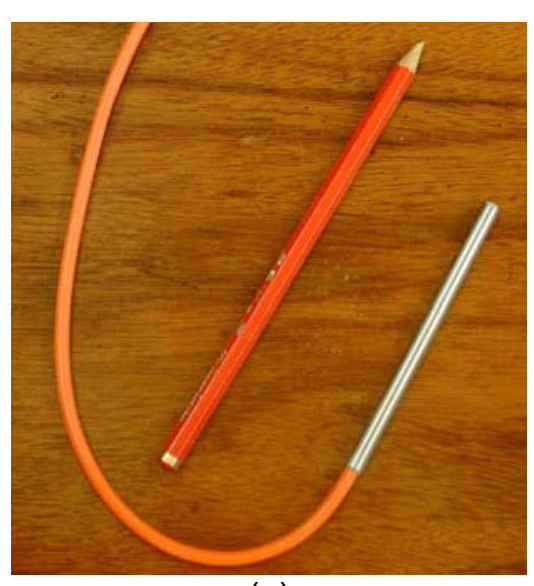

(a)

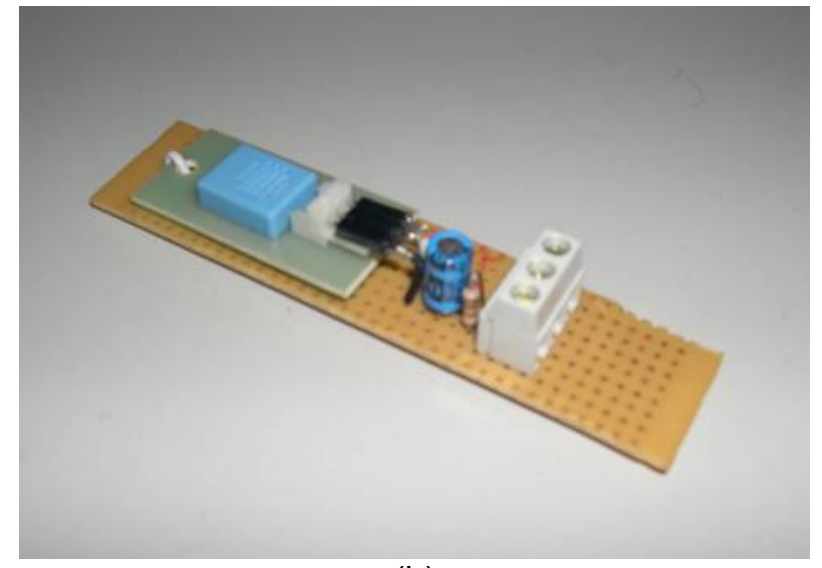

(b)

Figura 4.11 - Exemplos de sensores de temperatura (a) e umidade relativa (b) existentes na ponte. 
Tabela 4.3 - Distribuição dos sensores para medição de temperaturas e umidades relativas.

\begin{tabular}{c|c|c}
\cline { 2 - 3 } & \multicolumn{2}{c}{ Seção } \\
\hline Alinhamento & S2 & S5 \\
\hline $1-I$ & - & - \\
\hline \multirow{2}{*}{$1-A$} & $\begin{array}{l}\text { TS2-1A (interior) } \\
\text { HS2-1A (interior) }\end{array}$ & - \\
\hline \multirow{2}{*}{$1-S$} & $\begin{array}{l}\text { TS2-1A (exterior) } \\
\text { HS2-1A (exterior) }\end{array}$ & - \\
\hline $2-I$ & - & TS5-2I \\
\hline $2-S$ & - & TS5-2S \\
\hline
\end{tabular}

\subsubsection{Sistema de aquisição de dados}

O sistema de aquisição e de armazenamento do sinal proveniente dos sensores que se encontram instalados na ponte de forma definitiva é concentrado em dois postos de observação, designados PO1 e PO2, localizados no interior da ponte. O posto PO1 foi posicionado sobre o pilar P1, enquanto o posto PO2 foi instalado sobre o pilar P2, conforme ilustrado na figura 4.12.

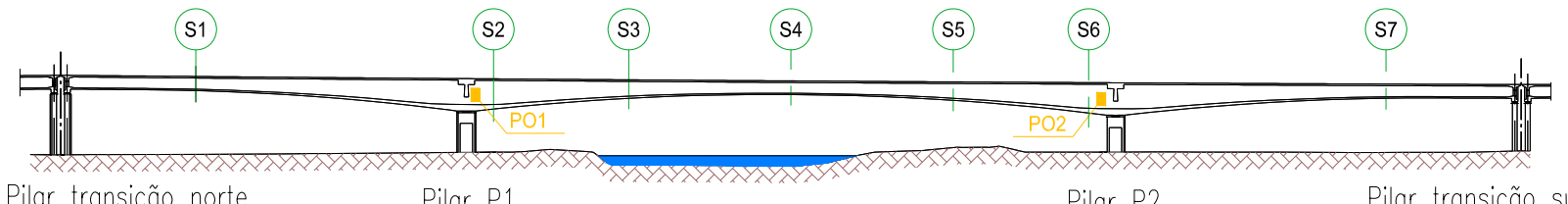

Figura 4.12 - Localização dos postos de observação do sistema de monitoração permanente.

Cada um dos sistemas de aquisição é constituído por um data logger dataTaker modelo DT500 e dois módulos de expansão, viabilizando a leitura simultânea de trinta sensores elétricos. No posto PO1 também foi instalado o sistema de aquisição e interrogação de sinal dos sensores ópticos, constituído por um equipamento da MicronOptics, de referência si425 Swept Laser Interrogator. $\mathrm{Na}$ figura 4.13 são ilustrados os equipamentos de aquisição elétrico e óptico. 


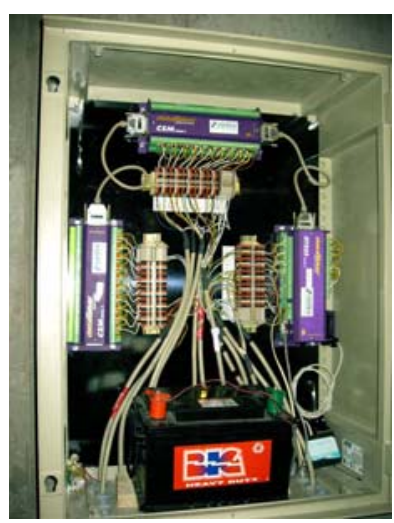

(a)

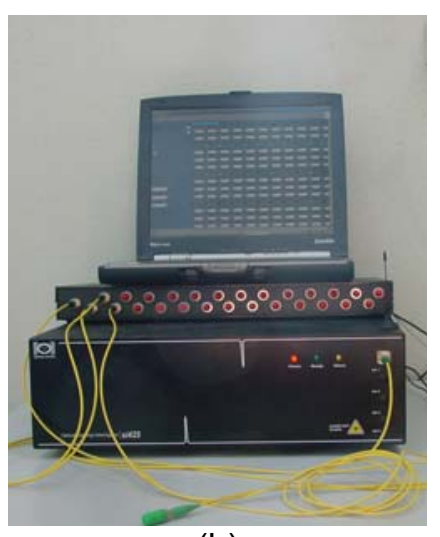

(b)

Figura 4.13 - Sistema de aquisição elétrico (a) e sistema de aquisição óptico (b).

Os equipamentos de aquisição e interrogação de sinal proveniente dos sensores elétricos e de fibra óptica instalados na ponte sobre o rio Sorraia permitem realizar aquisições em tempo real, possibilitando definir intervalos para aquisição automática e são compatíveis com sistemas para transmissão remota das informações recolhidas.

\subsubsection{Subsistema de comunicação}

O subsistema de comunicação é formado por dois modem GSM (Global System for Mobile Communications), que estabelecem a comunicação entre as unidades remotas (sistema de aquisição elétrico e óptico) e um computador configurado para funcionar como servidor HTTP, também chamado de servidor Web, o qual é capaz de processar solicitações HTTP, o protocolo padrão da Internet.

A configuração adotada aloca um dos modem na unidade remota, o qual é fisicamente conectado ao computador responsável pelo armazenamento dos valores aquisitados, enquanto o outro modem é fisicamente ligado ao computador que funciona como servidor. A finalidade deste subsistema é proporcionar o envio das informações provenientes do subsistema sensorial até o utilizador, interessado nos resultados, e permitir ao administrador do sistema de monitoração, por meio da interface Web desenvolvida, a configuração de parâmetros da aquisição. A arquitetura e funcionalidades deste subsistema são apresentados a seguir. 


\subsubsection{Arquitetura do subsistema de comunicação}

O funcionamento do subsistema de comunicação é baseado nas instruções e operações realizadas pela Unidade Central de Controle (UCC), localizada no servidor, e nas respostas provenientes dos sistemas de aquisição instalados remotamente, sendo que o tráfego das informações é realizado utilizando os modem instalados em cada uma das extremidades. No servidor, onde funciona a UCC, há um modem conectado em uma porta serial, utilizando o protocolo RS-232, por onde passa toda a informação transmitida para as unidades remotas. Para controlar o processo de tráfego de dados, a UCC conta com uma aplicação desenvolvida utilizando tecnologia Java $^{\mathrm{TM}}$, a qual viabiliza a comunicação periódica com as unidades remotas para adquirir a informação recolhida pelo sistema de aquisição e permite ainda a configuração dos parâmetros de aquisição, sendo que este último procedimento apenas é realizado quando solicitado pelo administrador do sistema. Os pedidos recebidos pelo servidor HTTP destinados às unidades remotas são interpretados pela UCC, aguardando em seguida pela respectiva resposta. O processamento do pedido pela UCC tem várias fases: a recepção do pedido, a identificação, o estabelecimento da ligação GSM/GPRS com o modem de destino, o envio do pedido por meio do modem, e recepção e reenvio da resposta. Ao estabelecer esta ligação com o modem de destino, o servidor consegue se comunicar com o sistema de aquisição em razão de o vínculo estabelecido ser equivalente a uma ligação física. A arquitetura do subsistema de comunicação é ilustrada na figura 4.14, que também apresenta a relação entre a UCC e o sistema de aquisição. 


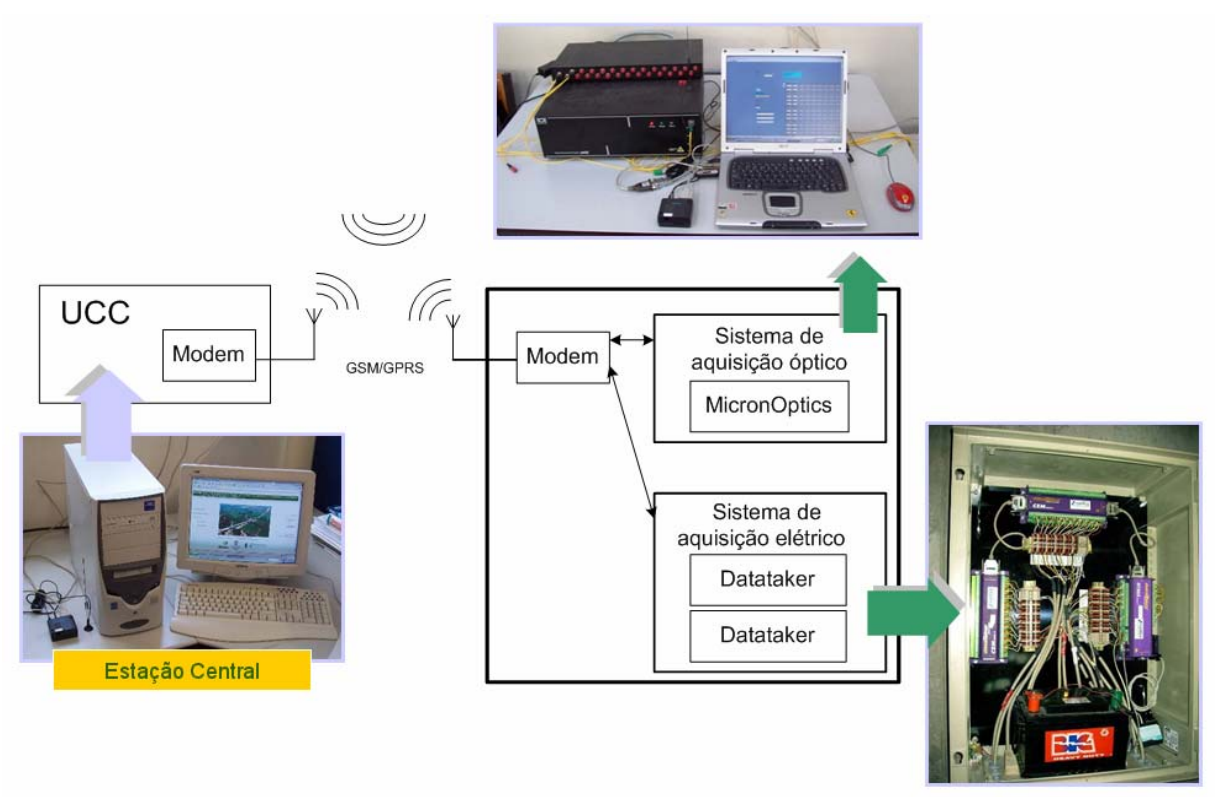

Figura 4.14 - Arquitetura do subsistema de comunicação.

No computador localizado na unidade remota há uma aplicação desenvolvida em LabVIEW capaz de recolher os dados provenientes dos sistemas de aquisição óptico (a partir do MicronOptics) e elétrico (a partir do Datataker). Os dados recolhidos são armazenados em arquivos para um posterior envio para o servidor.

No caso de o utilizador do sistema ser o administrador, ele terá a possibilidade de alterar os parâmetros de comunicação da porta serial, configurar o modem que se encontra ligado ao servidor e ainda configurar as unidades remotas de aquisição de dados, mediante a comunicação com o modem fisicamente ligado ao sistema de aquisição, utilizando o ambiente apresentado na figura 4.15.

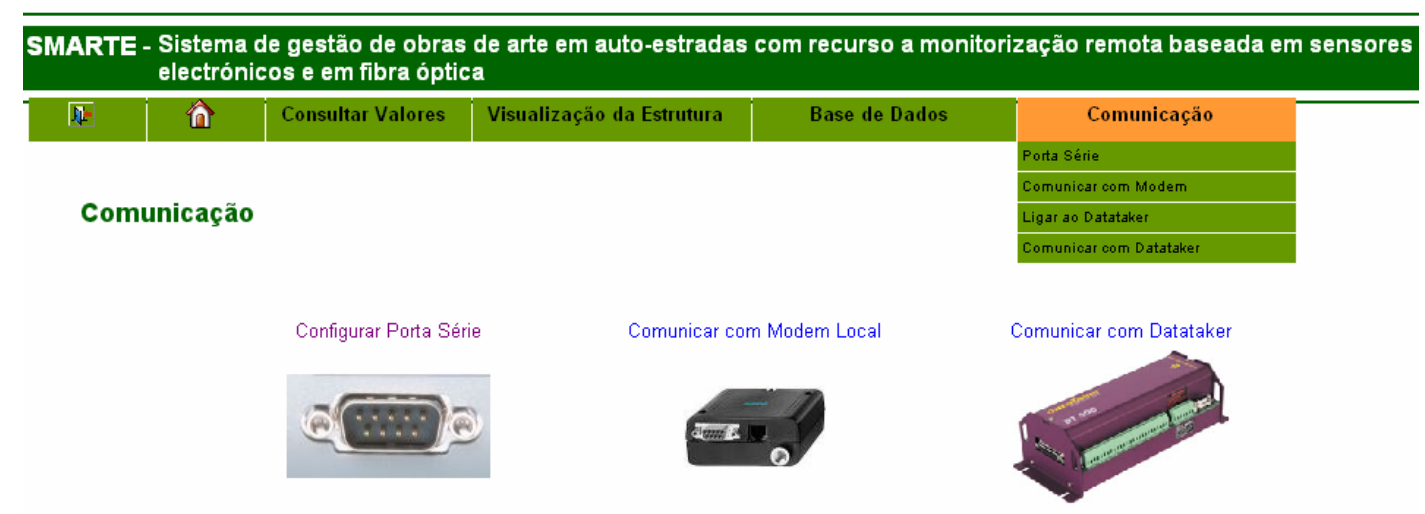

Figura 4.15 - Ambiente de configuração dos parâmetros da comunicação. 


\subsubsection{Subsistema de Processamento de Dados}

O subsistema de processamento de dados é responsável por todo o tratamento dos dados, desde o recolhimento por parte dos sensores até a sua disponibilização para exibição em uma interface Web desenvolvida. A seguir, será descrita a arquitetura do subsistema.

\subsubsection{Arquitetura do Subsistema de Processamento de Dados}

Este sistema é composto por três blocos funcionais, fisicamente separados entre si, a saber: os Utilizadores, a Unidade Local (UL) e as Unidades Remotas (UR's). A figura 4.16 apresenta os elementos constituintes do sistema.

Os pedidos efetuados por um utilizador passam por diferentes blocos até chegarem ao destino, que pode ser o sistema de aquisição localizado na UR ou as informações localizadas no servidor de bases de dados, na UL.

A UL é constituída por um servidor HTTP, pela Unidade Central de Controle (UCC) e por um servidor de bases de dados. A UL recebe, executa e responde aos pedidos recebidos do utilizador, além de transferir periodicamente os dados da UR, armazenados nos sistemas de aquisição, para a base de dados do sistema.

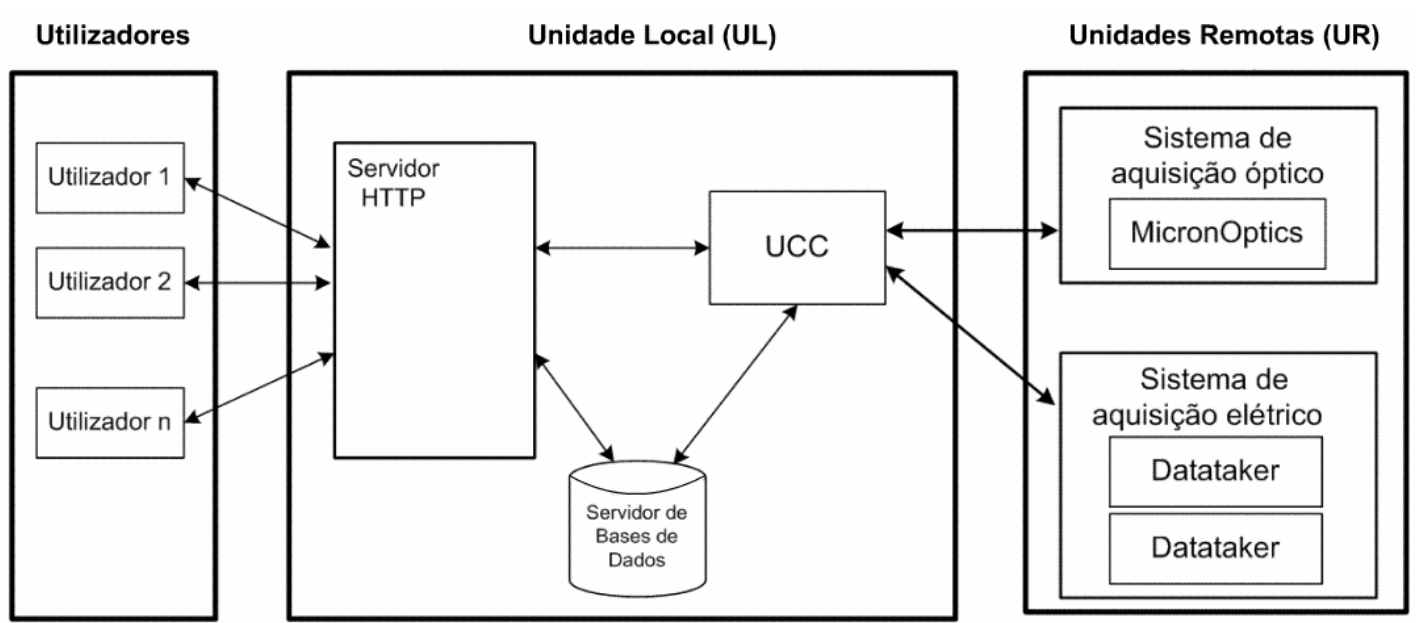

Figura 4.16 - Arquitetura do subsistema de processamento de dados. 
A UR recebe os pedidos do utilizador por meio da UL, executa-os e retorna uma resposta. Esta unidade é composta pelo sistema de aquisição de dados dos sensores elétricos e pelo sistema de aquisição de dados dos sensores ópticos, os quais fazem leituras periódicas dos respectivos sensores aos quais estão fisicamente ligados e armazenando toda a informação.

\subsubsection{Descrição do funcionamento do sistema}

O utilizador e o servidor HTTP utilizam a Internet como meio de comunicação de informações. Para a disponibilização dos serviços HTTP foi utilizado o servidor Apache, e as razões para seu emprego incluem sua excelente performance, segurança, compatibilidade com diversas plataformas e todos os seus recursos, além de seu uso poder ser feito gratuitamente, visto que é um software livre. Como servidor HTTP, o Apache permite que a máquina onde esteja instalado guarde documentos e informação para disponibilização posterior em outros computadores que façam os respectivos pedidos de acesso por meio do protocolo HTTP. A utilização da Web como meio de interligação apresenta diversas vantagens, sendo a mais relevante a vasta acessibilidade que resulta da utilização dos protocolos TCP/IP (Transfer Control Protocol / Internet Protocol) e HTTP na comunicação (figura 4.17).

Execução do lado do utilizador

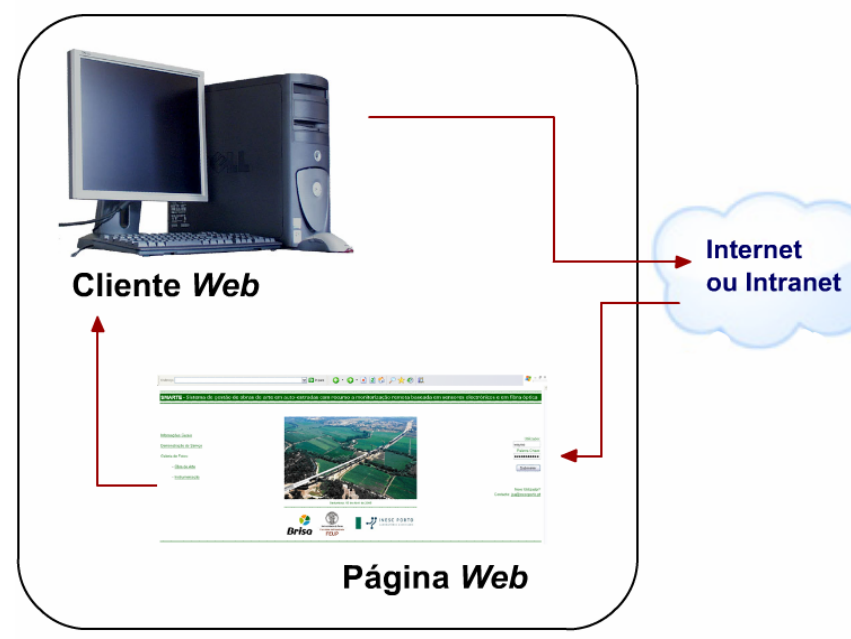

Execução do lado do servidor

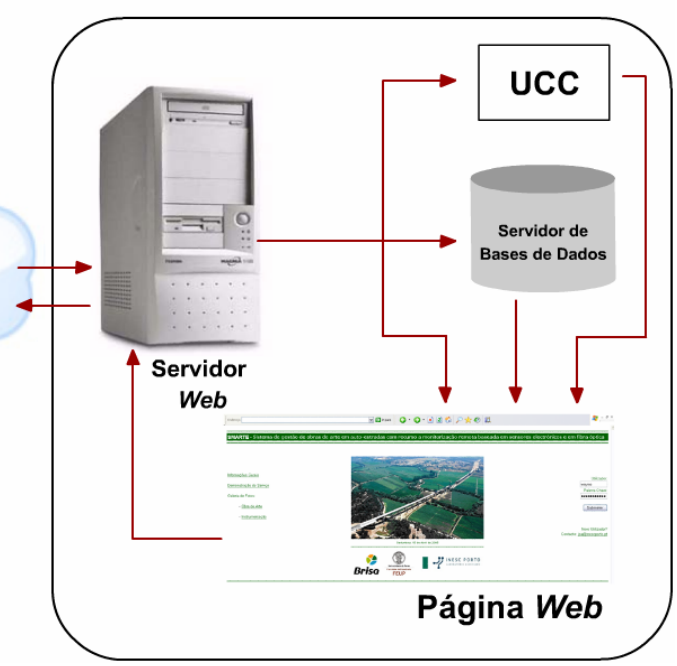

Figura 4.17 - Arquitetura utilizador/servidor. 
O servidor HTTP disponibiliza uma interface Web que executa o código PHP (Hypertext Preprocessor) embebido no código HTML (Hypertext Markup Language), reencaminha os pedidos e devolve as respostas aos respectivos utilizadores sob a forma de páginas HTML.

Os data loggers dataTaker fazem o recolhimento e o armazenamento temporário das medições efetuadas por meio dos sensores e também registram o instante em que foram feitas as medições, enquanto que o sistema MicronOptics apenas faz a recolha de dados, e o armazenamento é feito pela CPU (Central Processing Unit) localizada na UR. Quando é estabelecida a comunicação entre a UL e a UR, é permitido efetuar leituras de valores em tempo real, que ainda não se encontram na base de dados do servidor.

O recolhimento dos dados é um processo periódico executado pelo servidor. $\mathrm{O}$ armazenamento é realizado para que os dados colecionados maximizem o conhecimento acerca do comportamento da estrutura monitorada. Os dados armazenados na memória são guardados juntamente com a identificação do sensor (ou canal) do qual foi feita a leitura. Outra informação importante que também é coletada é a hora e a data da amostragem. O recolhimento de dados pode ser efetuado de modo periódico ou esporádico.

O recolhimento no modo periódico é efetuado quando existe um pedido do servidor com o objetivo de recolher todos os dados. Este processo ocorre periodicamente, sem intervenção humana, sendo esse período definido pelo administrador. Quando é realizada a recolha os dados, estes são guardados na base de dados da UL e é feita uma cópia de segurança na UR.

A comunicação entre a UL e a UR é efetuada recorrendo ao protocolo GSM, sendo iniciada por meio de uma chamada do modem localizado no servidor para o modem localizado na unidade remota pretendida. Para esta comunicação ser efetuada é necessária a configuração da interface serial e do modem.

\subsubsection{Sistema de consulta à base de dados (SCBD)}

O sistema de consulta assenta sobre uma base de dados construída de forma a maximizar a disponibilidade das informações relativamente à ponte sobre 0 
rio Sorraia, além de permitir a gestão eficiente dos resultados provenientes da rede sensora. $\mathrm{Na}$ base de dados são guardadas informações referentes a todo 0 equipamento instalado, utilizadores do serviço e os valores obtidos a partir das medições efetuadas. Para o desenvolvimento da base de dados, foi utilizado o MySQL, que é um sistema de gestão de bases de dados relacionais com mecanismo transacional e acesso do tipo ODBC (Object Data Base Connection), que aceita pedidos em Structured Query Language (SQL). Estas características tornam o sistema adequado a alterações frequentes. Na figura 4.18 são apresentadas as tabelas, campos e relações que compõem a estrutura da base de dados.

A tabela de utilizadores armazena a informação de todos os usuários do sistema. Esses dados são fornecidos pelo utilizador antes que possa acessar o ambiente virtual, sendo que o administrador do sistema é responsável pela habilitação do usuário, fornecendo-Ihe uma senha inicial e um nível de permissão de acesso. A permissão identifica se o utilizador possui perfil comum ou administrativo, o que por sua vez possui relação com as prerrogativas relacionadas com a alteração de parâmetros de aquisição, coleta de dados, acesso às informações armazenadas e habilitação de novos usuários. As tabelas Equipamento de Leitura, Cabeças Sensoras e Sensores agregam a informação referente a todo o material e equipamentos existentes, instalados ou não, pertinentes ao sistema de monitoração. Este material está associado à tabela Fornecedores, que contém a informação dos respectivos fornecedores ou fabricantes.

Quando um equipamento de leitura é instalado, são preenchidos todos os campos da tabela Instalação do Equipamento de Leitura, bem como os campos da tabela Cabeças Sensoras ligadas a esse equipamento. Também é inserida a informação relativa aos campos da tabela Sensores, ligados às Cabeças Sensoras.

Quando é feita a recolha dos dados, todos as informações recebidas do equipamento de leitura são guardadas na tabela de Valores, juntamente com a restante informação dos sensores para futuras consultas por parte de todos os utilizadores. O campo Permissão permite identificar quais os valores a que o utilizador comum tem acesso. 


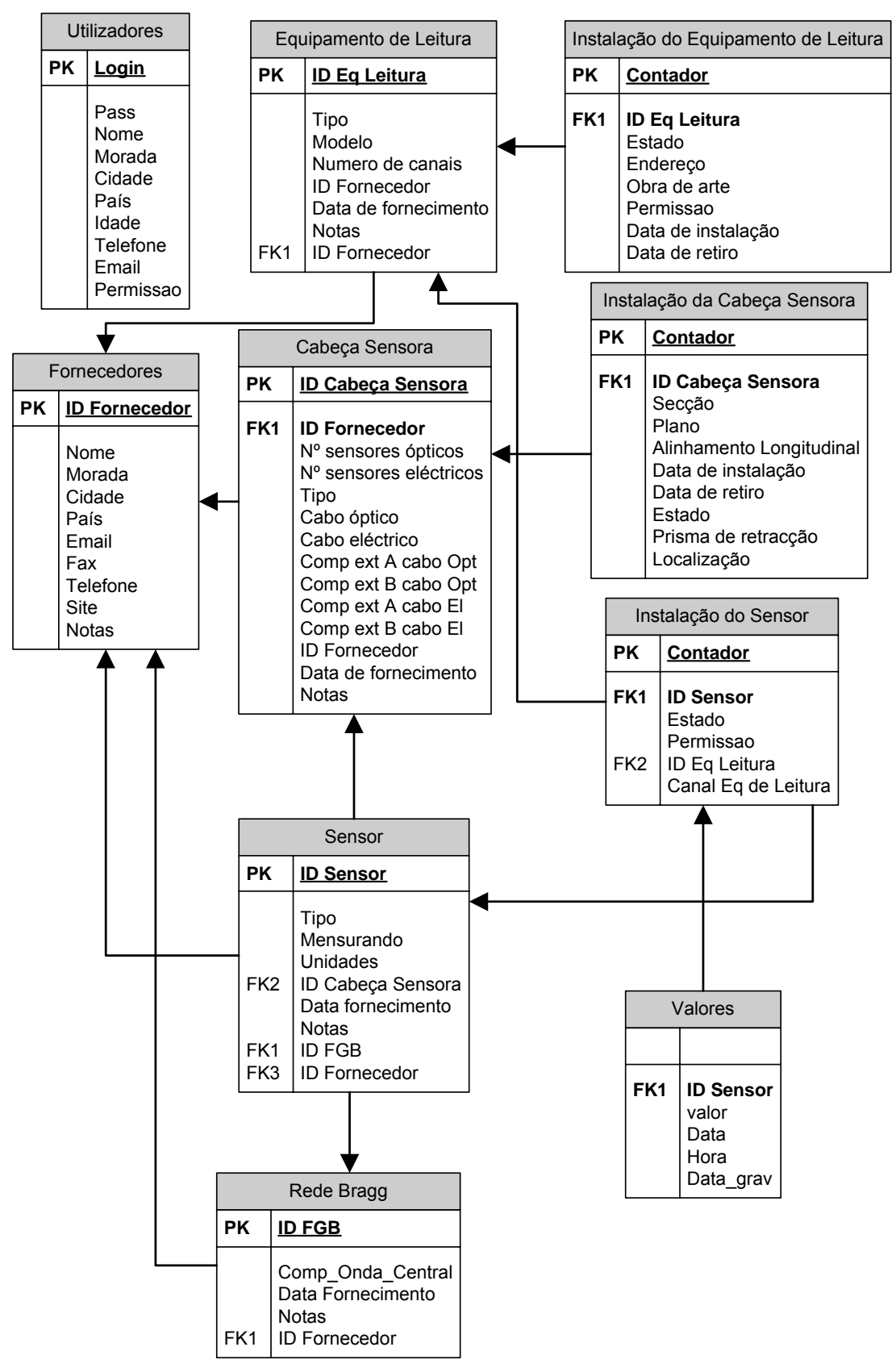

Figura 4.18 - Estrutura da base de dados.

Foram desenvolvidos dois filtros aplicáveis aos dados armazenados: um filtro de média e um filtro de média com variações, utilizando PHP. É importante ter conhecimento acerca do funcionamento destes filtros, uma vez que as informações que servirão de base para a geração dos dados apresentados no módulo de visualização do site são provenientes do SCBD, e estes poderão estar filtrados, de acordo com o interesse do utilizador.

O filtro de média deve permitir obter um novo conjunto de pontos, cujas ordenadas obedecem à equação 4.1 . 


$$
\begin{gathered}
y_{i}=\operatorname{Média}\left(J_{i}\right) \text { para } i=0,1,2, \ldots, \mathrm{n}-1, \\
J_{i}=\left\{x_{i-r}, x_{i-r+1} \ldots, x_{i-1}, x_{i}, x_{i+1} \ldots, x_{i+r-1}, x_{i+r}\right\}
\end{gathered}
$$

$\mathrm{Na}$ equação 4.1, $n$ corresponde ao número de pontos que constituem o gráfico original, de modo que o gráfico de saída apresenta número de pontos igual ao do gráfico de entrada, e yi representa o valor de cada uma das novas ordenadas, proveniente da média aritmética dos valores que pertencem a $J_{i}$. $O$ número de elementos de $J_{i}$ depende do valor atribuído a $r$, a janela do filtro, de modo que em $J_{i}$ sempre haverá $(2 r+1)$ elementos. Cada um dos constituintes de $J_{i}$ corresponde ao valor de uma ordenada, de maneira que $x_{i}$ representa a ordenada original do i-ésimo ponto do gráfico. O filtro fornecerá resultados válidos desde que $n>r \geq 0$. Caso esta condição não seja satisfeita, $y_{i}=0$ para $i=[0, n-1]$.

O filtro de média com variações possibilita o fornecimento de um conjunto de pontos com ordenadas de valor correspondente à média aritmética das leituras de sensores selecionados, permitindo ainda, para os valores considerados quando da geração desta média, construir um outro conjunto de pontos cujas ordenadas valem, para cada ponto, a diferença entre o valor original e a média. Desta forma:

$$
y_{i}=\frac{\sum_{i=0}^{n-1} X_{i}}{n} \text { para } i=0,1,2, \ldots, n-1
$$

Onde a variável $y_{i}$ representa o valor de cada uma das novas ordenadas, $\mathrm{n}$ corresponde ao número de pontos que constituem o gráfico original e $x_{i}$ representa a i-ésima ordenada original, de modo que o gráfico de saída apresenta número de pontos igual ao do gráfico de entrada. O gráfico que regerá as variações, com pontos de ordenadas $v_{i}$, obedecerá à equação 4.3 , a saber:

$$
v_{i}=x_{i}-\frac{\sum_{i=0}^{n-1} X_{i}}{n} \text { para } i=0,1,2, \ldots, n-1
$$

Nos dois filtros, as abscissas associadas às ordenadas originais não sofrem alterações. Assim, as abscissas dos pontos de ordenadas $y_{i}$ e $v_{i}$ são as mesmas dos pontos de ordenada $x_{i}$, para $i=[0, n-1]$. 


\subsubsection{Interface Web}

O servidor HTTP disponibiliza uma interface Web aos utilizadores, onde estes podem efetuar pedidos, por meio de formulários destinados à interação, nos quais são identificados os serviços de que pretende usufruir. A interface Web é constituída por páginas PHP que permitem a ligação à base de dados do lado do servidor, fornecendo ainda uma camada para a comunicação com o sistema de aquisição (MATOS et al., 2005; ATKINSON, 1999).

O utilizador pode acessar o URL (Universal Resource Locator) ou endereço do servidor na Internet, podendo obter, ainda que não esteja registrado, informações gerais relativas ao projeto de pesquisa e a uma galeria de fotos da ponte e da instrumentação do sistema de monitoração.

Para o utilizador ter acesso a outros serviços é necessário estar registrado. Este registro apenas é efetuado pelo administrador do sistema após um pedido por e-mail por parte do utilizador. Conforme foi anteriormente mencionado, o sistema admite dois perfis de utilizadores, os quais são diferenciados por meio do nome do usuário e da senha inseridos na página de entrada. O utilizador comum pode consultar os valores obtidos na monitoração que estão armazenados na base de dados, além dos valores de medições realizadas em tempo real. Outra funcionalidade aberta ao utilizador comum é a visualização de gráficos temporais gerados a partir das medições. O administrador, além das funções disponíveis ao utilizador comum, tem a possibilidade de configurar os parâmetros de aquisição das unidades remotas, configurar os parâmetros de comunicação e administrar todas as tabelas da base de dados. Na figura 4.19 é apresentada a página de entrada do site para acesso ao sistema. 


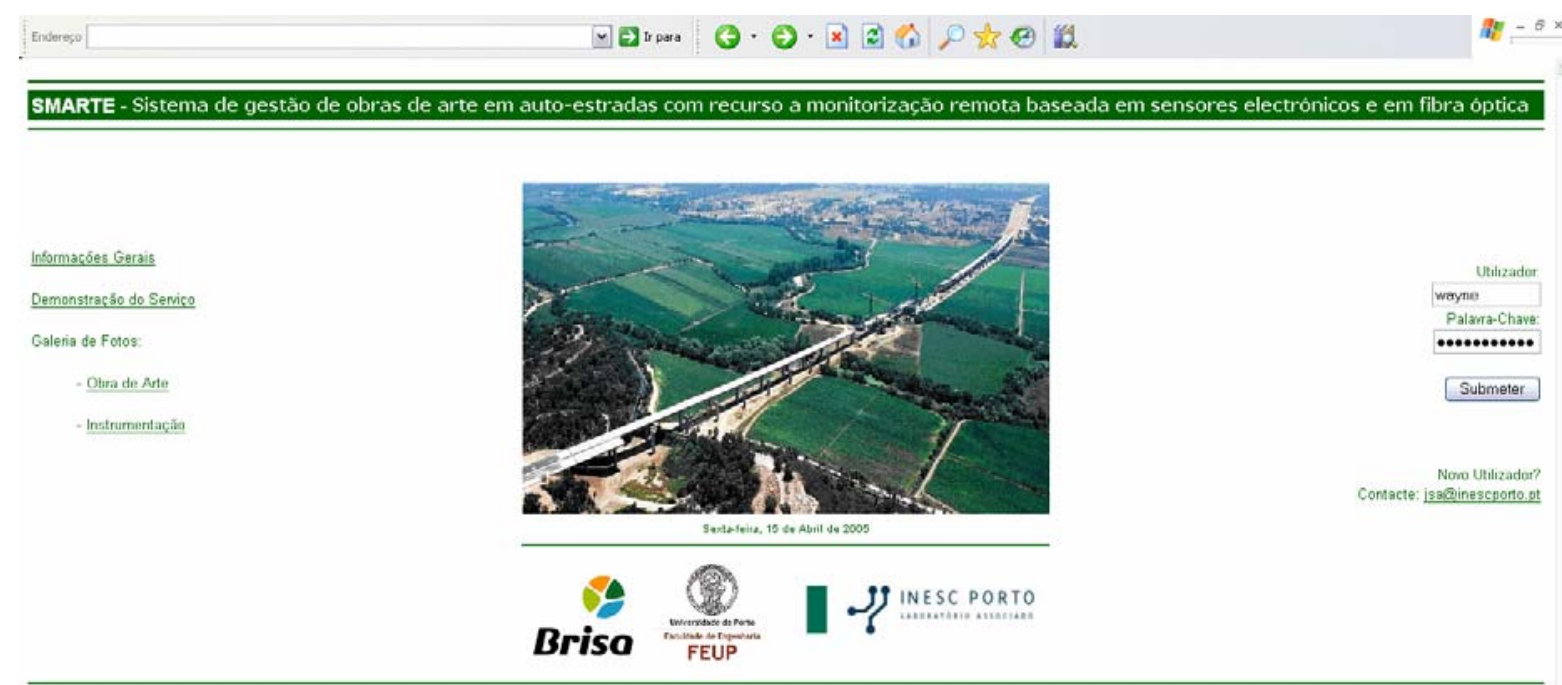

Figura 4.19 - Página de entrada do site.

Seja para utilizadores comuns ou administradores, o sistema permite a visualização dos resultados das medições a partir da consulta dos valores armazenados na base de dados ou a partir dos valores obtidos em tempo real. A consulta a partir da base de dados pode ser feita considerando-se a fase construtiva, o período da realização da prova de carga da ponte, a fase de serviço ou um intervalo de tempo qualquer, definido pelo usuário. Após a seleção do período pretendido, deve ser informado se a consulta será feita por seção, por alinhamento ou por sensor.

Na consulta por seção, é permitida a seleção múltipla envolvendo as sete seções instrumentadas (figura 4.20a), possibilitando a visualização dos resultados a partir dos alinhamentos de cada seção (figura 4.20b) ou a partir da seleção dos sensores instalados. Na figura 4.20c são apresentados os gráficos correspondentes às deformações das seções S1 e S4, em alinhamentos selecionados, durante a fase da prova de carga na qual os caminhões realizaram as posições estáticas. 


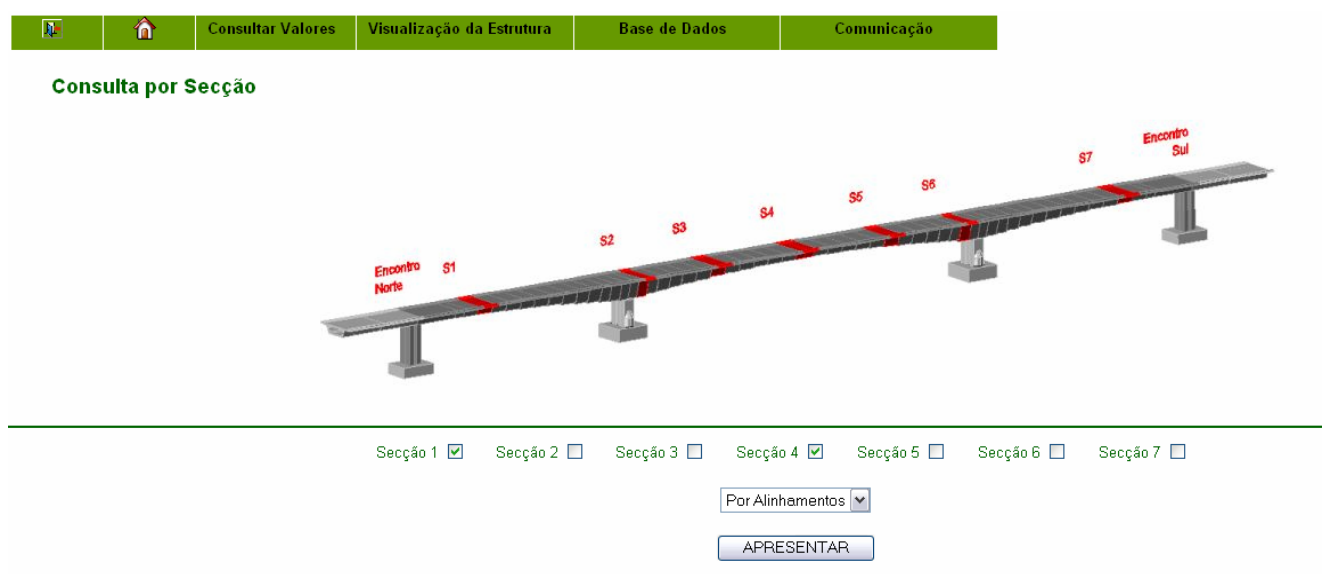

(a)

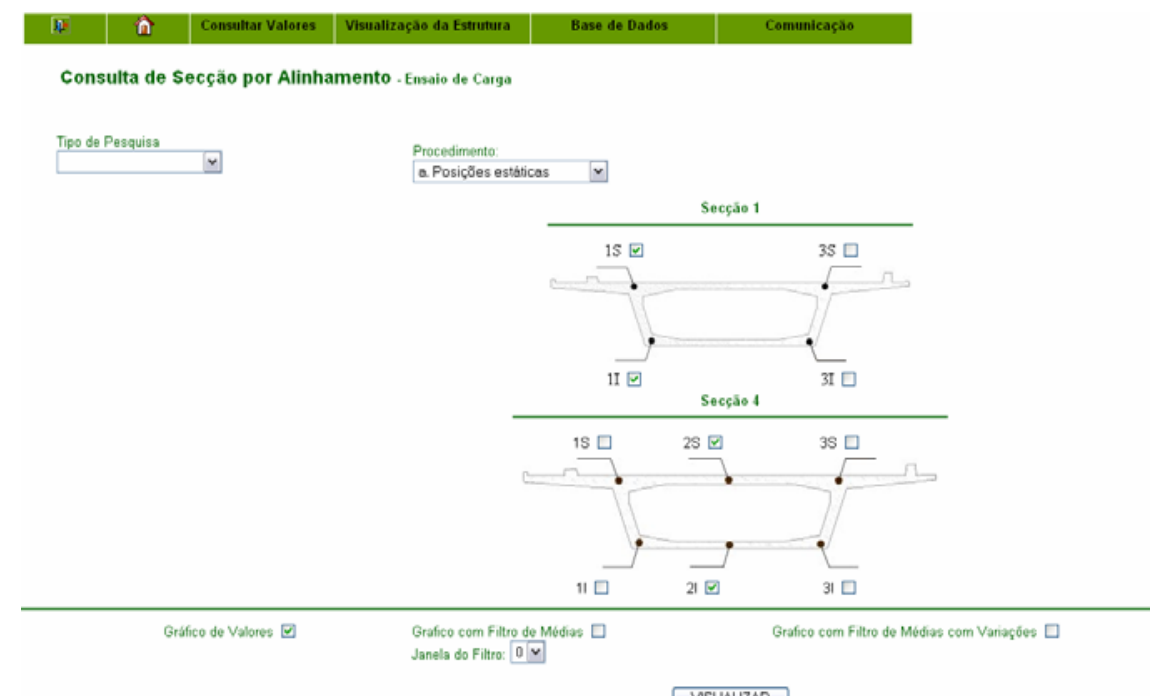

(b)

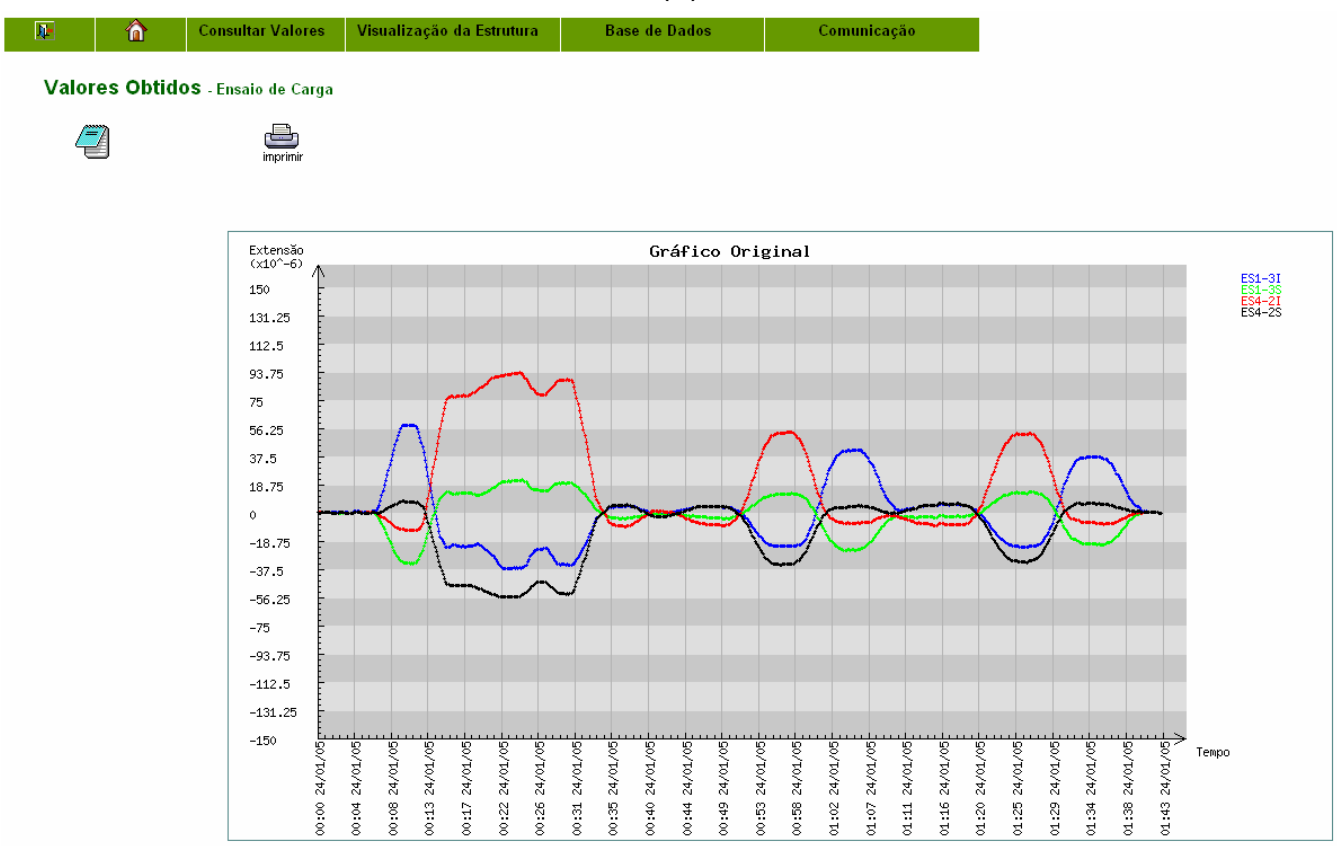

(c)

Figura 4.20 - Ambiente de consulta dos resultados a partir das seções instrumentadas (a), com sub-área para consulta por alinhamento, durante a prova de carga (b) e gráficos com resultados correspondentes às seleções realizadas (c). 
$\mathrm{Na}$ consulta por alinhamento o utilizador pode selecionar qualquer combinação entre os seis alinhamentos em que foram distribuídos os sensores em cada seção, e ter acesso às informações de todos os sensores instalados nos alinhamentos selecionados, ao longo de todas as sete seções da ponte (figura 4.21a). Os gráficos com as deformações das seções no alinhamento 2 , durante a fase da prova de carga na qual os caminhões realizaram as passagens lentas, são apresentados na figura $4.21 \mathrm{~b}$.

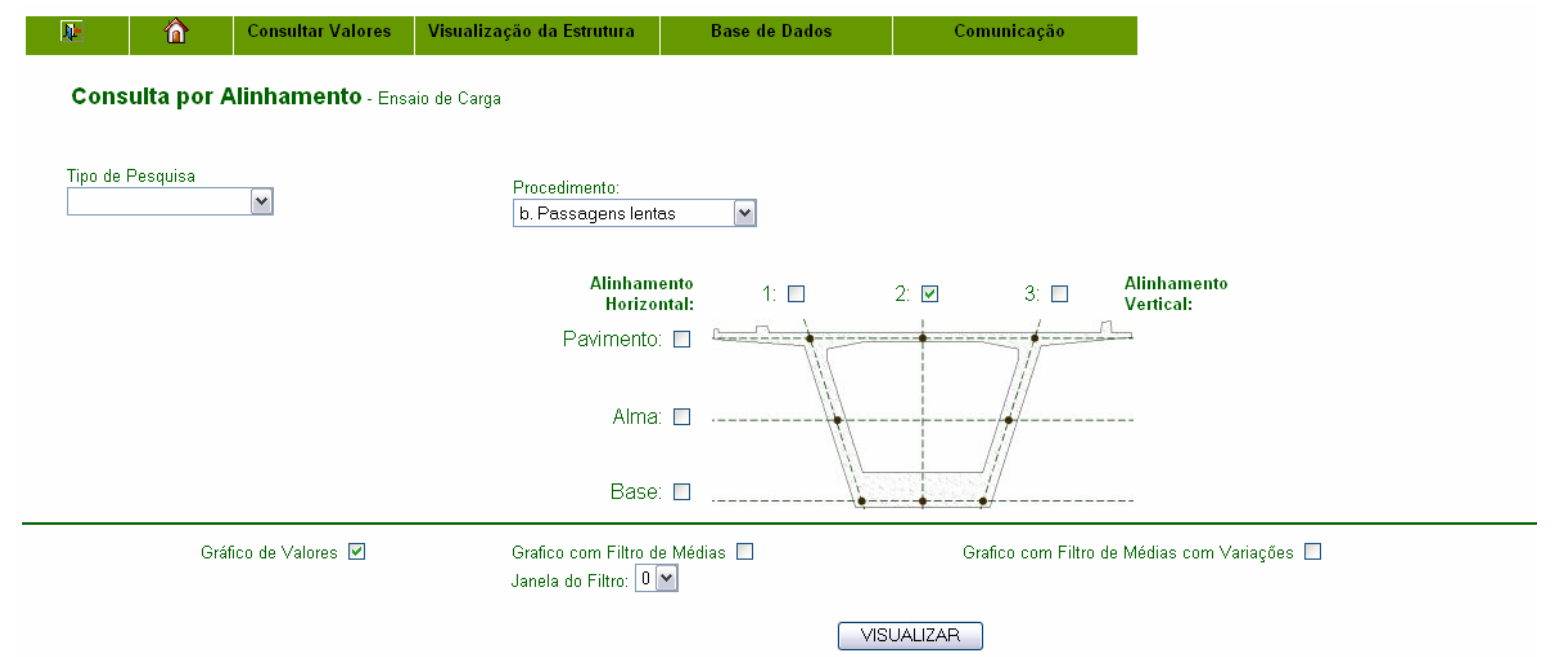

(a)

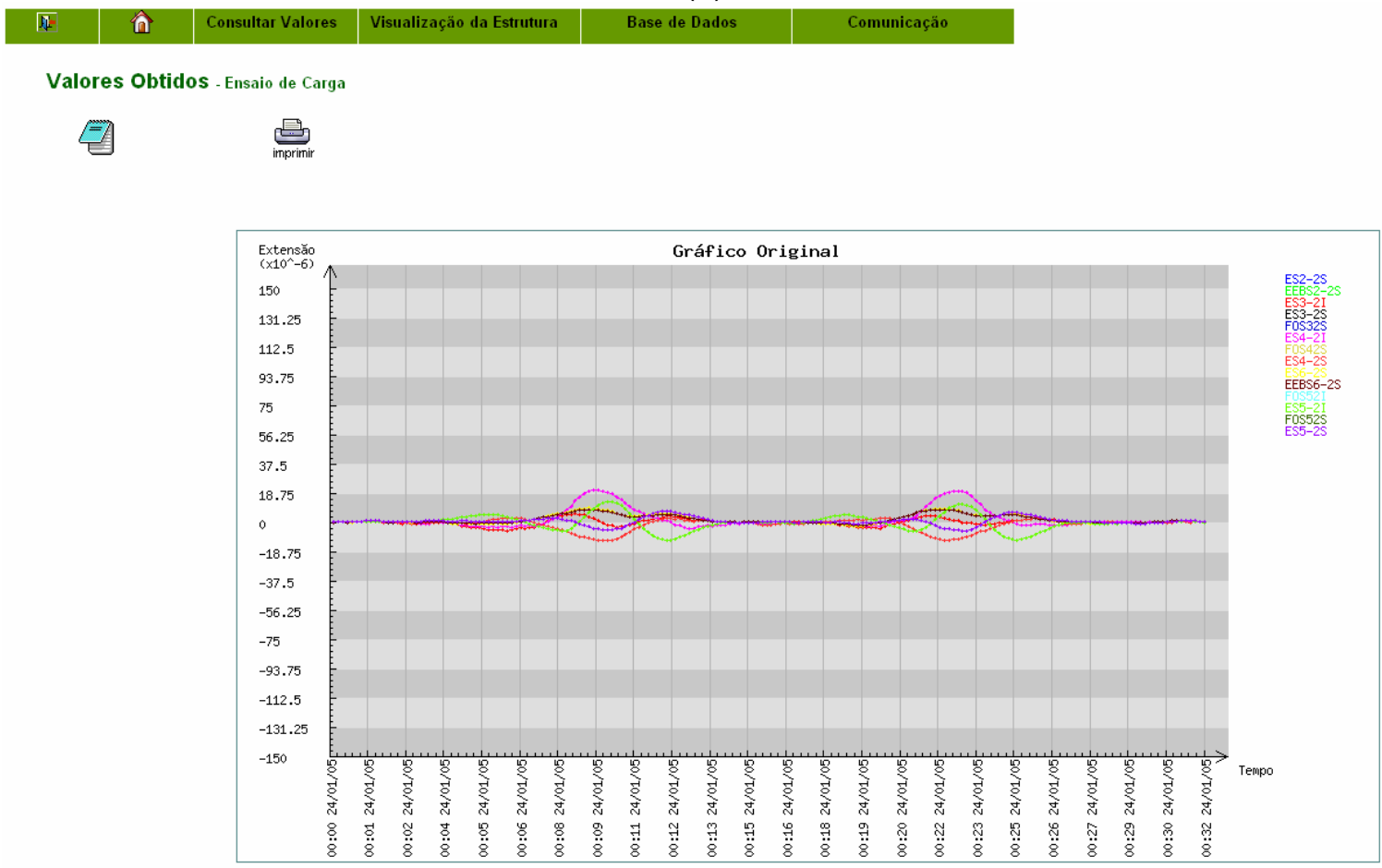

(b)

Figura 4.21 - Ambiente de consulta dos resultados a partir dos alinhamentos (a), e curvas com resultados correspondentes às seleções realizadas (b). 
Na consulta por sensor é dado acesso a uma lista dos sensores instalados, distribuídos de acordo com o tipo de grandeza medida (deformação, temperatura ou umidade), permitindo ver os resultados de um sensor, escolhido pelo utilizador (figura 4.22).

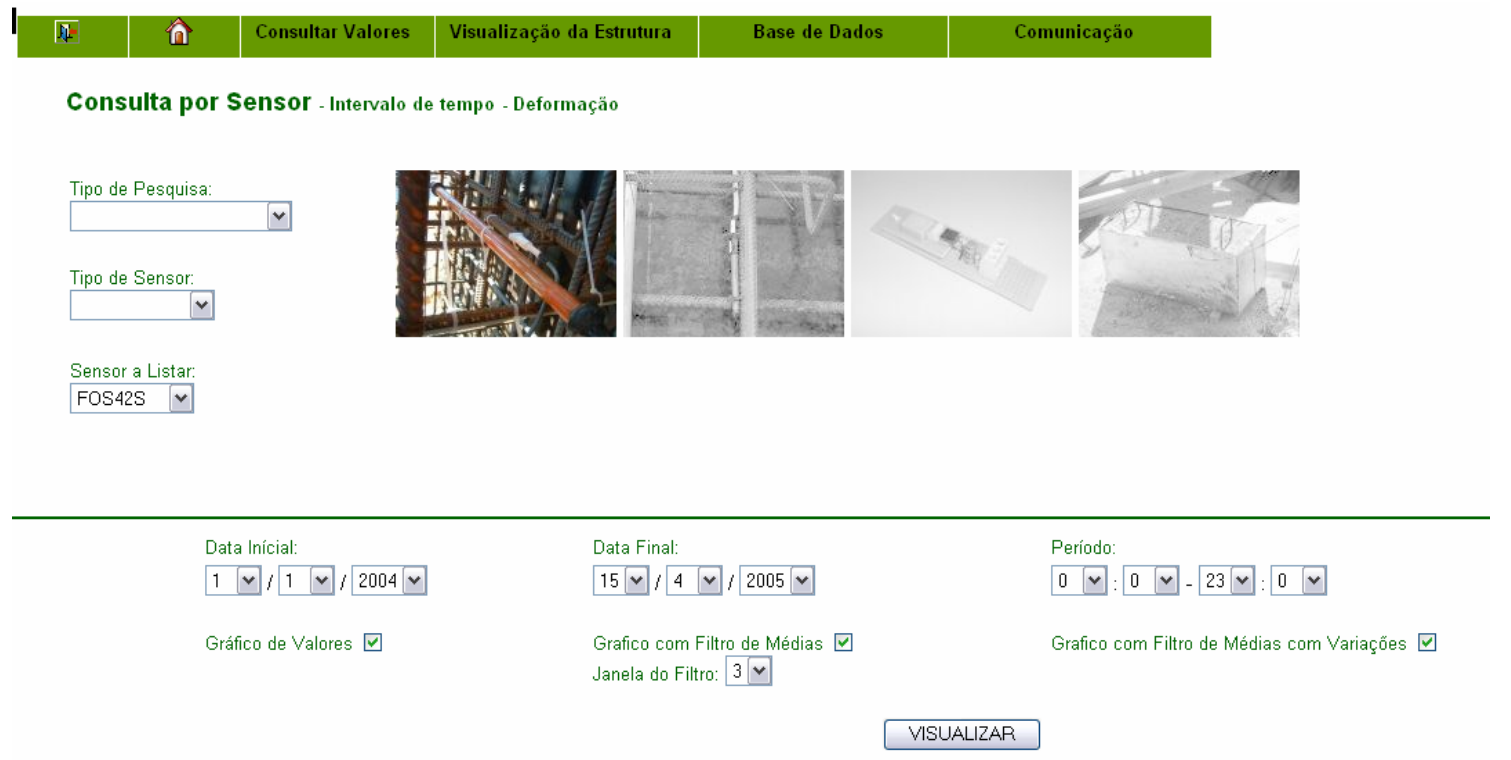

Figura 4.22 - Ambiente de consulta dos resultados a partir de um sensor, na opção intervalo de tempo.

A consulta em tempo real permite, a partir de comunicação remota, a obtenção dos valores mais recentes armazenados no equipamento de leitura, os quais são adicionados à base de dados e permitem a visualização atualizada do comportamento da estrutura. Assim como a função de consulta aos valores do banco de dados e a visualização das respostas estruturais, a consulta em tempo real pode ser feita por todos os usuários do sistema.

O item de menu Base de Dados, presente nas figuras 4.20 a 4.22, dá acesso a uma área administrativa com informações associadas aos equipamentos e sensores instalados, aos fornecedores dos equipamentos e aos utilizadores do sistema. A opção Comunicação também só está disponível para usuários com privilégios administrativos, e contém os ambientes para comunicação remota com os equipamentos instalados na obra.

$\mathrm{Na}$ figura 4.23 é apresentado o ambiente para comunicação com os equipamentos dataTaker instalados. A partir do site, é possível obter informações a respeito do status de cada data logger, enviar programas com novos procedimentos 
para a aquisição dos dados e controlar os parâmetros que regem o seu funcionamento.

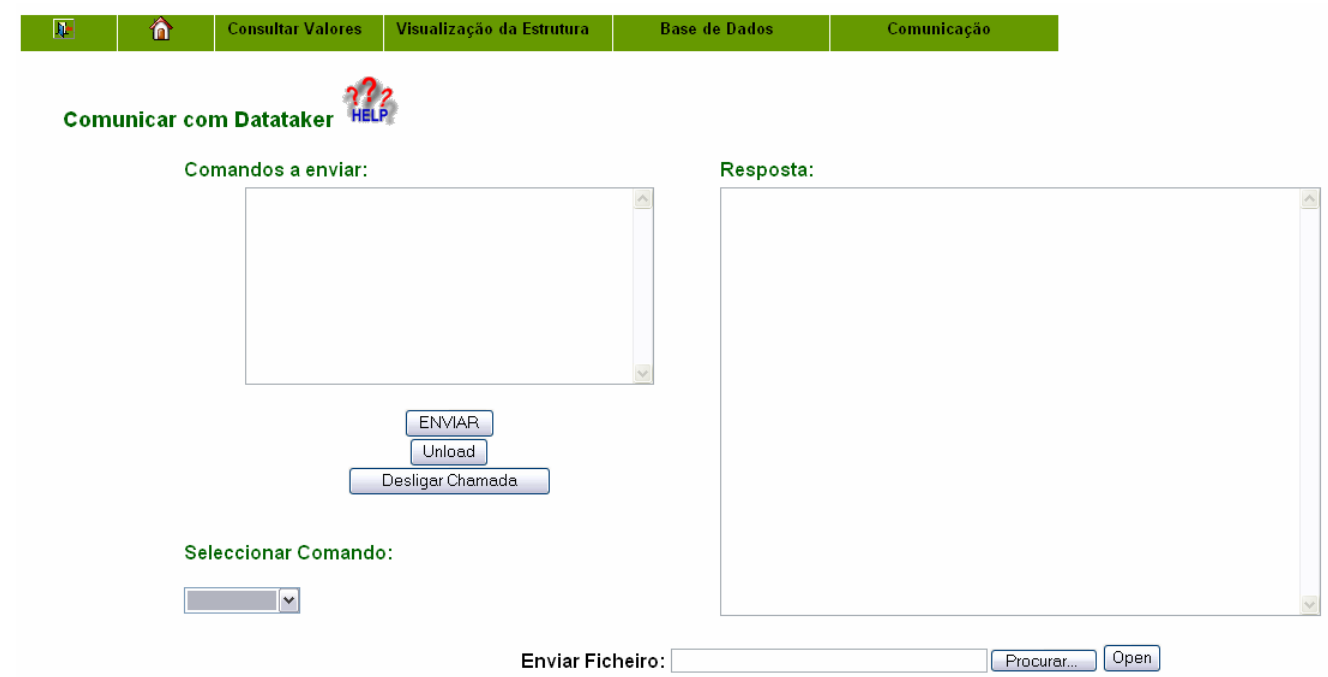

Figura 4.23 - Ambiente para comunicação com os dataTaker DT500 instalados na obra.

\subsubsection{Avaliação do sistema de monitoração}

A avaliação do sistema de monitoração da ponte sobre o rio Sorraia depende do desempenho de cada um dos seus componentes. Assim, nos próximos parágrafos serão feitas algumas considerações sobre os subsistemas tratados na seção 4.3, apresentando os principais aspectos positivos e negativos observados.

Sobre o subsistema sensorial, é possível afirmar que a instalação dos sensores e equipamentos foi realizada de forma adequada, em locais apropriados. Estes fatos refletem na qualidade dos resultados que vêm sendo obtidos, que têm permitido acompanhar o comportamento da estrutura confiavelmente. Os sensores ópticos instalados não puderam ser explorados em sua plenitude, em decorrência da ausência de energia elétrica na ponte até o segundo semestre de 2006 . Esta modalidade de energia é requerida para alimentação do sistema de aquisição óptico.

No âmbito da comunicação entre o servidor e as unidades remotas, podem ser utilizados modem GSM/GPRS, sendo que o protocolo atualmente em uso é o GSM. No protocolo GSM apenas é possível uma ligação em simultâneo, sendo a 
ligação apenas estabelecida no momento que existe uma troca de dados entre os dois pontos, de forma que não existe uma ligação permanente nem múltiplas ligações simultâneas, como acontece no protocolo GPRS. Como o sistema desenvolvido consiste no servidor e em uma unidade remota que congrega a informação dos sistemas óptico e elétrico, não há a necessidade de existirem ligações simultâneas.

A utilização do protocolo GSM tem algumas vantagens, dentre as quais pode-se destacar a largura da banda fixa, a capacidade garantida (sem nenhum congestionamento) e a pequena variação do atraso (o atraso é quase constante). Existem também algumas desvantagens na utilização deste protocolo, entre as quais o fato de não ser possível partilhar o circuito com outros utilizadores, visto que quando circuito está ocupado ou no máximo da capacidade, as novas ligações são bloqueadas. Um incoveniente do protocolo é a necessidade de ajustar a emissão e recepção de dados a uma mesma taxa, requerendo tempo para a realização de configurações sob pena de não se estabelecer a comunicação.

A avaliação do subsistema de comunicação adotado tem sido positiva, tendo em vista a eficiência da troca de informações entre o servidor e o sistema de aquisição. Entretanto, no caso de serem detectadas falhas ou a necessidade da introdução de novos sistemas de aquisição, a migração para o protocolo GPRS é uma possibilidade que deve ser admitida.

Sobre o subsistema de processamento de dados, que contém uma base de dados que congrega toda a informação proveniente da monitoração, além da informação de toda a instrumentação instalada, é possível afirmar que a escolha das ferramentas para a sua construção e o sistema de gestão dos dados são adequados aos interesses da monitoração estrutural, um vez que apresenta escalabilidade e flexibilidade capaz de ajustar-se a eventuais modificações da configuração da rede sensora e dos equipamentos utilizados, permitindo inclusive que o código seja reaproveitado para a gestão e processamento de informações de outras monitorações. Em relação à interface Web desenvolvida, sua utilização demonstrou que se trata de uma eficiente e útil ferramenta de apoio à visualização, gestão e controle da monitoração, viabilizando a disponibilização da informação de modo confiável, organizado e amigável, além de conferir segurança ao controle da aquisição por meio do uso de um ambiente de acesso autenticado. 
Levando em conta as considerações apresentadas, é possível afirmar que o sistema de monitoração da ponte sobre o rio Sorraia foi bem-sucedido, funcionando satisfatoriamente e proporcionando resultados confiáveis e de boa qualidade.

\subsection{Aplicação do sistema de visualização e tratamento de dados}

Neste item, será apresentado um caso de aplicação do sistema computacional de visualização e tratamento de dados, descrito no capítulo anterior, às informações provenientes do sistema de monitoração instalado na ponte sobre o rio Sorraia.

No estudo realizado, as deformações obtidas em uma das seções continuamente monitoradas serão compensadas em relação aos efeitos da temperatura, da fluência e da retração, mediante o emprego das metodologias consideradas no Capítulo 3.

Para este exemplo de aplicação, serão utilizadas as medições de deformações e temperaturas realizadas na seção S5.

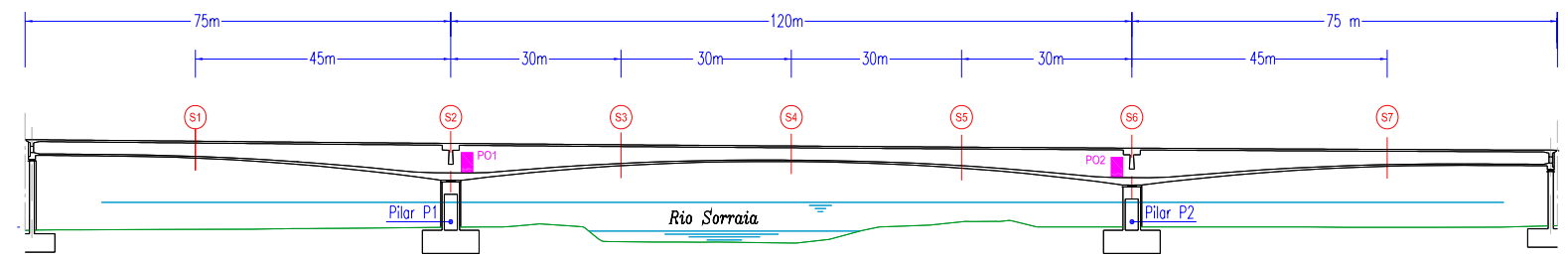

Figura 4.24 - Seções instrumentadas da ponte.

A seção S5 conta com três sensores para a medição de temperaturas, estando um deles no interior da camada de asfalto e os demais no interior do concreto, sendo um na laje superior (TS5-2S) e o outro na laje inferior (TS5-2I). Foram instalados duas cabeças sensoras para a medição de deformações, as quais encontram-se embutidas no concreto, sendo uma na laje superior e a outra na laje inferior. A informação oriunda desses sensores é adquirida pelo sistema de aquisição posicionado no posto de observação PO2. As deformações utilizadas nesse estudo são provenientes dos extensômteros de resistência elétrica embutidos 
ES5-2S e ES5-2I, enquanto as temperaturas lidas são provenientes dos sensores TS5-2S e TS5-2I. Na figura 4.25 são apresentadas as dimensões da seção S5 e os principais sensores instalados.

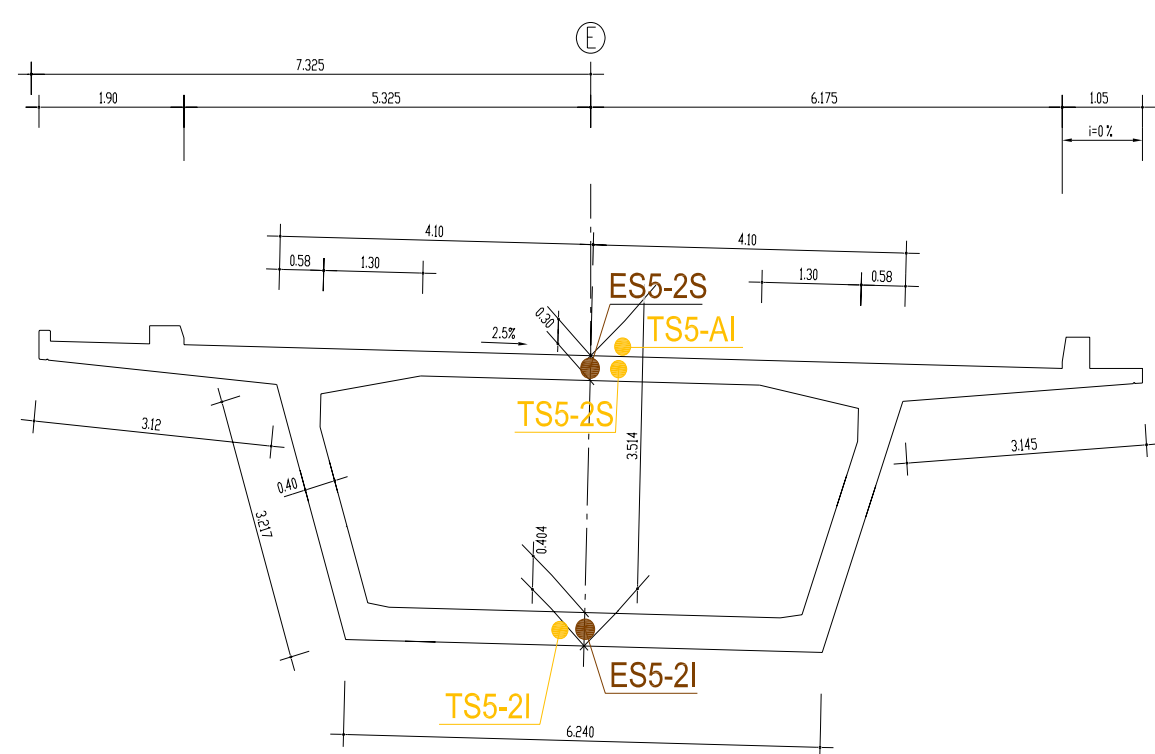

Figura 4.25 - Seção S5.

\subsubsection{Descrição do problema}

O problema que se pretende resolver consiste em remover de resultados de deformações provenientes da monitoração da seção S5, as parcelas de deformação ocasionadas pelos efeitos térmicos e pelos efeitos diferidos estimados, proporcionando como resposta sinais tratados isentos de tais parcelas.

Especificamente, as deformações lidas pelo sensor ES5-2S serão termicamente compensadas utilizando-se os valores das temperaturas dos sensores TS5-2S e TS5-2I, enquanto a fluência e a retração serão estimadas mediante a consideração das características obtidas em laboratório ou a partir das premissas do projeto. 


\subsubsection{Aplicação à seção S5}

As leituras de deformações utilizadas foram aquisitadas desde as $12 \mathrm{~h} 00 \mathrm{~min} 00 \mathrm{~s}$ do dia 06 de maio até as 03h00min00s do dia 25 de maio, em 2005 , com intervalo de 3 horas entre as medições.

A figura 4.26 apresenta o sistema solicitando o arquivo a ser lido, enquanto na figura 4.27 são ilustrados os dados do arquivo selecionado.

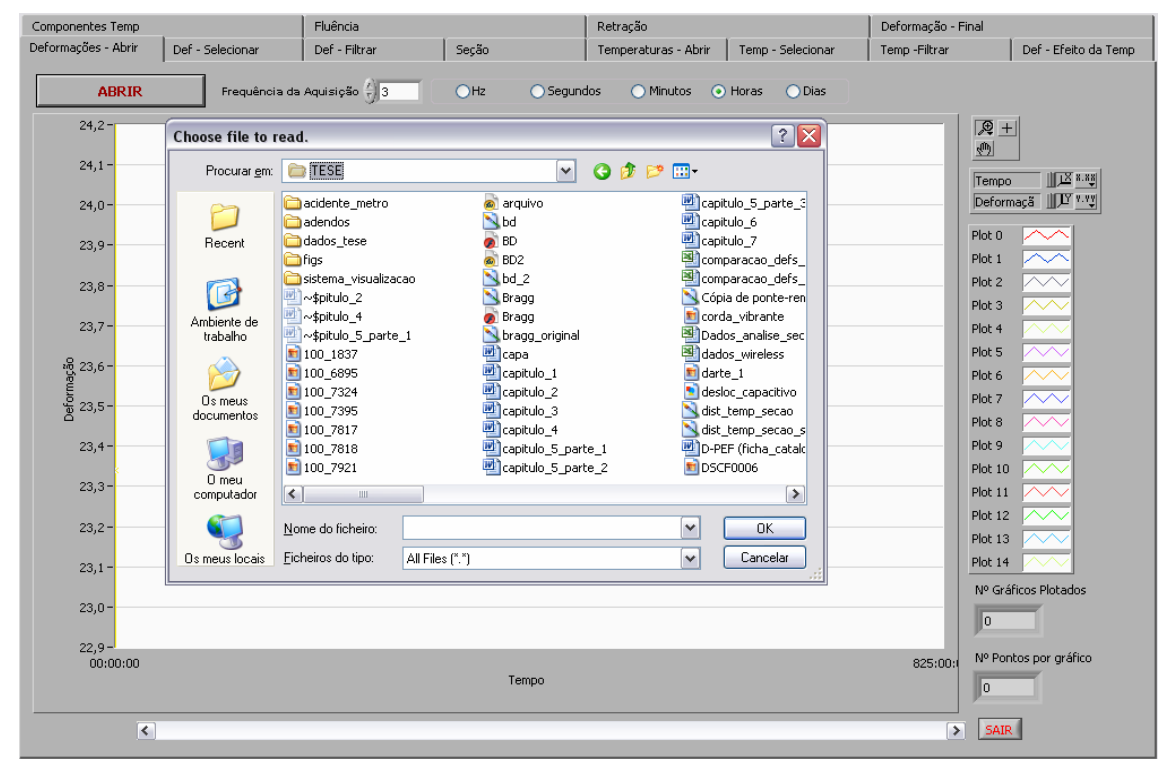

Figura 4.26 - Janela de seleção de arquivo a ser lido.

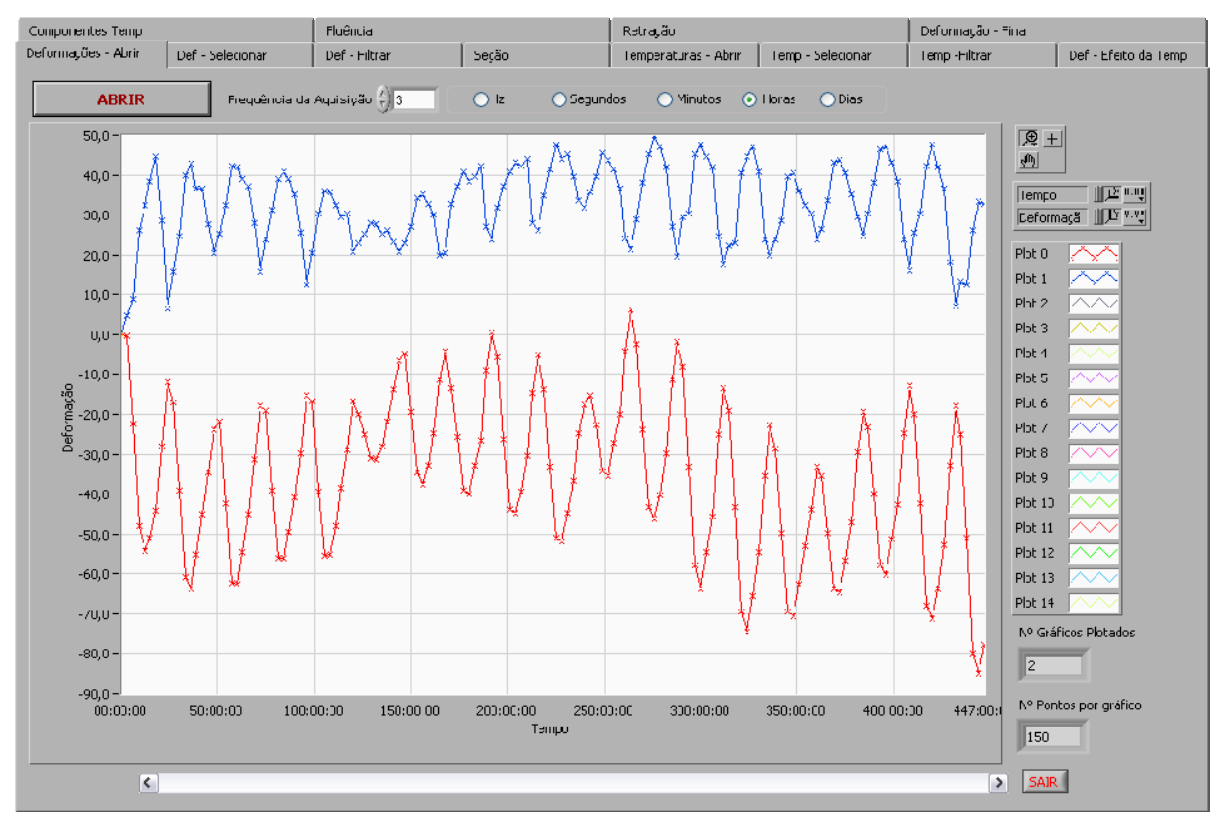

Figura 4.27 - Visualização das deformações. 
$\mathrm{Na}$ figura 4.27, o gráfico vermelho corresponde às deformações medidas pelo sensor ES5-2S, enquanto no gráfico azul encontram-se os valores medidos pelo sensor ES5-2I. Dos valores, percebe-se que a seção inferior encontra-se tracionada, enquanto a seção superior experimenta variações de deformações opostas às de seção inferior. Observa-se que os ciclos das medidas são periódicos, com duração de 8 amostras (24 horas), em média.

$\mathrm{Na}$ aba Def-Selecionar, podemos selecionar alguns dos gráficos apresentados na aba Deformações-Abrir. Para ilustrar, será selecionado o gráfico ES5-2S, apresentado na nova aba, na figura 4.28.

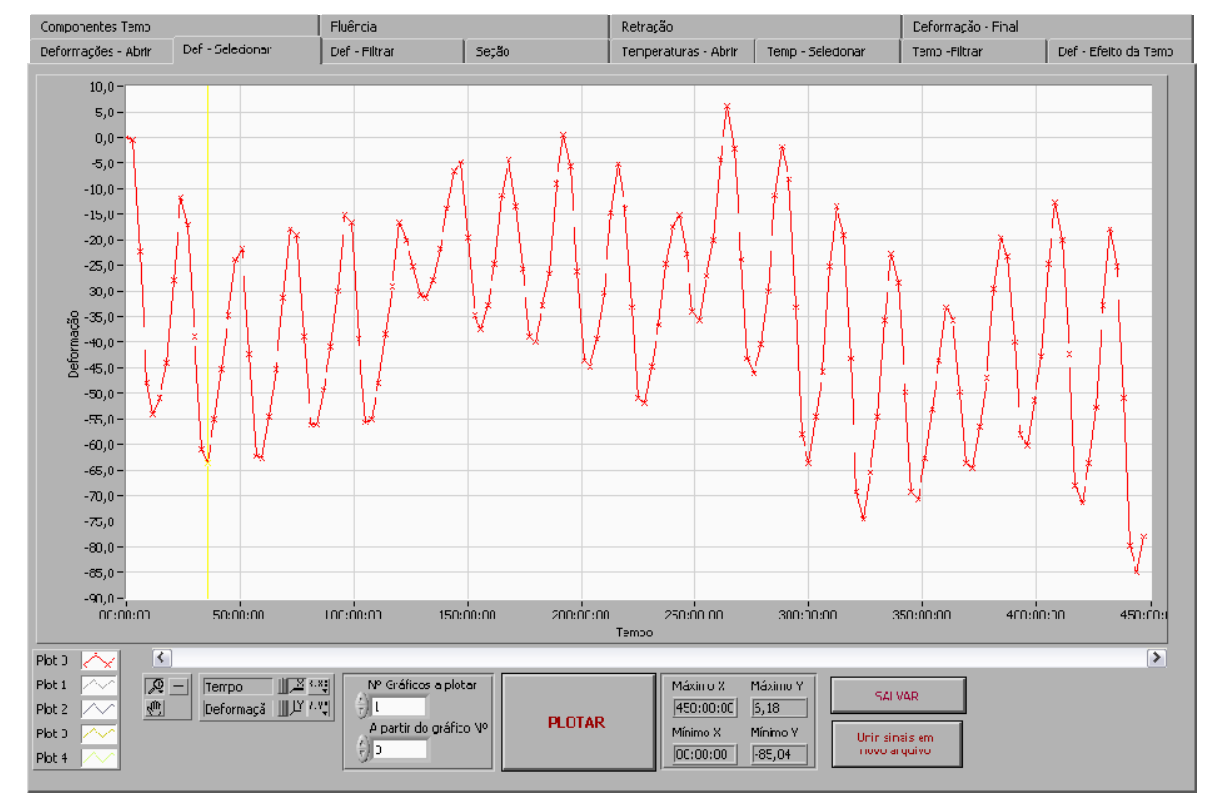

Figura 4.28 - Deformações selecionadas: ES5-2S.

Nesse ambiente, os valores extremos do gráfico são apresentados, considerando os dois eixos. Os resultados aparecem à direita do botão plotar, da figura 4.28 .

Embora não seja o caso, se fosse necessário extrair ruídos do sinal apresentado, bastaria utilizar os recursos da próxima aba, Def-Filtrar. Somente para apresentar as funcionalidades do ambiente, a figura 4.29 ilustra o sinal da figura 4.28 após ser submetido ao filtro de Savitzky-Golay, utilizando um polinômio de $1^{\circ} \mathrm{grau}$, com intervalo constituído por $(2 \times 7+1)$ elementos, onde 7 é a dimensão da janela escolhida. 


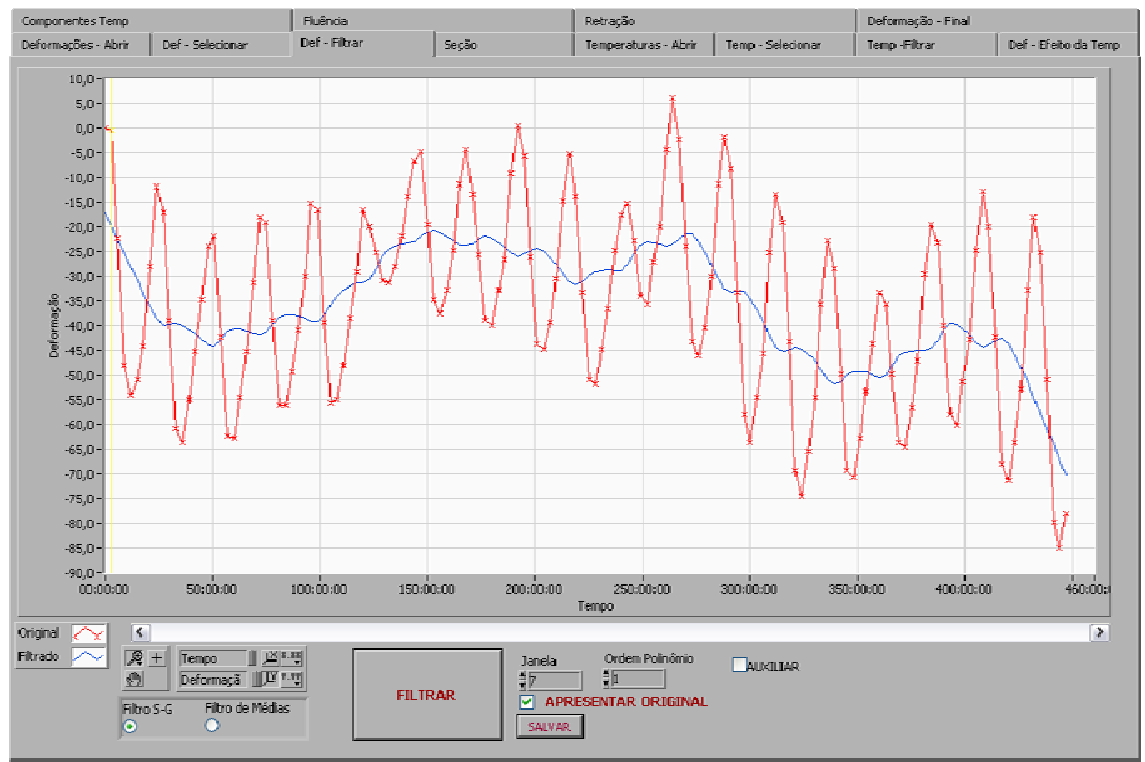

Figura 4.29 - Visualização dos valores originais e filtrados.

A figura 4.30 ilustra a ativação da janela auxiliar, com seleção de visualização das 10 primeiras medições.

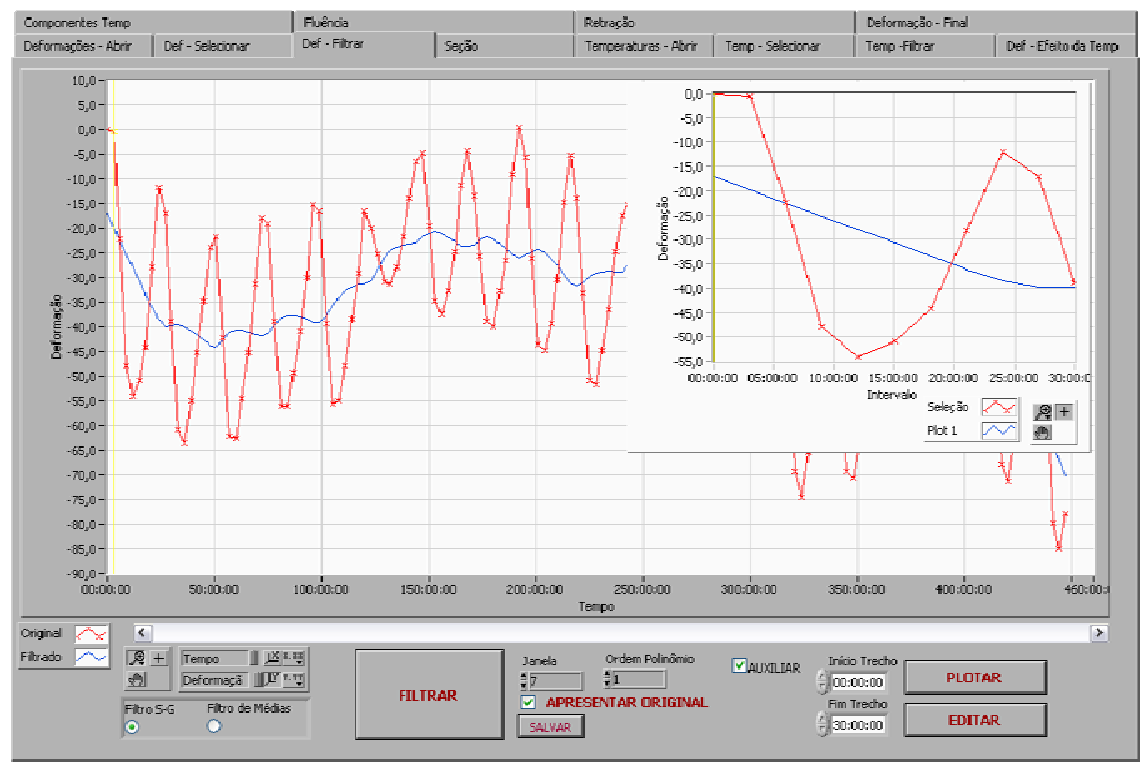

Figura 4.30 - Utilização da janela auxiliar.

Como no caso da seção S5 os valores das temperaturas nas posições dos sensores são conhecidas, não há necessidade de utilizar a aba seção, e nos dirigiremos à aba Temperaturas-Abrir. Nela, ao pressionarmos o botão Abrir será solicitada a seleção do arquivo com os dados da temperatura da seção. Na figura 4.31 são apresentadas as temperaturas na medidas por TS5-2S (gráfico preto)e TS5-2I (gráfico verde). 


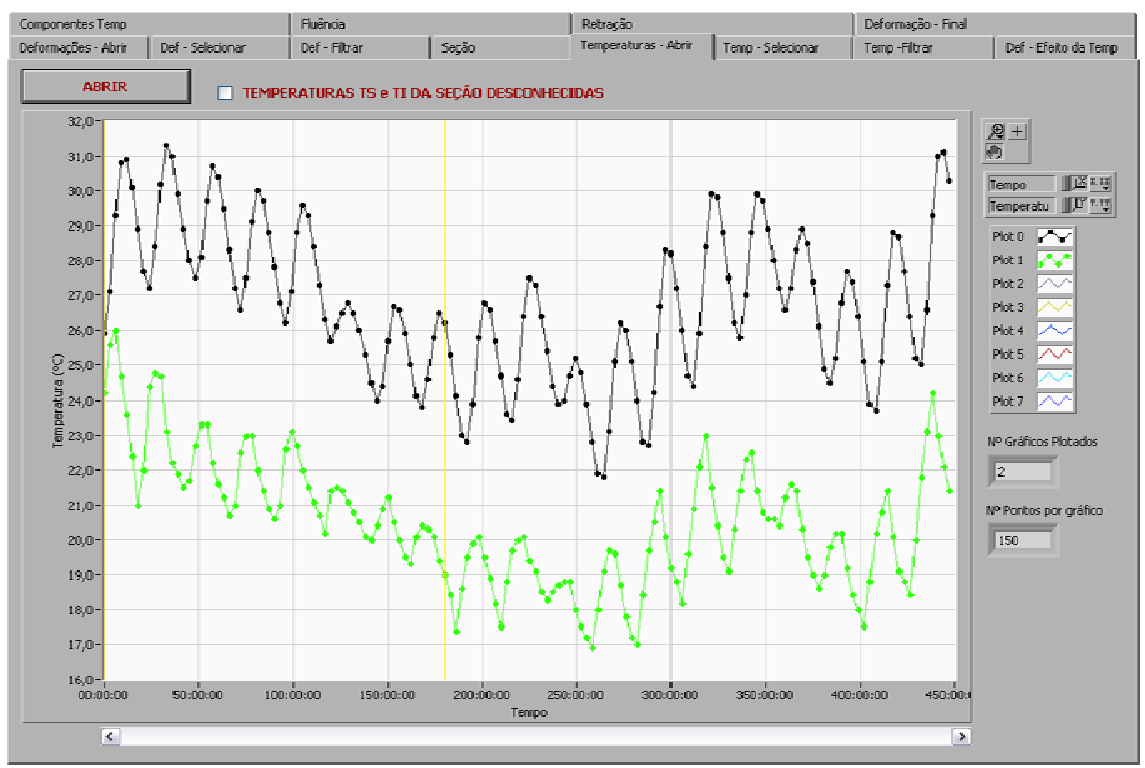

Figura 4.31 - Apresentação das temperaturas da seção.

Comparando-se os gráficos de deformação com os de temperatura, fica evidenciada a forte influência da variação da temperatura nos resultados medidos.

$\mathrm{Na}$ aba Temp-Selecionar, deve-se selecionar as temperaturas de interesse, que serão utilizadas para o cálculo das parcelas lineares da temperatura. Se na aba Temperaturas-Abrir os gráficos de interesse estivesse em meio a outros, eles poderiam ser selecionados nesse ambiente, que é apresentado na figura 4.32.

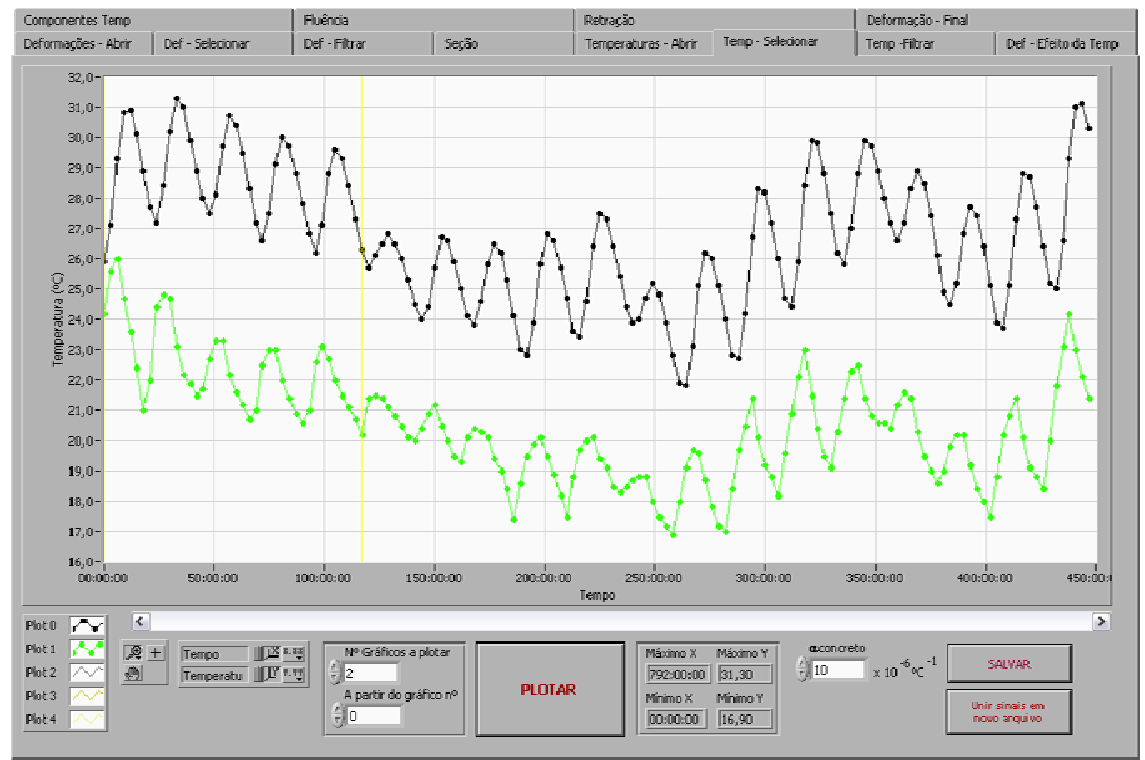

Figura 4.32 - Seleção das temperaturas da seção, para análise. 
O ambiente dispõe de um campo para introdução do valor do coeficiente de dilatação linear do concreto, que será utilizado no cômputo das deformações devidas à temperatura.

Como a aba Temp-Filtrar tem as mesmas funcionalidades da aba Def-filtrar, já vista, sua apresentação será omitida.

A aba Def-Efeito da Temp apresenta os resultados da deformação após remover os efeitos térmicos conforme a metodologia apresentada no capítulo anterior, gerando também um gráfico correspondente ao melhor ajuste polinomial às deformações corrigidas, utilizando o método dos mínimos quadrados. O grau do polinômio pode ser modificado pelo usuário, bastando introduzir um novo valor no campo. Na figura 4.33 são apresentadas:

a) a deformação original medida pelo sensor ES5-2S (gráfico vermelho);

b) a deformação compensada (gráfico cinza);

c) a curva de ajuste dos dados da deformação compensada (gráfico verde).

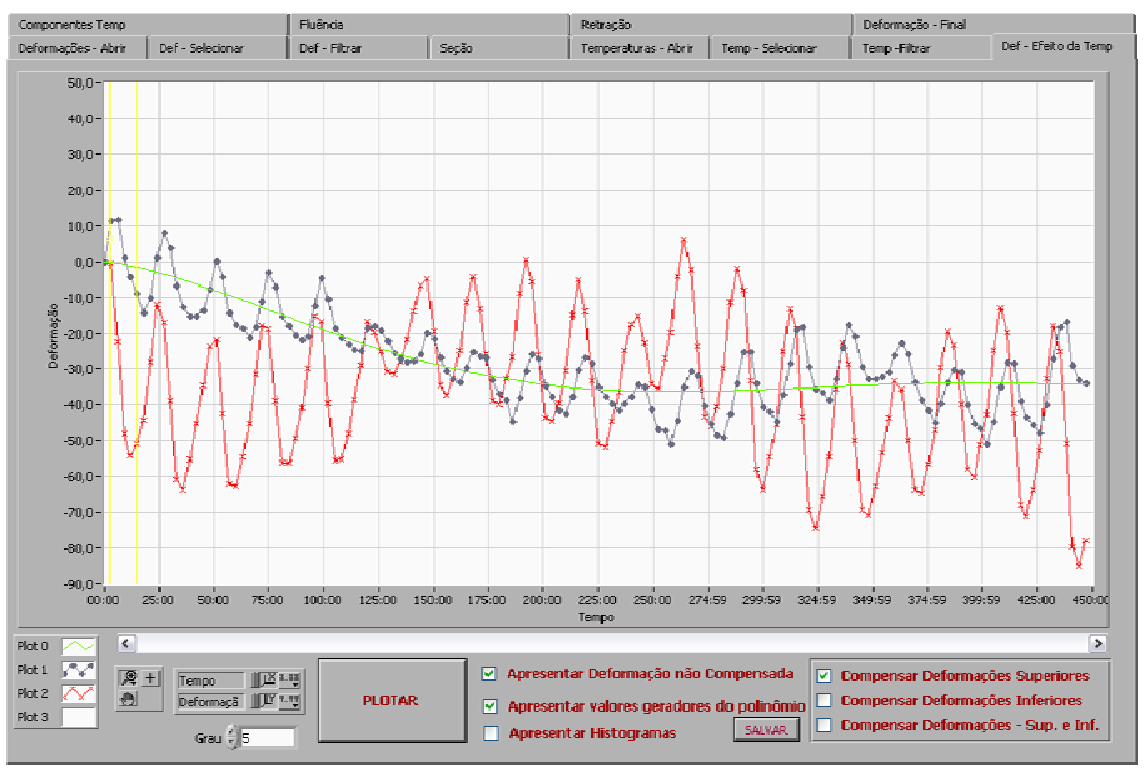

Figura 4.33 - Compensação dos efeitos térmicos.

Percebe-se que efetivamente houve uma significativa redução dos efeitos térmicos, embora ainda se perceba uma influência provavelmente oriunda de efeitos térmicos não-lineares. 
Após a apresentação dos resultados, é possível gerar os histogramas dos gráficos de deformação antes e após a compensação, conforme se vê na figura 4.34 .

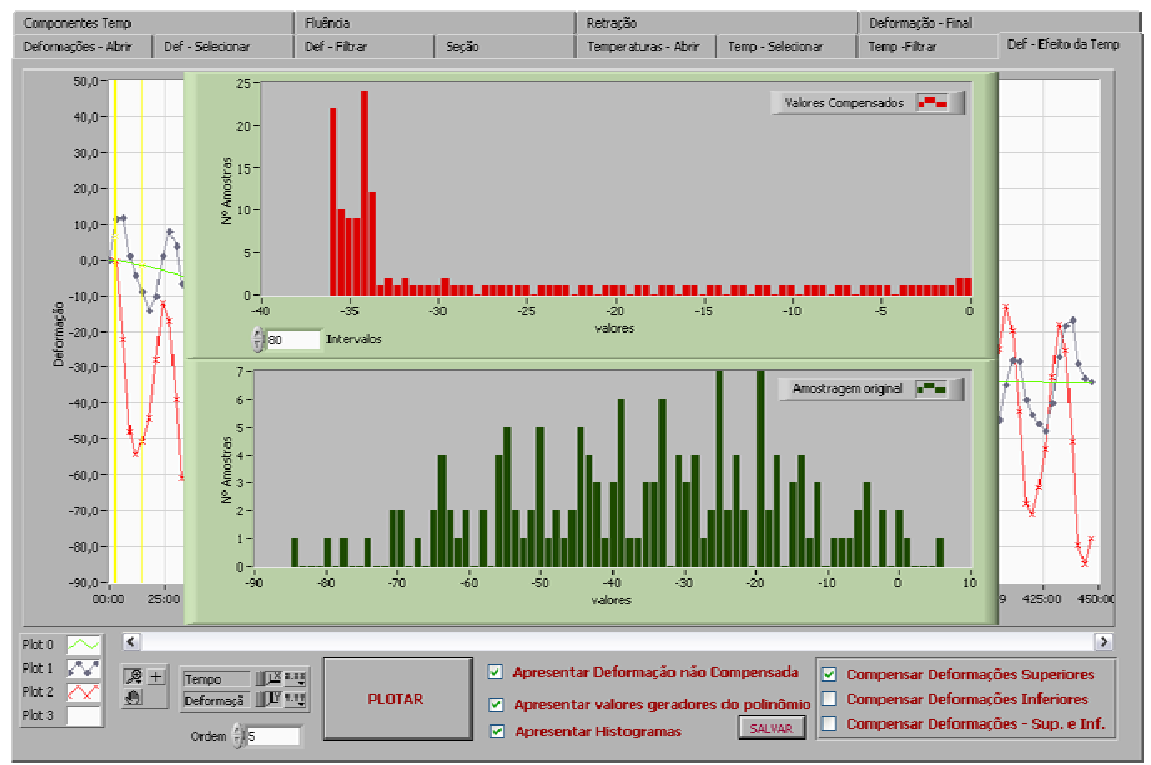

Figura 4.34 - Apresentação de histogramas da amostra original e dos valores compensados.

$\mathrm{Na}$ aba Componentes-Temp são apresentados os valores das temperaturas uniformes, do diferencial térmico e das temperaturas lineares superior e inferior, sendo apresentada na figura 4.35 com os valores calculados para o caso em estudo.

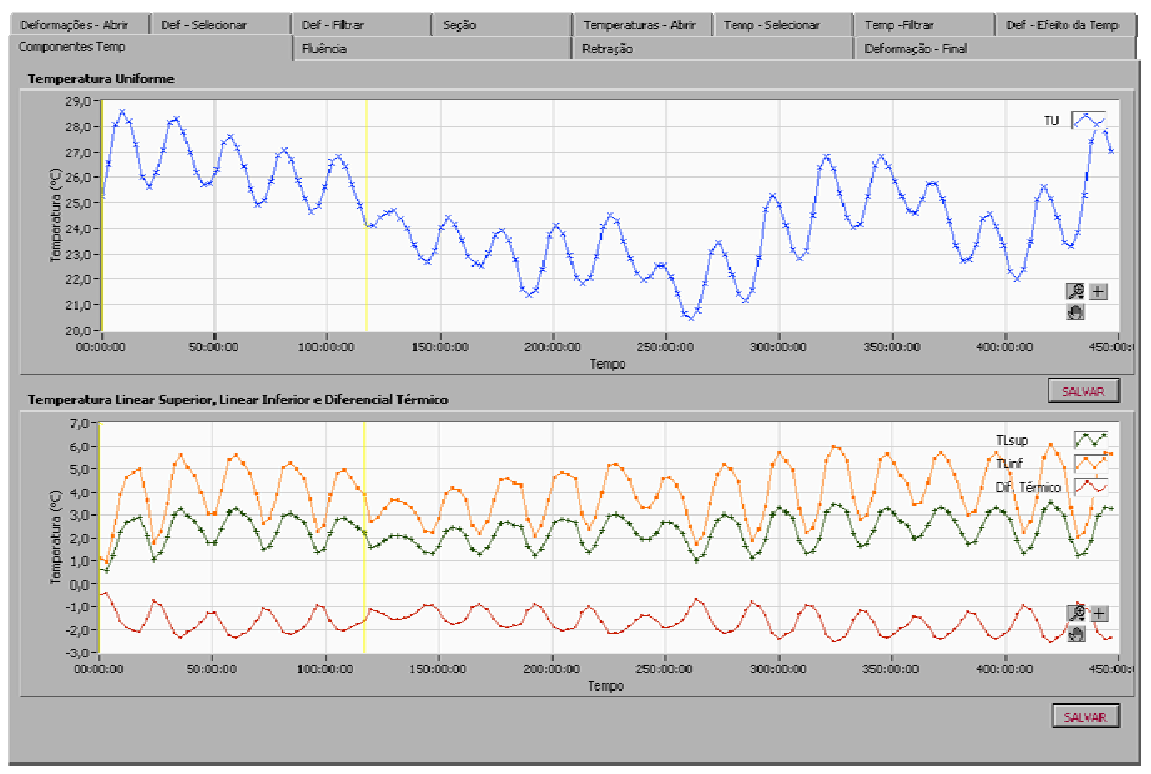

Figura 4.35 - Gráficos das parcelas térmicas computadas. 
Removidos os efeitos térmicos lineares, o próximo passo consiste em estimar a deformação devida aos efeitos diferidos. Na aba Fluência, apresentada na figura 4.36, os campos editáveis devem ser preenchidos com as informações da seção estudada. A temperatura utilizada será constante e igual à média anual de Santarém, onde a ponte está localizada, que é de $16^{\circ} \mathrm{C}$. A entrada dos dados da temperatura é feita mediante a leitura de um arquivo de dados fornecido pelo utilizador do sistema. Os demais parâmetros são adotados de acordo com 0 documento Ponte sobre o rio Sorraia - Projecto de Execução (GRID, 2003), pelo qual temos:

a) $t_{0}=7$ dias;

b) $t_{f}=360$ dias;

c) $\mathrm{rh}=70 \%$;

d) $A_{c}=10,478 \mathrm{~m}^{2}$;

e) $u=35,953 \mathrm{~m}$;

f) $\mathrm{f}_{\mathrm{cm}, 28}=43 \mathrm{MPa}$;

g) $\sigma=6,5 \mathrm{MPa}$;

h) tipo de cimento: $R$;

i) tipo de agregado: Quartzo (admitido).

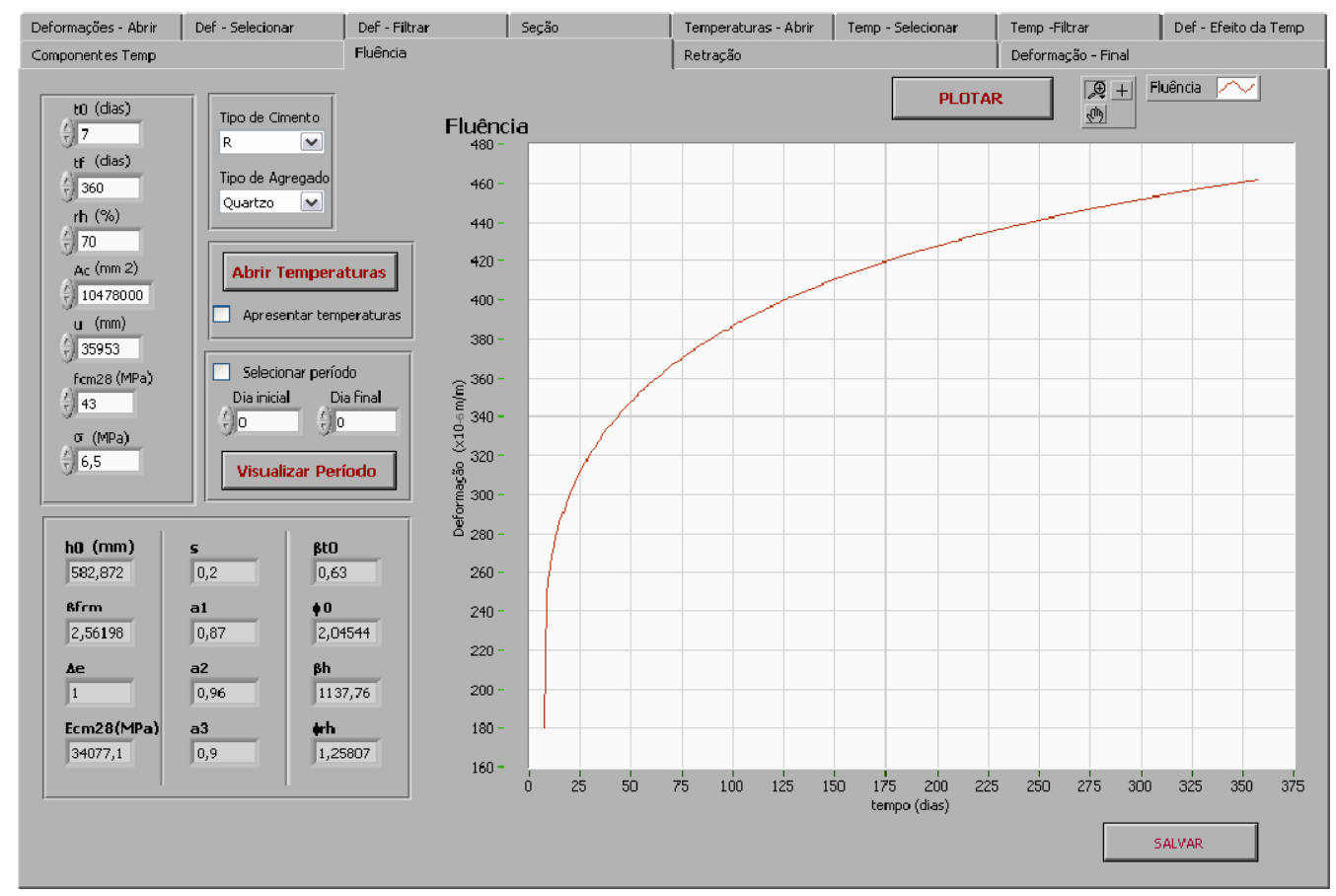

Figura 4.36 - Apresentação da estimativa das deformações devidas à fluência. 
As temperaturas utilizadas no cômputo da deformação por fluência podem ser consultadas, bastando selecionar a opção Apresentar temperaturas. Um gráfico contendo os dados fornecidos aparecerá na tela, conforme ilustrado na figura 4.37.

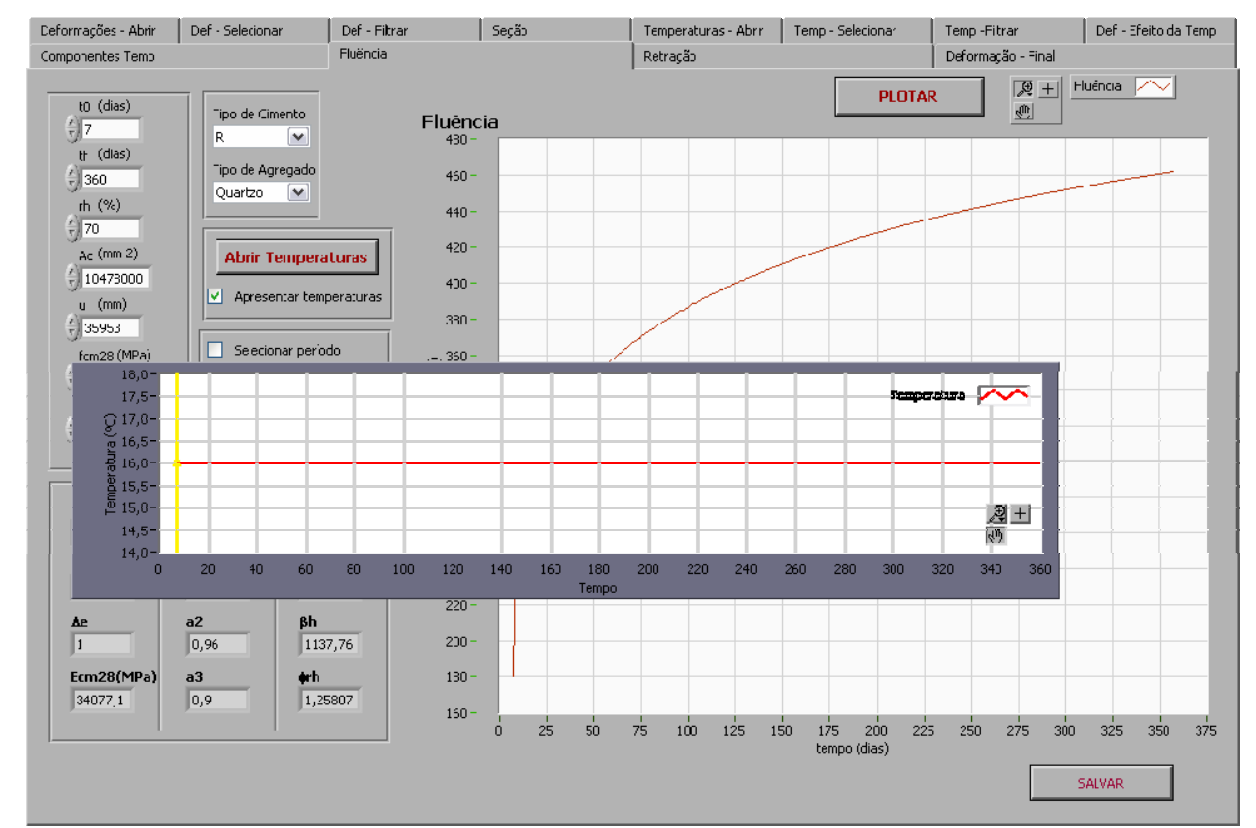

Figura 4.37 - Apresentação das temperaturas utilizadas na estimativa da deformação por fluência.

O sistema permite que, dentro do intervalo temporal fornecido, seja selecionado um período qualquer, sendo fornecidos os valores de deformação calculados. Caso seja preenchida a opção Selecionar período, a variação da deformação no período escolhido será considerada para fins de compensação.

No caso em questão, foi utilizado o período aproximado em que foram feitas as medições das deformações, admitindo-se o intervalo [dia inicial, dia final] igual a [336, 355]. A deformação por fluência no período foi estimada em $3,2.10^{-6} \mathrm{~m} / \mathrm{m}$ (figura 4.38), e este valor será distribuído no intervalo temporal das medições que serão compensadas. A distribuição é feita mediante a geração automática de índices intermediários no vetor das deformações por fluência selecionadas, de modo que são gerados os índices necessários à compatibilização dimensional entre o vetor de deformação original e o vetor das deformações por fluência selecionadas, tornando este último adequado à realização de operações envolvendo o vetor de deformação original. 


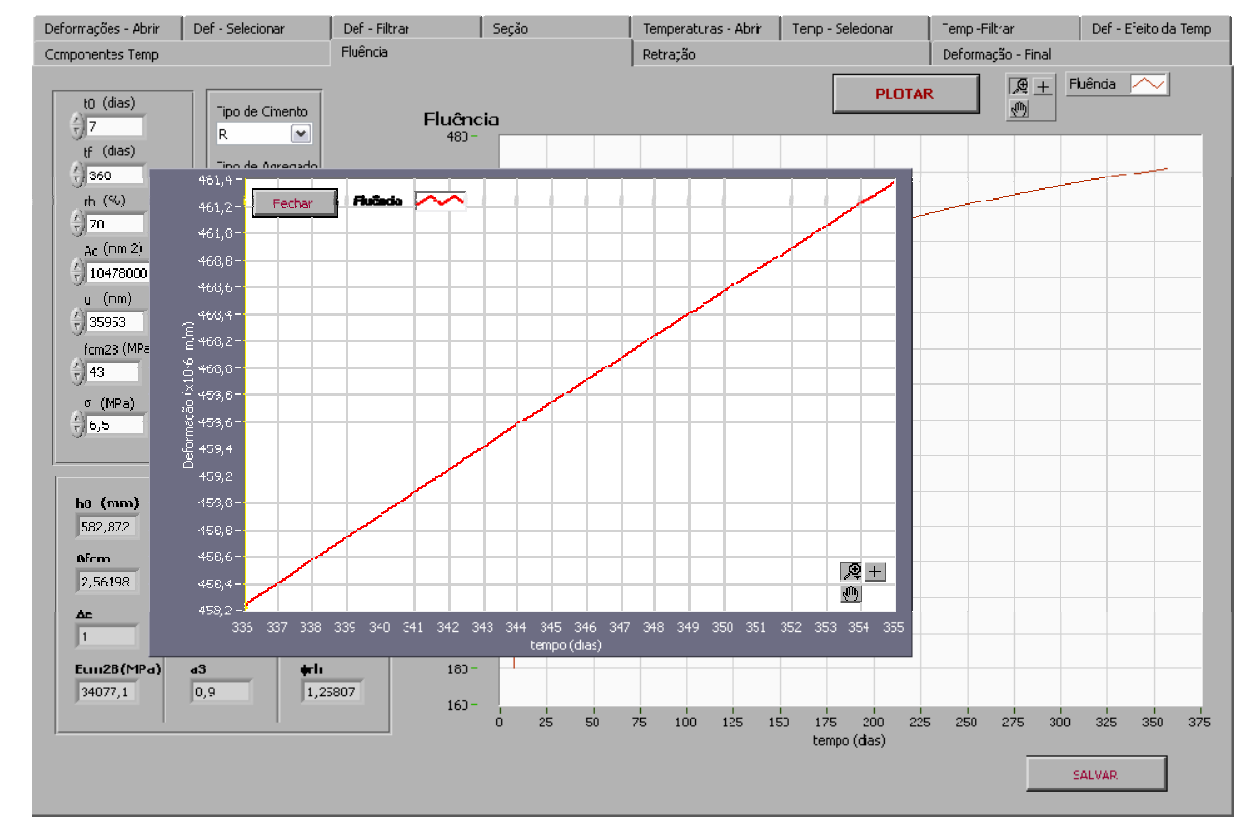

Figura 4.38 - Apresentação das deformações por fluência em um período selecionado.

A etapa seguinte consiste na estimativa da deformação provocada pela retração do concreto, sendo utilizadas as funcionalidades da aba Retração.

Como no caso da aba Fluência, na aba Retração os campos editáveis devem ser preenchidos com as informações da seção estudada. O método utilizado para a seleção e utilização de deformações por retração em um período também segue o mesmo princípio da aba Fluência. A temperatura utilizada será a mesma empregada no ambiente anterior, sendo constante e igual a $16{ }^{\circ} \mathrm{C}$. Os demais parâmetros também foram adotados de acordo com GRID (2003), pelo qual temos:
a) $\mathrm{t}_{0}=7$ dias;
b) $t_{f}=360$ dias;
c) $\mathrm{rh}=70 \%$;
d) $A_{c}=10,478 \mathrm{~m}^{2}$
e) $u=35,953 \mathrm{~m}$;
f) $\mathrm{f}_{\mathrm{cm}, 28}=43 \mathrm{Mpa}$;
g) tipo de cimento: $R$.

A curva de deformação por retração obtida é apresentada na figura 3.39, e a deformação por retração no intervalo $[336,355]$ foi estimada em $4,7.10^{-6} \mathrm{~m} / \mathrm{m}$ (figura 4.40). 


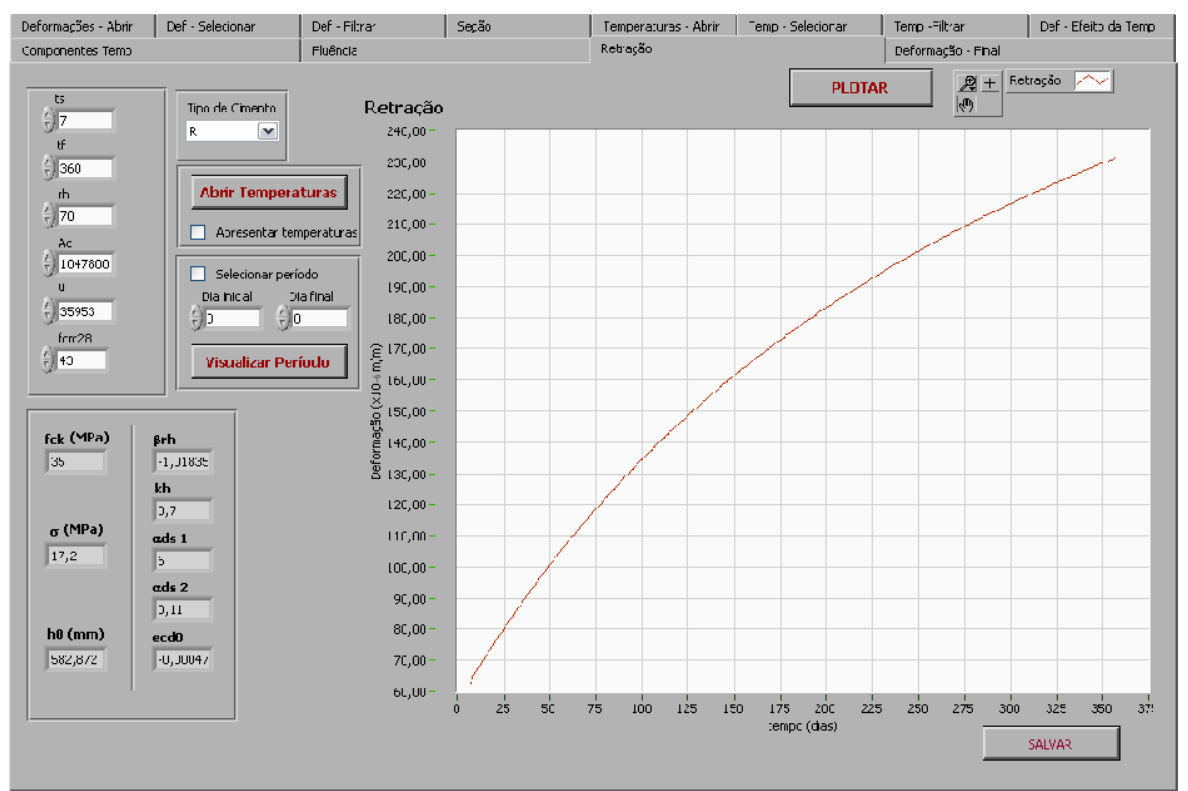

Figura 4.39 - Apresentação da estimativa das deformações devidas à retração.

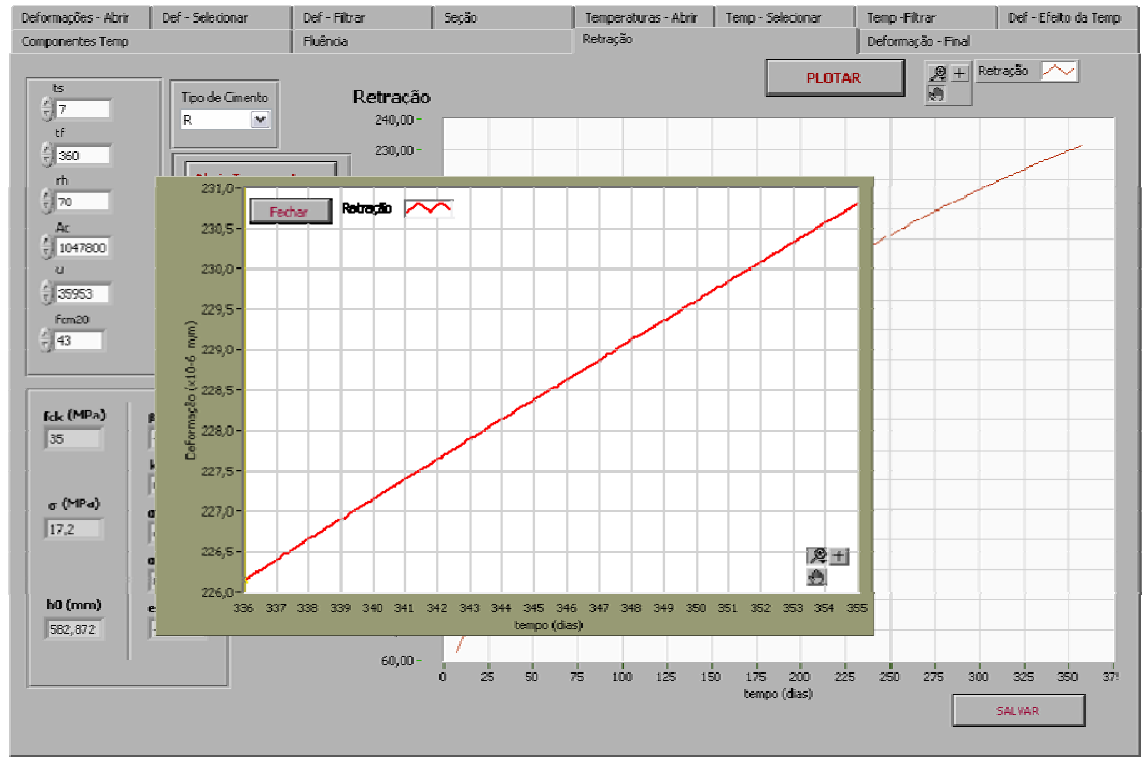

Figura 4.40 - Apresentação das deformações por retração em um período selecionado.

A próxima etapa consiste na operação de remover as deformações diferidas estimadas dos valores de deformação já compensados termicamente. O ambiente onde essa tarefa é realizada está na aba Deformação-Final. A figura 4.41 ilustra esse ambiente, apresentando o resultado final referente às deformações medidas pelo sensor ES5-2S, (gráfico azul). As deformações diferidas aplicadas ao período podem ser vistas na figura 4.42 (retração no gráfico rosa e fluência no gráfico preto). 


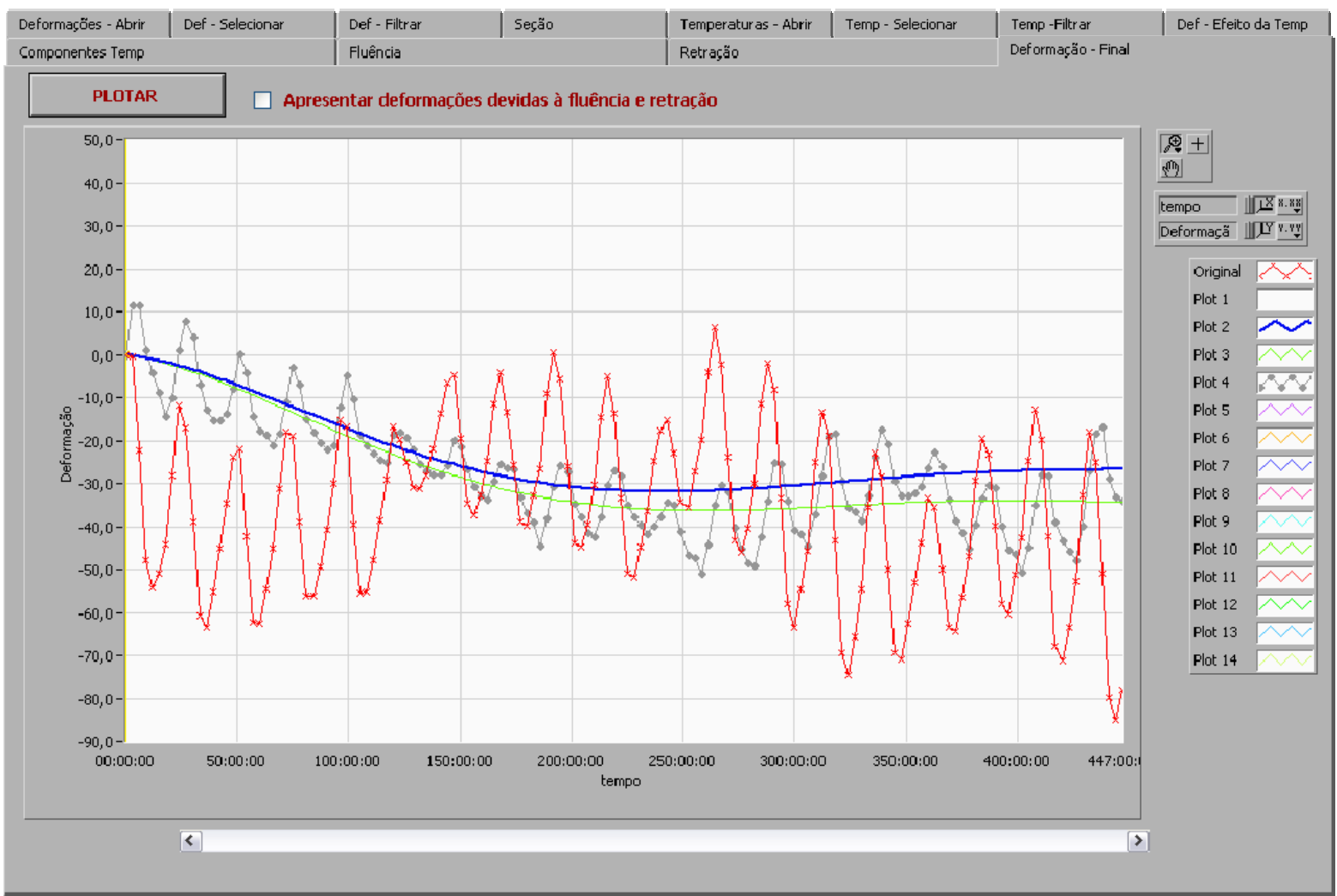

Figura 4.41 - Resultados do sensor ES5-2S antes (em vermelho) e depois das filtragens (em azul).

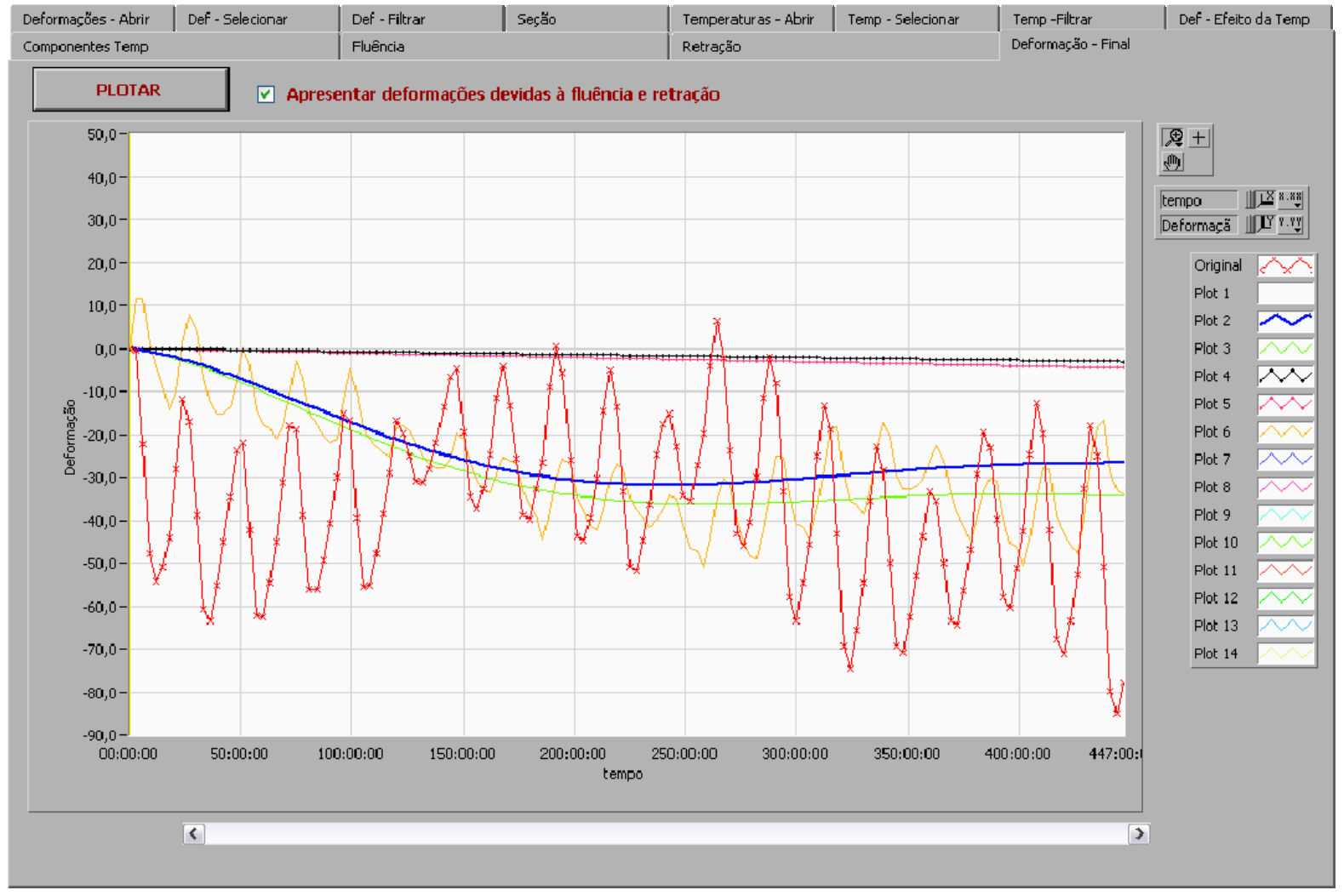

Figura 4.42 - Resultados finais com apresentação das parcelas devidas à fluência e à retração. 


\subsubsection{Análise dos resultados}

De posse dos resultados provenientes da monitoração e dos valores calculados, torna-se possível verificar que o valor médio das deformações medidas na seção ES5-2S no período utilizado no exemplo é igual a $-35,83 \times 10^{-6} \mathrm{~m} / \mathrm{m}$, enquanto o valor médio das deformações após a remoção da parcela devida aos efeitos térmicos lineares é igual a $-27,41 \times 10^{-6} \mathrm{~m} / \mathrm{m}$. Isso implica que o valor das deformações após a consideração dos efeitos térmicos é de $76,50 \%$ do valor medido, o que corresponde a dizer que os efeitos térmicos analisados respondem por $23,50 \%$ do valor medido, e atuaram promovendo um incremento de compressão na região analisada.

Percebe-se ainda que o desvio-padrão dos valores das deformações também é afetado pelos efeitos térmicos lineares. Enquanto as deformações medidas apresentam desvio-padrão igual a $19,66 \times 10^{-6} \mathrm{~m} / \mathrm{m}$, o valor deste para as deformações compensadas é igual a $13,48 \times 10^{-6} \mathrm{~m} / \mathrm{m}$, e estão associados às menores amplitudes dos ciclos das deformações compensadas, em relação aos valores observados nas deformações medidas.

Os valores da retração e da fluência do concreto no período estudado apresentaram uma evolução segundo uma taxa que pode ser admitida linear, e embora o efeito independente de cada um desses fenônemos ao longo da observação fosse reduzido, a consideração conjunta impactou visivelmente no final do período estudado (figuras 4.41 e 4.42), sendo responsável por uma variação de $14,41 \%$ do valor médio da deformação já compensada pelos efeitos térmicos. A média e o desvio-padrão das deformações, obtidos após a consideração dos efeitos térmicos e diferidos, valem respectivamente $-23,46 \times 10^{-6} \mathrm{~m} / \mathrm{m}$ e $12,04 \times 10^{-6} \mathrm{~m} / \mathrm{m}$, correspondendo a variações de $34,52 \%$ e $38,75 \%$ em relação à média e ao desvio- padrão dos valores de deformação medidos (figuras 4.43 e 4.44). 


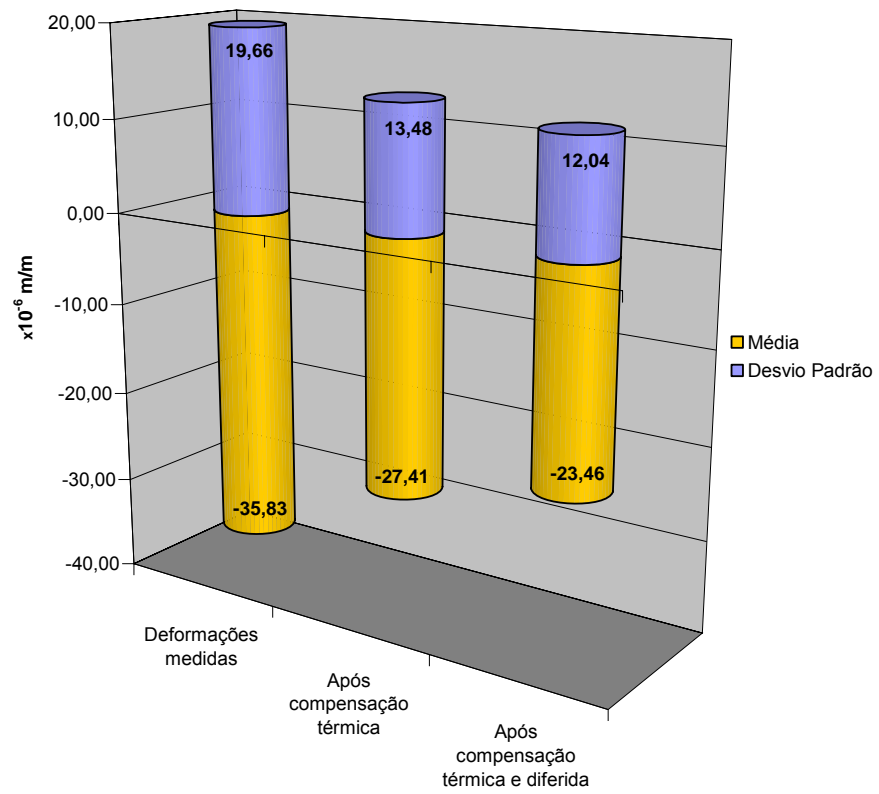

Figura 4.43 - Valores médios e desvios-padrão das deformações.

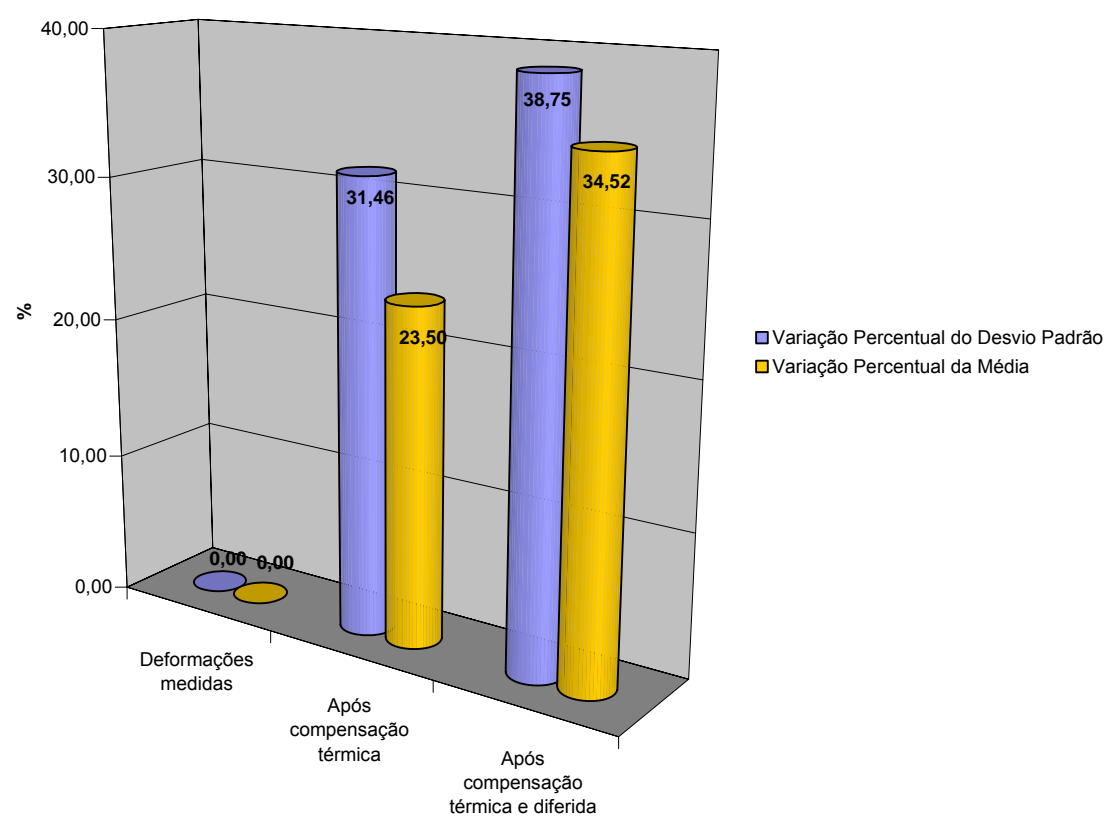

Figura 4.44 - Variação dos valores médios e dos desvios-padrão das deformações, em relação às deformações medidas.

Esses valores remetem claramente à importância da consideração dos efeitos térmicos e diferidos em resultados de monitoração obtidos a partir de estruturas sujeitas à influência da temperatura, retração e fluência. 


\subsection{Considerações finais}

Foram apresentadas as atividades referentes à monitoração da ponte de concreto armado e protendido construída sobre o rio Sorraia, em Portugal, descrevendo-se a estrutura da obra, o sistema de monitoração instalado e as ferramentas computacionais desenvolvidas para o sistema. No capítulo também é feita uma aplicação do sistema de visualização e tratamento de dados desenvolvido, utilizando os resultados da monitoração da obra.

Conforme detalhado no item 4.3.4, a avaliação do sistema de monitoração instalado, considerando o desempenho de cada um dos três subsistemas que o compõem, indica o sucesso do sistema implantado, a despeito da ausência de fornecimento de energia elétrica, que limitou algumas das funcionalidades inicialmente previstas, tais como a utilização contínua dos equipamentos e sensores ópticos. Nesse âmbito, é relevante referir que monitorações de porte o uso de baterias para a alimentação dos sistemas deve ser considerado provisório, visto que acarreta trabalhos adicionais de manutenção e apresenta maior probabilidade de falhas de fornecimento energético em relação à alimentação pela rede elétrica, aumentando as chances de ocorrência de interrupções de funcionamento do sistema.

A aplicação do sistema de visualização e tratamento de dados à seção S5 envolveu a compensação de deformações medidas nessa seção em relação aos efeitos da temperatura, da fluência e da retração, utilizando-se as metodologias apresentadas no Capítulo 3. Considera-se que os resultados obtidos validam o sistema, e demonstram que a influência dos efeitos térmicos e diferidos nos valores de deformação medidos são relevantes, de modo que durante a fase de análise dos dados a presença desses efeitos não deve ser omitida. 


\section{CAPÍTULO 5}

MONITORAÇÃO DO COMPORTAMENTO DA PONTE DO PINHÃO

\subsection{Introdução}

O presente capítulo refere-se às atividades de instrumentação e observação do comportamento da ponte metálica do Pinhão (figura 5.1) durante a prova de carga. Descreve-se a instrumentação utilizada e apresenta-se a realização da prova de carga, sendo abordados, de forma clara e objetiva, os resultados e as análises associadas às medições efetuadas durante a prova de carga. Refere-se que os sinais aquisitados foram tratados com o filtro de média móvel, que na época da realização das atividades descritas neste capítulo era o único que estava implementado no sistema de tratamento de dados.

A ponte está localizada sobre o rio Douro, em Portugal, e integra o complexo viário da Estrada Nacional 323, sendo uma importante ligação dos concelhos de Tabuaço, S. João da Pesqueira, Sabrosa e Alijó. A instrumentação foi executada pela equipe do LABEST - FEUP, com participação do autor, segundo as "Especificações para o ensaio de carga" elaborada pelo Gabinete de Engenharia e Geotecnia Ltda. (GEG). No documento são especificadas as seções a instrumentar, as grandezas a medir e são definidas as ações a atuarem sobre o tabuleiro (cargas e posicionamento dos veículos). A prova de carga foi realizada por solicitação do Instituto das Estradas de Portugal (IEP), com o objetivo de proporcionar informações para a avaliação das condições de segurança da estrutura. 


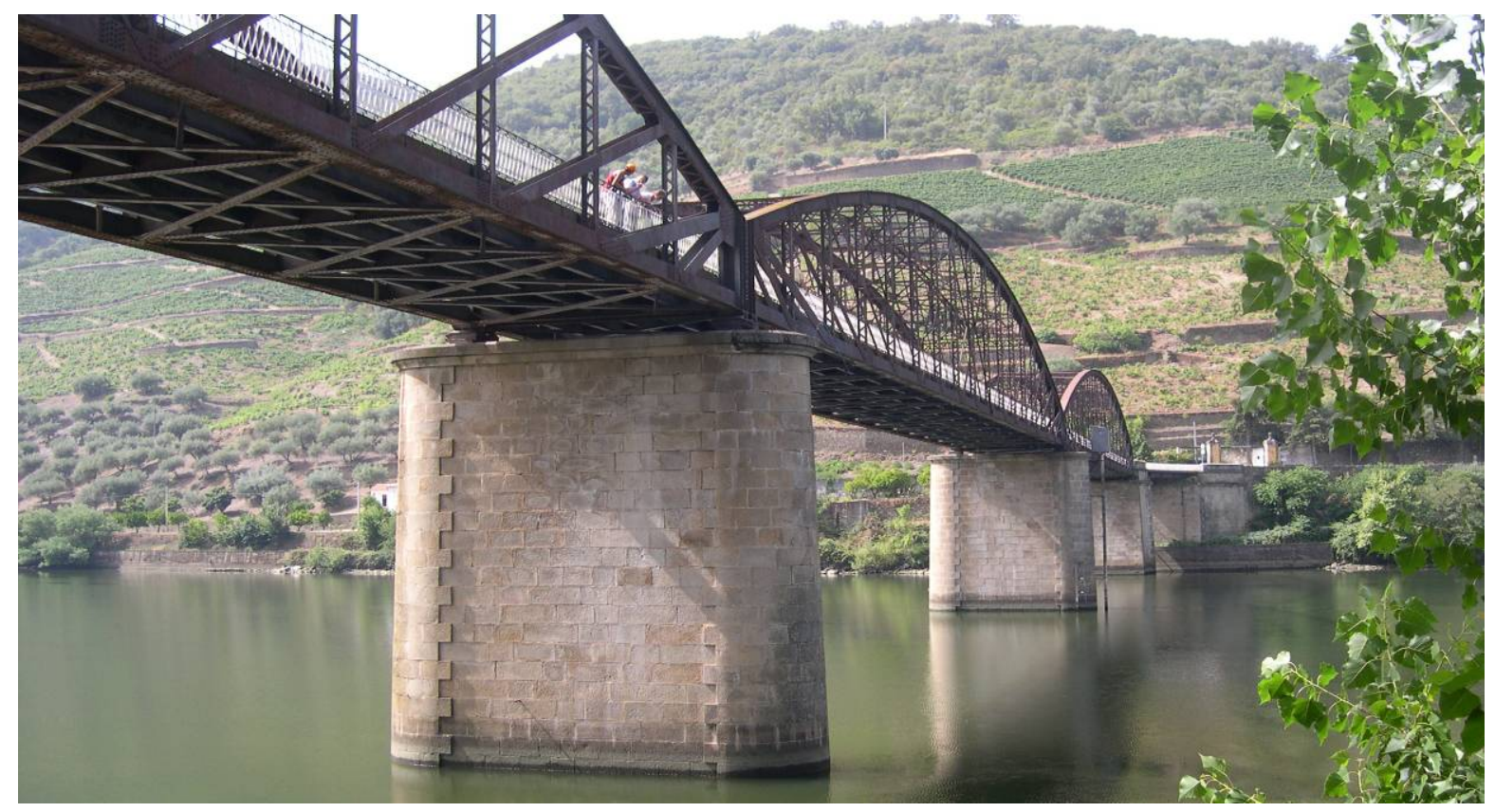

Figura 5.1 - Vista da ponte do Pinhão.

A construção da ponte do Pinhão foi da responsabilidade da Junta Autônoma de Estradas de Vila Real, tendo sido iniciada em 1906, embora não se saiba quanto tempo decorreu a construção nem quando a obra foi inaugurada. Esta obra de arte é considerada muito importante para o tráfego econômico e turístico na região, na medida em que liga as duas margens do rio Douro. Existe um conjunto de empresas, sobretudo ligadas aos setores de produção de vinhos e aos transportes, com sede no concelho de Alijó, que utilizam preferencialmente esta ligação. Em virtude da sua importância local, o tráfego na ponte é intenso, porém, em setembro de 2003, o IEP impôs limitações, por ter sido feita uma análise que detectou significativo desgaste dos materiais constituintes do tabuleiro. Foi proibida a passagem na ponte a veículos com mais de oito toneladas e a velocidade máxima sobre a ponte foi limitada a 10 quilômetros horários.

As atividades de instrumentação foram realizadas entre os dias 02 e 04 de Agosto de 2004, envolvendo a aplicação dos extensômetros elétricos exteriormente aos perfis metálicos para a medição das deformações locais, e a instalação de sensores de temperatura, transdutores de deslocamentos e inclinômetros.

Este capítulo é constituído por sete seções, incluindo a presente introdução. $\mathrm{Na}$ seção 5.2 é apresentada a descrição geral da ponte, com ilustrações dos elementos estruturais de maior interesse, enquanto na seção 5.3 é descrito o sistema de medição instalado em obra para obtenção das deformações, 
deslocamentos nos vãos, rotações dos apoios, temperatura e abertura de junta de dilatação, com ilustrações dos sensores e dos postos de observação instalados. $\mathrm{Na}$ seção 5.4 é descrita e ilustrada a sequência e a condução da prova de carga. Os principais resultados das medições são apresentados sob a forma de gráficos e tabelas na seção 5.5, enquanto na seção 5.6 é descrito o modelo numérico utilizado para a análise do comportamento estrutural, e são apresentados os resultados numéricos obtidos face às solicitações ocorridas durante a prova de carga. As considerações finais constituem o assunto da seção 5.7.

\subsection{Descrição da estrutura}

A ponte do Pinhão é constituída fundamentalmente por uma estrutura metálica composta por chapas e cantoneiras e possui tabuleiro misto de aço e concreto, apresentando três pilares e dois encontros de alvenaria de pedra. Um dos encontros possibilita o acesso a Pinhão, e o outro, ao Peso da Régua. A ponte desenvolve-se em três tramos (figura 5.2), com vãos de respectivamente 69,22 m, 69,21 m e 69,21 m, a partir do encontro do lado do Pinhão. O primeiro tramo está apoiado sobre o aparelho de apoio do encontro do lado do Pinhão (E1) e sobre o pilar P1, sendo que o apoio do pilar P1, ao contrário do apoio do encontro E1, permite deslocamentos horizontais. O segundo tramo está apoiado nos pilares P1 e P2, com liberdade de deslocamentos horizontais no apoio sobre o pilar P2. No terceiro tramo, os aparelhos de apoio estão localizados sobre os pilares P2 e P3, havendo liberdade de deslocamentos horizontais no apoio sobre o pilar P3. 


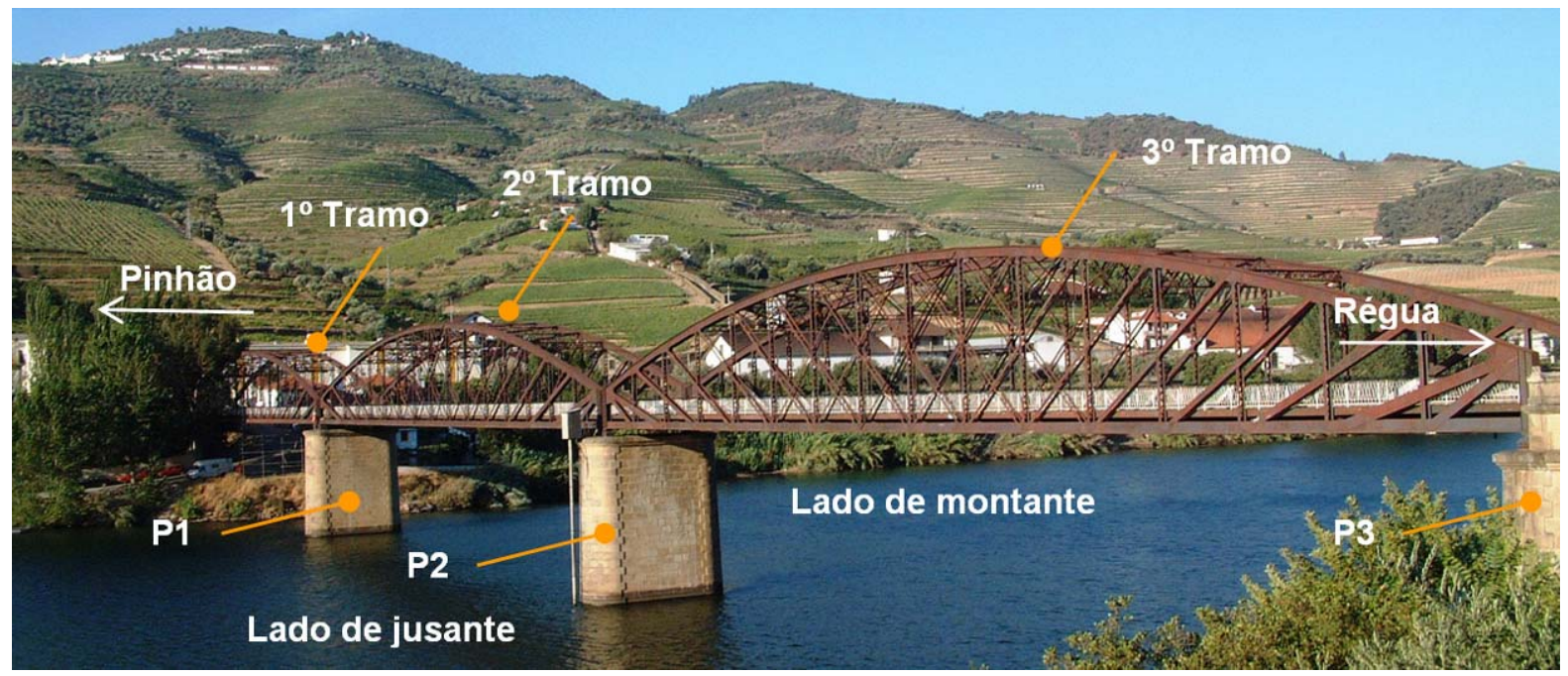

Figura 5.2 - Ponte do Pinhão, com indicação dos tramos e pilares.

O tabuleiro dispõe de uma largura total de aproximadamente 7,00 m, com altura de 0,75 $\mathrm{m}$ ao longo do eixo longitudinal, da qual 0,10 $\mathrm{m}$ devem-se às camadas de concreto $(0,08 \mathrm{~m})$ e asfalto $(0,02 \mathrm{~m})$ depositadas sobre a chapa metálica ondulada de $0,08 \mathrm{~m}$ de altura. A região do tabuleiro destinada às duas faixas de rodagem ocupa 4,68 m, e está apoiada transversalmente sobre cinco longarinas e longitudinalmente sobre dezessete transversinas, por tramo. Cada uma das vias é ladeada por um passeio de serviço com uma largura de 0,675 m, e conta com um guarda-corpo lateral de 1,00 m de altura. Cada longarina é constituída por chapas metálicas e cantoneiras, unidas às chapas por rebites. Uma seção típica é formada por uma chapa e quatro cantoneiras, das quais duas são instaladas na extremidade superior e duas na inferior, formando uma seção "I". As transversinas foram construídas utilizando-se chapas e cantoneiras. A seção típica das transversinas é formada por uma chapa com a maior dimensão na vertical, por duas chapas dispostas horizontalmente e quatro cantoneiras garantindo a união entre as chapas, mediante rebites. A seção originada tem forma de "I". Entre cada par de longarinas existem dois contraventamentos dispostos em forma de " $X$ ". Cada contraventamento inferior é constituído por duas cantoneiras unidas por rebites, dando origem a uma seção "T". A figura 5.3 apresenta seções típicas de longarinas, transversinas e contraventamentos inferiores. 


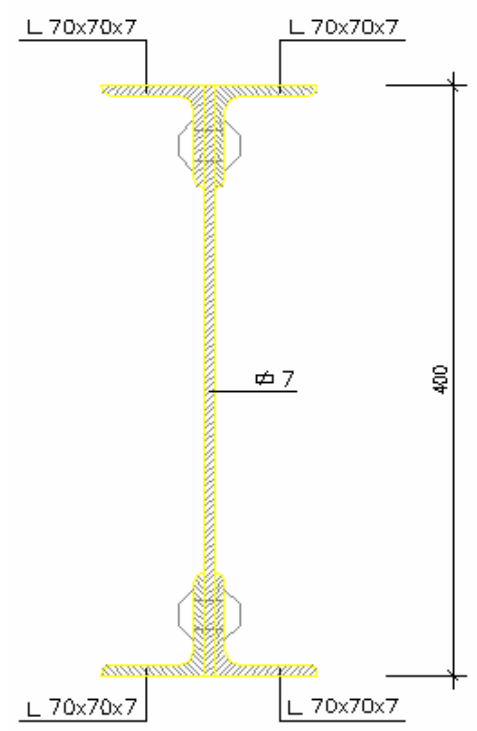

(a)

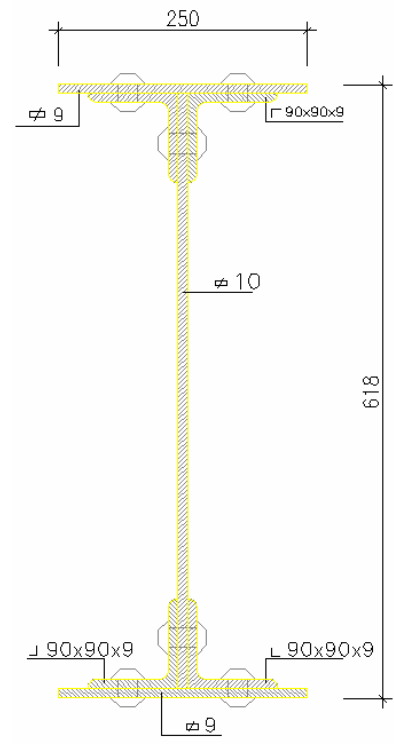

(b)

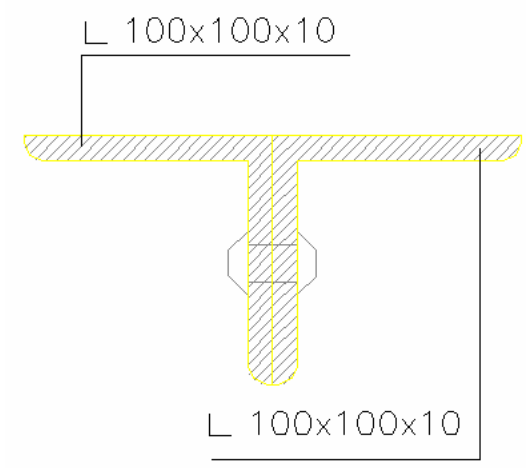

(c)

Figura 5.3 - Seções típicas: (a) longarina, (b) transversina e (c) contraventamento inferior.

Em cada tramo, para o apoio na direção transversal, além das cinco longarinas, existem ainda duas vigas metálicas que constituem as cordas inferiores,

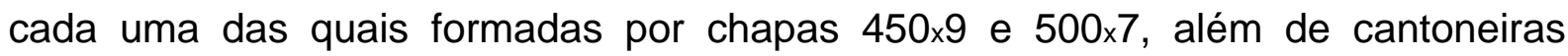
$90 \times 90 \times 10$. Nas duas cordas superiores de cada tramo, além das duas chapas e

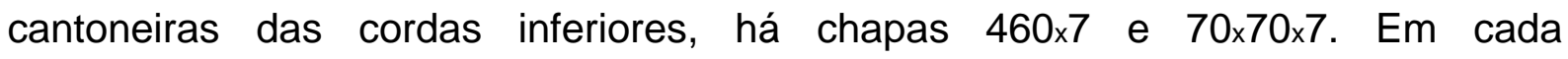
alinhamento, por tramo, a ligação entre a corda inferior e a corda superior é feita mediante dezessete montantes e vinte e duas diagonais. Os montantes são formados a partir da combinação de chapas de $9 \mathrm{~mm}$ e $10 \mathrm{~mm}$ de espessura, com altura variável, e cantoneiras de variadas dimensões. As diagonais são constituídas por chapas metálicas retangulares de seção variável, dispostas em pares e paralelamente, sendo a separação entre chapas igual a $31 \mathrm{~cm}$, em média. A união entre os arcos de cada tramo é assegurada por contraventamentos superiores, compostos por diagonais e cantoneiras de variadas dimensões, os quais unem os montantes dos lados de jusante aos do lado de montante, da quarta à décima quarta posição. A figura 5.4 ilustra um corte transversal apresentando uma seção da ponte, no primeiro tramo, segundo um plano localizado a meio-vão. Na próxima seção há desenhos e fotografias (ex.: figuras 5.5 e 5.6) que ilustram os elementos estruturais acima descritos. 


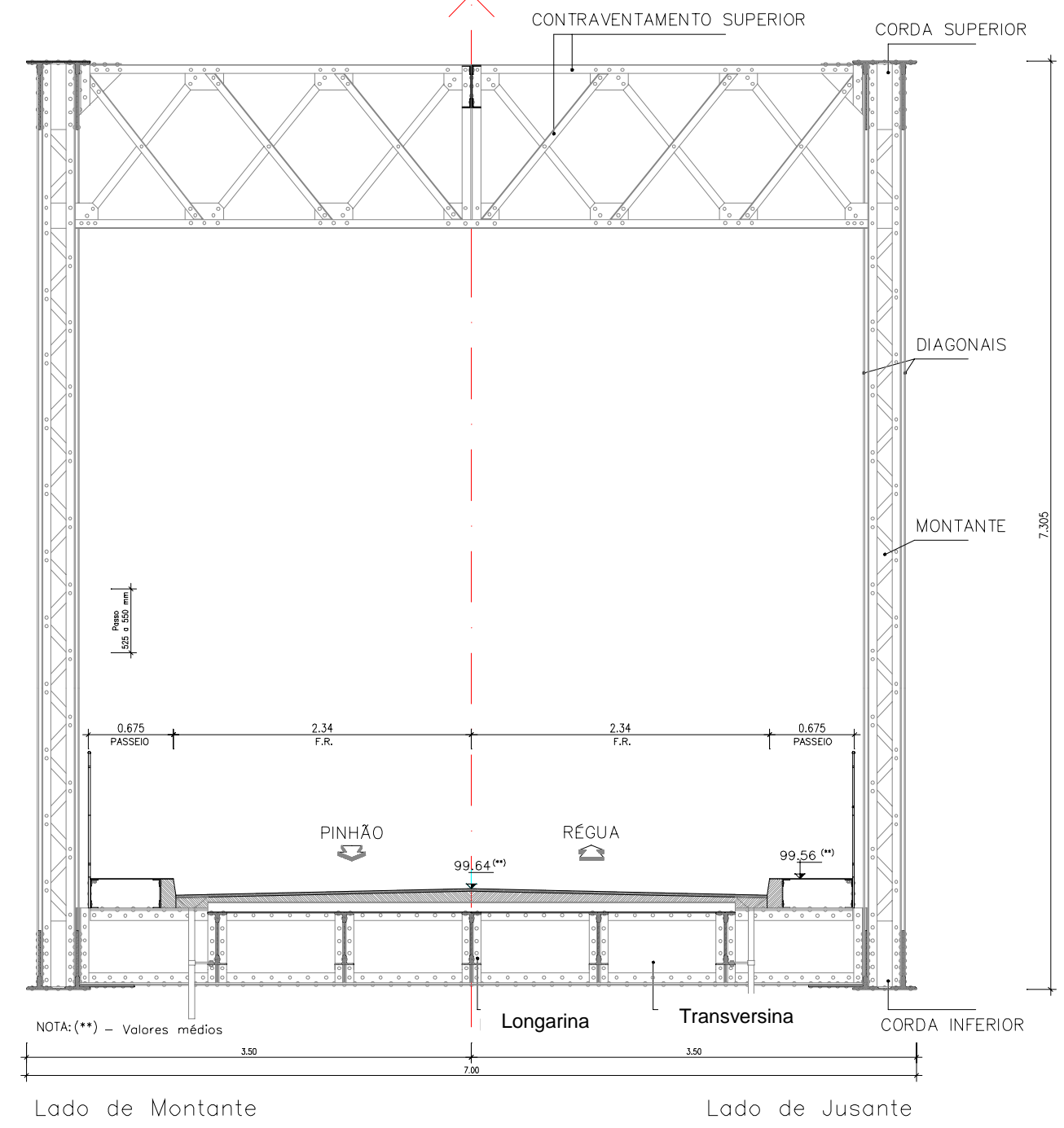

Figura 5.4 - Seção transversal de um dos tramos da ponte do Pinhão, passando a meio-vão.

\subsection{Sistema de medição instalado}

Na observação do comportamento do tabuleiro da Ponte do Pinhão durante a prova de carga procedeu-se à medição de cinco tipos de grandezas: (i) deformações em seções selecionadas nas cordas superior e inferior, em diagonais, transversinas, longarinas e montantes previamente escolhidos; (ii) deslocamentos verticais, para obtenção de deslocamentos a meio-vão e deslocamentos com referência ao solo; (iii) abertura de junta de dilatação junto ao apoio móvel do $1^{\circ}$ 
tramo; (iv) rotações do tabuleiro do $1^{0}$ tramo, junto ao aparelho de apoio do acesso ao Pinhão e (v) temperatura.

Foi utilizado um sistema de aquisição e registro integrado que permitiu a medição automática e simultânea destas grandezas, com o mínimo de intervenção de operadores. Daí que grande parte dos sensores utilizados é elétrica, quer alimentados diretamente a partir do sistema de aquisição como é o caso dos inclinômetros, dos sensores de pressão, dos comparadores elétricos e dos sensores de temperatura, quer com alimentação própria como é o caso dos LVDT's. Toda a instrumentação foi testada e calibrada antes da realização do ensaio.

Para referenciar a localização dos sensores foram definidos os lados de montante (designado no texto por LM) e jusante (designado por LJ), ilustrando-se nas figuras 5.5 e 5.6 a designação adotada para os elementos estruturais instrumentados.

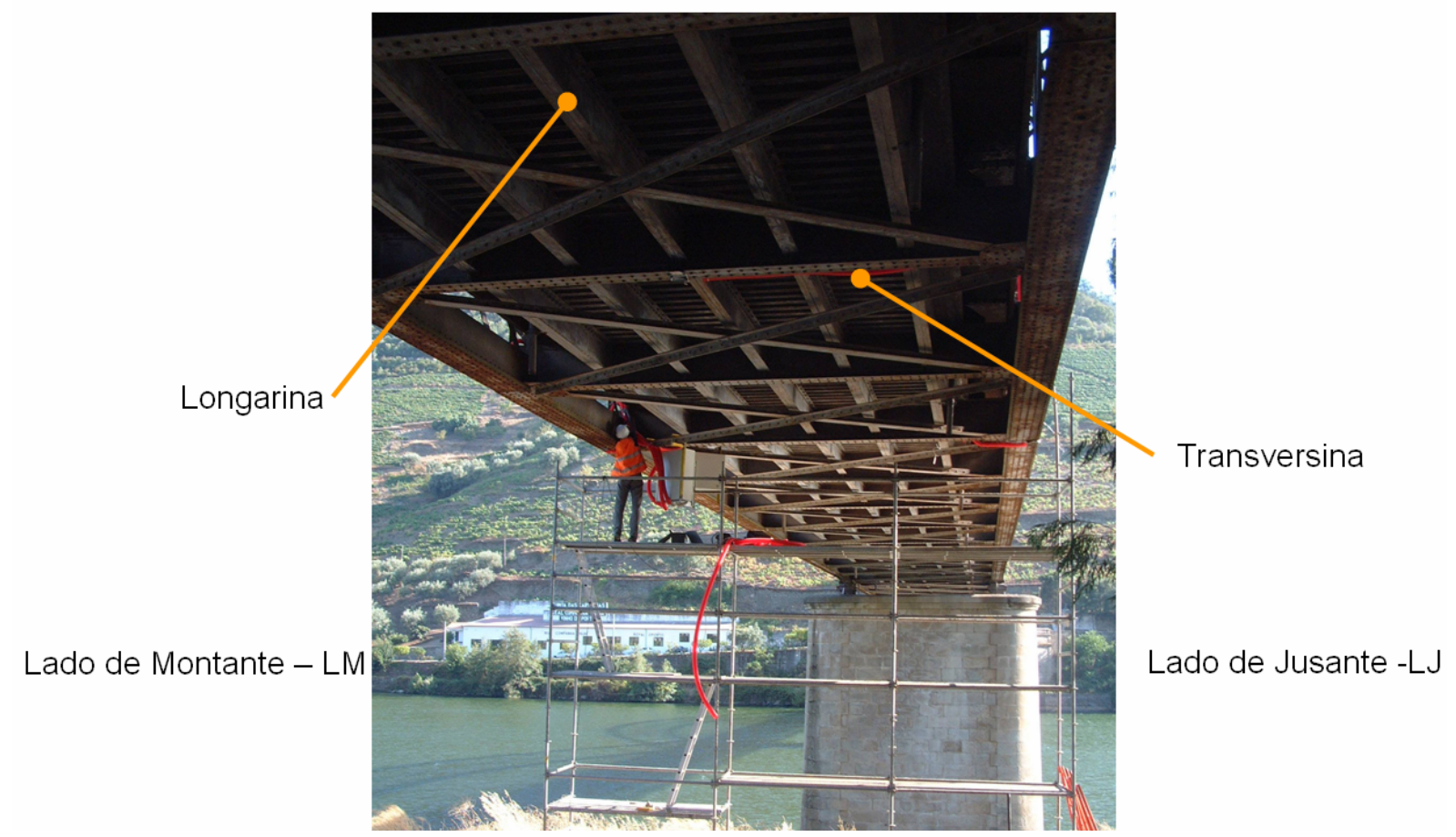

Figura 5.5 - Vista inferior do primeiro tramo da Ponte do Pinhão, apresentando a designação para os elementos estruturais instrumentados.

O acesso aos locais de instalação dos extensômetros, LVDT's e posto de observação foi feito com o apoio de plataforma disponibilizada por um empreiteiro local. 


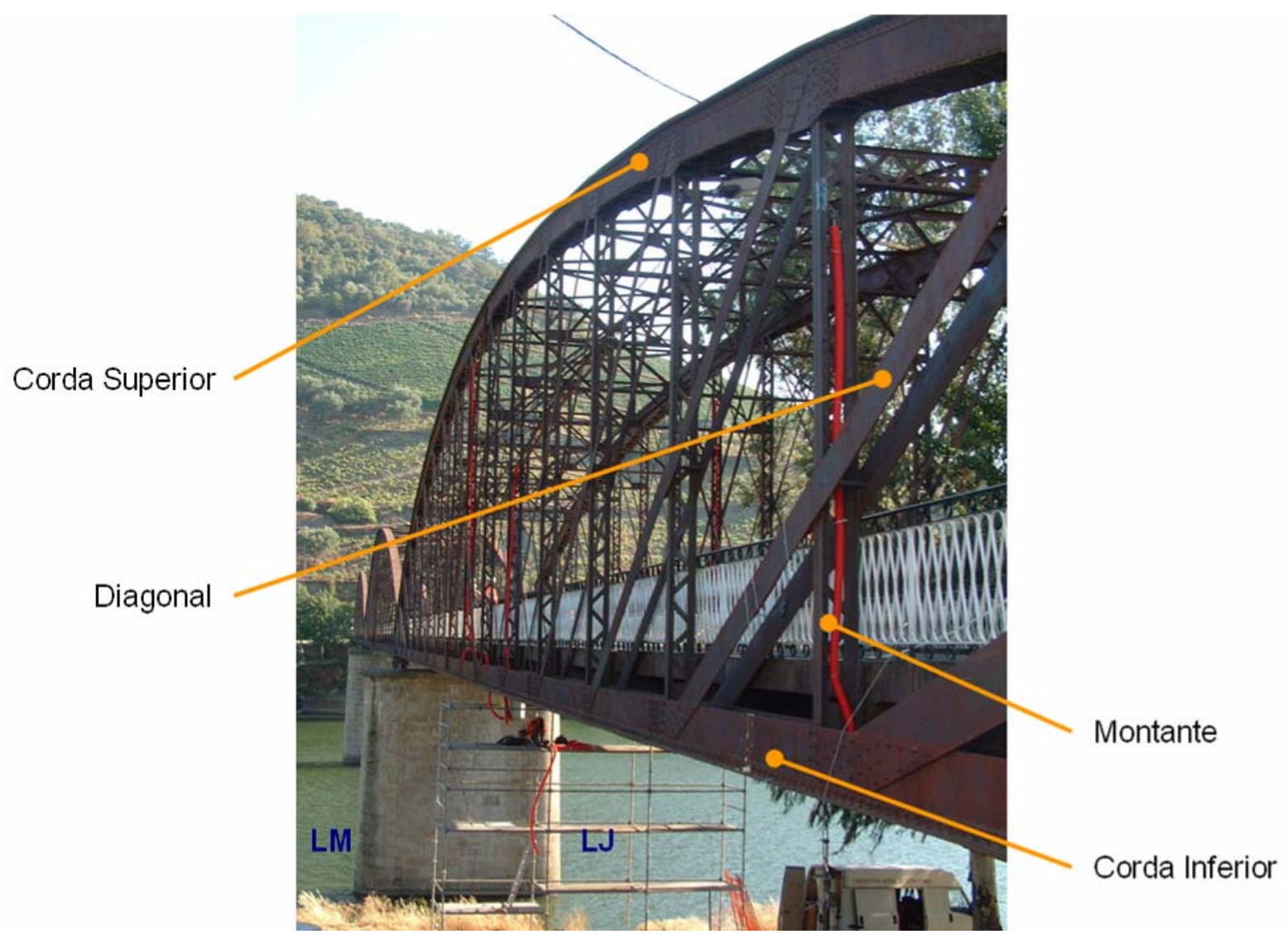

Figura 5.6 - Vista do lado de montante do primeiro tramo da Ponte do Pinhão, apresentando a designação para os elementos estruturais instrumentados.

\subsubsection{Medição das deformações}

A medição das deformações foi realizada utilizando extensômetros de resistência elétrica, devidamente preparados e protegidos em laboratório. Ao contrário das aplicações clássicas deste tipo de sensores em estruturas metálicas, no caso em apreço não se procedeu à colagem direta dos extensômetros na superfície metálica. Deste modo, foram fabricados elementos sensores à base de materiais compósitos, incorporando os extensômetros, que depois foram colados à estrutura observada.

Estes materiais são formados por dois constituintes, macroscopicamente distintos e com um efeito sinérgico nas propriedades globais. Um deles constitui a matriz que por combinação com o elemento reforçador à base de fibras de carbono, melhora as suas propriedades. A matriz recebe os esforços e transfere-os através 
da interface para o reforço, que atua como elemento rígido e resistente. Na presente aplicação o material utilizado como matriz é uma resina à base de epóxi.

O processo de manufatura consiste na colagem dos extensômetros de resistência elétrica ao sistema compósito, quando da impregnação das fibras com a resina, por intermédio do processo natural de cura desta. A figura 5.7 apresenta um extensômetro, preparado em conformidade com o processo apresentado, em condições de ser instalado.

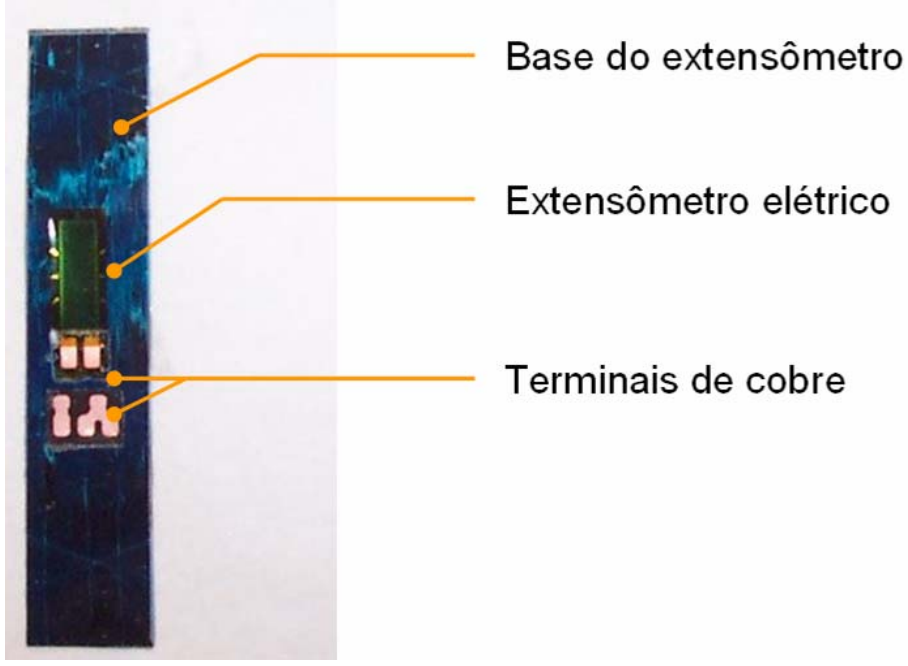

Figura 5.7 - Aspecto do extensômetro elétrico pronto para ser instalado.

A preparação da superfície metálica para a colagem dos extensômetros foi feita de acordo com os seguintes procedimentos:

1) abrasão mecânica da superfície metálica;

2) limpeza da superfície com solução neutra;

3) aplicação da cola (adesivo do tipo epóxi), exercendo-se pressão sobre o extensômetro contra a peça durante cerca de 5 minutos, tempo necessário para o início do ganho de adesividade.

A proteção dos sensores contra umidade, impactos e insolação direta foi feita aplicando resina sobre a zona dos terminais depois de se soldarem os fios. Em seguida, foi colocada uma camada de cortiça com $3 \mathrm{~mm}$ de espessura, e posteriormente foi colada uma tira de material compósito, constituída por fibras de carbono, sobre a zona do extensômetro (figura 5.8). As características técnicas dos extensômetros aplicados estão reunidas na tabela 5.1. 


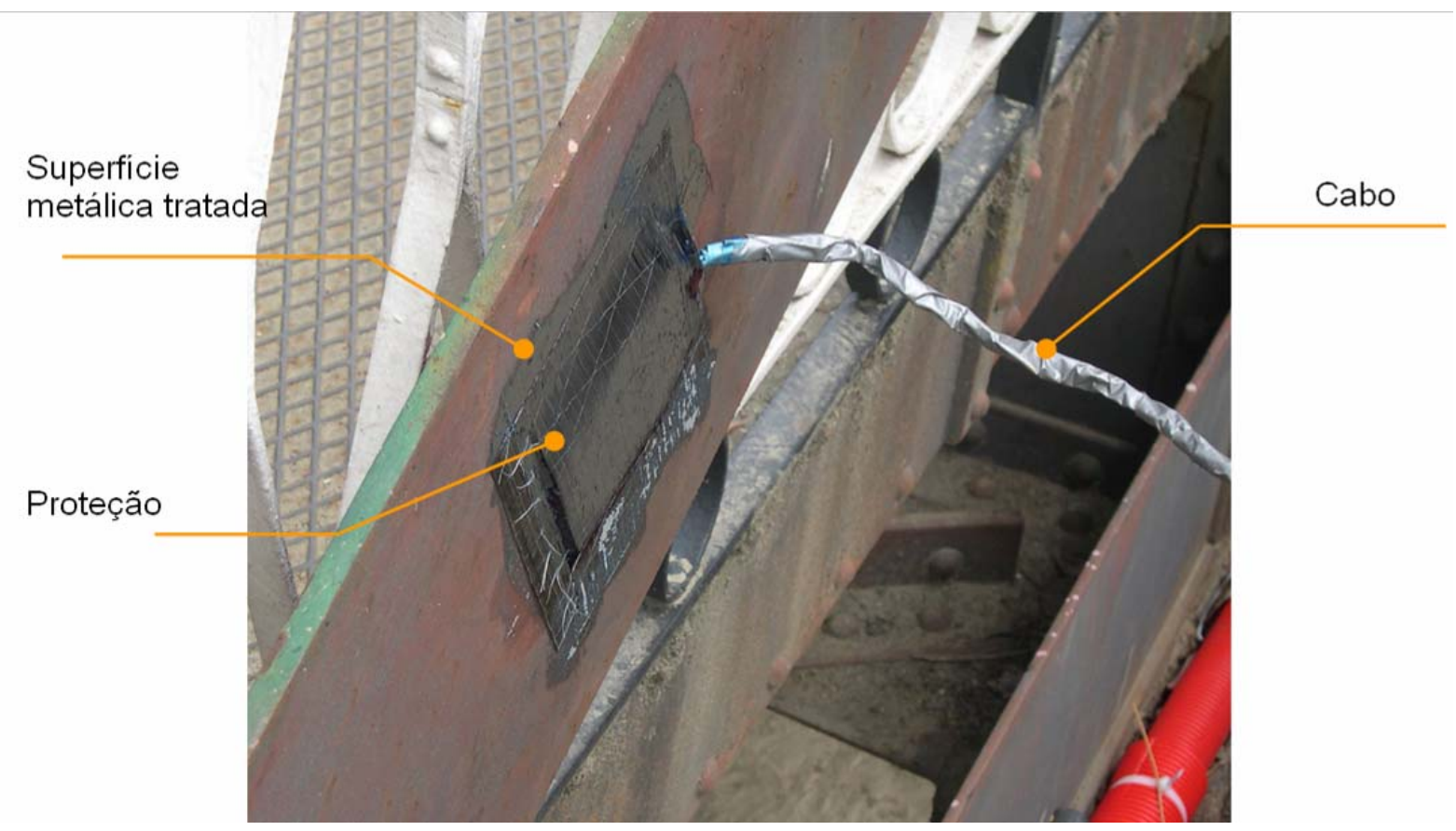

Figura 5.8 - Ilustração de um extensômetro colado na superfície metálica.

Tabela 5.1 - Principais características técnicas dos extensômetros elétricos utilizados.

\begin{tabular}{l|l}
\hline Característica & Especificação \\
\hline Resistência Elétrica & $350 \Omega$ \\
\hline $\begin{array}{l}\text { Fator de calibração } \\
\text { (Gage Factor), } \mathrm{k}\end{array}$ & 2,01 \\
\hline Temperatura de funcionamento & $-75^{\circ} \mathrm{a}+175^{\circ} \mathrm{C}$ \\
$(\mathrm{em}$ medições estáticas $)$
\end{tabular}

Os extensômetros foram colados em faces diametralmente opostas dos elementos estruturais. Os sensores de deformação foram colados aos pares para comparação das leituras e de forma a captar algum efeito de flexão, eventualmente existente. Ao todo, foram instrumentadas com extensômetros elétricos dezessete seções do $1^{\circ}$ tramo, sendo dois extensômetros por seção, com a distribuição apresentada a seguir. 
a) Cordas superior e inferior a meio-vão, dos lados de montante e de jusante (4 seções);

b) $2^{\mathrm{a}}$ e $3^{\mathrm{a}}$ diagonais do lado do Pinhão, dos lados de montante e de jusante (4 seções);

c) $3^{a}$ transversina do lado do Pinhão, a meio-vão e junto de uma das extremidades (2 seções);

d) $7^{a}$ transversina do lado do Pinhão, a meio-vão (1 seção);

e) $\quad 2^{\mathrm{a}}$ e $3^{\mathrm{a}}$ longarinas do lado de montante, a meio-vão (2 seções);

f) $3^{\circ}$ e $7^{\circ}$ montantes do lado do Pinhão dos lados montante e de jusante (4 seções).

Na tabela 5.2, apresentada a seguir, é especificada localização de cada um dos extensômetros instalados.

Procurou-se deste modo obter medições representativas do comportamento localizado da estrutura. Na figura 5.9 é apresentada a disposição dos extensômetros nas diagonais, montantes e nas cordas superior e inferior, do lado de montante.

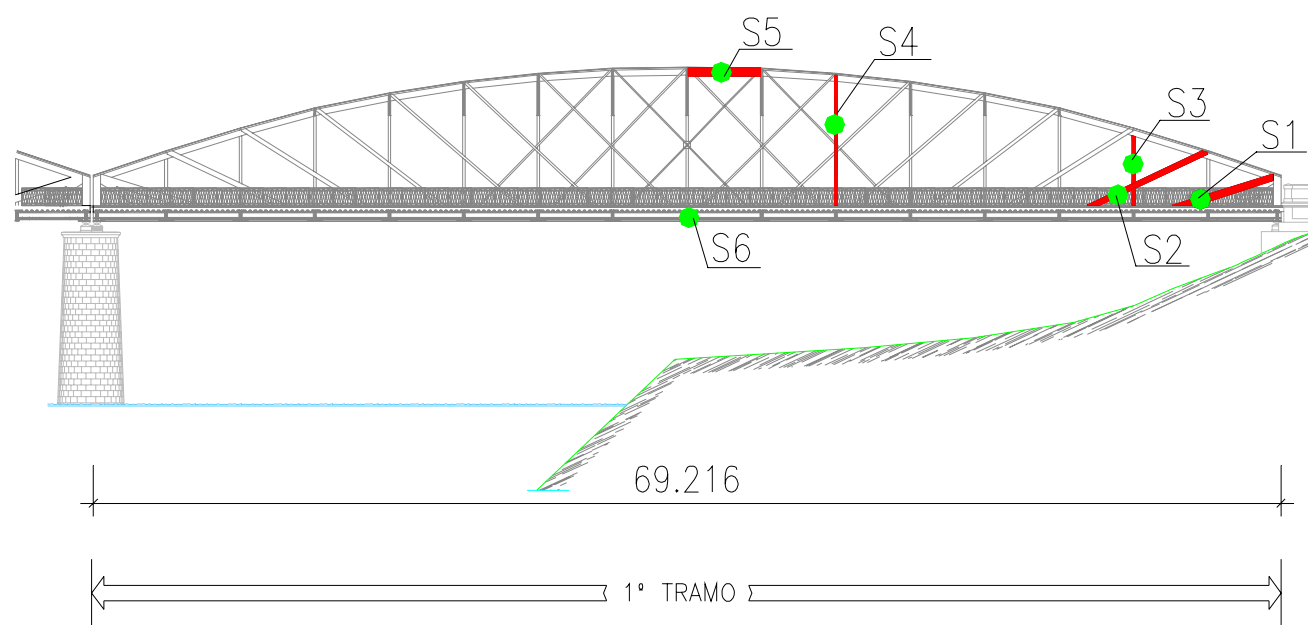

Figura 5.9 - Extensômetros instalados nas seções S1, S2, S3, S4, S5 e S6. 
Tabela 5.2 - Localização dos extensômetros instalados.

\begin{tabular}{|c|c|c|c|}
\hline Seção & & Localização & Referência \\
\hline \multirow{2}{*}{ S1 } & \multirow{12}{*}{ 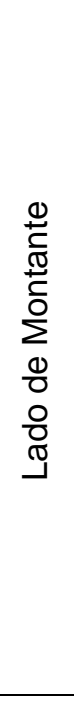 } & $2^{\mathrm{a}}$ diagonal- lado de jusante & ES1-1 \\
\hline & & $2^{\mathrm{a}}$ diagonal - lado de montante & ES1-2 \\
\hline \multirow{2}{*}{ S2 } & & $3^{\mathrm{a}}$ diagonal - lado de jusante & ES2-1 \\
\hline & & $3^{\mathrm{a}}$ diagonal - lado de montante & ES2-2 \\
\hline \multirow{2}{*}{ S3 } & & $3^{\circ}$ montante - lado de jusante & ES3-1 \\
\hline & & $3^{\circ}$ montante - lado de montante & ES3-2 \\
\hline \multirow{2}{*}{ S4 } & & $7^{\circ}$ montante - lado de jusante & ES4-1 \\
\hline & & $7^{\circ}$ montante - lado de montante & ES4-2 \\
\hline \multirow{2}{*}{ S5 } & & Corda superior - lado de jusante & ES5-1 \\
\hline & & Corda superior - lado de montante & ES5-2 \\
\hline \multirow[t]{2}{*}{ S6 } & & Corda inferior - lado de jusante & ES6-1 \\
\hline & & Corda inferior - lado de montante & ES6-2 \\
\hline \multirow{2}{*}{ S7 } & \multirow{12}{*}{ 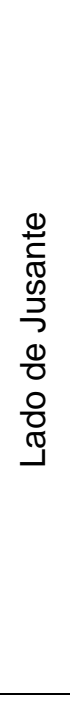 } & $2^{\mathrm{a}}$ diagonal- lado de montante & ES7-1 \\
\hline & & $2^{\mathrm{a}}$ diagonal - lado de jusante & ES7-2 \\
\hline \multirow{2}{*}{ S8 } & & $3^{\mathrm{a}}$ diagonal - lado de montante & ES8-1 \\
\hline & & $3^{\mathrm{a}}$ diagonal - lado de jusante & ES8-2 \\
\hline \multirow{2}{*}{ s9 } & & $3^{\circ}$ montante - lado de montante & ES9-1 \\
\hline & & $3^{\circ}$ montante - lado de jusante & ES9-2 \\
\hline \multirow{2}{*}{ S10 } & & $7^{\circ}$ montante - lado de montante & ES10-1 \\
\hline & & $7^{\circ}$ montante - lado de jusante & ES10-2 \\
\hline \multirow{2}{*}{ S11 } & & Corda superior - lado de montante & ES11-1 \\
\hline & & Corda superior - lado de jusante & ES11-2 \\
\hline \multirow{2}{*}{ S12 } & & Corda inferior - lado de montante & ES12-1 \\
\hline & & Corda inferior - lado de jusante & ES12-2 \\
\hline \multirow{2}{*}{ S13 } & \multirow{10}{*}{ 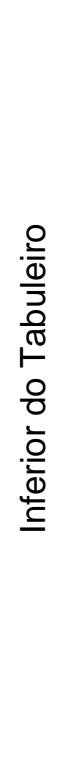 } & $2^{\mathrm{a}}$ longarina, a $1 / 2$ vão - cantoneira superior - $\mathrm{LJ}$ & ES13-1 \\
\hline & & $2^{\mathrm{a}}$ longarina, a $1 \frac{1}{2}$ vão - cantoneira inferior $-\mathrm{LJ}$ & ES13-2 \\
\hline \multirow{2}{*}{ S14 } & & $3^{\mathrm{a}}$ transversina - cantoneira inferior - lado da Régua & ES14-1 \\
\hline & & $3^{\mathrm{a}}$ trnasversina - cantoneira inferior - lado do Pinhão & ES14-2 \\
\hline \multirow{2}{*}{ S15 } & & $\begin{array}{l}3^{a} \text { transversina a } \frac{1}{2} 2 \text { vão - cantoneira inferior - lado da } \\
\text { Régua }\end{array}$ & ES15-1 \\
\hline & & $\begin{array}{l}3^{a} \text { transversina a } 1 \frac{1}{2} \text { vão - cantoneira inferior - lado do } \\
\text { Pinhão }\end{array}$ & ES15-2 \\
\hline \multirow{2}{*}{ S16 } & & $3^{\mathrm{a}}$ longarina, a $1 / 2$ vão - cantoneira superior $-\mathrm{LJ}$ & ES16-1 \\
\hline & & $3^{\mathrm{a}}$ longarina, a $1 \frac{1}{2}$ vão - cantoneira inferior - LJ & ES16-2 \\
\hline \multirow{2}{*}{ S17 } & & $\begin{array}{l}7^{a} \text { transversina a } 1 / 2 \text { vão - cantoneira inferior - lado do } \\
\text { Pinhão }\end{array}$ & ES17-1 \\
\hline & & $\begin{array}{l}7^{a} \text { transversina a } 1 / 2 \text { vão - cantoneira inferior - lado da } \\
\text { Régua }\end{array}$ & ES17-2 \\
\hline
\end{tabular}


A figura 5.10 ilustra o posicionamento dos extensômetros nas diagonais, montantes e nas cordas superior e inferior, do lado de jusante.

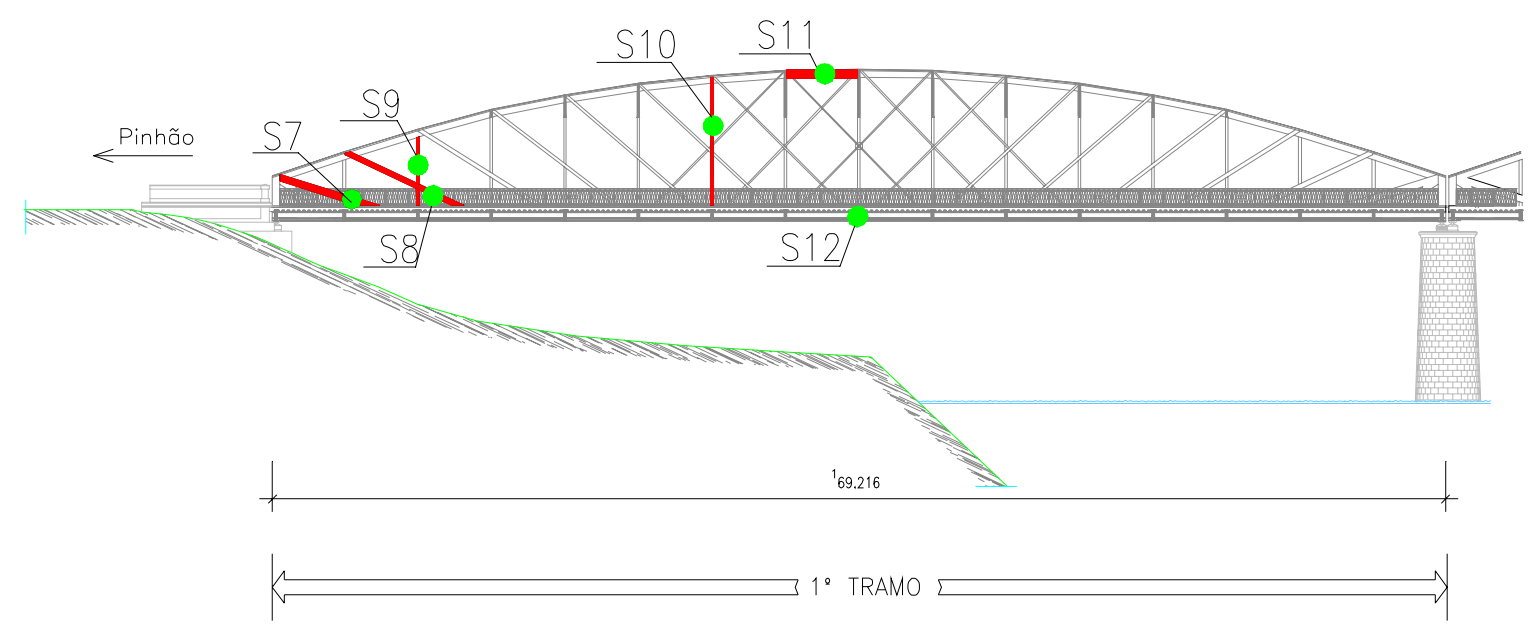

Figura 5.10 - Extensômetros instalados nas secções S7, S8, S9, S10, S11 e S12.

A figura 5.11 apresenta a planta superior e inferior do primeiro tramo, com a localização de algumas seções instrumentadas com extensômetros. As figuras 5.12 e 5.13 ilustram os extensômetros presentes nas seções S13 a S17. 
(a)
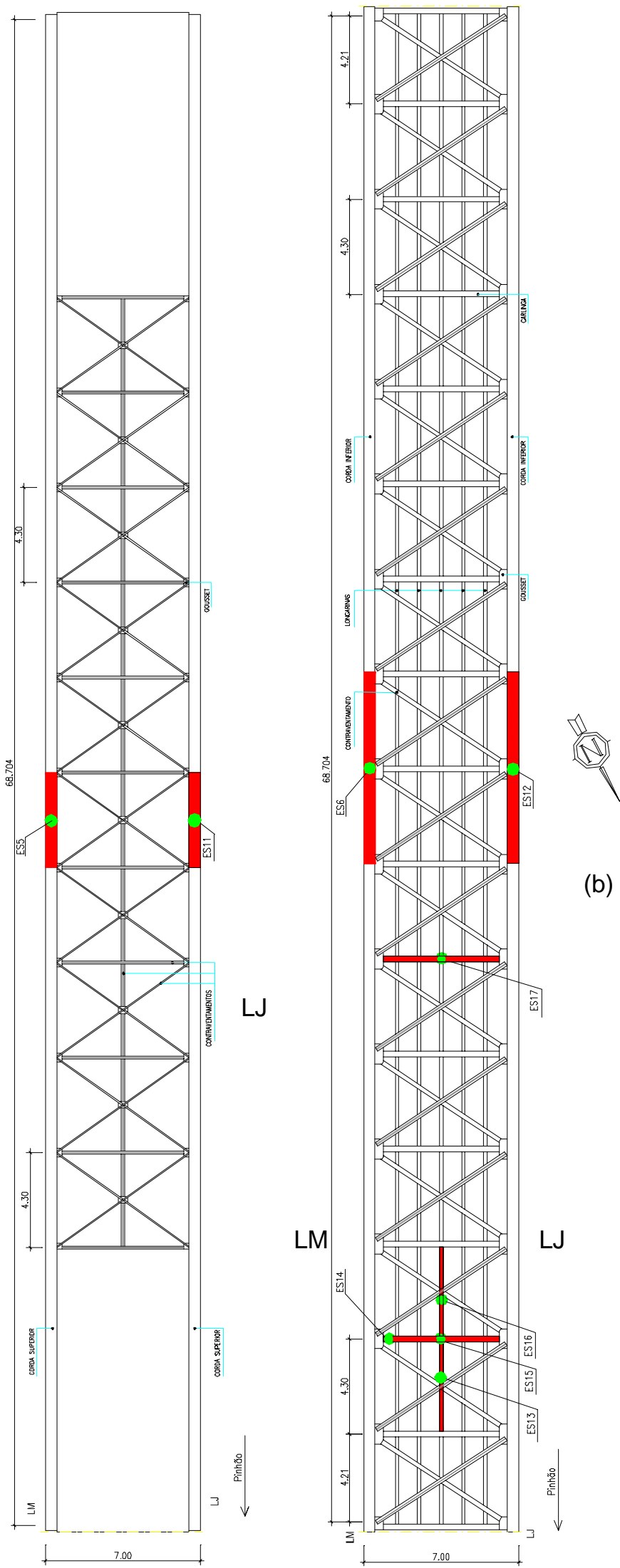

(b)

Figura 5.11 - Plantas do primeiro tramo: (a) superior e (b) inferior. 


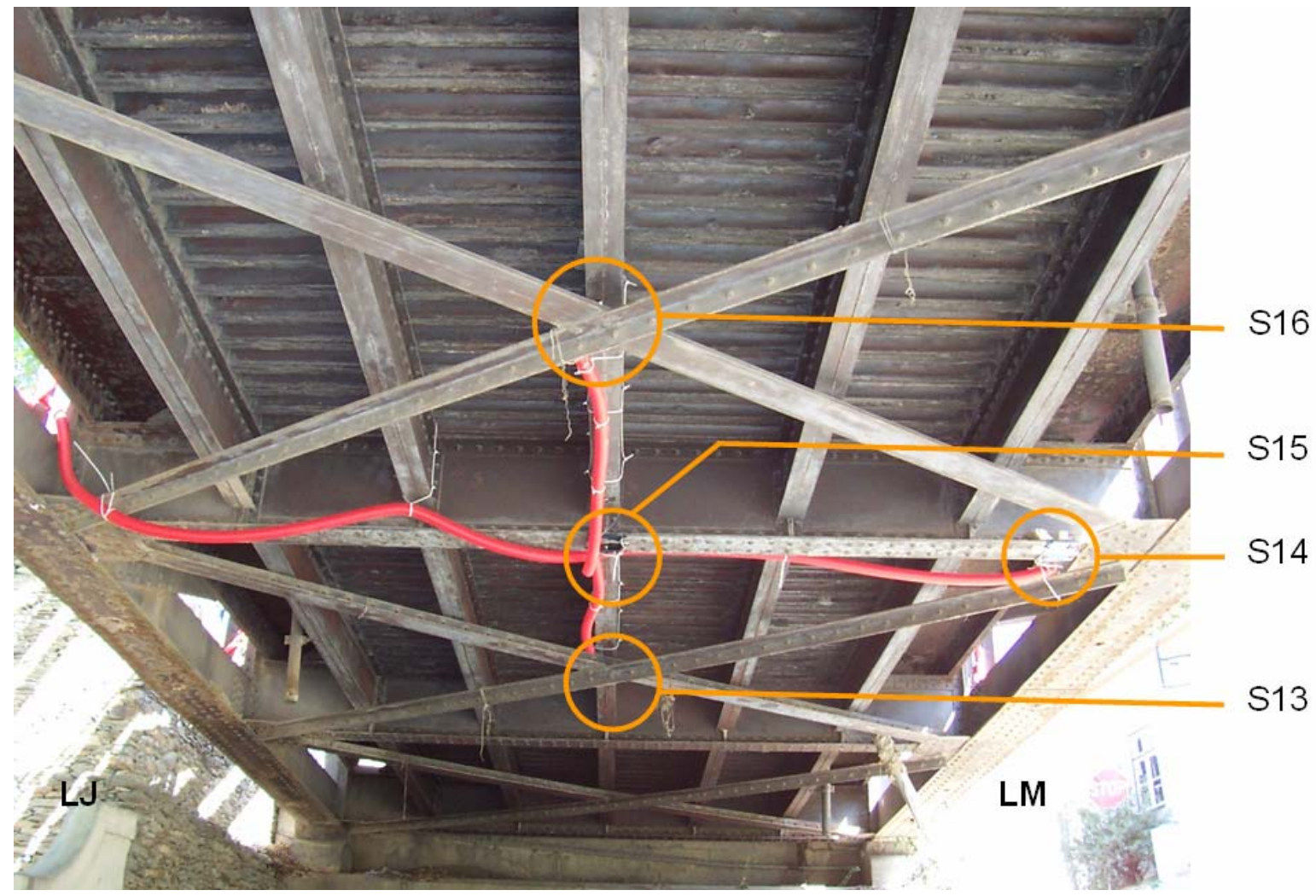

Figura 5.12 - Extensômetros instalados nas seções S13 a S16.

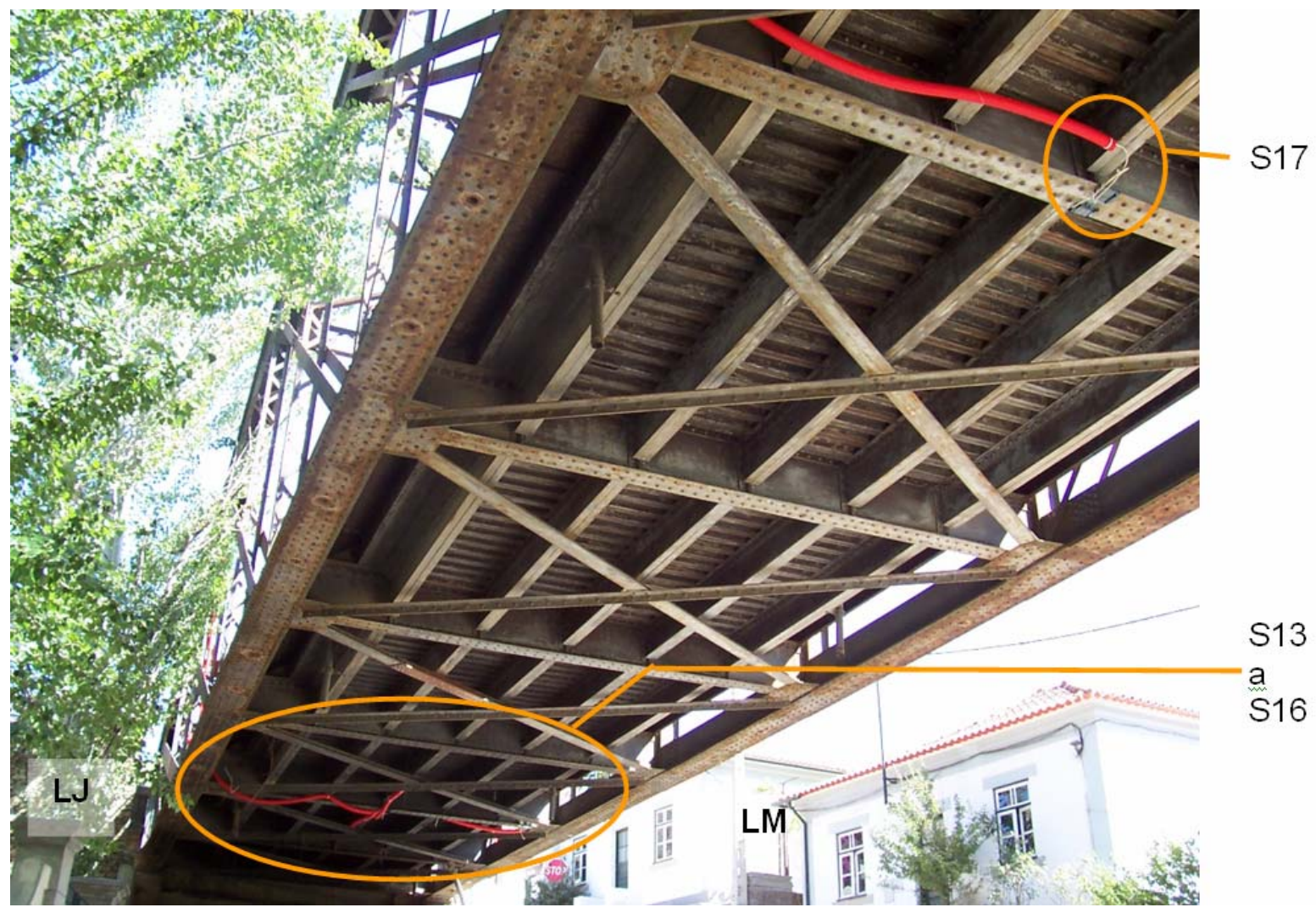

Figura 5.13 - Extensômetros instalados na seção S17. 
A seguir, é apresentada a localização dos extensômetros instalados nas seções S1 e S4, com desenhos e fotografias (figuras 5.14, 5.15, 5.16 e 5.17).

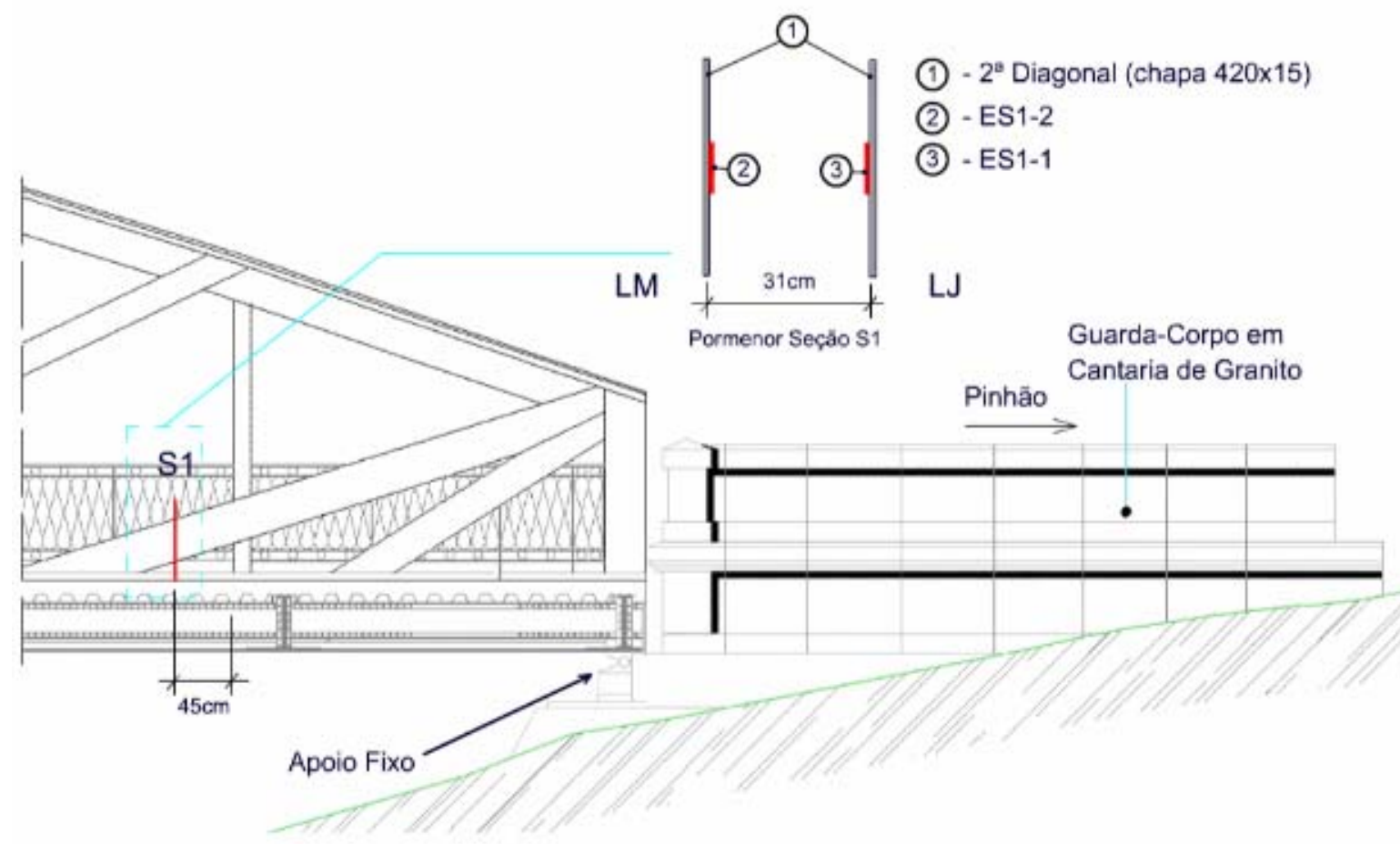

Figura 5.14 - Localização dos extensômetros instalados na seção S1.

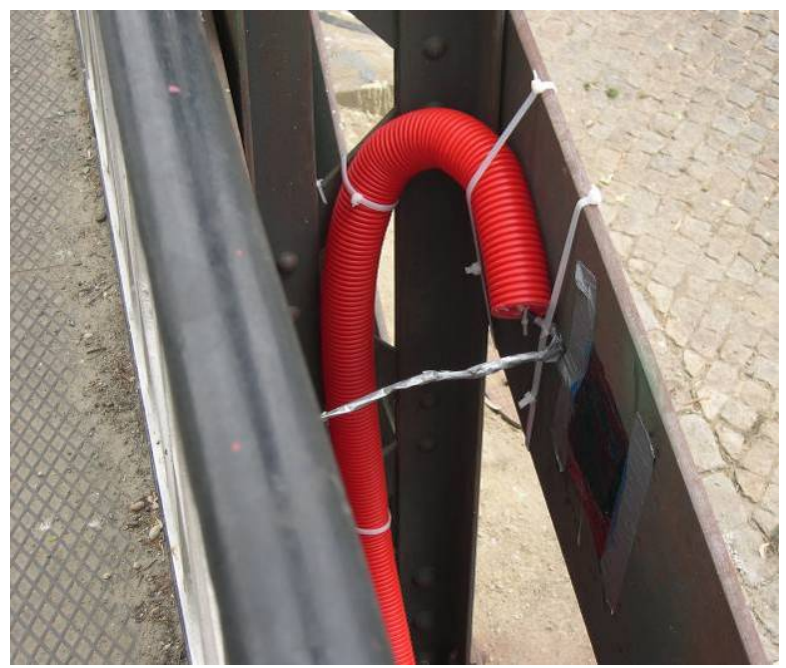

(a)

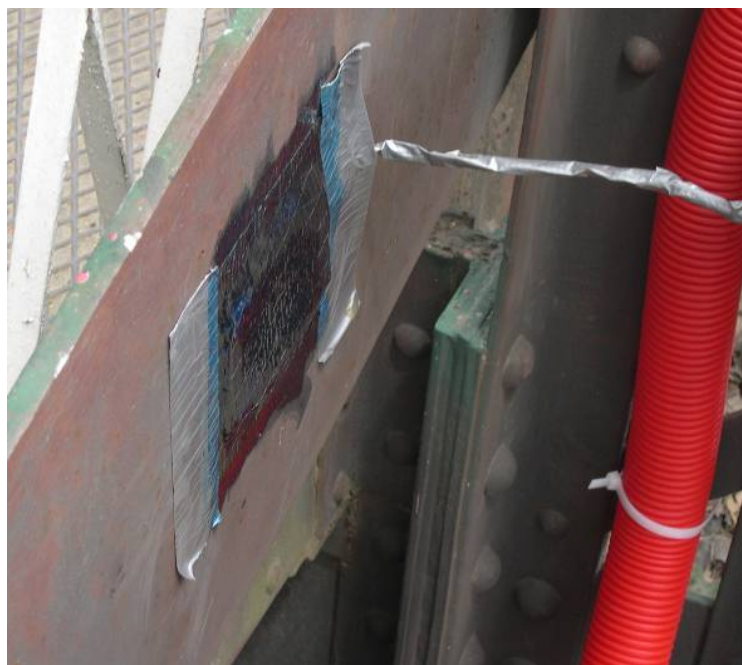

(b)

Figura 5.15 - Localização dos extensômetros ES1-2 (a) e ES1-1 (b), instalados na seção S1. 

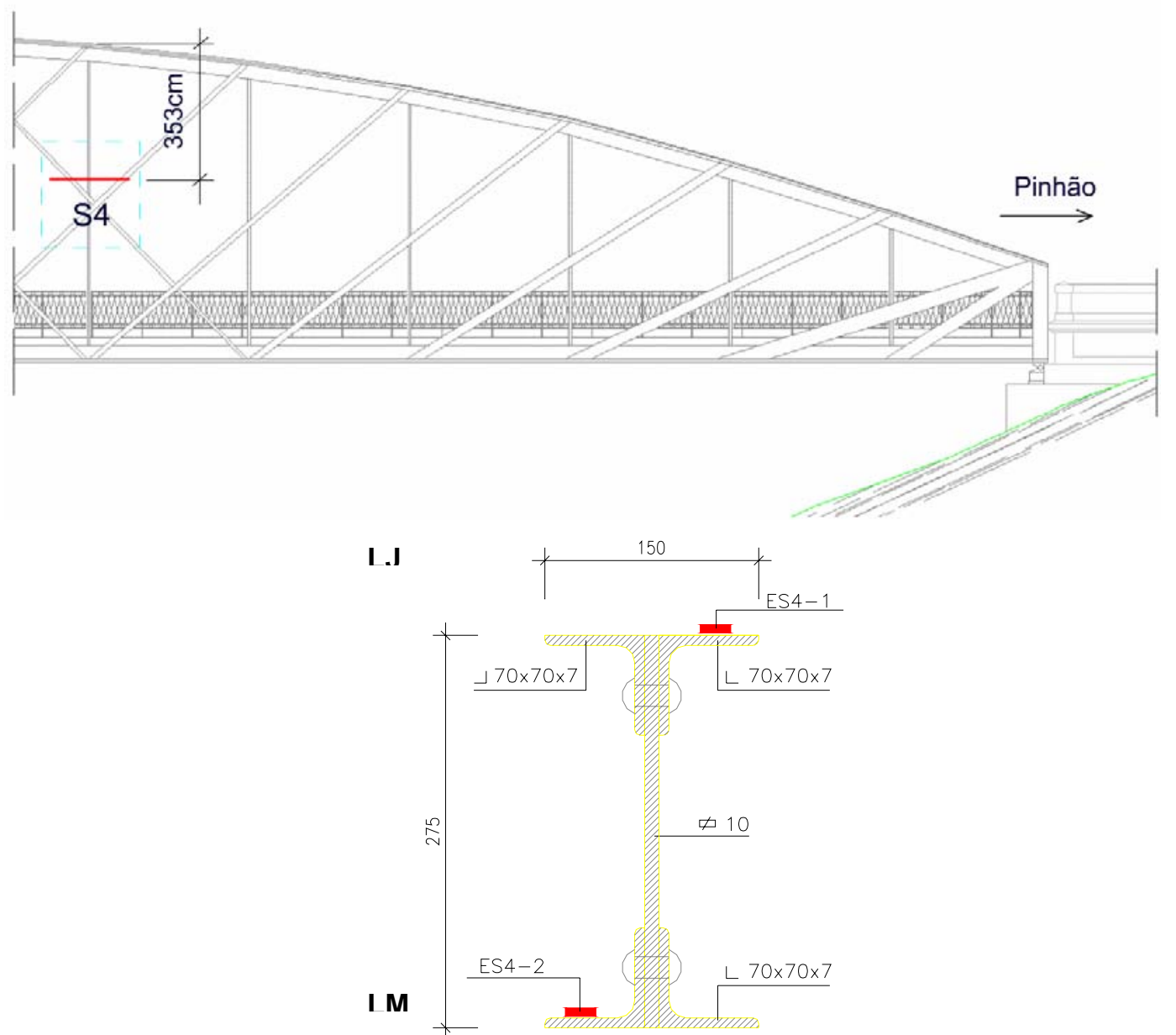

Figura 5.16 - Localização dos extensômetros instalados na seção S4.
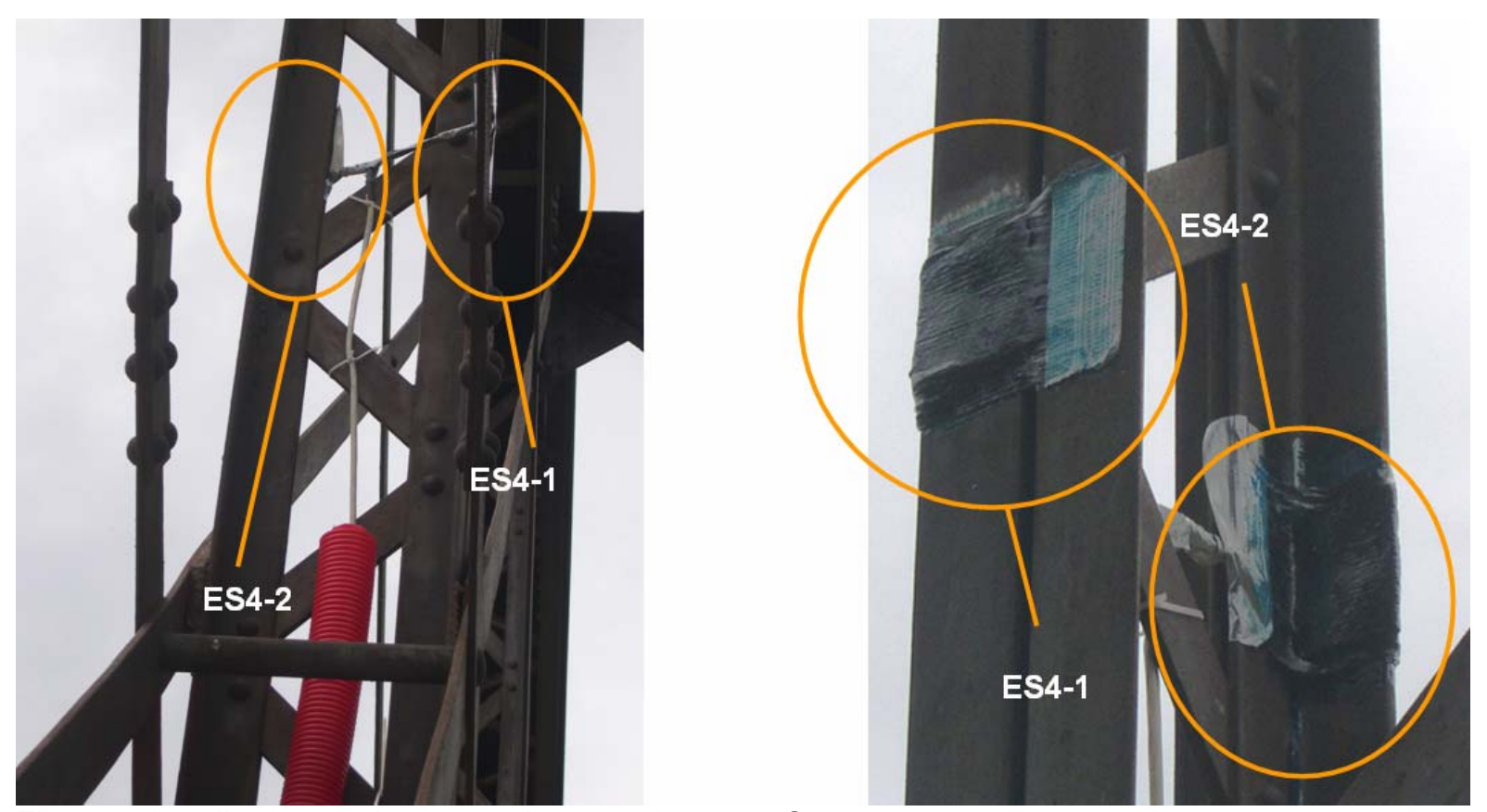

Figura 5.17 - Ilustração dos extensômetros da seção S4. 


\subsubsection{Medição de deslocamentos verticais}

$\mathrm{Na}$ medição dos deslocamentos verticais foram usados sensores de pressão e comparadores elétricos (figura 5.18). Os sensores de pressão foram montados em bases rígidas apoiadas no próprio tabuleiro, tendo como referência um dos encontros. Os comparadores elétricos foram montados em bases rígidas no solo, tendo como referência o próprio tabuleiro. As estruturas de suporte dos sensores de pressão eram constituídas por tripés metálicos assentados numa base metálica quadrada. No caso dos comparadores elétricos, as estruturas de suporte eram constituídas por prumos metálicos, cilíndricos e modulares, cuja verticalidade foi assegurada por um sistema de cabos de aço tensionados. Na tabela 5.3 é especificada a localização de cada um dos sensores de deslocamento instalados e a sua designação.

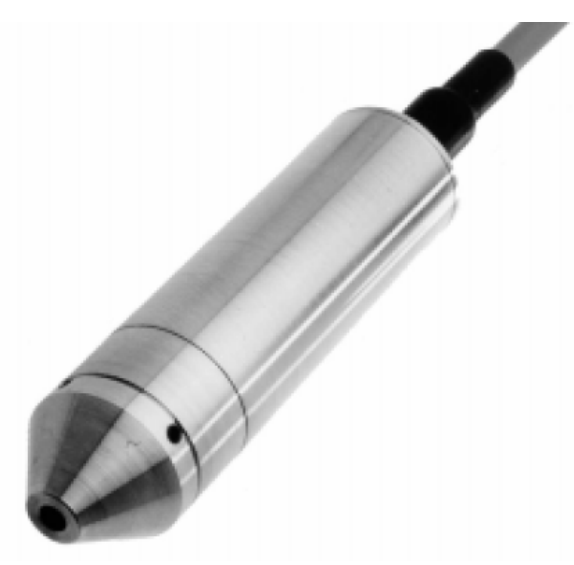

(a)

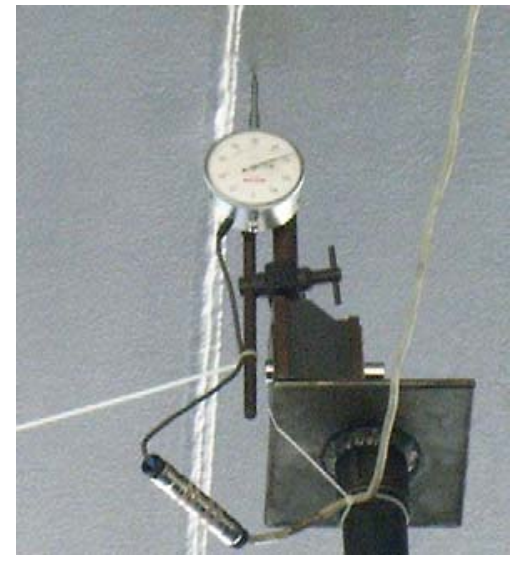

(b)

Figura 5.18 - Sensores de deslocamento utilizados: sensor de pressão (modelo TS-01) e comparador elétrico.

No total foram instalados oito sensores elétricos de deslocamento, sendo:

a) Três comparadores elétricos, sob a terceira transversina, para medição de flechas em relação ao solo;

b) Cinco sensores utilizando o sistema de níveis líquidos para medição das flechas nos três tramos da ponte, a meio dos vãos, com a seguinte distribuição: no primeiro tramo, dos lados de montante e de jusante (2); 
e no segundo e terceiro tramos, do lado de jusante (2), além do sensor de referência no encontro do lado do Pinhão, à montante (1).

Tabela 5.3 - Descrição dos sensores de deslocamento instalados.

\begin{tabular}{|c|c|c|c|}
\hline $\begin{array}{l}\text { Referência } \\
\text { do sensor }\end{array}$ & Tipo de sensor & Localização & Descrição \\
\hline DVO & \multirow{8}{*}{ Elétrico } & $\begin{array}{l}\text { Encontro do lado do } \\
\text { Pinhão }\end{array}$ & Sensor de referência \\
\hline DV1 & & $\begin{array}{l}\text { Alinhamento de } \\
\text { montante }\end{array}$ & $\begin{array}{l}\text { Deslocamento vertical a } \\
\text { meio-vão do } 1^{\circ} \text { tramo - } \\
\text { Alinhamento de } \\
\text { montante }\end{array}$ \\
\hline DV2 & & \multirow{3}{*}{$\begin{array}{l}\text { Alinhamento de } \\
\text { jusante }\end{array}$} & $\begin{array}{l}\text { Deslocamento vertical a } \\
\text { meio-vão do } 1^{\circ} \text { tramo - } \\
\text { Alinhamento de jusante }\end{array}$ \\
\hline DV3 & & & $\begin{array}{l}\text { Deslocamento vertical a } \\
\text { meio-vão do } 2^{\circ} \text { tramo }\end{array}$ \\
\hline DV4 & & & $\begin{array}{l}\text { Deslocamento vertical a } \\
\text { meio-vão do } 3^{\circ} \text { tramo }\end{array}$ \\
\hline DV5 & & $\begin{array}{l}\text { Extremidade do lado } \\
\text { de montante da } 3^{a} \\
\text { transversina }\end{array}$ & $\begin{array}{l}\text { Deslocamento vertical na } \\
\text { extremidade do lado de } \\
\text { montante da } 3^{\mathrm{a}} \\
\text { transversina }\end{array}$ \\
\hline DV6 & & $\begin{array}{l}\text { Meio-vão da } 3^{a} \\
\text { transversina }\end{array}$ & $\begin{array}{l}\text { Deslocamento vertical a } \\
\text { meio-vão da } 3^{\mathrm{a}} \\
\text { transversina }\end{array}$ \\
\hline DV7 & & $\begin{array}{l}\text { Extremidade do lado } \\
\text { de jusante da } 3^{a} \\
\text { transversina }\end{array}$ & $\begin{array}{l}\text { Deslocamento vertical na } \\
\text { extremidade a jusante da } \\
3^{\mathrm{a}} \text { transversina }\end{array}$ \\
\hline
\end{tabular}

Os locais do tabuleiro instrumentados com sensores de deslocamento são apresentados na figura 5.19. Na figura 5.20 são apresentados dois sensores de deslocamentos após a instalação, ao passo que as tabelas 5.4 e 5.5 fornecem as especificações técnicas referentes aos comparadores elétricos e sensores de pressão utilizados, respectivamente. 


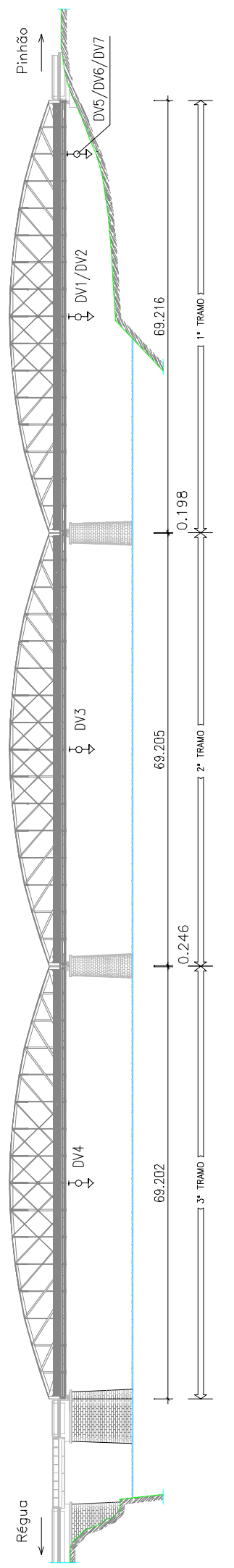

(a)

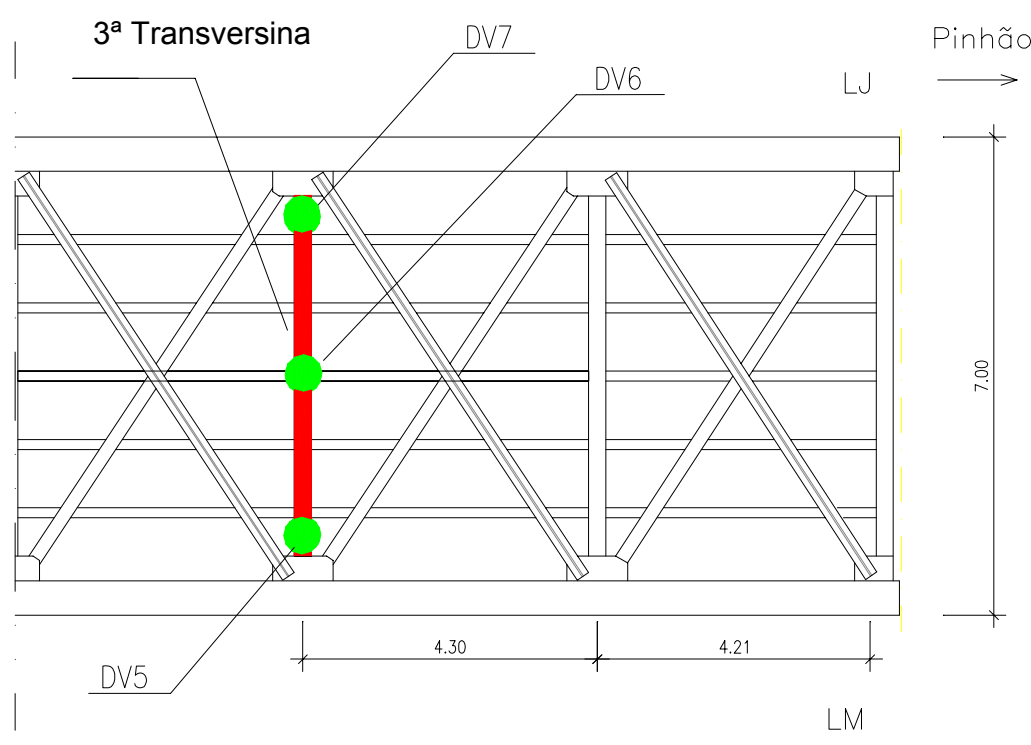

(b)

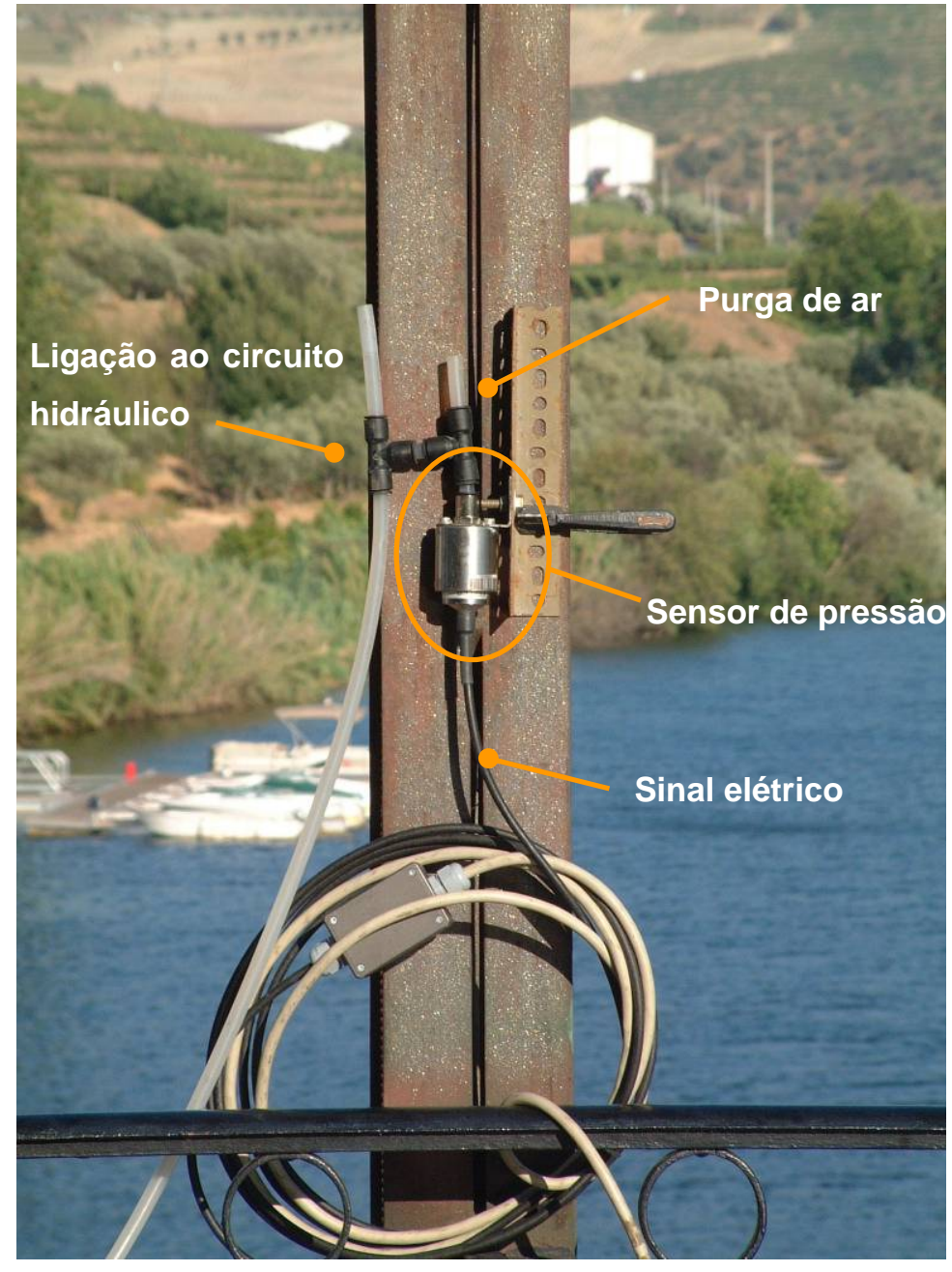

(c)

Figura 5.19 - Localização dos sensores de deslocamento: longitudinalmente (a), sob a $3^{\mathrm{a}}$ transversina (b) e esquema de ligação do sensor de pressão (c). 


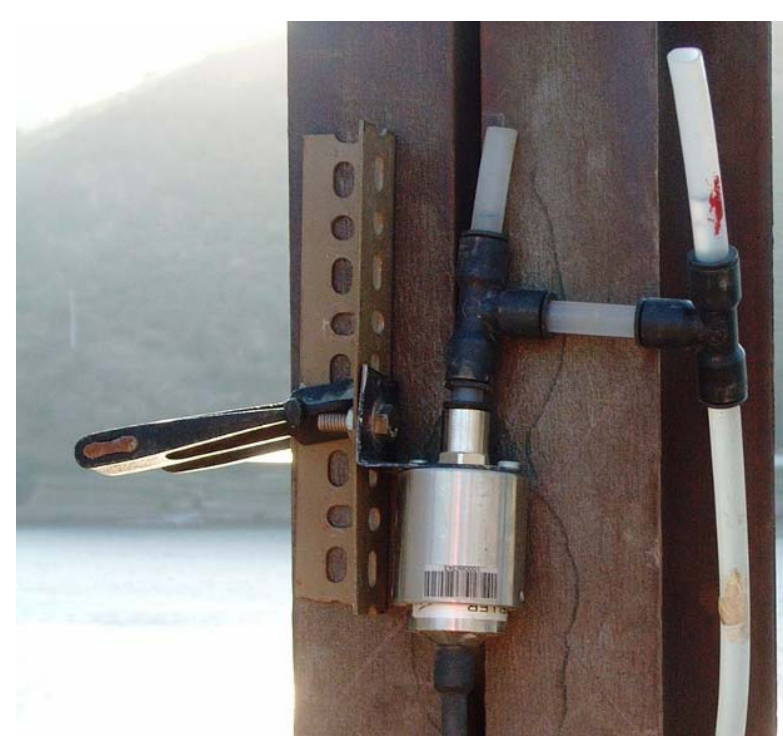

(a)

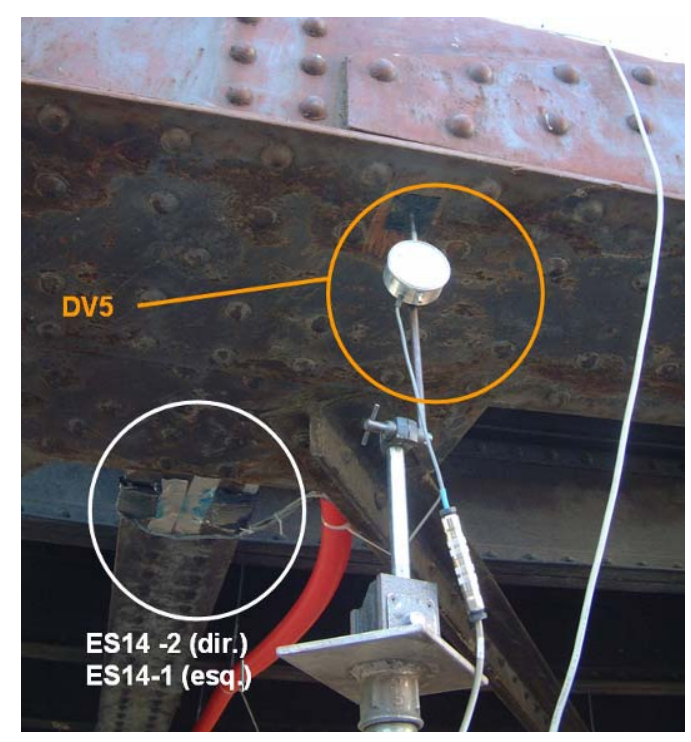

(b)

Figura 5.20 - Sensores de deslocamento após instalação: sensor de pressão DV3 (a) e comparador elétrico DV5.

Tabela 5.4 - Especificações técnicas dos comparadores elétricos utilizados.

\begin{tabular}{l|l}
\hline Característica & Especificação \\
\hline Gama de medição & $0-30 \mathrm{~mm}$ \\
\hline Linearidade & $0,20 \% \mathrm{RO}$ \\
\hline Sensibilidade & $100 \times 10^{-6} / \mathrm{mm}$ \\
\hline Tensão de excitação recomendada & $5 \mathrm{~V}$ se regulada \\
\hline Temperatura ideal de funcionamento & $23^{\circ} \mathrm{C}$ \\
\hline Umidade relativa ideal de funcionamento & $65 \%$ \\
\hline
\end{tabular}

Tabela 5.5 - Especificações técnicas dos sensores de pressão.

\begin{tabular}{l|l|l}
\hline \multirow{2}{*}{ Características } & \multicolumn{2}{c}{ Especificações } \\
\cline { 2 - 3 } & Modelo TS 01 & Modelo SN \\
\hline Gama de medição & 0 a $1 \mathrm{mH}_{2} \mathrm{O}$ & 0 a $20 \mathrm{cmH}_{2} \mathrm{O}$ \\
\hline Linearidade & $0,35 \% \mathrm{FS}$ & $0.03 \% \mathrm{FS}$ \\
\hline Sensibilidade & - & $0.800 \mathrm{~mA} / \mathrm{cmH}_{2} \mathrm{O}$ \\
\hline Tensão de excitação & 12 a $30 \mathrm{~V}$ & +8 a $28 \mathrm{~V}$ \\
\hline Gama de temperatura de funcionamento & -10 a $85^{\circ} \mathrm{C}$ & 0 a $50{ }^{\circ} \mathrm{C}$ \\
\hline
\end{tabular}




\subsubsection{Medição da abertura da junta de dilatação}

A medição da abertura da junta de dilatação do tabuleiro do primeiro tramo, nos locais definidos no plano de monitoração, foi obtida por meio de transdutores indutivos de deslocamentos (LVDT). Foram utilizados dois LVDT's para medir a abertura da junta de dilatação da ponte, localizados nos apoios móveis do primeiro tramo, medindo deslocamentos longitudinais (figura 5.21).

$2^{\circ}$ Tramo

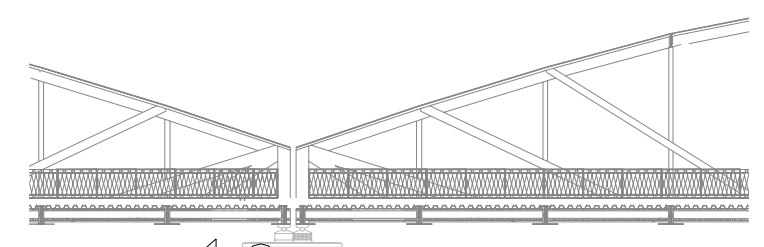

DJE1 e DJE2 $1^{\circ}$ Tramo

Figura 5.21 - Localização dos transdutores de deslocamento para abertura de junta DJE1 e DJE2.

A tabela 5.6 resume a localização dos LVDT's instalados, que são ilustrados na figura 5.22. Na tabela 5.7 são apresentadas as características técnicas dos transdutores utilizados.

Tabela 5.6 - Transdutores de deslocamentos para medição de aberturas de juntas.

\begin{tabular}{|c|c|c|}
\hline Referência & Localização & Descrição \\
\hline DJE1 & $\begin{array}{l}\text { Apoio móvel do } 1^{\circ} \text { tramo } \\
\text { Lado Montante }\end{array}$ & \multirow{2}{*}{$\begin{array}{l}\text { Medição deslocamentos longitudinais na ponte } \\
\text { (abertura de junta) }\end{array}$} \\
\hline DJE2 & $\begin{array}{c}\text { Apoio móvel do } 1^{\circ} \text { tramo } \\
\text { Lado Jusante }\end{array}$ & \\
\hline
\end{tabular}




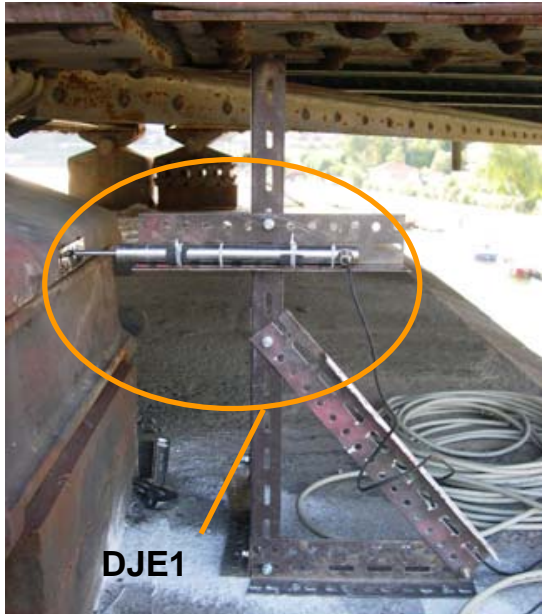

(a)

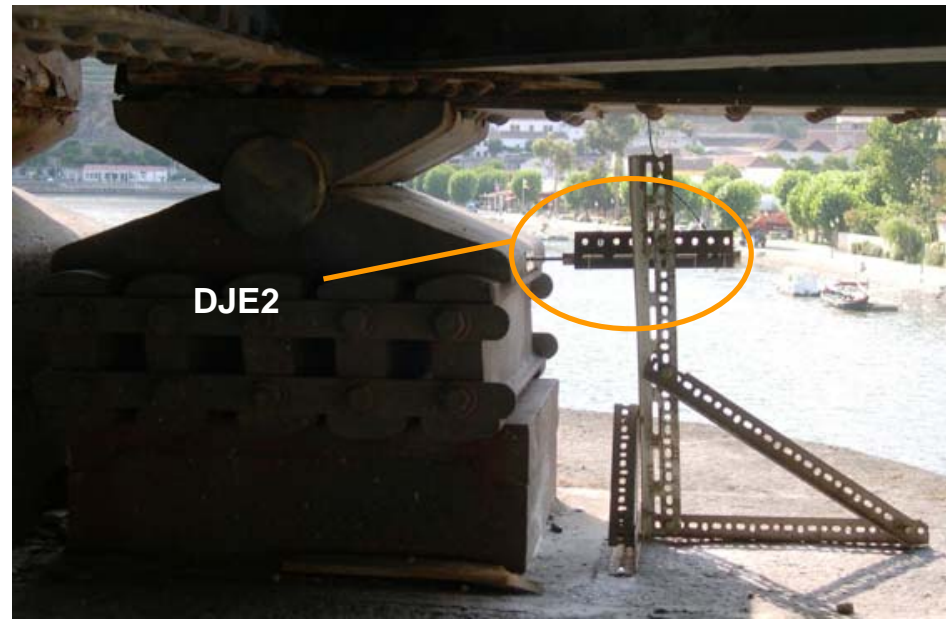

(b)

Figura 5.22 - Transdutores para medição de movimentos longitudinais DJE1 (a) e DJE2 (b).

Tabela 5.7 - Especificações técnicas dos LVDT's.

\begin{tabular}{l|l}
\hline Característica & Especificação \\
\hline Gama de medição & $\pm 25 \mathrm{~mm}$ \\
\hline Linearidade & $0,21 \% \mathrm{FS}$ \\
\hline Sensibilidade & $89.04 \mathrm{mV} / \mathrm{mm}$ \\
\hline Tensão de excitação recomendada & $5 \mathrm{~V}$ se regulada \\
\hline Gama de temperatura de funcionamento & $-50^{\circ} \mathrm{C}$ a $+70^{\circ} \mathrm{C}$ \\
\hline
\end{tabular}

\subsubsection{Medição de rotações}

Durante a realização da prova de carga, procedeu-se à medição das rotações de seções no primeiro tramo, no lado de jusante, sendo uma das seções localizada no encontro do Pinhão, e a outra, na face superior da corda inferior, junto ao apoio móvel. Para a monitoração das rotações foram utilizados inclinômetros biaxiais, que permitem medir a inclinação em relação a um plano horizontal segundo duas direções distintas. No ensaio realizado foi registrada a variação de inclinação na direção longitudinal do tabuleiro. A tabela 5.8 resume a localização dos inclinômetros instalados, enquanto a figura 5.23 ilustra-os após o devido posicionamento. As principais características dos inclinômetros adotados estão resumidas na tabela 5.9 . 
Tabela 5.8 - Inclinômetros instalados.

\begin{tabular}{c|l|c}
\hline Referência & \multicolumn{1}{|c|}{ Localização } & Descrição \\
\hline I1 & $1^{\circ}$ tramo, LJ, encontro lado do Pinhão & \multirow{2}{*}{ Medição de rotações na direção longitudinal } \\
\cline { 1 - 2 } I2 & $1^{\circ}$ tramo, LJ, no apoio móvel & \\
\hline
\end{tabular}

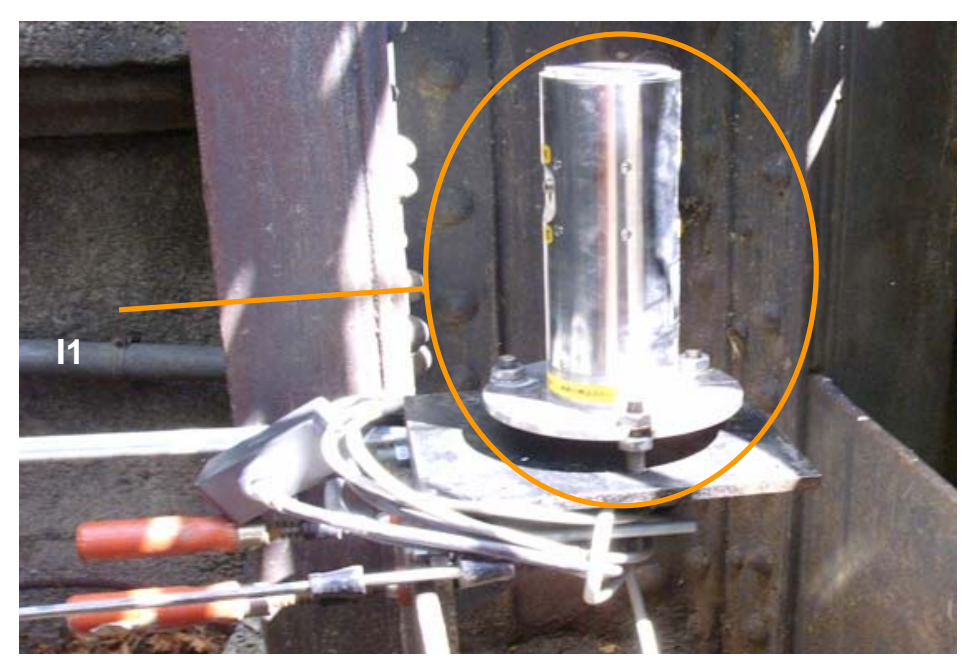

(a)

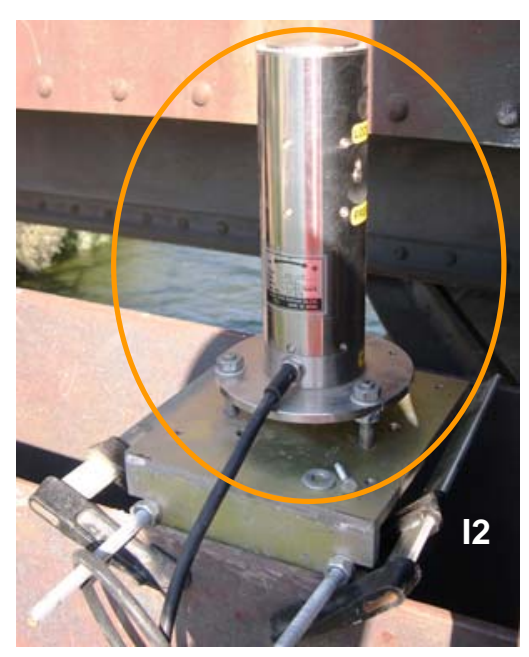

(b)

Figura 5.23 - Ilustração dos inclinômetros biaxiais I1 (a) e I2 (b).

Tabela 5.9 - Características técnicas dos inclinômetros elétricos utilizados.

\begin{tabular}{l|l}
\hline Característica & Especificação \\
\hline N. ${ }^{\circ}$ de eixos de medida & 2 Eixos (biaxial) \\
\hline Campo de medida & $\pm 1^{\circ}$ \\
\hline Ampliação & $1 \mathrm{mV} / \mathrm{V}$ \\
\hline Não linearidade & $0,1 \%$ \\
\hline Sensibilidade transversal & $2 \%$ \\
\hline Resistência & $350 \Omega$ \\
\hline Tensão de excitação recomendada & Inferior a 2 V \\
\hline Tensão máxima admissível & $5 \mathrm{~V}$ \\
\hline
\end{tabular}




\subsubsection{Medição da temperatura}

A medição da temperatura ambiente foi realizada por meio de quatro detectores resistivos do tipo PT100, identificados como T1, T2, T3 e T4. O invólucro dos sensores é constituído por um tubo de cobre, com $6 \mathrm{~mm}$ de diâmetro, formando um encapsulamento que garante a estanqueidade e a proteção mecânica do elemento sensor. A tabela 5.10 resume a localização dos sensores de temperatura instalados, apresentada na figura 5.24. A figura 5.25 ilustra o sensor T2 após a instalação.

Tabela 5.10 - Sensores de temperatura instalados.

\begin{tabular}{c|l|c}
\hline Referência & \multicolumn{1}{c|}{ Localização } & \multirow{2}{*}{ Descrição } \\
\cline { 1 - 2 } T1 & $\begin{array}{l}\text { Meio vão do } 1^{\circ} \text { tramo, região superior da } \\
\text { corda inferior - Lado de montante }\end{array}$ & \multirow{2}{*}{$\begin{array}{l}\text { Medição de temperatura } \\
\text { inferior - Lado do } 1^{\circ} \text { tramo, mesa da cordante }\end{array}$} \\
\cline { 1 - 2 } ambiente
\end{tabular}

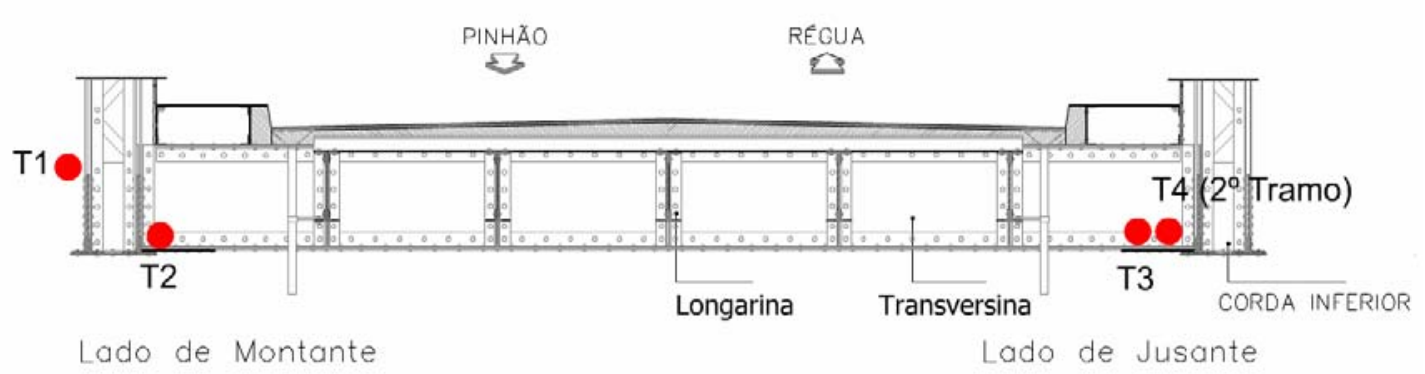

(a)

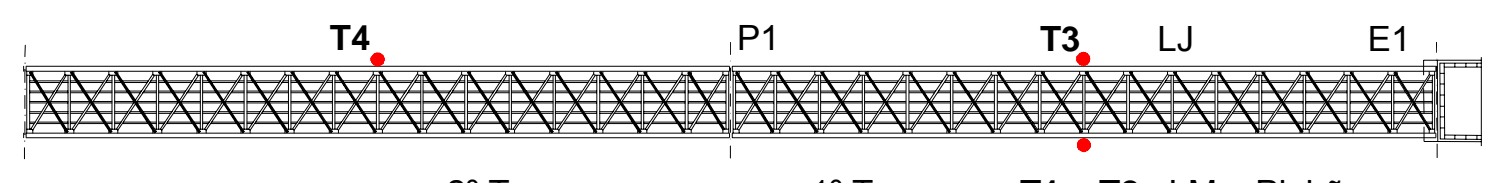
$2^{\circ}$ Tramo
$1^{\circ}$ Tramo T1 e T2 LM Pinhão $\rightarrow$

(b)

Figura 5.24 - Localização dos sensores T1, T2, T3 e T4: em corte (a) e em planta (b). 


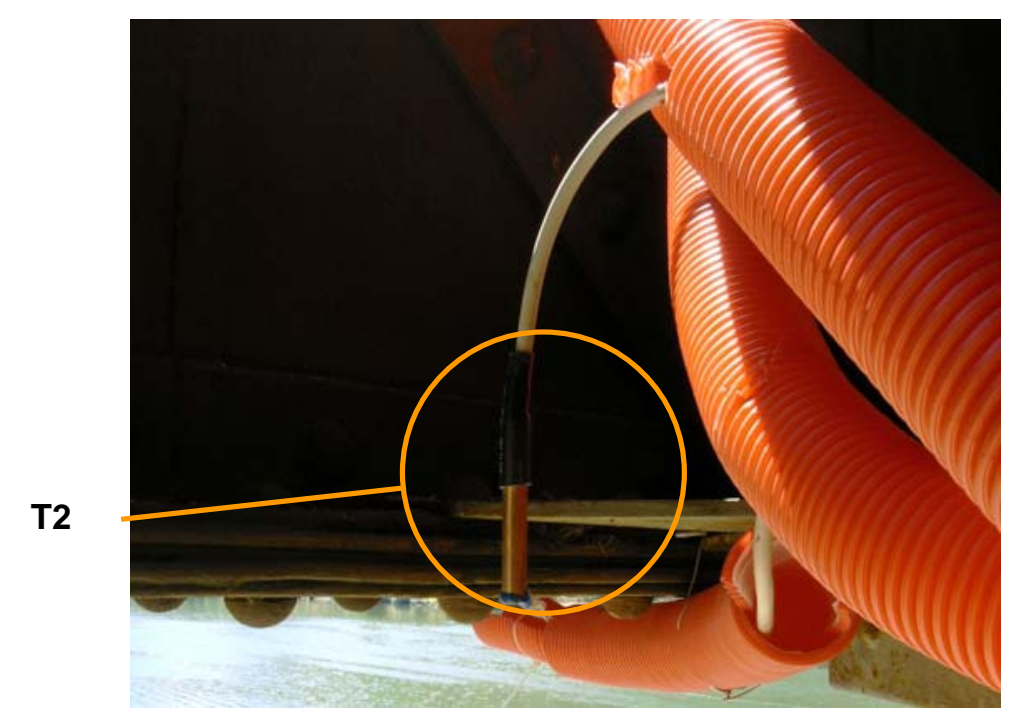

Figura 5.25 - Sensor de temperatura T2.

\subsubsection{Sistema de aquisição}

O sistema de aquisição e de armazenamento de sinal foi distribuído em dois postos de observação, designados por PO1 e PO2. No posto de observação PO1 foram instalados três data loggers do modelo dataTaker DT800, e neles ficaram ligados todos os extensômetros elétricos e sensores de temperatura. No PO2, foi instalado um data logger do modelo dataTaker DT800, e nele foram ligados os sensores de deslocamento (LVDT's e sensores de pressão) e inclinômetros.

O PO1 foi apoiado em um dos perfis de contraventamento sob o nono montante do primeiro tramo, do lado de montante. As figuras 5.26 e 5.27 ilustram a localização do posto de observação PO1 na estrutura.

O posto de observação $\mathrm{PO}$, de caráter provisório, foi posicionado junto ao guarda-corpo da ponte, no segundo tramo, do lado de jusante, em região sobre o pilar P1 (figuras 5.28 e 5.29). Instalado em 04 de agosto de 2004, este posto de observação foi utilizado apenas até ao final da prova de carga. Como as condições de segurança não permitiram a permanência dos inclinômetros e sensores de deslocamento no local de medição, estes foram removidos e com eles o PO2. 


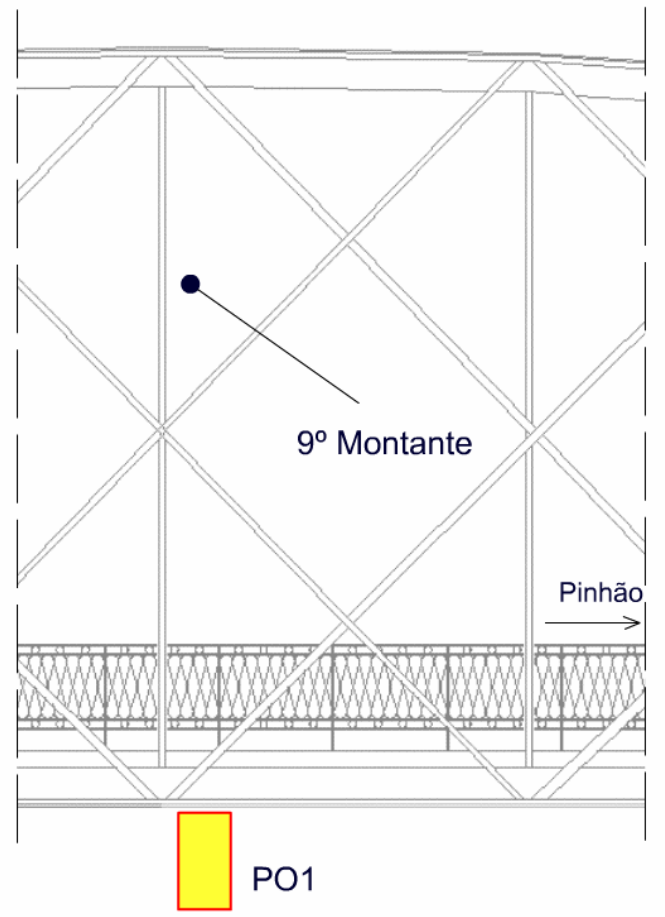

(a)

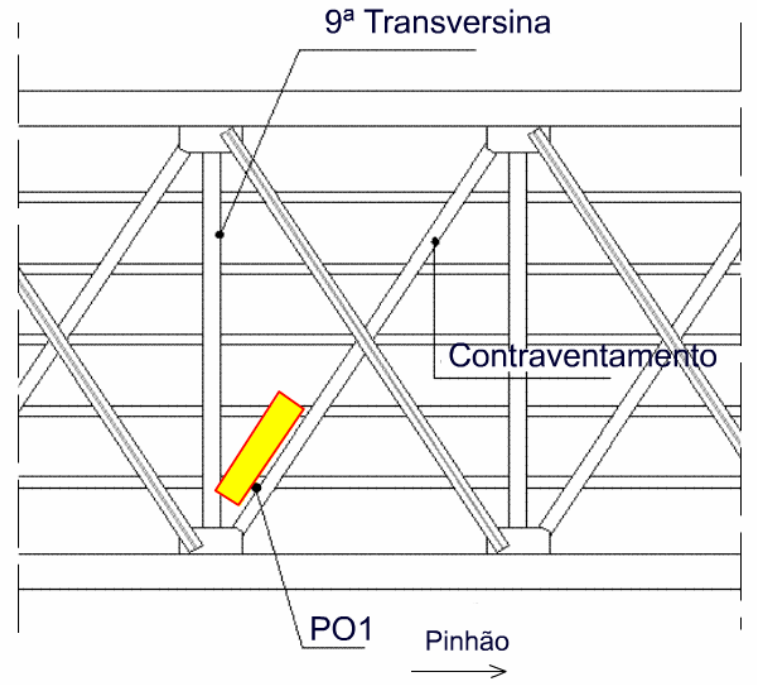

(b)

Figura 5.26 - Localização do posto de observação PO1: vista lateral (a) e em planta (b).

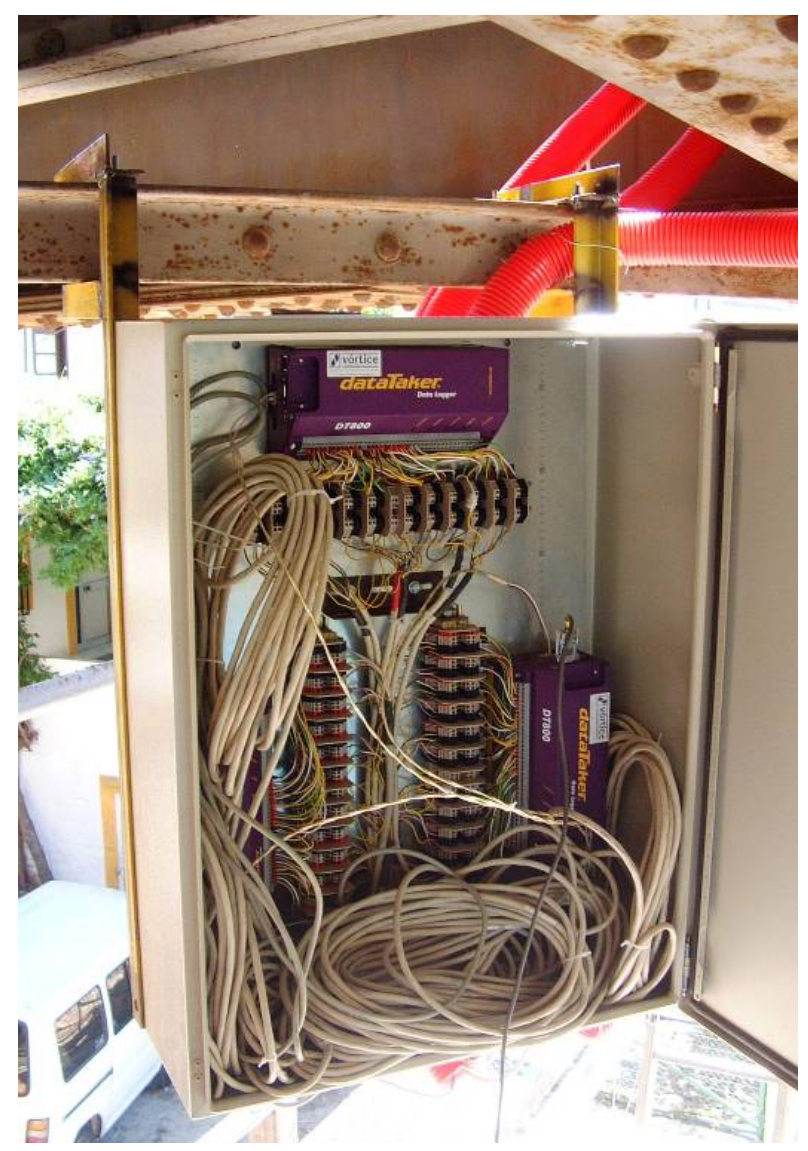

Figura 5.27 - Posto de observação PO1. 


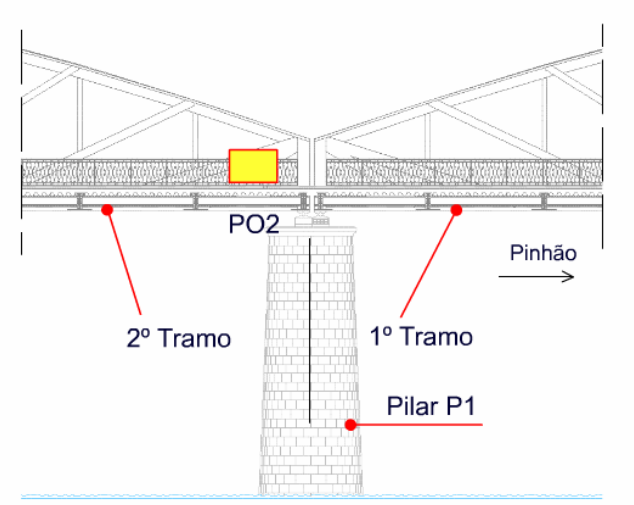

(a)

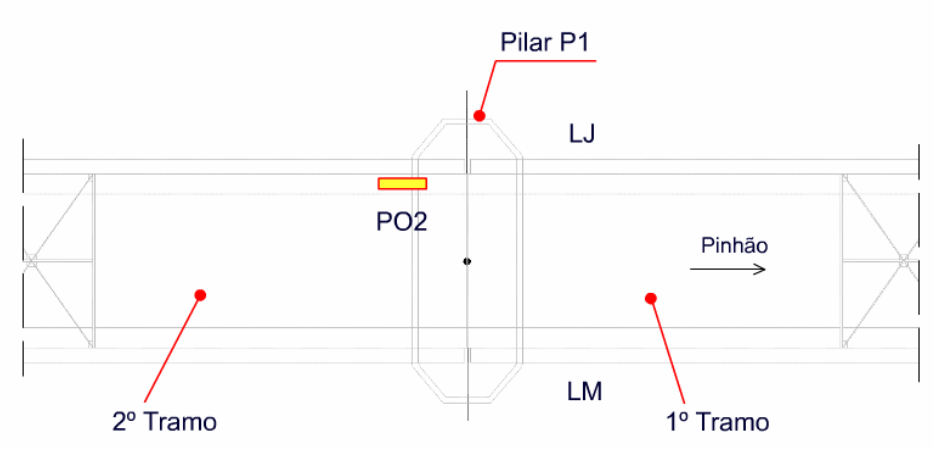

(b)

Figura 5.28 - Localização do posto de observação PO2: vista lateral (a) e em planta (b).

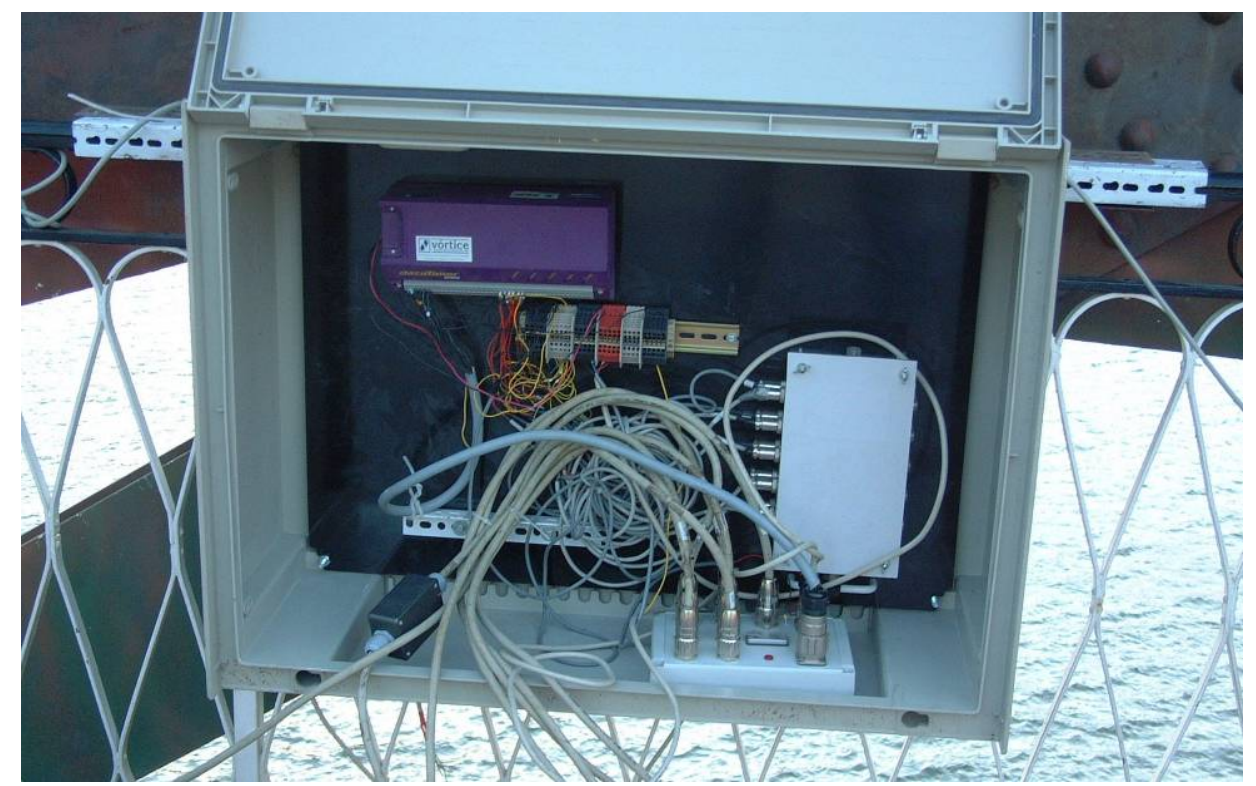

Figura 5.29 - Posto de observação PO2.

Durante a prova de carga a comunicação com o sistema de aquisição foi efetuada a partir de um computador portátil, instalado no laboratório móvel do LABEST, que permitiu o acompanhamento e visualização em tempo real das medições que iam sendo efetuadas, e uma melhor coordenação entre a medição e o carregamento da estrutura.

O sistema de aquisição possuía funcionamento autônomo e programável, permitindo definir previamente os intervalos de tempo entre aquisições. Durante a prova de carga foi definido um intervalo entre aquisições de 1 segundo. Após o ensaio, foi desmontada toda a instrumentação instalada para esse fim e o respectivo 
material de apoio, permanecendo os extensômetros e dois sensores de temperatura (T1 e T2).

\subsection{Condução da prova de carga}

Nesta seção são descritas as principais características dos veículos utilizados para a realização das sobrecargas, o seu posicionamento em perfil, a sequência adotada e os objetivos a atingir com os casos de carga definidos. A prova de carga na Ponte do Pinhão ocorreu no dia 05 de Agosto de 2004. No ensaio foram utilizados três veículos, dispostos nas condições consideradas mais desfavoráveis para as grandezas que foram medidas.

\subsubsection{Veículos utilizados}

Os três veículos utilizados na prova de carga da ponte são identificados na tabela 5.11, cujas características são apresentadas na figura 5.30 e nas tabelas 5.12 e 5.13. Os caminhões transitaram sobre a ponte com seu peso bruto, sem qualquer carga adicional.

Tabela 5.11 - Designação dos veículos.

\begin{tabular}{c|c}
\hline Designação & Placa \\
\hline A & $47-37-\mathrm{NC}$ \\
\hline B & $58-32-\mathrm{NJ}$ \\
\hline C & $52-87-\mathrm{PS}$ \\
\hline
\end{tabular}




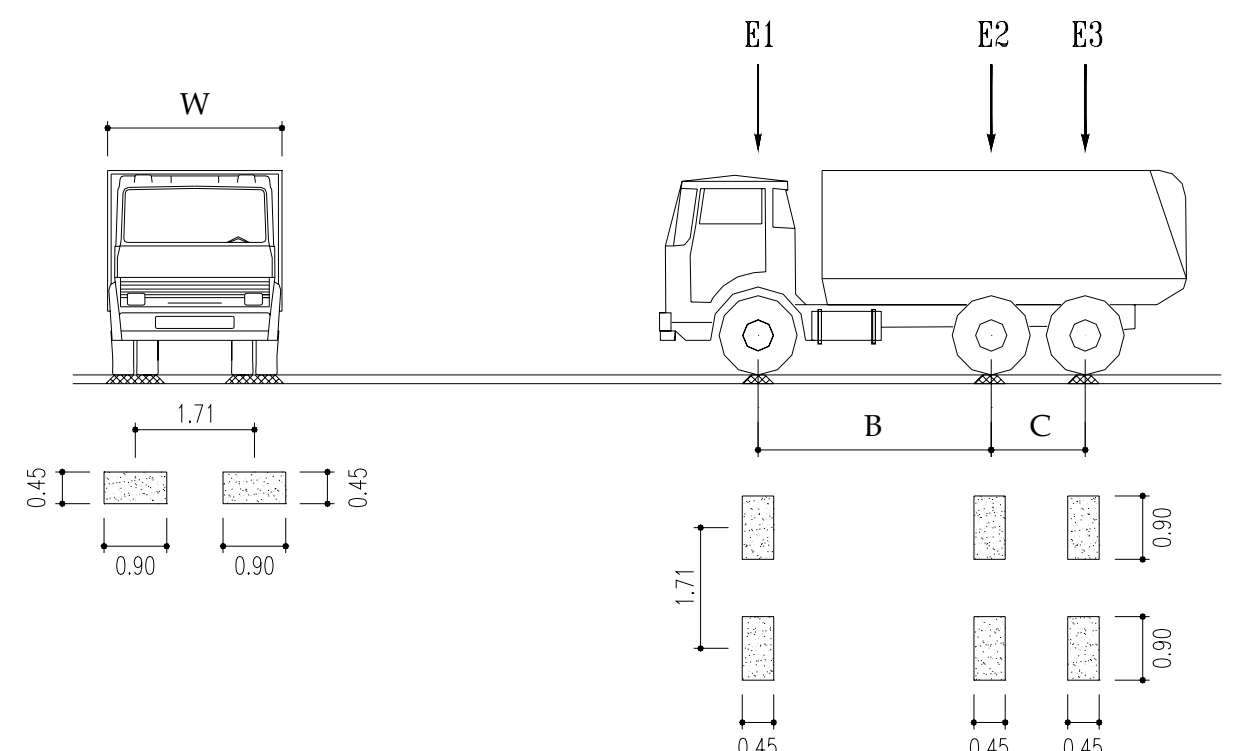

Figura 5.30 - Características do veículo proposto para a prova de carga.

Tabela 5.12 - Peso por eixo dos veículos utilizados na prova de carga.

\begin{tabular}{c|c|c|c}
\cline { 2 - 4 } \multicolumn{2}{c|}{} & \multicolumn{3}{c}{ Peso por eixo (kg) } \\
\hline Veículos & A & B & C \\
\hline E1 & 6120 & 6260 & 5140 \\
\hline E2 & 3140 & 3070 & 3440 \\
\hline E3 & 3140 & 3070 & 3440 \\
\hline Total & 12400 & 12400 & 12020 \\
\hline
\end{tabular}

Tabela 5.13 - Características geométricas e peso dos veículos utilizados na prova de carga.

\begin{tabular}{c|c|c|c|c}
\cline { 2 - 5 } & \multicolumn{3}{|c|}{ Dimensões (m) } & Peso \\
\hline Veículos & B & C & W & Tara (t) \\
\hline A & 4.10 & 1.40 & 2.50 & 12.40 \\
\hline B & 4.10 & 1.40 & 2.50 & 12.40 \\
\hline C & 4.30 & 1.40 & 2.50 & 12.02 \\
\hline
\end{tabular}

\subsubsection{Casos de carga}

Foram definidos nove casos de carga, em correspondência com as posições dos veículos imobilizados sobre o tabuleiro, ao longo de dois percursos 
designados por A e B. O percurso A corresponde ao sentido RÉGUA-PINHÃO, enquanto o percurso $B$ corresponde ao sentido PINHÃO-RÉGUA.

Os casos de carga propostos induzem os valores mais elevados das grandezas a medir nas seções instrumentadas. Para as posições de carga estáticas foram utilizados três veículos sobre o tabuleiro, enquanto para o caso de marcha lenta foi utilizado um veículo de cada vez, percorrendo toda a extensão da ponte seguindo o percurso B (PINHÃO-RÉGUA). A marcha lenta foi realizada adotando os seguintes critérios:

a) veículo $A$ em marcha lenta encostado na via mais a JUSANTE;

b) veículo $B$ em marcha lenta encostado na via mais a MONTANTE;

c) veículo $\mathrm{C}$ em marcha lenta centrado na faixa de rodagem.

Nas figuras 5.31 e 5.32 são apresentadas as posições longitudinais ocupadas por cada grupo de veículos sobre o tabuleiro durante a condução da prova de carga, em sua fase estática. A figura 5.33 ilustra a posição dos veículos na seção transversal do tabuleiro, quando das posições estáticas e também na ocasião da realização das marchas lentas.

Para garantir que a posição dos veículos imobilizados correspondia efetivamente à desejada, foram efetuadas marcas no pavimento. A tabela 5.14, apresentada na página a seguir, resume os principais resultados pretendidos para cada uma das posições. 
Tabela 5.14 - Principais resultados pretendidos.

\begin{tabular}{|c|c|c|c|}
\hline $\begin{array}{l}\text { Posição } \\
\text { dos } \\
\text { veículos }\end{array}$ & Descrição da ação & $\begin{array}{l}\text { Resultado } \\
\text { pretendido }\end{array}$ & $\begin{array}{c}\text { Sensores } \\
\text { interessados }\end{array}$ \\
\hline 1 & $\begin{array}{l}\text { Conjunto de } 3 \text { veículos posicionados a 1/2 vão do } 3^{\circ} \\
\text { tramo da ponte, separados por uma distância de } 0,5 \\
\text { metro. O eixo frontal do veículo central dista do } \\
\text { montante a } 1 \frac{1}{2} \text { vão cerca de } 1,55 \text { metro }\end{array}$ & $\begin{array}{l}\text { Máximo deslocamento } \\
\text { vertical no } 3^{\circ} \text { tramo }\end{array}$ & DV4 \\
\hline 2 & $\begin{array}{l}\text { Conjunto de } 3 \text { veículos posicionados a } 1 / 2 \text { vão do } 2^{\circ} \\
\text { tramo da ponte, separados por uma distância de } 0,5 \\
\text { metro. O eixo frontal do veículo central dista do } \\
\text { montante a } 1 \frac{1}{2} \text { vão cerca de } 1,40 \text { metro }\end{array}$ & $\begin{array}{l}\text { Máximo deslocamento } \\
\text { vertical no } 2^{\circ} \text { tramo }\end{array}$ & DV3 \\
\hline 3 & $\begin{array}{l}\text { Conjunto de } 3 \text { veículos posicionados a 1/2 vão do } 1^{0} \\
\text { tramo da ponte, separados por uma distância de } 0,5 \\
\text { metro. O eixo frontal do veículo central dista do } \\
\text { montante a } 1 / 2 \text { vão cerca de } 1,40 \text { metro }\end{array}$ & $\begin{array}{l}\text { Máximo deslocamento } \\
\text { vertical no } 1^{\circ} \text { tramo, } \\
\text { extensões máximas nas } \\
\text { cordas superiores e } \\
\text { inferiores e rotações } \\
\text { máximas nos apoios }\end{array}$ & $\begin{array}{l}\text { DV1, DV2, } \\
\text { ES5, ES6, } \\
\text { ES11, ES12, I1 } \\
\text { e I2 }\end{array}$ \\
\hline 4 & 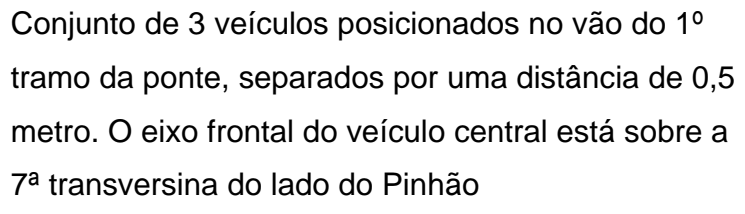 & $\begin{array}{l}\text { Deformações máximas } \\
\text { no } 7^{0} \text { montante e } 7^{a} \\
\text { transversina do lado do } \\
\text { Pinhão }\end{array}$ & $\begin{array}{c}\text { ES4, ES10 e } \\
\text { ES17 }\end{array}$ \\
\hline 5 & $\begin{array}{l}\text { Conjunto de } 3 \text { veículos posicionados no vão do } 1^{0} \\
\text { tramo da ponte, separados por uma distância de } 0,5 \\
\text { metro. O eixo frontal do veículo central está sobre a } \\
4^{\mathrm{a}} \text { transversina do lado do Pinhão }\end{array}$ & $\begin{array}{l}\text { Deformações máximas } \\
\text { na } 3^{\mathrm{a}} \text { diagonal e } 3^{\mathrm{a}} \\
\text { longarina do lado do } \\
\text { Pinhão }\end{array}$ & $\begin{array}{c}\text { ES2, ES8 e } \\
\text { ES16 }\end{array}$ \\
\hline 6 & 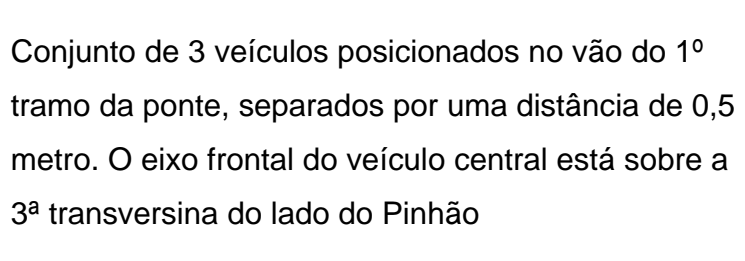 & $\begin{array}{l}\text { Deformações máximas } \\
\text { na } 2^{\mathrm{a}} \text { diagonal, } 3^{\mathrm{a}} \\
\text { transversina, } 3^{\circ} \\
\text { montante e } 2^{\mathrm{a}} \text { longarina } \\
\text { do lado do Pinhão }\end{array}$ & $\begin{array}{c}\text { ES1, ES3, } \\
\text { ES7, ES9, } \\
\text { ES13, ES14 e } \\
\text { ES15 }\end{array}$ \\
\hline
\end{tabular}




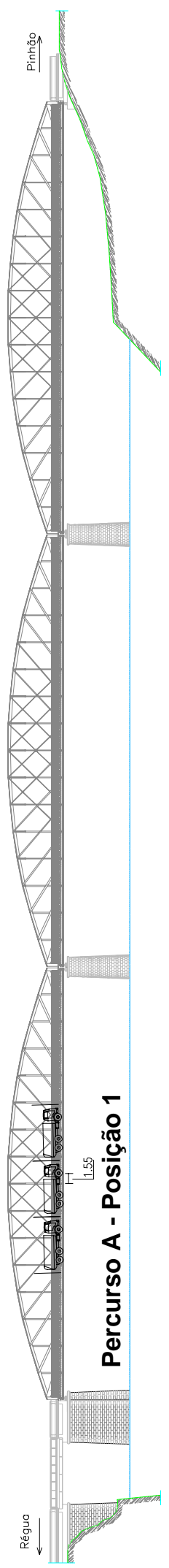

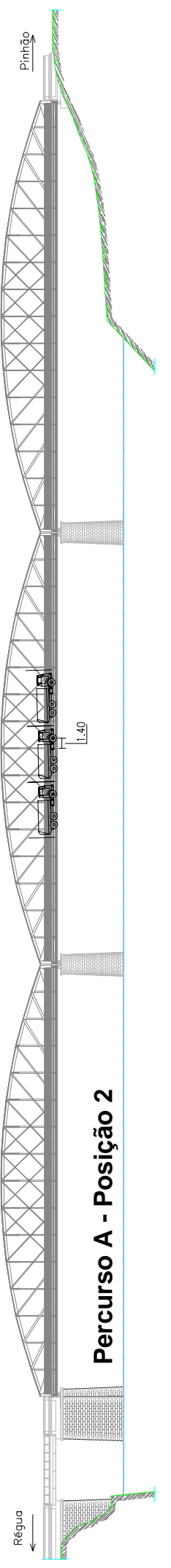

(a)
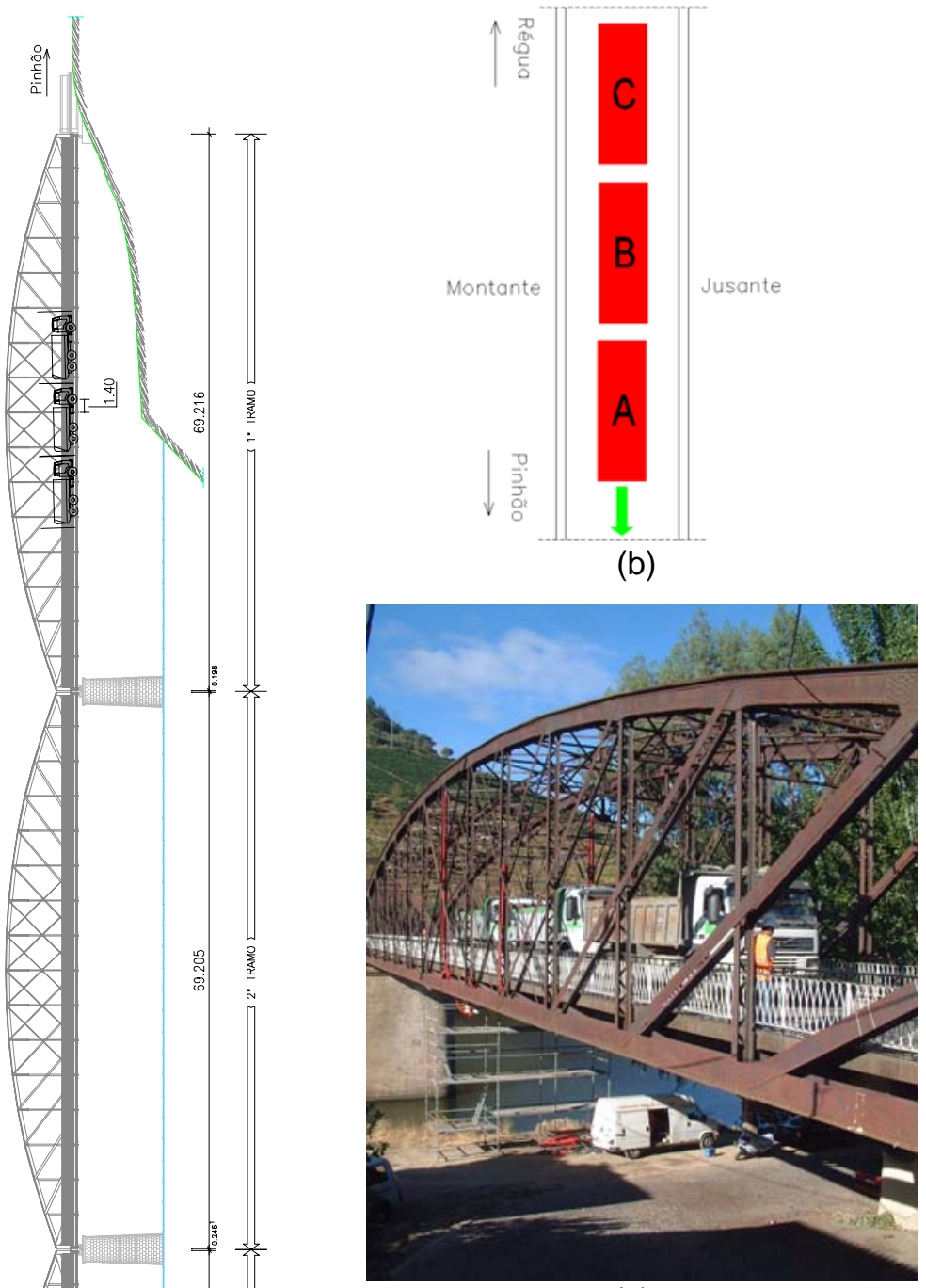

(c)

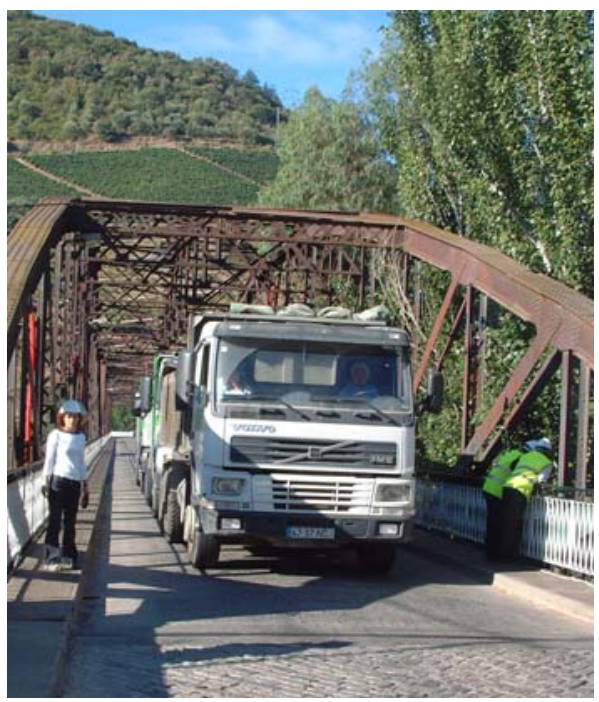

(d)

Figura 5.31 - Veículos durante o percurso A: posições 1 a 3 (a); disposição dos veículos (b);veículos na posição 3 (c) e na posição 4 (d). 

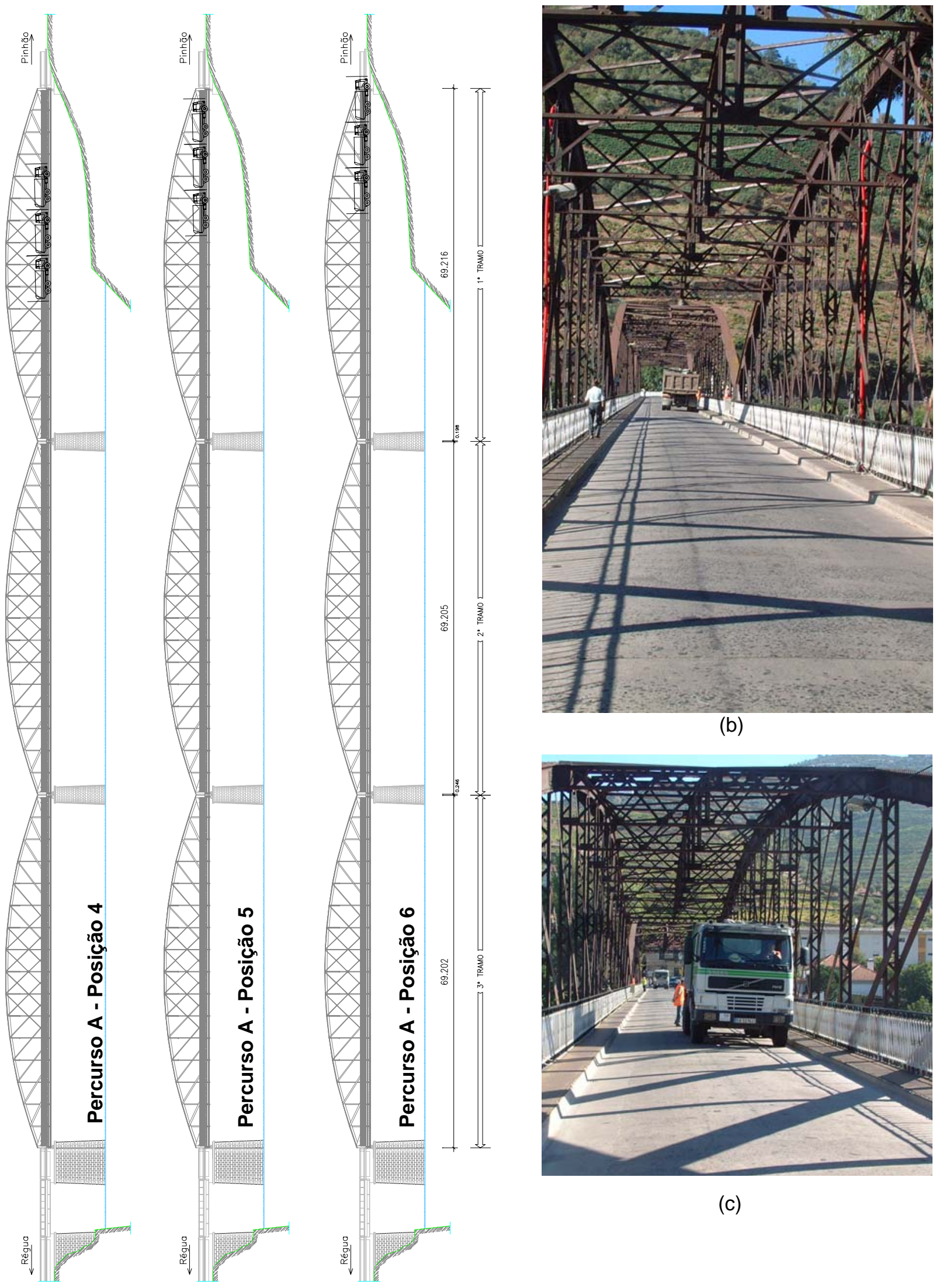

(b)

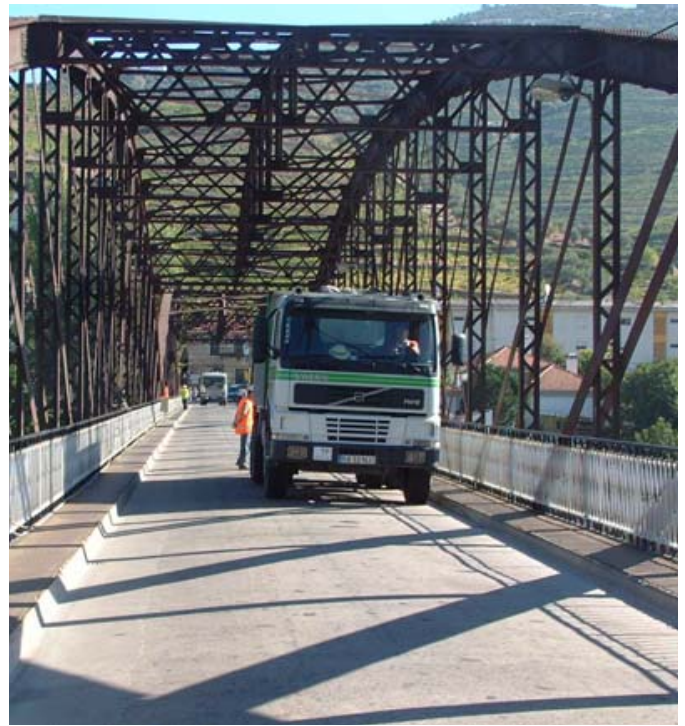

(c)

(a)

Figura 5.32 - Veículos durante o percurso A: posições 4 a 6 (a), veículo A (b) e veículo B (c) em marcha lenta. 


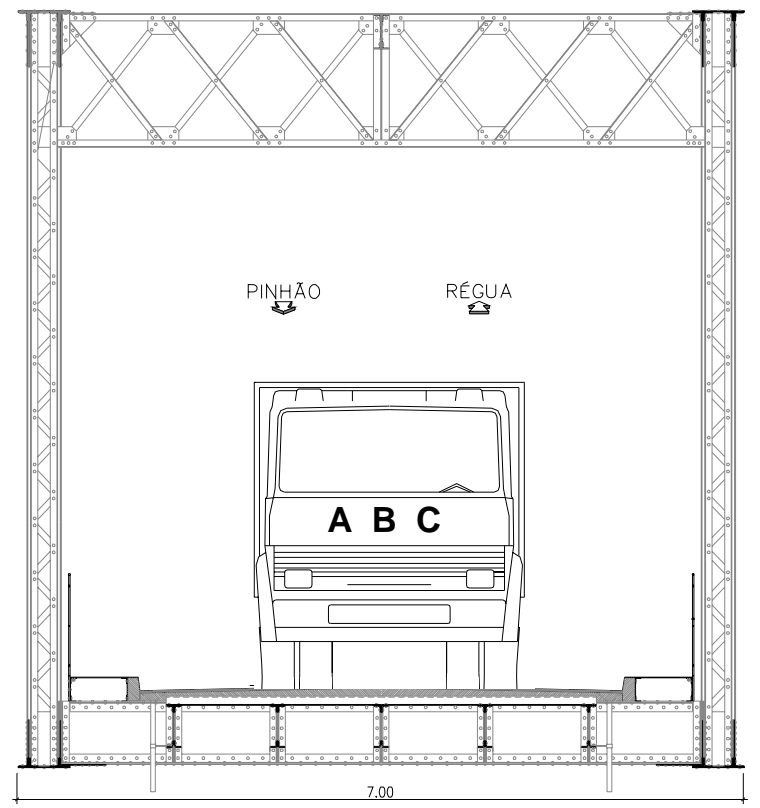

(a)

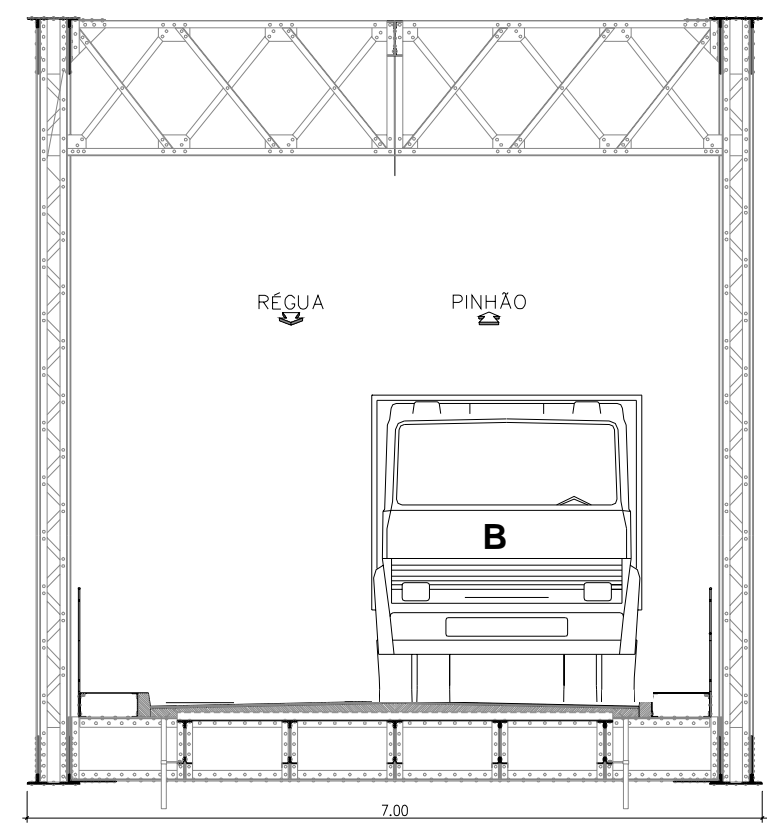

(c)

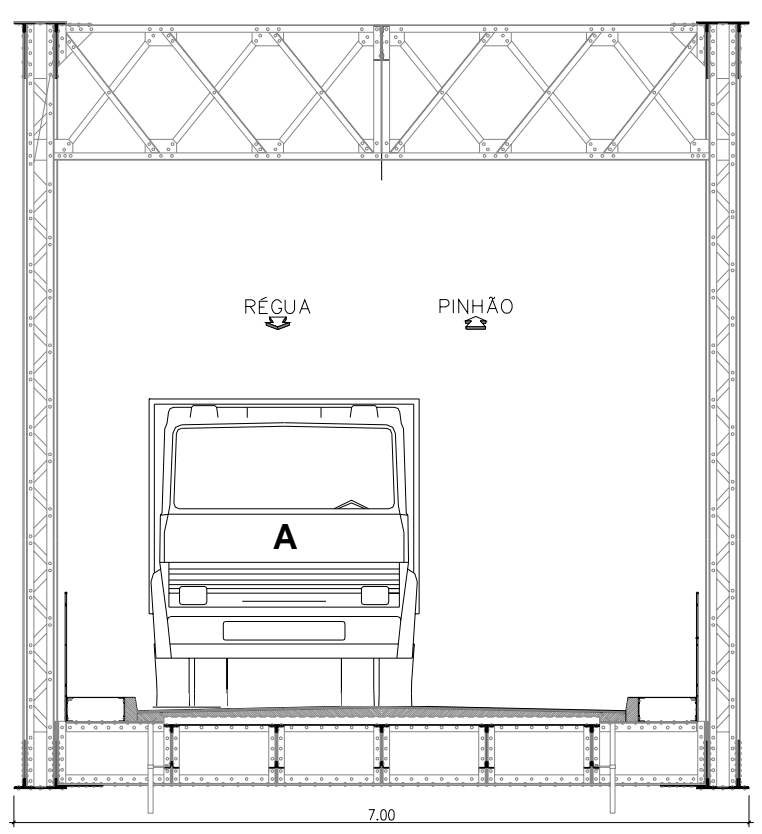

Lado de Jusonte

(b)

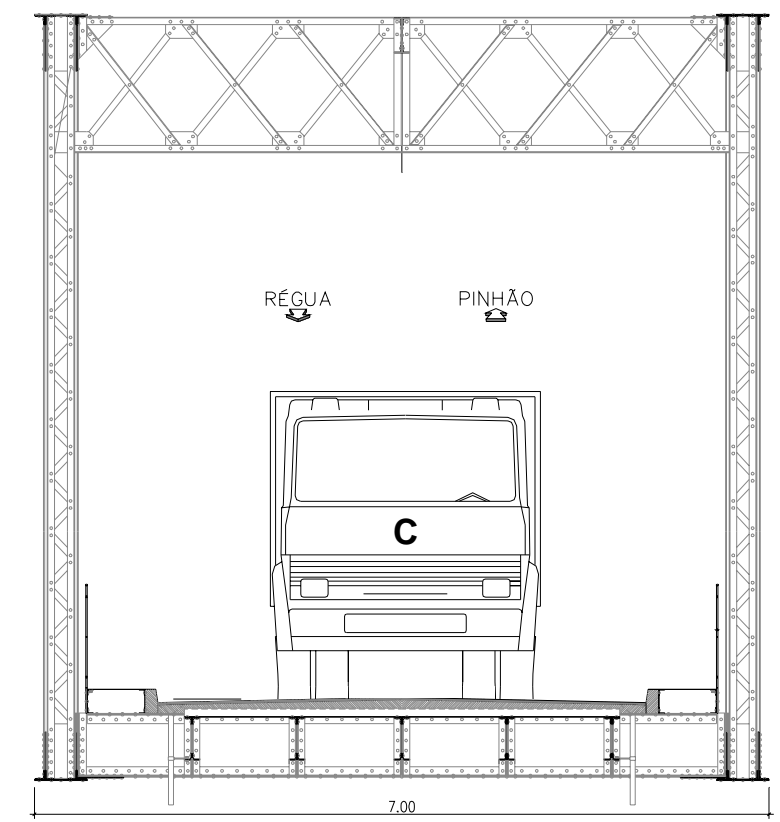

Lado de Jusante
Lado de Montante

(d)

Figura 5.33 - Posição dos veículos na seção transversal do tabuleiro: veículos A, B e C centrados na faixa de rodagem para os casos de carga 1a 6 (a), veículo $A$ em marcha lenta encostado na via mais a jusante (b), veículo $B$ em marcha lenta encostado na via mais a montante (c) e veículo $C$ em marcha lenta centrado na faixa de rodagem (d). 


\subsubsection{Realização do ensaio}

Foram definidos dois períodos de observação, associando-se a cada um deles uma sequência de posições de veículos. No primeiro período de observação estão incluídos os casos de carga correspondentes ao percurso A (figura 5.34), associado à movimentação dos veículos em direção ao Pinhão, e o segundo período de observação engloba os casos de carga correspondentes ao percurso $\mathrm{B}$, com o movimento dos veículos em direção à Régua.

A medição do zero de referência de todos os sensores com o tabuleiro sem qualquer veículo, caracterizando a situação de vazio, foi feita no início do ensaio, no intervalo entre os períodos referidos e no final do ensaio.

Durante a prova de carga o sistema de aquisição automático realizou a aquisição do sinal de forma contínua, com intervalo entre aquisições de 1 segundo. Registrou-se a hora de início e de fim de cada uma das fases relevantes da prova de carga, a saber: a situação de vazio e a imobilização dos veículos sobre o tabuleiro nas posições definidas. A tabela 5.15 resume a sequência das situações observadas durante a prova de carga com a indicação da hora de início e de fim de cada uma delas. Esta informação é útil para a interpretação dos gráficos que contém a evolução das medições efetuadas neste período. A prova de carga teve início às 08h30min00s e terminou às 09h32min00s (duração de 01h02min00s).

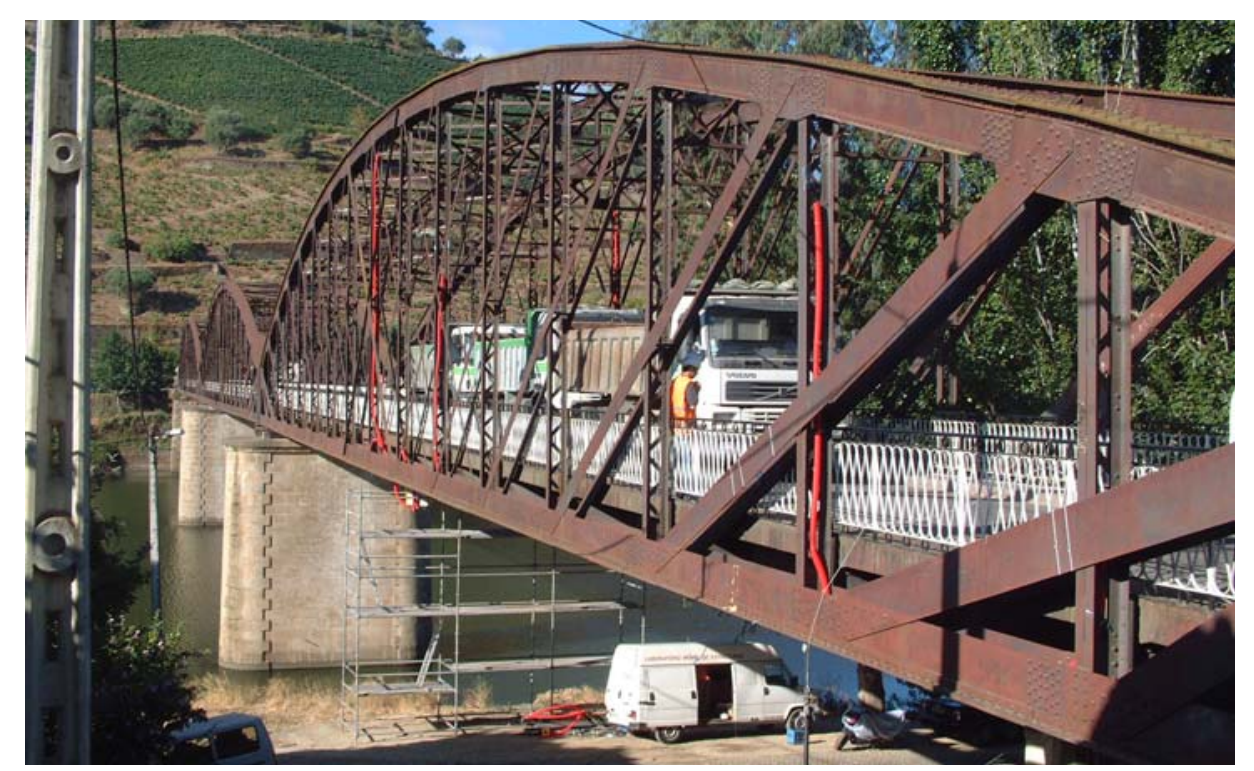

Figura 5.34 - Condução da prova de carga: Veículos durante o percurso A, na posição 3. 
Tabela 5.15 - Sequência da prova de carga.

\begin{tabular}{|c|c|c|c|}
\hline \multicolumn{2}{|c|}{$\begin{array}{l}\text { Descrição das fases de } \\
\text { observação }\end{array}$} & Hora inicial & Hora final \\
\hline \multicolumn{2}{|c|}{ Vazio } & 8:30:00 & 8:31:52 \\
\hline \multicolumn{2}{|c|}{1} & 8:33:05 & 8:40:17 \\
\hline \multicolumn{2}{|c|}{2} & 8:42:41 & $8: 47: 26$ \\
\hline \multicolumn{2}{|c|}{3} & 8:48:56 & 8:53:41 \\
\hline \multicolumn{2}{|c|}{4} & 8:54:14 & 8:58:58 \\
\hline \multicolumn{2}{|c|}{5} & 8:59:34 & 9:04:58 \\
\hline \multicolumn{2}{|c|}{6} & 9:06:08 & 9:08:16 \\
\hline \multicolumn{2}{|c|}{ Vazio } & 9:09:04 & 9:11:47 \\
\hline \multirow{3}{*}{$\begin{array}{c}7 \text { (Marcha lenta) } \\
\text { Veículo A }\end{array}$} & $1^{\circ}$ Tramo & 9:11:47 & 9:15:02 \\
\hline & $2^{\circ}$ Tramo & 9:15:04 & $9: 17: 48$ \\
\hline & $3^{\circ}$ Tramo & $9: 17: 50$ & 9:19:54 \\
\hline \multirow{3}{*}{$\begin{array}{c}8 \text { (Marcha lenta) } \\
\text { Veículo B }\end{array}$} & $1^{\circ}$ Tramo & $9: 20: 18$ & 9:22:48 \\
\hline & $2^{\circ}$ Tramo & 9:22:56 & $9: 25: 12$ \\
\hline & $3^{\circ}$ Tramo & $9: 25: 22$ & $9: 27: 13$ \\
\hline \multirow{3}{*}{$\begin{array}{c}9 \text { (Marcha lenta) } \\
\text { Veículo C }\end{array}$} & $1^{\circ}$ Tramo & 9:27:15 & 9:29:13 \\
\hline & $2^{\circ}$ Tramo & 9:29:15 & 9:30:56 \\
\hline & $3^{\circ}$ Tramo & 9:30:58 & 9:31:49 \\
\hline \multicolumn{2}{|c|}{ Vazio } & 9:31:49 & 9:32:00 \\
\hline
\end{tabular}

O registro das medições para situação de vazio (estrutura descarregada), nas duas fases do ensaio (início de cada percurso e no final), permitiu observar o efeito da variação da temperatura sobre a estrutura e sobre o próprio sistema de medição. Esta informação é útil no tratamento dos valores da medição associados a cada posição dos veículos (imobilizados) sobre a ponte. Assim, foi possível estabelecer a evolução dos zeros de referência ao longo do período de observação.

\subsection{Resultados da medição durante a prova de carga}

Nesta seção são apresentados os resultados mais significativos da medição efetuada na ponte durante a condução da prova de carga. A ordem de apresentação dos casos de carga está de acordo com a sequência adotada para as posições dos veículos no decorrer do ensaio. Os resultados que a seguir se apresentam traduzem 
a variação de cada uma das grandezas medidas em relação à primeira medida efetuada. Excetua-se a evolução da temperatura medida, cujos resultados apresentados representam o seu valor absoluto.

Uma vez que os resultados adquiridos se encontravam com elevado nível de ruído, o sistema de visualização e tratamento de dados foi intensamente utilizado para a filtragem dos dados, apresentados nos gráficos a seguir.

Nos gráficos, é apresentado no interior de círculos o número da posição que os veículos ocuparam em cada momento. A convenção de sinais adotada é a seguinte:

a) Deformação negativa - encurtamento;

b) Deformação positiva - alongamento;

c) Alongamento negativo - decréscimo da abertura da junta;

d) Alongamento positivo - incremento da abertura da junta;

e) Rotação positiva - para I1: sentido anti-horário (para um observador posicionado do lado de montante junto ao encontro E1); para 12: sentido horário (para um observador localizado no lado de montante junto ao pilar P1);

f) Rotação negativa - para 11: sentido horário (para um observador posicionado do lado de montante junto ao encontro E1); para 12: sentido anti-horário (para um observador localizado no lado de montante junto ao pilar P1);

g) Deslocamento negativo - deslocamento vertical ascendente;

h) Deslocamento positivo - deslocamento vertical descendente.

\subsubsection{Temperatura ambiente}

Na figura 5.35 são apresentados os resultados da medição da temperatura ambiente, a partir dos quatro sensores de temperatura instalados. A localização dos sensores é indicada no item 5.3.5.

Percebe-se dos gráficos que os sensores T2 e T4 apresentam uma variação linear da temperatura, de aproximadamente $2,50{ }^{\circ} \mathrm{C}$ por hora. Em relação ao sensor 
T1, que apresenta variação de temperatura não-linear e gradiente térmico bastante superior aos demais PT100, seu comportamento se deve ao seu posicionamento, junto à superfície metálica da corda inferior, com radiação solar incidindo diretamente sobre o sensor. Uma vez que os sensores T2 e T4 ficaram abrigados à sombra, e suficientemente distantes das superfícies metálicas dos elementos estruturais, não experimentaram as variações experimentadas por T1 e T3, e seus resultados serão utilizados para a compensação do efeito da temperatura nas medições realizadas pelos sensores de deformação.

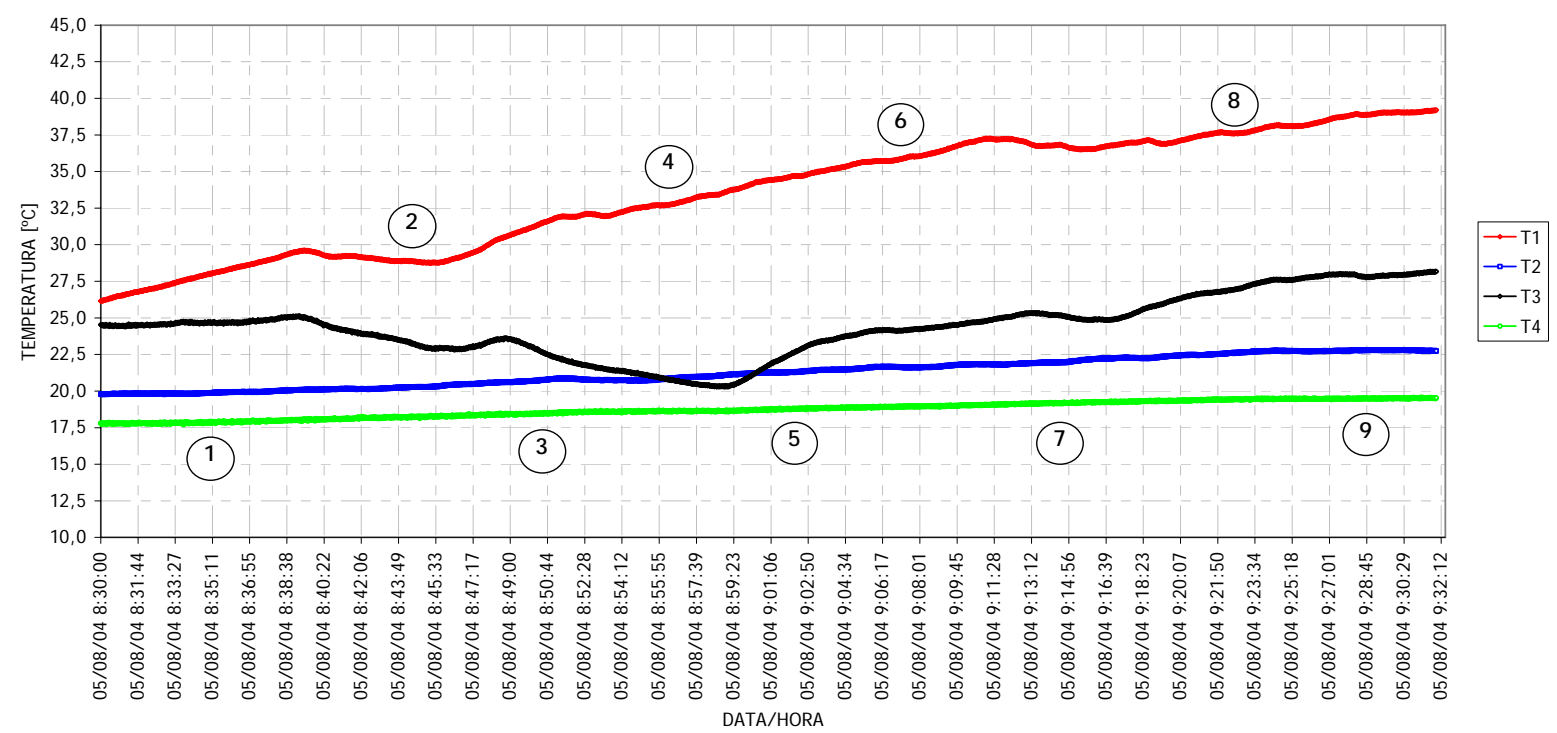

Figura 5.35 - Evolução da temperatura no decorrer do ensaio, medida pelos sensores T1, T2, T3 e T4.

\subsubsection{Deformações}

Nesta seção são apresentados os principais resultados referentes à medição das deformações, considerando-se todos os elementos estruturais monitorados.

Conforme mencionado anteriormente, durante a prova de carga a temperatura experimentou uma variação considerada linear, admitindo-se que também foi linear o efeito da sua variação sobre a estrutura. Para compensar o efeito induzido pela temperatura, neste estudo considera-se para o zero de referência de cada sensor, não o valor obtido no início da prova de carga, mas um 
valor obtido a partir deste, corrigido em função da sua variação no tempo. Para tal fim, é determinado para cada sensor um fator de variação do zero de referência dado pela equação abaixo:

$$
k=\frac{x_{o, f}-x_{o, i}}{t_{f}-t_{i}}
$$

onde:

$x_{o, f}$ - representa a medição em vazio no final de um percurso;

$x_{o, i}$ - representa a medição em vazio no início de um percurso;

$t_{f}$ — o instante em que foi realizada a medição final;

$t_{i}$ —o instante em que foi realizada a medição inicial.

O valor zero adotado como referência em cada caso de carga é dado por:

$$
x_{o, r e f}=x_{o, i}+k\left(t-t_{i}\right)
$$

Em que $t$ representa a hora a que o caso de carga é realizado. O efeito de um caso de carga numa dada grandeza, quando é lido no instrumento de medida

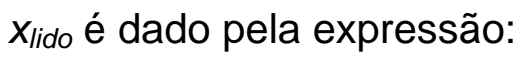

$$
x=x_{\text {lido }}-x_{o, r e f}
$$

O instante adotado para cada fase do ensaio foi a hora média do intervalo definido. O valor adotado na medição de cada grandeza foi o valor médio das medições efetuadas para cada situação de carregamento.

A tabela 5.16 apresenta os valores calculados para os extensômetros das duas longarinas instrumentadas, durante os casos de carga 1 a 6.

A tabela 5.17 contém os valores de deformação máximos obtidos para cada tipo de elemento estrutural instrumentado, em correspondência com os casos de carga adotados. Adicionalmente, também apresenta as respectivas variações de tensão, admitindo-se o módulo de elasticidade do aço igual a $210 \mathrm{GPa}$.

Nas figuras 5.36 a 5.41 podem ser vistos os gráficos cujos dados deram origem à tabela 5.17 . 
Tabela 5.16 - Deformações nas seções S13 e S16.

\begin{tabular}{|c|c|c|c|c|c|}
\hline & \multirow[b]{2}{*}{ Grandeza } & \multicolumn{4}{|c|}{ Deformações $\left(\times 10^{-6} \mathrm{~m} / \mathrm{m}\right)$} \\
\hline & & ES13-1 & ES13-2 & ES16-1 & ES16-2 \\
\hline \multirow[t]{3}{*}{ POSIÇÃO 1} & referência $\left(x_{o, \text { ref }}\right)$ & 4,5 & $-1,9$ & 0,7 & $-0,6$ \\
\hline & valor lido $\left(X_{\text {lido }}\right)$ & 3,9 & $-3,0$ & 1,9 & 0,4 \\
\hline & diferença $(x)$ & $-0,6$ & $-1,0$ & 1,2 & 1,0 \\
\hline \multirow[t]{3}{*}{ POSIÇÃO 2} & referência $(x$, ref $)$ & 5,9 & $-2,5$ & 3,2 & $-1,2$ \\
\hline & valor lido $\left(X_{\text {lido }}\right)$ & 6,7 & $-2,7$ & 3,9 & $-0,8$ \\
\hline & diferença $(x)$ & 0,8 & $-0,2$ & 0,7 & 0,4 \\
\hline \multirow[t]{3}{*}{ POSIÇÃO 3} & referência $\left(x_{o, \text { ref }}\right)$ & 7,0 & $-3,0$ & 5,1 & $-1,6$ \\
\hline & valor lido $\left(X_{\text {lido }}\right)$ & 9,6 & $-1,2$ & 13,1 & 3,7 \\
\hline & diferença $(x)$ & 2,6 & 1,8 & 8,0 & 5,3 \\
\hline \multirow[t]{3}{*}{ POSIÇÃO 4} & referência $\left(x_{o, \text { ref }}\right)$ & 7,8 & $-3,4$ & 6,7 & $-2,0$ \\
\hline & valor lido $\left(x_{\text {lido }}\right)$ & 10,9 & $-1,2$ & 14,8 & 0,5 \\
\hline & diferença $(x)$ & 3,1 & 2,2 & 8,1 & 2,4 \\
\hline \multirow[t]{3}{*}{ POSIÇÃO 5} & referência $\left(x_{o, \text { ref }}\right)$ & 8,8 & $-3,8$ & 8,4 & $-2,4$ \\
\hline & valor lido $\left(X_{\text {lido }}\right)$ & 11,1 & 11,0 & 10,6 & 13,5 \\
\hline & diferença $(x)$ & 2,3 & 14,8 & 2,2 & 15,8 \\
\hline \multirow[t]{4}{*}{ POSIÇÃO 6} & referência $\left(x_{o, \text { ref }}\right)$ & 9,6 & $-4,2$ & 9,9 & $-2,7$ \\
\hline & valor lido $\left(X_{\text {lido }}\right)$ & 12,5 & $-4,2$ & 15,4 & $-0,2$ \\
\hline & diferença $(x)$ & 2,9 & 0,0 & 5,6 & 2,5 \\
\hline & $K\left(\times 10^{-6} \mathrm{~m} / \mathrm{m} / \mathrm{s}\right)$ & 0,0027 & $-0,0012$ & 0,0050 & $-0,0011$ \\
\hline
\end{tabular}

Tabela 5.17 - Deformações máximas obtidas na prova de carga.

\begin{tabular}{l|c|c|c|c}
\hline \multicolumn{1}{c|}{ Peça } & Sensor & $\begin{array}{c}\text { Posição dos } \\
\text { veículos }\end{array}$ & $\begin{array}{c}\text { Deformação máxima } \\
\text { medida }\left(\times 10^{-6} \mathbf{m} / \mathbf{m}\right)\end{array}$ & $\begin{array}{c}\text { Variação de tensão } \\
(\Delta \sigma)[\mathrm{MPa}]\end{array}$ \\
\hline Diagonais & ES2-2 & 4 & 48,20 & 10,12 \\
\hline Montantes & ES3-1 & 4 & $-38,60$ & $-8,11$ \\
\hline Corda Superior & ES5-1 & 3 & $-46,00$ & $-9,66$ \\
\hline Corda Inferior & ES6-2 & 3 & 30,30 & 6,36 \\
\hline Longarinas & ES16-2 & 5 & 15,80 & 3,32 \\
\hline Transversinas & ES15-1 & 5 & 47,80 & 10,04 \\
\hline
\end{tabular}




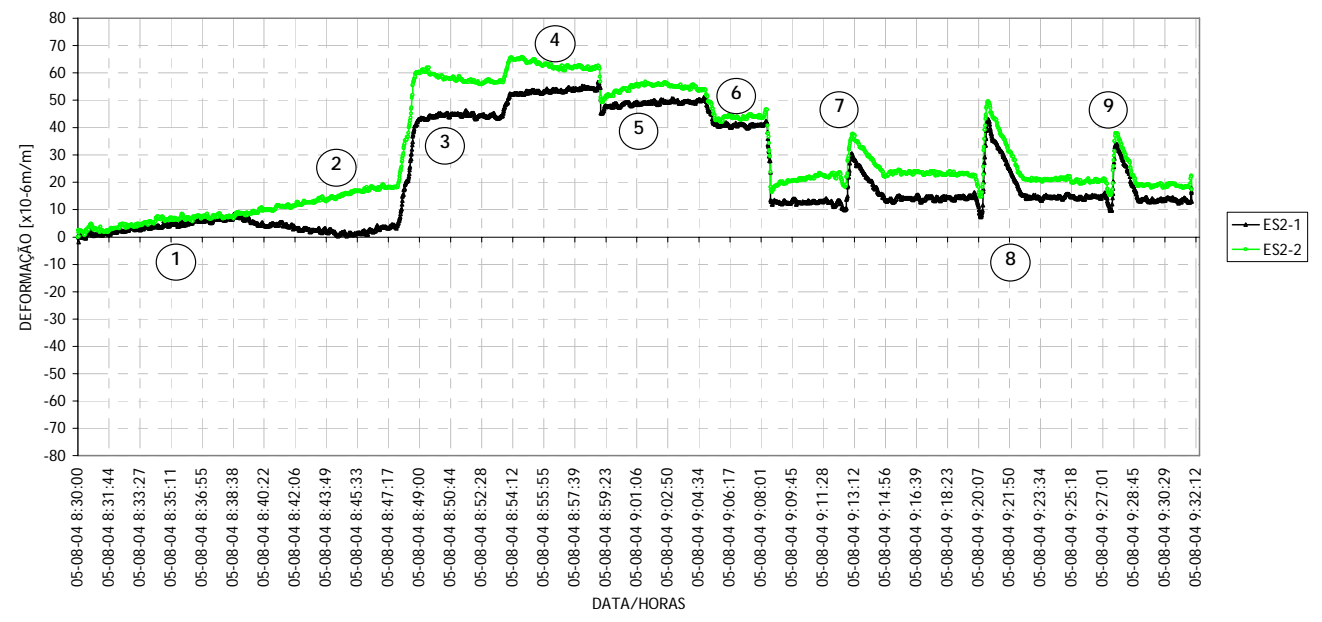

Figura 5.36 - Deformações registradas na seção S2 (3a diagonal a montante do lado do Pinhão).

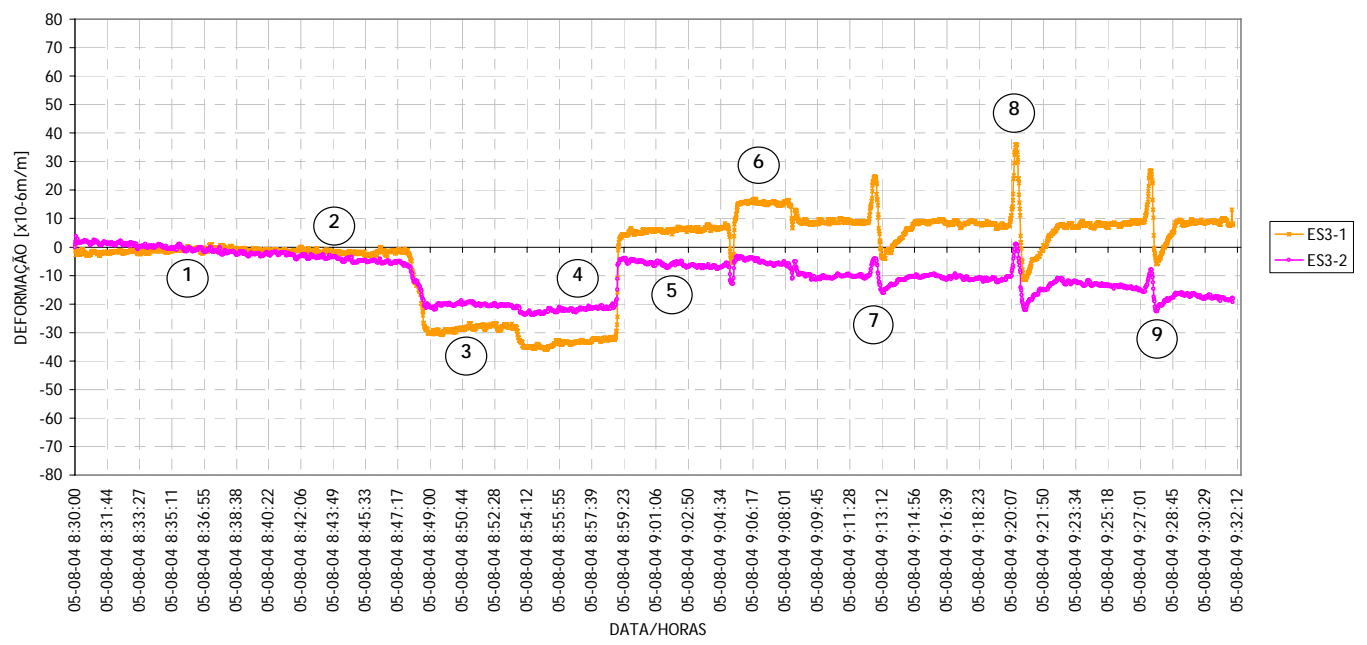

Figura 5.37 - Deformações registradas na seção S3 (3 montante a montante do lado do Pinhão).

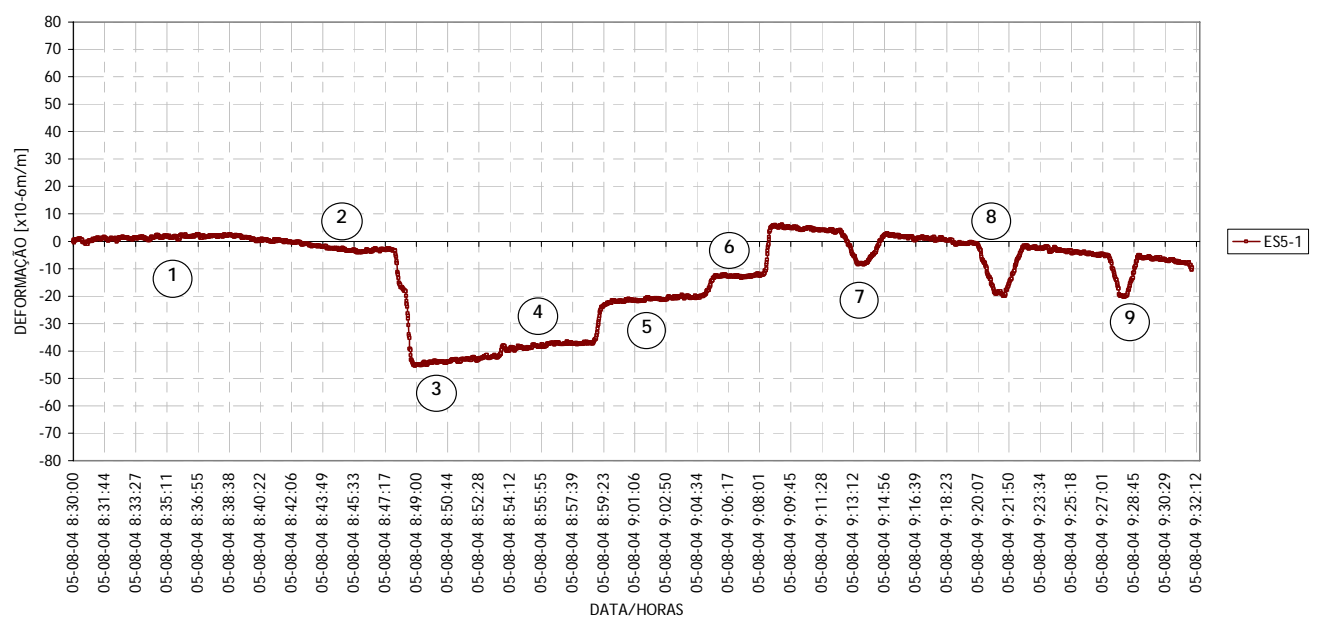

Figura 5.38 - Deformações registradas na seção S5 (corda superior a meio-vão do $1^{\circ}$ tramo do lado de montante). 


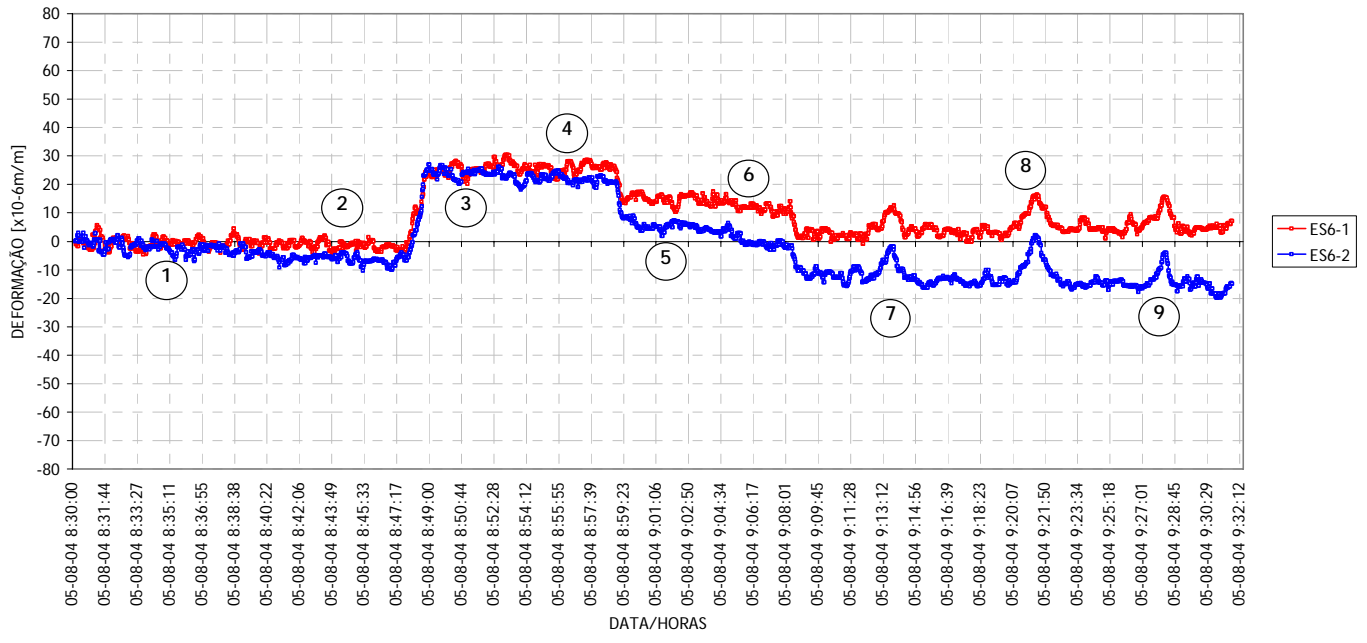

Figura 5.39 - Deformações registradas na seção S6 (corda inferior a meio-vão do $1^{\circ}$ tramo do lado de montante).

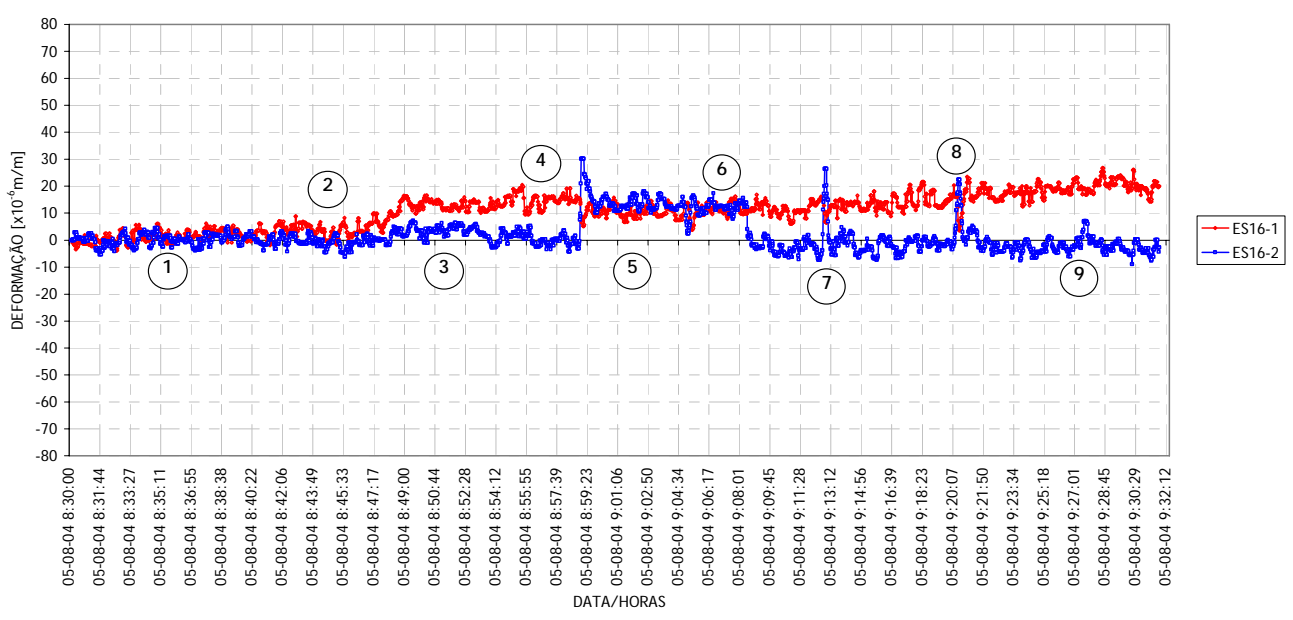

Figura 5.40 - Deformações registradas na seção S16 (meio-vão da 3ª longarina do lado do Pinhão).

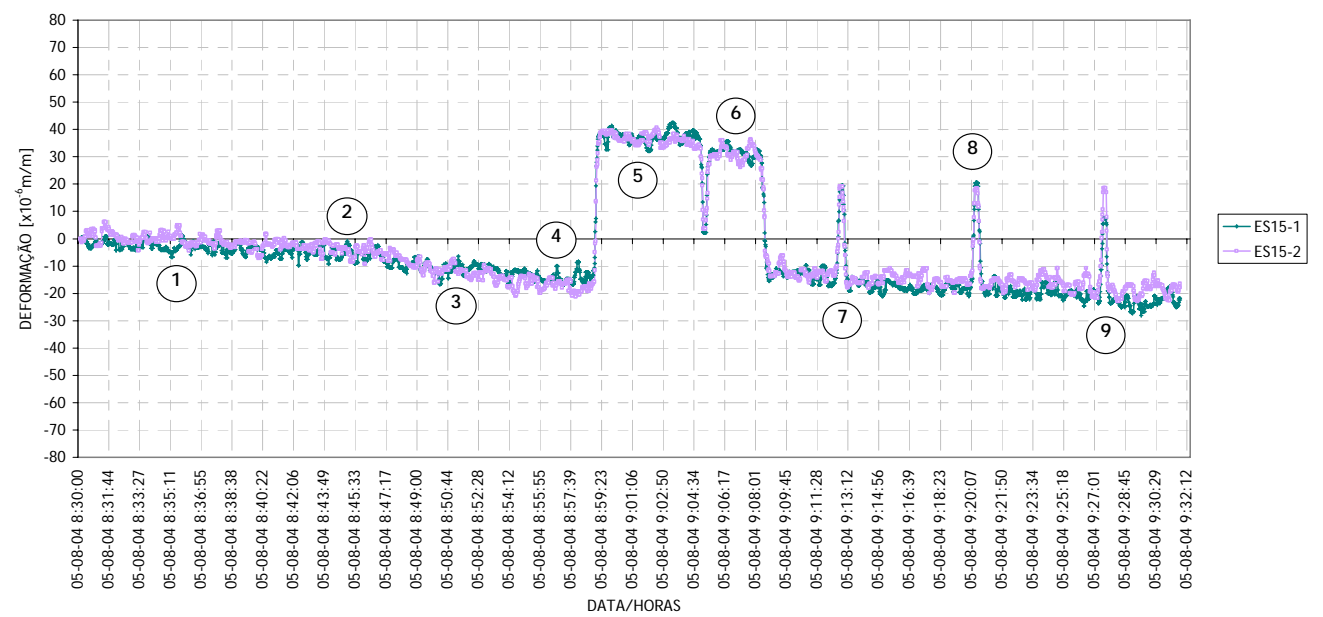

Figura 5.41 - Deformações registradas na seção S15 (meio-vão da $3^{a}$ transversina do lado do Pinhão). 
A tabela 5.18 apresenta os valores mais importantes observados durante as passagens lentas de cada um dos veículos isolados, correspondentes às posições 7, 8 e 9 , no percurso $B$.

Tabela 5.18 - Deformações máximas obtidas durante as passagens lentas.

\begin{tabular}{l|c|c|c}
\hline \multicolumn{1}{|c|}{ Peça } & Sensor & $\begin{array}{c}\text { Posição dos } \\
\text { veículos }\end{array}$ & $\begin{array}{c}\text { Deformação máxima } \\
\text { medida (x10 } \mathbf{m} / \mathbf{m})\end{array}$ \\
\hline Diagonais & ES2-1 & 8 & 27,14 \\
\hline Montantes & ES3-1 & 8 & 27,50 \\
\hline Corda Superior & ES5-1 & 8 & $-17,10$ \\
\hline Corda Inferior & ES6-2 & 8 & 15,18 \\
\hline Longarinas & ES16-2 & 7 & 31,99 \\
\hline Transversinas & ES15-1 & 8 & 40,59 \\
\hline
\end{tabular}

Dos resultados de deformação obtidos, percebe-se que em geral os valores máximos das medições efetuadas ao longo da prova de carga ocorreram para as posições estáticas, isto é, para os casos de carga 1 a 6 , em que os três veículos de 12 toneladas cada se encontravam em fila e imobilizados sobre o tabuleiro da ponte.

\subsubsection{Deslocamentos verticais}

Os mais expressivos valores de deslocamentos verticais ocorreram a meio dos vãos do tabuleiro, durante as posições estáticas (casos de carga 1 a 6). A tabela 5.19 contém os deslocamentos verticais máximos medidos pelos sensores instalados, enquanto a tabela 5.20 traz os deslocamentos máximos medidos durante as pasagens lentas.

Os resultados obtidos com os sensores de pressão são apresentados sob a forma de gráficos, na figura 5.42. A figura 5.43 traz os resultados dos deslocamentos obtidos a partir dos comparadores elétricos instalados na terceira transversina. 
Tabela 5.19 - Deslocamentos verticais máximos obtidos na prova de carga.

\begin{tabular}{l|c|c|c} 
& Sensor & $\begin{array}{c}\text { Posição dos } \\
\text { veículos }\end{array}$ & $\begin{array}{c}\text { Deslocamento máximo } \\
\text { medido }(\mathbf{m m})\end{array}$ \\
\hline Meio- vão de cada tramo & DV2 & 3 & 8,5 \\
\hline $3^{\text {a transversina }}$ & DV6 & 5 & 3,5 \\
\hline
\end{tabular}

Tabela 5.20 - Deslocamentos verticais máximos obtidos durante as passagens lentas.

\begin{tabular}{l|c|c|c}
\cline { 2 - 4 } & Sensor & $\begin{array}{c}\text { Posição dos } \\
\text { veículos }\end{array}$ & $\begin{array}{c}\text { Deslocamento máximo } \\
\text { medido }(\mathbf{m m})\end{array}$ \\
\hline Meio-vão de cada tramo & DV1 & 8 & 4,16 \\
\hline $3^{\mathrm{a}}$ transversina & DV6 & 7 & 1,70 \\
\hline
\end{tabular}

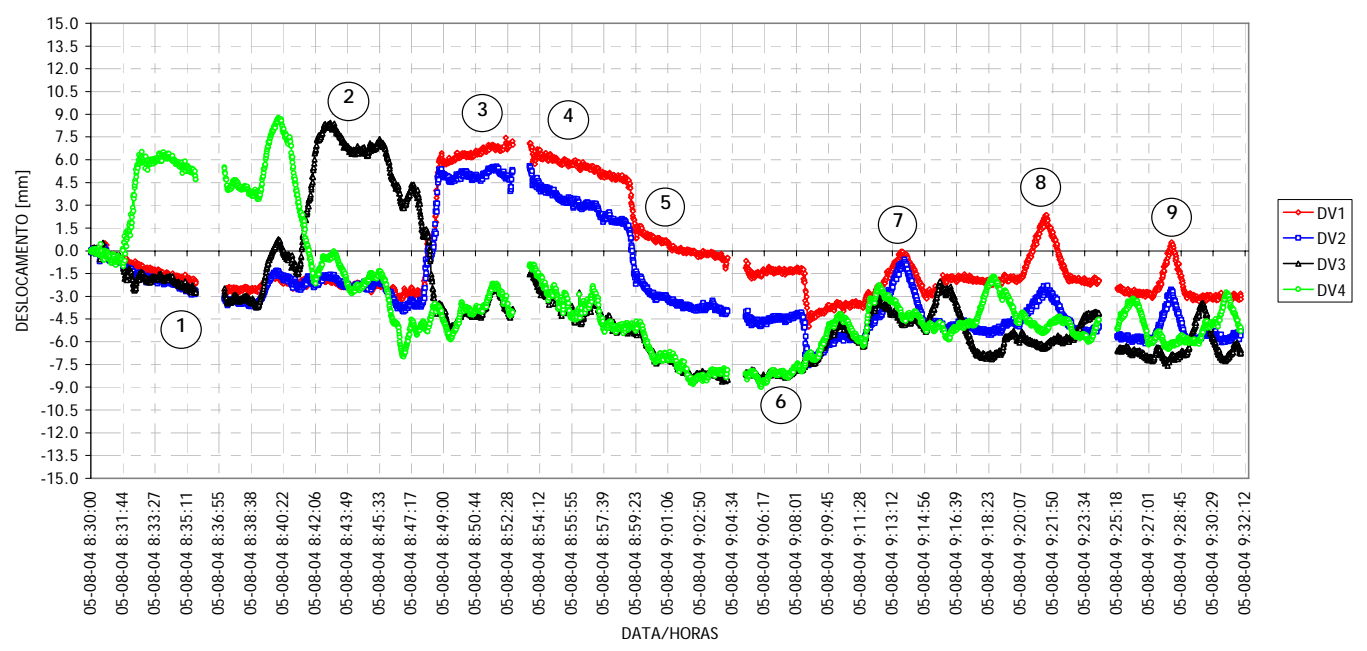

Figura 5.42 - Deslocamentos a meio-vão de cada tramo da ponte, medidos com os sensores de pressão DV1, DV2, DV3 e DV4.

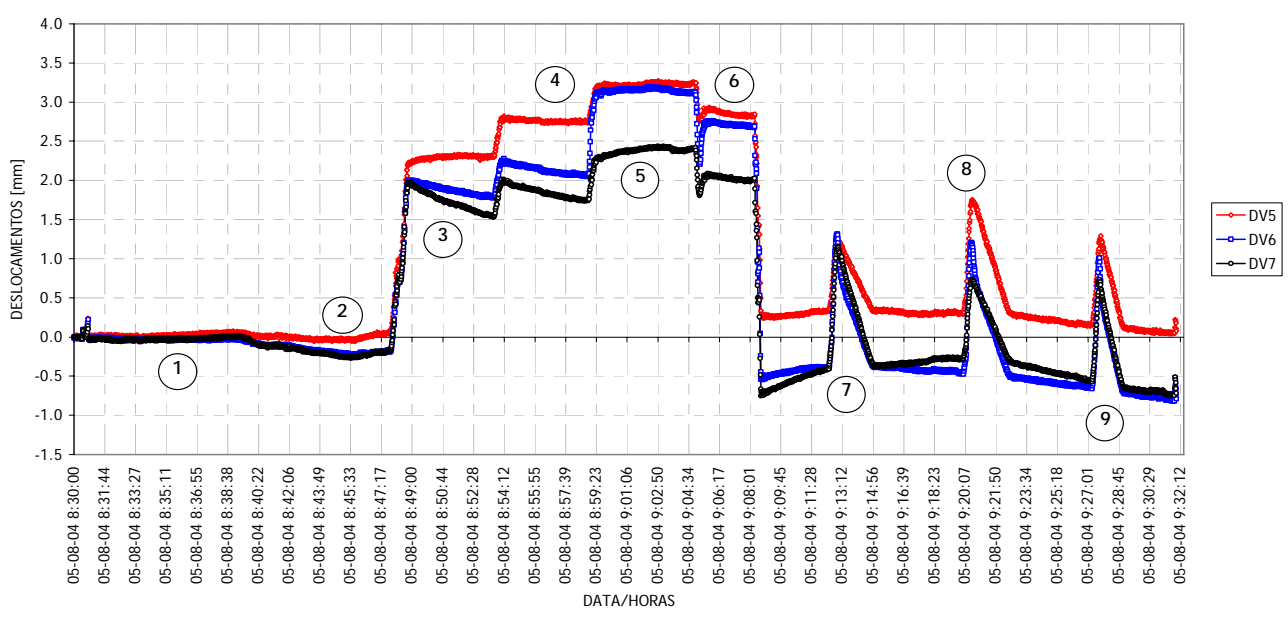

Figura 5.43 - Deslocamentos verticais medidos na $3^{\mathrm{a}}$ transversina do $1^{\circ}$ tramo, do lado do Pinhão, sendo utilizados os comparadores elétricos DV5, DV6 e DV7. 


\subsubsection{Abertura da junta de dilatação e rotações}

Os valores máximos da abertura da junta e das rotações da seção foram obtidos durante o caso de carga identificado pela posição 4. Os valores são indicados na tabela 5.21. Os resultados obtidos com os LVDT's e com os inclinômetros são apresentados sob a forma de gráficos, nas figuras 5.44 e 5.45, respectivamente.

Tabela 5.21 - Abertura de junta e rotações máximas obtidas na prova de carga.

\begin{tabular}{l|c|c|c}
\hline \multicolumn{1}{c|}{ Grandeza } & Sensor & $\begin{array}{c}\text { Posição dos } \\
\text { veículos }\end{array}$ & $\begin{array}{c}\text { Valor máximo } \\
\text { medido }\end{array}$ \\
\hline Abertura da junta & DJE1 & 4 & $-1,2 \mathrm{~mm}$ \\
\hline Rotações & 11 & 4 & $21,1 \times 10^{-3} \circ$ \\
\hline
\end{tabular}

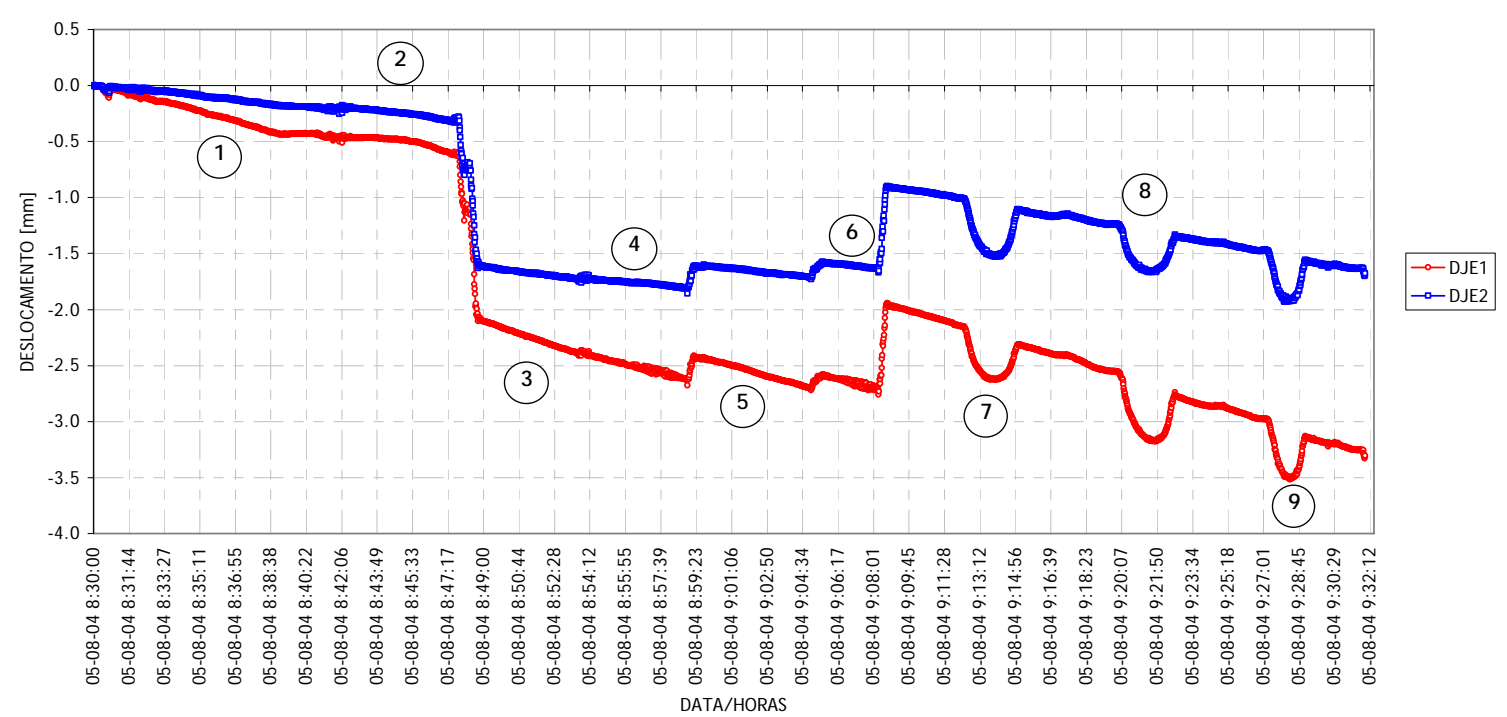

Figura 5.44 - Abertura da junta de dilatação localizada do lado do apoio móvel no $1^{\circ}$ tramo. 


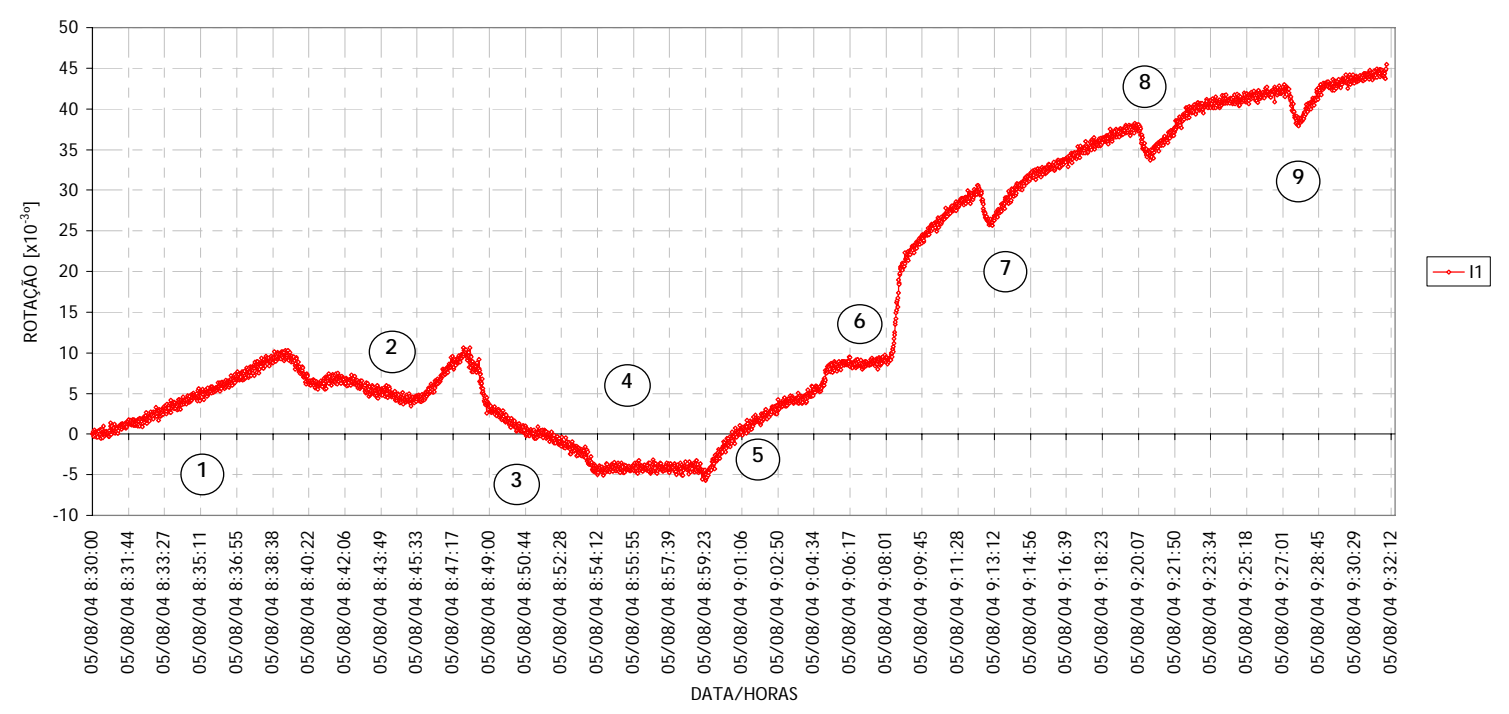

Figura 5.45 - Rotações da seção do encontro E1, com Pinhão, do lado de Jusante, segundo a direção longitudinal.

\subsection{Aferição e validação de resultados da prova de carga}

Com o intuito de preparar convenientemente a prova de carga, no que diz respeito à escolha da aparelhagem utilizada, dos métodos de colocação em obra e eleição das zonas a instrumentar, foi elaborado um modelo numérico para análise do comportamento estrutural, que permitiu avaliar qualitativa e quantitativamente as grandezas mecânicas face às solicitações a introduzir durante os ensaios. Por outro lado, este modelo numérico permitiu a interpretação dos resultados de observação numa fase posterior à experimentação, possibilitando a detecção de eventuais anomalias na estrutura e o estudo de eventuais intervenções a realizar.

A seguir, são apresentados alguns dos resultados obtidos com o modelo, os desvios registrados em relação às medições efetuadas durante o ensaio, e são feitas algumas conclusões sobre o comportamento estrutural verificado durante a realização do ensaio. 


\subsubsection{Modelo de análise}

Para a análise da estrutura foi elaborado um modelo numérico (ver figura 5.46), no qual a modelagem dos elementos estruturais que compõem a obra de arte foi a seguinte:

a) cordas, montantes e diagonais: elementos de barra;

b) contraventamentos superior e inferior: elementos de barra;

c) longarinas e transversinas: elementos finitos de casca nas almas (esforços de membrana) e elementos de barra nos banzos;

d) laje: elementos finitos de casca na face superior e elementos de barra transversais na face inferior;

e) chapas de ligação: elementos finitos de casca.

f) As condições de apoio junto ao encontro fixo, localizado na margem norte (lado do Pinhão) para o tramo 1, correspondem a travamentos dos deslocamentos em três direções ortogonais, paralelas aos eixos principais da ponte, na base dos montantes. A ligação entre o pilar P1 e a extremidade sul do tramo 1 foi assumida como um encontro móvel, isto é, o tabuleiro apóia simplesmente no pilar com travamento transversal, conforme o grau de liberdade aí possibilitado pelos aparelhos de apoio situados por debaixo dos montantes.

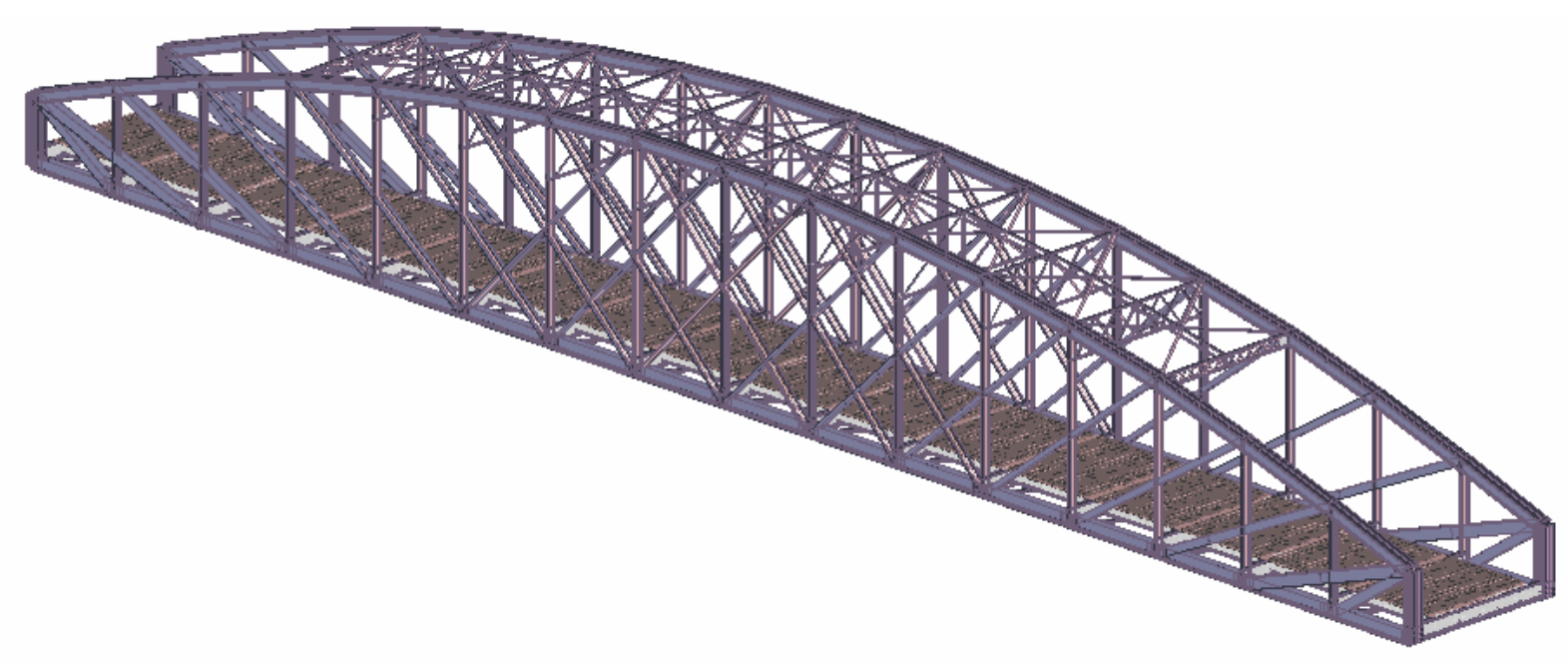

Figura 5.46 - Modelo numérico para análise. 
As características geométricas utilizadas para definir os elementos estruturais metálicos e de concreto, foram obtidas dos desenhos do projeto. As características de resistência e deformabilidade dos materiais utilizados no modelo numérico são as seguintes:

$$
\begin{aligned}
& \text { aço: } f_{y}=235 \mathrm{MPa}, \mathrm{f}_{\mathrm{u}}=360 \mathrm{MPa}, \mathrm{E}_{\mathrm{s}}=210 \mathrm{GPa} \\
& \text { concreto: } \mathrm{f}_{\mathrm{ck}}=12 \mathrm{MPa}, \mathrm{E}_{\mathrm{c}}=26 \mathrm{GPa} .
\end{aligned}
$$

A análise realizada pelo modelo é elástica linear, partindo do princípio que os níveis de carga aplicados à estrutura durante a realização do ensaio encontramse suficientemente distantes da carga última e bastante afastados de níveis passíveis de induzir comportamento não-linear significativo, apesar da fissuração existente na laje de concreto armado e a possível ocorrência de "escorregamentos" entre chapas de elementos distintos em alguns dos nós de ligação das peças metálicas, motivados pela deficiente solidarização proporcionada por rebites e chapas oxidados.

\subsubsection{Interpretação de resultados da análise numérica}

Ao comparar as deformações máximas obtidas a partir do modelo numérico descrito, considerando ações equivalentes àquelas aplicadas durante a prova de carga, nas posições de interesse, com as deformações monitoradas, constata-se que o erro observado varia entre $0,72 \%$ e 57,57\%. Na tabela 5.22, apresentada a seguir, é possível verificar os mais importantes valores medidos, para cada uma das peças instrumentadas com extensômetros elétricos, possibilitando-se comparar os valores obtidos durante a prova de carga com os correspondentes provenientes do modelo numérico.

É possível perceber que as hipóteses adotadas por ocasião da construção do modelo proporcionaram bons resultados em relação ao comportamento global da estrutura, sendo bastante relevante, no âmbito das deformações, perceber que para praticamente todas as peças instrumentadas os resultados apresentam-se bastante coerentes com o que foi observado durante o ensaio. O fato de as deformações 
medidas experimentalmente serem semelhantes às obtidas pelo modelo implica que as premissas consideradas na geração do mesmo são potencialmente válidas. A hipótese da elasticidade linear assumida adquire assim bastante credibilidade quanto à aplicação neste caso, permitindo-se concluir que as cargas introduzidas durante o ensaio não induziram a plastificação das seções mais solicitadas dos perfis metálicos da estrutura, pois de outro modo os valores medidos seriam significativamente superiores aos obtidos pelo modelo elástico.

Tabela 5.22 - Deformações nos elementos estruturais: valores medidos e resultado numérico.

\begin{tabular}{|c|c|c|c|c|c|}
\hline \multicolumn{2}{|c|}{ Peças instrumentadas } & \multirow{2}{*}{$\begin{array}{c}\begin{array}{c}\text { Posição } \\
\text { dos veículos }\end{array} \\
5\end{array}$} & \multirow{2}{*}{$\begin{array}{c}\begin{array}{c}\text { Valor máximo } \\
\text { medido }\end{array} \\
39,50 \times 10^{-6} \mathrm{~m} / \mathrm{m}\end{array}$} & \multirow{2}{*}{$\begin{array}{c}\begin{array}{c}\text { Resultado análise } \\
\text { numérica }\end{array} \\
36,45 \times 10^{-6} \mathrm{~m} / \mathrm{m}\end{array}$} & \multirow{2}{*}{$\begin{array}{c}\text { Erro (\%) } \\
6,32\end{array}$} \\
\hline \multirow{8}{*}{ Diagonais } & ES1-1 & & & & \\
\hline & ES1-2 & 5 & $39,50 \times 10^{-6} \mathrm{~m} / \mathrm{m}$ & $33,05 \times 10^{-6} \mathrm{~m} / \mathrm{m}$ & 13,38 \\
\hline & ES7-1 & 5 & $36,10 \times 10^{-6} \mathrm{~m} / \mathrm{m}$ & $36,45 \times 10^{-6} \mathrm{~m} / \mathrm{m}$ & $-0,72$ \\
\hline & ES7-2 & 5 & $37,10 \times 10^{-6} \mathrm{~m} / \mathrm{m}$ & $33,05 \times 10^{-6} \mathrm{~m} / \mathrm{m}$ & 8,40 \\
\hline & ES2-1 & 4 & $44,90 \times 10^{-6} \mathrm{~m} / \mathrm{m}$ & $43,05 \times 10^{-6} \mathrm{~m} / \mathrm{m}$ & 3,84 \\
\hline & ES2-2 & 4 & $48,20 \times 10^{-6} \mathrm{~m} / \mathrm{m}$ & $41,02 \times 10^{-6} \mathrm{~m} / \mathrm{m}$ & 14,90 \\
\hline & ES8-1 & 4 & $40,70 \times 10^{-6} \mathrm{~m} / \mathrm{m}$ & $41,08 \times 10^{-6} \mathrm{~m} / \mathrm{m}$ & $-0,79$ \\
\hline & ES8-2 & 4 & $40,40 \times 10^{-6} \mathrm{~m} / \mathrm{m}$ & $41,15 \times 10^{-6} \mathrm{~m} / \mathrm{m}$ & $-1,56$ \\
\hline \multirow{8}{*}{ Montantes } & ES3-1 & 4 & $-38,60 \times 10^{-6} \mathrm{~m} / \mathrm{m}$ & $-30,06 \times 10^{-6} \mathrm{~m} / \mathrm{m}$ & $-17,72$ \\
\hline & ES3-2 & 4 & $-15,80 \times 10^{-6} \mathrm{~m} / \mathrm{m}$ & $-23,94 \times 10^{-6} \mathrm{~m} / \mathrm{m}$ & 16,89 \\
\hline & ES9-1 & 5 & $3,80 \times 10^{-6} \mathrm{~m} / \mathrm{m}$ & $2,33 \times 10^{-6} \mathrm{~m} / \mathrm{m}$ & 3,05 \\
\hline & ES9-2 & 5 & $3,90 \times 10^{-6} \mathrm{~m} / \mathrm{m}$ & $0,94 \times 10^{-6} \mathrm{~m} / \mathrm{m}$ & 6,14 \\
\hline & ES4-1 & 5 & $34,70 \times 10^{-6} \mathrm{~m} / \mathrm{m}$ & $21,95 \times 10^{-6} \mathrm{~m} / \mathrm{m}$ & 26,45 \\
\hline & ES4-2 & 5 & $15,70 \times 10^{-6} \mathrm{~m} / \mathrm{m}$ & $28,11 \times 10^{-6} \mathrm{~m} / \mathrm{m}$ & $-25,75$ \\
\hline & ES10-1 & 5 & $16,90 \times 10^{-6} \mathrm{~m} / \mathrm{m}$ & $21,71 \times 10^{-6} \mathrm{~m} / \mathrm{m}$ & $-9,98$ \\
\hline & ES10-2 & 5 & $22,40 \times 10^{-6} \mathrm{~m} / \mathrm{m}$ & $28,10 \times 10^{-6} \mathrm{~m} / \mathrm{m}$ & $-11,82$ \\
\hline \multirow{3}{*}{ Corda Superior } & ES5-1 & 3 & $-46,00 \times 10^{-6} \mathrm{~m} / \mathrm{m}$ & $-31,12 \times 10^{-6} \mathrm{~m} / \mathrm{m}$ & $-30,87$ \\
\hline & ES11-1 & 3 & $-3,20 \times 10^{-6} \mathrm{~m} / \mathrm{m}$ & $-30,95 \times 10^{-6} \mathrm{~m} / \mathrm{m}$ & 57,57 \\
\hline & ES11-2 & 3 & $-19,60 \times 10^{-6} \mathrm{~m} / \mathrm{m}$ & $-30,90 \times 10^{-6} \mathrm{~m} / \mathrm{m}$ & 23,44 \\
\hline \multirow{4}{*}{ Corda Inferior } & ES6-1 & 3 & $24,40 \times 10^{-6} \mathrm{~m} / \mathrm{m}$ & $33,01 \times 10^{-6} \mathrm{~m} / \mathrm{m}$ & $-17,86$ \\
\hline & ES6-2 & 3 & $30,30 \times 10^{-6} \mathrm{~m} / \mathrm{m}$ & $37,54 \times 10^{-6} \mathrm{~m} / \mathrm{m}$ & $-15,02$ \\
\hline & ES12-1 & 3 & $29,40 \times 10^{-6} \mathrm{~m} / \mathrm{m}$ & $33,63 \times 10^{-6} \mathrm{~m} / \mathrm{m}$ & $-8,78$ \\
\hline & ES12-2 & 3 & $29,70 \times 10^{-6} \mathrm{~m} / \mathrm{m}$ & $38,10 \times 10^{-6} \mathrm{~m} / \mathrm{m}$ & $-17,43$ \\
\hline \multirow{2}{*}{$2^{\circ}$ Longarina } & ES13-1 & 5 & $2,30 \times 10^{-6} \mathrm{~m} / \mathrm{m}$ & $-0,91 \times 10^{-6} \mathrm{~m} / \mathrm{m}$ & 6,66 \\
\hline & ES13-2 & 5 & $14,80 \times 10^{-6} \mathrm{~m} / \mathrm{m}$ & $20,51 \times 10^{-6} \mathrm{~m} / \mathrm{m}$ & $-11,85$ \\
\hline \multirow{2}{*}{$3^{a}$ Longarina } & ES16-1 & 5 & $2,20 \times 10^{-6} \mathrm{~m} / \mathrm{m}$ & $0,07 \times 10^{-6} \mathrm{~m} / \mathrm{m}$ & 4,42 \\
\hline & ES16-2 & 5 & $15,80 \times 10^{-6} \mathrm{~m} / \mathrm{m}$ & $10,97 \times 10^{-6} \mathrm{~m} / \mathrm{m}$ & 10,02 \\
\hline \multirow{2}{*}{$\begin{array}{l}3^{a} \text { Transversina } \\
\text { (1/2 vão) }\end{array}$} & ES15-1 & 5 & $47,80 \times 10^{-6} \mathrm{~m} / \mathrm{m}$ & $66,65 \times 10^{-6} \mathrm{~m} / \mathrm{m}$ & $-39,11$ \\
\hline & ES15-2 & 5 & $45,70 \times 10^{-6} \mathrm{~m} / \mathrm{m}$ & $37,63 \times 10^{-6} \mathrm{~m} / \mathrm{m}$ & 16,74 \\
\hline \multirow{2}{*}{$\begin{array}{l}3^{a} \text { Transversina } \\
\text { (extremidade) }\end{array}$} & ES14-1 & 3 & $-28,30 \times 10^{-6} \mathrm{~m} / \mathrm{m}$ & $-30,21 \times 10^{-6} \mathrm{~m} / \mathrm{m}$ & 3,96 \\
\hline & ES14-2 & 3 & $26,10 \times 10^{-6} \mathrm{~m} / \mathrm{m}$ & $22,54 \times 10^{-6} \mathrm{~m} / \mathrm{m}$ & 7,39 \\
\hline \multirow{2}{*}{$\begin{array}{l}7^{a} \text { Transversina } \\
(1 / 2 \text { vão) }\end{array}$} & ES17-1 & 3 & $24,20 \times 10^{-6} \mathrm{~m} / \mathrm{m}$ & $47,55 \times 10^{-6} \mathrm{~m} / \mathrm{m}$ & $-48,44$ \\
\hline & ES17-2 & 3 & $42,90 \times 10^{-6} \mathrm{~m} / \mathrm{m}$ & $58,35 \times 10^{-6} \mathrm{~m} / \mathrm{m}$ & $-32,05$ \\
\hline
\end{tabular}


Esta conclusão é corroborada pelos dados que constam da tabela 5.23, que diz respeito respectivamente aos deslocamentos e rotações mais relevantes, nos quais é patente a observação de valores absolutos das grandezas medidas próximos aos valores obtidos por meio da análise numérica.

Tabela 5.23 - Flechas, abertura da junta e rotações da ponte do Pinhão: valores medidos e resultado numérico.

\begin{tabular}{|c|c|c|c|c|c|c|}
\hline Grandeza & \multicolumn{2}{|c|}{ Peças instrumentadas } & \multirow{2}{*}{\begin{tabular}{|c|}
$\begin{array}{c}\text { Posição } \\
\text { dos veículos }\end{array}$ \\
3
\end{tabular}} & \multirow{2}{*}{$\begin{array}{c}\begin{array}{c}\text { Valor } \\
\text { máximo } \\
\text { medido }\end{array} \\
8,4 \mathrm{~mm} \\
\end{array}$} & \multirow{2}{*}{$\begin{array}{c}\begin{array}{c}\text { Resultado } \\
\text { análise } \\
\text { numérica }\end{array} \\
6,2 \mathrm{~mm} \\
\end{array}$} & \multirow{2}{*}{$\begin{array}{c}\text { Erro (\%) } \\
25,88\end{array}$} \\
\hline \multirow{7}{*}{$\begin{array}{l}\text { Deslocamento } \\
\text { vertical }\end{array}$} & \multirow{2}{*}{$1^{\circ}$ Tramo (1/2 vão) } & DV1 & & & & \\
\hline & & DV2 & 3 & $8,5 \mathrm{~mm}$ & $6,2 \mathrm{~mm}$ & 27,06 \\
\hline & $2^{\circ}$ Tramo (1/2 vão) & DV3 & 2 & $8,4 \mathrm{~mm}$ & - & - \\
\hline & $3^{\circ}$ Tramo (1/2 vão) & DV4 & 1 & $8,2 \mathrm{~mm}$ & - & - \\
\hline & \begin{tabular}{|l}
$3^{\mathrm{a}}$ Transversina \\
(Extr. a montante) \\
\end{tabular} & DV5 & 5 & $3,0 \mathrm{~mm}$ & $2,8 \mathrm{~mm}$ & 5,71 \\
\hline & $3^{\mathrm{a}}$ Transversina (1/2 vão) & DV6 & 5 & $3,5 \mathrm{~mm}$ & $3,4 \mathrm{~mm}$ & 2,86 \\
\hline & $\begin{array}{l}3^{\mathrm{a}} \text { Transversina } \\
\text { (Extr. a Jusante) }\end{array}$ & DV7 & 5 & $2,8 \mathrm{~mm}$ & $2,8 \mathrm{~mm}$ & 0,00 \\
\hline \multirow{2}{*}{$\begin{array}{c}\text { Abertura da } \\
\text { Junta }\end{array}$} & Apoio móvel (Montante) & DJE1 & 4 & $-1,2 \mathrm{~mm}$ & $-1,6 \mathrm{~mm}$ & 33,33 \\
\hline & Apoio móvel (Jusante) & DJE2 & 4 & $-1,1 \mathrm{~mm}$ & $-1,6 \mathrm{~mm}$ & 41,67 \\
\hline Rotações & $\begin{array}{l}\text { Seção junto ao apoio fixo } \\
\text { (lado do Pinhão) }\end{array}$ & 11 & 4 & $21,1 \times 10^{-3} 0$ & $11,0 \times 10^{-30}$ & 47,87 \\
\hline
\end{tabular}

Da comparação efetuada considerando as medições de deformações, deslocamentos e rotações, foi possível constatar que a estrutura da ponte se comportou de forma menos rígida do que o modelo numérico que serviu para comparação. As diferenças observadas podem ser justificadas pelos seguintes fatores:

a) Simplificações adotadas no modelo numérico, sobretudo em relação às ligações dos diversos elementos estruturais;

b) Propriedades elásticas do concreto diferirem das adotadas. 


\subsection{Considerações finais}

Neste capítulo foram apresentadas as várias atividades e resultados relacionados com a prova de carga da ponte do Pinhão, sobre o rio Douro. Foram medidas deformações em seções das barras metálicas, flechas a meio-vão de cada tramo e em elementos estruturais selecionados, rotações e aberturas de junta (deslocamento dos aparelhos de apoio). A medição da temperatura completa o sistema de instrumentação para avaliar os efeitos das ações aplicadas à estrutura. A ação aplicada ao tabuleiro da ponte foi efetivada com a utilização de três veículos, cada um pesando aproximadamente 12 toneladas.

A aquisição do sinal de todos os sensores instalados foi totalmente automatizada com a concentração e armazenamento da medição em dois postos de observação (PO), e a sua ligação a um computador portátil, junto à obra, permitiu o acompanhamento em tempo real das medições efetuadas. O fator "erro humano" não teve assim, diretamente, interferência na quantificação das grandezas medidas e expressas nos gráficos e quadros apresentados.

Da comparação efetuada entre os resultados experimentais e os obtidos com o modelo numérico de análise, constatou-se que a diferença de rigidez entre o modelo e a estrutura ronda os $20 \%$. Essa diferença pode dever-se às simplificações adotadas na modelagem das ligações dos diversos elementos estruturais e na modelagem do tabuleiro.

Em face dos resultados obtidos, é possível concluir que, para os carregamentos introduzidos durante a prova de carga, a estrutura da Ponte do Pinhão apresentou comportamento em conformidade com o esperado (ASSIS et al., 2004). 


\section{CAPÍTULO 6}

\section{MONITORAÇÃO DA LAJE DE FUNDO DA ESTAÇÃO METROVIÁRIA \\ ALTO DO IPIRANGA}

\subsection{Introdução}

O presente capítulo descreve as atividades envolvidas no planejamento, instrumentação e monitoração do comportamento da laje de fundo do poço da Estação Alto do Ipiranga (figura 6.1), edificação atualmente em construção que está localizada na Linha 2 - Verde, da rede de transportes metropolitanos da cidade de São Paulo. A construção da obra está sob responsabilidade da Construtora Norberto Odebrecht, por meio da sua subsidiária CBPO Engenharia Ltda.

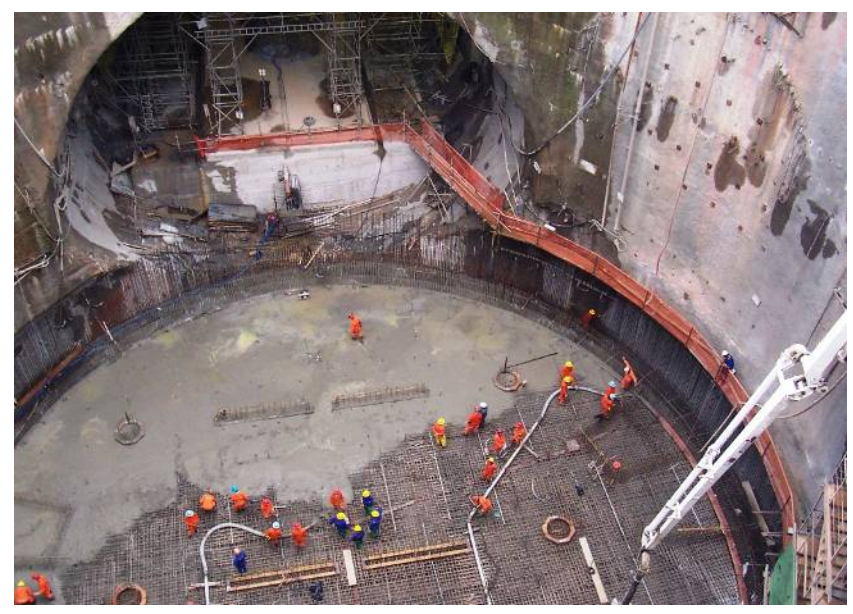

(a)

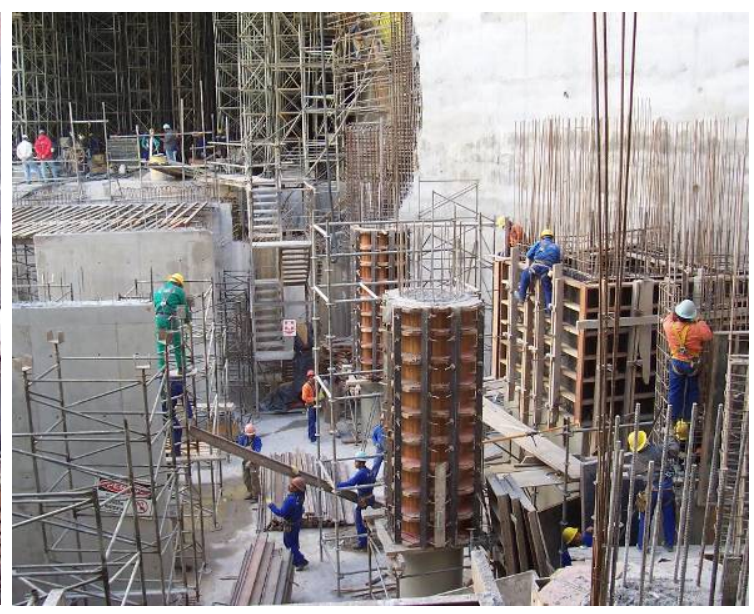

(b)

Figura 6.1 - Construção da Estação Alto do Ipiranga, em São Paulo. Fotografias tiradas nos dias 25 de maio (a) e 22 de agosto de 2006 (b).

A instrumentação foi realizada pela equipe do Laboratório de Estruturas e Materiais Estruturais (LEM), da Escola Politécnica da Universidade de São Paulo (EPUSP), e pela equipe da Gávea Sensors - empresa brasileira pioneira no desenvolvimento de soluções de medição utilizando sensores de fibra óptica - em 
conformidade com as diretrizes fornecidas pela Companhia do Metropolitano de São Paulo (Metrô) e indicações apresentadas na reunião realizada no dia 17 de Março de 2006 na sede do Metrô. Nesta reunião, na qual participaram técnicos do Metrô, do LEM - EPUSP e da Universidade Estadual de Campinas (UNICAMP), foram discutidos assuntos relacionados ao alcance dos resultados esperados, à localização das seções a instrumentar e às grandezas a serem medidas (ASSIS, TRAUTWEIN, BITTENCOURT, 2006). A partir das decisões tomadas na reunião, foi elaborado um plano de monitoração tendo em vista, por meio da instrumentação e posterior acompanhamento dos resultados, ser possível avaliar qualitativamente as informações provenientes do sistema de monitoração e apurar as dificuldades enfrentadas quando da implementação de um sistema de monitoração em uma estrutura metroviária de grande porte durante a fase construtiva.

Na próxima seção é feita uma descrição geral da obra e das grandezas físicas de interesse, sendo feita a apresentação do sistema de medição instalado e das atividades de instrumentação na seção 6.3. Os resultados obtidos constituem o assunto da seção 6.4, e as considerações finais são feitas na seção 6.5.

\subsection{Descrição da obra}

O poço da Estação Alto do Ipiranga é uma obra enterrada cujas paredes são constituídas por uma camada de concreto projetado (revestimento primário), conforme apresentado na figura 6.2a, e por uma segunda camada, de concreto moldado (revestimento secundário), que pode ser vista na figura 6.2b.

A espessura total da parede que circunda a estação é de $1,86 \mathrm{~m}$, que repousa sobre uma laje de fundo de concreto armado com 2,00 m de espessura, a qual, por sua vez, está assentada sobre uma camada de solo argiloso. A figura 6.3 apresenta a estação durante a fase de construção da laje de fundo. 


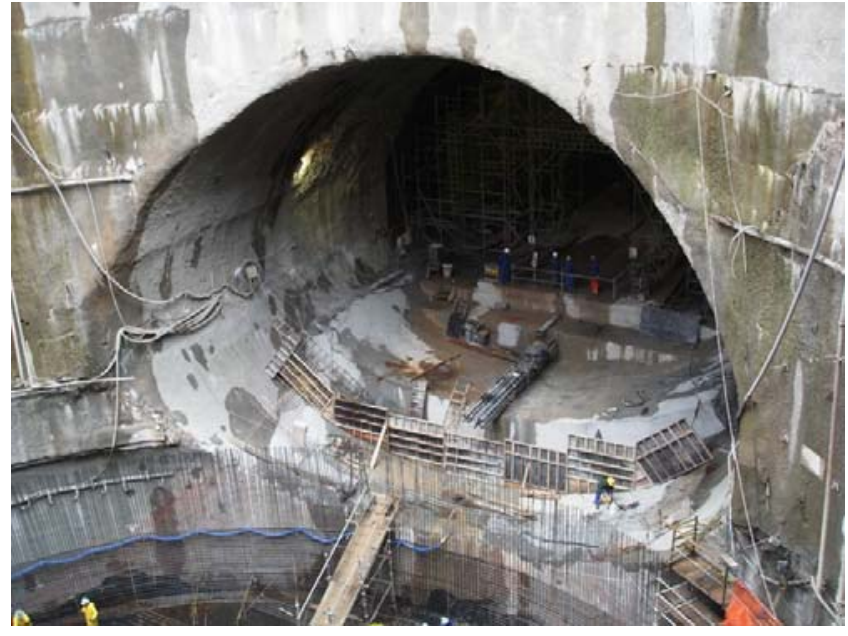

(a)

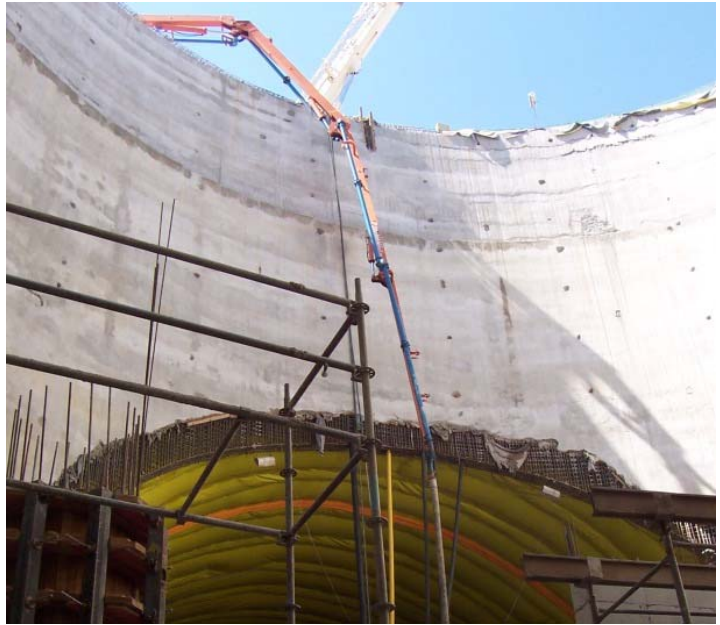

(b)

Figura 6.2 - Parede da estação. Camada de concreto projetado (a) e camada de concreto moldado (b). Fotografias de 12 de maio e 22 de agosto de 2006, respectivamente.

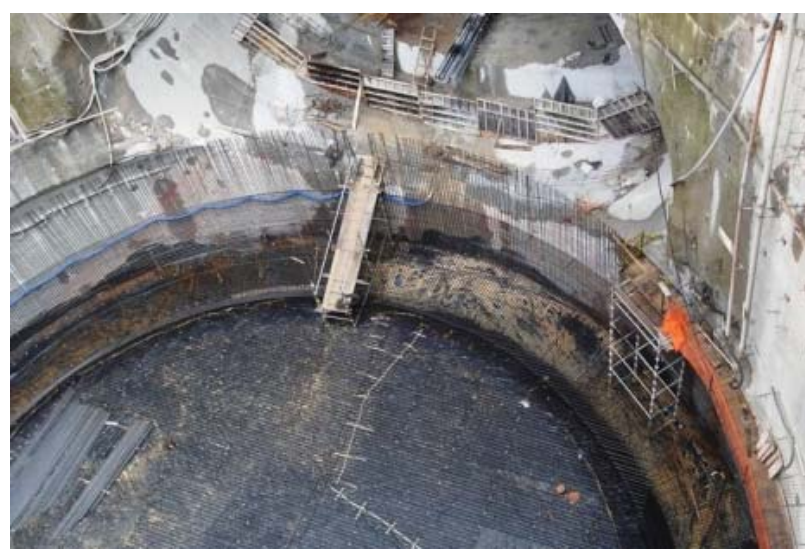

(a)

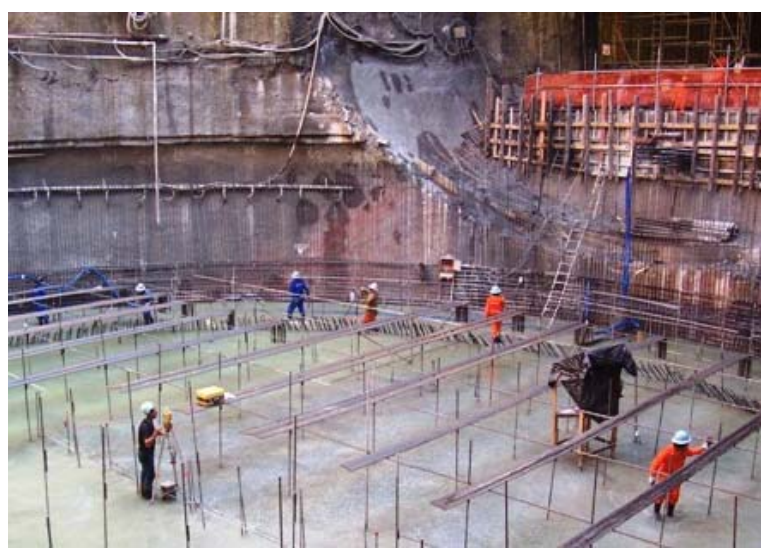

(b)

Figura 6.3 - Execução da laje de fundo da estação. Preparação da superfície para lançamento do lastro de concreto magro (a) e posicionamento das armaduras negativas da laje (b). Fotografias de 12 de maio e 19 de maio de 2006, respectivamente.

A Estação Alto do Ipiranga terá $8.485 \mathrm{~m}^{2}$ de área total e nela convergirão dois túneis, construídos utilizando o método construtivo NATM - New Austrian Tunnelling Method, também conhecido como "túnel mineiro". Esse método é utilizado com sucesso na construção de túneis e de estações subterrâneas de grandes dimensões, proporcionando menor impacto na superfície, menor volume de desapropriações e reduzidas interrupções de tráfego.

Após a conclusão, a estação contará com dois acessos, uma bilheteria, sete bloqueios, sete escadas fixas, seis escadas rolantes e três elevadores. A nova estação terá um desnível de 24,16 m, entre o hall da bilheteria e a plataforma e será a mais profunda do trecho leste da Linha 2. Quando concluída, a estação atenderá, 
em média, a cinqüenta mil passageiros por dia. A implantação da Estação Alto do Ipiranga, com as desapropriações necessárias e a aquisição de dois novos trens, exigirá do Estado de São Paulo investimentos de cerca de 295 milhões de reais. As obras foram iniciadas no primeiro semestre de 2005 e têm previsão de conclusão para o primeiro semestre de 2007.

\subsection{Sistema de medição instalado}

Na observação do comportamento da laje de fundo da Estação Alto do Ipiranga procedeu-se à medição de cinco tipos de grandezas: (i) pressões na cota da face inferior da laje, (ii) deformações no concreto e em armaduras selecionadas e (iii) temperatura do concreto. Na monitoração todos os sensores utilizados foram baseados na tecnologia de fibra óptica, não tendo sido instalados sensores convencionais ou elétricos. A instrumentação foi instalada em uma região sob o pilar P1, indicada na figura 6.4, sendo que a escolha do local foi feita de modo a atender a duas questões importantes: a obtenção de resultados apreciáveis e a facilidade de acesso à região instrumentada após a conclusão da obra.

A preocupação em identificar pontos de instrumentação com boas probabilidades de fornecer resultados significativos justifica-se sobretudo no tocante à medição das deformações, que a depender da região escolhida poderia fornecer variações pouco expressivas, tendo em vista a espessura da laje de fundo. Para evitar esse cenário, foi escolhida a região imediatamente abaixo do pilar P1, que no projeto estrutural figura como um mais solicitados da estação. Outro fator importante para a opção pela região junto ao pilar P1 foi a proximidade da mesma em relação a uma futura sala técnica, o que proporcionaria o acesso fácil às fibras dos sensores, para a realização de medições durante o período de funcionamento da estação. 


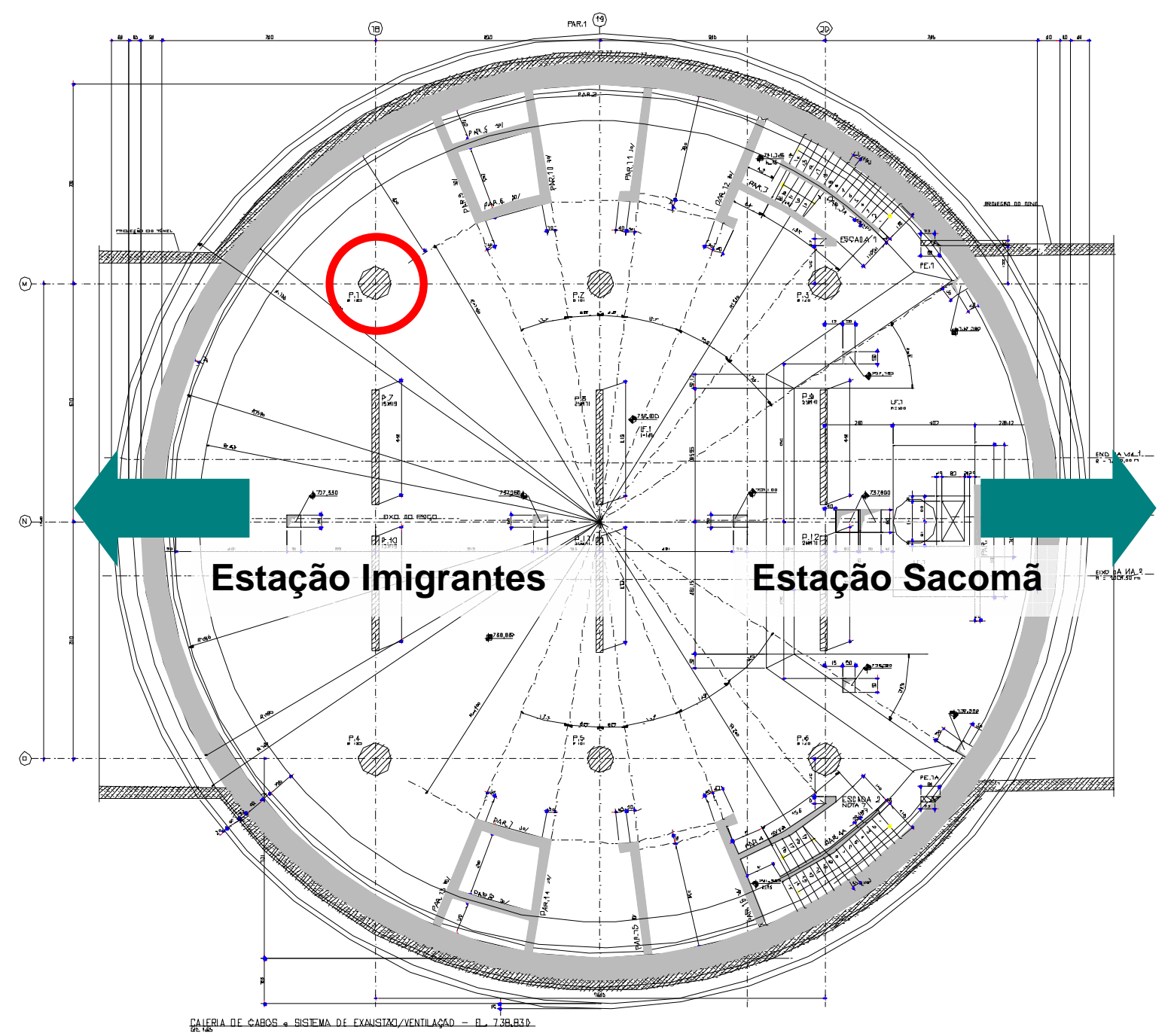

Figura 6.4 - Planta da Estação Metroviária Alto do Ipiranga, na cota da laje de fundo. A região delimitada pela circunferência vermelha corresponde à área monitorada, sob o pilar P1.

A justificativa para o emprego de sensores ópticos reside nas diversas vantagens técnicas que esta classe de sensores apresentam em relação aos sensores convencionais ou elétricos, apresentadas no Capítulo 2. De fato, as propriedades inerentes aos sensores ópticos tornam a adoção dessa tecnologia uma solução interessante para a monitoração de estruturas de Engenharia Civil, que inclusive já vem sendo adotada em diversas obras em países como os Estados Unidos, Canadá, Portugal, Suíça, França, Itália, China e Japão, por exemplo.

$\mathrm{Na}$ Estação Alto do Ipiranga foi empregado o sistema de aquisição de sinais ópticos modelo Braggmeter, fabricado pela Fibersensing, empresa portuguesa fabricante de sensores e dispositivos ópticos que concedeu o equipamento à EPUSP sob regime de comodato, para utilização laboratorial e aquisição dos sinais 
provenientes da rede sensora instalada. Na figura 6.5 são apresentados os dois modelos de Braggmeter utilizados.

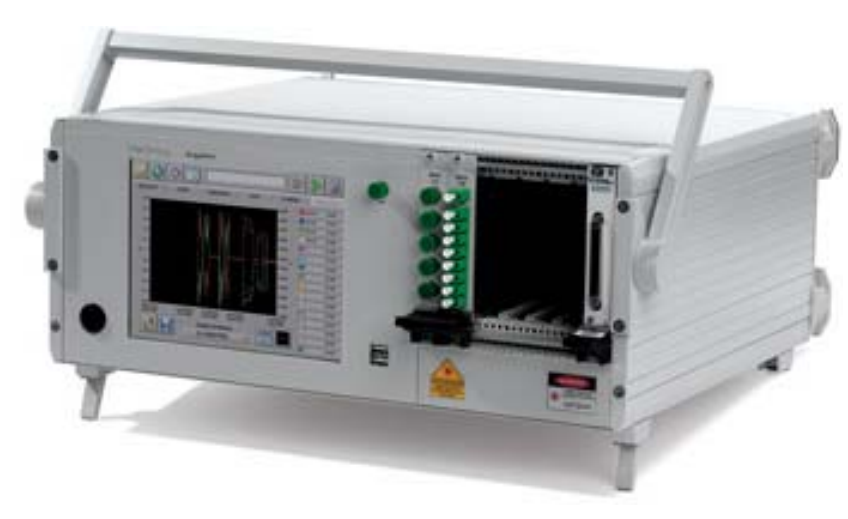

(a)

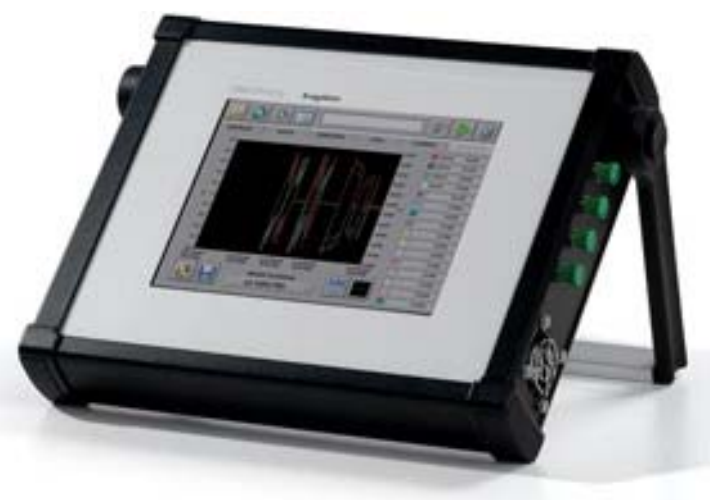

(b)

Figura 6.5 - Unidades de medição para sensores ópticos utilizados na monitoração da estação: braggmeter de bancada (a) e braggmeter portátil (b).

Toda a instrumentação foi testada e calibrada antes da instalação. Para permitir o acesso aos conectores dos cabos de fibra óptica com os sinais dos sensores após a instalação, foram providenciadas caixas de passagem.

\subsubsection{Medição das pressões}

A fim de monitorar as pressões atuantes na face inferior da laje de fundo, foi empregado um sensor de poro-pressão óptico indicado para a monitoração em obras geotécnicas. Este sensor, fabricado pela Gávea Sensors, é apresentado na figura 6.6. Em virtude das características mecânicas dos materiais empregados no encapsulamento das fibras ópticas do sensor, que foram especificadas de modo a permitir que o sensor resista à corrrosão e a ataques oriundos de solos agressivos, espera-se do piezômetro que o mesmo apresente elevada durabilidade e resultados confiáveis a longo prazo.

O sensor piezométrico foi instalado a $30 \mathrm{~cm}$ sob o lastro de concreto simples da laje de fundo da estação, tendo sido disposto na vertical, segundo o eixo que passa pelo centro de gravidade do pilar P1 (figura 6.7). As operações de instalação do piezômetro são apresentadas no item 6.3.4. 


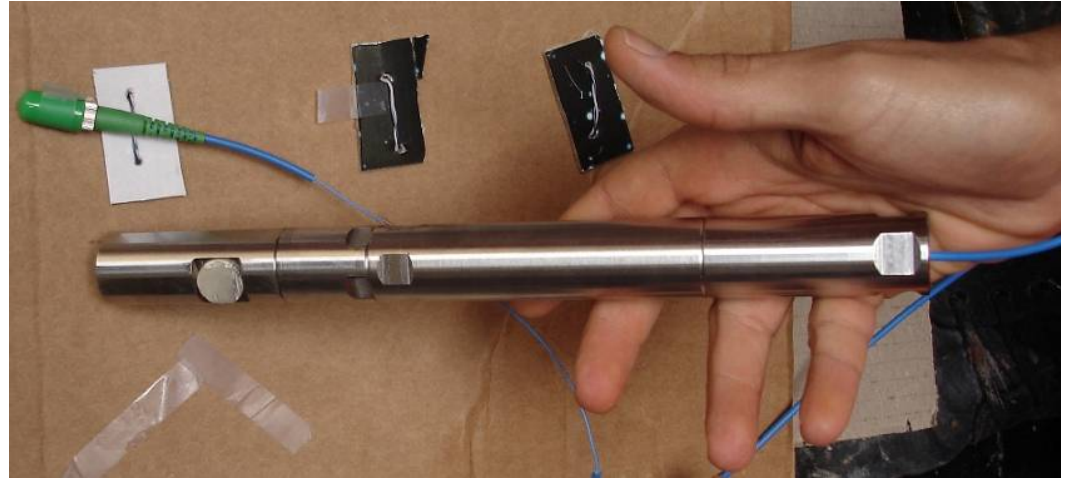

(a)

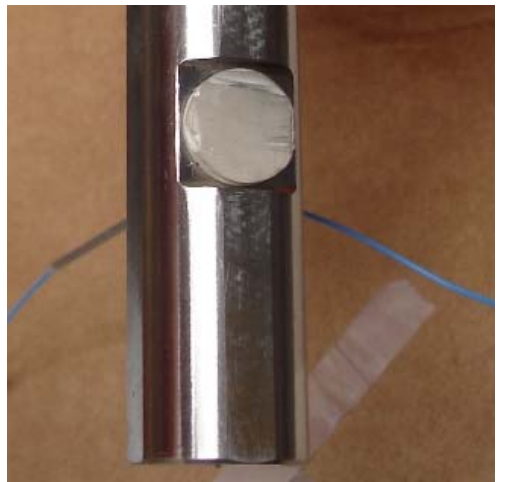

(b)

Figura 6.6 - Sensor para medição de pressões sob a laje de fundo da estação (a) e detalhe da região sensível à variação da pressão, revestida por uma pedra porosa (b).

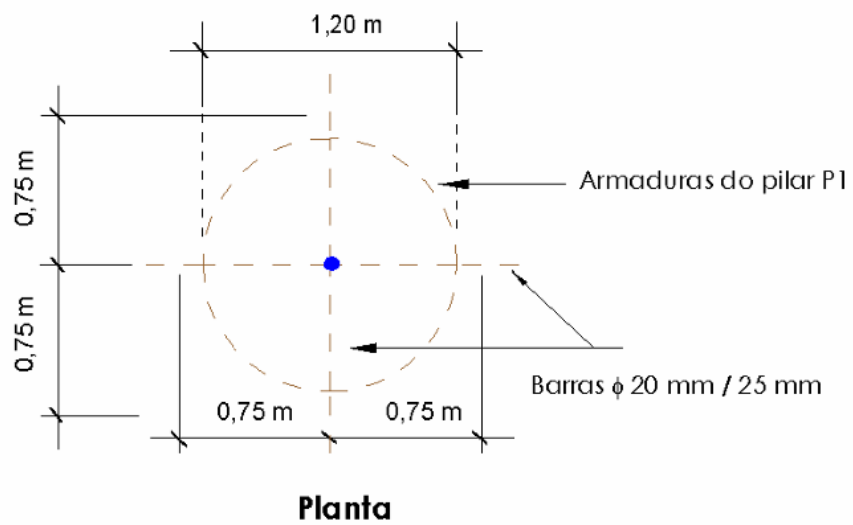

- Sensor de poro - pressão

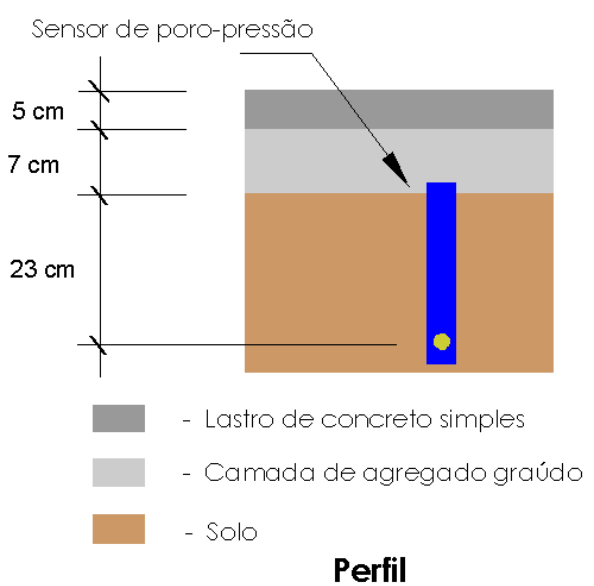

(b)

(a)

Figura 6.7 - Localização do sensor de poro-pressão, instalado sob o pilar P1, em planta (a) e em perfil (b).

As principais características técnicas do sensor utilizado são apresentadas na tabela 6.1. 
Tabela 6.1 - Principais características técnicas do sensor de poro-pressão.

\begin{tabular}{l|l}
\hline Característica & Especificação \\
\hline Comprimento de onda central & $1530 \mathrm{~nm}$ a $1570 \mathrm{~nm}$ \\
\hline Largura espectral & $<0.8 \mathrm{~nm}( \pm 0.2 \mathrm{~nm})$ \\
\hline Refletividade & $>65 \%( \pm 10 \%)$ \\
\hline Sensibilidade & $3 \mathrm{pm} / \mathrm{kPa}( \pm 0.5 \mathrm{pm})$ \\
\hline Encapsulamento & $17-4 \mathrm{PH}(\mathrm{AISI} 630)$ \\
\hline Temperatura de operação & $-20{ }^{\circ} \mathrm{C}$ a $80{ }^{\circ} \mathrm{C}$ \\
\hline Escala máxima de leitura & 0 a $500 \mathrm{kPa}$ \\
\hline Umidade relativa de operação & $<90 \%($ sem condensação) \\
\hline Modelo & $\mathrm{GS} 6600-$ Piezometer \\
\hline
\end{tabular}

\subsubsection{Medição das deformações}

Para a medição das deformações foram utilizados dois modelos de sensores ópticos, um dos quais para a medição da deformação nas armaduras e o outro para a medição da deformação no concreto (figura 6.8). Os sensores ópticos de deformação empregados na monitoração de armaduras da laje de fundo da estação são constituídos basicamente por uma fibra óptica na qual em trechos selecionados foram inscritas redes de Bragg. Estes trechos inscritos constituíram as regiões sensíveis à variação da deformação, os quais foram inicialmente colados nas armaduras, nos pontos de medição, e em seguida receberam uma proteção apropriada. Para a monitoração do concreto foram utilizados sensores ópticos de embeber que contam com um revestimento metálico especial na região sensora, além de conectores com proteção metálica e conexões especialmente projetadas para resistir com integridade ao lançamento do concreto e às operação típicas do processo de concretagem. Convém mencionar que na monitoração das deformações na laje de fundo foram utilizados até quatro sensores em uma só fibra óptica, o que foi viabilizado pela possibilidade de realizar a multiplexação dos sinais dos sensores. Esta característica da tecnologia óptica traz significativas vantagens econômicas em aplicações de larga escala. 


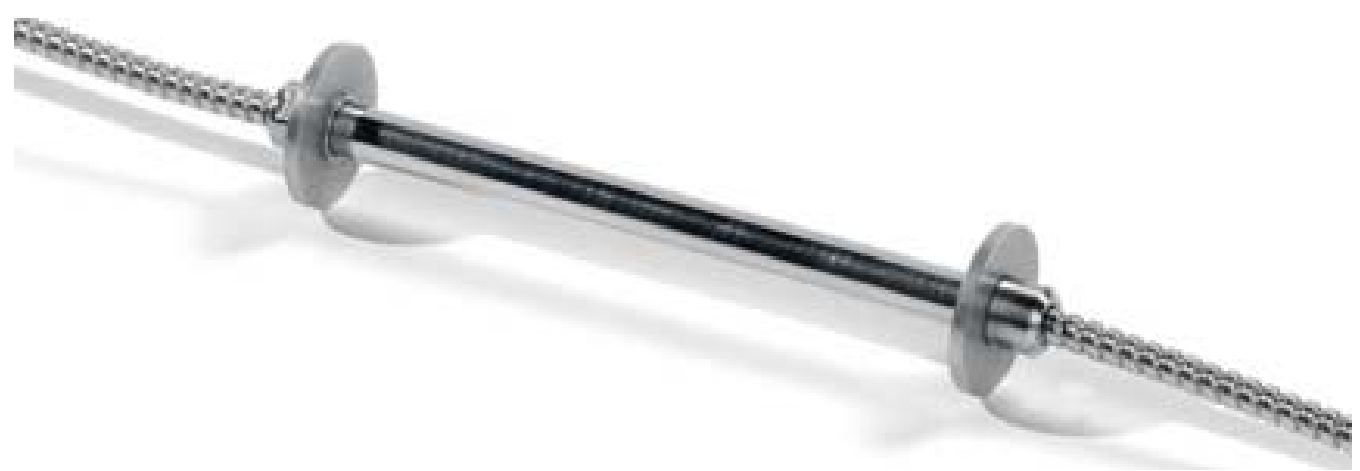

Figura 6.8 - Sensor óptico para medição de deformações, com revestimento da região sensora e proteção metálica do cabo. Este tipo de sensor foi empregado na monitoração, e é adequado para ser embebido no concreto.

As deformações no concreto e nas armaduras foram medidas em pontos selecionados da laje de fundo em uma região sob o pilar P1, sendo que no concreto foram instalados sensores ópticos de deformação em quatro pontos, enquanto que as armaduras foram contempladas com sete pontos de medição. As principais informações técnicas dos sensores utilizados são apresentadas na tabela 6.2.

A distribuição dos sensores na laje de fundo está apresentada na figura 6.9 e foi feita de modo a captar efeitos de flexão eventualmente existentes, além de obter medições representativas do comportamento localizado da estrutura. O procedimento de instalação dos sensores de deformação é tratado no item 6.3.4.

Tabela 6.2 - Principais características técnicas dos sensores ópticos de deformação para concreto.

\begin{tabular}{l|l}
\hline Característica & Especificação \\
\hline Comprimento de onda central & $1530 \mathrm{~nm}$ a $1570 \mathrm{~nm}$ \\
\hline Largura espectral & $<0.2 \mathrm{~nm}$ \\
\hline Refletividade & $>75 \%$ \\
\hline Sensibilidade & $1.2 \mathrm{pm} / \mathrm{m}$ \\
\hline Encapsulamento & Aço inoxidável \\
\hline Temperatura de operação & $-20{ }^{\circ} \mathrm{C}$ a $80^{\circ} \mathrm{C}$ \\
\hline Umidade relativa de operação & $<90 \%$ (sem condensação) \\
\hline Modelo & FS $6200-$ Strain Sensors \\
\hline
\end{tabular}




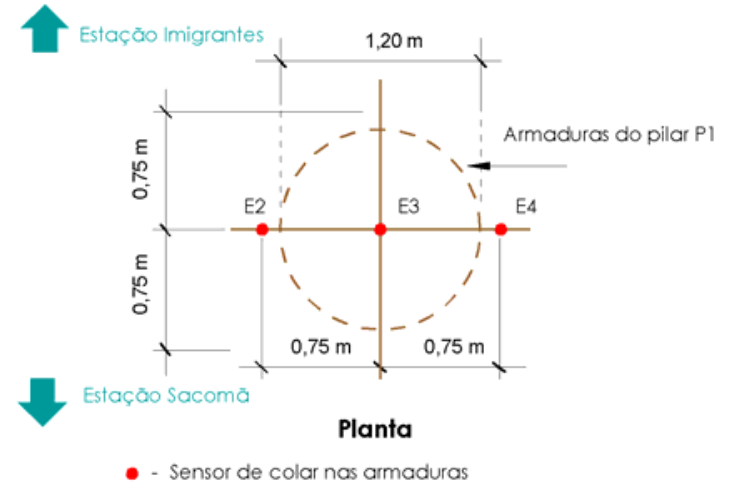

(a)

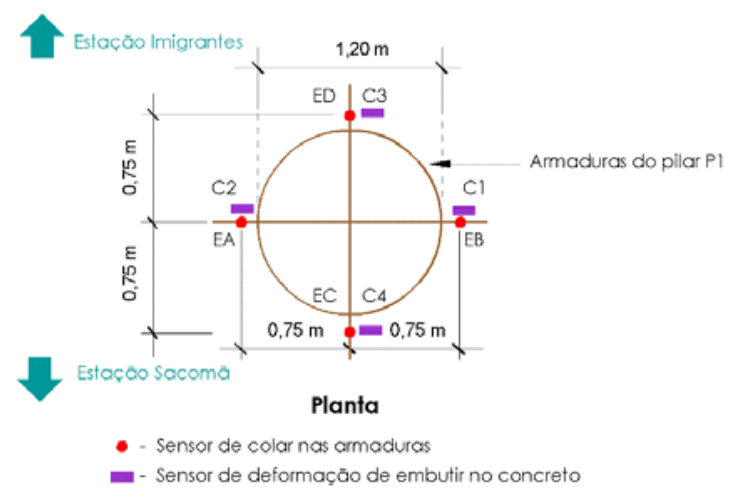

(b)

Figura 6.9 - Localização dos sensores de deformação nas armaduras (E2, E3, E4, EA, EB, EC e ED) e dos sensores de deformação de embeber no concreto (C1, C2, C3 e C4). Sensores da região inferior (a) e superior (b) da laje de fundo.

\subsubsection{Medição da temperatura do concreto}

Para a medição da temperatura do concreto foram utilizados dois termômetros ópticos de embeber no contreto, fabricados pela Fibersensing (figura 6.10). Assim como no caso dos sensores ópticos de deformação para concreto, estes termômetros apresentam um revestimento metálico especial na região sensora, bem como conectores com proteção metálica e conexões projetadas para resistir ao lançamento do concreto e às operação de concretagem. Cada uma das duas camadas de concreto utilizadas para constituir a laje de fundo recebeu um termômetro, sempre posicionado próximo aos sensores de deformação.

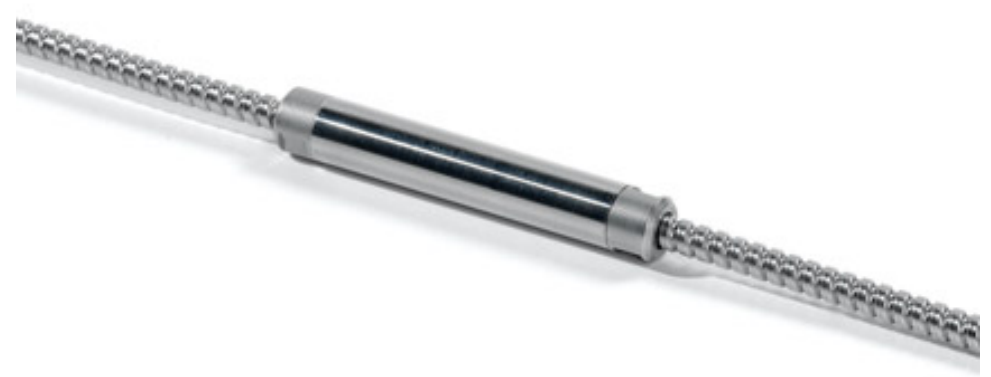

Figura 6.10 - Sensor óptico para medição de temperaturas utilizado, com revestimento da região sensora e proteção metálica do cabo.

A tabela 6.3 traz as principais características técnicas dos sensores de temperatura utilizados. 
Tabela 6.3 - Principais características técnicas dos sensores ópticos para medição de temperaturas utilizados.

\begin{tabular}{l|l}
\hline Característica & Especificação \\
\hline Comprimento de onda central & $1530 \mathrm{~nm}$ a $1570 \mathrm{~nm}$ \\
\hline Largura espectral & $<0.2 \mathrm{~nm}$ \\
\hline Refletividade & $>75 \%$ \\
\hline Sensibilidade & $10 \mathrm{pm} /{ }^{\circ} \mathrm{C}$ \\
\hline Encapsulamento & Aço inoxidável \\
\hline Temperatura de operação & $-20{ }^{\circ} \mathrm{C}$ a $80^{\circ} \mathrm{C}$ \\
\hline Umidade relativa de operação & $<90 \%$ (sem condensação) \\
\hline Modelo & $\mathrm{FS} 6300-$ Temperature Sensors \\
\hline
\end{tabular}

\subsubsection{Atividades de instalação}

As atividades de instalação dos sensores e equipamentos para a monitoração foram distribuídas em três etapas, que tiveram lugar após eventos importantes na história da construção da laje de fundo. Os trabalhos envolvidos nas operações de instalação foram previamente informados à equipe de fiscalização do Metrô e aos engenheiros e mestres-de-obras da CBPO, responsáveis pela construção da estação. Por meio do aviso antecipado das atividades que precisariam ocorrer antes e após as concretagens, foi possível minimizar o impacto da presença da equipe de monitoração nas datas agendadas, bem como preparar adequadamente o local a instrumentar.

As etapas em que foram divididas as atividades de instalação de sensores e equipamentos, bem como os eventos relacionados e suas respectivas durações estão indicados na tabela 6.4. O grupo de trabalho foi constituído pelas pessoas indicadas a seguir. 
1) Eng. Wayne Assis (EPUSP);

2) Eng. Leandro Trautwein (EPUSP);

3) Eng. Alexandre Ribeiro (Gávea Sensors);

4) Eng. Álvaro Viana (Gávea Sensors);

5) Téc. Fellipe Moreno (Gávea Sensors).

Tabela 6.4 - Atividades de instrumentação.

\begin{tabular}{|c|c|c|}
\hline & Início & Após o endurecimento do lastro de concreto \\
\hline 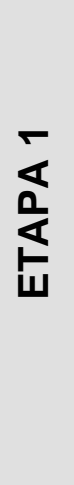 & $\begin{array}{c}\text { Término } \\
\text { 15/05 }\end{array}$ & $\begin{array}{l}\text { Atividades } \\
\text { - Instalação de sensor de pressão sob o lastro de concreto } \\
\text { simples } \\
\text { - Instalação de } 3 \text { sensores de deformação nas armaduras } \\
\text { - Instalação de sensor de temperatura para concreto } \\
\text { - Instalação de caixa de passagem para proteção dos cabos } \\
\text { ópticos } \\
\text { - Teste da instrumentação instalada }\end{array}$ \\
\hline \multirow[b]{2}{*}{ 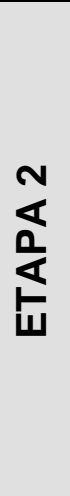 } & & Após o endurecimento da primeira camada de concreto \\
\hline & $\begin{array}{c}\text { Término } \\
\text { 24/05 }\end{array}$ & $\begin{array}{l}\text { Atividades } \\
\text { - Instalação de } 4 \text { sensores de deformação nas armaduras } \\
\text { - Instalação de } 4 \text { sensores de deformação no concreto } \\
\text { - Instalação de sensor de temperatura para concreto } \\
\text { - Instalação de caixa de passagem para proteção dos cabos } \\
\text { ópticos } \\
\text { - Teste da instrumentação instalada }\end{array}$ \\
\hline \multirow[b]{2}{*}{$\frac{m}{\mathbb{a}}$} & Início & Após o endurecimento da segunda camada de concreto \\
\hline & $\begin{array}{c}\text { Término } \\
\text { 16/11 }\end{array}$ & $\begin{array}{l}\text { Atividades } \\
\text { - Coleta de resultados } \\
\text { - Introdução de duto para o transporte de sinais à superfície } \\
\text { - Emenda dos conectores ópticos }\end{array}$ \\
\hline
\end{tabular}




\subsubsection{Etapa 1}

O início das atividades de instalação de sensores e equipamentos ocorreu no dia 12 de maio de 2006, poucos dias após o endurecimento do lastro de concreto simples com $5 \mathrm{~cm}$ de espessura, utilizado para regularização da superfície na qual seriam dispostas as armaduras positivas da laje de fundo.

Antes da chegada da equipe, foi feita uma abertura no lastro de concreto simples, pela qual posteriormente foi introduzido o sensor óptico de poro-pressão no solo sob a estação (figura 6.11).

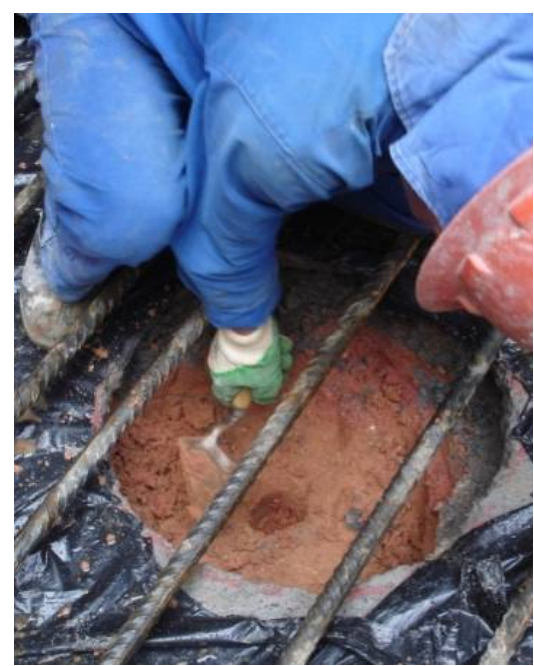

(a)

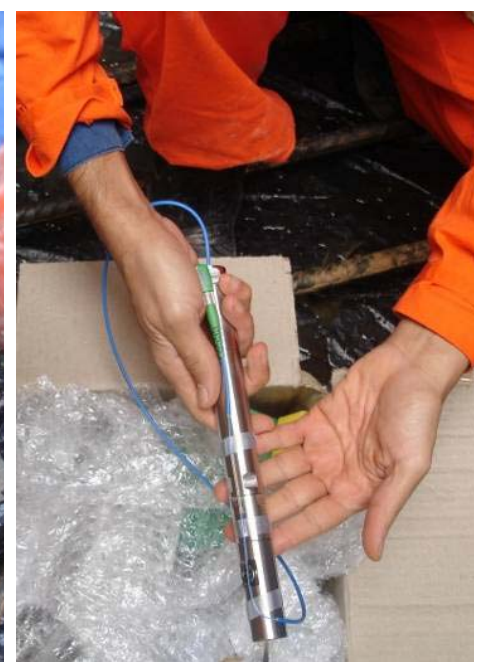

(b)

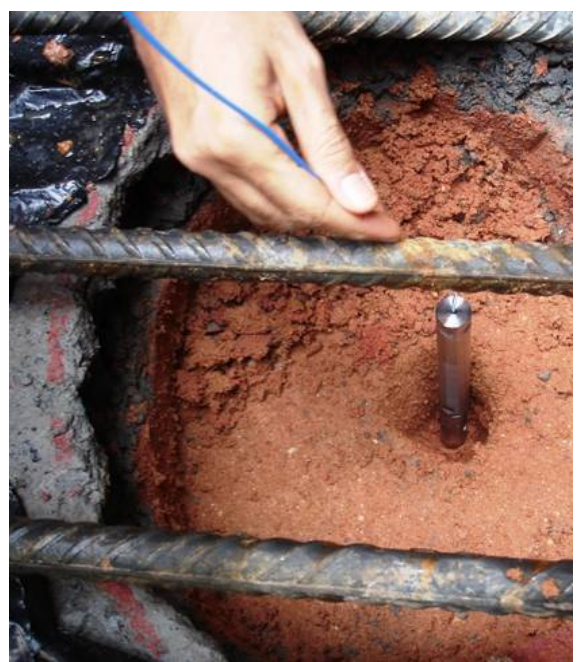

(c)

Figura 6.11 - Instalação do sensor de poro-pressão. Realização de abertura no lastro de concreto (a) para introdução do piezômetro (b, c).

Após a instalação, foram realizados testes para verificação do sinal do sensor, e em seguida foi feito o preenchimento da abertura em duas camadas, utilizando o solo previamente retirado e concreto simples, respectivamente (figura 6.12). 


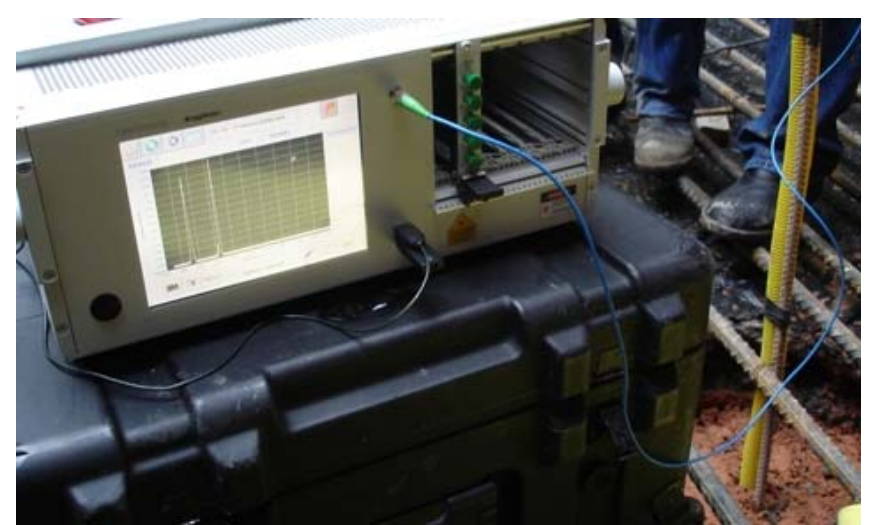

(a)

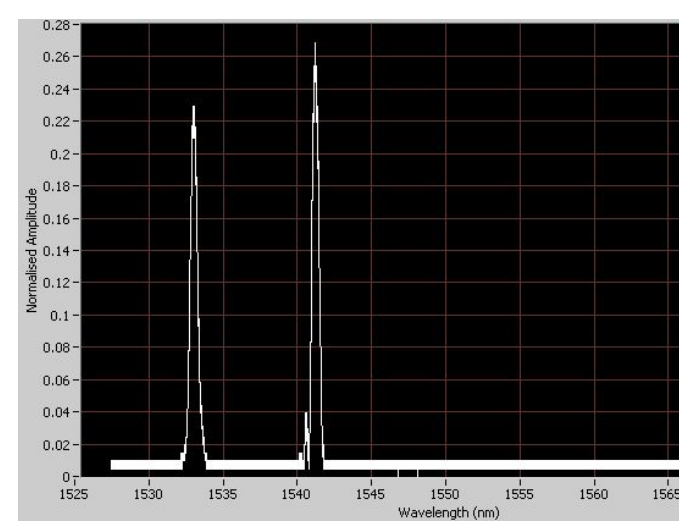

(b)

Figura 6.12 - Testes para verificação do sinal fornecido pelo sensor de poro-pressão (a) e resultados obtidos (b), os quais confirmaram o adequado funcionamento do piezômetro.

No dia 14 de maio, foram instalados três sensores para medição de deformação nas armaduras. Os sensores foram introduzidos em uma das armaduras da laje, com bitola igual a $25 \mathrm{~mm}$. A distribuição foi feita de tal modo que um dos sensores (E3) ficou no ponto relativo à interseção do eixo vertical que passa pelo centro de gravidade do pilar P1 com o plano de deposição das armaduras, enquanto os outros dois foram posicionados a uma distância de $75 \mathrm{~cm}$ do sensor E3, em sentidos opostos (figura 6.9a).

Antes da colagem dos sensores nas armaduras foi necessário preparar a superfície de aplicação, por meio da sua regularização e limpeza (figura 6.13). Tais cuidados foram necessários pelo fato de a região sensora da fibra não ter recebido qualquer revestimento ou proteção, de modo que sua aplicação direta sobre as mossas da armadura poderia ocasionar a produção de resultados indesejáveis, além da danificação do sensor.

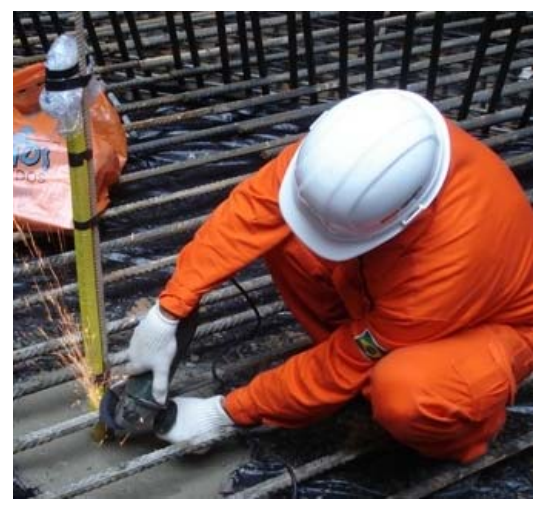

(a)

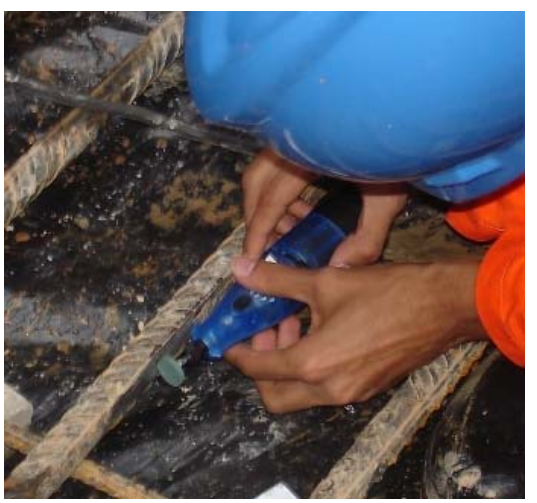

(b)

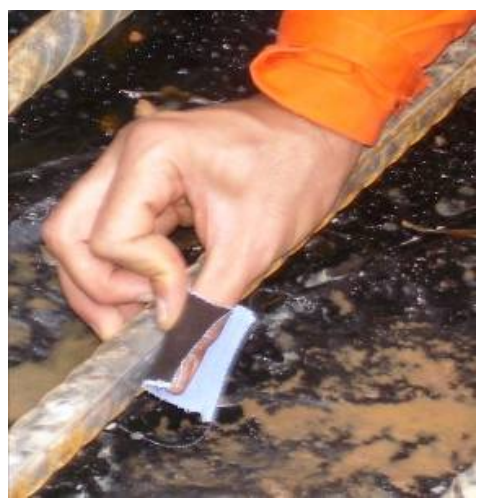

(c)

Figura 6.13 - Preparação da superfície para colagem dos sensores de deformação nas armaduras $(a, b, c)$. 
Após a regularização, a aplicação dos sensores na armadura foi feita cuidadosamente, tendo em vista a manutenção da integridade da região da fibra sensível às deformações, indicada na figura 6.14.

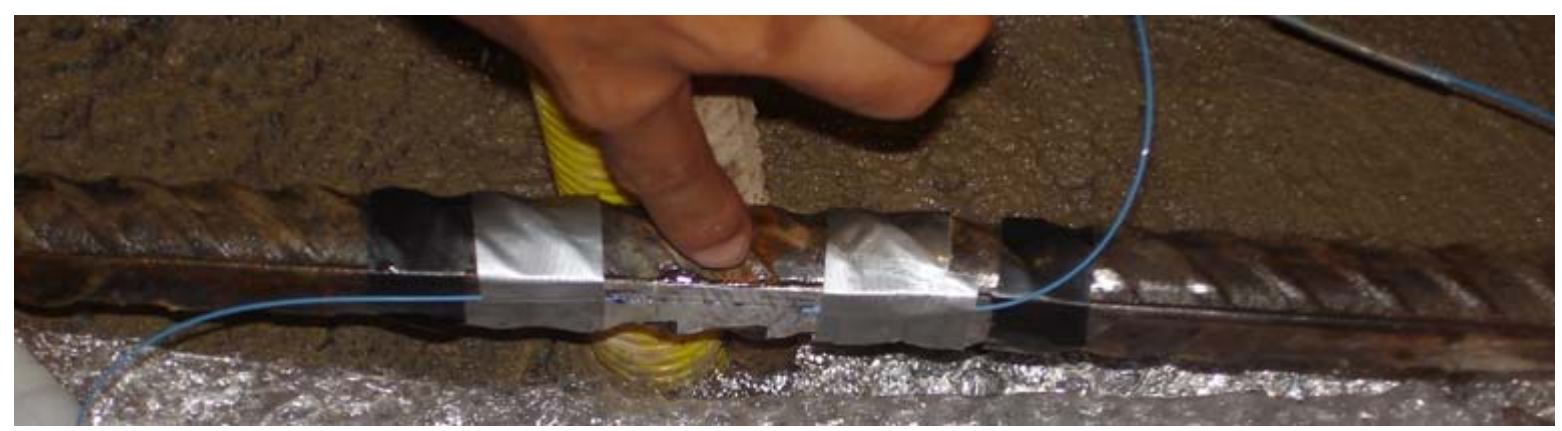

Figura 6.14 - Aspecto do sensor de deformação imediatamente após colagem na armadura. 0 dedo aponta para a região sensora da fibra.

Depois da colagem, realizou-se a proteção dos sensores, visando impedir a danificação dos mesmos, e a fibra óptica que continha os três sensores foi introduzida em um eletroduto de PVC flexível. Concluída a instalação destes sensores, foi feita a verificação do sinal proveniente da fibra óptica, que apresentou bons resultados associados aos três sensores instalados.

Concluída a instalação dos sensores de deformação, procedeu-se à introdução de um sensor de temperatura (T1), o qual, por ter a fibra e a região sensora adequadamente protegidos (figura 6.15a), não requereu cuidados especiais para sua instalação, sendo simplesmente ligado por meio de fitas isolantes e silver tape à mesma armadura na qual foram colados os sensores de deformação. Em seguida, o sinal do sensor foi verificado. Na figura $6.15 \mathrm{~b}$ é apresentado um sensor de temperatura após a instalação.

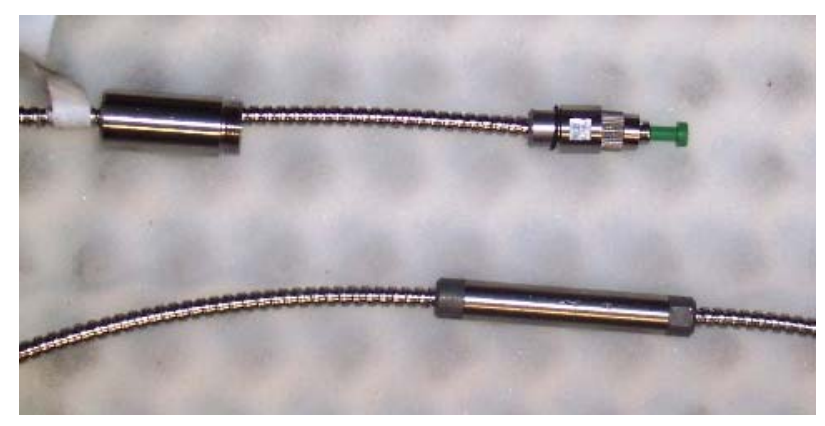

(a)

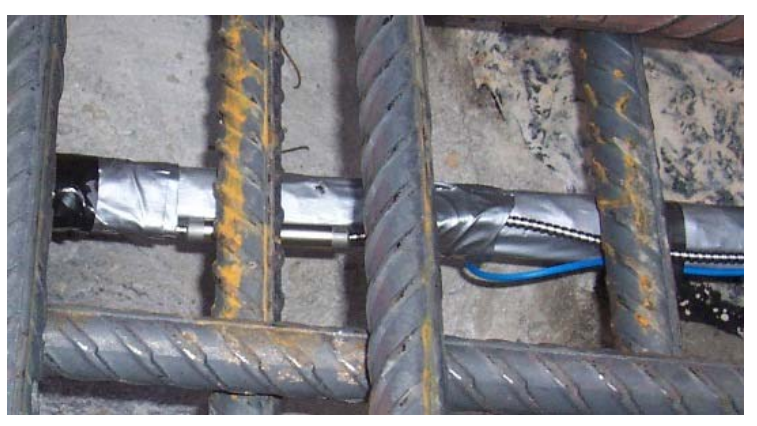

(b)

Figura 6.15 - Sensor de temperatura antes da instalação, com região sensora, fibra e conectores protegidos (a), e após a instalação. 
No dia 15 de maio os conectores de todos os sensores foram introduzidos em uma caixa de passagem (figura 6.16), situada a $70 \mathrm{~cm}$ do lastro de concreto, para que pudessem ser acessados após a primeira fase da concretagem da laje de fundo, que ocorreu no dia 18 de maio e originou uma camada de concreto com 40 cm de espessura. Após a inclusão da caixa de passagem (CP1) e finalização da instrumentação, os sinais de todos os sensores foram verificados, apresentando resultados indicativos de bom funcionamento.

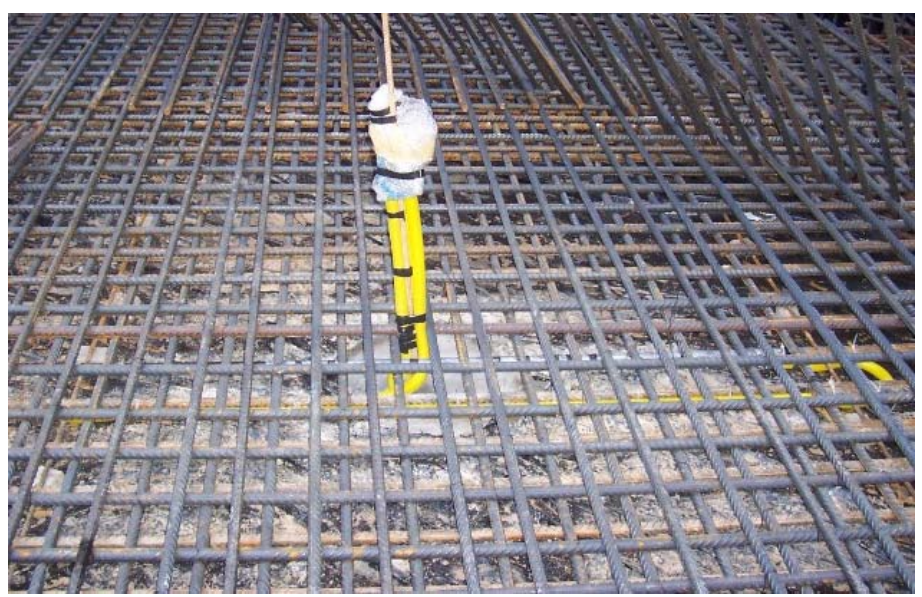

(a)

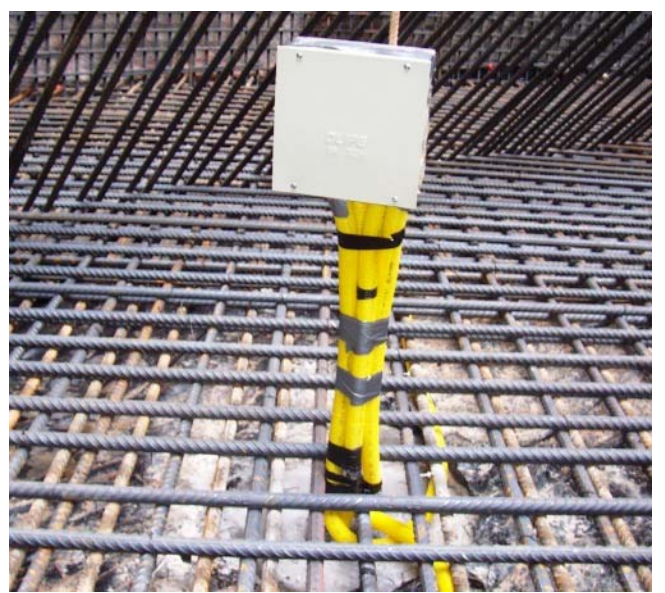

(b)

Figura 6.16 - Arranjo da instalação no dia 15 de maio, antes da introdução da caixa de passagem (a) e aspecto final, com caixa de passagem para protegendo os conectores.das operações da concretagem (b).

Na figura 6.17, para melhor visualização, é apresentada esquematicamente a distribuição dos sensores e materiais de apoio na laje de fundo, ao longo das etapa 1.

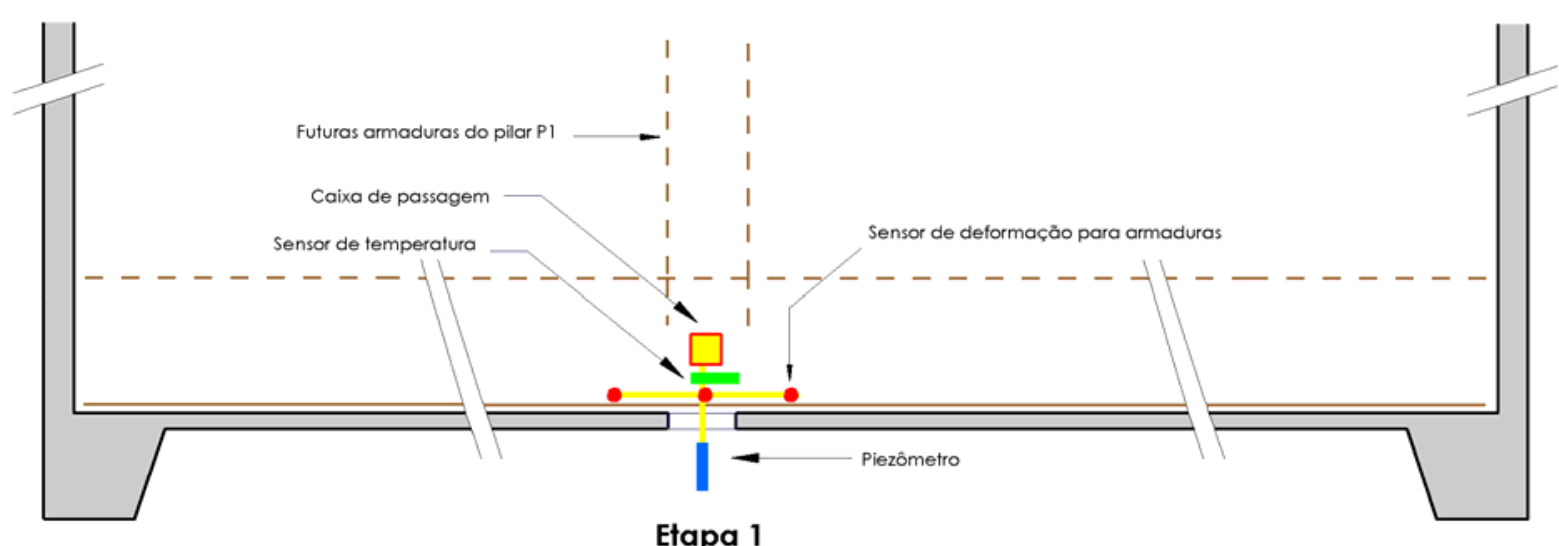

Figura 6.17 - Apresentação esquemática dos sensores instalados na etapa 1. 


\subsubsection{Etapa 2}

O início da segunta etapa de instalação de sensores e equipamentos ocorreu no dia 22 de maio de 2006, logo em seguida ao endurecimento da camada de $40 \mathrm{~cm}$ de concreto, lançado quatro dias antes. Antes da entrada da equipe de monitoração, no dia 19 de maio, os operários dispuseram as armaduras negativas da laje de fundo, conforme é possível ver na figura 6.18. Aproximadamente no meio da figura 6.18a vê-se a caixa de passagem, que ficou acima do nível da água excedente utilizada para a cura do concreto.

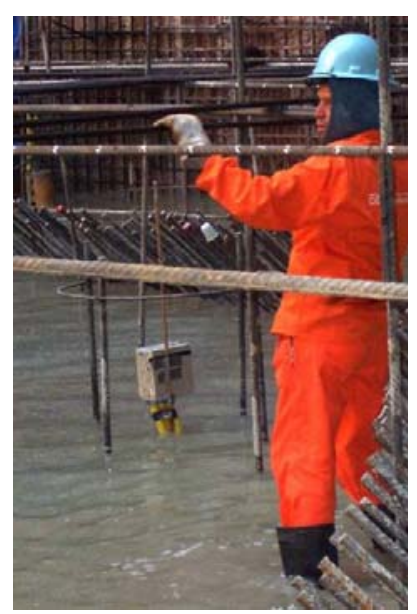

(a)

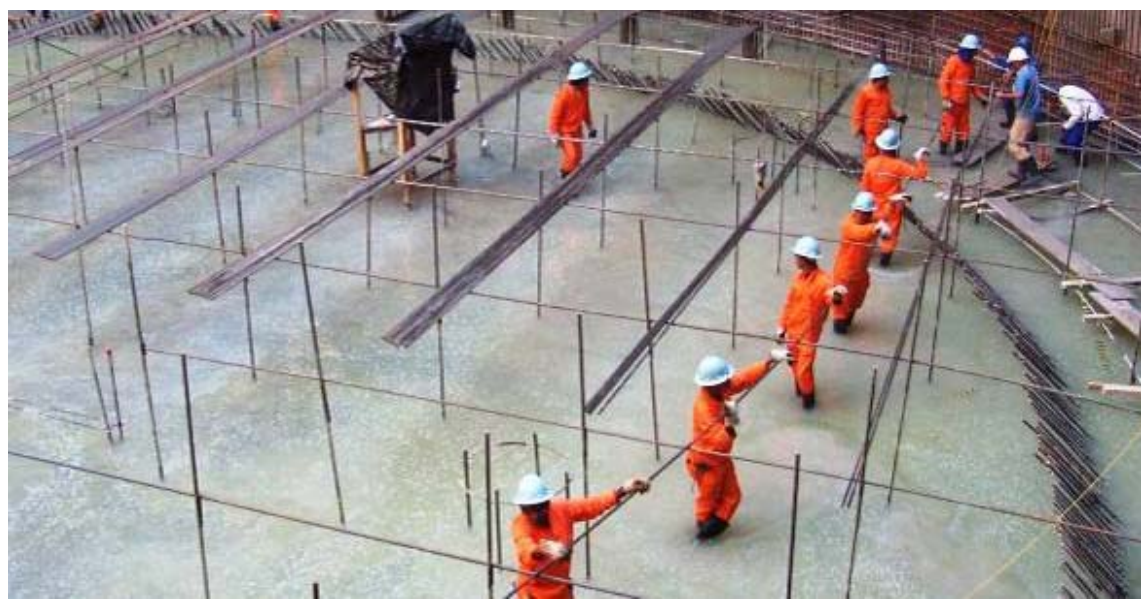

(b)

Figura 6.18 - Condições da obra três dias antes do início das atividades da segunda etapa.

No dia do início dos trabalhos de instrumentação a maior parte das armaduras já havia sido posicionada, e já era possível transitar, embora com alguma dificuldade, sobre a grelha resultante (figura 6.19). 


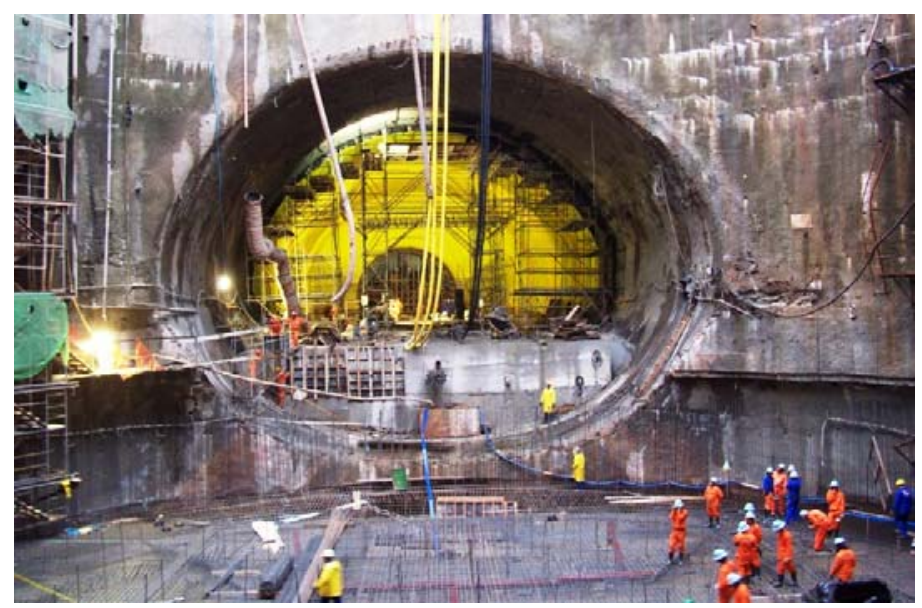

Figura 6.19 - Vista geral da obra no dia de início dos trabalhos da segunda etapa.

A primeira atividade do dia foi a instalação de quatro sensores para medição de deformação nas armaduras. Os sensores foram introduzidos em duas armaduras selecionadas da laje, as quais eram perpendiculares entre si. Foram aplicados dois sensores em cada barra, com distância de $150 \mathrm{~cm}$ entre os sensores de uma mesma barra, segundo indicado na figura 6.9b. Na distribuição adotada, a interseção das duas barras ficou aproximadamente na interseção do eixo vertical que passa pelo centro de gravidade do pilar P1 com o plano das armaduras.

Tal como ocorreu na primeira etapa, descrita no item 6.3.4.1, antes da colagem dos sensores nas armaduras foi preciso regularizar e limpar a superfície da área de medição (figura 6.20), visto que os sensores utilizados apresentavam as mesmas características mecânicas e as mesmas fragilidades dos sensores de deformação de colar nas armaduras empregados na etapa 1. Após a regularização, procedeu-se à aplicação dos sensores. 


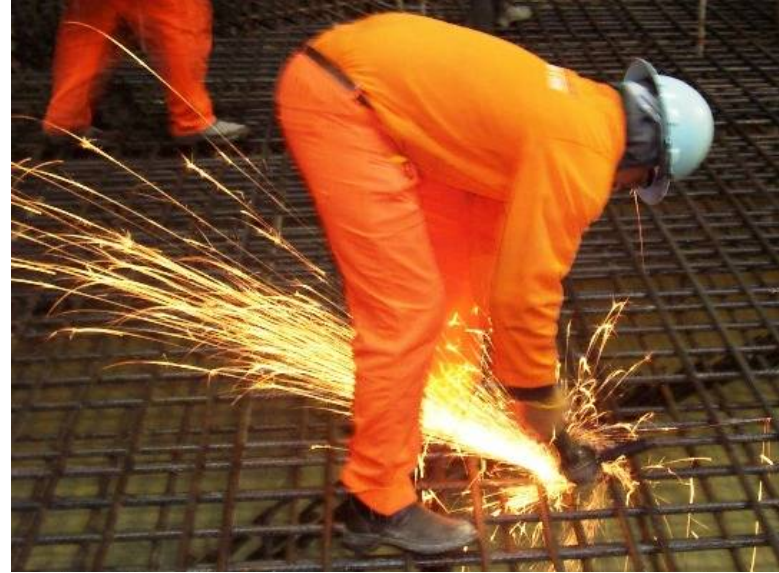

(a)

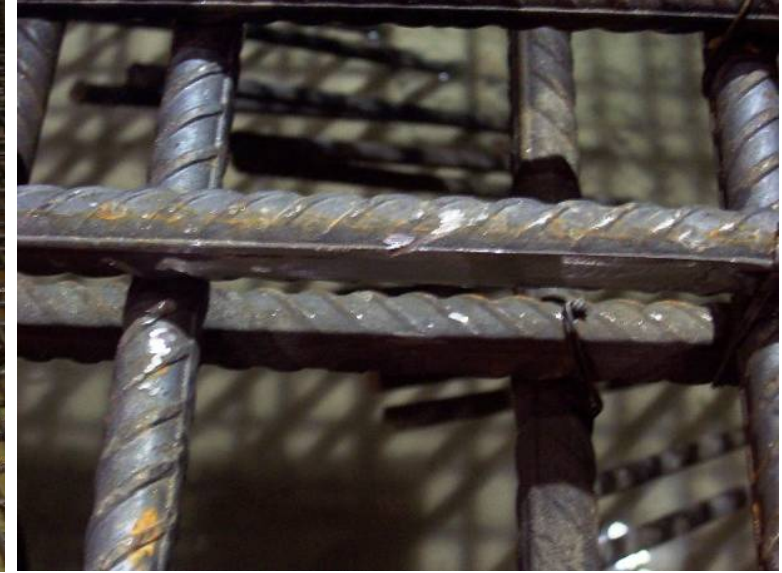

(b)

Figura 6.20 - Trabalho de regularização das armaduras (a), e aspecto final da região de aplicação do sensor, já regularizado e limpo (b).

Depois da colagem, foi feita a proteção dos sensores e a identificação da posição dos mesmos por meio de fita adesiva tipo silver tape, ao passo que a fibra óptica foi cuidadosamente envolvida em fita isolante (figura 6.21a). Concluída a instalação dos sensores, foi realizada a verificação dos sinais, com bons resultados (figura 6.21b).

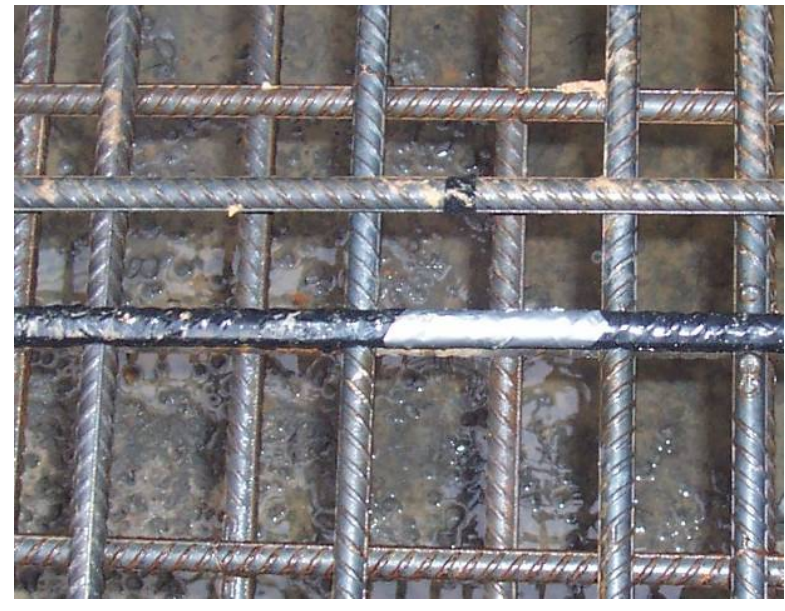

(a)

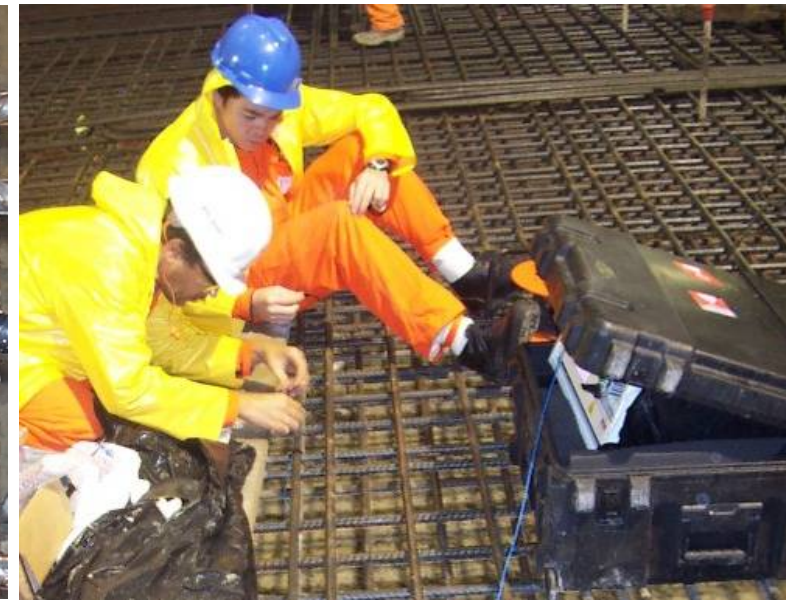

(b)

Figura 6.21 - Aspecto dos sensores e da fibra óptica após a proteção (a) e trabalho de verificação dos sinais dos sensores instalados (b).

Finalizada a instalação dos sensores de deformação das armaduras, no dia 23 de maio foram instalados os quatro sensores para medição de deformações no concreto (C1, C2, C3 e C4). Estes sensores apresentam excelente robustez, com a fibra, região sensora e conectores adequadamente protegidos (figura 6.22a), e não requereram cuidados especiais para sua instalação. Eles foram posicionados 
próximos aos sensores de deformação nas armaduras (figura 6.9b), e o local da instalação foi preservado unindo o revestimento metálico das fibras às armaduras utilizando fitas isolantes e silver tape (figura 6.22b). Na sequência, realizou-se a verificação dos sinais, obtendo-se bons resultados.

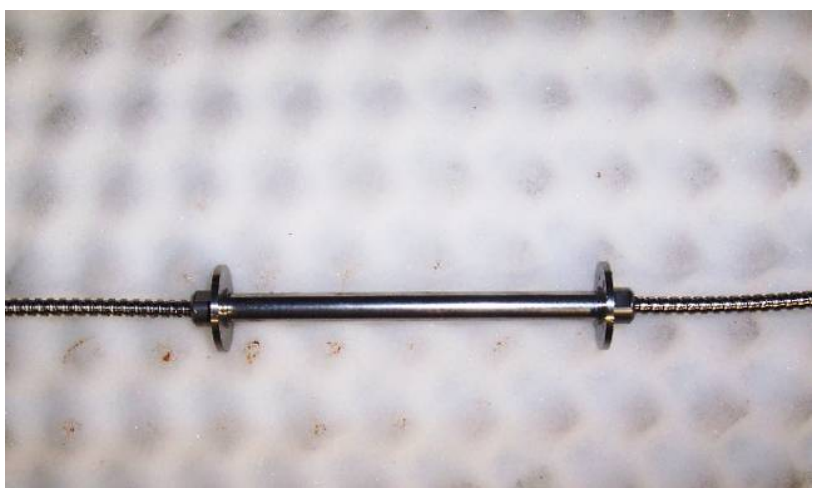

(a)

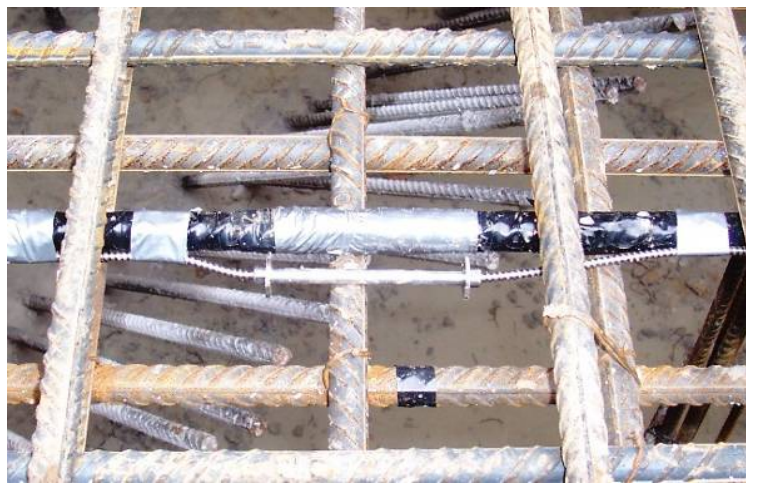

(b)

Figura 6.22 - Sensor para medição de deformações no concreto antes da instalação, com região sensora e fibra protegidos (a), e após a instalação (b), ao lado dosensor de deformação colado na armadura.

Seguindo-se à introdução dos sensores de deformação, no dia 24 de maio foi instalado um sensor de temperatura (T2), o qual, à semelhança do sensor utilizado na primeira etapa, por contar com a fibra, região sensora e conectores bem protegidos, não exigiu cuidados especiais na instalação, e foi ligado por meio de fitas isolantes e silver tape a uma barra ortogonal ao plano das armaduras, próxima dos sensores EA e C2 (figura 6.9b), a $70 \mathrm{~cm}$ de profundidade. Buscou-se com essa posição obter a temperatura no interior do concreto. Em seguida, o sinal do sensor foi verificado. Na figura 6.23 é apresentado os sensor de temperatura após a instalação.

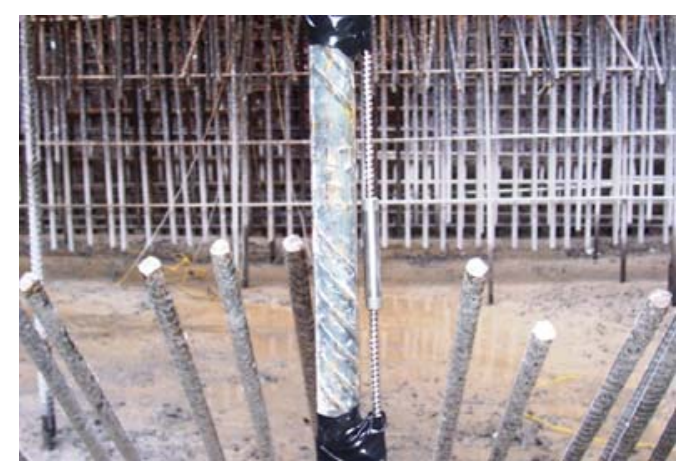

Figura 6.23 - Sensor de temperatura após a instalação. 
Logo depois da instalação dos sensores de temperatura, foi preparada uma nova caixa de passagem (CP2) para abrigar os conectores de todos os sensores já instalados. Tinha-se em vista, quando da introdução da CP2, ter acesso aos conectores de todos os sensores das duas etapas após a segunda e última fase da concretagem da laje de fundo. Para transportar os conectores da caixa de passagem instalada no dia 15 de maio (CP1) até a CP2 foi utilizado um eletroduto de PVC flexível. Após a condução bem sucedida dos conectores da CP1 até a CP2, a CP1 foi selada, utilizando-se silicone e fitas isolantes e silver tape. A figura $6.24(a, b)$ apresenta os preparativos para o transporte dos conectores da CP1 para a CP2, além do aspecto final da CP1 selada e os dutos com os conectores (figura 6.24c).

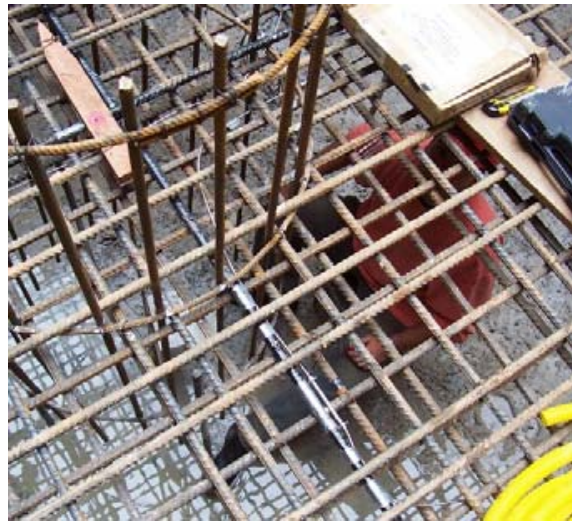

(a)

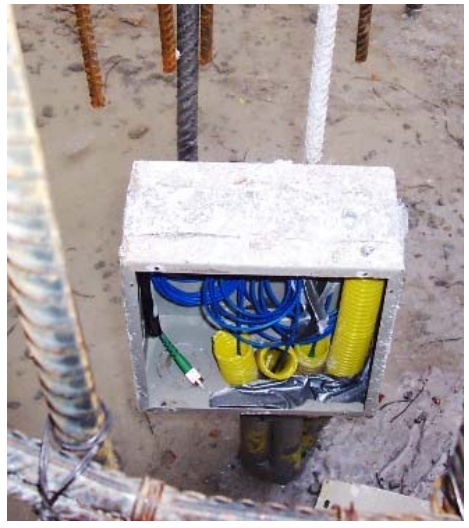

(b)

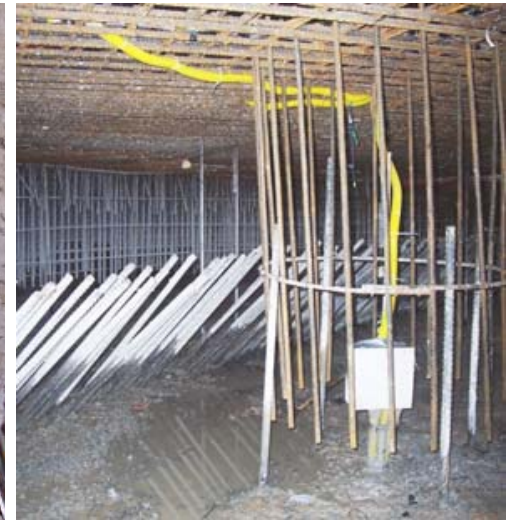

(c)

Figura 6.24 - Preparativos para o transporte dos conectores dos sensores instalados na etapa 1 para a novacaixa de passagem. $(a, b)$, que foi feito utilizando eletrodutos (c).

A segunda fase da concretagem da laje de fundo ocorreu no dia 25 de maio e foi responsável pela geração de uma camada de concreto com $160 \mathrm{~cm}$ de espessura. Somando-se aos $40 \mathrm{~cm}$ previamente concretados, a espessura total da laje de fundo atingiu o valor previsto em projeto, de $200 \mathrm{~cm}$. A figura 6.25 ilustra a CP2 a poucas horas do final da concretagem. Na figura 6.26 é apresentada esquematicamente a distribuição dos sensores e materiais de apoio na laje de fundo, ao longo da etapa 2. 


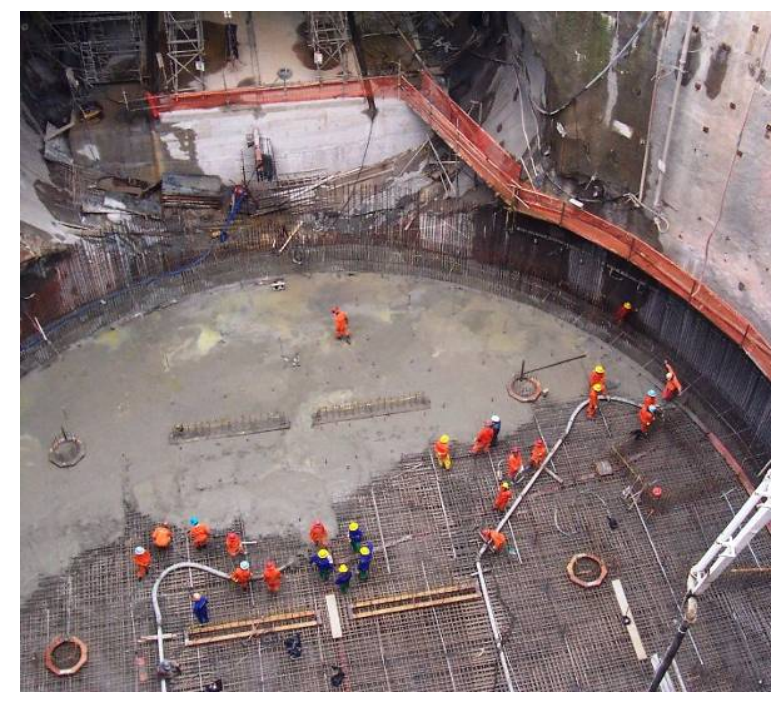

(a)

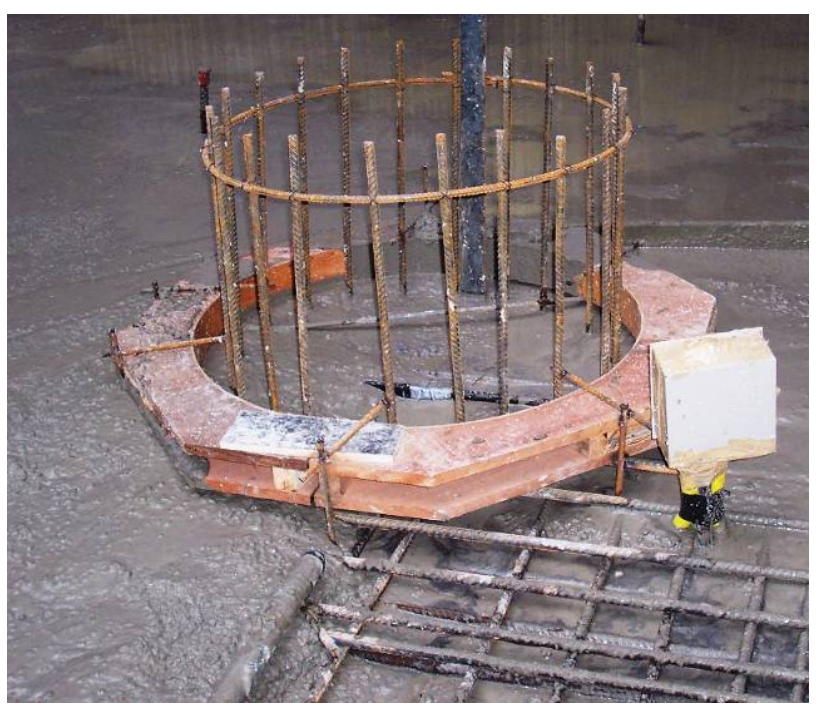

(b)

Figura 6.25 - Concretagem da segunda camada da laje de fundo da Estação Alto do Ipiranga (a) e caixa de passagem instalada no dia anterior.

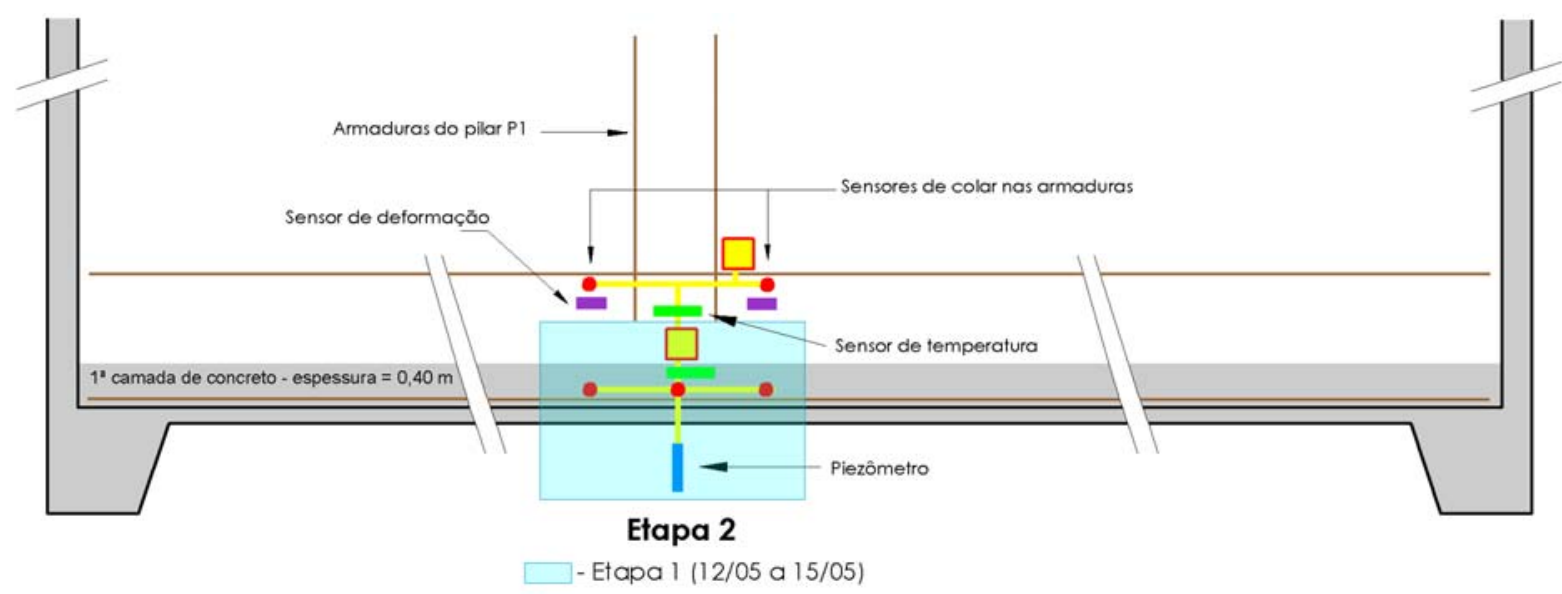

Figura 6.26 - Representação esquemática dos sensores instalados na etapa 2.

\subsubsection{Etapa 3}

A terceira etapa de atividades foi iniciada no dia 26 de maio de 2006, estendendo-se até o dia 16 de novembro. Consistiu na coleta de resultados da rede sensora instalada, constituída por 14 sensores ópticos, na introdução de um duto para transporte dos sinais dos sensores até a superfície e na emenda dos conectores para possibilitar a coleta de resultados sem ser necessário descer ao fundo do poço da estação. Uma vez que as campanhas de medição e os resultados 
obtidos serão apresentados em detalhe na seção 6.4, os próximos parágrafos tratarão das outras duas atividades da terceira etapa.

A motivação para os trabalhos de transporte dos sinais dos sensores à superfície reside em problemas enfrentados durante as Etapas 1 e 2, especialmente em relação ao transporte da unidade óptica de medição (figura 5a) da superfície até a laje de fundo, a $30 \mathrm{~m}$ de profundidade. Havia duas opções para o transporte do equipamento de $25 \mathrm{~kg}$ e preço estimado em USD 40.000,00: utilizar o guindaste da obra ou a escada (figura 6.27).

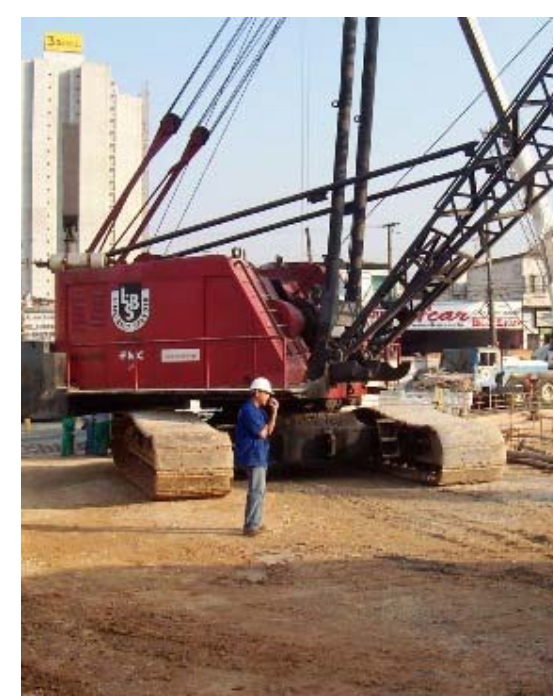

(a)

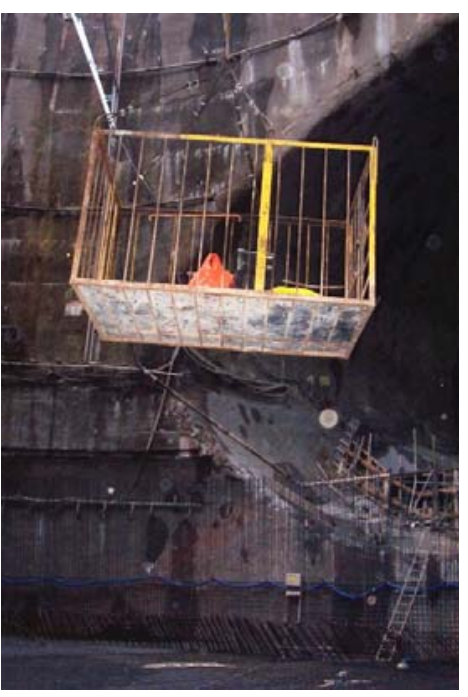

(b)

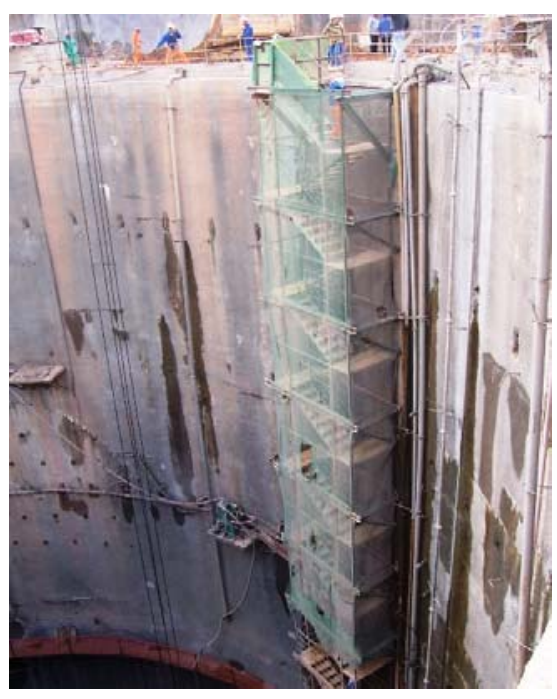

(c)

Figura 6.27 - Opções de transporte do equipamento óptico de medição:guindaste $(a, b)$ ou escada da obra (c).

Durante as Etapas 1 e 2, anteriormente descritas, o sistema de medição apresentou problemas por duas vezes, sendo necessário inclusive, em uma das ocasiões, transportá-lo até o Rio de Janeiro para a realização dos reparos necessários. Tudo indica que a fonte dos problemas verificados encontrava-se nas duras circunstâncias de transporte do equipamento na obra, que levou ao afrouxamento de cabos e ligações internas, além de outros danos. Esses fatos fizeram a USP e a Gávea Sensors adotar temporariamente uma versão portátil do equipamento de medição, que não estava sujeito aos inconvenientes e dificuldades de transporte mencionados (figura 6.28). 


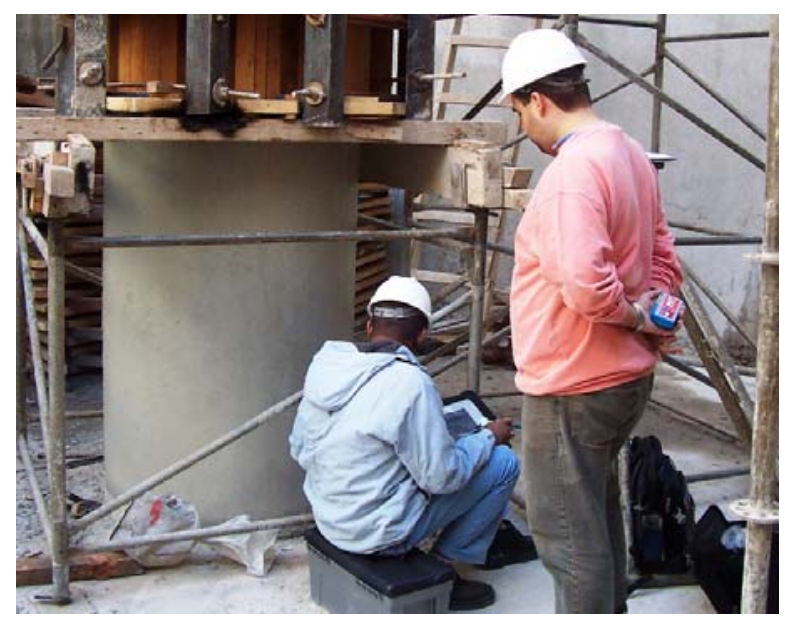

Figura 6.28 - Utilização da versão portátil da unidade óptica de medição.

Uma vez que a unidade de medição portátil permanecia a quase totalidade do tempo fora da USP e não se considerava seguro transportar o equipamento de bancada até a laje de fundo, foi concebida a alternativa de transportar os sinais até a superfície da estação, eliminando os problemas de transporte do equipamento de aquisição e leitura dos sinais ópticos (figura 6.29).

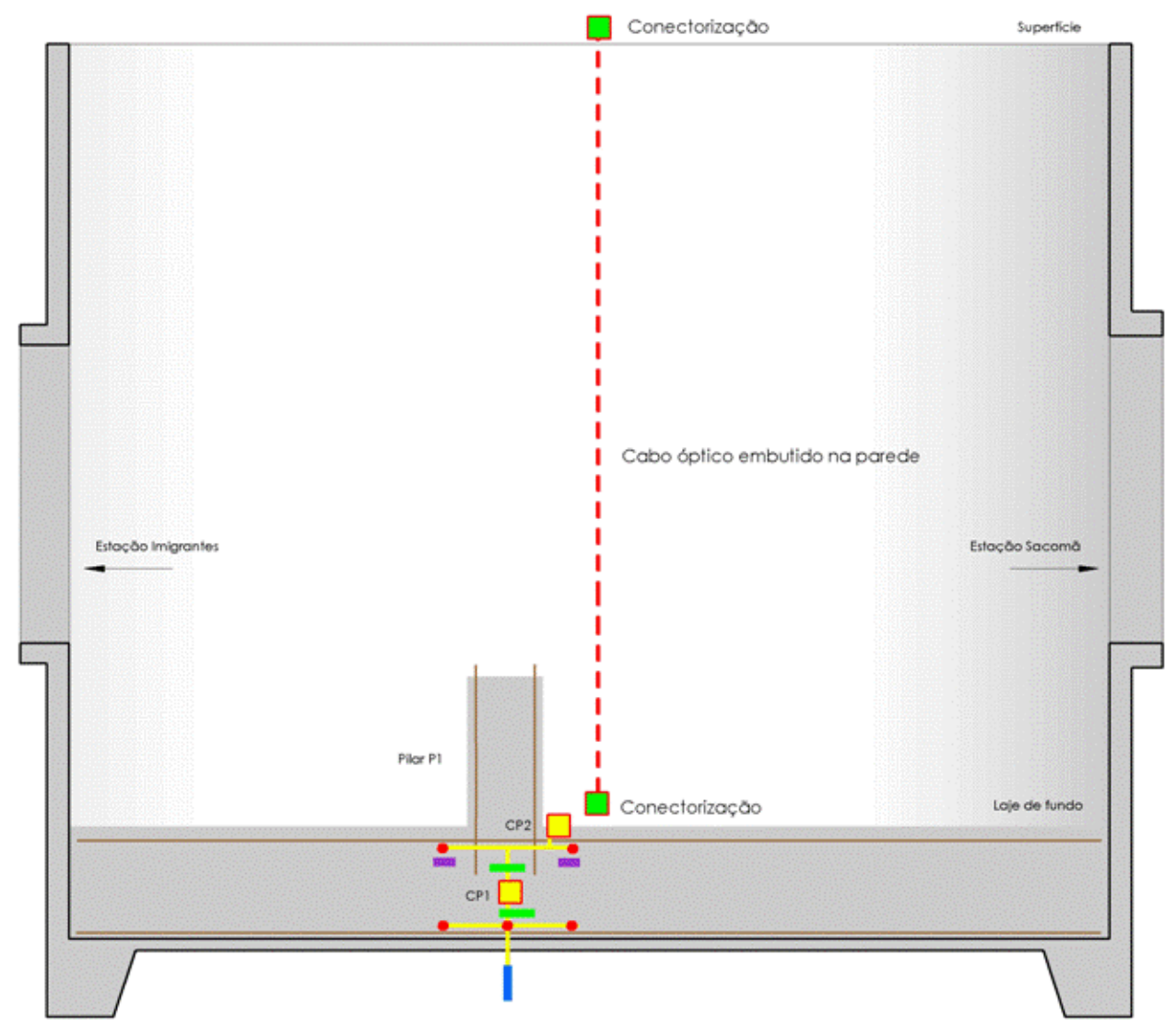

Figura 6.29 - Etapa 3: coleta de resultados mediante transporte dos sinais da laje de fundo à superfície. 
A condução dos sinais envolvia duas tarefas básicas: instalar um cabo óptico com condições de transportar os sinais de todos os sensores da laje de fundo até a superfície e, uma vez instalado o cabo, emendar os conectores da CP2 na extremidade inferior do cabo e conectorizar as fibras da extremidade superior do cabo, para viabilizar a realização das leituras.

Durante o mês de julho foi providenciada a introdução de um eletroduto durante o processo de concretagem da parede da estação, bem como a compra do cabo óptico. No dia 22 de agosto o cabo foi introduzido e as conectorizações na superfície foram realizadas, conforme apresentado na figura 6.30 .

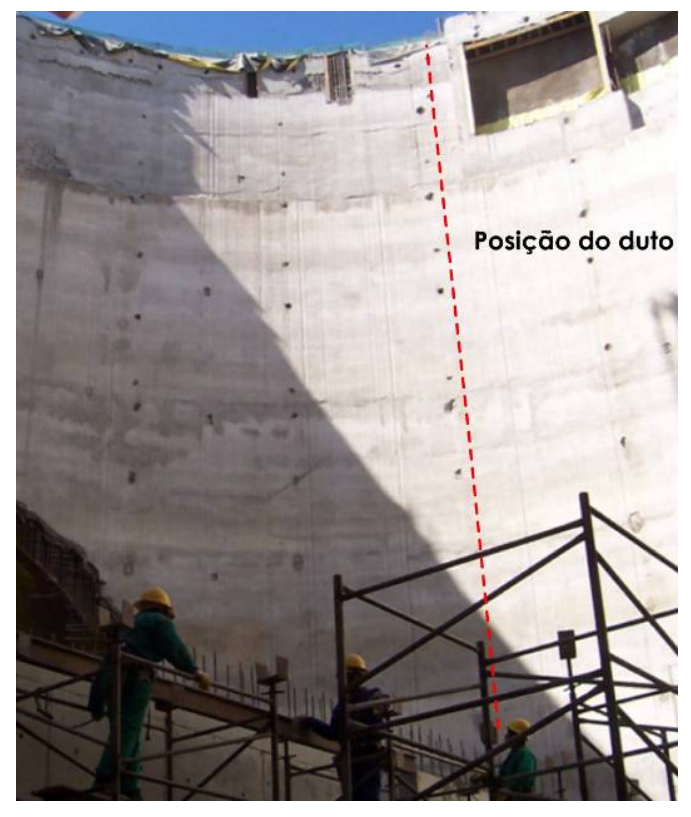

(a)

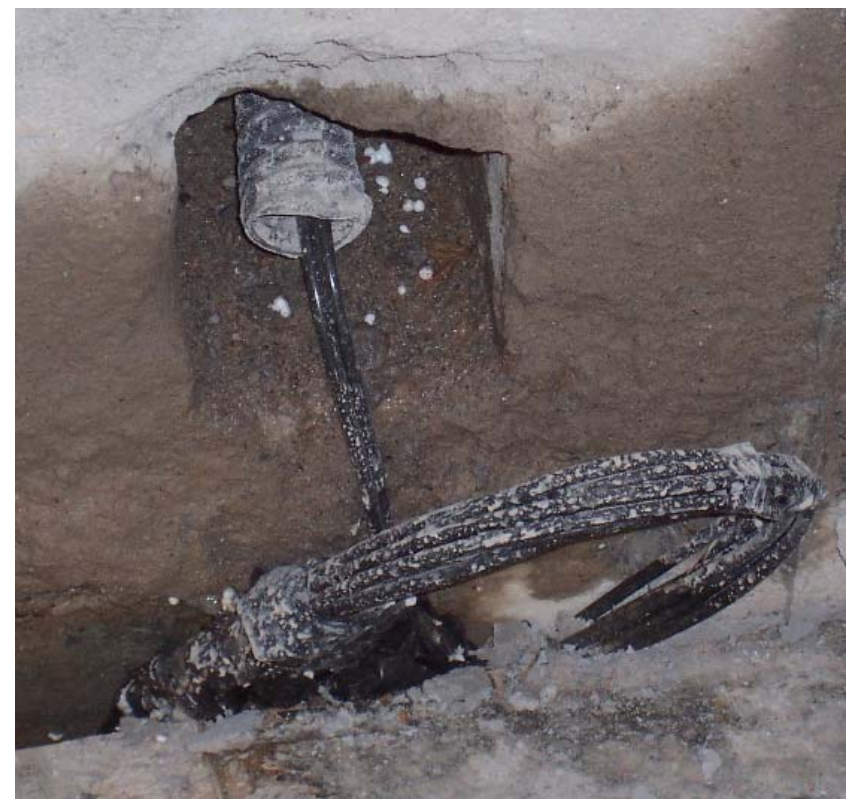

(b)

Figura 6.30 - Posicionamento do duto (a) e do cabo óptico (b).

Para a emenda das fibras ópticas foi solicitado o apoio técnico do Centro de Computação Eletrônica da Universidade de São Paulo (CCE), que forneceu os equipamentos e mão-de-obra especializada necessários à realização desta tarefa (figura 6.31).

Em setembro foi realizada a junção do cabo óptico às fibras alojadas na CP2. Nesta ocasião, verificou-se a perda do sinal oriundo de três sensores, a saber: EC, ED (deformação - armaduras) e C4 (deformação - concreto). Todos estes sensores foram instalados na segunda etapa. 


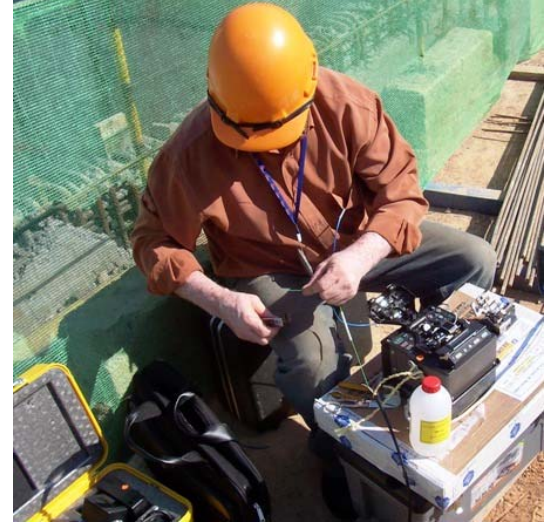

(a)

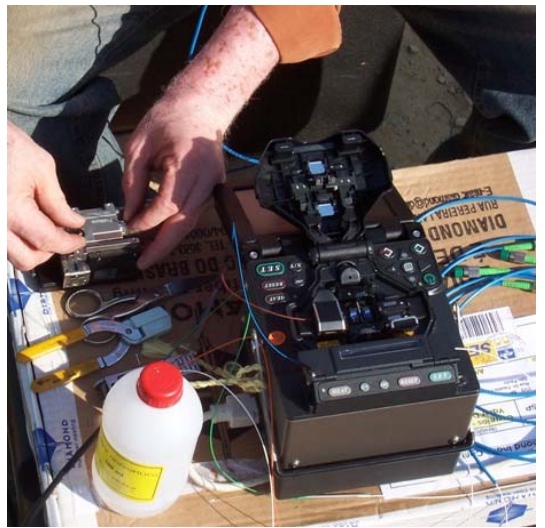

(b)

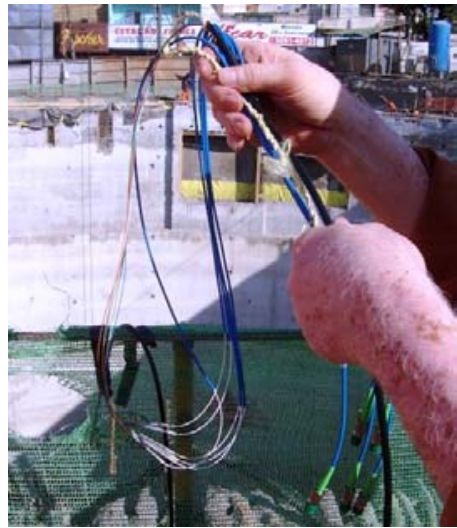

(c)

Figura 6.31 - Emenda de fibras ópticas durante operações de introdução de conectores.

\subsection{Apresentação dos resultados}

A instrumentação realizada na estação proporcionou a realização de medições de grandezas físicas na laje de fundo, visando determinar pressões na cota da face inferior da laje, deformações no concreto e nas armaduras e temperatura do concreto.

Neste capítulo os resultados da monitoração serão apresentados, sendo que os mesmos traduzem a variação de cada uma das grandezas medidas em relação à primeira efetuada. Nos gráficos apresentados a convenção de sinais adotada é a seguinte:

a) Deformação negativa - encurtamento;

b) Deformação positiva - alongamento.

Para cada sensor foram realizadas sete leituras, em um período de seis meses, para avaliar a alteração das grandezas físicas ao longo do tempo e também com o andamento da obra. As leituras dos sensores foram realizadas nas seguintes datas: 

1) $12 / 05 / 2006$;
2) $24 / 05 / 2006$;
3) 22/08/2006;
4) $06 / 09 / 2006$;
5) 29/09/2006;
6) $11 / 10 / 2006$;
7) $26 / 11 / 2006$.

O considerável intervalo entre a segunda e a terceira leitura deve-se à avaria da unidade óptica de medição utilizada para a leitura dos sinais, e ao atraso da sua reparação em virtude da falta de peças no Brasil.

Conforme exposto anteriormente, foram instalados 14 sensores ópticos, sendo que 3 sensores foram danificados durante o processo de concretagem da laje de fundo. Os sensores danificados eram destinados à medição de deformações nas armaduras (2 sensores) e deformação do concreto (1 sensor). Os demais sensores funcionaram e apresentaram resultados coerentes durante todo o período da monitoração da obra, conforme será apresentado adiante.

\subsubsection{Pressão na cota inferior da laje de fundo}

Para monitorar as pressões atuantes na face inferior da laje de fundo, foi instalado um piezômetro óptico, posicionado sob o pilar P1. A tabela 6.5 e a figura 6.32 apresentam os resultados das medições de pressões realizadas nas datas anteriormente especificadas.

Tabela 6.5 - Pressões na laje de fundo obtidas por meio da monitoração.

\begin{tabular}{|c|c|c|c|c|c|c|c|}
\hline \multirow{2}{*}{$\begin{array}{c}\text { Sensor de } \\
\text { poro-pressão }\end{array}$} & \multicolumn{7}{|c|}{ Data da leitura } \\
\hline & $12 / 05 / 06$ & $24 / 05 / 06$ & $22 / 08 / 06$ & 06/09/06 & $29 / 09 / 06$ & $11 / 10 / 06$ & $16 / 11 / 06$ \\
\hline Pressão (mca) & 0,71 & 18,99 & 14,94 & 13,74 & 15,26 & 17,39 & 14,76 \\
\hline Temperatura $\left({ }^{\circ} \mathrm{C}\right)$ & 20,0 & 11,6 & 18,3 & 18,7 & 16,7 & 14,4 & 17,6 \\
\hline
\end{tabular}




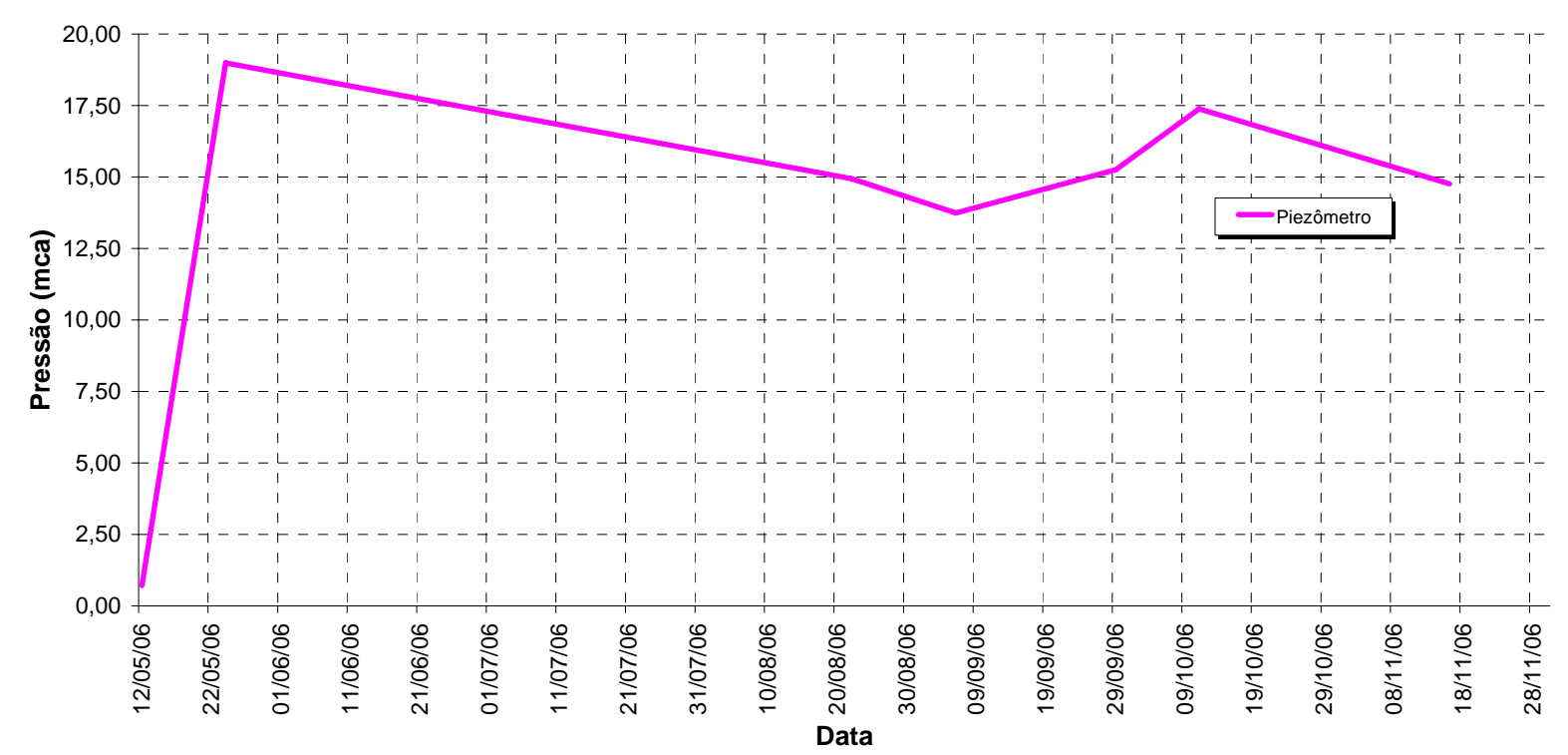

Figura 6.32 - Evolução da pressão na laje de fundo durante a monitoração.

A pressão máxima obtida na face inferior da laje de fundo está dentro do esperado, próxima de $15 \mathrm{mca}$, entretanto não se recomenda utilizar os valores obtidos por esta monitoração para fins de análise da estrutura ou tomada de decisões, uma vez que o piezômetro, embora tenha sido calibrado, não passou pelo processo de envelhecimento, o que acarreta drift da medida ao longo do tempo. Entretanto, a tendência apresentada relativa à evolução da pressão ao longo do tempo é bastante razoável, e mostra que o sensor está plenamente funcional. Visto que o objetivo da introdução deste sensor estava focado em apresentar sua viabilidade de implantação em obras metroviárias, pode-se afirmar que tal meta foi alcançada.

\subsubsection{Deformação do concreto}

As deformações do concreto foram obtidas a partir de três sensores de embutir ( $\mathrm{C} 1, \mathrm{C} 2$ e C3), localizados na segunda camada de concreto de espessura de 1,60 $\mathrm{m}$ e dispostos ao redor do perímetro do pilar (figura 6.9b). A tabela 6.6 e a figura 6.33 apresentam as deformações do concreto obtidas durante o período de monitoração da laje de fundo. 
Tabela 6.6 - Deformações do concreto da laje de fundo.

\begin{tabular}{c|c|c|c|c|c|c|c}
\hline \multirow{2}{*}{$\begin{array}{c}\text { Sensor de } \\
\text { deformação } \\
\text { para concreto }\end{array}$} & \multicolumn{7}{c}{ Data da leitura } \\
\cline { 2 - 8 } & $12 / 05 / 06$ & $24 / 05 / 06$ & $22 / 08 / 06$ & $06 / 09 / 06$ & $29 / 09 / 06$ & $11 / 10 / 06$ & $16 / 11 / 06$ \\
\cline { 2 - 8 } & \multicolumn{7}{|c}{ Deformação $\left(\times 10^{-6} \mathbf{m} / \mathbf{m}\right)$} \\
\hline C1 & - & 0,000 & $-40,817$ & $-49,980$ & $-18,326$ & $-5,831$ & $-21,658$ \\
\hline C2 & - & 0,000 & $-95,795$ & $-129,115$ & $-92,463$ & $-79,135$ & $-101,626$ \\
\hline C3 & - & 0,000 & $-108,290$ & $-131,614$ & $-99,127$ & $-65,807$ & $-78,302$ \\
\hline
\end{tabular}

A evolução das deformações mostra que os sensores de embutir no concreto funcionaram muito bem e que foram capazes de obter as variações nas deformações com o andamento da obra. Da análise do gráfico da figura 6.33, percebe-se duas modificações de tendência. A primeira ocorreu entre os dias $06 \mathrm{e}$ 29 de setembro, caracterizada por uma redução das deformações (em valores absolutos) em todos os sensores, permitindo inferir um alívio de carga no perímetro do pilar P1. A segunda alteração ocorreu entre os dias 11 de outubro e 16 de novembro, quando os sensores passaram a registrar um aumento nos valores absolutos das deformações, possibilitando supor o aumento da carga transmitida pelo pilar à laje, gerando mais compressão na área próxima de P1.

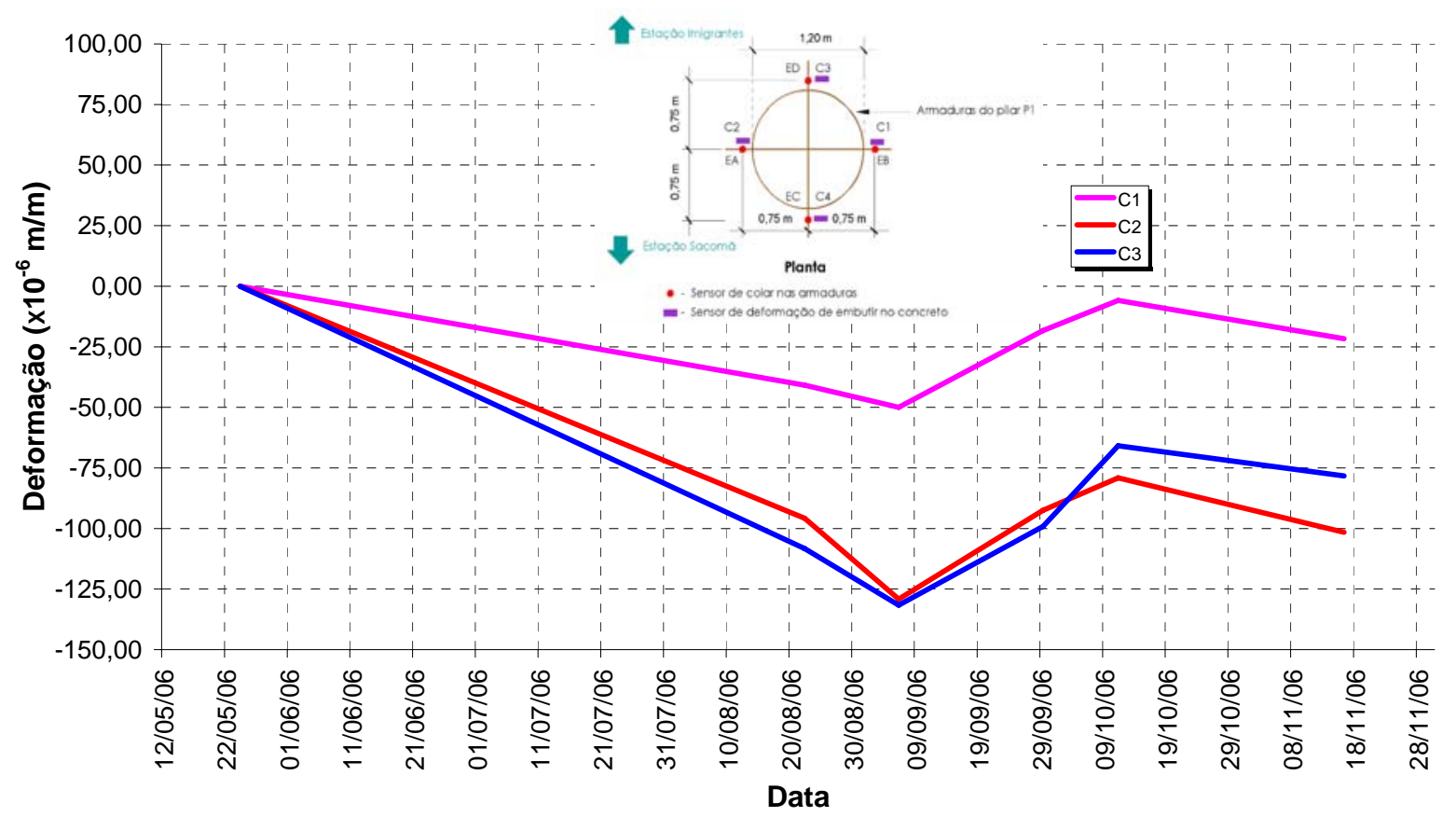

Figura 6.33 - Evolução da deformação do concreto da laje de fundo. 
Acredita-se que as razões deste comportamento estejam associadas à evolução construtiva da obra, embora não se possa comprovar tal hipótese para a primeira modificação de tendência, visto que a equipe desconhece a história da obra nesse período. Em relação à segunda modificação de tendência, associada ao aumento da compressão no concreto, o carregamento oriundo da construção das plataformas de embarque e desembarque de passageiros pode constituir uma explicação plausível para os valores medidos.

Uma constatação que se mostrará mais significativa quando confrontada com a análise das deformações nas armaduras diz respeito às discrepâncias entre os valores medidos pelos sensores C2 e C1, que estão na mesma barra, porém dispostos simetricamente em relação ao plano que passa pelo eixo do pilar P1 e pelo sensor C3. Dos resultados verifica-se que a região onde está instalado C2 encontra-se mais comprimida que a região de $\mathrm{C} 1$, sugerindo a ocorrência de excentricidade da força normal transferida pelo pilar, com componente na direção C1 - C2 no sentido do eixo do pilar para o sensor C2. Estas conclusões são representadas na figura 6.34, que também apresenta esquematicamente a provável distribuição das tensões de compressão $\left(\sigma_{\mathrm{c} 1}\right.$ e $\left.\sigma_{\mathrm{c} 2}\right)$ no plano de $\mathrm{C} 1$ e C2, na região entre estes sensores.

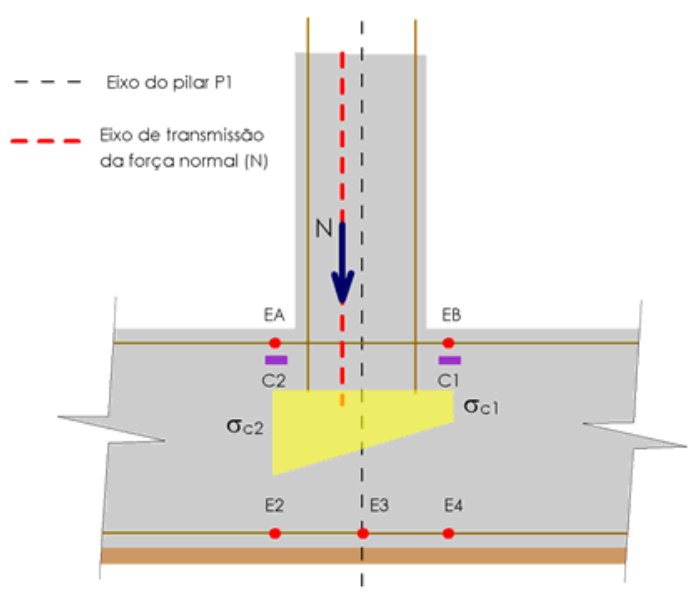

Figura 6.34 - Excentricidade da força normal e provável distribuição simplificada das tensões no concreto, entre C2 e C1.

Visto que o sinal do sensor C4 não foi obtido em nenhum outro momento a não ser quando da instalação, não é possível informar qual o sentido da componente da eventual excentricidade na direção C3 - C4. Esse fato demonstra a necessidade de ser considerada certa redundância de sensores quando da monitoração de 
estruturas, sob pena de não ser possível tirar conclusões relevantes sobre aspectos relativos ao funcionamento dos elementos estudados.

\subsubsection{Deformação das armaduras}

Foram instalados sensores na armadura superior da laje de fundo (EA e EB) e também sensores na armadura inferior da laje (E2, E3 e E4). A tabela 6.7 e a figura 6.5 apresentam as deformações das armaduras posicionadas na face superior da laje de fundo monitorada. Nos sensores EA e EB, que estavam posicionados na mesma barra, a evolução das deformações para os dois sensores foi bastante semelhante do ponto de vista qualitativo, e embora seja verificada uma diferença considerável de comportamento entre as leituras do intervalo de 24/05/05 a 22/08/06 e as demais medições, não se pode concluir que a alteração na resposta do sensor tenha sido iniciada em data próxima a 22 de agosto, visto que houve um significativo espaçamento entre as medições, devido a ocorrência de uma avaria no equipamento de aquisição de sinais. Comparando-se os resultados provenientes de EA e EB com os obtidos de C2 e C1, respectivamente, percebe-se que embora a armadura que contém EA e EB esteja comprimida nos pontos de instalação dos sensores, o sensor EA, posicionado bastante próximo a C2, está mais comprimido do que o sensor EB, que por sua vez está próximo de C1. Essa constatação concorda com o que foi concluído a partir dos valores medidos por C2 e C1, que indica a presença de uma zona mais comprimida nos arredores de C2. Adquire-se assim mais confiança em relação a esta conclusão, o que aponta também para a coerência qualitativa e validade dos resultados fornecidos pelos sensores de deformação. 
Tabela 6.7 - Deformações das armaduras posicionadas na face superior da laje de fundo.

\begin{tabular}{c|c|c|c|c|c|c|c}
\hline \multirow{2}{*}{$\begin{array}{c}\text { Sensor de } \\
\text { deformação } \\
\text { para armadura }\end{array}$} & \multicolumn{7}{c}{ Data da leitura } \\
\cline { 2 - 8 } & $12 / 05 / 06$ & $24 / 05 / 06$ & $22 / 08 / 06$ & $06 / 09 / 06$ & $29 / 09 / 06$ & $11 / 10 / 06$ & $16 / 11 / 06$ \\
\cline { 2 - 8 } & \multicolumn{7}{|c}{ Deformação $\left(\times 10^{-6} \mathrm{~m} / \mathbf{m}\right)$} \\
\hline EA & - & 0,000 & $-557,277$ & $-323,204$ & $-297,381$ & $-264,061$ & $-280,721$ \\
\hline EB & - & 0,000 & $-294,882$ & $-169,932$ & $-38,318$ & $-19,159$ & 3,332 \\
\hline
\end{tabular}

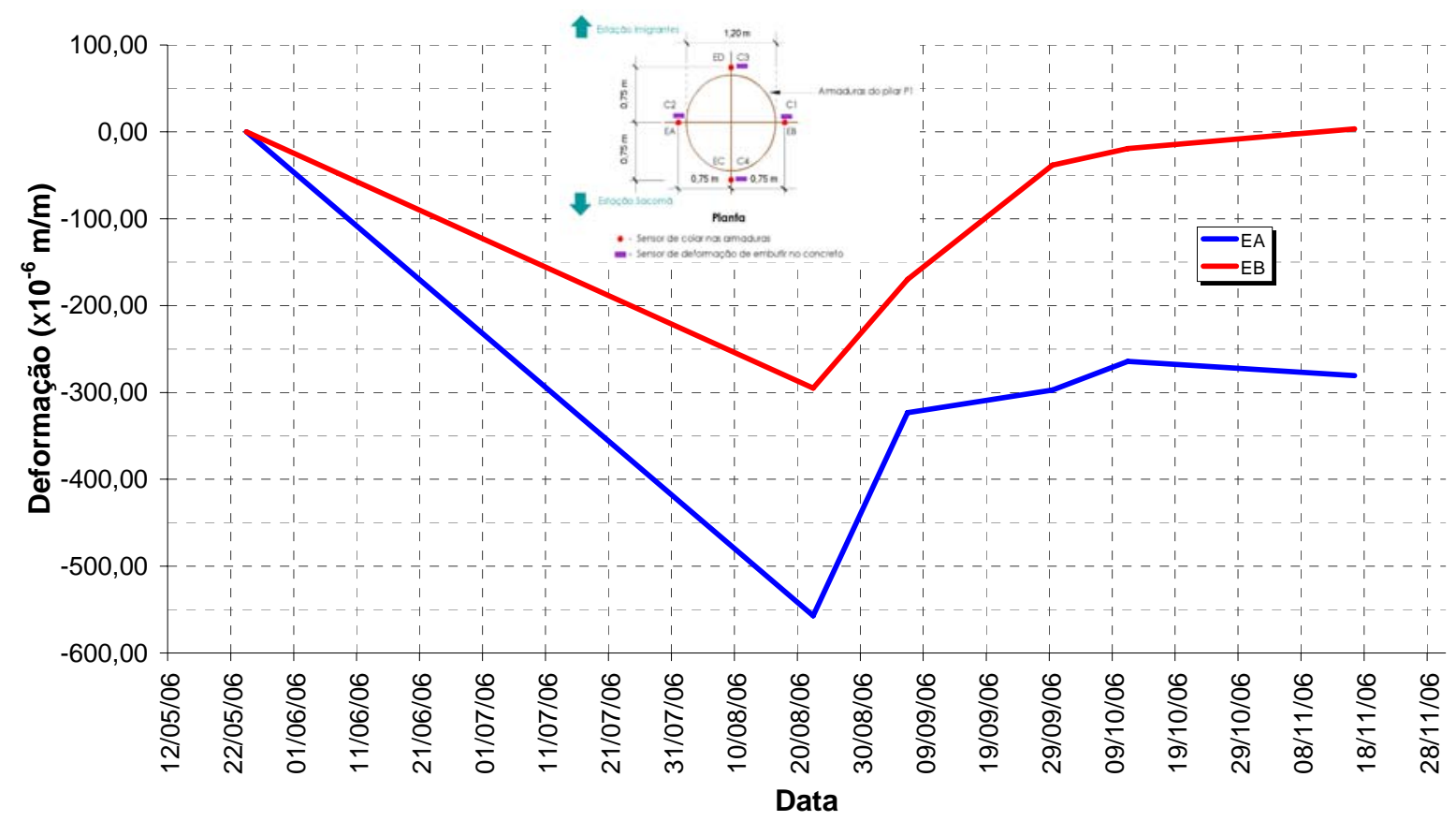

Figura 6.35 - Evolução das deformações das armaduras posicionadas na face superior da laje de fundo.

Visto que os sensores EC e ED não puderam ser recuperados após a concretagem da segunda camada, também não é possível neste caso avaliar a excentricidade no plano ortogonal a EC e ED (que é o mesmo que passa pelos sensores C3 e C4).

A tabela 6.8 apresenta as deformações da armadura inferior, enquanto a figura 6.36 trata da evolução das deformações da armadura inferior ao longo do tempo.

A partir da análise do gráfico da figura 6.36, é possível perceber que a evolução das deformações obtidas pelos sensores E2 e E3 são qualitativa e quantitativamente coerentes. 
Tabela 6.8 - Deformações da armadura inferior da laje de fundo.

\begin{tabular}{c|c|c|c|c|c|c|c}
\hline \multirow{2}{*}{$\begin{array}{c}\text { Sensor de } \\
\text { deformação } \\
\text { para armadura }\end{array}$} & \multicolumn{7}{|c}{ Data da leitura } \\
\cline { 2 - 8 } & $12 / 05 / 06$ & $24 / 05 / 06$ & $22 / 08 / 06$ & $06 / 09 / 06$ & $29 / 09 / 06$ & $11 / 10 / 06$ & $16 / 11 / 06$ \\
\cline { 2 - 8 } & \multicolumn{7}{|c}{ Deformação (x10-6 m/m) } \\
\hline E2 & 0,000 & $-51,646$ & $-180,761$ & $-196,588$ & $-214,081$ & $-204,085$ & $-197,421$ \\
\hline E3 & 0,000 & $-73,304$ & $-130,781$ & $-155,771$ & $-142,443$ & $-129,115$ & $-113,288$ \\
\hline E4 & 0,000 & 407,337 & 388,178 & 375,683 & 370,685 & 380,681 & 386,512 \\
\hline
\end{tabular}

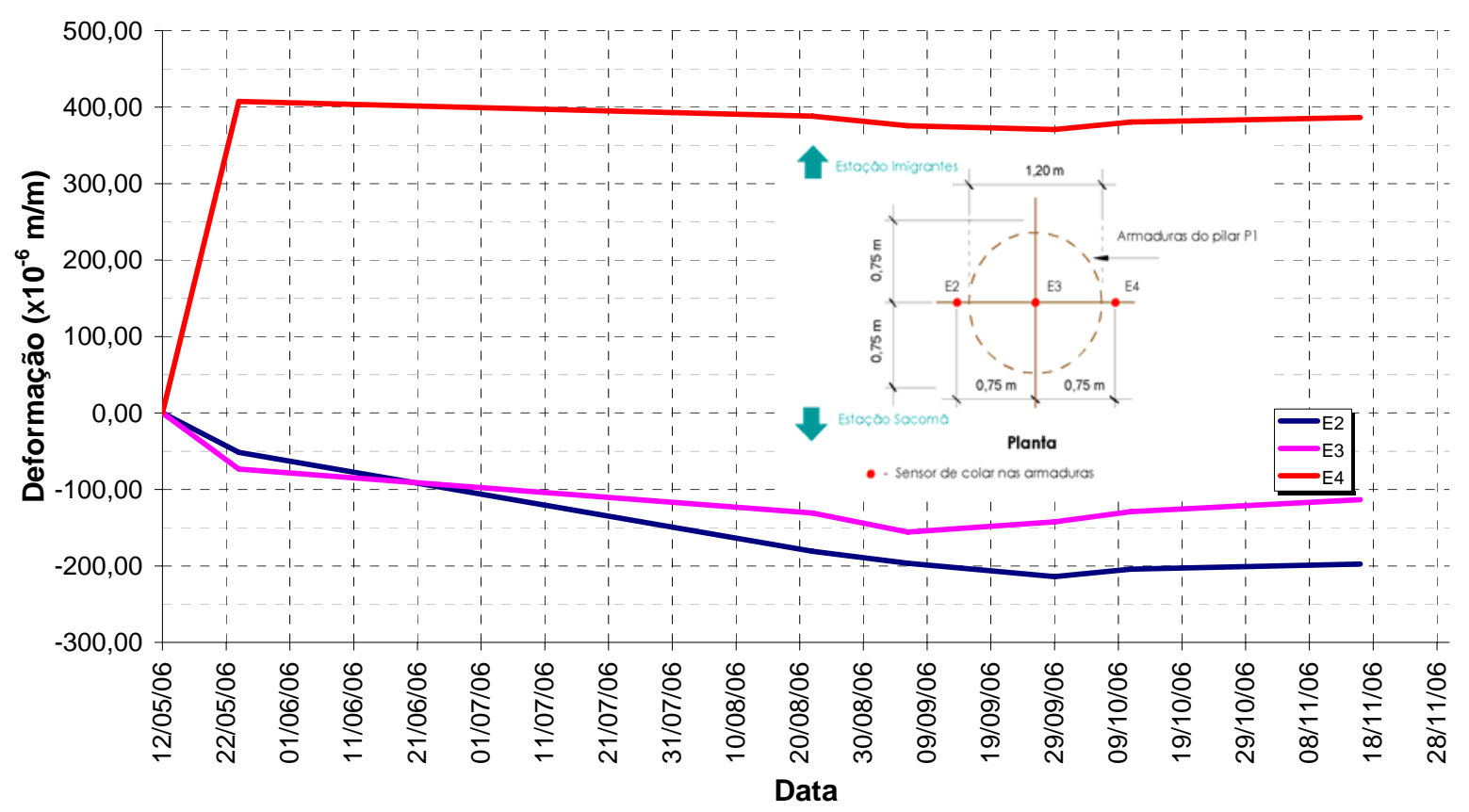

Figura 6.36 - Evolução das deformações da armadura inferior da laje de fundo durante a monitoração.

Nos pontos de instalação de E2 e E3, as medições indicam a existência de uma região comprimida da armadura, e entre E3 e E4, uma região tracionada. Mais uma vez, corroborando as análises extraídas dos sensores de deformação já apresentados, constata-se que no plano ao qual pertencem os sensores EA, EB, C1, C2, E2, E3 e E4, a carga transferida pelo pilar é excêntrica, e está posicionada conforme indicado no esquema da figura 6.34 . 


\subsubsection{Temperatura do concreto}

Para medir a temperatura do concreto foram instalados dois sensores de temperatura, um posicionado na primeira camada da laje de fundo (espessura de 40 $\mathrm{cm}$ ) e o outro na segunda camada da laje (espessura de $160 \mathrm{~cm}$ ). É importante ressaltar que os sensores de temperatura não receberam calibração antes da instalação, visto que a mesma não foi viabilizada em razão dos custos envolvidos, não justificados em vista do caráter experimental e qualitativo desta monitoração, na visão da Gávea Sensors, doadora dos sensores. A tabela 6.9 apresenta a temperatura do concreto da primeira camada da laje de fundo monitorada. A temperatura inicial para o sensor T1 foi tomada como referência igual a $20^{\circ} \mathrm{C}$. Analisando o gráfico da figura 6.37 é possível perceber que a variação de temperatura do concreto foi pequena. Devido ao problema com o equipamento de leitura, não foi possível realizar a leitura da temperatura durante a concretagem da laje de fundo. Não há resultados do sensor de temperatura posicionado na segunda camada (T2), uma vez este foi perdido devido à queda de um tubo de grandes dimensões sobre a fibra óptica que o continha, durante a realização de leituras no dia 26 de maio.

Tabela 6.9 - Temperatura do concreto da primeira camada da laje de fundo.

\begin{tabular}{c|c|c|c|c|c|c|c}
\hline \multirow{2}{*}{$\begin{array}{c}\text { Sensor de } \\
\text { Temperatura } \\
\text { para concreto }\end{array}$} & \multicolumn{7}{|c}{ Data da leitura } \\
\cline { 2 - 8 } & $12 / 05 / 06$ & $24 / 05 / 06$ & $22 / 08 / 06$ & $06 / 09 / 06$ & $29 / 09 / 06$ & $11 / 10 / 06$ & $16 / 11 / 06$ \\
\cline { 2 - 8 } & \multicolumn{7}{|c}{ Temperatura ( $\left.{ }^{\circ} \mathrm{C}\right)$} \\
\hline T1 & - & 20,0 & - & 19,3 & 17,9 & 18,2 & 18,5 \\
\hline
\end{tabular}




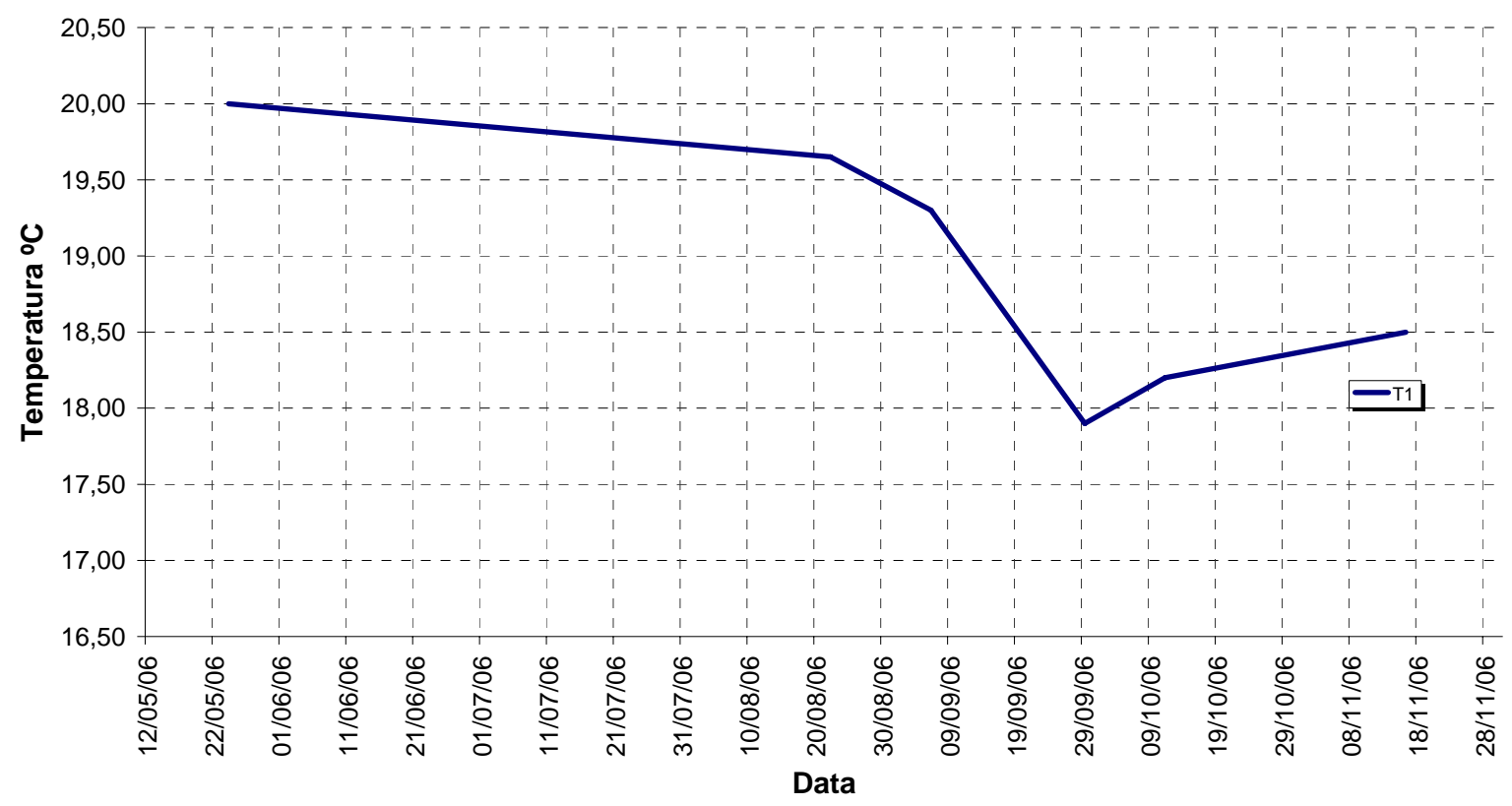

Figura 6.37 - Evolução da temperatura no concreto.

\subsection{Considerações finais}

Considera-se que o objetivo deste trabalho foi alcançado, uma vez que os resultados apresentados comprovam o potencial e confiabilidade dos sensores ópticos para fins de monitoração de estruturas metroviárias. Nesta monitoração, os resultados obtidos têm caráter mais qualitativo do que quantitativo, uma vez que os sensores utilizados não foram apropriadamenete calibrados, mas tendo em vista as análises que puderam ser extraídas dos resultados dos sensores de deformação, têm-se uma amostra do que pode ser constatado em termos de comportamento estrutural mediante o emprego da monitoração.

As atividades realizadas forneceram subsídios e informações importantes para que em uma próxima ocasião seja possível realizar uma nova instalação, devidamente dimensionada a fim de ser possível realizar análises aprofundadas a respeito do comportamento estrutural dos elementos monitorados. Deve-se também informar que a EPUSP pretende dar continuidade aos trabalhos iniciados na Estação Alto do Ipiranga, mediante a realização de novas leituras e obtenção de informações que possam auxiliar na compreensão dos fenômenos já verificados. 
Com este trabalho foi possível identificar problemas encontrados quando da monitoração de estruturas metroviárias e propor soluções para os mesmos. É importante destacar também que apesar da adversidade das condições de trabalho, foi possível instalar todos os sensores previstos e realizar as leituras sem interferir no normal andamento da obra. 


\section{CAPÍTULO 7}

\section{CONCLUSÕES E TRABALHOS FUTUROS}

\subsection{Conclusões}

Neste trabalho foram apresentados os sistemas computacionais desenvolvidos para suporte às atividades de aquisição, visualização e tratamento de dados em sistemas de monitoração de estruturas civis. Paralelamente à construção dos recursos informáticos, foram realizadas diversas atividades de campo, nas quais foi possível obter experiência relativa à componente prática do estabelecimento de sistemas de monitoração, adquirindo-se informações importantes referentes à sua adequada implantação e funcionamento.

Os recursos desenvolvidos, a saber: um módulo de aquisição de dados, um sistema de visualização e tratamento de dados e um sistema integrado para acesso remoto, gestão e visualização de dados via Internet (este último no seio de uma equipe multidisciplinar), foram aplicados em estruturas monitoradas, obtendo-se em geral resultados bastante satisfatórios. O uso desses sistemas promoveu uma expressiva redução do esforço e do tempo envolvido na realização de diversas atividades envolvendo os dados da monitoração, caracterizando-os como uma efetiva contribuição à área.

No âmbito da construção do sistema de visualização e tratamento de dados, foi desenvolvida uma metodologia para a estimativa de temperaturas em uma seção qualquer, a partir das temperaturas em uma seção instrumentada. Em testes de validação, os resultados decorrentes da aplicação do método mostraram-se bastante próximos dos valores monitorados, conferindo confiabilidade à proposta. Em relação ao método desenvolvido para a consideração das parcelas térmicas e diferidas que compõem a deformação medida em obra, a aplicação do sistema aos resultados obtidos em uma das seções da ponte sobre o rio Sorraia apontam à relevância dos 
valores dessas parcelas, conduzindo à conclusão que durante a fase de análise dos dados a quantificação dos efeitos térmicos e diferidos não deve ser omitida.

Para a quantificação da retração e da fluência do concreto, foram utilizados os modelos teóricos do Eurocode 2. Reconhece-se as limitações desta abordagem, que pode ser aprimorada utilizando-se resultados experimentais oriundos de corposde-prova concretados simultaneamente com a estrutura, com o mesmo concreto nela utilizado, os quais devem permanecer na obra de forma a ficarem submetidos às mesmas condições ambientais da estrutura monitorada. Nesse cenário, corposde-prova adicionais podem ser estudados em laboratório com a finalidade de quantificar a influência dos fatores intrínsecos da retração e fluência no concreto da obra.

As funcionalidades do sistema de visualização e tratamento de dados promoveram agilidade na realização de tarefas como a remoção dos efeitos da fluência, da retração e das parcelas lineares da temperatura nas medidas de deformação, mostrando-se também bastante úteis para a filtragem de ruídos em sinais de temperatura e deformações, sobretudo quando da análise de dados de ensaios de carga, nos quais o intervalo temporal entre aquisições geralmente é curto e os ruídos são expressivos. Nesses casos, é necesário avaliar com cuidado a resposta produzida pela filtragem utilizada, o que fica facilitado com o uso do sistema, que permite a realização instantânea de filtragens. Desse modo, o responsável pela análise dos dados pode testar o efeito da aplicação dos filtros e visualizar os respectivos resultados imediatamente, sem recorrer a planilhas eletrônicas e programações.

O sistema computacional para acesso remoto, gestão e visualização de dados da ponte sobre o rio Sorraia demonstrou ser uma eficiente e útil ferramenta, evitando os deslocamentos à obra quando da realização de leituras ou alterações dos parâmetros da aquisição. Esse sistema reúne e organiza todos os dados provenientes da rede sensora instalada, e contém a informação da instrumentação que integra o sistema de monitoração da ponte, com flexibilidade para edição de conteúdo, permitindo, por exemplo, a inclusão de novos sensores ou utilizadores do sistema, entre outras opções. Os usuários do sistema, por meio da interface Web, podem ter acesso remoto aos resultados da monitoração, visualizando-os por meio de gráficos dinamicamente gerados após a definição dos sensores de interesse, do intervalo de tempo e de parâmetros adicionais disponíveis. Posteriormente, os dados 
consultados podem ser exportados em formato apropriado para a alimentação de programas de tratamento de dados.

O módulo de aquisição construído foi utilizado em diversas situações práticas, com algumas vantagens em relação à maioria dos sistemas de aquisição convencionais: a possibilidade de realizar operações com os sinais à medida em que são aquisitados, a facilidade inerente à configuração de alarmes e a visualização dos sinais aquisitados e/ou modificados em tempo real.

Em relação às atividades de campo, o autor trabalhou com equipes na implantação de sistemas de monitoração em três obras: na ponte sobre o rio Sorraia e na ponte do Pinhão, em Portugal, e na Estação Metroviária Alto do Ipiranga em São Paulo. A experiência adquirida nos trabalhos de campo em Portugal mostrou-se bastante importante na idealização e execução do plano de monitoração da estação metroviária, e permitiu que as funcionalidades dos sistemas computacionais de apoio fossem implementadas de acordo com as reais necessidades.

Das atividades de monitoração da ponte sobre o rio Sorraia e da Estação Alto do Ipiranga, verifica-se a necessidade de existência de uma boa comunicação entre a equipe de monitoração e os responsáveis pela execução da obra durante a fase de instrumentação, a fim de que a instalação dos dispositivos de medição seja realizada em tempo oportuno, de acordo com o cronograma da obra e com os objetivos da monitoração. Outro aspecto relevante relaciona-se com o fato que embora a instalação de sensores e equipamentos não sejam tarefas difíceis de realizar, é necessário ter em mente que o posicionamento dos dispositivos deve obedecer ao que se encontra disposto do plano de instrumentação, a fim de que os resultados obtidos tenham relação com os que se pretendem. De modo a evitar problemas e custos desnecessários, recomenda-se que toda a instrumentação a ser instalada seja previamente testada em laboratório, calibrando-se os sensores que necesitarem desse cuidado. Sempre que possível, deve ser feita uma visita prévia ao local para verificação das condições de trabalho, que geralmente são árduas e podem exigir cuidados especiais de segurança.

A experiência de utilização de sensores a fibra óptica, realizada na ponte sobre o rio Sorraia e na Estação Alto do Ipiranga, demonstra que eles são muito interessantes para monitoração de estruturas de Engenharia Civil, embora seja necessário que aspectos como o custo total dos equipamentos e a realização de emendas e reparos das fibras ópticas em campo necessitem evoluir. 
Por solicitação do IEP - Instituto das Estradas de Portugal, procedeu-se à instrumentação e condução da prova de carga da ponte do Pinhão, no âmbito das atividades de avaliação das condições de segurança da estrutura. Os principais resultados das medições provenientes da rede sensora instalada, que foram tratados utilizando os recursos do sistema de visualização construído pelo autor, são ilustrados em gráficos e têm os valores mais significativos apresentados em tabelas. Para fins de comparação e análise dos resultados do ensaio, a equipe de trabalho desenvolveu um modelo numérico de um dos tramos da ponte, cujas características geométricas e mecânicas foram pormenorizadamente introduzidas. No modelo, foi considerado o funcionamento dos elementos estruturais no regime elástico. A análise dos resultados permite concluir que as cargas introduzidas durante o ensaio não induziram a plastificação das seções mais solicitadas dos perfis metálicos da estrutura, pois de outro modo seria esperado que os valores medidos fossem significativamente superiores aos obtidos pelo modelo numérico. Apesar de a análise dos resultados do ensaio não ter apontado para sérios riscos de colapso estrutural em decorrência da utilização normal da ponte, alguns meses após o ensaio a ponte passou por atividades de manutenção, que envolveram a substituição do concreto e do revestimento asfáltico do tabuleiro, bem como a remoção de vários perfis metálicos oxidados, sendo introduzidos perfis novos com maior capacidade resistente.

Baseado no que foi discutido e apresentado, percebe-se que a monitoração das estruturas de Engenharia Civil de médio e grande porte tem, cada vez mais, um papel fundamental no acompanhamento do processo construtivo e na avaliação da segurança estrutural durante a fase de serviço. É necessário, entretanto, ressaltar que embora a utilização de bons sistemas de monitoração propicie diversos benefícios à estrutura observada, por questões de custo, praticidade e limitações técnicas, as redes sensoras não têm como cobrir toda a estrutura e monitorar aspectos relacionados à degradação da obra promovida por agentes químicos ou biológicos, por exemplo. Por isso, deve-se ter em mente que a monitoração não deve substituir ou eclipsar as campanhas de inspeção visual, que devem ser periodicamente realizadas por equipes devidamente preparadas. 
Por fim, considera-se que este trabalho atendeu aos objetivos propostos, fornecendo úteis ferramentas de apoio à monitoração de estruturas civis, contribuindo também no âmbito das atividades envolvidas no tratamento e interpretação de resultados.

\subsection{Propostas para trabalhos futuros}

Tendo em vista a continuidade e o aprimoramento dos estudos na linha de pesquisa abordada, são propostos os trabalhos apresentados a seguir:

Investigação dos efeitos hiperestáticos da variação da temperatura em estruturas - Dos resultados de deformação obtidos a partir da remoção dos efeitos das parcelas lineares da temperatura, verifica-se a existência de um padrão nos valores cuja origem certamente possui caráter térmico. Sugere-se portanto o desenvolvimento de métodos simplificados para a remoção dos efeitos hiperestáticos da variação de temperatura nas deformações de estruturas de concreto.

Investigação dos efeitos diferidos baseados em técnicas de retroanálise - Desde que a obra monitorada disponha de prismas com geometria, instrumentação e acondicionamento adequados à medição da fluência e da retração, mediante investigações baseadas no comportamento reológico das estruturas e no emprego de técnicas de retroanálise podem ser feitas estimativas bastante realistas dos efeitos diferidos na obra. Propõe-se assim a realização de trabalhos nesse sentido.

Implementação de novos filtros - Os filtros de suavização de ruído implementados atuam diretamente sobre o sinal e não sobre as freqüências que o compõem. Esta característica torna os filtros de suavização pouco seletivos, isto é, incapazes de diferenciar o que é sinal do que é ruído e, portanto, no processo de suavização de ruído uma parcela da informação útil contida no sinal é simultaneamente removida. Propõe-se portanto a implementação de filtros atuantes 
sobre as frequências, como o filtro de Fourier, por exemplo, estudando-se os critérios a adotar em relação às frequências de corte.

Desenvolvimento de algoritmos para detecção de danos - Uma das limitações do atual conceito de monitoração da integridade estrutural reside na dificuldade em fornecer, de forma segura e em tempo oportuno, a localização e quantificação de danos estruturais a partir dos resultados da monitoração. Geralmente, mesmo os sistema de monitoração que permitem o acesso remoto e a visualização dos dados em tempo real não dispõem de ferramentas para o rápido tratamento do conjunto das informações, sobretudo tendo em vista a avaliação da integridade e da vida útil residual da estrutura. Sugere-se assim a construção de ferramentas computacionais orientadas à detecção e medição automática de danos estruturais, considerando-se os dados provenientes da rede sensora. O uso de técnicas de reconhecimento de padrões, utilizando redes neurais artificiais ou lógica Fuzzy, constitui uma possível abordagem para o desenvolvimento desses algoritmos. 


\section{REFERÊNCIAS BIBLIOGRÁFICAS}

AFFONSO, H. M. M. Estudo dos medidores de deslocamentos em barragens de enrocamento. Dissertação de mestrado. Pontifícia Universidade Católica do Rio de Janeiro, Rio de Janeiro, 2004.

ALLEN, D. W. Software for manipulating and embedding data interrogation algorithms into integrated systems - Special application to Structural Health Monitoring. Master of Science Thesis. Virginia Polytechnic Institute, Virginia, 2004.

ALMEIDA, P. A. O. Transdutores para medida de deslocamentos lineares. Apostila do curso de pós-graduação PEF 5794 - Análise Experimental de Estruturas. EPUSP, São Paulo, 2004.

ASSOCIAÇÃO BRASILEIRA DE CIMENTO PORTLAND. Vocabulário de teoria das estruturas. ABCP, São Paulo, 1967, 58 p.

ASSIS, W. S.; TRAUTWEIN, L. M.; BITTENCOURT, T. N. Monitoração do comportamento da laje de fundo da estação alto do Ipiranga. Escola Politécnica da Universidade de São Paulo, São Paulo, 2006.

ASSIS, W. S. et al. Avaliação do sistema de monitoração da ponte sobre o Rio Sorraia. VI Simpósio EPUSP sobre Estruturas de Concreto, São Paulo, 8-11 Abril, CD-ROM, p.659-672, 2006. ISBN: 85-86686-36-0.

ASSIS, W. S. et al. Instrumentação e Observação do Comportamento da Ponte do Pinhão durante Ensaio de Carga. Relatório técnico, Faculdade de Engenharia da Universidade do Porto, Porto, 2004. 112 p.

ASSOCIAÇÃO BRASILEIRA DE NORMAS TÉCNICAS. Projeto de estruturas de concreto - procedimento. NBR 6118/2003, ABNT, Rio de Janeiro, 2003.

ASSOCIAÇÃO BRASILEIRA DE NORMAS TÉCNICAS. Projeto e execução de pontes de concreto armado e protendido: NBR 7187, ABNT, Rio de Janeiro, 1987. 
ATKINSON, L. Core PHP programming: using PHP to build dynamic Web sites. Prentice Hall PTR, New Jersey, 1999.

BARBOSA, T. M. G. A. et al. Arquitetura de software para redes de sensores sem fios: a proeminência do Middleware. XXV Congresso da Sociedade Brasileira de Computação. São Leopoldo, 2005.

BARNES, J. et al. The monitoring of bridge movements using GPS and pseudolites. Proceedings of the $11^{\text {th }}$ International Symposium on Deformation Measurements, Santorini, 25-28 May, 2003. p. 563-572.

BASTOS, A. M. S. Métodos de avaliação, inspecção e monitorização de estruturas. Apostila da disciplina Instrumentação e Observação de Estruturas. Faculdade de Engenharia da Universidade do Porto, Porto, 2004.

BASSEVILLE, M. et tal. Statistical inference for Structural Health Monitoring. Activity Report. INRIA - Institut National de Recherche en Informatique et en Automatique. Rennes, 2004.

BELLEVILLE, C.; DUPLAIN, G. White-light interferometric multimode fiber-optic strain sensor, Optics Letters, v. 18, nº. 1, p. 78-80, 1993.

BERGMEISTER, K.; SANTA, U. Global monitoring concepts for bridges. Structural Concrete. v. 2, n. 1, p. 29-39, March 2001.

BERNSTEIN, J. An overview of MEMS inertial sensing technology. Sensors, 2003. Disponível em: http://www.sensorsmag.com/articles/0203/14/main.shtml.

BISHOP, R. H. Learning with LabVIEW 6i. Prentice-Hall, 2001. 505 p.

BONFIGLIOLI, B; PASCALE, G. Internal strain measurements in concrete elements by fiber optic sensors.Journal of Materials in Civil Engineering, v. 15, $n^{\circ}$. 2, p.125133, ASCE, 2003.

BORCHARDT, I. G. O Circuito ponte para medição de impedâncias e grandezas físicas. Caderno técnico, PPGEMM - Programa de Pós-Graduação em Engenharia de Minas, Metalúrgica e dos Materiais, UFRGS, Porto Alegre, 1995. 
BORINSKI, J. W. et al. Fiber optic sensors for predictive health monitoring. AUTOTESTCON Proceedings. IEEE Systems Readiness Technology Conference, 2001, p. 250-262.

BRANCO, F. A.; MENDES, P. A. Thermal actions for concrete bridge design. Journal of structural engineering, v. 119, n. 8, 1993, p. 2313-2331.

BRUYNINCKX, H. Bayesian Probability Theory, 60 p., 2005 .Disponível em: http://www.roble.info/basicST/stat/pdf/Bayes-1.pdf.

CAMPILHO, A. Instrumentação electrónica. Métodos e técnicas de medição. Faculdade de Engenharia da Universidade do Porto, Porto, 2000.

CARDEN, E. P.; FANNING, P. Vibration Based Condition Monitoring: A Review.Structural Health Monitoring, Sage publications, v. 3:4, p. 355-377, 2004.

CARVALHO, M. M. Componentes de software em LabVIEW para integração em sistemas de informação industriais. Anais do Encontro Nacional do Colégio de Engenharia Electrotécnica (ENCEE), Ordem dos Engenheiros, p. 27-34, 2001.

CASAS, J. R.; CRUZ, P. J. Fiber optic sensors for bridge monitoring. Journal of Bridge Engineering, V. 8, No. 6, ASCE, November 2003, p. 362-373. ISSN 10840702/2003/6-362-373.

CASAS, J. R.; CRUZ, P. J.; VILLALBA, V. Structural monitoring systems based on fiber optics. State of the art. Proceedings of the IABMAS 06 - Bridge Maintenance, Safety, Management, Life-Cycle Performance and Cost. Taylor \& Francis Group. Porto, July 2006.

FALKNER, H.; ZICHNER, T. Thermal effects in concrete structures. Comité EuroInternational du Béton. Bulletin d'information n. 167, Lausanne, 1985.

CEFETES - Centro Federal de Educação Tecnológica do Espírito Santo. Curso de automação industrial - módulo temperatura. $1^{a}$ edição, janeiro de 2006, 43 p.

ÇELEBI, M. GPS in dynamic monitoring of long-period structures. Soil Dynamics and Earthquake Engineering. V. 20, p. 477-483, Elsevier, 2000. 
CERQUEIRA, E. O. et al. Utilização de filtro de transformada de Fourier para a minimização de ruídos em sinais analíticos. Química Nova, v. 23, n. 5, 2000.

CHAN, T. H. T. et al. Fiber Bragg grating sensors for structural health monitoring of Tsing Ma bridge: Background and experimental observation. Engineering Structures, v. 28, p. 648-659, Elsevier, 2006.

CHANG, P.; FLATAU, A.; LIU, S. C. Review Paper: Health monitoring of civil infrastructure. Structural Health Monitoring, v. 2, p. 257-267, Sage Publications, 2003.

CHASE, S. The role of smart structures in managing an aging highway infrastructure. Proceedings of the SPIE Conference, New Beach, California, 2001. Disponível em http://www.tfhrc.gov/hnr20/nde/ppt/sld001.htm.

CHAVES, J. C. Uso da tecnologia GPS na monitoração de deformação: sistemas, etapas e experimentos. Tese de doutorado. Universidade de São Paulo, São Carlos, 2001. 155 p.

CHINTALAPUDI, K. et al. Structural damage detection and localization using NetSHM. The fifth international conference on information processing in sensor networks, IPSN 2006, p. 475-482, 2006. ISBN 1-59593-334-4.

CHOQUET, P.; LEROUX, R.; JUNEAU, F. New Fabry-Perot Fiber optic sensors for structural and geotechnical monitoring applications, Transportation Research Record, nº 1596, p. 39-44, 1997.

CODD, E. F. A relational model of data for large Shared data banks. Communications of the ACM, v. 13, n. 6, 1970. Disponível em:

http://www.csee.umbc.edu/ pmundur/courses/CMSC661-05/codd1970.pdf.

COMITE EURO-INTERNATIONAL DU BETON. CEB-FIP Model code 1990. Lausanne, 1991. (Bulletin d'Information, 203).

COZZA, E. Faltou remédio. Construção São Paulo, São Paulo, n. 2576, p. 4-9, jun. 1997.

CREMONA, C. Dynamic monitoring applied to the detection of structural modifications: a high-speed railway bridge study. Repair and Rehabilitation - Prog. Struct. Engng. Mater., 2004, v.6, p. 147-161. 
CRUZ, N. S. Interface humano para sistemas de aquisição de dados e processamento digital de sinal. Relatório. Universidade de Coimbra, Coimbra, 2000.

CTL GROUP - Construction Technology Laboratories. Bridging the globe. Illinois, 2006.

CUNHA, C. H. M.; FRANÇA, R. L. S. Deformabilidade das estruturas de concreto: impacto das novas tipologias estruturais e das modificações dos materiais, cimentos, agregados e aditivos. Anais do IV Simpósio EPUSP sobre estruturas de concreto. EPUSP, São Paulo, 2000.

DOEBELIN, E. O. Measurement systems: application and design. $4^{\text {th }}$ ed., McGrawHill, New York, 1990, 960p.

DOMINGUES, P. H. Noções básicas de circuitos elétricos simples. Apostila para disciplina de graduação do Instituto de Física da Universidade Federal do Rio de Janeiro - Fisexp3, Rio de Janeiro, 2006, 10 p.

DOORNINK, J. D. e tal. Fiber bragg grating sensing for structural health monitoring of civil structures. International Symposium on Advances and Trends in Fiber Optics and Applications, Chongqing, China, 2004.

DORMAN LONG TECHNOLOGY. Integrated heavy lifting contractor and construction consultant. Disponível em:

http://www.dormanlongtechnology.com/English/projects/Jiangyin.htm.

DUPONT, J. Comportements de capteurs à fibres optiques, noyés ou fixés en surface d'ouvrages en béton. These de Doctorat. Ecole Nationale des Ponts et Chaussees, 2002, 218 p.

DYNAMAG - New technology for civil engeneering, 2003. Disponível em: http://www.dynamag.com/main/technology/Applications/references/ashidagawa/.

EC2 - Eurocode 2: Design of concrete structures- part 1.1: General rules and rules for buildings. prEN 1992-1-1, April 2003.

EMBRAPA - Empresa Brasileira de Pesquisa Agropecuária. Satélites de monitoramento, 2004. Disponível em: http://www.sat.cnpm.embrapa.br/satelite/galileo.html. 
EREN, H. Acceleration, vibration, and shock measurement. Measurement, instrumentation and sensors handbook. WEBSTER, J. G. (editor), Cap. 17, CRC Press, Madison, 1999. ISBN: 9780849321450.

ESTEPA, A. L. Diseño de un acelerómetro basado en tecnología MEMS. Sistemas Electrónicos Avanzados, Universidad de Sevilla, Sevilla, 2006.

ESTRIN, D. et al. Next century challenges: Scalable coordination in sensor networks. USC/Information Sciences Institute, Seattle, 1999.

FARHEY, D. N. Quantitative assessment and forecast for structurally deficient bridge diagnostics. Structural Health Monitoring, Sage publications, v. 6, No. 1, p. 39-48, 2007.

FÉLIX, C. M. Monitoração e análise do comportamento de obras de arte. Tese de doutorado. Faculdade de Engenharia da Universidade do Porto, Porto, 2005.

FENG, M. Q. et al. Baseline models for bridge performance monitoring. Journal of Engineering Mechanics, p. 562-569, American Society of Civil Engineers (ASCE), 2004.

FERNANDES, J. A.; SANTOS, L. O. Pontes atirantadas do Guadiana e do Arade. Laboratório Nacional de Engenharia Civil (LNEC), Lisboa,1992.

FERNANDO, G. F. et al. Structural integrity monitoring of concrete structures via optical fiber sensors: Sensor protection systems. Structural Health Monitoring, v. 2, p. 123-135. Sage Publications, 2003.

FERREIRA, E. C. Sensores e condicionamento de sinais. Apostila do curso de pósgraduação IE 763 - Sensores e Condicionamento de Sinais. Unicamp, Campinas, 2000.

FÉDÉRATION INTERNATIONALE DU BÉTON. Monitoring and safety evaluation of existing concrete structures. State-of-art report prepared by Task Group 5.1, FIB, March, 2003.

FIGUEIREDO, E. J. F. Monitorização e avaliação do comportamento de obras de arte. Dissertação de mestrado. Faculdade de Engenharia da Universidade do Porto, Porto, 2006. 191 p. 
FIGUEIREDO, K.; VELASCO, M.; PACHECO, M. A. Hierarchical neuro-fuzzy models based on reinforcement learning for intelligent agents. Computational Intelligence and bioinspired systems. Proceedings of the $8^{\text {th }}$ international work conference on artificial neural networks, IWANN, Barcelona, 2005.

FONSECA, A. A.; BASTOS, R. Ponte Infante Dom Henrique: uma ponte inovadora. Anais do $V$ Simpósio EPUSP sobre estruturas de concreto. Escola Politécnica da Universidade de São Paulo. São Paulo, 2003.

FOWLES, G. R. Introduction to modern optics. $2^{\text {th }}$ edition, Dover, New York, 1989.

GAO, Y. Structural health monitoring strategies for smart sensor networks. Ph.D. Thesis, University of Illinois at Urbana-Champaign. Urbana, USA, 2005.

GHOSH, J. K. et al. Measurement of deflection of bridge using GPS. Advances in Bridge Engineering, March 24 - 25, 2006. p. 605-611.

GLISIC, B.; INAUDI, D.; VURPILLOT, S. Structural monitoring of concrete structures. Third World Conference on Structural Control, Como, Italy, april 2002. 10 p.

GRID. Ponte sobre o rio Sorraia - Projecto de execução. Volume 7: Cálculos justificativos da ponte. Grid consultas, estudos e projectos de engenharia Lda. Lisboa, 2003.

GROSSO, A. D. et al. Monitoring of bridges and concrete structures with fibre optic sensors in Europe. IABSE Conference, Seoul,2001.

HARRIS, H. G.; SABNIS, G. M. Structural modeling and experimental techniques $2^{\text {nd }}$ edition, CRC, Boca Raton, 1999. ISBN 0-8493-2469-6.

HETENYI, M. Handbook of experimental stress analysis. Wiley, New York, 1950.

HOOKE, R. De potentia restitutiva. London, 1678.

HOFFMANN, K. Pratical hints for the application of strain gauges. Hottinger Baldwin Messtechnik GmbH, 1984. 
HOFFMANN, K. An introduction to measurements using strain gages. Hottinger Baldwin Messtechnik GmbH, Darmstadt, 1989. 291 p.

INAUDI, D. et al. Lessons learned in the use of fiber optic sensor for civil structural monitoring. The present and the future in health monitoring, Weimar, 2000.

INAUDI, D. et al. Long-term monitoring of a concrete bridge with 100+ fiber optic long-gage sensors. Nondestructuve Evaluation Techniques for Aging Infrastructure \& Manufacturing, Newport Beach, USA, 1999.

INAUDI, D. Overview of fibre optic sensing to structural health monitoring applications. ISISS'2005, International Symposium on Innovation \& Sustainability of Structures in Civil Engineering, Nanjing, China, 2005.

INSTITUTO NACIONAL DE METROLOGIA, NORMALIZAÇÃO E QUALIDADE INDUSTRIAL. Vocabulário Internacional de Metrologia. Portaria INMETRO $\mathrm{n}^{\circ} 029$, de 10 de março de 1995.

JIANG, J.; LU, X.; GUO, J. Study for real-time monitoring of large-span bridge using GPS. Proc. ISSST 2002, Progress in Safety Science and Technology, Science Press, HUANG, P.; WANG, Y. J.; LI, S. C.; QIAN, X. M. (eds.) Beijing/New York, 2002. p. 308-312.

JORDAN, M. I.; BISHOP, C. M. Neural Networks. ACM Computing Surveys, v. 28, n. 1, p. 73-75, 1996.

KEIL, S. On the strain gage's $50^{\text {th }}$ jubilee - a review of its evolution and of 33 years strain gage production at Darmstadt. Reports in Applied Measurement. v. 4, n. 2, 1988, p.39-48.

KISS, P. Obras-de-arte: Praga no capim. Téchne - Revista de tecnologia da construção, PINI editora, São Paulo, no 40, p. 35-38, maio/junho de 1999. ISSN 0104-1053.

KO, J. M.; NI, Y. Q. Technology developments in structural health monitoring of large-scale bridges. Engineering Structures, v. 27, p. 1715-1725. Elsevier, 2005.

$\mathrm{KOH}, \mathrm{H} . \mathrm{M}$; KIM, S.; CHOO, J. F. Recent Development of Bridge Health Monitoring System in Korea. In: Sensing Issues in Civil Structural Health Monitoring. ANSARI, F. (Editor), Springer Netherlands, 2005, p. 33-42. ISBN 978-1-4020-3660-6. 
LAL, R. et al. MEMS: technology, design, CAD and applications. Proceedings of the $15^{\text {th }}$ International Conference on VLSI Design (VLSID'02), Institute of Electrical and Electronics Engineers - IEEE, 2002, 0-7695-1441-3/02.

LAROCCA, A. P. C. O uso do GPS como instrumento de controle de deslocamentos dinâmicos de obras civis - Aplicação na área de transportes. Tese de doutorado. Universidade de São Paulo, São Carlos, 2004. 193 p.

$\mathrm{LI}, \mathrm{H}$. et al. Structural health monitoring system for the Shandong Binzhou Yellow River highway bridge. Computer-Aided Civil and Infrastructure Engineering, v. 21, p. 306-317. Blackwell Publishing, 2006.

LEIDERMAN, R. Desenvolvimento de um sistema de medição de deformações utilizando redes de Bragg em fibras ópticas. Dissertação de mestrado. Pontifícia Universidade Católica do Rio de Janeiro, Rio de Janeiro, 1998.

LEUCKERT, C. Sistema portátil de aquisição de dados para análise dinâmica de estruturas mecânicas. Dissertação de mestrado. Universidade Federal do Rio Grande do Sul, Porto Alegre, 2000, 108 p.

$\mathrm{LI}, \mathrm{H}$. et al. Structural health monitoring system for the shandong binzhou yellow river highway bridge. Computer-Aided Civil and Infrastructure Engineering, Blackwell Publishing, Oxford, 2006, v. 21, p 306-317.

LIENHART, W.; BRUNNER, F. K. Monitoring of bridge deformations using embedded fiber optical sensors. Proceedings $11^{\text {th }}$ International Symposium on Deformation Measurements, p. 555-561, Santorini, 2003.

LOUREIRO, A. A. F. et al. Redes de sensores sem fios. XXI Simpósio Brasileiro de Redes de Computadores, p. 179-226, Natal, 2003.

LYNCH, J. P. Overview of wireless sensors for real-time health monitoring of civil structures. Proceedings of the $4^{\text {th }}$ International Workshop on Structural Control and Monitoring, New York City, NY, USA, June 10-11, 2004.

LYNX TECNOLOGIA. Conceitos básicos de aquisição de dados. Disponível em http://www.lynxtec.com.br/tutor aqd1.htm . 
MATOS, J. C. et al. Structure assessment by continuous monitoring - Application to Sorraia River Bridge. FIB Symposium "Keep Concrete Attractive". CEB-FIB, Budapest, 2005.

MEASURES, R. M. Structural monitoring with fiber optic technology. Academic Press, Toronto, 2001.

MELLO, C. A. Redes neurais e técnicas de pré-processamento de sinais em espectroscopia de reflectância no infravermelho próximo. Tese de doutorado. Universidade Estadual de Campinas, Campinas, 1998. 147 p.

MENG, X.; ROBERTS, G. W.; COSSER, E.; DODSON, A.. Real-time bridge deflection and vibration monitoring using an integrated GPS/accelerometer/ pseudolite system. Proceedings of the $11^{\text {th }}$ International Symposium on Deformation Measurements, Santorini, 2003.

MENZORI, M. Classificação da exatidão de coordenadas obtidas com a fase da portadora L1 do GPS. Tese de doutorado. Universidade de São Paulo, São Carlos, 2005. $141 \mathrm{p}$.

MERZBACHER, C. I.; KERSEY, A. D.; FRIEBELE, E. J. Fiber optic sensors in concrete structures: a review. smart materials and structures, V.5, p. 196-208, 1996.

METHA, P. K.; MONTEIRO, P. J. M. Concreto: estrutura, propriedades e materiais. PINI .São Paulo, 1994.

MITUTOYO CORPORATION. Small Tool Instruments and Data Management, 2005. Disponível em: http://www.mitutoyo.co.jp/eng/products/dialgauge/Digital indicator.pdf.

MIZUNO, Y; FUJINO, Y.; ABE, M. Proposal of data management architecture for bridge management system. Proceedings of the IABMAS 04 - Bridge Maintenance, Safety, Management and Cost. Taylor \& Francis Group, Kyoto, October 2004.

MOSZKOWICZ, V. N. Monitoração de deformações em dutos utilizando sensores a fibra óptica com base em Rede de Bragg. Boletim técnico Petrobrás. Rio de Janeiro, 2002.

MUFTI, A. Guidelines for Structural Health Monitoring. ISIS Canada Corporation, Manitoba, 2001. 
MUFTI, A. FRPs and FOSs lead to innovation in Canadian civil engineering structures. Construction and Building Materials, v. 17, pp. 379-387, Elsevier, 2003.

NASCIMENTO, L. V.; DUARTE, E. Fibras e cabos ópticos. Trabalho do curso de Automação Industrial. Escola Técnica Federal de Santa Catarina, 2002. 31 p.

NATIONAL INSTRUMENTS. EBook Catalog 2007, p. 156 e 386 . Disponível em: http://www.nxtbook.com/nxtbooks/ni/catalog2007/index.php.

NATIONAL INSTRUMENTS. LabVIEW User Manual. National Instruments Corporation, 2003, 349 p.

NEVILLE, A. M. Propriedades do concreto, 2ª Edição, PINI; São Paulo,1997.

NOLL, V. Tecnologia de transdutores. Apostila do curso superior de tecnologia em sistemas digitais, Florianópolis, 2003.

NPL - National Physical Laboratory. Sensors \& Functional Materials: Functional MEMS. Teddington, Middlesex, UK, 2007. Disponível em:

http://www.npl.co.uk/materials/functional/thin film/mems/index.htm.

OGAJA, C. et al. A dynamic GPS system for on-line structural monitoring. Int. Symp. on Kinematic Systems in Geodesy, Geomatics \& Navigation (KIS2001), Banff, Canada, 2001, p. 290-297.

OLIVIERI, B. S. Sistema de interrogação de sensores a rede de Bragg utilizando multiplexação no tempo e multiplexação no comprimento de onda. Dissertação de mestrado. Pontifícia Universidade Católica do Rio de Janeiro, 2004, 97 p.

OLSHAUSEN, B. A. Aliasing. PSC129 - Sensory processes. University of California, Berkeley, 2000.

OMEGA ENGINEERING, INC. Omega engineering technical reference 2006. Disponível em: www.omega.com/prodinfo/StrainGages.html.

OMNI INSTRUMENTS. Measurement, control \& data acquisition. Web catalog 2007. Disponível em: http://www.omniinstruments.net/gyro/gyro.html. 
OTHONOS, A.; KALLI, K. Fiber Bragg Grattings - Fundamentals and applications in telecommunications and sensing, Norwood, Artech House, 1999.

PCMAG - PC Magazine Encyclopedia, 2007. Disponível em:

http://www.pcmag.com/encyclopedia term/0,2542,t=MEMS\&i=46791,00.asp.

QUIMBY, R. S. Photonics and Lasers: An Introduction. Wiley, John \& Sons, Incorporated, 2006, 536 p. ISBN: 978-0-471-71974-8.

QUIRION, M.; BALLIVY, G. Concrete strain monitoring with Fabry-Pérot fiber-optic sensor. Journal of Materials in Civil Engineering, v. 12, $n^{\circ}$. 3, p. 254-261, ASCE, 2000.

QUIRION, M.; BALLIVY, G. Revue de la technologie des capteurs à fibre optique et applications en génie civil. $5^{\text {ième }}$ Colloque du CRIB - Sherbrooke sur les infrastructures de béton. Nouvelles techniques d'auscultation et d'instrumentation, 1998.

RAO, Y. J.; HUANG, S. Applications of fiber optic sensors. Fiber Optic Sensors, cap. 10. YU, F. T. S.; YIN, S. (eds.), Marcel Dekker Inc, New York, 2002. ISBN: 0-82470732-X.

REGAZZI, R. D.; PEREIRA, P. S.; SILVA JR., M. F. Soluções práticas de instrumentação e automação - Utilizando a programação gráfica LabVIEW, Rio de Janeiro, 2005, 456 p.

RIEKER ELECTRONICS INC. Catalog of inclinometers, accelerometers and tilt indicating instruments, 2006. Disponível em:

http://www.riekerinc.com/Catalogs/Rieker Inclinometer Catalog.pdf.

ROBERTS, G. W.; MENG, X.; DODSON, A. H. Using adaptive filtering to detect multipath and cycle slips in GPS/accelerometer bridge deflection monitoring data. FIG XXII Internacional Congress, Washington, 2002.

ROBERTS-WOLLMAN, C. L.; BREEN, J. E.; CAWRSE, J. Measurements of thermal gradients and their effects on segmental concrete bridge. Journal of Bridge Engineering, May/June 2002, p. 166-174.

ROTRONIC INSTRUMENT CORP. Rotronic Hygromer CS 30 Humidity Sensor, 2001. Disponível em: http://www.rotronic-usa.com/ds/CS30.pdf. 
SAFAAI-JAZI, A. Optical fibers and applications. Optics \& Laser Technology, Elsevier Science Ltd., v. 33, 2001.

SANTOS; J. C. Apostila do curso de pós-graduação PEA 5716 - Componentes e Sistemas de Sensoreamento a Fibras Ópticas. EPUSP, São Paulo, 2004.

SANTOS, L. M. P. O. Observação e análise do comportamento diferido de pontes de betão. Tese de doutorado. Laboratório Nacional de Engenharia Civil (LNEC). Lisboa, 2002.

SAVITZKY, A.; GOLAY, M. J. E. Smoothing and Differentiation of Data by Simplified Least Squares Procedures. Analytical Chemistry, 36, 1964, p.1627-1639.

SCHULZ, W. L. et al. Single and multiaxis fiber grating based strain sensors for civil structure applications. SPIE Proceedings, v. 3489, p.71, 1999.

SEIPPEL, R. G. Transducers, sensors and detectors, Reston publishing company Inc., ISBN 0-8359-7797-8, Reston, 1983, 299 p.

SHINOZUKA M. et al. MEMS based wireless real-time health monitoring of bridges, Third international conference on earthquake engineering, Nanjing University of Technology, 2004.

SILVA, P. J. et al. Automatização de laboratórios de medida de componentes ópticos e electrónicos através de LabVIEW, Revista do Departamento de Electrónica e Telecomunicações da Universidade de Aveiro, v. 2, n. 4, Universidade de Aveiro, p. 449-458, 1999.

SILVA, R. A. C. Inteligência Artificial aplicada a ambientes de Engenharia de Software: uma visão geral. INFOCOMP - Journal of Computer Science, v. 4, n. 4, p. 27-37, Lavras, 2005.

SILVA, T. I. et al. Desenvolvimento de um sensor a corda vibrante para aplicações em Engenharia de Reabilitação. Memorias II Congresso Latinoamericano de Ingenieria Biomédica. Artículo 00272, La Habana, 2001.

SILVEIRA, A. P. C. A influência das acções térmicas no comportamento de pontes de betão armado pré-esforçado. Tese de doutorado. Laboratório Nacional de Engenharia Civil (LNEC). Lisboa, 1996. 
SIMON, M. Galileo: the European programme for global navigation services. ESA European Space Agency Publications Division, Noordwijk, 2005. 36 p.

SINAENCO - Sindicato Nacional das Empresas de Arquitetura e Engenharia Consultiva. Viadutos e pontes da capital estão sem manutenção, diz estudo, 2005. Disponível em: http://www.sinaenco.com.br/noticias midia detalhe.asp?id=51.

SLOWIK, V., SCHLATTNER E., KLINK, T. Fibre bragg grating sensors in concrete technology. LACER, v. 3, p. 109-119, 1998.

SMARTEC. Structural Health Monitoring Systems and Services - Civil Engineering, 2007. Disponível em http://www.smartec.ch/Pages/Civil.htm.

SMARTEC. 3DeMoN GPS - 3 dimensional deformation monitoring network, Manno, 2006. Disponível em: http://www.smartec.ch/Pages/Products.htm\#3DeMoN.

SOHN, H.; LAW, K. A bayesian probabilistic approach to damage detection for civil structures, Report No. 131, Department of Civil and Environmental Engineering, Stanford University, 1999.

SONDHI, J. S. Bridge condition monitoring issues for railway bridges. Advances in Bridge Engineering, pp. 377-390, 2006.

SOUKHOV, D. Thermal actions in the Eurocode 1 "Actions on structures". LACER $n^{\circ}$ 5, 2000, p. 379-386.

SOUSA, H. et al. Ensaio de carga da ponte sobre o rio sorraia - Auto-estada A13 (Almeirim-Marateca). Relatório Técnico. Porto-Portugal: FEUP, Junho de 2005. 82p.

STARMER, C. F., 2006. Disponível em:

http://oldcooperriverbridge.org/large/jul 17 ravenel pearman grace.jpg.

STARRET COMPANY. Starret online catalog - Dial \& Electronic Indicators \& Gages. Electronic indicators No. 3600 series AGD group 2, 2006. Disponível em: http://catalog.starrett.com/catalog/catalog/groupf.asp?groupid=755.

STEPHENSON, R. J. et al. Temperature measurement. Measurement, instrumentation and sensors handbook. WEBSTER, J. G. (editor), Cap. 32, CRC Press, Madison, 1999. ISBN: 9780849321450. 
STRAUSS, A.; BERGMEISTER, K. Target reliability index regarding monitoring systems. Proc., IABMAS 04 - Bridge Maintenance, Safety, Management and Cost. Taylor \& Francis Group, Kyoto, October 2004.

SUMITRO, S.; WANG, M. L. Sustainable structural health monitoring system. Structural Control and Health Monitoring, v. 12, p. 445-467, John Wiley \& Sons, Ltd., 2005.

TAHA, M. M. R.; LUCERO, J. Damage identification for structural health monitoring using fuzzy pattern recognition. Engineering Structures, v. 27, p. 1774-1783, Elsevier, 2005.

TÉCHNE - REVISTA DE TECNOLOGIA DA CONSTRUÇÃO. A experiência da ponte Bernardo Goldfarb. PINI editora, São Paulo, nº 40, p. 37, maio/junho de 1999. ISSN 0104-1053.

TENNYSON, R. C. Installation, use and repair of fibre optic sensors. Design Manual, ISIS Canada Corporation, 2001. ISBN 0-9689006-3-1.

TENNYSON, R. C. et al. Fibre optic sensors in civil engineering structures. Canadian Journal of Civil Engineering, v. 27, p. 880-889, 2000.

THAKKAR, S. K.; GHOSH, G.; SINGH, Y. Structural damage identification and health monitoring and damage identification of Bridges. Advances in Bridge Engineering, March 24-25, p. 11-30, 2006.

THOMPSON, W. On the electro-dynamic quality of metals. Philosophical Transactions of the Royal Society of London, 1856.

THURSTON, S.; PRIESTLEY, M.; COOKE, N. Influence of cracking on thermal response of reinforced concrete bridges. Concrete International, 84 (Aug.), 1984, p. 36-43.

TIBIRIÇÁ, C. A. G. Uma abordagem híbrida Fuzzy-Bayes para modelagem de incertezas. Dissertação de Mestrado. Universidade Federal de Santa Catarina, Florianópolis, 2005.

UDD, E. (editor) Fiber Optic Sensors: An Introduction for Engineers and Scientists. Wiley, New York, 2006, 476 p. ISBN: 978-0-470-06810-6. 
U. S. ARMY CORPS OF ENGINEERS. Instrumentations for concrete structures. Engineer Manual, 30 November 1987, EM 1110-2-4300.

VALENTE, L. C. G. et al. Técnicas de leitura para sensores a fibra óptica baseados em redes de Bragg, VI conferência sobre tecnologia de equipamentos, Salvador, 2002.

VURPILLOT, S. et al. Bridge spatial displacement monitoring with 100 fiber optic sensors deformations: sensors network and preliminary results. SPIE Conference on Smart Structures and Materials, San Diego, 1997.

WHEATSTONE, C. An account of several new instruments and processes for determining the constants of a voltaic circuit. Philosophical Transactions of the Royal Society of London, v. 133, 1843, p. 303-329.

WIKIPEDIA: The Free Encyclopedia. Illustration of a linear variable differential transformer, 2004. Disponível em http://en.wikipedia.org/wiki/lmage:LVDT.png.

WONG, K. Y.; HUI, M. C. H. The structural health monitoring approach for stonecutters bridge IABSE reports, IABSE, 2004.

YUAN, S.; WANG, L.; PENG, G. Neural network method based on a new damage signature for structural health monitoring. Thin-Walled Structures, v. 43, p. 553-563, Elsevier, 2005.

ZHANG, L.; ZHANG, W.; BENNION, I. In-Fiber Grating Optic Sensors. Fiber Optic Sensors, cap. 4. YU, F. T. S.; YIN, S. (eds.), Marcel Dekker Inc, New York, 2002. ISBN: 0-8247-0732-X.

ZHANG, B.; BENMOKRANE, B.; NICOLE, J. Laboratory evaluation of fiber-optic sensors for strain monitoring. Journal of Materials in Civil Engineering, v. 15, nº 4, p. 381-390, ASCE, 2003.

ZINGONI, A. Structural health monitoring, damage detection and long-term performance. Engineering Structures, Elsevier, v. 27, p. 1713-1714, 2005.

ZIMMERMANN, A. C. et al. Sensores baseados em redes de Bragg e fibras ópticas para medição de grandezas em sistemas elétricos de alta tensão. Anais do Simpósio Brasileiro de Sistemas Elétricos 2006, Campina Grande, SBSE, 2006. 